Cochrane Database of Systematic Reviews

\title{
Gefitinib for advanced non-small cell lung cancer (Review)
}

Sim EHA, Yang IA, Wood-Baker R, Bowman RV, Fong KM

Sim EHA, Yang IA, Wood-Baker R, Bowman RV, Fong KM.

Gefitinib for advanced non-small cell lung cancer.

Cochrane Database of Systematic Reviews 2018, Issue 1. Art. No.: CD006847.

DOI: 10.1002/14651858.CD006847.pub2. 
TABLE OF CONTENTS

HEADER 1

ABSTRACT

PLAIN LANGUAGE SUMMARY

SUMMARY OF FINDINGS

BACKGROUND

OBJECTIVES

METHODS

RESULTS

Figure 1.

Figure 2.

Figure 3.

Figure 4.

Figure 5.

Figure 6.

DISCUSSION

AUTHORS' CONCLUSIONS

ACKNOWLEDGEMENTS

REFERENCES

CHARACTERISTICS OF STUDIES

DATA AND ANALYSES

Analysis 1.1. Comparison 1 Gefitinib versus placebo, Outcome 1 HR Overall survival.

Analysis 1.2. Comparison 1 Gefitinib versus placebo, Outcome 2 HR Progression-free survival.

Analysis 1.3. Comparison 1 Gefitinib versus placebo, Outcome 31 -year survival rate.

Analysis 1.4. Comparison 1 Gefitinib versus placebo, Outcome 4 Skin rash.

Analysis 1.5. Comparison 1 Gefitinib versus placebo, Outcome 5 Pruritus.

Analysis 1.6. Comparison 1 Gefitinib versus placebo, Outcome 6 Diarrhoea.

Analysis 1.7. Comparison 1 Gefitinib versus placebo, Outcome 7 Constipation.

Analysis 1.8. Comparison 1 Gefitinib versus placebo, Outcome 8 Nausea.

Analysis 1.9. Comparison $1 \mathrm{Gefitinib}$ versus placebo, Outcome 9 Vomiting.

Analysis 1.10. Comparison 1 Gefitinib versus placebo, Outcome 10 Anorexia.

Analysis 1.11. Comparison 1 Gefitinib versus placebo, Outcome 11 Fatigue.

Analysis 1.12. Comparison 1 Gefitinib versus placebo, Outcome 12 Asthenia.

Analysis 1.13. Comparison 1 Gefitinib versus placebo, Outcome 13 Respiratory tract infection.

Analysis 1.14. Comparison 1 Gefitinib versus placebo, Outcome 14 Dyspnoea.

Analysis 1.15. Comparison 1 Gefitinib versus placebo, Outcome 15 Anaemia.

Analysis 1.16. Comparison 1 Gefitinib versus placebo, Outcome 16 Abdominal pain.

Analysis 1.17. Comparison 1 Gefitinib versus placebo, Outcome 17 Increased ALT.

Analysis 1.18. Comparison 1 Gefitinib versus placebo, Outcome 18 Increased AST.

Analysis 1.19. Comparison 1 Gefitinib versus placebo, Outcome 19 Neutropenia.

Analysis 1.20. Comparison 1 Gefitinib versus placebo, Outcome 20 Anaemia.

Analysis 1.21. Comparison 1 Gefitinib versus placebo, Outcome 21 Thrombocytopaenia.

Analysis 1.22. Comparison 1 Gefitinib versus placebo, Outcome 22 Overall response rate.

Analysis 1.23. Comparison 1 Gefitinib versus placebo, Outcome 23 Disease control rate.

Analysis 2.1. Comparison 2 Gefitinib versus placebo (Asian subgroup), Outcome 1 HR Overall survival.

Analysis 2.2. Comparison 2 Gefitinib versus placebo (Asian subgroup), Outcome 2 HR Progression-free survival.

Analysis 2.3. Comparison 2 Gefitinib versus placebo (Asian subgroup), Outcome 3 1-year survival rate.

Analysis 2.4. Comparison 2 Gefitinib versus placebo (Asian subgroup), Outcome 4 Overall response rate.

Analysis 3.1. Comparison 3 Gefitinib versus placebo (biomarker subgroup), Outcome 1 HR Overall survival.

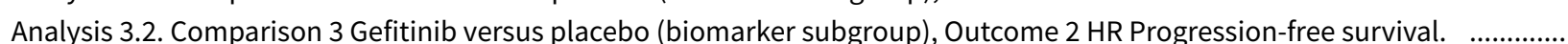

Analysis 4.1. Comparison 4 Gefitinib versus chemotherapy, Outcome 1 HR Overall survival.

Analysis 4.2. Comparison 4 Gefitinib versus chemotherapy, Outcome 2 HR Progression-free survival. 
Analysis 4.3. Comparison 4 Gefitinib versus chemotherapy, Outcome 3 1-year survival rate.

Analysis 4.4. Comparison 4 Gefitinib versus chemotherapy, Outcome 4 Skin rash.

Analysis 4.5. Comparison 4 Gefitinib versus chemotherapy, Outcome 5 Constipation.

Analysis 4.6. Comparison 4 Gefitinib versus chemotherapy, Outcome 6 Fatigue.

Analysis 4.7. Comparison 4 Gefitinib versus chemotherapy, Outcome 7 Asthenia.

Analysis 4.8. Comparison 4 Gefitinib versus chemotherapy, Outcome 8 Neurotoxicity.

Analysis 4.9. Comparison 4 Gefitinib versus chemotherapy, Outcome 9 Neutropenia.

Analysis 4.10. Comparison 4 Gefitinib versus chemotherapy, Outcome 10 Leukopenia.

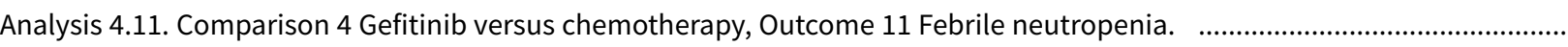

Analysis 4.12. Comparison 4 Gefitinib versus chemotherapy, Outcome 12 Pruritus.

Analysis 4.13. Comparison 4 Gefitinib versus chemotherapy, Outcome 13 Diarrhoea.

Analysis 4.14. Comparison 4 Gefitinib versus chemotherapy, Outcome 14 Vomiting.

Analysis 4.15. Comparison 4 Gefitinib versus chemotherapy, Outcome 15 Anorexia.

Analysis 4.16. Comparison 4 Gefitinib versus chemotherapy, Outcome 16 Stomatitis.

Analysis 4.17. Comparison 4 Gefitinib versus chemotherapy, Outcome 17 Arthralgia/myalgia.

Analysis 4.18. Comparison 4 Gefitinib versus chemotherapy, Outcome 18 Peripheral oedema.

Analysis 4.19. Comparison 4 Gefitinib versus chemotherapy, Outcome 19 Respiratory tract infection.

Analysis 4.20. Comparison 4 Gefitinib versus chemotherapy, Outcome 20 Dyspnoea.

Analysis 4.21. Comparison 4 Gefitinib versus chemotherapy, Outcome 21 Cough.

Analysis 4.22. Comparison 4 Gefitinib versus chemotherapy, Outcome 22 Anaemia.

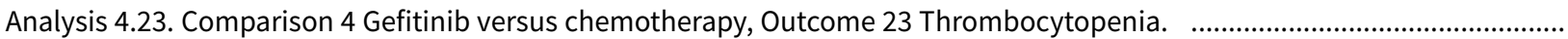

Analysis 4.24. Comparison 4 Gefitinib versus chemotherapy, Outcome 24 Hypokalaemia.

Analysis 4.25. Comparison 4 Gefitinib versus chemotherapy, Outcome 25 Pyrexia.

Analysis 4.26. Comparison 4 Gefitinib versus chemotherapy, Outcome 26 Overall response rate.

Analysis 4.27. Comparison 4 Gefitinib versus chemotherapy, Outcome 27 Disease control rate.

Analysis 4.28. Comparison 4 Gefitinib versus chemotherapy, Outcome 28 FACT-L QOL improvement rate.

Analysis 4.29. Comparison 4 Gefitinib versus chemotherapy, Outcome 29 LCS QOL improvement rate.

Analysis 4.30. Comparison 4 Gefitinib versus chemotherapy, Outcome 30 TOI QOL improvement rate.

Analysis 4.31. Comparison 4 Gefitinib versus chemotherapy, Outcome 31 PSI QOL improvement rate.

Analysis 5.1. Comparison 5 Gefitinib versus chemotherapy (Asian subgroup), Outcome $1 \mathrm{HR}$ Overall survival = 1st line.

Analysis 5.2. Comparison 5 Gefitinib versus chemotherapy (Asian subgroup), Outcome 2 HR Overall survival $=2$ nd line. .........

Analysis 5.3. Comparison 5 Gefitinib versus chemotherapy (Asian subgroup), Outcome 3 HR Overall survival = Maintenance. ..

Analysis 5.4. Comparison 5 Gefitinib versus chemotherapy (Asian subgroup), Outcome 4 HR Progression-free survival $=1$ st line.

Analysis 5.5. Comparison 5 Gefitinib versus chemotherapy (Asian subgroup), Outcome 5 HR Progression-free survival $=2$ nd line.

Analysis 5.6. Comparison 5 Gefitinib versus chemotherapy (Asian subgroup), Outcome 6 HR Progression-free survival = Maintenance.

Analysis 5.7. Comparison 5 Gefitinib versus chemotherapy (Asian subgroup), Outcome 7 1-year survival rate.

Analysis 5.8. Comparison 5 Gefitinib versus chemotherapy (Asian subgroup), Outcome 8 Nausea.

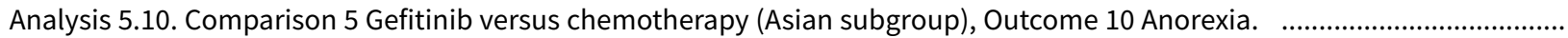

Analysis 5.11. Comparison 5 Gefitinib versus chemotherapy (Asian subgroup), Outcome 11 Fatigue.

Analysis 5.12. Comparison 5 Gefitinib versus chemotherapy (Asian subgroup), Outcome 12 Arthralgia/myalgia. ....................

Analysis 5.13. Comparison 5 Gefitinib versus chemotherapy (Asian subgroup), Outcome 13 Asthenia.

Analysis 5.14. Comparison 5 Gefitinib versus chemotherapy (Asian subgroup), Outcome 14 Neurotoxicity.

Analysis 5.15. Comparison 5 Gefitinib versus chemotherapy (Asian subgroup), Outcome 15 Neutropenia.

Analysis 5.16. Comparison 5 Gefitinib versus chemotherapy (Asian subgroup), Outcome 16 Anaemia.

Analysis 5.17. Comparison 5 Gefitinib versus chemotherapy (Asian subgroup), Outcome 17 Leukopenia.

Analysis 5.18. Comparison 5 Gefitinib versus chemotherapy (Asian subgroup), Outcome 18 Thrombocytopenia.

Analysis 5.19. Comparison 5 Gefitinib versus chemotherapy (Asian subgroup), Outcome 19 Febrile neutropenia. ...................

Analysis 5.20. Comparison 5 Gefitinib versus chemotherapy (Asian subgroup), Outcome 20 Skin rash. 
Analysis 5.21. Comparison 5 Gefitinib versus chemotherapy (Asian subgroup), Outcome 21 Diarrhoea.

Analysis 5.22. Comparison 5 Gefitinib versus chemotherapy (Asian subgroup), Outcome 22 Increased ALT.

Analysis 5.23. Comparison 5 Gefitinib versus chemotherapy (Asian subgroup), Outcome 23 Increased AST.

Analysis 5.24. Comparison 5 Gefitinib versus chemotherapy (Asian subgroup), Outcome 24 Overall response rate. .................

Analysis 5.25. Comparison 5 Gefitinib versus chemotherapy (Asian subgroup), Outcome 25 Stable disease.

Analysis 5.26. Comparison 5 Gefitinib versus chemotherapy (Asian subgroup), Outcome 26 Disease control rate. ...................

Analysis 5.27. Comparison 5 Gefitinib versus chemotherapy (Asian subgroup), Outcome 27 FACT-L QOL improvement rate. ....

Analysis 5.28. Comparison 5 Gefitinib versus chemotherapy (Asian subgroup), Outcome 28 LCS QOL improvement rate. ........

Analysis 5.29. Comparison 5 Gefitinib versus chemotherapy (Asian subgroup), Outcome 29 TOI QOL improvement rate. .........

Analysis 6.1. Comparison 6 Gefitinib versus chemotherapy (EGFR mutation), Outcome $1 \mathrm{HR}$ Overall survival $=1$ st line. $\quad . . . . . . . . . .$. Analysis 6.2. Comparison 6 Gefitinib versus chemotherapy (EGFR mutation), Outcome 2 HR Overall survival $=2$ nd line. ..........

Analysis 6.3. Comparison 6 Gefitinib versus chemotherapy (EGFR mutation), Outcome 3 HR Progression-free survival $=1$ st line.

Analysis 6.4. Comparison 6 Gefitinib versus chemotherapy (EGFR mutation), Outcome 4 HR Progression-free survival $=$ 2nd line.

Analysis 6.5. Comparison 6 Gefitinib versus chemotherapy (EGFR mutation), Outcome 5 Overall response rate. ......................

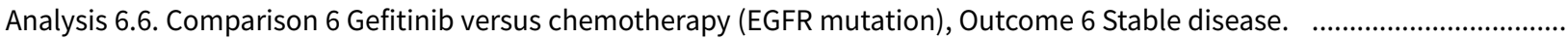
Analysis 6.7. Comparison 6 Gefitinib versus chemotherapy (EGFR mutation), Outcome 7 Disease control rate. ......................... Analysis 7.1. Comparison 7 Gefitinib $250 \mathrm{mg}$ versus gefitinib $500 \mathrm{mg}$, Outcome 11 -year survival rate.

Analysis 7.2. Comparison 7 Gefitinib $250 \mathrm{mg}$ versus gefitinib $500 \mathrm{mg}$, Outcome 2 Skin rash.

Analysis 7.3. Comparison 7 Gefitinib $250 \mathrm{mg}$ versus gefitinib $500 \mathrm{mg}$, Outcome 3 Acne.

Analysis 7.4. Comparison 7 Gefitinib $250 \mathrm{mg}$ versus gefitinib $500 \mathrm{mg}$, Outcome 4 Pruritus.

Analysis 7.5. Comparison 7 Gefitinib $250 \mathrm{mg}$ versus gefitinib $500 \mathrm{mg}$, Outcome 5 Diarrhoea.

Analysis 7.6. Comparison 7 Gefitinib $250 \mathrm{mg}$ versus gefitinib $500 \mathrm{mg}$, Outcome 6 Nausea.

Analysis 7.7. Comparison 7 Gefitinib $250 \mathrm{mg}$ versus gefitinib $500 \mathrm{mg}$, Outcome 7 Vomiting.

Analysis 7.8. Comparison 7 Gefitinib $250 \mathrm{mg}$ versus gefitinib $500 \mathrm{mg}$, Outcome 8 Anorexia.

Analysis 7.9. Comparison 7 Gefitinib $250 \mathrm{mg}$ versus gefitinib $500 \mathrm{mg}$, Outcome 9 Asthenia.

Analysis 7.10. Comparison 7 Gefitinib $250 \mathrm{mg}$ versus gefitinib $500 \mathrm{mg}$, Outcome 10 Overall response rate.

Analysis 7.11. Comparison 7 Gefitinib $250 \mathrm{mg}$ versus gefitinib $500 \mathrm{mg}$, Outcome 11 Partial response.

Analysis 7.12. Comparison 7 Gefitinib $250 \mathrm{mg}$ versus gefitinib $500 \mathrm{mg}$, Outcome 12 FACT-L Symptom improvement rate. .........

Analysis 7.13. Comparison 7 Gefitinib $250 \mathrm{mg}$ versus gefitinib $500 \mathrm{mg}$, Outcome 13 TOI QOL improvement rate.

Analysis 8.1. Comparison 8 Gefitinib versus gefitinib + chemotherapy, Outcome 1 HR Progression-free survival.

Analysis 8.2. Comparison 8 Gefitinib versus gefitinib + chemotherapy, Outcome 21 -year survival rate.

Analysis 8.3. Comparison 8 Gefitinib versus gefitinib + chemotherapy, Outcome 31 -year progression-free survival. ................

Analysis 8.4. Comparison 8 Gefitinib versus gefitinib + chemotherapy, Outcome 4 Skin rash.

Analysis 8.5. Comparison 8 Gefitinib versus gefitinib + chemotherapy, Outcome 5 Diarrhoea.

Analysis 8.6. Comparison 8 Gefitinib versus gefitinib + chemotherapy, Outcome 6 Constipation.

Analysis 8.7. Comparison 8 Gefitinib versus gefitinib + chemotherapy, Outcome 7 Fatigue.

Analysis 8.8. Comparison 8 Gefitinib versus gefitinib + chemotherapy, Outcome 8 Leukopenia.

Analysis 8.9. Comparison 8 Gefitinib versus gefitinib + chemotherapy, Outcome 9 Anaemia.

Analysis 8.10. Comparison 8 Gefitinib versus gefitinib + chemotherapy, Outcome 10 Thrombocytopenia. .............................

Analysis 8.11. Comparison 8 Gefitinib versus gefitinib + chemotherapy, Outcome 11 Neutropenia.

Analysis 8.12. Comparison 8 Gefitinib versus gefitinib + chemotherapy, Outcome 12 Increased ALT.

Analysis 8.13. Comparison 8 Gefitinib versus gefitinib + chemotherapy, Outcome 13 Increased AST.

Analysis 8.14. Comparison 8 Gefitinib versus gefitinib + chemotherapy, Outcome 14 Vomiting.

Analysis 8.15. Comparison 8 Gefitinib versus gefitinib + chemotherapy, Outcome 15 Nausea.

Analysis 8.16. Comparison 8 Gefitinib versus gefitinib + chemotherapy, Outcome 16 Overall response rate.

Analysis 8.17. Comparison 8 Gefitinib versus gefitinib + chemotherapy, Outcome 17 Partial response.

Analysis 8.18. Comparison 8 Gefitinib versus gefitinib + chemotherapy, Outcome 18 Stable disease.

Analysis 9.1. Comparison 9 Gefitinib + chemotherapy versus chemotherapy, Outcome 1 HR Overall survival. 
Analysis 9.5. Comparison 9 Gefitinib + chemotherapy versus chemotherapy, Outcome 5 Acne.

Analysis 9.6. Comparison 9 Gefitinib + chemotherapy versus chemotherapy, Outcome 6 Diarrhoea.

Analysis 9.7. Comparison 9 Gefitinib + chemotherapy versus chemotherapy, Outcome 7 Pruritus.

Analysis 9.8. Comparison 9 Gefitinib + chemotherapy versus chemotherapy, Outcome 8 Vomiting.

Analysis 9.9. Comparison 9 Gefitinib + chemotherapy versus chemotherapy, Outcome 9 Nausea.

Analysis 9.10. Comparison 9 Gefitinib + chemotherapy versus chemotherapy, Outcome 10 Anorexia.

Analysis 9.11. Comparison 9 Gefitinib + chemotherapy versus chemotherapy, Outcome 11 Asthenia.

Analysis 9.12. Comparison 9 Gefitinib + chemotherapy versus chemotherapy, Outcome 12 Dyspnoea.

Analysis 9.13. Comparison 9 Gefitinib + chemotherapy versus chemotherapy, Outcome 13 Anaemia.

Analysis 9.14. Comparison 9 Gefitinib + chemotherapy versus chemotherapy, Outcome 14 Neutropenia.

Analysis 9.15. Comparison 9 Gefitinib + chemotherapy versus chemotherapy, Outcome 15 Leukopenia.

Analysis 9.16. Comparison 9 Gefitinib + chemotherapy versus chemotherapy, Outcome 16 Overall response rate. 
[Intervention Review]

\section{Gefitinib for advanced non-small cell lung cancer}

Esther HA Sim ${ }^{1}$, Ian A Yang2,3, Richard Wood-Baker ${ }^{4}$, Rayleen V Bowman³, Kwun M Fong 3

1GenesisCare Radiation Oncology, Urraween, Australia. 2UQ Thoracic Research Centre, School of Medicine, The University of Queensland, Brisbane, Australia. ${ }^{3}$ Department of Thoracic Medicine, The Prince Charles Hospital, Brisbane, Australia. ${ }^{4}$ School of Medicine, University of Tasmania, Hobart, Australia

Contact address: Esther HA Sim, GenesisCare Radiation Oncology, 1 Medical Place, Urraween, Queensland, 4655, Australia. esther.h.sim@gmail.com.

Editorial group: Cochrane Lung Cancer Group.

Publication status and date: New, published in Issue 1, 2018.

Citation: Sim EHA, Yang IA, Wood-Baker R, Bowman RV, Fong KM. Gefitinib for advanced non-small cell lung cancer. Cochrane Database of Systematic Reviews 2018, Issue 1. Art. No.: CD006847. DOI: 10.1002/14651858.CD006847.pub2.

Copyright @ 2018 The Cochrane Collaboration. Published by John Wiley \& Sons, Ltd.

\section{A B S T R A C T}

\section{Background}

The role of gefitinib for the treatment of advanced non-small cell lung cancer (NSCLC) is evolving. We undertook a systematic review to evaluate the available evidence from all randomised trials.

\section{Objectives}

To determine the effectiveness and safety of gefitinib as first-line, second-line or maintenance treatment for advanced NSCLC.

\section{Search methods}

We performed searches in CENTRAL, MEDLINE and Embase from inception to 17 February 2017. We handsearched relevant conference proceedings, clinical trial registries and references lists of retrieved articles.

\section{Selection criteria}

We included trials assessing gefitinib, alone or in combination with other treatment, compared to placebo or other treatments in the firstor successive-line treatment of patients with NSCLC, excluding compassionate use.

\section{Data collection and analysis}

We used the standard Cochrane methodology. Two authors independently assessed the search results to select those with sound methodological quality. We carried out all analyses on an intention-to-treat basis. We recorded the following outcome data: overall survival, progression-free survival, toxicity, tumour response and quality of life. We also collected data for the following subgroups: Asian ethnicity and positive epidermal growth factor receptor (EGFR) mutation.

\section{Main results}

We included 35 eligible randomised controlled trials (RCTs), which examined 12,089 patients.

\section{General population}

Gefitinib did not statistically improve overall survival when compared with placebo or chemotherapy in either first- or second-line settings. Second-line gefitinib prolonged time to treatment failure (TTF) (hazard ratio (HR) $0.82,95 \%$ confidence interval $(\mathrm{Cl}) 0.75$ to $0.90, \mathrm{P}<0.0001$ ) when compared with placebo. Maintenance gefitinib improved progression-free survival ( $\mathrm{HR} 0.70,95 \% \mathrm{Cl} 0.53$ to $0.91, \mathrm{P}=0.007)$ after firstline therapy. 


\section{Studies in patients of Asian ethnicity or that conducted subgroup analyses}

Second-line gefitinib prolonged overall survival over placebo ( $\mathrm{HR} 0.66,95 \% \mathrm{Cl} 0.48$ to $0.91, \mathrm{P}=0.01$ ). In the first-line setting, progressionfree survival was improved with gefitinib over chemotherapy alone $(\mathrm{HR} 0.65,95 \% \mathrm{Cl} 0.43$ to $0.98, \mathrm{P}=0.04$, moderate quality of evidence). Gefitinib given in combination with a chemotherapy regimen improved progression-free survival versus either gefitinib alone or chemotherapy alone ( $\mathrm{HR} 0.69,95 \% \mathrm{Cl} 0.49$ to $0.96, \mathrm{P}=0.03 ; \mathrm{HR} 0.69,95 \% \mathrm{Cl} 0.62$ to $0.77, \mathrm{P}<0.00001$, respectively). In the second-line setting, progression-free survival was superior in patients given gefitinib over placebo or chemotherapy $(\mathrm{HR} 0.69,95 \% \mathrm{Cl} 0.52$ to $0.91, \mathrm{P}$ $=0.009 ; \mathrm{HR} 0.71,95 \% \mathrm{Cl} 0.57$ to $0.88, \mathrm{P}=0.002$; moderate quality of evidence, respectively). Combining gefitinib with chemotherapy in the second-line setting was superior to gefitinib alone ( $\mathrm{HR} 0.65,95 \% \mathrm{Cl} 0.43$ to $0.97, \mathrm{P}=0.04)$. As maintenance therapy, gefitinib improved progression-free survival when compared with placebo ( $\mathrm{HR} 0.42,95 \% \mathrm{Cl} 0.33$ to $0.54, \mathrm{P}<0.00001$ ).

\section{Patients with EGFR mutation-positive tumours}

Studies in patients with EGFR mutation-positive tumours showed an improvement in progression-free survival in favour of gefitinib over first-line and second-line chemotherapy ( $\mathrm{HR} 0.47,95 \% \mathrm{Cl} 0.36$ to $0.61, \mathrm{P}<0.00001$; HR $0.24,95 \% \mathrm{Cl} 0.12$ to 0.47 , $\mathrm{P}<0.0001$, respectively). Gefitinib as maintenance therapy following chemotherapy improved overall and progression-free survival $(\mathrm{HR} 0.39,95 \% \mathrm{Cl} 0.15$ to $0.98, \mathrm{P}$ $=0.05 ; \mathrm{HR} 0.17,95 \% \mathrm{Cl} 0.07$ to $0.41, \mathrm{P}<0.0001$, respectively) in one phase III study when compared to placebo.

Toxicities from gefitinib included skin rash, diarrhoea and liver transaminase derangements. Toxicities from chemotherapy included anaemia, neutropenia and neurotoxicity.

In terms of quality of life, gefitinib improved Functional Assessment of Cancer Therapy-Lung (FACT-L) (standardised mean difference (SMD) $10.50,95 \% \mathrm{Cl} 9.55$ to $11.45, \mathrm{P}<0.000001$ ), lung cancer subscale (SMD 3.63, 95\% Cl 3.08 to 4.19, $\mathrm{P}<0.00001$ ) and Trial Outcome Index (SMD $9.87,95 \% \mathrm{Cl} 1.26$ to $18.48, \mathrm{P}<0.00001$ ) scores when compared with chemotherapy.

\section{Authors' conclusions}

This systematic review shows that gefitinib, when compared with standard first- or second-line chemotherapy or maintenance therapy, probably has a beneficial effect on progression-free survival and quality of life in selected patient populations, particularly those with tumours bearing sensitising EGFR mutations.

Patients with EGFR mutations lived longer when given maintenance gefitinib than those given placebo.

One study conducted subgroup analysis and showed that gefitinib improved overall survival over placebo in the second-line setting in patients of Asian ethnicity. All other studies did not detect any benefit on overall survival. The data analysed in this review were very heterogenous. We were limited in the amount of data that could be pooled, largely due to variations in study design. The risk of bias in most studies was moderate, with some studies not adequately addressing potential selection, attrition and reporting bias. This heterogeneity may have an impact on the applicability of the results

Combining gefitinib with chemotherapy appears to be superior in improving progression-free survival to either gefitinib or chemotherapy alone, however further data and phase III studies in these settings are required.

Gefitinib has a favourable toxicity profile when compared with current chemotherapy regimens. Although there is no improvement in overall survival, gefitinib compares favourably with cytotoxic chemotherapy in patients with EGFR mutations with a prolongation of progression-free survival and a lesser side effect profile.

\section{PLAIN LANGUAGE SUMMARY}

\section{A comparison of gefitinib with no therapy or chemotherapy for non-small cell lung cancer}

\section{Review question}

Do patients with non-small cell lung cancer live longer if they are given gefitinib?

\section{Background}

Non-small cell lung cancer (the most common type of lung cancer) is a leading cause of cancer death worldwide. People diagnosed with advanced lung cancer may be offered chemotherapy.

Some lung cancers have been found to have a gene mutation, which is an alteration in the chromosome sequence inside the cells. This mutation affects the epidermal growth factor receptor (EGFR), which is a switch on the surface of the cell leading to uncontrolled growth and spread. Gefitinib is a drug that targets cells with mutated EGFR, thus stopping their growth. Studies have found that this mutation is more commonly found in people who are non-smokers, female, of Asian heritage and with adenocarcinoma (a type of lung cancer).

\section{Study characteristics}


We searched for relevant trials up to 17 February 2017. There were a total of 35 studies conducted between 2000 and 2017 , evaluating 12,089 participants from multiple countries including North America, Europe and Asia.

\section{Key results}

This review showed that patients with advanced lung cancer do not live longer when treated with gefitinib when compared with no other treatment or chemotherapy. In people whose lung cancer has worsened after initial therapy, gefitinib may prolong the time before the cancer progresses further, but only in a selected group of patients of Asian ethnicity or with EGFR mutations. Combining gefitinib with chemotherapy probably increases the time to cancer progression over either gefitinib or chemotherapy alone. For EGFR-mutation positive patients who are stable after chemotherapy, ongoing gefitinib has been shown to improve survival when compared to placebo.

Severe side effects, such as low red and white blood cell counts and nerve symptoms, occurred more frequently in patients given chemotherapy compared to those given gefitinib. Side effects caused by gefitinib included a skin rash, diarrhoea and liver dysfunction.

Quality of life may be improved in favour of gefitinib when compared with chemotherapy.

\section{Quality of the evidence}

When comparing gefitinib as a first- and second-line treatment with chemotherapy, we downgraded the quality of the evidence to moderate for the outcomes overall survival and progression-free survival because the results were not precise and they may not be applicable to all patients due to the inclusion of a population only over 70 years of age. However, the quality of the evidence when we compared toxicities from gefitinib with chemotherapy was high. 
SUMMARY OF FINDINGS

Summary of findings for the main comparison. Gefitinib compared to chemotherapy for first-line treatment of advanced NSCLC

Gefitinib compared to chemotherapy for first-line treatment of advanced NSCLC

Patient or population: advanced NSCLC

Settings: first-line treatment

Intervention: gefitinib

Comparison: chemotherapy

\begin{tabular}{|c|c|c|c|c|c|c|}
\hline \multirow[t]{3}{*}{ Outcomes } & \multicolumn{2}{|c|}{ Illustrative comparative risks* $(95 \% \mathrm{CI})$} & \multirow{3}{*}{$\begin{array}{l}\text { Relative effect } \\
(95 \% \mathrm{CI})\end{array}$} & \multirow{3}{*}{$\begin{array}{l}\text { No of partici- } \\
\text { pants } \\
\text { (studies) }\end{array}$} & \multirow{3}{*}{$\begin{array}{l}\text { Quality of the } \\
\text { evidence } \\
\text { (GRADE) }\end{array}$} & \multirow[t]{3}{*}{ Comments } \\
\hline & Assumed risk & Corresponding risk & & & & \\
\hline & Chemotherapy & Gefitinib & & & & \\
\hline $\begin{array}{l}\text { Overall survival } \\
\text { (OS) }\end{array}$ & $\begin{array}{l}\text { The mean OS ranged } \\
\text { across control groups } \\
\text { from } 3.5 \text { to } 8 \text { months }\end{array}$ & $\begin{array}{l}\text { The mean OS in the in- } \\
\text { tervention group ranged } \\
\text { from } 2.2 \text { to } 5.9 \text { months }\end{array}$ & $\begin{array}{l}\text { HR } 0.98 \text { (0.91 to } \\
1.46)\end{array}$ & $\begin{array}{l}275 \\
\text { (2 RCTs) }\end{array}$ & $\begin{array}{l}\oplus \oplus \oplus \ominus \\
\text { MODERATE } 1\end{array}$ & $\begin{array}{l}\text { OS similar in the Asian (HR } 0.94,0.82 \\
\text { to } 1.06 \text { ) and EGFR mutation positive } \\
\text { subgroups (HR } 0.97,0.77 \text { to } 1.21 \text { ) }\end{array}$ \\
\hline $\begin{array}{l}\text { Progres- } \\
\text { sion-free sur- } \\
\text { vival (PFS) }\end{array}$ & $\begin{array}{l}\text { The PFS ranged across } \\
\text { control groups from } 2 \\
\text { to } 2.9 \text { months }\end{array}$ & $\begin{array}{l}\text { The mean PFS in the in- } \\
\text { tervention group ranged } \\
\text { from } 1.9 \text { to } 2.7 \text { months }\end{array}$ & $\begin{array}{l}\text { HR } 1.19 \text { (0.86 to } \\
1.65)\end{array}$ & $\begin{array}{l}275 \\
\text { (2 RCTs) }\end{array}$ & $\begin{array}{l}\oplus \oplus \oplus \ominus \\
\text { MODERATE } 1\end{array}$ & $\begin{array}{l}\text { PFS improved with gefitinib in the } \\
\text { Asian subgroup (HR } 0.65,0.43 \text { to } 0.98 \text { ) } \\
\text { and the EGFR mutation positive sub- } \\
\text { group (HR } 0.47,0.36 \text { to } 0.61 \text { ) }\end{array}$ \\
\hline
\end{tabular}

*The basis for the assumed risk (e.g. the median control group risk across studies) is provided in footnotes. The corresponding risk (and its $95 \%$ confidence interval) is based on the assumed risk in the comparison group and the relative effect of the intervention (and its $95 \% \mathrm{Cl}$ ).

Cl: confidence interval; EGFR: epidermal growth factor receptor; HR: hazard ratio; NSCLC: non-small cell lung cancer; OS: overall survival; PFS: progression-free survival;

RCT: randomised controlled trial

GRADE Working Group grades of evidence

High quality: Further research is very unlikely to change our confidence in the estimate of effect.

Moderate quality: Further research is likely to have an important impact on our confidence in the estimate of effect and may change the estimate.

Low quality: Further research is very likely to have an important impact on our confidence in the estimate of effect and is likely to change the estimate.

Very low quality: We are very uncertain about the estimate.

1 We downgraded the quality of evidence by one level because of serious indirectness as one study included only elderly patients (> 70 years old).

Summary of findings 2 . Gefitinib compared to chemotherapy for second-line treatment of advanced NSCLC

Gefitinib compared to chemotherapy for second-line treatment of advanced NSCLC

$\rightarrow$ 
Patient or population: advanced NSCLC

Settings: second-line therapy

Intervention: gefitinib

Comparison: chemotherapy

\begin{tabular}{|c|c|c|c|c|c|c|}
\hline \multirow[t]{3}{*}{ Outcomes } & \multicolumn{2}{|c|}{ Illustrative comparative risks* $(95 \% \mathrm{CI})$} & \multirow{3}{*}{$\begin{array}{l}\text { Relative effect } \\
(95 \% \mathrm{CI})\end{array}$} & \multirow{3}{*}{$\begin{array}{l}\text { No of partici- } \\
\text { pants } \\
\text { (studies) }\end{array}$} & \multirow{3}{*}{$\begin{array}{l}\text { Quality of the } \\
\text { evidence } \\
\text { (GRADE) }\end{array}$} & \multirow[t]{3}{*}{ Comments } \\
\hline & Assumed risk & Corresponding risk & & & & \\
\hline & Chemotherapy & Gefitinib & & & & \\
\hline $\begin{array}{l}\text { Overall survival } \\
\text { (OS) }\end{array}$ & $\begin{array}{l}\text { The mean OS ranged } \\
\text { across control groups } \\
\text { from } \mathbf{7 . 1} \text { to } 8 \text { months }\end{array}$ & $\begin{array}{l}\text { The mean OS in the in- } \\
\text { tervention group ranged } \\
\text { from } \mathbf{7 . 5} \text { to } \mathbf{7 . 6} \text { months }\end{array}$ & $\begin{array}{l}\text { HR } \mathbf{1 . 0 2} \text { (0.91 to } \\
1.15)\end{array}$ & $\begin{array}{l}1607 \\
\text { (2 RCTs) }\end{array}$ & $\begin{array}{l}\oplus \oplus \oplus \ominus \\
\text { MODERATE } 1\end{array}$ & $\begin{array}{l}\text { OS similar in Asian patients (HR } 0.94 \text {, } \\
0.79 \text { to } 1.12 \text { ) and EGFR mutation positive } \\
\text { patients (HR } 0.83,0.41 \text { to } 1.66 \text { ). }\end{array}$ \\
\hline $\begin{array}{l}\text { Progres- } \\
\text { sion-free sur- } \\
\text { vival (PFS) }\end{array}$ & $\begin{array}{l}\text { The mean PFS ranged } \\
\text { across control groups } \\
\text { from } \mathbf{2 . 7} \text { to } \mathbf{3 . 4} \text { months }\end{array}$ & $\begin{array}{l}\text { The mean PFS in the in- } \\
\text { tervention group ranged } \\
\text { from } \mathbf{2 . 2} \text { to } \mathbf{3} \text { months }\end{array}$ & $\begin{array}{l}\text { HR } 1.04 \text { ( } 0.92 \text { to } \\
1.17)\end{array}$ & $\begin{array}{l}1607 \\
\text { (2 RCTs) }\end{array}$ & $\begin{array}{l}\oplus \oplus \oplus \ominus \\
\text { MODERATE } 1\end{array}$ & $\begin{array}{l}\text { PFS significantly improved in Asian pa- } \\
\text { tients (HR } 0.71,0.57 \text { to } 0.88 \text { ) and in pa- } \\
\text { tients positive for EGFR mutation (HR } \\
0.24,0.12 \text { to } 0.47 \text { ) (ranged from } 2.7 \text { to } 4.1 \\
\text { months versus } 4.5 \text { to } 7 \text { months). }\end{array}$ \\
\hline
\end{tabular}

*The basis for the assumed risk (e.g. the median control group risk across studies) is provided in footnotes. The corresponding risk (and its $95 \%$ confidence interval) is based on the assumed risk in the comparison group and the relative effect of the intervention (and its $95 \% \mathrm{Cl}$ ).

CI: confidence interval; EGFR: epidermal growth factor receptor; HR: hazard ratio; NSCLC: non-small cell lung cancer; OS: overall survival; PFS: progression-free survival; RCT: randomised controlled trial

GRADE Working Group grades of evidence

High quality: Further research is very unlikely to change our confidence in the estimate of effect.

Moderate quality: Further research is likely to have an important impact on our confidence in the estimate of effect and may change the estimate.

Low quality: Further research is very likely to have an important impact on our confidence in the estimate of effect and is likely to change the estimate.

Very low quality: We are very uncertain about the estimate.

${ }^{1}$ We downgraded the quality of evidence by one level because of imprecision based on the wide confidence interval.

Summary of findings 3. Gefitinib compared to chemotherapy for advanced NSCLC - toxicity

Gefitinib compared to chemotherapy for advanced NSCLC

Patient or population: advanced NSCLC

Settings: first-line and second-line therapy

Intervention: gefitinib

Comparison: chemotherapy 


\begin{tabular}{|c|c|c|c|c|c|}
\hline \multirow[t]{3}{*}{ Outcomes } & \multicolumn{2}{|c|}{ Illustrative comparative risks* $(95 \% \mathrm{Cl})$} & \multirow{3}{*}{$\begin{array}{l}\text { Relative effect } \\
(95 \% \mathrm{CI})\end{array}$} & \multirow{3}{*}{$\begin{array}{l}\text { No of participants } \\
\text { (studies) }\end{array}$} & \multirow{3}{*}{$\begin{array}{l}\text { Quality of the evi- } \\
\text { dence } \\
\text { (GRADE) }\end{array}$} \\
\hline & Assumed risk & Corresponding risk & & & \\
\hline & Chemotherapy & Gefitinib & & & \\
\hline \multirow[t]{2}{*}{ Skin rash } & \multicolumn{2}{|l|}{ Study population } & \multirow{2}{*}{$\begin{array}{l}\text { RR } 2.40 \\
\text { (1.08 to } 5.31 \text { ) }\end{array}$} & \multirow{2}{*}{$\begin{array}{l}1858 \\
\text { (4 RCTs) }\end{array}$} & \multirow{2}{*}{$\begin{array}{l}\oplus \oplus \oplus \oplus \\
\mathrm{HIGH}\end{array}$} \\
\hline & 9 per 1000 & $\begin{array}{l}21 \text { per } 1000 \\
(9 \text { to } 46)\end{array}$ & & & \\
\hline \multirow[t]{2}{*}{ Constipation } & \multicolumn{2}{|l|}{ Study population } & \multirow{2}{*}{$\begin{array}{l}\text { RR } 0.41 \\
\text { (0.17 to } 0.97 \text { ) }\end{array}$} & \multirow{2}{*}{$\begin{array}{l}1719 \\
\text { (3 studies) }\end{array}$} & \multirow{2}{*}{$\begin{array}{l}\oplus \oplus \oplus \oplus \\
\mathrm{HIGH}\end{array}$} \\
\hline & 19 per 1000 & $\begin{array}{l}8 \text { per } 1000 \\
(3 \text { to } 18)\end{array}$ & & & \\
\hline \multirow[t]{2}{*}{ Fatigue } & \multicolumn{2}{|l|}{ Study population } & \multirow{2}{*}{$\begin{array}{l}\text { RR } 0.16 \\
\text { (0.03 to } 0.88 \text { ) }\end{array}$} & \multirow{2}{*}{$\begin{array}{l}275 \\
\text { ( } 2 \text { studies) }\end{array}$} & \multirow{2}{*}{$\begin{array}{l}\oplus \oplus \oplus \ominus \\
\text { MODERATE } 1\end{array}$} \\
\hline & 65 per 1000 & $\begin{array}{l}10 \text { per } 1000 \\
(2 \text { to } 57)\end{array}$ & & & \\
\hline \multirow[t]{2}{*}{ Asthenia } & \multicolumn{2}{|l|}{ Study population } & \multirow{2}{*}{$\begin{array}{l}\text { RR } 0.51 \\
\text { (0.35 to } 0.75)\end{array}$} & \multirow{2}{*}{$\begin{array}{l}1773 \\
\text { (3 studies) }\end{array}$} & \multirow{2}{*}{$\begin{array}{l}\oplus \oplus \oplus \oplus \\
\mathrm{HIGH}\end{array}$} \\
\hline & 79 per 1000 & $\begin{array}{l}40 \text { per } 1000 \\
(28 \text { to } 60)\end{array}$ & & & \\
\hline \multirow[t]{2}{*}{ Neurotoxicity } & \multicolumn{2}{|l|}{ Study population } & \multirow{2}{*}{$\begin{array}{l}\text { RR } 0.07 \\
(0.01 \text { to } 0.34)\end{array}$} & \multirow{2}{*}{$\begin{array}{l}1529 \\
\text { (2 studies) }\end{array}$} & \multirow{2}{*}{$\begin{array}{l}\oplus \oplus \oplus \oplus \\
\mathrm{HIGH}\end{array}$} \\
\hline & 29 per 1000 & $\begin{array}{l}2 \text { per } 1000 \\
(0 \text { to } 10)\end{array}$ & & & \\
\hline \multirow[t]{2}{*}{ Neutropenia } & Study population & & \multirow{2}{*}{$\begin{array}{l}\text { RR } 0.04 \\
\text { (0.02 to } 0.06)\end{array}$} & \multirow{2}{*}{$\begin{array}{l}1857 \\
\text { (4 studies) }\end{array}$} & \multirow{2}{*}{$\begin{array}{l}\oplus \oplus \oplus \oplus \\
\mathrm{HIGH}\end{array}$} \\
\hline & 505 per 1000 & $\begin{array}{l}20 \text { per } 1000 \\
(10 \text { to } 30)\end{array}$ & & & \\
\hline \multirow{2}{*}{$\begin{array}{l}\text { Febrile neutrope- } \\
\text { nia }\end{array}$} & Study population & & \multirow{2}{*}{$\begin{array}{l}\text { RR } 0.12 \\
\text { (0.06 to } 0.23 \text { ) }\end{array}$} & \multirow{2}{*}{$\begin{array}{l}1768 \\
\text { (3 studies) }\end{array}$} & \multirow{2}{*}{$\begin{array}{l}\oplus \oplus \oplus \oplus \\
\mathrm{HIGH}\end{array}$} \\
\hline & 92 per 1000 & $\begin{array}{l}11 \text { per } 1000 \\
(6 \text { to } 21)\end{array}$ & & & \\
\hline
\end{tabular}

${ }^{\star}$ The basis for the assumed risk (e.g. the median control group risk across studies) is provided in footnotes. The corresponding risk (and its $95 \%$ confidence interval) is based on the assumed risk in the comparison group and the relative effect of the intervention (and its $95 \% \mathrm{Cl}$ ). 
GRADE Working Group grades of evidence

High quality: Further research is very unlikely to change our confidence in the estimate of effect.

Moderate quality: Further research is likely to have an important impact on our confidence in the estimate of effect and may change the estimate.

Low quality: Further research is very likely to have an important impact on our confidence in the estimate of effect and is likely to change the estimate.

Very low quality: We are very uncertain about the estimate.

${ }^{1}$ We downgraded the quality of evidence by one level because of serious indirectness as one study included only elderly patients (> 70 years old) 


\section{B A C K G R O U N D}

\section{Description of the condition}

Non-small cell lung cancer (NSCLC) accounts for $14 \%$ of all cancerrelated deaths and is by far the leading cause of cancer death among both men and women. In the United States, it was predicted that about 234,030 new cases of NSCLC would be diagnosed, and 154,050 deaths would result from NSCLC in 2018 (ACS 2018). The survival rate for people diagnosed with NSCLC will vary according to the extent (stage) of the cancer. People with locally advanced NSCLC (stage III or more) have a five-year survival rate of $5 \%$ to $36 \%$, and survival estimates do vary according to stage at diagnosis (ACS 2018). Active treatment of NSCLC consists of surgery, radiotherapy and chemotherapy, given as single therapies or in combination. Although there have been major medical therapeutic advances in recent times, these have not been sufficient to significantly affect the high mortality and morbidity rates associated with lung cancer.

The pathogenesis of lung neoplasms is multifactorial, however most can be directly attributed to tobacco smoke exposure. NSCLC arising in smokers has a different spectrum of molecular abnormalities from those in non-smokers, suggesting differences in aetiology, pathogenesis and possibly prognosis. Mutations of tumour suppressor genes such as p53 and retinoblastoma; stimulation of proto-oncogenes such as K-ras, c-myc and c-raf; and production of autocrine growth factors are some of the potential pathogenic mechanisms so far described in the development of lung cancer. Recent research has identified two oncogenic drivers, epidermal growth factor receptor (EGFR) mutation and EML4/ALK fusion, for which targeted therapies are available.

\section{Description of the intervention}

The epidermal growth factor receptor (EGFR) family of genes encodes a widely expressed transmembrane molecule that is frequently expressed in solid tumours. Overexpression of EGFR has been associated with the pathogenesis, proliferation, invasion and metastasis of various solid tumours, including NSCLC. EGFR is overexpressed in around $40 \%$ to $80 \%$ of documented cases of primary NSCLC and around $88 \%$ of advanced cases of NSCLC (Smith 2005).

Tyrosine kinase inhibitors (TKIs) bind to the intracellular domain of the tyrosine kinase and may inhibit EGFR downstream signalling. Inhibition of tyrosine kinase may, therefore, block EGFR-mediated cancer cell propagation. TKIs may be classified as reversible or irreversible, and as selective against EGFR or active against other members of the receptor family. Somatic mutations in the region of EGFR that encodes the tyrosine kinase domain of the receptor (exons 18 through 21) have been identified in lung cancer. Such mutations occur more frequently in patients with NSCLC who have the adenocarcinoma sub-type, women, Asian people and those who have never smoked (Kosaka 2004; Paez 2004). EGFR mutations are associated with both increased growth factor signalling and increased responsiveness to tyrosine kinase inhibitors (Mok 2011).

\section{How the intervention might work}

Gefitinib (Iressa, ZD 1839) is an orally active anilinoquinazoline that selectively and reversibly inhibits intracellular EGFR tyrosine kinase activity. Two large, randomised phase II clinical trials assessed the efficacy and safety of gefitinib monotherapy in patients with locally advanced or metastatic NSCLC who failed previous chemotherapy regimens (Fukuoka 2003 IDEAL I; Kris 2003 IDEAL II). Both showed no added benefit in terms of survival, time to progression or response rates compared with standard chemotherapy alone. However these monotherapy trials demonstrated a favourable safety profile. A phase III trial comparing gefitinib to placebo in advanced NSCLC patients who had received prior chemotherapy showed an improvement in progression-free survival but no prolongation in overall survival (Thatcher 2005 ISEL). Since these early trials, a number of other randomised controlled trials (RCTs) have examined the effectiveness of gefitinib versus placebo or chemotherapy, or in combination with chemotherapy in the first- and secondline settings. Several studies have also examined its role as maintenance therapy following treatment in patients with advanced NSCLC.

\section{Why it is important to do this review}

The precise clinical effectiveness of gefitinib in a range of clinical situations remains to be established. This review will bring together all the current evidence of effectiveness, in order to guide clinical management and the discussion of treatment risks and benefits in patients with NSCLC.

\section{O B J E C T I VES}

To determine the effectiveness and safety of gefitinib as first-line, second-line or maintenance treatment for advanced NSCLC.

\section{METHODS}

\section{Criteria for considering studies for this review Types of studies}

We considered all published and unpublished randomised, controlled, phase II and phase III clinical trials of gefitinib as first- or second-line or maintenance therapy in advanced NSCLC. We included any placebo-controlled trials and trials using comparators. Trials with random allocation, double-blinding and intention-to-treat analysis were preferred. We excluded crossover studies, studies that were quasi-randomised and those that investigated the compassionate use of gefitinib.

\section{Types of participants}

Eligible trials included adult participants aged 18 years or older of either sex with histologically or cytologically confirmed NSCLC (stage IIIB/IV) not curable with surgery.

\section{Types of interventions}

We considered any administration of gefitinib for advanced NSCLC. This included the use of any dosage of gefitinib as first- or secondline therapy or maintenance therapy:

1. Gefitinib at any dose compared with placebo or best supportive care.

2. Gefitinib at any dose compared with chemotherapeutic agents.

3. Gefitinib at a specific dose versus gefitinib at a different dose.

4. Gefitinib versus gefitinib combined with a chemotherapy regimen.

5. Gefitinib at any dose in combination with chemotherapeutic agents versus the same chemotherapy agents alone. 
6. Gefitinib at any dose in combination with chemotherapeutic agents versus a different combination of chemotherapeutic agents.

\section{Types of outcome measures}

\section{Primary outcomes}

- Overall survival (OS), assessed from date of randomisation to date of patient death (time to death).

- Progression-free survival (PFS):

* Measured from the date of randomisation to the date of objective disease progression, based on Response Evaluation Criteria in Solid Tumours (RECIST), the revised version of the International Union Against Cancer/WHO criteria (Therasse 2000).

* Time to treatment failure (TTF): measured from the date of randomisation to the date of study discontinuation (for any reason). This may be reported instead of PFS in some studies.

- Toxicity (graded according to the National Cancer Institute Common Toxicity Criteria or the World Health Organization criteria (NCI CTCAE 2010).

* However, we accepted whatever definitions had been used in the individual trials. A risk ratio (RR) significantly greater than $1(R R>1)$ is a positive response in favour of gefitinib.

\section{Secondary outcomes}

- Median overall survival (OS) and progression-free survival (PFS).

- Survival rate at one year (1YSR).

- Tumour response - defined according to the RECIST criteria (Therasse 2000):

* Complete response (CR) defined as the disappearance of all target lesions.

* Partial response (PR) defined as at least a 30\% decrease in the sum of the longest diameter of target lesions.

* Overall response rate (ORR) taken as the sum of complete response (CR) rate and partial response (PR) rates.

* Stable disease (SD) defined as neither sufficient shrinkage to qualify for partial response nor sufficient increase to qualify for progressive disease.

* Disease control rate (DCR) defined as the sum of the ORR and SD rate. This represents all lesions that have either responded to the treatment or stabilised as a result of treatment.

- Quality of life (QOL) and symptom response measured by the Functional Assessment of Cancer Therapy-Lung (FACT-L) quality of life instrument, the lung cancer subscale (LCS), the Trial Outcome Index (TOI) and the Pulmonary Symptom Index (PSI) (Cella 1995).

\section{Search methods for identification of studies}

\section{Electronic searches}

We electronically searched for eligible studies using:

- The Cochrane Central Register of Controlled Trials (CENTRAL 2017, Issue 2) (Appendix 1);

- MEDLINE via PubMed (1966 to 17 February 2017) (Appendix 2);

- Embase via OVID (1980 to Week 08, 2017) (Appendix 3).
We developed the search string for MEDLINE according to the Cochrane Highly Sensitive Search Strategy, sensitivity-maximising version (2008 version) as referenced in Chapter 6.4.11.1 and detailed in box 6.4.b of the Cochrane Handbook for Systematic Reviews of Interventions (Higgins 2011).

\section{Searching other resources}

The authors (ES, IY) also screened reference lists of included and excluded studies, attempted to contact authors of relevant studies and examined registers of ongoing trials: ClinicalTrials.gov (ClinicalTrials.gov) and Current Controlled Trials (isrctn.com) to locate all significant published and unpublished data. We also reviewed conference proceedings of the American Society of Clinical Oncology, the European Cancer Conference, the European Society of Medical Oncology and the International Association for the Study of Lung Cancer, from January 1990 to February 2017. When two articles or more used the same data, we only used the most updated article, unless we found some additional information in that article.

\section{Data collection and analysis}

\section{Selection of studies}

We assessed the eligibility of retrieved articles from the title and abstract. Two investigators (ES, IY) reviewed potential trials for inclusion and extracted data from the published manuscripts. We resolved disagreements about relevance either by consensus or by referral to a third investigator (RWB). There was no blinding of the authors as to origin or conclusions of the articles for eligibility assessment, data extraction or 'Risk of bias' assessment. We sought data for all patients randomised in all eligible randomised trials. Two review authors (ES, IY) independently carried out data extraction using a specifically designed data extraction form. We recorded study details, including year of publication, numbers of people randomised and analysed per arm, age, sex, race/ethnicity of participants, staging and histological cell type, performance status and any previous treatment. We also recorded the dose and duration of gefitinib treatment, as well as the use of any chemotherapeutic agents. We double-checked all data for consistency, plausibility and integrity of randomisation and followup.

\section{Data extraction and management}

We extracted data from included studies using the guidelines set out in the Cochrane Handbook for Systematic Reviews of Interventions (Higgins 2011).

\section{Assessment of risk of bias in included studies}

Two authors (ES, IY) independently assessed the risk of bias of included studies according to the areas and criteria proposed in the Cochrane Handbook for Systematic Reviews of Interventions (Higgins 2011). We considered studies to be at low risk of bias when true randomisation occurred, when there was blinding of assessors to treatment received, when all patients were accounted for and included in the analysis on an 'intention-to-treat' basis and when all outcome measures were reported. We also considered studies that were terminated early to have a source of bias of interest.

The results of these judgements are presented in the 'Risk of bias' tables (Characteristics of included studies). 


\section{(1) Sequence generation (checking for possible selection bias)}

For each included study, we assessed the method used to generate the allocation sequence in sufficient detail to allow an evaluation of whether it should produce comparable groups.

We assessed risk of bias as:

- Low risk: any truly random process, e.g. random number table, computer random number generator.

- High risk: any non-random process, e.g. odd or even date of birth, hospital or clinic record number.

- Unclear risk: insufficient information about sequence generation process to permit judgement of risk.

\section{(2) Allocation concealment (checking for possible selection bias)}

For each included study, we assessed the method used to conceal the allocation sequence to determine whether intervention allocations could have been foreseen in advance of, or during, enrolment.

We assessed risk of bias as:

- Low risk: e.g. central or telephone allocation, sequentially numbered drug containers of identical appearance.

- High risk: e.g. open random allocation, unsealed or non-opaque envelopes, alternation or rotation, date of birth.

- Unclear risk: insufficient information to permit judgement of 'low risk' or 'high risk' or the study did not address this outcome.

\section{(3) Blinding (checking for possible performance bias)}

For each included study, we described the methods used, if any, to blind study participants and personnel from knowledge of which intervention a participant received.

We assessed risk of bias as:

- Low risk: blinding of participants and key study personnel was ensured and it was unlikely that the blinding could have been broken, or there was no blinding of outcome measurement, but outcome measurement is unlikely to be influenced by the lack of blinding.

- High risk: no blinding or incomplete blinding and the outcome is likely to be influenced by lack of blinding.

- Unclear risk: insufficient information to permit judgement of 'low risk' or 'high risk' or the study did not address this outcome.

\section{(4) Incomplete outcome data (checking for attrition bias)}

For each included study, we reported the completeness of data including attrition and exclusions, the numbers included in the analysis at each stage and the reasons for attrition or exclusion.

\section{We assessed risk of bias as:}

- Low risk: e.g. if there were any missing outcome data, the reasons for missing outcome data were unlikely to be related to true outcome.

- High risk: e.g. reasons for missing outcome data are likely to be related to true outcome.
- Unclear risk: insufficient reporting of attrition/exclusions to permit judgement of 'low risk' or 'high risk' or the study did not address this outcome.

\section{(5) Selective reporting (checking for whether the prespecified outcomes were met)}

For each included study, we assessed if the study's protocol was available and that the study's prespecified (primary and secondary) outcomes had been reported in the prespecified way, utilising prespecified measurements and analysis methods.

We assessed risk of bias as:

- Low risk: e.g. the study protocol was available and all of the study's prespecified (primary and secondary) outcomes that are of interest in the review have been reported in the prespecified way, or if the protocol was not available, that the published report included all expected outcomes.

- High risk: e.g. not all prespecified outcomes are reported, primary outcomes are reported using measurements or analysis methods that were not prespecified, the primary outcome reported was not prespecified, incomplete reporting of any outcomes, failure to include results for a key outcome that would be expected to have been reported.

- Unclear risk: insufficient information available to permit a judgement of 'low risk' or 'high risk'.

\section{(6) Other bias}

For each included study, we assessed for bias due to problems are not covered elsewhere in the table.

We assess risk of bias as:

- Low risk: e.g. study appears free of other bias.

- High risk: e.g. there is at least one important risk of bias, such as a potential source of bias related to study design, or the study has been claimed to have been fraudulent.

- Unclear risk: insufficient information or evidence that an identified problem will introduce bias.

\section{Measures of treatment effect}

Treatment effects are divided into quantitative data and patientreported outcomes. We analysed quantitative data such as survival and toxicity as dichotomous outcomes using the risk ratio (RR). We pooled time-to-event outcomes, such as hazard ratios (HR) for overall survival and progression-free survival, provided that authors had analysed data using a Cox proportional hazards model. We summarised proportional outcomes, such as the proportion who survived, using a risk ratio (RR). We combined continuous outcomes with the inverse variance method. We combined quality of life outcomes if the same validated instrument was used, otherwise we utilised a descriptive approach. If data were combined, we presented the change from baseline as the standardised mean difference (SMD). All measures of effect included a $95 \%$ confidence interval $(\mathrm{Cl}), \mathrm{P}$ values and for pooled measures the 12 statistic value.

\section{Assessment of heterogeneity}

We performed tests for heterogeneity with Review Manager (RevMan 2014) using the $1^{2}$ statistic and interpreting the $I^{2}$ value 
using the guidance in the Cochrane Handbook for Systematic Reviews of Interventions (Higgins 2011). An 12 value of greater than $75 \%$ is likely to represent considerable heterogeneity, a value of $50 \%$ to $90 \%$ is likely to represent substantial heterogeneity and a value of $30 \%$ to $60 \%$ represents moderate heterogeneity.

\section{Data synthesis}

We combined quantitative data using Review Manager 5.3 (RevMan 2014). We calculated hazard ratios (HR) for data presented as survival curves using logrank expected number of events and variance. We pooled hazard ratios across trials using a fixedeffect model. We combined continuous data, where the mean, standard deviation (SD) and number of participants in each arm were available, generating a mean difference (MD) and 95\% $\mathrm{Cl}$. We planned to use a fixed-effect model in the meta-analysis if heterogeneity was deemed to be small (an $1^{2}$ value of less than $50 \%$ ). We applied a random-effects model to comparisons demonstrating significant heterogeneity (with an $\mathrm{I}^{2}$ value of greater than 50\%).

\section{GRADE and 'Summary of findings' tables}

We employed the GRADE approach to interpret findings (Schünemann 2011). We used GRADEProGDT (GRADEpro GDT 2015) to import data from Review Manager (RevMan 2014) to create 'Summary of findings' tables for major comparisons in this review. These tables provide information concerning the overall quality of the evidence from the included studies, the magnitude of the effect of the interventions and the sum of available data on the primary outcome and selected secondary outcomes. We selected the most relevant comparison for presentation in the 'Summary of findings' tables and we selected the following outcomes that we considered important to clinical decision-making for inclusion in these tables:

- Overall survival.
- Progression-free survival.

- Toxicity.

\section{Subgroup analysis and investigation of heterogeneity}

We performed subgroup analyses for the outcomes of survival and tumour response. We categorised data from included studies into the following subgroups:

- Asian population: if the study presented data specifically from patients who were of Asian ethnicity.

- EGFR mutation positive: if the study presented data specifically from patients who were found to have EGFR activating mutations.

We undertook these subgroup analyses to determine whether there are differences between treatment groups depending on these biological and genomic factors.

\section{Sensitivity analysis}

Where applicable, we planned to perform a sensitivity analysis based on study quality, to assess the effect of this on the reported outcomes. We also applied a random-effects model as part of our sensitivity analysis.

\section{RE S U L T S}

\section{Description of studies}

\section{Results of the search}

The search strategy yielded 5703 studies or abstracts of which 127 studies were possibly eligible. Of these, we included 62 publications in this review, representing 35 primary studies and 27 publications that presented data from their respective primary studies. Fifty-six were published in abstract form only and we found the remaining nine studies to be ineligible (Figure 1). 
Figure 1. Study flow diagram for searches 1966-2017. (EGFR: epidermal growth factor receptor)

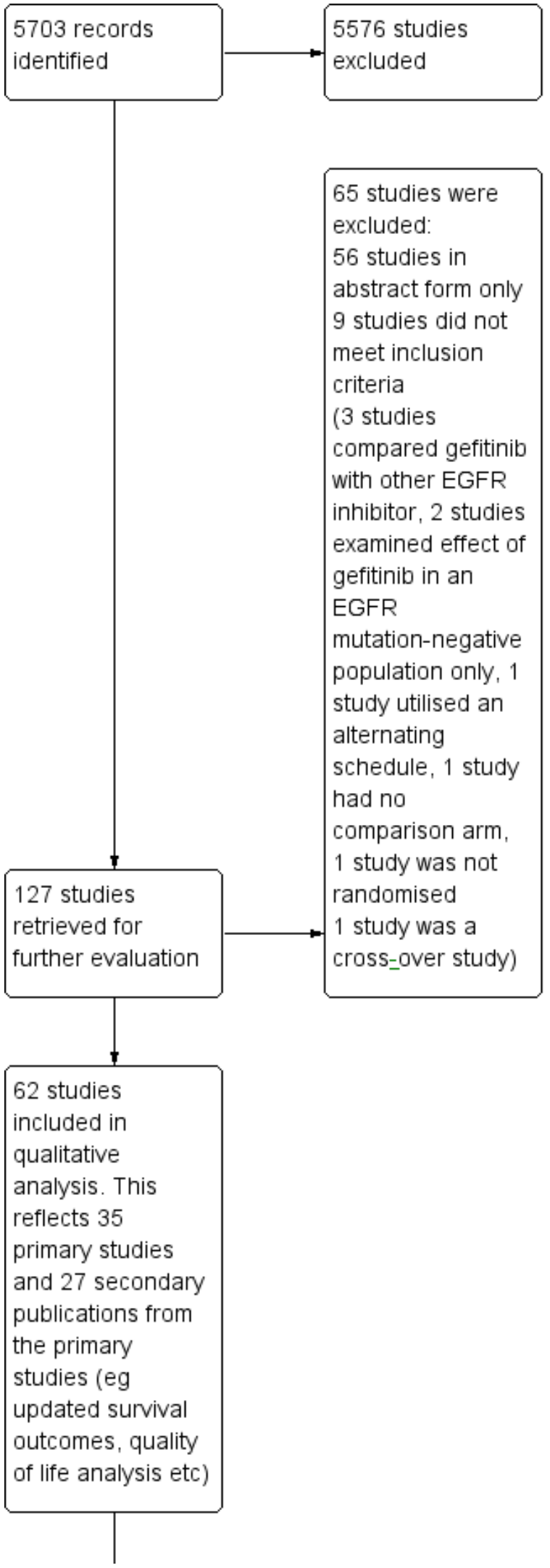


Figure 1. (Continued)

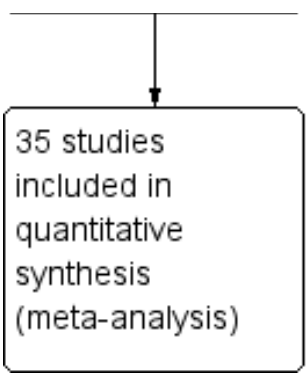

\section{Included studies}

We included a total of 35 separate primary studies in this review and these trials randomised a total of 12,089 patients. Seventeen of the eligible studies were multicentre, phase III trials (Gaafar 2011 EORTC08021; Giaccone 2004 INTACT I; Han 2012 First SIGNAL; Herbst 2004 INTACT II; Kelly 2008 SWOG S0023; Kim 2008 INTEREST; Lee 2010 ISTANA; Maemondo 2010 NEJ002; Maruyama 2008 V-15-32; Mitsudomi 2010 WJTOG3405; Mok 2009 IPASS; Soria 2015 IMPRESS; Sun 2012 KCSG-LU08-01; Takeda 2010 WJTOG0203; Thatcher 2005 ISEL; Yang 2014; Zhang 2012 INFORM). The remaining 18 were phase II studies (Ahn 2012; An 2016; Chen 2007; Chen 2011; Cheng 2016; Crino 2008 INVITE; Cufer 2006 SIGN; Dai 2013; Fukuoka 2003 IDEAL I; Goss 2009 INSTEP; Kim 2016; Kris 2003 IDEAL II; Li 2010; Lou 2014; Morere 2010 IFCT-0301; Xu 2015; Xue 2015; Yu 2014). A summary of the 35 included primary studies is presented in Table 1 . An additional 14 publications analysed data from their respective primary studies (Bell 2005; Boye 2016; Cella 2005; Chang 2006; Douillard 2010; Fukuoka 2011; Hirsch 2006; Herbst 2005; Inoue 2013; Oizumi 2012; Sekine 2009; Thongprasert 2011; Yamamoto 2010; Yang 2015). If we used data from these secondary studies, we did not duplicate with data from the respective primary studies and vice versa.

The duration of gefitinib therapy varied between studies. Most studies continued therapy until there was disease progression, unacceptable toxicity or withdrawal. Two studies administered gefitinib for six or eight weeks (Chen 2007; Morere 2010 IFCT-0301). The shortest reported median duration of treatment was 50 days (Goss 2009 INSTEP) and the longest 308 days (Maemondo 2010 NEJ002).

Please refer to the Characteristics of included studies for full details of included studies. Study characteristics have also been summarised in Table 1.

The various comparisons can be seen in the Data and analyses section.

\section{Gefitinib at any dose compared with placebo or best supportive care for NSCLC}

- General population (Comparison 1)

Three phase III studies (Gaafar 2011 EORTC08021; Kelly 2008 SWOG S0023; Thatcher 2005 ISEL) and a single phase II study (Goss 2009 INSTEP) compared gefitinib with placebo. The ISEL (Thatcher 2005 ISEL), INSTEP (Goss 2009 INSTEP), EORTC 08021 (Gaafar 2011 EORTC08021) and SWOGS0023 (Kelly 2008 SWOG S0023) trials examined survival outcomes, objective response rates and toxicity in the general population. The INSTEP study randomised chemotherapy-naive patients to $250 \mathrm{mg}$ of gefitinib or placebo as first-line therapy. The ISEL study studied its effects as second-line therapy in advanced NSCLC. Detailed subgroup analysis was conducted in the ISEL population and subsequently published. These two studies are also presented below as subgroup analyses (Chang 2006; Hirsch 2006). Subgroups were assessed for evidence by subgroup interactions, thus ensuring that outcomes were indeed different. Pre-planned subgroup analysis of patients of Asian ethnicity was presented in Chang 2006 and analysis of molecular predictors of outcome was presented in Hirsch 2006. The SWOGS0023 and EORTC08021 studies assessed the effect of gefitinib versus placebo as maintenance therapy after initial treatment. In the SWOG study, patients were included after receiving concurrent cisplatin/etoposide chemotherapy with thoracic radiation (45 Gy, 1.8 Gy per fraction). The EORTC08021 trial included patients not progressing after first-line platinum doublet chemotherapy. We studied a total of 2605 patients in this group.

\section{- Asian population (Comparison 2)}

The INFORM study assessed the use of gefitinib as maintenance therapy in an East Asian patient group (Zhang 2012 INFORM). These patients had achieved disease control after first-line platinumbased chemotherapy. Chang 2006 selected only ISEL patients who were of Asian ethnicity. This subgroup represented $20 \%$ of the original ISEL population, a total of 342 patients. We included a total of 638 patients in this group.

\section{- EGFR mutation positive population (Comparison 3)}

Zhang 2012 INFORM performed planned subgroup analysis on EGFR mutation positive patients and 30 of $79(38 \%)$ tissue tumour samples were positive for EGFR mutations. Hirsch 2006 analysed ISEL tumour biopsy samples to examine the relationships between biomarkers and clinical outcome after gefitinib administration. Two-hundred and fifteen of 1692 patients (12.7\%) in the ISEL trial were assessable for mutation detection. Of these, 26 (12.1\%) patients were positive for EGFR mutations. Other biomarkers examined included EGFR gene copy number, EGFR and p-Akt protein expression and KRAS and BRAF mutations. Data from these other biomarkers are beyond the scope of this review.

\section{Gefitinib at any dose compared with other chemotherapeutic agents}

We included 18 primary studies in this analysis (Ahn 2012; Crino 2008 INVITE; Cufer 2006 SIGN; Dai 2013; Han 2012 First SIGNAL; Kim 2008 INTEREST; Kim 2016; Lee 2010 ISTANA; Li 2010; Lou 2014; Maemondo 2010 NEJ002; Maruyama 2008 V-15-32; Mitsudomi 2010 WJTOG3405; Mok 2009 IPASS; Morere 2010 IFCT-0301; Sun 2012 
KCSG-LU08-01; Xu 2015; Yang 2014). Nine of these studies were multicentre, randomised, phase III trials.

These 18 primary studies randomised a total of 5400 patients.

\section{- General population (Comparison 4)}

Four studies, SIGN (Cufer 2006 SIGN), INTEREST (Kim 2008 INTEREST), INVITE (Crino 2008 INVITE) and IFCT-0301 (Morere 2010 IFCT-0301), compared gefitinib with chemotherapy in 1888 patients and data from these are presented in Comparison 4. Two studies compared gefitinib with first-line chemotherapy (Crino 2008 INVITE; Morere 2010 IFCT-0301) and the other two studies compared it with second-line chemotherapy (Cufer 2006 SIGN; Kim 2008 INTEREST). 'Iressa in NSCLC versus Vinorelbine Investigation in the Elderly' (INVITE) was a randomised, multicentre, phase II trial that compared gefitinib with vinorelbine as first-line therapy in elderly patients (Crino 2008 INVITE). IFCT-0301 compared gefitinib, gemcitabine and docetaxel in chemotherapy-naive patients with a performance status of 2 or 3 (Morere 2010 IFCT-0301). SIGN (Second-line Indication of Gefitinib in NSCLC) was a phase II, randomised study comparing gefitinib with docetaxel as secondline therapy (Cufer 2006 SIGN). INTEREST (Iressa NSCLC Trial Evaluating Response and Survival again Taxotere) was a phase III trial, which assessed the non-inferiority of gefitinib to docetaxel as second-line therapy (Kim 2008 INTEREST). Douillard 2010 performed a preplanned secondary analysis to investigate the relationship between biomarkers and clinical outcomes in the INTEREST population. We included a total of 1888 patients in this group.

\section{- Asian population (Comparison 5)}

Fourteen studies selected Asian patients only (Ahn 2012; Dai 2013; Han 2012 First SIGNAL; Kim 2016; Lee 2010 ISTANA; Li 2010; Lou 2014; Maruyama 2008 V-15-32; Mok 2009 IPASS; Mitsudomi 2010 WJTOG3405; Maemondo 2010 NEJ002; Sun 2012 KCSG-LU08-01; Xu 2015; Yang 2014), of which all except six (Ahn 2012; Dai 2013; Kim 2016; Li 2010; Lou 2014; Xu 2015) were phase III studies. We included a total of 3512 patients in this group.

\section{First-line studies}

Five phase III studies (Han 2012 First SIGNAL; Maemondo 2010 NEJ002; Mitsudomi 2010 WJTOG3405; Mok 2009 IPASS; Yang 2014) and one phase II study (Lou 2014) compared gefitinib with first-line chemotherapy. IPASS compared gefitinib with carboplatin-paclitaxel, but in Asian patients with adenocarcinoma who were light or never-smokers (Mok 2009 IPASS). Maemondo 2010 NEJ002 randomised Asian chemotherapy-naive patients with EGFR mutations to receive gefitinib or carboplatin-paclitaxel. WJTOG3405 compared gefitinib with cisplatin plus docetaxel in Asian patients with EGFR mutations (Mitsudomi 2010 WJTOG3405). First-SIGNAL compared first-line gefitinib with gemcitabine plus cisplatin in Asian never-smokers with lung adenocarcinoma (Han 2012 First SIGNAL). The phase III study by Yang 2014 compared firstline pemetrexed and cisplatin followed by gefitinib maintenance therapy with gefitinib monotherapy alone in Asian non-smoking patients. Patients were randomised at trial entry to either gefitinib or pemetrexed plus cisplatin chemotherapy. Patients in both arms then continued with maintenance gefitinib. Data were analysed in the intention-to-treat population and only data from the first phase of the study were included in this analysis. In the phase II study by
Lou 2014, gefitinib was compared with carboplatin and paclitaxel in Asian patients who were either non-smokers or light ex-smokers.

We analysed a total of 2224 patients from the six studies in this group.

\section{Second-line studies}

Three phase III studies (Lee 2010 ISTANA; Maruyama 2008 V-15-32; Sun 2012 KCSG-LU08-01) and three phase II studies (Dai 2013; Kim 2016; Li 2010) compared gefitinib with second-line chemotherapy. ISTANA (Lee 2010 ISTANA), V-15-32 (Maruyama 2008 V-15-32) and the phase II study by Li 2010 included patients of Asian ethnicity but where mutation status was not always known, and compared gefitinib with docetaxel. KCSG-LU08-01 (Sun 2012 KCSG-LU08-01), Dai 2013 and Kim 2016 selected Asian patients with unknown EGFR status and compared gefitinib with second-line pemetrexed. Secondary studies published by Sekine 2009 and Yamamoto 2010 conducted analyses on quality of life and disease control respectively in the $\mathrm{V}-15-32$ trial.

We analysed a total of 1030 patients from the six studies in this group.

\section{Maintenance studies}

Two phase II studies compared the role of gefitinib as maintenance to chemotherapy. Ahn 2012 randomised Asian non-smokers not progressing after first-line pemetrexed-cisplatin, to receive either gefitinib or pemetrexed \pm cisplatin, in a two-staged study design. Xu 2015 compared single-agent pemetrexed with gefitinib in Asian patients not progressing after four to eight cycles of first-line chemotherapy.

We analysed 258 patients in this group.

\section{- EGFR mutation positive population (Comparison 6)}

Nine studies were included in this group, six of which were first-line studies (Crino 2008 INVITE; Han 2012 First SIGNAL; Maemondo 2010 NEJ002; Mitsudomi 2010 WJTOG3405; Mok 2009 IPASS; Yang 2014) and three of which were second-line studies (Kim 2008 INTEREST; Maruyama 2008 V-15-32; Sun 2012 KCSG-LU08-01).

We included a total of 879 patients in this group.

Two phase III studies selected patients of Asian ethnicity who were also positive for EGFR mutations and compared gefitinib with first-line carboplatin and paclitaxel or cisplatin and docetaxel respectively (Maemondo 2010 NEJ002; Mitsudomi 2010 WJTOG3405). In contrast, the IPASS (Mok 2009 IPASS) and FirstSIGNAL (Han 2012 First SIGNAL) studies selected Asian patients with adenocarcinomas, and conducted planned subgroup analyses on the EGFR mutation positive patients. IPASS compared firstline gefitinib with carboplatin and paclitaxel and First-SIGNAL compared gefitinib with gemcitabine and cisplatin. Yang 2014 conducted a post-hoc analysis of EGFR mutation positive patients and compared first-line pemetrexed and cisplatin followed by gefitinib maintenance with gefitinib alone. The INVITE phase II study in elderly patients that compared first-line gefitinib with vinorelbine also conducted analysis of EGFR mutation positive patients but this study did not include any data that could be pooled (Crino 2008 INVITE). 
We analysed a total of 802 patients in this group.

A further three phase III studies compared second-line gefitinib with chemotherapy and conducted subgroup analyses in the EGFR mutation positive patients (Kim 2008 INTEREST; Maruyama 2008 V-15-32; Sun 2012 KCSG-LU08-01). INTEREST and V-15-32 compared gefitinib with docetaxel and KCSG-LU08-01 compared gefitinib with pemetrexed in this second-line setting. The INTEREST study also analysed other biomarkers, such as EGFR gene copy number, EGFR protein expression and KRAS mutations, in addition to EGFR mutations. One study did not publish data that could be pooled (Maruyama $2008 \mathrm{~V}$-15-32) and thus we included a total of 77 patients in this group.

\section{Gefitinib at a specific dose versus a different dose (Comparison 7)}

Three phase II studies compared the effect of two different doses of gefitinib, $250 \mathrm{mg}$ and $500 \mathrm{mg}$ in 527 patients (Fukuoka 2003 IDEAL I; Kris 2003 IDEAL II; Xue 2015). IDEAL I (Fukuoka 2003 IDEAL I) and IDEAL II (Kris 2003 IDEAL II) were multicentre, randomised, doubleblind, phase II studies that evaluated two doses of gefitinib (250 $\mathrm{mg} /$ day and $500 \mathrm{mg}$ /day) as second- or third-line therapy.

We analysed 431 patients in this group.

The third study randomised 96 patients who were stable after one month of gefitinib ( $250 \mathrm{mg} /$ day) to either $250 \mathrm{mg} /$ day or $500 \mathrm{mg} /$ day as maintenance therapy (Xue 2015).

\section{Gefitinib versus gefitinib combined with a chemotherapy regimen (Comparison 8 )}

Four studies compared gefitinib alone or in combination with chemotherapy. Two recently published studies examined the addition of chemotherapy to gefitinib versus gefitinib alone in the first-line setting. A small study by An 2016 recruited 90 East Asian patients with an EGFR mutation and randomised them to receive gefitinib or gefitinib plus pemetrexed $\left(500 \mathrm{mg} / \mathrm{m}^{2}\right)$. In this study, pemetrexed or placebo was administered via intravenous infusion on day 1 of a 21-day cycle. Gefitinib $250 \mathrm{mg}$ was administered on days 2 to 16. A multicentre, phase II study by Cheng 2016 also compared gefitinib with and without pemetrexed as first-line therapy. This study recruited 191 East Asian patients from China, Japan, Korea and Taiwan with advanced non-squamous NSCLC with an activating EGFR mutation. Patients either received gefitinib $250 \mathrm{mg}$ per day or gefitinib plus pemetrexed $\left(500 \mathrm{mg} / \mathrm{m}^{2}\right)$ infusion on day 1 of a 21 -day cycle.

We included a total of 281 patients in this group.

Chen 2007 compared $250 \mathrm{mg}$ of daily oral gefitinib with gefitinib plus vinorelbine $\left(15 \mathrm{mg} / \mathrm{m}^{2}\right)$ every two weeks in 48 patients of Asian ethnicity with stage IV adenocarcinoma who had failed at least two lines of chemotherapy. Chen 2011 compared gefitinib alone with the combination of gefitinib plus tegafur $(100 \mathrm{mg}) / \mathrm{uracil}(224 \mathrm{mg})$ in 115 Taiwanese patients with stage IIIB or IV adenocarcinoma who had failed first-line chemotherapy.

We included a total of 163 patients in this group.

\section{Gefitinib at any dose in combination with other chemotherapeutic agents versus the same chemotherapy agents alone (Comparison 9)}

Five studies examined survival outcomes, objective response rates and toxicity (Giaccone 2004 INTACT I; Herbst 2004 INTACT II; Soria 2015 IMPRESS; Takeda 2010 WJTOG0203; Yu 2014). Overall, we included a total of 3110 patients.

INTACT I (Giaccone 2004 INTACT I) and INTACT II (Herbst 2004 INTACT II) were large, multicentre trials that examined the effect of the addition of two different doses of gefitinib to a chemotherapy regimen with the chemotherapy alone in chemotherapy-naive patients. INTACT I compared the effect of the addition of gefitinib to a chemotherapy regimen that included gemcitabine and cisplatin and INTACT II a paclitaxel and carboplatin regime. WJTOG0203 compared the addition of $250 \mathrm{mg}$ of gefitinib to platinum-doublet chemotherapy in chemotherapy-naive Japanese patients (Takeda 2010 WJTOG0203). In this study, patients were randomised to receive platinum doublet chemotherapy (Arm A) or platinumdoublet chemotherapy for three cycles followed by gefitinib until disease progression (Arm B). The phase II study by Yu 2014 examined the addition of gefitinib to a first-line pemetrexed and cisplatin chemotherapy schedule in Asian patients who were nonsmokers or light ex-smokers.

In this group, we included 2845 patients.

The IMPRESS study was a phase III, multicentre study conducted across Europe and the Asia-Pacific region (Soria 2015 IMPRESS). This study selected patients with EGFR mutation positive advanced NSCLC who had failed first-line therapy with gefitinib. This study compared second-line gefitinib plus chemotherapy (cisplatin and pemetrexed) with placebo plus the same chemotherapy regimen (cisplatin and pemetrexed). Two hundred and sixty-five patients were included in this trial.

\section{Gefitinib at any dose in combination with other chemotherapeutic agents versus a different combination of chemotherapeutic agent (Comparison 10)}

No studies compared gefitinib in combination with a chemotherapeutic regime with a different regime of agents.

Data for all endpoints were not available in all published reports. A summary of efficacy and survival data is presented in Table 2.

\section{Risk of bias in included studies}

We included trials that met our inclusion criteria. We checked all data extracted for accuracy and final database entries. We resolved any discrepancies through discussion. Overall, the risk of bias in the 35 included studies was moderate. The results of the 'Risk of bias' assessment are depicted graphically in Figure 2. 
Figure 2. 'Risk of bias' summary: review authors' judgements about each risk of bias item for each included study.

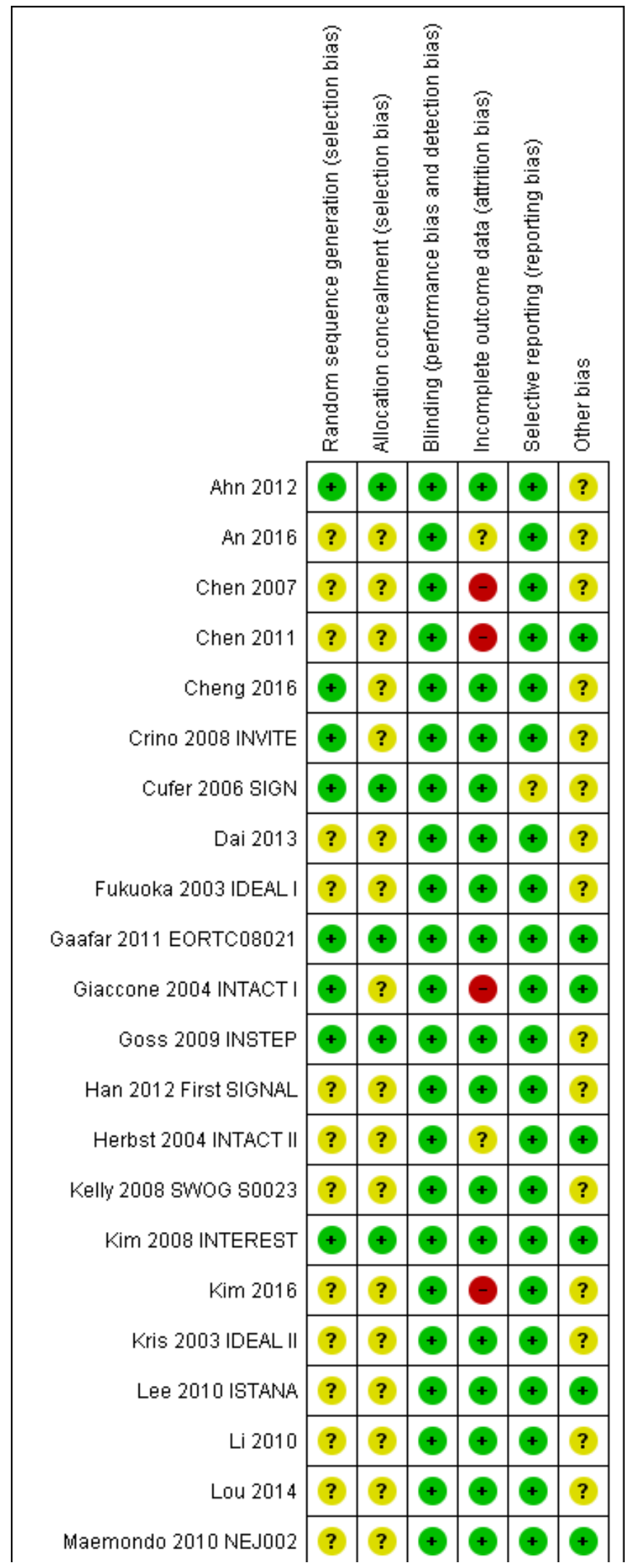


Figure 2. (Continued)

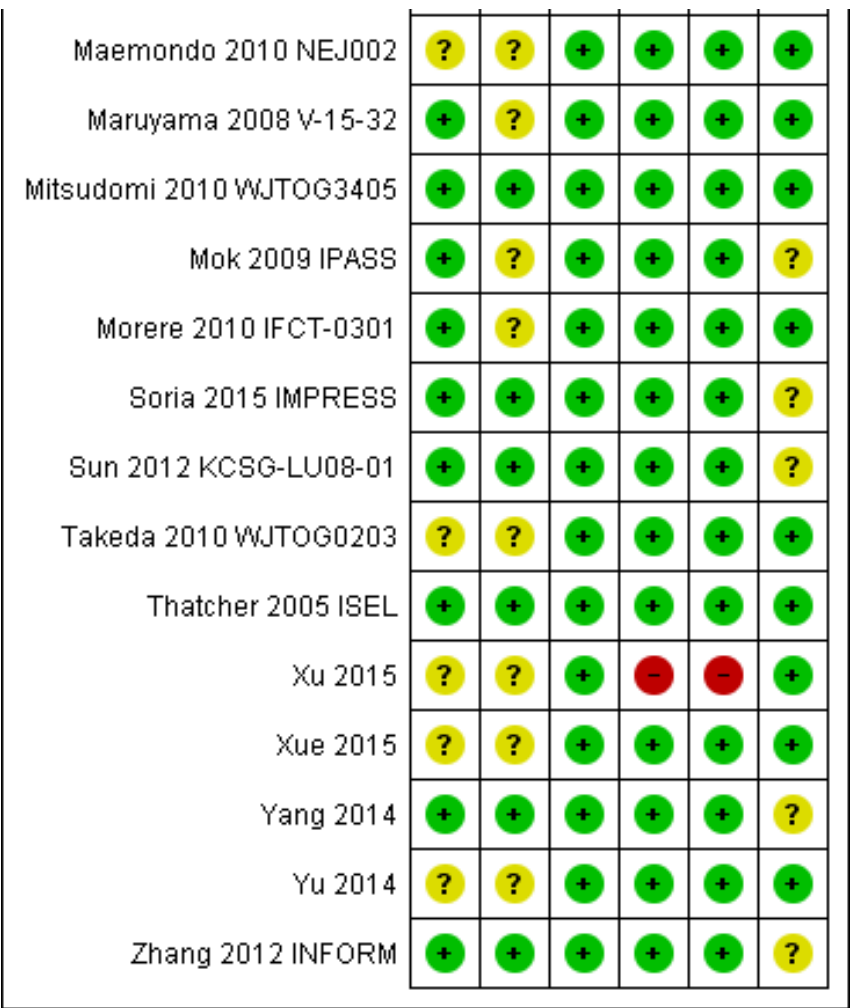

\section{Allocation}

\section{Sequence generation}

Seventeen of the 35 included studies reported adequate sequence generation (Ahn 2012; Cheng 2016; Crino 2008 INVITE; Cufer 2006 SIGN; Gaafar 2011 EORTC08021; Giaccone 2004 INTACT I; Goss 2009 INSTEP; Kim 2008 INTEREST; Maruyama 2008 V-15-32; Mitsudomi 2010 WJTOG3405; Mok 2009 IPASS; Morere 2010 IFCT-0301; Soria 2015 IMPRESS; Sun 2012 KCSG-LU08-01; Thatcher 2005 ISEL; Yang 2014; Zhang 2012 INFORM). The remaining 18 studies were all described as randomised, but none provided any further information and so we classified them as having an uncertain risk of bias (An 2016; Chen 2007; Chen 2011; Dai 2013; Fukuoka 2003 IDEAL I; Han 2012 First SIGNAL; Herbst 2004 INTACT II; Kelly 2008 SWOG S0023; Kim 2016; Kris 2003 IDEAL II; Lee 2010 ISTANA; Li 2010; Lou 2014; Maemondo 2010 NEJ002; Takeda 2010 WJTOG0203; Xu 2015; Xue 2015; Yu 2014).

\section{Allocation concealment}

Allocation concealment was adequate in 11 of the included studies (Ahn 2012; Cufer 2006 SIGN; Gaafar 2011 EORTC08021; Goss 2009 INSTEP; Kim 2008 INTEREST; Mitsudomi 2010 WJTOG3405; Soria 2015 IMPRESS; Sun 2012 KCSG-LU08-01; Thatcher 2005 ISEL; Yang 2014; Zhang 2012 INFORM). Most of these studies used a minimisation method or centralised allocation procedure. The remaining studies did not report whether allocation was concealed and so are possibly at risk of bias.

\section{Blinding}

Of the 35 included trials, we judged blinding to be adequate in all studies. Eight studies blinded participants and investigators using an identical placebo (Fukuoka 2003 IDEAL I; Gaafar 2011 EORTC08021; Giaccone 2004 INTACT I; Goss 2009 INSTEP; Soria 2015 IMPRESS; Thatcher 2005 ISEL; Yang 2014; Zhang 2012 INFORM). The remaining 27 studies were unblinded or open-label (for example comparing gefitinib with intravenous chemotherapy), but we judged that this would not affect the measured outcomes.

\section{Incomplete outcome data}

The majority of studies adequately addressed incomplete outcome data. Of the 35 included trials, 28 had a low risk of bias from incomplete outcome data. Studies cited reasons such as death, disease progression and drug toxicity for dropouts. Five phase II studies did not address withdrawals or patients lost to follow-up and thus are potentially at high risk of bias (Chen 2007; Chen 2011; Giaccone 2004 INTACT I; Kim 2016; Xu 2015). Two studies did not provide adequate outcome data and so are at a risk of bias from incomplete outcome data analysis (An 2016; Herbst 2004 INTACT II).

\section{Selective reporting}

We judged 33 of the 35 included studies as at low risk of reporting bias. One study reported an outcome (progression-free survival) that was not pre-specified (Cufer 2006 SIGN). We judged this as an unclear risk of bias. Another study did not report an outcome that was prespecified in the methods ("survival time"), with no reason provided for this in the paper (Xu 2015). We judged this as a high risk of bias

\section{Other potential sources of bias}

Three trials were stopped early (Kelly 2008 SWOG S0023; Maemondo 2010 NEJ002; Mitsudomi 2010 WJTOG3405), which may be another source of bias. The SWOGS0023 study was 
stopped because an unplanned interim analysis concluded that the alternate hypothesis of improved survival would not be met. The NEJ002 and WJTOG3405 studies were concluded early following the presentation of contemporary data showing a progression-free survival benefit in EGFR mutated patients. These studies were then closed to accrual.

We judged the remaining studies as having an unclear risk of bias listed due to conflicts of interest, in particular pharmaceutical funding or significant affiliations, or because they did not adequately declare any conflicts of interest (Ahn 2012; An 2016; Chen 2007; Cheng 2016; Crino 2008 INVITE; Cufer 2006 SIGN; Dai 2013; Fukuoka 2003 IDEAL I; Goss 2009 INSTEP; Han 2012 First SIGNAL; Kelly 2008 SWOG S0023; Kim 2008 INTEREST; Kim 2016; Kris 2003 IDEAL II; Li 2010; Mok 2009 IPASS; Soria 2015 IMPRESS; Sun 2012 KCSG-LU08-01; Yang 2014; Zhang 2012 INFORM).

\section{Effects of interventions}

See: Summary of findings for the main comparison Gefitinib compared to chemotherapy for first-line treatment of advanced NSCLC; Summary of findings 2 Gefitinib compared to chemotherapy for second-line treatment of advanced NSCLC; Summary of findings 3 Gefitinib compared to chemotherapy for advanced NSCLC - toxicity

See: Summary of findings for the main comparison ('Gefitinib compared to chemotherapy for first-line treatment of advanced NSCLC'); Summary of findings 2 ('Gefitinib compared to chemotherapy for second-line treatment of advanced NSCLC'); Summary of findings 3 ('Gefitinib compared to chemotherapy for advanced NSCLC - toxicity').

\section{Gefitinib versus placebo or best supportive care}

\section{Survival}

See Analysis 1.1; Analysis 1.2; Analysis 1.3.

Four studies compared gefitinib with placebo in a general population (Gaafar 2011 EORTC08021; Goss 2009 INSTEP; Kelly 2008 SWOG S0023; Thatcher 2005 ISEL). The data presented examines the effect of gefitinib compared with placebo in the first-line, second-line and maintenance settings. Total pooling of data was not conducted for first- or second-line therapy as only single studies were included. Pooling of data was only possible for maintenance treatment, as two studies were included (Gaafar 2011 EORTC08021; Kelly 2008 SWOG S0023). Gefitinib did not improve overall survival when compared with placebo, either when administered as first-line (Goss 2009 INSTEP; hazard ratio (HR) 0.84, $95 \%$ confidence interval $(\mathrm{Cl}) 0.62$ to $1.14, \mathrm{P}=0.27$ ), second-line (Thatcher 2005 ISEL; HR $0.89,95 \% \mathrm{Cl} 0.79$ to $1.01, \mathrm{P}=0.06$ ) or maintenance therapy (Gaafar 2011 EORTC08021; Kelly 2008 SWOG S0023; pooled HR $1.14,95 \% \mathrm{Cl} 0.61$ to $2.14, \mathrm{P}=0.69, \mathrm{I}=85 \%$, random-effects model).

One-year survival rates were improved by administration of gefitinib versus placebo as second-line therapy (risk ratio (RR) 1.28 , $95 \% \mathrm{Cl} 1.05$ to $1.57, \mathrm{P}=0.02$ ), but not as maintenance therapy (RR $0.90,95 \% \mathrm{Cl} 0.78$ to $1.04, \mathrm{P}=0.15$ ). Progression-free survival was not improved when gefitinib was compared with placebo as first-line therapy and median progression-free survival was reported as 1.4 months in both groups (HR 0.82, 95\% $\mathrm{Cl} 0.60$ to $1.12, \mathrm{P}=0.21$ ). Time to treatment failure was improved in favour of gefitinib as second- line therapy, with a HR of $0.82(95 \% \mathrm{Cl} 0.75$ to $0.90, \mathrm{P}<0.0001)$ : median progression-free survival was 3 months with gefitinib, 2.6 months with placebo. Maintenance use of gefitinib after first-line treatment improved progression-free survival (HR $0.70,95 \% \mathrm{Cl} 0.53$ to $\left.0.91, P=0.007,1^{2}=32 \%\right)$.

\section{Toxicity}

See Analysis 1.4; Analysis 1.6.

We have pooled reported toxicity data from three studies in this comparison so as to examine the differences in toxicity between gefitinib and placebo or best supportive care (Gaafar 2011 EORTC08021; Goss 2009 INSTEP; Thatcher 2005 ISEL). Administration of gefitinib was significantly associated with Common Toxicity Criteria (CTC) grade 3 to 4 events such as skin rash (RR 7.92, 95\% Cl 1.46 to $43.03, \mathrm{P}=0.02, \mathrm{I}^{2}=0 \%$ ) and diarrhoea (RR $2.48,95 \% \mathrm{Cl} 1.15$ to $\left.5.35, \mathrm{P}=0.02, \mathrm{I}^{2}=0 \%\right)$. One study reported a statistically significant increase in alanine aminotransferase (ALT) with gefitinib (RR $9.11,95 \% \mathrm{Cl} 1.18$ to $70.32, \mathrm{P}=0.03$ ). The risk of all other adverse events was either not estimable or not significantly different between the two groups.

\section{Efficacy}

See Analysis 1.22; Analysis 1.23.

Response was reported in only three of the four included studies (Gaafar 2011 EORTC08021; Goss 2009 INSTEP; Thatcher 2005 ISEL). We did not pool the data as the INSTEP study compared gefitinib with placebo as first-line therapy, ISEL did so as second-line therapy and the EORTC08021 trial as maintenance therapy. As first-line therapy, gefitinib did not improve the overall response rate (RR $6.06,95 \% \mathrm{Cl} 0.74$ to $49.43, \mathrm{P}=0.09$ ) or the disease control rate (RR $1.36,95 \% \mathrm{Cl} 0.86$ to $2.16, \mathrm{P}=0.19$ ). This was reported as an overall response rate of $6 \%$ and $1 \%$ in the gefitinib and placebo groups, respectively, and the disease control rate was $31 \%$ and $23 \%$, respectively. As second-line therapy, the overall response rate was higher for gefitinib-treated cases than for placebo (RR 6.42, $95 \% \mathrm{Cl} 2.82$ to $14.64, \mathrm{P}<0.00001)$ and the disease control rate was also significantly higher for gefitinib (RR $1.24,95 \% \mathrm{Cl} 1.06$ to $1.44, \mathrm{P}=0.006$ ). The overall response rate was $8 \%$ in the gefitinib group and $1 \%$ in the placebo group, and the disease control rate was $40 \%$ and $32 \%$, respectively. Similarly, gefitinib improved the overall response rate and the disease control rate when used as maintenance therapy (RR $10.12,95 \% \mathrm{Cl} 1.32$ to $77.33, \mathrm{P}=0.03$; RR $1.21,95 \% \mathrm{Cl} 1.00$ to $1.46, \mathrm{P}=0.05$, respectively).

\section{Quality of life and symptom improvement scores}

Thatcher 2005 ISEL reported that the addition of gefitinib to "best supportive care" produced no significant changes in the quality of life subscale of the Functional Assessment of Cancer TherapyLung (FACT-L) questionnaire when compared with best supportive care alone. Gefitinib was associated with a statistically significant improvement in the symptom score (mean change from baseline -0.86 to $-1.38 ; P=0.019$ ), but this did not meet predefined criteria. As described by Cella 2002, for changes in disease-related symptoms to be classed as clinically relevant, the score must increase by two points. Goss 2009 INSTEP reported improvements in FACT-L quality of life, FACT-L Trial Outcome Index (TOI), lung cancer subscale (LCS) and Pulmonary Symptom Index (PSI) that were statistically nonsignificant. 


\section{Subgroup analysis: Asian population}

See Analysis 2.1; Analysis 2.2; Analysis 2.3; Analysis 2.4.

The INFORM study prospectively recruited patients of East Asian ethnic origin without disease progression after first-line chemotherapy (Zhang 2012 INFORM). Pre-planned subgroup analysis in the ISEL trial found marked heterogeneity in survival between patient groups (Thatcher 2005 ISEL).

The ISEL study conducted a subgroup analysis in 342 patients of Asian ethnicity who were enrolled in the ISEL trial. Two hundred and thirty-five patients received second-line gefitinib and 107 received placebo. Pre-planned analysis reported that gefitinib significantly improved overall survival ( $\mathrm{HR} 0.66,95 \% \mathrm{Cl} 0.48$ to $0.91, \mathrm{P}=0.01)$, the one-year survival rate $(\mathrm{RR} 1.75,95 \% \mathrm{Cl} 1.20$ to $2.55, \mathrm{P}=0.004)$ and progression-free survival (HR 0.69, 95\% $\mathrm{Cl} 0.52$ to $0.91, \mathrm{P}=0.009$ ) compared to placebo. Median overall survival was 9.5 months for gefitinib compared with 5.5 months for placebo. Covariate analysis of demographic subgroups further demonstrated a survival advantage across multiple subgroups. Overall survival in this Asian subgroup of patients was also greater in never-smokers ( $\mathrm{HR} 0.37,95 \% \mathrm{Cl} 0.21$ to $0.64, \mathrm{P}=0.0004$ ) compared with smokers (HR $0.85,95 \% \mathrm{Cl} 0.58$ to $1.25, \mathrm{P}=0.40$ ); females (HR $0.46,95 \% \mathrm{Cl} 0.26$ to $0.79, \mathrm{P}=0.0045$ ) compared with males (HR $0.80,95 \% \mathrm{Cl} 0.54$ to $1.18, \mathrm{P}=0.26$ ); and patients with adenocarcinoma ( $\mathrm{HR} 0.66,95 \% \mathrm{Cl} 0.45$ to $0.97, \mathrm{P}=0.04$ ) compared with non-adenocarcinoma ( $\mathrm{HR} 0.86,95 \% \mathrm{Cl} 0.50$ to $1.47, \mathrm{P}=0.58$ ). Objective response rates were higher in Asian patients treated with gefitinib compared with placebo (RR $6.03,95 \% \mathrm{Cl} 1.46$ to $24.91, \mathrm{P}$ $=0.01)$.

The INFORM study showed that gefitinib in the maintenance setting did not improve overall survival ( $\mathrm{HR} 0.88,95 \% \mathrm{Cl} 0.68$ to $1.14, \mathrm{P}=$ 0.335). However, gefitinib improved progression-free survival over placebo (HR $0.42,95 \% \mathrm{Cl} 0.33$ to $0.54, \mathrm{P}<0.00001$ ), and median progression-free survival was improved from 2.6 months to 4.8 months. The objective response rate was greater with gefitinib (RR $35.00,95 \% \mathrm{Cl} 4.86$ to $252.15, \mathrm{P}=0.0004$ ). There was no difference in reported toxicities.

Quality of life improvement rates were higher in those administered gefitinib compared with placebo, as measured by FACT-L (improvement rates $55 \%$ versus $24 \%, P<0.001$ ), TOI ( $51 \%$ versus $21 \%, P<0.001)$ and LCS $(50 \%$ versus $22 \%, P<0.001)$ in the INFORM study (Zhang 2012 INFORM). Gefitinib also increased the time-toworsening of quality of life when compared with placebo (FACT-L: 2.8 months versus 1.4 months, $P=0.019$; TOI: 3.5 months versus 1.4 months $P=0.006$; LCS: 2.8 months versus 1.4 months $P=0.028$ ). The relationship between the change in quality of life score and prognosis was also analysed in the INFORM study. Patients with an improvement in quality of life had significantly longer progressionfree survival and overall survival when compared with those that had a stable or worsened quality of life (FACT-L: 9.4 months versus 2.8 months versus 2.7 months, $\mathrm{P}<0.001$ and 25.4 months versus 19.9 months versus 14.4 months, $\mathrm{P}=0.003$, respectively).

\section{Subgroup analysis: biomarker}

See Analysis 3.1; Analysis 3.2.

Subgroup analysis of patients from the ISEL trial reported that the overall response rate was higher in patients with epidermal growth factor receptor (EGFR) mutations (37.5\%; 6 of 16 patients) than those who were EGFR mutation negative (2.6\%; 3 of 116 patients).

The INFORM study reported improved overall survival in 30 patients with EGFR mutations (HR $0.39,95 \% \mathrm{Cl} 0.15$ to $0.98, \mathrm{P}=0.036$ ) with median overall survival improving from 20.97 months to 46.87 months when given gefitinib versus placebo. Whilst this subgroup only contained a very small number of patients, the study was able to show that gefitinib doubled the median overall survival. However, those with no detectable EGFR mutation or an unknown EGFR mutation status did not benefit from gefitinib maintenance therapy (HR 1.27, 95\% Cl 0.7 to 2.3, $\mathrm{P}=0.431$; HR 0.92, 95\% Cl 0.68 to $1.25, P=0.603$, respectively).

Progression-free survival was also improved with gefitinib (HR 0.17 , $95 \% \mathrm{Cl} 0.07$ to $0.41, \mathrm{P}<0.0001$ ) over placebo. Median progressionfree survival improved from 2.8 months to 16.6 months in this subgroup analysis of the INFORM trial.

\section{Gefitinib versus chemotherapy}

\section{Survival}

See Analysis 4.1; Analysis 4.2; Analysis 4.3.

\section{Gefitinib versus first-line chemotherapy}

As first-line therapy, only one study reported hazard ratios for survival (Crino 2008 INVITE). Gefitinib did not prolong overall survival ( $\mathrm{HR} 0.98,95 \% \mathrm{Cl} 0.66$ to $1.46, \mathrm{P}=0.92$, moderate quality of evidence) or progression-free survival (HR $1.19,95 \% \mathrm{Cl} 0.86$ to $1.65, \mathrm{P}=0.30$, moderate quality of evidence) when compared with vinorelbine in this general population of patients aged at least 70 years. This study selected patients over the age of 70 years old, therefore this limits the applicability of the data to other patients and thus we downgraded the quality of evidence to moderate.

Two studies reported selected survival outcomes comparing gefitinib with first-line chemotherapy (Crino 2008 INVITE; Morere 2010 IFCT-0301). When we pooled data from these two studies there was no difference in one-year survival rates between gefitinib and first-line chemotherapy (RR $0.93,95 \% \mathrm{Cl} 0.63$ to $1.38, \mathrm{P}=0.73, \mathrm{I}^{2}=$ $26 \%$ ). Median overall survival ranged from 2.2 to 5.9 months and 3.5 to 8 months in the gefitinib and chemotherapy groups, respectively. Median progression-free survival ranged from 1.9 to 2.7 months and 2.0 to 2.9 months in the gefitinib and chemotherapy groups, respectively.

\section{Gefitinib versus second-line chemotherapy}

The SIGN and INTEREST studies compared gefitinib with docetaxel as second-line therapy (Cufer 2006 SIGN; Kim 2008 INTEREST). Only Kim 2008 INTEREST reported survival outcomes and neither overall survival (HR 1.02, $95 \% \mathrm{Cl} 0.91$ to $1.15, \mathrm{P}=0.74$, moderate quality of evidence) nor progression-free survival (HR 1.04, 95\% Cl 0.92 to $1.17, \mathrm{P}=0.51$, moderate quality of evidence) were prolonged by gefitinib. Median overall survival ranged from 7.5 to 7.6 months and 7.1 to 8 months in the gefitinib and chemotherapy groups, respectively. There was no difference in the one-year survival rate (RR $0.94,95 \% \mathrm{Cl} 0.82$ to $1.09, \mathrm{P}=0.44$ ). Median progressionfree survival in the non-selected population ranged from 2.2 to 3 months and 2.7 to 3.4 months in the gefitinib and chemotherapy groups, respectively. 
Cufer 2006 SIGN randomised patients to either second-line gefitinib or docetaxel, however the trial was not formally powered to detect any statistical differences for any endpoint. We judged this to be at risk of serious imprecision and thus downgraded it one level.

\section{Toxicity}

See Analysis 4.4; Analysis 4.5; Analysis 4.6; Analysis 4.7; Analysis 4.8; Analysis 4.9; Analysis 4.10; Analysis 4.11.

We combined data to compare the toxicity profile of gefitinib with chemotherapy for first- and second-line therapy to assess the overall effect in both groups. Data from Cufer 2006 SIGN, Crino 2008 INVITE, Kim 2008 INTEREST and Morere 2010 IFCT-0301 were included. Gefitinib was generally better tolerated than chemotherapy. Gefitinib was associated with an increased risk of skin rash when compared with chemotherapy (RR 2.40, 95\% $\mathrm{Cl} 1.08$ to $5.31, \mathrm{P}=0.03, \mathrm{I}^{2}=4.7 \%$, high quality of evidence). Gefitinib was associated with a decreased risk of constipation (RR $0.41,95 \% \mathrm{Cl} 0.17$ to $0.97, \mathrm{P}=0.04, \mathrm{I}^{2}=0 \%$, high quality of evidence), fatigue ( $R R 0.16,95 \% \mathrm{Cl} 0.03$ to $0.88, \mathrm{P}=0.04, \mathrm{I}=8.2 \%$, moderate quality of evidence), asthenia (RR $0.51,95 \% \mathrm{Cl} 0.35$ to $0.75, P=0.0007,1^{2}=0 \%$, high quality of evidence), neurotoxicity (RR $0.07,95 \% \mathrm{Cl} 0.01$ to $0.34, \mathrm{P}=0.001, \mathrm{I}^{2}=0 \%$, high quality of evidence), neutropenia (RR $0.04,95 \% \mathrm{Cl} 0.02$ to $0.06, \mathrm{P}<0.00001$, $\mathrm{I}^{2}=43.1 \%$, high quality of evidence), leukopenia (RR $0.03,95 \% \mathrm{Cl}$ 0.00 to $0.22, P=0.0005, I^{2}=0 \%$, high quality of evidence) and febrile neutropenia (RR $0.12,95 \% \mathrm{Cl} 0.06$ to $0.23, \mathrm{P}<0.00001$, $\mathrm{I}^{2}=0 \%$, high quality of evidence). There were no differences between groups for any other measured adverse side effects including pruritus, diarrhoea, vomiting, anorexia, stomatitis, arthralgia, peripheral oedema, respiratory tract infection, dyspnoea, cough, anaemia, thrombocytopenia, hypokalaemia or pyrexia.

We assessed most of the toxicity outcomes as high-quality evidence. We downgraded one outcome, fatigue, to a moderate quality of evidence as the study by Crino 2008 INVITE enrolled only 190 patients who were older than 70 years old, thus there was a risk of serious indirectness.

\section{Efficacy}

See Analysis 4.26; Analysis 4.27.

Only one first-line study presented data on disease control rates and there was no reported improvement when administering gefitinib versus vinorelbine ( $R R=0.82,95 \% \mathrm{Cl} 0.61$ to $1.10, \mathrm{P}=$ 0.19) (Crino 2008 INVITE). Disease control rates were $43.3 \%$ and $53.5 \%$ for gefitinib and chemotherapy, respectively. Two second- line studies reported efficacy data (Cufer 2006 SIGN; Kim 2008 INTEREST). Pooled data showed that there was no improvement in overall response rate when comparing gefitinib and docetaxel as second-line therapy ( $R R 1.16,95 \% \mathrm{Cl} 0.85$ to $1.59, \mathrm{P}=0.35, \mathrm{l}=0 \%$ ). Overall response rates were $9 \%$ to $13 \%$ for both the gefitinib and chemotherapy groups.

\section{Quality of life and symptom improvement scores}

See Analysis 4.28; Analysis 4.29; Analysis 4.30; Analysis 4.31.

We pooled data from the INVITE (Crino 2008 INVITE) and INTEREST (Kim 2008 INTEREST) studies. Patients who received gefitinib reported statistically significant improvements in quality of life as assessed by scores on the FACT-L (standardised mean difference (SMD) $10.50,95 \% \mathrm{Cl} 9.55$ to $11.45, \mathrm{P}<0.00001, \mathrm{I}^{2}=21 \%$ ), LCS (SMD $3.63,95 \% \mathrm{Cl} 3.08$ to $4.19, \mathrm{P}<0.00001, \mathrm{I}^{2}=0 \%$ ) and TOI (SMD 9.87, $95 \% \mathrm{Cl} 1.26$ to $\left.18.48, \mathrm{P}=0.02, \mathrm{I}^{2}=59 \%\right)$. One study also described an improvement in PSI scores (SMD 5.60, 95\% Cl 3.55 to $7.65, \mathrm{P}<$ 0.00001 ) in patients who received gefitinib (Crino 2008 INVITE).

\section{Subgroup analysis: Asian population}

\section{Survival}

See Analysis 5.1; Analysis 5.2; Analysis 5.3; Analysis 5.4; Analysis 5.5; Analysis 5.6; Analysis 5.7.

\section{Gefitinib versus first-line chemotherapy}

Five phase III studies compared gefitinib with first-line platinum doublet chemotherapy (Han 2012 First SIGNAL; Maemondo 2010 NEJ002; Mitsudomi 2010 WJTOG3405; Mok 2009 IPASS; Yang 2014). The IPASS (Mok 2009 IPASS) and NEJ002 (Maemondo 2010 NEJ002) studies compared gefitinib with carboplatin-paclitaxel. The WJTOG3405 study compared gefitinib with cisplatin-docetaxel (Mitsudomi 2010 WJTOG3405). The First-SIGNAL study compared gefitinib with gemcitabine-cisplatin (Han 2012 First SIGNAL). The study by Yang 2014 compared gefitinib monotherapy with pemetrexed-cisplatin followed by gefitinib maintenance.

Pooled analysis showed that gefitinib did not improve overall survival (HR 0.94, 95\% Cl 0.82 to $1.06, \mathrm{P}=0.31, \mathrm{~L} 2=0 \%$ ) or the oneyear survival rate (RR $1.03,95 \% \mathrm{C} 0.97$ to $1.09, \mathrm{P}=0.33, \mathrm{~L}=1 \%$ ). One study reported median overall survival as 22 months in both groups. Progression-free survival was higher in the gefitinib group than in the chemotherapy group (HR $0.65,95 \% \mathrm{Cl} 0.43$ to $0.98, \mathrm{P}=$ $0.04,12=93 \%$ ). Median progression-free survival ranged from 5.5 to 6.4 months with chemotherapy to 5.7 to 10.4 months with gefitinib. Please refer to Figure 3 for the pooled progression-free survival data from first-line studies that included Asian patients. 
Figure 3. Progression-free survival: Gefitinib versus first-line chemotherapy in an Asian population (Analysis 5.4).

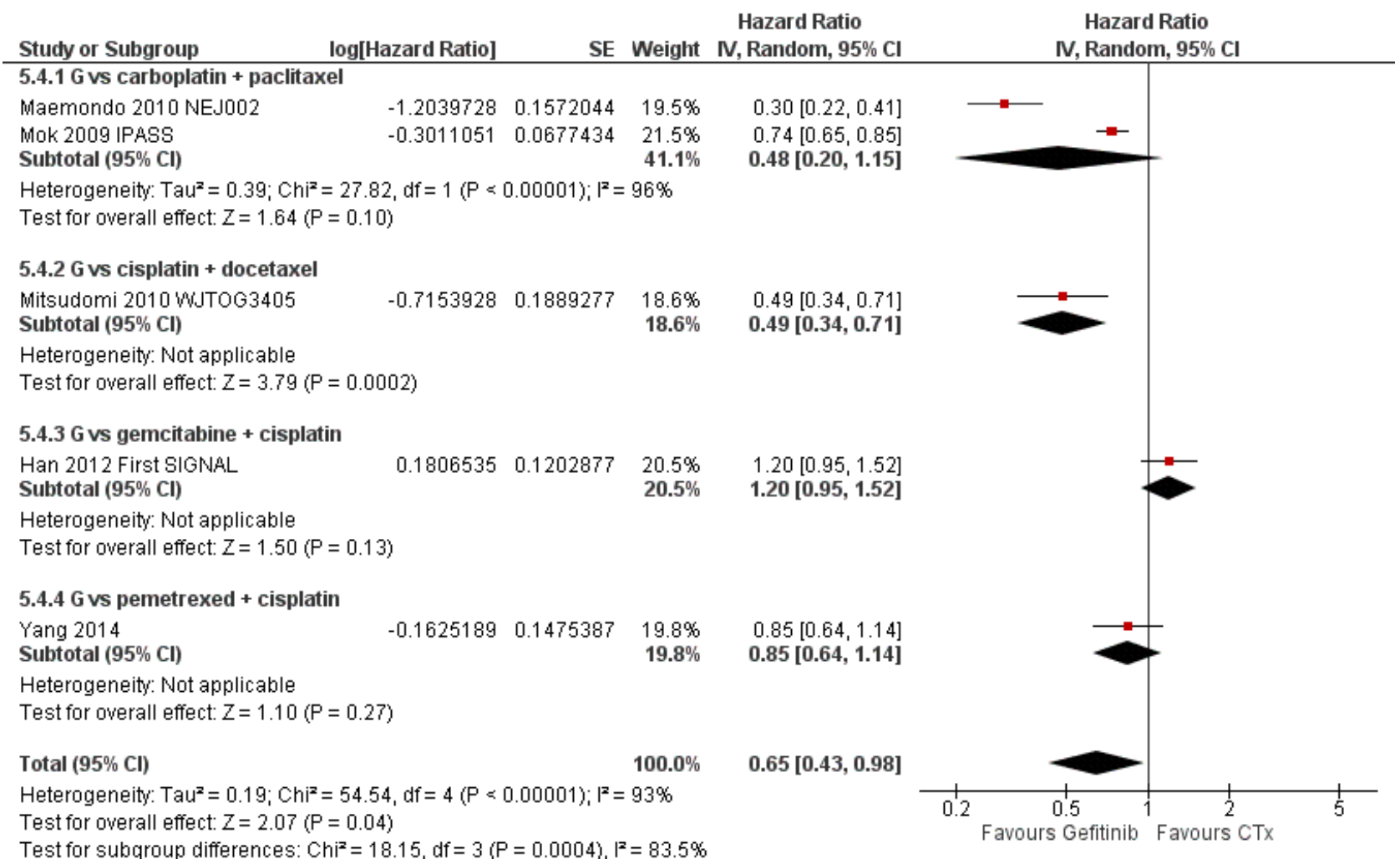

\section{Gefitinib versus second-line chemotherapy}

Two phase III studies compared gefitinib with second-line docetaxel in patients of Asian ethnicity (Lee 2010 ISTANA; Maruyama $2008 \mathrm{~V}-15-32)$ and one phase III study compared gefitinib with pemetrexed (Sun 2012 KCSG-LU08-01). In pooled analysis of these three trials, there was no benefit on either overall survival or the one-year survival rate for gefitinib over second-line chemotherapy
(HR $0.94,95 \% \mathrm{Cl} 0.79$ to $1.12, \mathrm{P}=0.50, \mathrm{~L} 2=0 \%$; RR $0.94,95 \% \mathrm{Cl} 0.81$ to $1.11, P=0.48,1^{2}=0 \%$, respectively). Progression-free survival was prolonged (HR $0.71,95 \% \mathrm{Cl} 0.57$ to $0.88, \mathrm{P}=0.002, \mathrm{I}^{2}=40 \%$; see Figure 4) in favour of gefitinib. Median progression-free survival was 2 to 6.8 months with second-line chemotherapy, and 2 to 10 months with gefitinib in the second-line setting.

Figure 4. Progression-free survival: Gefitinib versus second-line chemotherapy in an Asian population (Analysis 5.5).

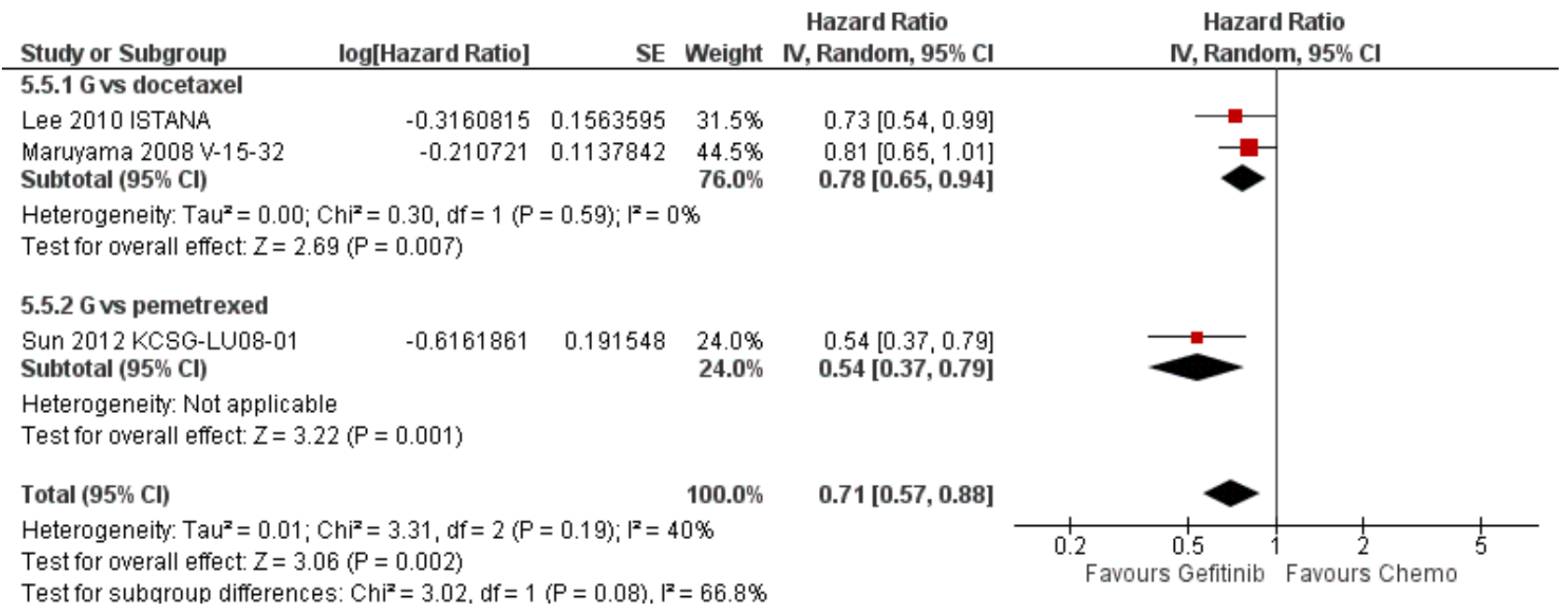




\section{Gefitinib versus maintenance chemotherapy}

Two phase II studies compared maintenance gefitinib with chemotherapy, however only one of them presented survival data (Ahn 2012). There was no difference in overall survival (HR 2.15, 95\% $\mathrm{Cl} 0.83$ to $5.55, \mathrm{P}=0.11$ ) or progression-free survival (HR 0.53, 95\% $\mathrm{Cl} 0.27$ to $1.04, \mathrm{P}=0.06$ ) between the gefitinib and chemotherapy treatment arms. There was an improved one-year survival rate (RR $0.79,95 \% \mathrm{Cl} 0.65$ to $0.98, \mathrm{P}=0.03$ ) with maintenance gefitinib over chemotherapy.

\section{Toxicity}

See Analysis 5.8; Analysis 5.9; Analysis 5.10; Analysis 5.11; Analysis 5.12; Analysis 5.13; Analysis 5.14; Analysis 5.15; Analysis 5.16; Analysis 5.17; Analysis 5.18; Analysis 5.19; Analysis 5.20; Analysis 5.21; Analysis 5.22; Analysis 5.23.

Gefitinib was generally well tolerated in this population. We pooled toxicity data from all studies. Compared to chemotherapy, the gefitinib group reported fewer adverse side effects such as nausea (RR $0.34,95 \% \mathrm{Cl} 0.17$ to $0.64, \mathrm{P}=0.001, \mathrm{I}^{2}=0 \%$ ), vomiting (RR $0.19,95 \% \mathrm{Cl} 0.05$ to $0.77, \mathrm{P}=0.02, \mathrm{I}=56 \%$, random-effects model), anorexia (RR $0.36,95 \% \mathrm{Cl} 0.27$ to $0.49, \mathrm{P}<0.00001, \mathrm{~L}=18 \%$ ), fatigue (RR $0.32,95 \% \mathrm{Cl} 0.22$ to $0.46, \mathrm{P}<0.00001, \mathrm{I}^{2}=50 \%$ ), arthralgia (RR $0.14,95 \% \mathrm{Cl} 0.03$ to $0.61, \mathrm{P}=0.009, \mathrm{I}=0 \%$ ), asthenia (RR $0.22,95 \%$ $\mathrm{Cl} 0.08$ to $0.58, \mathrm{P}=0.002, \mathrm{~L}=13 \%$ ), neurotoxicity (RR $0.07,95 \%$ $\mathrm{Cl} 0.02$ to $0.24, \mathrm{P}<0.0001, \mathrm{I}^{2}=0 \%$ ), neutropenia (RR $0.11,95 \% \mathrm{Cl}$ 0.05 to $0.27, \mathrm{P}<0.00001, \mathrm{I}^{2}=82 \%$, random-effects model), anaemia (RR $0.18,95 \% \mathrm{Cl} 0.12$ to $0.29, \mathrm{P}<0.00001, \mathrm{I}^{2}=4 \%$ ), leukopenia (RR $0.07,95 \% \mathrm{Cl} 0.02$ to $0.23, \mathrm{P}<0.00001, \mathrm{I}^{2}=77 \%$, random-effects model), thrombocytopaenia ( $\mathrm{RR} 0.32,95 \% \mathrm{Cl} 0.14$ to $0.72, \mathrm{P}=0.006$, $\mathrm{I}^{2}=22 \%$ ) and febrile neutropenia ( $\mathrm{RR} 0.09,95 \% \mathrm{Cl} 0.03$ to $0.28, \mathrm{P}<$ $0.0001,12=0 \%)$. Other side effects were seen more frequently in the gefitinib group. Skin rash (RR $3.11,95 \% \mathrm{Cl} 1.28$ to $7.55, \mathrm{P}=0.01,12$ $=60 \%$, random-effects model), diarrhoea (RR $2.79,95 \% \mathrm{Cl} 1.57$ to 4.94, $\mathrm{P}=0.0005, \mathrm{I}^{2}=0 \%$ ), increased alanine aminotransferase (ALT) (RR 10.03, 95\% Cl 5.23 to $19.26, \mathrm{P}<0.00001, \mathrm{I}^{2}=37 \%$ ) and increased aspartate transaminase (AST) (RR $7.73,95 \% \mathrm{Cl} 2.78$ to $21.46, \mathrm{P}<$ $0.0001,12=0 \%$ ) were more frequent in gefitinib-treated cases.

\section{Efficacy}

See Analysis 5.24; Analysis 5.25; Analysis 5.26.

Objective response rates were higher in the gefitinib group when compared with first-line chemotherapy (RR $1.43,95 \% \mathrm{Cl} 1.13$ to $1.82, \mathrm{P}=0.003, \mathrm{I}^{2}=76 \%$, random-effects model). The overall response rate ranged from $43 \%$ to $62.1 \%$ in the gefitinib group and $30.7 \%$ to $32.2 \%$ in the chemotherapy group. There was no effect on the disease control rate ( $\mathrm{RR} 0.99,95 \% \mathrm{Cl} 0.86$ to $1.13, \mathrm{P}=0.86$, $1^{2}=80 \%$, random-effects model): $73 \%$ to $94 \%$ and $78 \%$ to $81 \%$, respectively.

The overall response rate was not significantly improved in the gefitinib group compared with second-line chemotherapy (RR 1.43, $95 \% \mathrm{Cl} 0.92$ to $2.22, \mathrm{P}=0.11, \mathrm{I}^{2}=46 \%$ ). Two studies found that overall response rates were poor overall, but the gefitinib group performed better (23\% to $28 \%$ ) than the second-line chemotherapy group (8\% to 13\%) (Lee 2010 ISTANA; Maruyama $2008 \mathrm{~V}-15-32$ ). The disease control rate (RR $0.99,95 \% \mathrm{Cl} 0.78$ to $1.25, \mathrm{P}=0.92$, $12=46 \%$ ) was statistically similar for both groups ( $34 \%$ and $33 \%$, respectively).

Pooled data from two maintenance studies found that gefitinib improved the stable disease rate and the disease control rate (RR $0.64,95 \% \mathrm{Cl} 0.44$ to $0.93, \mathrm{P}=0.02$; RR $0.65,95 \% \mathrm{Cl} 0.49$ to 0.85 , $\mathrm{P}=0.002$, respectively). There was no improvement in the overall response rate with maintenance gefitinib (RR $0.88,95 \% \mathrm{Cl} 0.41$ to $1.87, \mathrm{P}=0.06, \mathrm{~L}=73 \%$, random-effects model).

\section{Quality of life and symptom improvement scores}

Three studies explored the impact of gefitinib versus chemotherapy on quality of life, but unfortunately the data could not be pooled (Lee 2010 ISTANA; Maruyama 2008 V-15-32; Mok 2009 IPASS). All three studies reported significantly improved quality of life in patients who received gefitinib as measured by the Trial Outcome Index (TOI). Mok 2009 IPASS and Maruyama 2008 V-15-32 stated that improvements as measured by FACT-L were significant, but none recorded significant improvements on the lung cancer subscale (LCS).

\section{Subgroup analysis: EGFR mutation positive population Survival}

See Analysis 6.1; Analysis 6.2; Analysis 6.3; Analysis 6.4.

\section{Gefitinib versus first-line chemotherapy}

Five studies compared gefitinib with first-line chemotherapy. Two of these studies selected patients with EGFR mutations (Maemondo 2010 NEJ002; Mitsudomi 2010 WJTOG3405), and the others selected patients based on clinical features and conducted subgroup analyses on patients positive for EGFR mutations (Han 2012 First SIGNAL; Mok 2009 IPASS; Yang 2014). We have separately analysed studies that selected EGFR mutants and those that selected patients based on clinical features then conducted subgroup analyses and progression-free survival results are presented in Figure 5. 
Figure 5. Progression-free survival: Gefitinib versus first-line chemotherapy in an EGFR mutation positive population (Analysis 6.3).

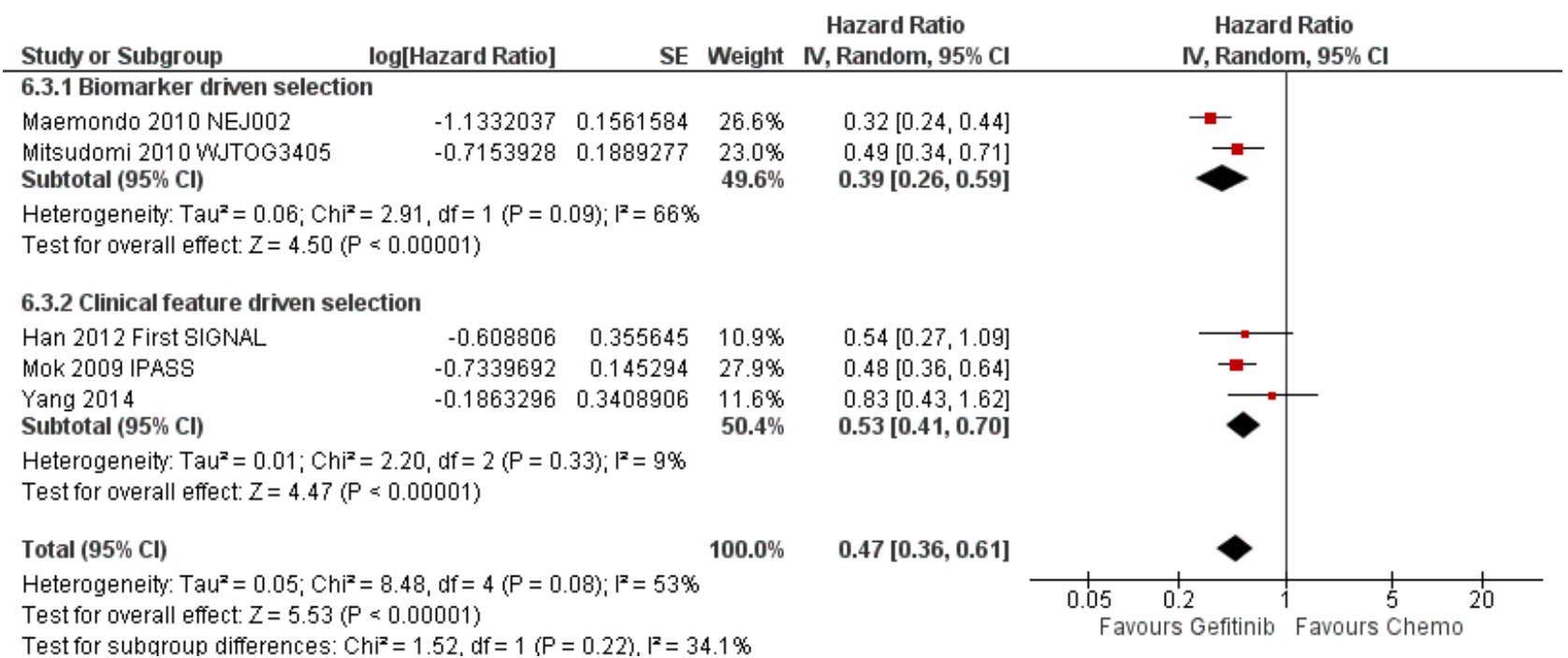

The two biomarker driven studies did not show any improvement in overall survival (HR $0.98,95 \% \mathrm{Cl} 0.72$ to $1.33, \mathrm{P}=0.90, \mathrm{I} 2=54 \%$ ). Progression-free survival was significantly increased with gefitinib compared with first-line chemotherapy (HR $0.39,95 \% \mathrm{Cl} 0.26$ to $0.59, \mathrm{P}<0.00001, \mathrm{I}^{2}=66 \%$, random-effects model).

Three phase III studies conducted subgroup analyses in EGFR mutation positive patients. There was no improvement in overall survival ( $\mathrm{HR} 0.95,95 \% \mathrm{Cl} 0.68$ to $1.33, \mathrm{P}=0.75, \mathrm{I}=20 \%$ ). However, there was a statistically significant improvement in progressionfree survival ( $\mathrm{HR} 0.53,95 \% \mathrm{Cl} 0.41$ to $0.70, \mathrm{P}<0.00001, \mathrm{~L}=9 \%$ ).

Pooled analysis of all first-line studies that examined EGFR mutation positive patients showed that there was no difference in overall survival ( $\mathrm{HR} 0.97,95 \% \mathrm{Cl} 0.77$ to $1.21, \mathrm{P}=0.76, \mathrm{I}=15 \%$ ). However, pooled data from these five studies showed that gefitinib

was able to prolong progression-free survival when compared with first-line chemotherapy (HR $0.47,95 \% \mathrm{Cl} 0.36$ to $0.61, \mathrm{P}<0.00001$, $1^{2}=53 \%$, random-effects model), with median progression-free survival improving from 5.5 to 6.3 months in the chemotherapy group to 9.2 to 10.4 months in the gefitinib group.

\section{Gefitinib versus second-line chemotherapy}

When comparing gefitinib with second-line chemotherapy, data were available from two studies (Kim 2008 INTEREST; Sun 2012 KCSG-LU08-01). This showed that gefitinib did not improve overall survival ( $\mathrm{HR} 0.83,95 \% \mathrm{Cl} 0.41$ to $1.66, \mathrm{P}=0.60$ ). There was a statistically significant improvement in progression-free survival (HR $0.24,95 \% \mathrm{Cl} 0.12$ to $0.47, \mathrm{P}<0.0001, \mathrm{I} 2=0 \%$ ) in EGFR mutation positive patients. Progression-free survival for this analysis is presented in Figure 6.

\section{Figure 6. Progression-free survival: Gefitinib versus second-line chemotherapy in an EGFR mutation positive} population (Analysis 6.4).

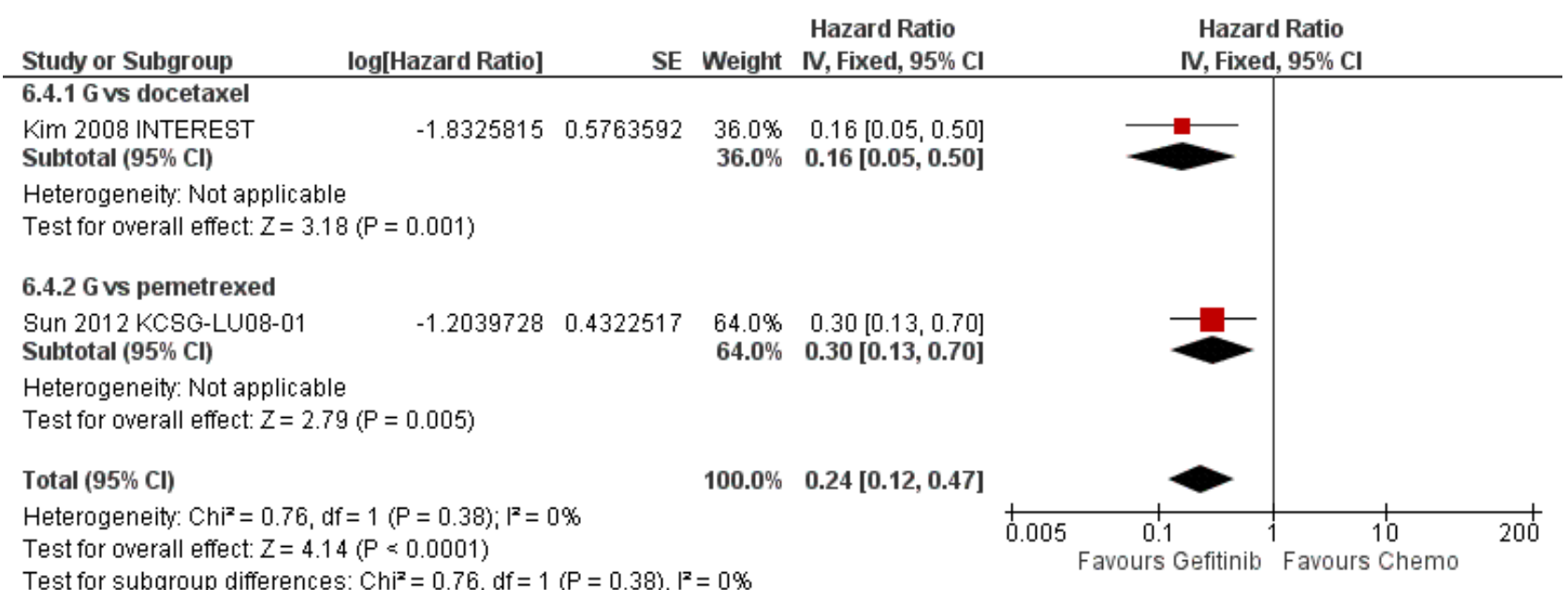




\section{Efficacy}

See Analysis 6.5; Analysis 6.6; Analysis 6.7.

\section{Gefitinib versus first-line chemotherapy}

Pooled analysis comparing first-line gefitinib with chemotherapy showed that the overall response rate was significantly improved in favour of gefitinib. The two studies that selected patients with EGFR mutations (Maemondo 2010 NEJ002; Mitsudomi 2010 WJTOG3405), as well as the phase III studies that conducted subgroup analyses on EGFR mutation positive patients found significant improvements in overall response rate (RR $2.23,95 \% \mathrm{Cl}$ 1.75 to $2.85, \mathrm{P}<0.00001, \mathrm{l} 2=0 \%$ and $\mathrm{RR} 1.45,95 \% \mathrm{Cl} 1.05$ to $1.99, \mathrm{P}=$ $0.02,12=53 \%$, random-effects model, respectively). Pooled analysis of all studies showed that first-line gefitinib improved the overall response rate over chemotherapy $(\mathrm{RR} 1.73,95 \% \mathrm{Cl} 1.29$ to $2.31, \mathrm{P}=$ $0.002,1^{2}=70 \%$, random-effects model) and overall response rates ranged from $62 \%$ to $76 \%$ in the gefitinib group, compared with $31 \%$ to $47 \%$ in the first-line chemotherapy group. The stable disease rate was improved in favour of first-line chemotherapy (RR $0.52,95 \% \mathrm{Cl}$ 0.28 to $0.97, \mathrm{P}=0.04, \mathrm{I}^{2}=66 \%$, random-effects model) but there was no difference in the disease control rate (RR 1.06, 95\% Cl 0.91 to $1.22, \mathrm{P}=0.46, \mathrm{I}^{2}=82 \%$, random-effects model).

\section{Gefitinib versus second-line chemotherapy}

Gefitinib as second-line therapy did not result in a significant difference in overall response rate $(\mathrm{RR} 1.65,95 \% \mathrm{Cl} 0.88$ to $3.09, \mathrm{P}=$ 0.12 ). Overall response rates were reported as $67 \%$ in the gefitinib group and $46 \%$ in the chemotherapy group.

\section{Gefitinib at a specific dose versus gefitinib at a different dose}

\section{Survival}

See Analysis 7.1.

Two multicentre, randomised, double-blind, phase II studies evaluated differing doses of gefitinib $(250 \mathrm{mg}$ and $500 \mathrm{mg}$ ) in the second-line setting (Fukuoka 2003 IDEAL I; Kris 2003 IDEAL II). There was no significant effect on one-year survival (RR $0.83,95 \% \mathrm{Cl}$ 0.61 to $\left.1.11, P=0.21, \mathrm{I}^{2}=0 \%\right)$. HRs were not available for metaanalysis. Median overall survival ranged from 7 to 7.6 months in patients given $250 \mathrm{mg}$, and 6 to 8 months in those given $500 \mathrm{mg}$ of gefitinib. Median progression-free survival ranged from 2.7 to 7 months and from 2.8 to 6 months in patients given $250 \mathrm{mg}$ and 500 $\mathrm{mg}$, respectively.

One study examined the effect of a higher dose of gefitinib in patients that had been stable after one month of $250 \mathrm{mg} /$ day dosing of gefitinib (Xue 2015). In this study, there was no difference in progression-free or overall survival with a higher dose of gefitinib ( $500 \mathrm{mg} /$ day versus $250 \mathrm{mg} /$ day: median progression-free survival 5.30 months versus 6.23 months, $P=0.167$; median overall survival 13.70 months versus 18.87 months, $\mathrm{P}=0.156$ ).

\section{Toxicity}

See Analysis 7.2; Analysis 7.3; Analysis 7.4; Analysis 7.5; Analysis 7.6; Analysis 7.7; Analysis 7.8; Analysis 7.9.

Data from all three studies were available for pooling (Fukuoka 2003 IDEAL I; Kris 2003 IDEAL II; Xue 2015). A gefitinib dose of 500 mg had a marginally worse toxicity profile when compared with the lower dose of $250 \mathrm{mg}$. This higher dose was associated with an increased rate of diarrhoea ( $R R 8.36,95 \% \mathrm{Cl} 1.58$ to $44.34, \mathrm{P}=0.01$, $\mathrm{I}^{2}=0 \%$ ) and skin rash (RR $8.13,95 \% \mathrm{Cl} 1.51$ to $43.72, \mathrm{P}=0.01, \mathrm{I}^{2}=$ $0 \%)$. Other reported side effects such as pruritus, acne, vomiting, anorexia, asthenia, neutropenia, leukopenia and dyspnoea were not significantly different between doses.

\section{Efficacy}

See Analysis 7.10; Analysis 7.11.

Pooled analysis of two studies found no significant difference in overall response rate $\left(\mathrm{RR} 0.92,95 \% \mathrm{Cl} 0.58\right.$ to $1.46, \mathrm{P}=0.72, \mathrm{I}^{2}$ $=0 \%$ ) between doses (Fukuoka 2003 IDEAL I; Kris 2003 IDEAL II). Overall response rates in the $250 \mathrm{mg}$ arm were reported as $18 \%$ and $12 \%$ in the IDEAL I and IDEAL II trials respectively, compared with ORR rates of $19 \%$ and $9 \%$ respectively, in patients receiving $500 \mathrm{mg}$ of gefitinib. Complete and partial response rates were only reported individually in the IDEAL I paper, and were $10 \%$ and $18.1 \%$, respectively.

A higher dose of gefitinib as maintenance treatment did not improve the overall response rate $(12.5 \%$ versus $12.5 \%, P=1$ ) (Xue 2015).

\section{Quality of life and symptom improvement scores}

See Analysis 7.12; Analysis 7.13.

Two studies reported changes in quality of life and symptom improvement scores (Fukuoka 2003 IDEAL I; Kris 2003 IDEAL II).

Quality of life improvements were also measured using the Trial Outcome Index (TOI), a summary score of the physical and functional domains of FACT-L and the lung cancer subscale (a validated subscale of the FACT-L questionnaire). No statistically significant difference was found between $250 \mathrm{mg}$ and $500 \mathrm{mg}$ of gefitinib in the rate of change of the FACT-L and TOI scales (SMD $3.70,95 \% \mathrm{Cl}-7.28$ to $14.69 ; \mathrm{P}=0.51, \mathrm{~L}=0 \%$ and SMD $7.38,95 \%$ $\mathrm{Cl}-2.30$ to $17.05 ; \mathrm{P}=0.14, \mathrm{I}^{2}=0 \%$, respectively). Unfortunately, extractable data from the published papers were inconsistently reported and thus not all data were pooled for analysis.

Data from the IDEAL II study further correlated symptom improvement with objective response and survival. When given a dose of $250 \mathrm{mg}$ of gefitinib, all patients who experienced a partial response also experienced symptom improvement. Patients with stable or progressive disease who experienced symptom improvement also had a longer median survival time compared to those in the same tumour progression category without symptom improvement.

\section{Subgroup analysis}

Both studies performed subgroup analyses.

Fukuoka 2003 IDEAL I found that the objective tumour response rate was higher for Japanese patients versus non-Japanese patients (27.5\% versus $10.4 \%$; odds ratio (OR) $3.27 ; \mathrm{P}=0.0023$ ). A planned subgroup multivariate analysis revealed seven factors that predicted response in Japanese patients: baseline lung cancer subscale, body mass index, performance status, prior radiotherapy, histology, prior immuno/hormonal therapy and gender. After accounting for all the baseline imbalances, the odds ratio indicated that Japanese patients had response rates 1.64 times that of 
non-Japanese patients, but this was not considered statistically significant.

Kris 2003 IDEAL II reported observation of symptom improvement and radiographic responses in all patient subgroups. Multivariate analysis identified female gender to be predictive of both symptom improvement and radiographic responses.

Symptom improvement was rapid, with a median time to onset of less than two weeks: 10 days in the $250 \mathrm{mg}$ group (95\% Cl 8 to 22 days) and 9 days ( $95 \% \mathrm{Cl} 9$ to 16 days) in the $500 \mathrm{mg}$ group.

It was also reported that patients receiving third-, fourth- and fifthline and above therapy had similar rates of symptom improvement both for $250 \mathrm{mg}$ and $500 \mathrm{mg}$ doses of gefitinib. Post-hoc analysis showed that RRs for symptom improvement for the subgroup of patients who had previously received a platinum and taxane were $24 \%$ at $250 \mathrm{mg}$ and $28 \%$ at $500 \mathrm{mg}$ and for patients who had previously received platinum and docetaxel, $24 \%$ and $26 \%$ for the $250 \mathrm{mg}$ and $500 \mathrm{mg}$ groups, respectively.

\section{Gefitinib versus gefitinib plus chemotherapy}

\section{Survival}

See Analysis 8.1; Analysis 8.2; Analysis 8.3.

In the first-line setting, two studies compared gefitinib alone with gefitinib plus pemetrexed (An 2016; Cheng 2016). One study reported no difference in median survival between the gefitinib and gefitinib plus chemotherapy group (32 months versus 34 months respectively) (An 2016). The other study did not present survival data (Cheng 2016). There was, however, a statistically significant improvement in progression-free survival in favour of gefitinib plus chemotherapy over gefitinib alone (HR $0.69,95 \% \mathrm{Cl} 0.49$ to 0.96 ; $\mathrm{P}$ $=0.03$; median progression-free survival 12.6 months versus 18.3 months) (Cheng 2016).

In the second-line or greater setting, median overall survival improved from 13.3 months (Chen 2007) and 18.3 months (Chen 2011) to 23.4 months and 23.6 months, respectively. This improvement was not statistically significant. Combining gefitinib with either vinorelbine or tegafur/uracil did not improve the oneyear survival rate (RR $1.15,95 \% \mathrm{Cl} 0.92$ to $1.43 ; \mathrm{P}=0.22 ; \mathrm{I}^{2}=43 \%$ ). Gefitinib plus chemotherapy improved one-year progression-free survival (RR 2.29, $95 \% \mathrm{Cl} 1.38$ to $3.80 ; \mathrm{P}=0.001$ ). However, the HR for progression-free survival was only presented in Chen 2011 (HR $0.65,95 \% \mathrm{Cl} 0.43$ to $0.97 ; \mathrm{P}=0.04$ : median progression-free survival improved from 7.1 months (Chen 2007) and 5.3 months (Chen 2011) to 12.8 months and 8.3 months, respectively).

\section{Toxicity}

See Analysis 8.4; Analysis 8.5; Analysis 8.6; Analysis 8.7; Analysis 8.8; Analysis 8.9; Analysis 8.10; Analysis 8.11; Analysis 8.12; Analysis 8.13; Analysis 8.14; Analysis 8.15.

We pooled toxicity data from three studies (An 2016; Chen 2007; Cheng 2016). Both regimens were well tolerated with no significant difference in rates of skin rash, diarrhoea, constipation, fatigue, blood counts, nausea or vomiting.

Pooled data from both first-line studies did show that the addition of pemetrexed chemotherapy to gefitinib resulted in higher rates of raised ALT (RR 2.57, 95\% Cl 1.09 to 6.04; $\mathrm{P}=0.03 ; \mathrm{I}^{2}=63 \%$ ) but not AST (RR 1.47, 95\% Cl 0.56 to $3.88 ; \mathrm{P}=0.44 ; \mathrm{I}^{2}=0 \%$ ).

\section{Efficacy}

See Analysis 8.16; Analysis 8.17; Analysis 8.18.

When comparing gefitinib alone to gefitinib plus chemotherapy as first-line therapy, there was no improvement in overall response rate ( $\mathrm{RR} 1.02,95 \% \mathrm{Cl} 0.89$ to $1.17 ; \mathrm{P}=0.73 ; \mathrm{I}^{2}=26 \%$ ) or rate of stable disease (RR $0.67,95 \% \mathrm{Cl} 0.39$ to $1.16 ; \mathrm{P}=0.16 ; \mathrm{I}^{2}=0 \%$ ).

In the second-line setting, the addition of chemotherapy to gefitinib did not result in an improvement in either partial radiological response (RR $1.02,95 \% \mathrm{Cl} 0.71$ to $1.47 ; \mathrm{P}=0.92 ; \mathrm{I}^{2}=0 \%$ ) or stable disease (RR 1.30, 95\% Cl 0.84 to $2.03 ; P=0.24 ;\left.\right|^{2}=16 \%$ ).

\section{Gefitinib plus chemotherapy versus chemotherapy}

\section{Survival}

See Analysis 9.1; Analysis 9.2; Analysis 9.3.

Meta-analysis of two phase II, first-line trials examining 1411 patients showed that the addition of gefitinib ( $250 \mathrm{mg} /$ day) to a chemotherapy regimen in chemotherapy-naive patients did not change the one-year survival rate $(\mathrm{RR} 0.95,95 \% \mathrm{Cl} 0.84$ to $1.08, \mathrm{P}=$ $0.44, I^{2}=0 \%$ ) (Giaccone 2004 INTACT I; Herbst 2004 INTACT II).

Two trials compared the addition of first-line gefitinib to chemotherapy with chemotherapy alone in Asian patients only (Takeda 2010 WJTOG0203; Yu 2014). There was no improvement in overall survival $(\mathrm{HR} 0.86,95 \% \mathrm{Cl} 0.72$ to $1.02, \mathrm{P}=0.08, \mathrm{I}=$ $0 \%$, however there was a statistically significant improvement in progression-free survival (HR $0.69,95 \% \mathrm{Cl} 0.62$ to $0.77, \mathrm{P}<0.00001$, $\left.\mathrm{I}^{2}=18 \%\right)$.

A single phase III trial recruited only EGFR mutation positive patients who had failed prior first-line gefitinib, and the addition of gefitinib to chemotherapy did not improve progressionfree survival ( $\mathrm{HR} 0.86,95 \% \mathrm{Cl} 0.65$ to $1.13, \mathrm{P}=0.28$ ) (Soria 2015 IMPRESS). Overall survival appeared to be better in the chemotherapy alone group ( $\mathrm{HR} 1.62,95 \% \mathrm{Cl} 1.05$ to $2.50, \mathrm{P}=0.03$ ).

\section{Toxicity}

See Analysis 9.4; Analysis 9.5; Analysis 9.6.

Pooled data from all five trials showed that the addition of gefitinib to a chemotherapeutic regimen resulted in increased rates of skin rash (RR 2.98, $95 \% \mathrm{Cl} 1.54$ to $5.77, \mathrm{P}=0.001, \mathrm{~L}=28 \%$ ), acne (RR 4.95, $95 \% \mathrm{Cl} 1.09$ to $22.51, \mathrm{P}=0.04, \mathrm{~L}=0 \%$ ) and diarrhoea $(\mathrm{RR} 2.04,95 \% \mathrm{Cl}$ 1.17 to $\left.3.58, P=0.01, I^{2}=17 \%\right)$. Other measured side effects such as pruritus, vomiting, nausea, anorexia, asthenia, dyspnoea, anaemia, neutropenia and leukopenia were not significantly increased.

\section{Efficacy}

\section{See Analysis 9.16.}

In the first-line setting, the addition of gefitinib to chemotherapy did not effect the overall response rate in either the unselected population ( $\mathrm{RR} 1.07,95 \% \mathrm{Cl} 0.94$ to $1.22, \mathrm{P}=0.28, \mathrm{~L}=0 \%$ ) or the Asian population ( $\mathrm{RR} 1.14,95 \% \mathrm{Cl} 0.93$ to $1.40, \mathrm{P}=0.20, \mathrm{I} 2=0 \%$ ). The 
overall response rate ranged from $30 \%$ to $51 \%$ in the gefitinib plus chemotherapy group and $29 \%$ to $50 \%$ in the chemotherapy group.

There was also no improvement in the overall response rate in the second-line setting ( $R R 0.93,95 \% \mathrm{Cl} 0.66$ to $1.31, \mathrm{P}=0.66, \mathrm{I}^{2}$ $=0 \%$ ), and the overall response rate was $32 \%$ in the gefitinib plus chemotherapy group and $34 \%$ in the chemotherapy alone group.

\section{Quality of life and symptom improvement scores}

In the first-line setting, the WJTOG0203 study reported a disease-related symptoms assessment (Takeda 2010 WJTOG0203). Sequential administration of gefitinib was reported to provide better symptom control, however these differences were not statistically significant. The adjusted mean of initial summed scores of the lung cancer subscale were 20.3 for Arm A and 20.6 for Arm B. The adjusted lung cancer subscale scores at 12 and 18 weeks were 21 and 20.9 for Arm A and 21.8 and 21.2 for Arm B, respectively.

In the second-line setting, the IMPRESS study reported that the improvements in quality of life were no different when gefitinib plus chemotherapy was compared to placebo plus chemotherapy as measured by the Trial Outcome Index (TOI) (29\% versus $30.2 \%$, respectively), FACT-L ( $35.5 \%$ versus $38 \%$, respectively) or lung cancer subscale (43.5\% versus 42.6\%, respectively) (Soria 2015 IMPRESS). There was also no difference in the time to worsening of health-related quality of life as measured by the TOI, FACT-L and lung cancer subscale.

These data could not be pooled for meta-analysis.

\section{Subgroup analysis}

A planned exploratory subgroup analysis in Japanese patients of overall survival by histological group reported that patients with adenocarcinoma that were given sequential gefitinib had better outcomes than patients given chemotherapy alone $(n=467$; progression-free survival: $\mathrm{HR} 0.79,95 \% \mathrm{Cl} 0.65$ to $0.98, \mathrm{P}=0.03$; overall survival: $\mathrm{HR} 0.60,95 \% \mathrm{Cl} 0.50$ to $0.73, \mathrm{P}<0.001$ ) (Takeda 2010 WJTOG0203). There was no difference in overall survival or progression-free survival in those with non-adenocarcinoma (overall survival: $\mathrm{HR} 1.24,95 \% \mathrm{Cl} 0.85$ to $1.79, \mathrm{P}=0.25$ and progression-free survival: $\mathrm{HR} 1.14,95 \% \mathrm{Cl} 0.80$ to $1.62, \mathrm{P}=0.47$ ). This study also reported that smokers also experienced improved survival with sequential gefitinib ( $\mathrm{HR} 0.79,95 \% \mathrm{Cl} 0.64$ to 0.98 ), as opposed to non-smokers (HR $0.94,95 \% \mathrm{Cl} 0.66$ to 1.33 ), however P values were not published.

\section{DISCUSSION}

This meta-analysis examined published data on the effectiveness and safety of gefitinib in patients with non-small cell lung cancer (NSCLC). We performed an extensive search of electronic databases and carried out handsearching, and 35 randomised studies fulfilled the inclusion criteria. Some were phase II, open-label design trials and limited pooling of data was possible due to methodological differences between studies.

\section{Summary of main results}

A total of 35 studies were included in this review.

Five studies compared gefitinib with placebo: one study in the first-line, one study in the second-line and three studies in the maintenance setting. Gefitinib did not improve survival in the first-line setting in a general population of NSCLC patients. The ISEL study found that gefitinib as a second-line therapy was able to reduce the risk of disease progression by $18 \%$, and improve the objective response rate from $1 \%$ to $6 \%$ when compared to placebo (Thatcher 2005 ISEL). Three studies compared gefitinib with placebo in the maintenance setting. Gefitinib reduced the risk of disease progression by $31 \%$.

In patients of Asian ethnicity, preplanned subgroup analysis in the ISEL study found that second-line gefitinib improved overall and progression-free survival by $34 \%$ and $31 \%$, respectively (Chang 2006). The INFORM study compared gefitinib with placebo in the maintenance setting and selected patients of Asian ethnicity (Zhang 2012 INFORM). This study found that gefitinib prolonged progression-free survival by $58 \%$ and the overall response rate improved from $1 \%$ to $24 \%$. Quality of life analysis from the INFORM study also showed that improvement rates as measured by the Functional Assessment of Cancer Therapy-Lung (FACT-L), Trial Outcome Index (TOI) and lung cancer subscale were higher in the patients who were given gefitinib as maintenance therapy. These patients also experienced a longer time-to-worsening of quality of life scores.

In patients positive for an epidermal growth factor receptor (EGFR) mutation, subgroup analysis of the INFORM study showed an improvement in median overall survival from 21 months to 47 months and maintenance gefitinib reduced the risk of death by 61\% (Zhang 2012 INFORM). Maintenance gefitinib also improved progression-free survival from 2.8 months to 16.6 months.

Several phase II and III studies compared gefitinib with chemotherapy. Eighteen randomised studies have examined the effectiveness of gefitinib compared with recommended chemotherapy regimes. Meta-analysis of four studies failed to demonstrate any benefit for survival or response rate in a general population (moderate quality of evidence). (Please refer to Summary of findings for the main comparison and Summary of findings 2). Quality of life was significantly better for patients on gefitinib than for those having chemotherapy, and gefitinib was significantly less toxic and generally well tolerated when compared with chemotherapy (high quality of evidence), in keeping with results from other studies. Skin rash, diarrhoea and increased liver transaminases were more frequent in the gefitinib group, but other significant side effects such as neutropenia, anaemia, leukopenia and febrile neutropenia were less frequent. (Please refer to Summary of findings 3 ).

Fourteen trials included patients exclusively of Asian ethnicity, with some additionally selecting by EGFR mutation status or clinical criteria that are likely to have enriched EGFR mutations. Gefitinib improved the overall response rate by $43 \%$ and progression-free survival by $35 \%$ when compared with first-line chemotherapy, but this did not translate into an improvement in overall survival. Comparing gefitinib with second-line chemotherapy found that progression-free survival was improved by $29 \%$, but there was no effect on overall survival or overall response rate. The effect of Asian ethnicity is complicated, and may be confounded by higher rates of EGFR mutation and the biologically plausible predictive biomarker characteristic of EGFR mutations. Two trials compared maintenance gefitinib with maintenance chemotherapy. There was no difference in either progression-free survival or overall survival, but gefitinib was able to improve the one-year survival rate by $21 \%$ and the disease control rate by $35 \%$. Skin rash, 
diarrhoea and elevated liver transaminases were more common in those treated with gefitinib, however severe adverse side effects such as haematological derangements, neurotoxicity, nausea, anorexia, fatigue and arthralgia were much more common in the chemotherapy group.

Eight studies either selected patients with tumours expressing EGFR mutations for comparison or conducted subgroup analyses in these patients. Use of gefitinib in the first-line setting improved progression-free survival over platinum-doublet chemotherapy. Studies that selected patients with EGFR mutations exclusively were able to show a $61 \%$ improvement in progression-free survival over first-line chemotherapy. Two studies recruited patients with clinical features likely to respond favourably to gefitinib, and showed a $51 \%$ improvement in progression-free survival after subgroup analysis of EGFR mutation positive patients. Gefitinib also improved the overall response rate by $73 \%$ over first-line chemotherapy. However, none were able to demonstrate an improvement in overall survival, arguably due to high rates of crossover. When comparing gefitinib with second-line chemotherapy, a similar improvement in progression-free survival of $76 \%$ was seen. There was no impact on overall survival or overall response rate.

Increasing the dose of gefitinib from $250 \mathrm{mg} /$ day to $500 \mathrm{mg} /$ day yielded no additional benefit in survival or response rate in three phase II trials. This increased dose, however, was associated with greater toxicity.

Two phase II studies compared pemetrexed plus gefitinib with gefitinib alone as first-line treatment. Progression-free survival was improved by $31 \%$ with a median improvement from 12.6 months to 18.3 months. There were, however, increased rates of raised ALT in this treatment arm. All other toxicities were similar. The two studies comparing gefitinib plus chemotherapy with gefitinib alone in the second-line setting showed improved one-year progressionfree survival when chemotherapy was added to gefitinib.

Five studies showed that the addition of gefitinib to a chemotherapy regimen compared to chemotherapy alone did not confer any survival benefit. In patients of Asian ethnicity, two studies showed that first-line gefitinib plus chemotherapy improved progression-free survival by $31 \%$ compared to chemotherapy alone. One phase III study compared gefitinib plus chemotherapy to chemotherapy alone and found that survival was improved in favour of chemotherapy alone. All patients in this study were EGFR mutation positive, but had failed prior first-line therapy with gefitinib.

A summary of the efficacy results is presented in Table 2.

\section{Overall completeness and applicability of evidence}

Much of the data analysed in this review has predated the routine assessment of EGFR mutation status in NSCLC. This testing is now done routinely in many countries before starting treatment, and the status of EGFR mutation now guides the therapeutic options. Gefitinib has already been registered in occidental countries for treatment of NSCLC with EGFR activating mutations. The treatment options for patients with advanced NSCLC continue to evolve rapidly and although some of the data in this review may be considered historical, it still provides a foundation upon which ongoing studies examining the relationship between the effectiveness of gefitinib and the timing of its use with other treatment modalities can be built.

The inclusion criteria for selecting patients for these studies may have adversely affected their ability to provide statistically significant results. For example, some studies selected patients with highly refractory disease who may have been less likely to respond to any additional therapy. Some studies selected chemotherapy-naive patients for inclusion (Giaccone 2004 INTACT I; Herbst 2004 INTACT II), whereas others included patients who had received at least one prior platinum-containing chemotherapy regimen (Kris 2003 IDEAL II; Fukuoka 2003 IDEAL I). Thatcher 2005 ISEL selected patients who had recurrence or progressive disease during treatment or within 90 days of the last dose of chemotherapy.

In some studies, patients who progressed on a certain treatment were allowed the opportunity to switch to the comparison arm. This was reported in some studies (e.g. Mok 2009 IPASS) and in some data were censored accordingly (e.g. Mitsudomi 2010 WJTOG3405). The impact of this cross-over is difficult to analyse and may contribute to a lack of survival benefit seen in these large phase III studies.

We analysed EGFR mutation positive patients in this review, finding that gefitinib improved progression-free survival over first- and second-line chemotherapy and over placebo in the maintenance setting. However, patients with EGFR wild type NSCLC were not formally included in this meta-analysis. Studies such as Zhou 2014 CTONG 0806 were excluded from this meta-analysis as they selected only EGFR wild type NSCLC. This study showed that second-line pemetrexed chemotherapy was superior to gefitinib in terms of progression-free survival but a trend towards improved overall survival was also seen. Thus, this highlights the importance of determining the EGFR mutation status in patients with advanced NSCLC, as this result will guide further management decisions.

Patients with progressive NSCLC who have failed to respond to first-line chemotherapy have an extremely poor prognosis and often exhibit severe symptoms. One difficulty with meta-analyses of quality of life data is that outcomes are not consistently reported in the published papers, limiting the pooling of data. Some studies reported changes in FACT-L and the lung cancer subscale that reached the pre-defined criteria for clinical significance (Cella 2005; Kris 2003 (DEAL II), whereas others failed to show any improvement (Fukuoka 2003 IDEAL I; Thatcher 2005 ISEL). Cella 2005 reported a correlation between symptom improvement, objective response and survival, and found that $30 \%$ of patients showed a quality of life improvement that was correlated with tumour response. Kris 2003 IDEAL II reported that symptoms improved in $96 \%$ of patients with partial radiographic responses. Pre-planned subgroup analysis in Thatcher 2005 ISEL found that gefitinib was associated with a significant improvement in symptom score compared with placebo in never-smokers and patients of Asian origin.

\section{Quality of the evidence}

The 'Risk of bias' tables have enabled a methodical and thorough assessment of the quality of evidence. We included a total of 35 randomised controlled trials (RCTs) randomising 12,089 patients in this review. (Please refer to Figure 2). Trials included in this meta-analysis generally had a low risk of selection and attrition bias. Unfortunately, differences in reporting of outcomes, such 
as survival times, and a lack of survival curves, meant that only extractable data could be included in the analyses. The duration of gefitinib treatment and duration of follow-up may also have affected outcomes in these RCTs. Despite these limitations, the included RCTs were generally consistent with their findings.

For studies that compared gefitinib with first-line chemotherapy, we judged the quality of evidence as moderate. One study enrolled elderly patients (over 70 years old) and thus we downgraded the quality of evidence as this may be at serious risk of indirectness (Crino 2008 INVITE). When comparing gefitinib with second-line chemotherapy, we also judged the quality of evidence as moderate as one study was not statistically powered to detect differences in any end point and was thus at serious risk of imprecision (Cufer 2006 SIGN). When considering toxicity outcomes, generally the quality of data was high, except for fatigue, which we judged as moderate quality of evidence. We downgraded this outcome one level, as we judged one study as having a serious risk of indirectness for enrolling only patients over the age of 70 years old (Crino 2008 INVITE).

\section{Agreements and disagreements with other studies or reviews}

Two published meta-analyses also examined the effect of gefitinib in NSCLC. The first by Ibrahim 2010 reported on seven studies that included chemotherapy-naive patients (Crino 2008 INVITE; Giaccone 2004 INTACT I; Goss 2009 INSTEP; Herbst 2004 INTACT II; Kelly 2008 SWOG S0023; Mok 2009 IPASS; Takeda 2010 WJTOG0203), analysing a total of 2545 and 1939 patients in the gefitinib and control arms. The same seven studies also fulfilled the inclusion criteria for this review; however our review included a further 17 studies that analysed the use of gefitinib as second- or third-line and maintenance therapy. The authors were not able to show any benefit in objective response rate, progression-free survival or overall survival in this general population. In a small subset of patients with EGFR mutations, gefitinib was shown to significantly improve the overall response rate (odds ratio (OR) $2.81,95 \% \mathrm{Cl}$ 1.71 to $4.62, \mathrm{P}<0.0001)$. This benefit was not associated with a progression-free or overall survival advantage in that group. Only three of the included seven studies reported on quality of life, showing a measurable and statistically significant improvement as measured by FACT-L.

The second meta-analysis by Jiang 2011 compared gefitinib with docetaxel as second-line therapy. Four studies were included, all of which were also included in this review (Cufer 2006 SIGN; Kim 2008 INTEREST; Lee 2010 ISTANA; Maruyama 2008 V-15-32). A total of 2247 patients received either gefitinib or docetaxel as second-line therapy. Similar results were also found in this meta-analysis. There was an improved overall response rate with gefitinib compared with docetaxel (risk ratio (RR) $1.58,95 \% \mathrm{Cl} 1.02$ to $2.45, \mathrm{P}=0.04$ ) and quality of life as measured with the FACT-L and TOI questionnaires (RR $1.55,95 \% \mathrm{Cl} 1.27$ to $1.88, \mathrm{P}<0.001$; RR $1.86,95 \% 1.43$ to 2.42 , $P<0.001$, respectively). There was no benefit in overall survival or progression-free survival.

Both of these systematic reviews reported results similar to those of this meta-analysis.

Patients with tumours bearing EGFR mutations derive benefit from gefitinib treatment. It has been shown that in patients of Asian ethnicity with tumours with EGFR mutations, progression- free survival and overall response rate were significantly improved by the use of gefitinib as first-line therapy; however there was no effect on overall survival, perhaps because of cross-over between study interventions.

An interaction between ethnicity, EGFR mutation status and other clinical features is likely to confound a straightforward analysis of factors predictive of a gefitinib response. Patients of Asian descent, who are non-smokers or with adenocarcinoma histology are also more likely to have tumours harbouring EGFR mutations.

There is increasing evidence to justify the use of molecular markers in clinical practice and the EGFR mutation status appears to be a significant predictor of benefit in terms of progression-free survival and response to gefitinib. Other markers of EGFR status such as EGFR protein expression and EGFR gene copy number appear to be related to EGFR mutations, but interpretation criteria still need to be established. Further research into optimal sampling, mutation testing methods and the precise spectrum of predictive EGFR mutations is required.

\section{AUTHORS' CONCLUSIONS}

\section{Implications for practice}

- In patients of Asian ethnicity or who are epidermal growth factor receptor (EGFR) mutation positive, first-line gefitinib significantly improves progression-free survival and overall response rate but not overall survival when compared with chemotherapy.

- Side effects such as skin rash, diarrhoea and increased alanine aminotransferase (ALT) and aspartate transaminase (AST) are more common with gefitinib. Side effects such as nausea, vomiting, anorexia, fatigue, arthralgia, asthenia, neurotoxicity, neutropenia, leukopenia, thrombocytopaenia and anaemia are more common with chemotherapy.

- In patients of Asian ethnicity, first-line gefitinib plus chemotherapy improves progression-free survival over either gefitinib or chemotherapy alone.

- In the second-line setting, gefitinib is more effective than placebo, with improvements in the one-year survival rate, progression-free survival and overall response rate. There was no improvement in overall survival.

- One study demonstrated an improvement in overall survival, time to treatment failure and overall response rate when comparing second-line gefitinib to placebo in patients of Asian ethnicity. However, the prevalence of EGFR mutations in cancers from Asian patients means that caution needs to be exercised in interpreting these results.

- Second-line gefitinib plus chemotherapy is probably more effective in improving progression-free survival than gefitinib alone.

- One second-line study selected EGFR mutation positive patients and showed that chemotherapy is more effective in improving survival than gefitinib plus chemotherapy in patients who have failed first-line gefitinib.

- Maintenance treatment with gefitinib was shown to be more effective in improving overall survival and progression-free survival than placebo in patients with EGFR mutation positive tumours. In unselected patients or those of Asian ethnicity, gefitinib improves progression-free survival but not overall survival or overall response rate over placebo. 
- Increasing the dose of gefitinib from $250 \mathrm{mg} /$ day to $500 \mathrm{mg} /$ day results in significantly more adverse side effects, without any impact on response rate, survival or reported quality of life.

- Quality of life is higher in patients who receive gefitinib than those who either receive placebo or chemotherapy.

\section{Implications for research}

- Extended follow-up of existing trials and the inclusion of other randomised trials will provide additional evidence on the use of gefitinib in advanced non-small cell lung cancer.

- Gaining a clearer understanding of why most, but not all, patients with tumours bearing EGFR mutations respond to gefitinib, as well as identifying new predictive factors, and the mechanisms and the management of drug resistance, are highpriority research issues.

\section{ACK N OWLEDGEMENTS}

We would like to thank the Cochrane Lung Cancer Review Group, including Fédérico Capuzzo, Jean-Paul Sculier, Noelle O'Rourke, Fergus Macbeth, Virginie Westeel, Corynne Marchal, Tom Haswell and Marta Roqué for expert advice and extensive support with this review.

We would also like to thank Vivian Sun, Senior Clinical Research Co-ordinator (50\% Melanoma), Adult Oncology Research Centre, Auckland Regional Cancer and Blood Service for her translation of the Dai 2013 and Li 2010 studies that were published in Mandarin.

Esther Sim was supported by an Australian Lung Foundation/ Lung Cancer Consultative Group Cochrane Review Scholarship in 2007. Ian Yang was supported by an NHMRC Career Development Fellowship, and project grants from NHMRC, Cancer Council Queensland, The Prince Charles Hospital Foundation and Queensland Smart State grants. Rayleen Bowman was supported by project grants from NHMRC, Dust Diseases Board, Cancer Australia, Cancer Council Queensland and The Prince Charles Hospital Foundation. Kwun Fong was supported by an NHMRC Practitioner Fellowship, and project grants from NHMRC, Cancer Australia, Dust Diseases Board, Cancer Council Queensland, The Prince Charles Hospital Foundation and Queensland Smart State grants. Richard Wood-Baker was supported by project grants from NHMRC and Royal Hobart Hospital Research Foundation. 


\section{R E F E R E N C E S}

\section{References to studies included in this review}

Ahn 2012 \{published data only\}

* Ahn MJ, Yang JCH, Liang J, Kang JH, Xiu Q, Chen YM, et al. Randomized phase II trial of first-line treatment with pemetrexed-cisplatin, followed sequentially by gefitinib or pemetrexed, in East Asian, never-smoker patients with advanced non-small cell lung cancer. Lung Cancer 2012;77:346-52.

\section{An 2016 \{published data only\}}

* An C, Zhang J, Chu H, Gu C, Xiao F, Zhu F, et al. Study of gefitinib and pemetrexed as first-line treatment in patients with advanced non-small cell lung cancer harboring EGFR mutation. Pathology and Oncology Research 2016;22:763-8.

\section{Chen 2007 \{published data only\}}

Chen YM, Liu JM, Chou TY, Perng RP, Tsai CM, Whang-Peng J. Phase II randomized study of daily gefitinib treatment alone or with vinorelbine every 2 weeks in patients with adenocarcinoma of the lung who failed at least 2 regimens of chemotherapy. Cancer 2007;109(9):1821-8.

\section{Chen 2011 \{published data only\}}

* Chen YM, Fan WC, Tsai CM, Liu SH, Shih JF, Chou TY, et al. A phase II randomized trial of gefitinib alone or with Tegafur/ uracil treatment in patients with pulmonary adenocarcinoma who had failed previous chemotherapy. Journal of Thoracic Oncology 2011;6:1110-6.

\section{Cheng 2016 \{published data only\}}

Cheng Y, Murakami H, Yang PC, He J, Nakagawa K, Kang JH, et al. Randomized phase II trial of gefitinib with and without pemetrexed as first-line therapy in patients with advanced nonsquamous non-small-cell lung cancer with activating epidermal growth factor receptor mutations. Journal of Clinical Oncology 2016;27(20):3258-66.

\section{Crino 2008 INVITE \{published data only\}}

Crino L, Cappuzzo F, Zatloukal P, Reck M, Pesek M, Thompson JC, et al. Gefitinib versus vinorelbine in chemotherapy-naive elderly patients with advanced non-smallcell lung cancer (INVITE): a randomized, phase II study. Journal of Clinical Oncology 2008;26(26):4253-60.

\section{Cufer 2006 SIGN \{published data only\}}

Cufer T, Vrdoljak E, Gaafar R, Erensoy I, Pemberton K, SIGN study group. Phase II, open-label, randomized study (SIGN) or singleagent gefitinib (IRESSA) or docetaxel as second-line therapy in patients with advanced (stage IIIb or IV) non-small-cell lung cancer. Anticancer Drugs 2006;17(4):401-9.

\section{Dai 2013 \{published data only\}}

Dai H, Xu L, Xia C, Chen W. A randomized clinical study of gefitinib and pemetrexed as second line therapy for advanced non-squamous non-small cell lung cancer. Chinese Journal of Lung Cancer 2013;16:405-10.

\section{Fukuoka 2003 IDEAL I \{published data only\}}

Baelga J, Kris M, Yano S, Natale R, Giaccone G, Brahmer J, et al. Phase II trials (IDEAL 1 and IDEAL 2) of ZD1839 in advanced or metastatic non-small cell lung cancer (NSCLC) patient. Annals of Oncology 2002;13(Suppl 5):131 Abs 481.

Douillard JY, Giaccone G, Horai T, Noda K, Vansteenkiste JF, Takata I, et al. Improvement in disease-related symptoms and quality of life in patients with advanced non-small cell lung cancer (NSCLC) treated with ZD1839 ('Iressa') (IDEAL 1) [abstract]. 38th Annual Meeting of the American Society of Clinical Oncology; 18-21 May 2002; Orlando, Florida, USA. 2002; Vol. 21 Pt 1:299a, Abs 1195.

Douillard JY, Skarin A, Baselga J, Natale R, Giaccone G, Maddox AM, et al. Improvement in disease-related symptoms and quality of life (QOL) for advanced non-small cell lung cancer (NSCLC) patients treated with ZD1839 in IDEAL 1 and IDEAL 2. Annals of Oncology 2002;13 Suppl 5:131, Abs 480.

* Fukuoka M, Yano S, Giaccone G, Tamura T, Nakagawa K, Douillard JY, et al. Multi-institutional randomized phase II trial of gefitinib for previously treated patients with advanced non-small-cell lung cancer. Journal of Clinical Oncology 2003;21(12):2237-46.

Fukuoka M, Yano S, Giaccone G, et al. [Final results from a phase II trial of ZD1839 ('Iressa') for patients with advanced non-small cell lung cancer (IDEAL 1) [abstract]]. 38th Annual Meeting of the American Society of Clinical Oncology; 18-21 May 2002; Orlando, Florida, USA. 2002; Vol. 21 Pt 1:298a, Abs 1188.

Manegold C, Gatzemeier U, Kaukel E. Results from a randomised, double blind phase II trial of ZD1839 (IRESSA) as 2nd/3rd-line monotherapy in advanced non small cell lung cancer (NSCLC) (IDEAL 1). Journal of Cancer Research \& Clinical Oncology 2002;128 Suppl 1:S45.

Nishiwaki Y, Yano S, Tamura T, Nakagawa K, Kudoh S, Horai T, et al. Subset analysis of data in the Japanese patients with NSCLC from IDEAL I study on gefitinib. Gan to Kagaku Ryoho. Cancer \& Chemotherapy 2004;31(4):567-73.

Vansteenkiste J, Natale R, Giaccone G, et al. Two randomised, double-blind studies of ZD1839 in 425 patients with pretreated advanced non-small-call lung cancer (IDEAL 1 and IDEAL 2) [abstract]. European Respiratory Society Annual Congress. Stockholm, 2002:Abstract 2537.

\section{Gaafar 2011 EORTC08021 \{published data only\}}

Gaafar R M, Surmont V, Scagliotti G, Van Klaveren R, Papamichael D, Welch J, et al. A double-blind, randomized, placebo-controlled phase III intergroup study of gefitinib (G) in patients (pts) with advanced NSCLC, non-progressing after first-line platinum-based chemotherapy (EORTC 08021-ILCP 01/03). 2010 Annual Meeting of the Americal Society of CLinical Oncology, ASCO, Chicago, IL United States. American Society of Clinical Oncology, 2010; Vol. 28.

* Gaafar RM, Surmont VF, Scagliotti GV, Van Klaveren RJ, Papamichael D, Welch JJ, et al. A double-blind, randomised, 
placebo-controlled phase III intergroup study of gefitinib in patients with advanced NSCLC, non-progressing after first line platinum-based chemotherapy (EORTC 08021/ILCP 01/03). European Journal of Cancer 2011;47:2331-40.

Surmont VF, Gaafar RM, Scagliotti GV, Van Klaveren RJ, Papamichael D, Hasan B, et al. A double-blind, randomized, placebo-controlled phase III study of gefitinib (G) versus placebo $(P)$ in patients (pts) with advanced NSCLC, non progressing after first-line platinum-based chemotherapy (EORTC 08021- ILCP). 35th ESMO Congress Milan Italy. Oxford University Press, 2010; Vol. 21:viii124.

\section{Giaccone 2004 INTACT I \{published data only\}}

Bell DW, Lynch TJ, Maserlat SM, Harris PL, Okimoto FA, Brannigan BW, et al. Epidermal growth factor receptor mutations and gene amplification in non-small-cell lung cancer: molecular analysis of the IDEAL/INTACT gefitinib trials. Journal of Clinical Oncology 2005;23(31):8081-92.

* Giaccone G, Herbst RS, Manegold C, Scagliotti G, Rosell R, Miller V, et al. Gefitinib in combination with gemcitabine and cisplatin in advanced non-small cell lung cancer: a phase III trial - INTACT I. Journal of Clinical Oncology 2004;22(5):777-84.

Giaccone G, Johnson DH, Manegold C, et al. A phase III clinical trial of ZD1839 ('Iressa') in combination with gemcitabine and cisplatin in chemotherapy-naive patients with advanced nonsmall cell lung cancer (INTACT 1). Annals of Oncology 2002;13 Suppl 5:2, Abstract 4.

\section{Goss 2009 INSTEP \{published data only\}}

Goss G, Ferry D, Wierzibicki R, Laurie SA, Thompson J, Biesma B, et al. Randomized phase II study of gefitinib compared with placebo in chemotherapy-naive patients with advanced nonsmall-cell lung cancer and poor performance status. Journal of Clinical Oncology 2009;27(13):2253-60.

\section{Han 2012 First SIGNAL \{published data only\}}

* Han JY, Park K, Kim SW, Lee DH, Kim HY, Kim HT, et al. FirstSIGNAL: first-line single-agent Iressa versus gemcitabine and cisplatin trial in never-smokers with adenocarcinoma of the lung. Journal of Clinical Oncology 2012;30:1122-8.

Han JY, Yoon KA, Park JH, Lee YJ, Lee GK, Han JH, et al. DNA repair gene polymorphisms and benefit from gefitinib in never-smokers with lung adenocarcinoma. Cancer 2011;117(14):3201-8.

\section{Herbst 2004 INTACT II \{published data only\}}

* Herbst RS, Giaccone G, Schiller JH, Natale RB, Miller V, Manegold C, et al. Gefitinib in combination with paclitaxel and carboplatin in advanced non-small cell lung cancer: a phase III trial - INTACT 2. Journal of Clinical Oncology 2004;22(5):785-94.

Johnson DH, Herbst R, Giaccone G, et al. ZD1839 ('Iressa') in combination with paclitaxel \& carboplatin in chemotherapynaive patients with advanced non-small cell lung cancer (NSCLC): results from a phase III clinical trial (INTACT 2). Annals of Oncology 2002;13 Suppl 5:127, Abstract 468.

\section{Kelly 2008 SWOG S0023 \{published data only\}}

* Kelly K, Chansky K, Gaspar LE, Albain KS, Jett J, Ung YC, et al. Phase III trial of maintenance gefitinib or placebo after concurrent chemoradiotherapy and docetaxel consolidation in inoperable stage III non-small-cell lung cancer: SWOG S0023. Journal of Clinical Oncology 2008;26(15):2450-6. [SWOG S0023]

Kelly K, Gaspar LE, Chansky K, Albain KS, Crowley J, Gandara DR. Low incidence of pneumonitis on SWOG 0023: A preliminary analysis of an ongoing phase III trial of concurrent chemoradiotherapy followed by consolidation docetaxel and Iressa/placebo maintenance in patients with inoperable stage III non-small cell lung cancer [abstract]. 41st Annual Meeting of the American Society of Clinical Oncology, Orlando, FL, 13-17 May, 2005 (Abstract No. 7058). 2005; Vol. 23:634.

\section{Kim 2008 INTEREST \{published data only\}}

Douillard JY, Shephard FA, Hirsh V, Mok T, Socinski MA, Gervais R, et al. Molecular predictors of outcome with gefitinib and docetaxel in previously treated non-small-cell lung cancer: from the randomized phase III INTEREST Trial. Journal of Clinical Oncology 2010;28(5):744-52.

Horgan AM, Bradbury PA, Amir E, Ng R, Douillard JY, Kim ES, et al. An economic analysis of the INTEREST trial, a randomized trial of docetaxel versus gefitinib as second-/third-line therapy in advanced non-small-cell lung cancer. Annals of Oncology. United Kingdom: Oxford University Press (Great Clarendon Street, Oxford OX2 6DP, United Kingdom), 2011; Vol. 22:1805-11.

Horgan AM, Shepherd FA, Bradbury PA, Ng R, Leighl NB. Preliminary cost-consequence analysis of the INTEREST trial, a randomized trial of docetaxel versus gefitinib as 2 nd line therapy in advanced non-small cell lung cancer [abstract no. 8110]. Journal of Clinical Oncology: ASCO Annual Meeting Proceedings 2008;25(15 Suppl Pt 1):451.

* Kim ES, Hirsh V, Mok T, Socinski MA, Gervais R, Wu YL, et al. Gefitinib versus docetaxel in previously treated non-small-cell lung cancer (INTEREST): a randomized phase III trial. Lancet 2008;372:1809-18.

\section{Kim 2016 \{published data only\}}

* Kim YS, Cho EK, Woo HS, Hong J, Ahn HK, Park I, et al. Randomized phase II study of pemetrexed versus gefitinib in previously treated patients with advanced non-small cell lung cancer. Cancer Research and Treatment 2016;48(1):80-7.

\section{Kris 2003 IDEAL II \{published data only\}}

Cella D, Herbst RS, Lynch TJ, Prager D, Belani CP, Schiller JH, et al. Clinically meaningful improvement in symptoms and quality of life for patients with non-small cell lung cancer receiving gefitinib in a randomized controlled trial. Journal of Clinical Oncology 2005;23(13):2946-54.

Kris MG, Natale RB, Herbst RS, et al. A phase II trial of ZD1839 ('Iressa') in advanced non-small cell lung cancer (NSCLC) patients who had failed platinum- and docetaxel-based regimens (IDEAL 2) [abstract]. 38th Annual Meeting of the American Society of Clinical Oncology; 18-21 May 2002; Orlando, Florida, USA. 2002; Vol. 21 Pt 1:292a Abstract 1166. 
* Kris MG, Natale RB, Herbst RS, Lynch TJ, Prager D, Belani CP, et al. Efficacy of gefitinib, an inhibitor of the epidermal growth factor receptor tyrosine kinase, in symptomatic patients with non-small cell lung cancer: a randomized trial. JAMA 2003;290(16):2149-58.

Natale RB, Skarin A, Maddox AM, et al. Improvement in symptoms and quality of life for advanced non-small cell lung cancer patients receiving ZD1839 ('Iressa') in IDEAL 2 [abstract]. 38th Annual Meeting of the American Society of Clinical Oncology; 18-21 May 2002; Orlando, Florida, USA. 2002; Vol. 21 Pt 1:292a, Abstract 1167.

\section{Lee 2010 ISTANA \{published data only\}}

Lee D, Kim S, Park K, et al. A randomized open-label study of gefitinib versus docetaxel in patients with advanced/metastatic non-small cell lung cancer (NSCLC) who have previously received platinum-based chemotherapy [abstract no. 8025]. Journal of Clinical Oncology: ASCO Annual Meeting Proceedings 2008;26(15 Suppl Pt I):430.

* Lee DH, Park K, Kim JH, Lee JS, Shin SW, Kang JH, et al. Randomized phase III trial of gefitinib versus docetaxel in nonsmall-cell lung cancer patients who have previously received platinum-based chemotherapy. Clinical Cancer Research 2010;16(4):1307-14. [ISTANA]

\section{Li 2010 \{published data only\}}

Li H, Wang X, Hua F. Second-line treatment with gefitinib or docetaxel for advanced non-small cell lung cancer. Chinese Journal of Clinical Oncology 2010;37:16-8.

\section{Lou 2014 \{published data only\}}

Lou N, Yang J, Yan H, Qing Z, Liao R, Xu C, et al. Efficacies of gefitinib versus paclitaxel/carboplatin for patients with advanced pulmonary adenocarcinoma. National Medical Journal of China 2014;94(30):2337-41.

\section{Maemondo 2010 NEJ002 \{published data only\}}

Fukuhara T, Maemondo M, Inoue A, Kobayashi K, Sugawara S, Oizumi S, et al. Factors associated with a poor response to gefitinib in the NEJ002 study: smoking and the L858R mutation. Lung Cancer 2015;88:181-6.

\begin{abstract}
* Inoue A, Kobayashi K, Maemondo M, Sugawara S, Oizumi S, Isobe $\mathrm{H}$, et al. Updated overall survival results from a randomized phase III trial comparing gefitinib with carboplatinpaclitaxel for chemo-naive non-small cell lung cancer with sensitive EGFR gene mutations (NEJ002). Annals of Oncology. United Kingdom: Oxford University Press (Great Clarendon Street, Oxford OX2 6DP, United Kingdom), 2013; Vol. 24:54-9.
\end{abstract}

Inoue A, Kobayashi K, Maemondo M, et al. A randomized phase III study comparing gefitinib with carboplatin (CBDCA) plus paclitaxel (TXL) for the first-line treatment of non-small cell lung cancer (NSCLC) with sensitive EGFR mutations: NEJ002 study. European Journal of Cancer. 2009:Abstract 9LBA.

\footnotetext{
* Maemondo M, Inoue A, Kobayashi K, Sugawara S, Oizumi S, Isobe $\mathrm{H}$, et al. Gefitinib or chemotherapy for non-small-cell lung cancer with mutated EGFR. New England Journal of Medicine 2010;362(25):2380-8.
}

Miyauchi E, Inoue A, Kobayashi K, Maemondo M, Sugawara S, Oizumi S, et al. Efficacy of chemotherapy after first-line gefitinib therapy in EGFR mutation-positive advanced non-small cell lung cancer - data from a randomized phase III study comparing gefitinib with carboplatin plus paclitaxel (NEJ002). Japanese Journal of Clinical Oncology 2015;45(7):670-6.

Oizumi S, Kobayashi K, Inoue A, Maemondo M, Sugawara S, Yoshizawa $\mathrm{H}$, et al. Quality of life with gefitinib in patients with EGFR-mutated non-small cell lung cancer: quality of life analysis of North East Japan study group 002 trial. Oncologist. United States: AlphaMed Press (318 Blackwell St. Suite 260, Durham NC 27701-2884, United States), 2012; Vol. 17:863-70.

Yoshizawa H, Kobayashi K, Inoue A, Maemondo M, Sugawara S, Oizumi S, et al. QOL analysis from NEJ 002 study comparing gefitinib to chemotherapy for non-small cell lung cancer with mutated EGFR. 35th ESMO Congress Milan Italy. Oxford University Press, 2010; Vol. 21:viii122.

\section{Maruyama 2008 V-15-32 \{published data only\}}

Leki R, Kawahara M, Watanabe $\mathrm{H}$, et al. The impact of response evaluation committee in a Phase III study (V-15-32) of gefitinib versus docetaxel in Japanese patients with non-small cell lung cancer [Abstract No. 298P]. Annals of Oncology 2009;19 Suppl 8:109-10.

* Maruyama R, Nishiwaki Y, Tamura T, Yamamoto N, Tsuboi M, Nakagawa K, et al. Phase III study, V-15-32, of gefitinib versus docetaxel in previously treated Japanese patients with non-small-cell lung cancer. Journal of Clinical Oncology 2008;26(26):4245-52.

Sekine I, Ichinose Y, Nishiwaki Y, Yamamoto N, Tsuboi M, Nakagawa K, et al. Quality of life and disease-related symptoms in previously treated Japanese patients with non-smallcell lung cancer: results of a randomized phase III study (V-15-32) of gefitinib versus docetaxel. Annals of Oncology 2009;20(9):1483-8.

Yamamoto N, Nishiwaki Y, Negoro S, Jiang H, Itoh Y, Saijo N, et al. Disease control as a predictor of survival with gefitinib and docetaxel in a phase III study (V-15-32) in advanced nonsmall-cell lung cancer patients. Journal of Thoracic Oncology 2010;5(7):1042-7.

\section{Mitsudomi 2010 WJTOG3405 \{published data only\}}

Mitsudomi T, Morita S, Yatabe Y, Negoro S, Okamoto I, Seto T, et al. Updated overall survival results of WJTOG 3405, a randomized phase III trial comparing gefitinib (G) with cisplatin plus docetaxel (CD) as the first-line treatment for patients with non-small cell lung cancer harboring mutations of the epidermal growth factor receptor (EGFR). 2012 Annual Meeting of the American Society of Clinical Oncology, ASCO Chicago, IL United States. American Society of Clinical Oncology, 2012; Vol. 30 .

* Mitsudomi T, Morita S, Yatabe Y, Negoro S, Okamoto I, Tsurutani J, et al. Gefitinib versus cisplatin plus docetaxel in patients with non-small-cell lung cancer harbouring mutations of the epidermal growth factor receptor (WJTOG3405): an open label, randomised phase III trial. Lancet 2010;11:121-8. 
Tsurutani J, Mitsudomi T, Mori S, Okamoto I, Nozaki K, Tada H, et al. A phase III, first-line trial of gefitinib versus cisplatin plus docetaxel for patients with advanced or recurrent non-small cell lung cancer (NSCLC) harboring activating mutation of the epidermal growth factor receptor (EGFR) gene: a preliminary results of WJTOG 3405 [abstract 0-9002]. European Journal of Cancer. 2009; Vol. 7 Suppl:505.

\section{Mok 2009 IPASS \{published data only\}}

Fukuoka M, Wu YL, Thongprasert S, Sunpaweravong P, Leong SS, Sriuranpong V, et al. Biomarker analyses and final overall survival results from a phase III, randomized, openlabel, first-line study of gefitinib versus carboplatin/paclitaxel in clinically selected patients with advanced non - smallcell lung cancer in Asia (IPASS). Journal of Clinical Oncology 2011;29:2866-74.

Mok T, Wu Y-L, Thongprasert S, et al. Phase III, randomised, open-label, first-line study of gefitinib (G) vs carboplatin/ paclitaxel (C/P) in clinically selected patients (PTS) with advanced non-small cell lung cancer (NSCLC) (IPASS). Annals of Oncology 2008;19 Suppl 8:Viii1.

* Mok TS, Wu YL, Thongprasert S, Yang CH, Chu DT, Saijo N, et al. Gefitinib or carboplatin-paclitaxel in pulmonary adenocarcinoma. New England Journal of Medicine 2009;361(10):947-57.

Ohe Y, Ichinose Y, Nishiwaki Y, et al. Phase III, randomized, open-label, first-line study of gefitinib (G) versus carboplatin/ paclitaxel $(C / P)$ in selected patients (pts) with advanced nonsmall-cell lung cancer (NSCLC) (IPASS): Evaluation of recruits in Japan. Journal of Clinical Oncology 2009;29(15 Suppl 1):8044.

Thongprasert S, Duffield E, Saijo N, Wu YL, Yang JC, Chu DT, et al. Health-related quality-of-life in a randomized phase III firstline study of gefitinib versus carboplatin/paclitaxel in clinically selected patients from Asia with advanced NSCLC (IPASS). Journal of Thoracic Oncology 2011;6:1872-80.

Thongprasert S, Duffield E, Wu Y, et al. Quality of life (QOL) in a randomized phase III first-line study of gefitinib $(G)$ vs carboplatin/paclitaxel (CP) in clinically selected Asian patients (pts) with advanced NSCLC (IPASS). Journal of Thoracic Oncology 2010;5(5 Suppl 1):S80.

Wu Y, Chu D, Han B, Liu X, Zhang L, Zhou C, et al. Phase III, randomized, open-label, first-line study in Asia of gefitinib versus carboplatin/paclitaxel in clinically selected patients with advanced non-small-cell lung cancer: evaluation of patients recruited from mainland China. Asia-Pacific Journal of Clinical Oncology 2012;8:232-43.

Wu Y, Fukuoka M, Mok T S K, Saijo N, Thongprasert S, Yang J C $\mathrm{H}$, et al. Tumour response, skin rash and health-related quality of life (HRQOL) - Post-HOC data from the IPASS study. European Multidisciplinary Cancer Congress Stockholm Sweden. Elsevier Ltd, 2011; Vol. 47:S633-4.

Wu Y, Mok T, Chu D, et al. Evaluation of clinically selected patients (pts) with advanced non-small cell lung cancer (NSCLC) recruited in China in a phase III, randomized, open-label, firstline study in Asia of gefitinib (G) versus carboplatin/paclitaxel
(C/P) (IPASS). Journal of Clinical Oncology. 2009; Vol. 27 (15 Suppl 1):8041.

Wu YL, Fukuoka M, Mok TSK, Saijo N, Thongprasert S, Yang JCH, et al. Tumor response and health-related quality of life in clinically selected patients from Asia with advanced nonsmall-cell lung cancer treated with first-line gefitinib: post hoc analyses from the IPASS study. Lung Cancer 2013;81:280-7.

Yang CH, Fukuoka M, Mok TS, Wu YL, Thongprasert S, Saijo N, et al. Final overall survival (OS) results from a phase III, randomised, open-label, first-line study of gefitinib $(G) v$ carboplatin/paclitaxel (C/P) in clinically selected patients with advanced nonsmall cell lung cancer (NSCLC) in Asia (IPASS). 35th ESMO Congress Milan Italy. Oxford University Press, 2010; Vol. 21:viii1-2.

Yang J, Wu Y L, Saijo N, Thongprasert S, Chu D T, Chen Y M, et al. Efficacy outcomes in first-line treatment of advanced NSCLC with gefitinib (G) vs carboplatin/paclitaxel (C/P) by epidermal growth factor receptor (EGFR) gene-copy number score and by most common EGFR mutation subtypes - Exploratory data from IPASS. 2011 European Multidisciplinary Cancer Congress Stockholm Sweden. Elsevier Ltd, 2011; Vol. 47:S633.

Yang J, Wu Y, Chan V, Kurnianda J, Nakagawa K. Epidermal growth factor receptor mutation analysis in previously unanalyzed histology samples and cytology samples from the phase III Iressa Pan-ASia Study (IPASS). Lung Cancer 2014;83:174-81.

Yang JCH, Wu YL, Chan V, Kurnianda J, Nakagawa K, Saijo N, et al. Epidermal growth factor receptor mutation analysis in previously unanalyzed histology samples and cytology samples from the phase III Iressa Pan-ASia Study (IPASS). Lung Cancer 2014;83:174-81.

\section{Morere 2010 IFCT-0301 \{published data only\}}

Des Guetz G, Landre T, Westeel V, Milleron B, Vaylet F, Urban T, et al. Similar survival rates with first-line gefitinib, gemcitabine or docetaxel in a randomized phase II trial in elderly patients with advanced non-small cell lung cancer and a poor performance status (IFCT-0301). Journal of Geriatric Oncology 2015;6:233-40.

Morere J, Westeel V, Morin F, et al. Randomized phase II trial of first-line gefitinib,gemcitabine or docetaxel in performance status (PS) 2 or 3 non-small-cell lung cancer (NSCLC) patients (IFCT-0301) [abstract no. 8086]. Journal of Clinical Oncology: ASCO Annual Meeting Proceedings 2008;26(15 Suppl Pt I):445.

* Morere JF, Brechot JM, Westeel V, Gounant V, Lebeau B, Vaylet $F$, et al. Randomized phase II trial of gefitinib or gemcitabine or docetaxel chemotherapy in patients with advanced non-small-cell lung cancer and a performance status of 2 or 3 (IFCT-0301 study). Lung Cancer 2010;70(1):301-7.

\section{Soria 2015 IMPRESS \{published data only\}}

Soria JC, Wu YL, Nakagawa K, Kim SW, Yang JJ, Ahn MJ, et al. Gefitinib plus chemotherapy versus placebo plus chemotherapy in EGFR-mutation-positive non-small-cell lung cancer after progression on first-line gefitinib (IMPRESS): a phase 3 randomised trial. Lancet Oncology 2015;16:990-8. 


\section{Sun 2012 KCSG-LU08-01 \{published data only\}}

Ahn M, Sun J, Ahn JS, Kim S, Min YJ, Yun HJ, et al. Randomized phase III trial of gefitinib or pemetrexed as second-line treatment in patients with non-small cell lung cancer previously treated with platinum-based chemotherapy (KCSG-LU08-01). ASCO Annual Meeting 2011 Chicago, IL United States. American Society of Clinical Oncology, 2011; Vol. 29.

Ahn MJ, Sun JM, Lee KH, Ahn JS, Kim SW, Min YJ, et al. Randomized phase III trial of gefitinib or pemetrexed as secondline treatment in patients with non-small cell lung cancer previously treated with platinum-based chemotherapy (KCSGLU08-01). 14th World Conference on Lung Cancer Amsterdam Netherlands. International Association for the Study of Lung Cancer, 2011; Vol. 6:S317.

* Sun JM, Lee KH, Kim SW, Lee DH, Min YJ, Yun HJ, et al. Gefitinib versus pemetrexed as second-line treatment in patients with nonsmall cell lung cancer previously treated with platinum-based chemotherapy (KCSG-LU08-01): an open-label, phase 3 trial. Cancer 2012;118:6234-42.

\section{Takeda 2010 WJTOG0203 \{published data only\}}

Okamoto I, Hida T, Kashii T, et al. Randomized phase III study of platinum-doublet chemotherapy followed by gefitinib versus continued platinum-doublet chemotherapy in patients (pts) with advanced non-small cell lung cancer (NSCLC): Results of West Japan Thoracic Oncology Group Trial (WJTOG0203) [Abstract No. 2 33PD]. Annals of Oncology 2008;19 Suppl 8:91.

Takeda K, Hida T, Sato T, Ando M, Seto T, Satouchi M, et al. Randomized phase III trial of platinum-doublet chemotherapy followed by gefitinib comparted with continued platinumdoublet chemotherapy in Japanese patients with advanced non-small cell lung cancer: results of a West Japan Thoracic Oncology Group Trial (WJTOG0203). Journal of Clinical Oncology 2010;28(5):753-60.

\section{Thatcher 2005 ISEL \{published data only\}}

Chang A, Parikh P, Thongprasert S, Tan EH, Perng RP, Ganzon D, et al. Gefitinib (IRESSA) in patients of Asian origin with refractory advanced non-small cell lung cancer: subset analysis from the ISEL study. Journal of Thoracic Oncology 2006;1(8):847-55.

Hirsch FR, Dziadziuszko R, Thatcher N, Mann H, Watkins C, Parums DV, et al. Epidermal growth factor receptor immunohistochemistry: comparison of antibodies and cutoff points to predict benefit from gefitinib in a phase 3 placebocontrolled study in advanced non small-cell lung cancer. Cancer 2008;112(5):1114-21.

Hirsch FR, Varella-Garcia M, Bunn Jr PA, Franklin WA, Dziadziuszko R, Thatcher N, et al. Molecular predictors of outcome with gefitinib in a phase III placebo-controlled study in advanced non-small cell lung cancer. Journal of Clinical Oncology 2006;24(31):5034-42.

* Thatcher N, Chang A, Parikh P, Rodrigues Pereira J, Ciuleanu T, von Pawel J, et al. Gefitinib plus best supportive care in previously treated patients with refractory advanced non-smallcell lung cancer: results from a randomised, placebo-controlled, multicentre study (Iressa Survival Evaluation in Lung Cancer). Lancet 2005;366(9496):1527-37.

\section{Xu 2015 \{published data only\}}

$\mathrm{Xu} \mathrm{YH,} \mathrm{Mei} \mathrm{JS,} \mathrm{Zhou} \mathrm{J.} \mathrm{Randomized} \mathrm{study} \mathrm{of} \mathrm{gefitinib} \mathrm{versus}$ pemetrexed as maintenance treatment in patients with advanced glandular non-small cell lung cancer. International Journal of Clinical and Experimental Medicine 2015;8(4):6242-6.

Xue 2015 \{published data only\}

* Xue C, Hong S, Li N, Feng W, Jia J, Peng J, et al. Randomized, multicenter study of gefitinib dose-escalation in advanced nonsmall-cell lung cancer patients achieved stable disease after one-month gefitinib treatment. Scientific Reports 2015;5:10648.

Zhang L, Xue C, Li N, Feng W, Jia J, Peng J, et al. Randomized, open-label, multi-center study of gefitinib dose-escalation $(500 \mathrm{mg} / \mathrm{d}$ versus $250 \mathrm{mg} / \mathrm{d})$ in advanced NSCLC patient achieved stable disease (SD) after one-month gefitinib treatment. 15th World Conference on Lung Cancer Sydney, NSW Australia. International Association for the Study of Lung Cancer, 2013; Vol. 8:S1185.

\section{Yang 2014 \{published data only\}}

Boye M, Wang X, Srimuninnimit V, Kang JH, Tsai CM, Orlando M, et al. First-line pemetrexed plus cisplatin followed by gefitinib maintenance therapy versus gefitinib monotherapy in East Asian never-smoker patients with locally advanced or metastatic nonsquamous non-small cell lung cancer: quality of life results from a randomized phase III trial. Clinical Lung Cancer 2016;17(2):150-60.

Kang JH, Ahn M, Kim D, Cho EK, Kim J, Shin SW, et al. Tolerability and outcomes of first-line pemetrexed-cisplatin followed by gefitinib maintenance therapy versus gefitinib monotherapy in Korean patients with advanced non-squamous non-small cell lung cancer: a post hoc descriptive subgroup analysis of a randomized, phase 3 trial. Cancer Research and Treatment 2015;48(2):458-64.

* Yang JC, Kang JH, Mok T, Ahn M, Srimuninnimit V, Lin C, et al. First-line pemetrexed plus cisplatin followed by gefitinib maintenance therapy versus gefitinib monotherapy in East Asian patients with locally advanced or metastatic nonsquamous non-small cell lung cancer: a randomised, phase 3 trial. European Journal of Cancer 2014;50:2219-30.

Yang JC, Park K, Mok TSK, Kang JH, Srimuninnimit V, Lin CC, et al. A randomized phase 3 study comparing first-line pemetrexed plus cisplatin followed by gefitinib as maintenance with gefitinib monotherapy in east Asian patients with locally advanced or metastatic nonsquamous non-small cell lung cancer (NSQNSCLC). 15th World Conference on Lung Cancer Sydney, NSW Australia. International Association for the Study of Lung Cancer, 2013; Vol. 8:S288.

Yang JC, Srimuninnimit V, Ahn M, Lin C, Kim S, Tsai C, et al. A randomized phase 3 study comparing first-line pemetrexed plus cisplatin followed by gefitinib maintenance (PC/G) with gefitinib monotherapy (G) in East Asian patients (pts) with locally advanced or metastatic nonsquamous non-small cell lung cancer (nSqNSCLC): final survival results. Journal of Clinical Oncology 2015;15 Suppl:8041. 
* Yang JC, Srimunninnimit V, Ahn M, Lin C, Kim S, Tsai C, et al. First-line pemetrexed plus cisplatin followed by gefitinib maintenance therapy versus gefitinib monotherapy in East Asian never-smoker patients with locally advanced or metastatic nonsquamous non-small cell lung cancer: final overall survival results from a randomized phase 3 study. Journal of Thoracic Oncology 2016;11(3):370-9.

\section{Yu 2014 \{published data only\}}

Yu H, Zhang J, Wu X, Luo Z, Wang H, Sun S, et al. A phase II randomized trial evaluating gefitinib intercalated with pemetrexed/platinum chemotherapy or pemetrexed/platinum chemotherapy alone in unselected patients with advanced non-squamous non-small cell lung cancer. Cancer Biology and Therapy 2014;15(7):832-9.

\section{Zhang 2012 INFORM \{published data only\}}

Yang Y, Ma Y, Zhao Y, Fang W, Hong S, et al. QoL analyses from INFORM study, a phase III study of gefitinib versus placebo as maintenance therapy in advanced NSCLC. Scientific Reports 2015;5:11934.

* Zhang L, Ma S, Song X, Han B, Cheng Y, Huang C, et al. Gefitinib versus placebo as maintenance therapy in patients with locally advanced or metastatic non-small-cell lung cancer (INFORM; C-TONG 0804): a multicentre, double-blind randomised phase 3 trial. Lancet Oncology 2012;13:466-75.

Zhang L, Ma SL, Song XQ, Cheng Y, Huang C, Yang SJ, et al. Preplanned subgroup analyses from the phase III, randomised, placebo-controlled, parallel-group study of gefitinib (G) as maintenance therapy in patients (pts) with locally advanced or metastatic non-small-cell lung cancer (NSCLC) (INFORM; C-TONG 0804). European Multidisciplinary Cancer Congress Stockholm Sweden. Elsevier Ltd, 2011; Vol. 47:S622-3.

Zhang L, Ma SL, Song XQ, Han BH, Cheng Y, Huang C, et al. Efficacy, tolerability and biomarker analyses from a phase III, randomized, placebo controlled, parallel group study of gefitinib as maintenance therapy in patients with locally advanced or metastatic non-small-cell lung cancer (NSCLC) in China (INFORM) (C-TONG 0804). 14th World Conference on Lung Cancer Amsterdam Netherlands. International Association for the Study of Lung Cancer, 2011; Vol. 6:S558-9.

Zhang L, Shenglin M, Song X, Han B, Cheng Y, Huang C, et al. Efficacy, tolerability, and biomarker analyses from a phase III, randomized, placebo-controlled, parallel group study of gefitinib as maintenance therapy in patients with locally advanced or metastatic non-small cell lung cancer (NSCLC; INFORM; C-TONG 0804). ASCO Annual Meeting 2011 Chicago, IL United States. American Society of Clinical Oncology, 2011; Vol. 29.

* Zhao H, Fan Y, Ma S, Song X, Han B, Cheng Y, et al. Final overall survival results from a phase III, randomized placebocontrolled, parallel-group study of gefitinib versus placebo as maintenance therapy in patients with advanced or metastatic non-small-cell lung cancer (INFORM; C-TONG 0804). Journal of Thoracic Oncology 2015;10(4):655-64.

\section{References to studies excluded from this review}

\section{Choi 2015 \{published data only\}}

Choi YJ, Lee DH, Choi CM, Lee JS, Lee SJ, Ahn J, et al. Randomized phase II study of paclitaxel/carboplatin intercalated with gefitinib compared to paclitaxel/carboplatin alone for chemotherapy-naive non-small cell lung cancer in a clinically selected population excluding patients with nonsmoking adenocarcinoma or mutated EGFR. BMC Cancer 2015;15:763.

\section{Kim 2012 \{published data only\}}

* Kim ST, Uhm JE, Lee J, Sun JM, Sohn I, Kim SW, et al. Randomized phase II study of gefitinib versus erlotinib in patients with advanced non-small cell lung cancer who failed previous chemotherapy. Lung Cancer 2012;75:82-8.

\section{Lee 2009 \{published data only\}}

Lee $\mathrm{KH}$, Lee KY, Jeon YJ, et al. A phase IV, multicenter, nonrandomized, open-labelled study to evaluate the efficacy of gefitinib (Iressa ${ }^{\circledR}$ ) as a second-line therapy in Korean patients with non-small cell lung cancer (NSCLC). Respirology. 2009; Vol. 14 Suppl S3:A161.

\section{Manegold 2005 \{published data only\}}

Manegold C, Gatzemeier U, Buchholz E, Smith RP, Fandi A. A pilot trial of gefitinib in combination with docetaxel in patients with locally advanced or metastatic non-small-cell lung cancer. Clinical Lung Cancer 2005;6(6):343-9.

\section{Natale 2009 \{published data only\}}

Natale RB, Bodkin D, Govindan R, Sleckman BG, Rizvi NA, Capo $A$, et al. Vandetanib versus gefitinib in patients with advanced non-small-cell lung cancer: results from a two-part, double-blind, randomized phase II study. Journal of Clinical Oncology 2009;27(15):2523-9.

\section{Shi 2013 ICOGEN \{published data only\}}

* Shi Y, Zhang L, Liu X, Zhou C, Zhang L, Zhang S, et al. Icotinib versus gefitinib in previously treated advanced non-small-cell lung cancer (ICOGEN): a randomised, double-blind phase 3 noninferiority trial. Lancet Oncology 2013;14:953-61.

Sun Y, Shi Y, Zhang L, Liu X, Zhou C, Li Z, et al. Final overall survival and updated biomarker analysis results from the randomized phase III ICOGEN trial. 2012 Annual Meeting of the American Society of Clinical Oncology, ASCO Chicago, IL United States. American Society of Clinical Oncology, 2012; Vol. 30.

Sun Y, Shi Y, Zhang L, Liu X, Zhou C, Wang D, et al. A randomized, doubleblind phase III study of icotinib versus gefitinib in patients with advanced non-small cell lung cancer (NSCLC) previously treated with chemotherapy (ICOGEN). 14th World Conference on Lung Cancer Amsterdam Netherlands. International Association for the Study of Lung Cancer, 2011; Vol. 6:S317-8.

\section{Sugawara 2015 \{published data only\}}

Sugawara S, Oizumi S, Minato K, Harada T, Inoue A, Fujita Y, et al. Randomized phase II study of concurrent versus sequential alternating gefitinib and chemotherapy in previously untreated 
non-small cell lung cancer with sensitive EGFR mutations: NEJ005/TCOG0902. Annals of Oncology 2015;26:888-94.

Urata 2016 \{published data only\}

* Urata Y, Katakami N, Morita S, Kaji R, Yoshioka H, Seto T, et al. Randomized phase III study comparing gefitinib with erlotinib in patients with previously treated advanced lung adenocarcinoma: WJOG 5108L. Journal of Clinical Oncology 2016;34(27):3248-57.

\section{Zhou 2014 CTONG 0806 \{published data only\}}

Yang J, Cheng Y, Zhao M, Zhou Q, Yan HH, Zhang L, et al. A phase II trial comparing pemetrexed with gefitinib as the secondline treatment of nonsquamous NSCLC patients with wildtype EGFR (CTONG0806). 2013 Annual Meeting of the American Society of Clinical Oncology, ASCO Chicago, IL United States. American Society of Clinical Oncology, 2013; Vol. 31.

* Zhou Q, Cheng Y, Yang JJ, Zhao MF, Zhang L, Zhang XC, et al. Pemetrexed versus gefitinib as second-line treatment in advanced non-squamous nonsmall-cell lung cancer patients harbouring wild-type EGFR (CTONG 0806): a multicenter randomized trial. Annals of Oncology 2014;25(12):2385-91.

Zhou Q, Cheng Y, Zhao MF, Yang JJ, Yan H H, Zhang L, et al. Final results of CTONG 0806: a phase II trial comparing pemetrexed with gefitinib as second-line treatment of advanced non-squamous NSCLC patients with wild-type EGFR. 15th World Conference on Lung Cancer Sydney, NSW Australia. International Association for the Study of Lung Cancer, 2013; Vol. 8:S194-5.

\section{References to ongoing studies}

Bhatnagar 2012 \{published data only\}

Bhatnagar AR, Singh DP, Sharma R, Kumbhaj P. Docetaxel versus geftinib in patients with locally advanced or metastatic NSCLC pretreated with platinum-based chemotherapy. 4th Australian Lung Cancer Conference, ALCC 2012 Adelaide, SA Australia. International Association for the Study of Lung Cancer, 2012; Vol. 7:S159.

\section{Gaafar 2010 \{published data only\}}

Gaafar RM, Surmont V, Scagliotti G, Van Klaveren R, Papamichael G, Welch J, et al. A double-blind, randomized, placebo-controlled phase III intergroup study of gefitinib $(G)$ in patients (pts) with advanced NSCLC, non-progressing after firstline platinum-based chemotherapy (EORTC 08021-ILCP 01/03). Journal of Clinical Oncology. 2010; Vol. 28 Suppl 15.

\section{Hong 2010 \{published data only\}}

Hong J, Kyung SY, Lee SP, Park JW, Jung SH, Sym SJ, et al. Randomized phase II study of pemetrexed versus gefitinib for patients with previously treated non-small cell lung cancer. 4th Asia Pacific Lung Cancer Conference, APLCC 2010 Seoul, South Korea. International Association for the Study of Lung Cancer, 2010; Vol. 5:S401.

\section{Laurie 2000 \{published data only\}}

Laurie SA, Miller VA, Johnson D, Ng KK, Heelan RT, Pizzo BA, et al. Pilot trial of ZD1839 (Iressa-TM-), an oral inhibitor of epidermal growth factor receptor (EGFR) tyrosine kinase, in combination with carboplatin $(\mathrm{C})$ and paclitaxel $(\mathrm{P})$ in previously untreated advanced non-small cell lung cancer. Lung Cancer. 2000; Vol. 29 Suppl 1:S71.

Lee 2013 \{published data only\}

Lee DH, Kim JE, Choi YJ, Choi CM, Lee JS, Kim SW. Randomized phase II study comparing paclitaxel/carboplatin intercalated with gefitinib to paclitaxel/carboplatin alone for chemotherapynaive non-small cell lung cancer patients either with history of smoking or with wild-type EGFR. AACR-NCI-EORTC International Conference: Molecular Targets and Cancer Therapeutics 2013 Boston, MA United States. American Association for Cancer Research Inc, 2013; Vol. 12.

\section{Liang 2010 \{published data only\}}

Liang J, Ahn M, Kang J, et al. First-line treatment (txt) with pemetrexed-cisplatin (PC), followed sequentially by gefitinib (G) or pemetrexed, in Asian, never-smoker (n/smkr) patients (pts) with advanced NSCLC: An open-label, randomized phase II trial. Journal of Clinical Oncology 2010;28(15 Suppl 1):Abstract 7591.

\section{Nokihara 2006 \{published data only\}}

Nokihara $\mathrm{H}$, Ohe Y, Kawaishi M, et al. A randomized phase II study of sequential carboplatin/paclitaxel (CP) and gefitinib $(G)$ in chemotherapy-naive patients with advanced nonsmall-cell lung cancer (NSCLC): Preliminary results. Journal of Clinical Oncology: ASCO Annual Meeting Proceedings 2006;24(18 Suppl):7096.

Nokihara H, Ohe Y, Yamada K, et al. Randomized phase II study of sequential carboplatin/paclitaxel (CP) and gefitinib (G) in chemotherapy-naive patients with advanced non-small-cell lung cancer (NSCLC): final results [abstract no. 8069]. Journal of Clinical Oncology: ASCO Annual Meeting Proceedings 2008;26(15 Suppl Pt I):441.

\section{Puri 2013 \{published data only\}}

Puri T, Orlando M, Barraclough H, Enatsu S. A randomized phase 2 trial of pemetrexed $(P)$ and gefitinib $(G)$ versus g as first-line treatment for patients with stage IV non-squamous (NS) nonsmall cell lung cancer (NSCLC) with activating epidermal growth factor receptor (EGFR) mutations. 15th World Conference on Lung Cancer Sydney, NSW Australia. International Association for the Study of Lung Cancer, 2013; Vol. 8:S1156-7.

\section{Additional references \\ ACS 2018}

American Cancer Society. Cancer facts and figures 2018. Available at: http://www.cancer.org/cancer/lungcancer-nonsmallcell/ (accessed 11th Jan 2018).

\section{Bell 2005}

Bell DW, Lynch TJ, Maserlat SM, Harris PL, Okimoto FA, Brannigan BW, et al. Epidermal growth factor receptor mutations and gene amplification in non-small-cell lung cancer: molecular analysis of the IDEAL/INTACT gefitinib trials. Journal of Clinical Oncology 2005;23(31):8081-92. 


\section{Boye 2016}

Boye M, Wang X, Srimuninnimit V, Kang JH, Tsai CM, Orlando M, et al. First-line pemetrexed plus cisplatin followed by gefitinib maintenance therapy versus gefitinib monotherapy in east Asian never-smoker patients with locally advanced or metastatic nonsquamous non-small cell lung cancer: quality of life results from a randomized phase III trial. Clinical Lung Cancer 2016;17(2):150-60.

\section{Cella 1995}

Cella D, Bonomi AE, Lloyd SR, Tulsky DS, Kaplan E, Bonomi P. Reliability and validity of the Functional Assessment of Cancer Therapy - Lung (FACT-L) quality of life instrument. Lung Cancer 1995;12:199-220.

\section{Cella 2002}

Cella D, Eton DT, Fairclough DL, Bonomi P, Heyes AE, Silberman $C$, et al. What is a clinically meaningful change on the Functional Assessment of Cancer Therapy-Lung (FACT-L) Questionnaire? Results from Eastern Cooperative Oncology Group (ECOG) Study 5592. Journal of Clinical Epidemiology 2002;55:285-95.

\section{Cella 2005}

Cella D, Herbst RS, Lynch TJ, Prager D, Belani CP, Schiller JH, et al. Clinically meaningful improvement in symptoms and quality of life for patients with non-small cell lung cancer receiving gefitinib in a randomized controlled trial. Journal of Clinical Oncology 2005;23(13):2946-54.

\section{Chang 2006}

Chang A, Parikh P, Thongprasert S, Tan EH, Perng RP, Ganzon D, et al. Gefitinib (IRESSA) in patients of Asian origin with refractory advanced non-small-cell lung cancer: Subset analysis from the ISEL study. Journal of Thoracic Oncology 2006;1(8):847-55.

\section{Douillard 2010}

Douillard JY, Shephard FA, Hirsh V, Mok T, Socinski MA, Gervais R, et al. Molecular predictors of outcome with gefitinib and docetaxel in previously treated non-small-cell lung cancer: from the randomized phase III INTEREST trial. Journal of Clinical Oncology 2010;28(5):744-52.

\section{Fukuoka 2011}

Fukuoka M, Wu YL, Thongprasert S, Sunpaweravong P, Leong SS, Sriuranpong V, et al. Biomarker analyses and final overall survival results from a phase III, randomized, openlabel, first-line study of gefitinib versus carboplatin/paclitaxel in clinically selected patients with advanced non - small-cell lung cancer in Asia (IPASS). Journal of Clinical Oncology. United States: American Society of Clinical Oncology (330 John Carlyle Street, Suite 300, Alexandria VA 22314, United States), 2011; Vol. 29:2866-74.

\section{GRADEpro GDT 2015 [Computer program]}

McMaster University (developed by Evidence Prime). GRADEpro GDT. Hamilton (ON): McMaster University (developed by Evidence Prime), 2015.

\section{Herbst 2005}

Herbst RS, Prager D, Hermann R, Fenrenbacher L, Johnson BE, Sandler A, et al. TRIBUTE: a phase III trial of erlotinib hydrochloride (OSI-774) combined with carboplatin and paclitaxel chemotherapy in advanced non-small-cell lung cancer. Journal of Clinical Oncology 2005;23(25):5892-9.

\section{Higgins 2011}

Higgins JPT, Green S (editors). Cochrane Handbook for Systematic Reviews of Interventions Version 5.1.0 [updated March 2011]. The Cochrane Collaboration, 2011. Available from www.cochrane-handbook.org. [www.cochrane-handbook.org]

\section{Hirsch 2006}

Hirsch FR, Varella-Garcia M, Bunn Jr PA, Franklin WA, Dziadziuszko R, Thatcher N, et al. Molecular predictors of outcome with gefitinib in a phase III placebo-controlled study in advanced non-small cell lung cancer. Journal of Clinical Oncology 2006;24(31):5034-42.

\section{Ibrahim 2010}

Ibrahim EM. Frontline gefitinib in advanced non-small cell lung cancer: meta-analysis of published randomized trials. Annals of Thoracic Medicine 2010;5(3):153-60.

\section{Inoue 2013}

Inoue A, Kobayashi K, Maemondo M, Sugawara S, Oizumi S, Isobe $\mathrm{H}$, et al. Updated overall survival results from a randomized phase III trial comparing gefitinib with carboplatinpaclitaxel for chemo-naive non-small cell lung cancer with sensitive EGFR gene mutations (NEJ002). Annals of Oncology 2013;24:54-9.

\section{Jiang 2011}

Jiang J, Huang L, Liang X, Zhou X, Huang R, Chu Z, et al. Gefitinib versus docetaxel in previously treated advanced non-small-cell lung cancer: a meta-analysis of randomized controlled trials. Acta Oncologica 2011;50(4):582-8.

\section{Kosaka 2004}

Kosaka T, Yatabe Y, Endoh H, Kuwano H, Takahashi T, Mitsudomi T. Mutations of the epidermal growth factor receptor gene in lung cancer: biological and clinical implications. Cancer Research 2004;64:8919-23.

\section{Mok 2011}

Mok TSK. Personalized medicine in lung cancer: what we need to know. Nature Reviews Clinical Oncology 2011;8:661-8.

\section{NCI CTCAE 2010}

National Cancer Institute. Cancer Therapy Evaluation Program. Common terminology criteria for adverse events. Common toxicity criteria, version 4.0. https://evs.nci.nih.gov/ftp1/CTCAE/ CTCAE_4.03_2010-06-14_QuickReference_5x7.pdf (accessed 17 February 2017).

\section{Oizumi 2012}

Oizumi S, Kobayashi K, Inoue A, Maemondo M, Sugawara S, Yoshizawa $\mathrm{H}$, et al. Quality of life with gefitinib in patients with EGFR-mutated non-small cell lung cancer: quality of life analysis of north east Japan study group 002 trial. Oncologist. United 
States: AlphaMed Press (318 Blackwell St. Suite 260, Durham NC 27701-2884, United States), 2012; Vol. 17:863-70.

\section{Paez 2004}

Paez JG, Jänne PA, Lee JC, Tracy S, Greulich H, Gabriel S, et al. EGFR mutations in lung cancer: correlation with clinical response to gefitinib therapy. Science 2004;304:1497-500.

\section{RevMan 2014 [Computer program]}

The Nordic Cochrane Centre, The Cochrane Collaboration. Review Manager (RevMan). Version 5.3. Copenhagen: The Nordic Cochrane Centre, The Cochrane Collaboration, 2014.

\section{Schünemann 2011}

Schünemann HJ, Oxman AD, Vist GE, Higgins JPT, Deeks JJ, Glasziou P, et al. Chapter 12: Interpreting results drawing conclusions. In: Higgins JPT, Green S (editors). Cochrane Handbook for Systematic Reviews of Interventions Version 5.1.0 [updated March 2011]. The Cochrane Collaboration, 2011. Available from www.cochrane-handbook.org.

\section{Sekine 2009}

Sekine I, Ichinose Y, Nishiwaki Y, Yamamoto N, Tsuboi M, Nakagawa K, et al. Quality of life and disease-related symptoms in previously treated Japanese patients with non-smallcell lung cancer: results of a randomized phase III study (V-15-32) of gefitinib versus docetaxel. Annals of Oncology 2009;20(9):1483-8.

\section{Smith 2005}

Smith J. Erlotinib: small molecule targeted therapy in the treatment of non-small-cell lung cancer. Clinical Therapeutics 2005;27(10):1513-34.

\section{Therasse 2000}

Therasse P, Arbuck SG, Eisenhauer EA, Wanders J, Kaplan RS, Rubinstein $\mathrm{L}$, et al. New guidelines to evaluate the response to treatment in solid tumors. European Organization for Research and Treatment of Cancer, National Cancer Institute of the United States, National Cancer Institute of Canada. Journal of the National Cancer Institute 2000;92(3):205-16.

\section{Thongprasert 2011}

Thongprasert S, Duffield E, Saijo N, Wu YL, Yang JC, Chu DT, et al. Health-related quality-of-life in a randomized phase III firstline study of gefitinib versus carboplatin/paclitaxel in clinically selected patients from Asia with advanced NSCLC (IPASS). Journal of Thoracic Oncology 2011;6:1872-80.

\section{Yamamoto 2010}

Yamamoto N, Nishiwaki Y, Negoro S, Jiang H, Itoh Y, Saijo N, et al. Disease control as a predictor of survival with gefitinib and docetaxel in a phase III study (V-15-32) in advanced nonsmall-cell lung cancer patients. Journal of Thoracic Oncology 2010;5(7):1042-7.

\section{Yang 2015}

Yang YP, Ma YX, Huang Y, Zhao YY, Fang WF, Hong SD, et al. QoL analyses from INFORM study, a phase III study of gefitinib versus placebo as maintenance therapy in advanced NSCLC. Scientific Reports 2015;5:11934.

\section{References to other published versions of this review} Sim 2007

Sim EH, Yang IA, Fong K, Wood-Baker R, Bowman R. Gefitinib for advanced non-small cell lung cancer. Cochrane Database of Systematic Reviews 2007, Issue 4. [DOI: 10.1002/14651858.CD006847]

* Indicates the major publication for the study

\section{CHARACTERISTICS OF STUDIES}

Characteristics of included studies [ordered by study ID]

Ahn 2012

\begin{tabular}{ll} 
Methods & Design: parallel-group \\
Randomisation: yes, method stated \\
Blinding: open-label \\
Withdrawals: stated \\
\hline Setting: multicentre study, hospital outpatient department \\
Number eligible: 86 \\
Number enrolled: 73 \\
Number in treatment group: 39 \\
Number in control group: 31 \\
Number of withdrawals (treatment/control): TP1 14/31; TPII $25 / 24$
\end{tabular}


Ahn 2012 (Continued)

Number completing trial (treatment/control): 0/0

Age range: (treatment/control) 35 to 73 years/29 to 76 years

Sex: $15 \mathrm{M}, 55 \mathrm{~F}$

Ethnicity: East Asian

NSCLC diagnosis: histologic/cytologic diagnosis of NSCLC, stage IIIB to IV disease

Inclusion criteria: stage IIIB to IV NSCLC with at least one measurable lesion, ECOG PS 0 or 1, EGFR mu-

tation status unknown

Exclusion criteria: received treatment for NSCLC other than palliative radiotherapy, smoker of more than 100 cigarettes in lifetime, life expectancy of $<12$ weeks

Baseline characteristics of treatment/control groups: comparable

\begin{tabular}{ll}
\hline Interventions & TP1 \\
& All patients received first-line chemotherapy: \\
& Pemetrexed $500 \mathrm{mg} / \mathrm{m}^{2}+$ cisplatin $75 \mathrm{mg} / \mathrm{m}^{2}$ \\
Intravenously on day 1 of 3-week cycle for 4 cycles & TPII \\
& Received either: \\
& Gefitinib $250 \mathrm{mg} /$ day OR \\
& Pemetrexed $500 \mathrm{mg} / \mathrm{m}^{2}$ with optional cisplatin $75 \mathrm{mg} / \mathrm{m}^{2}$ in first 2 cycles intravenously \\
\hline Outcomes & Progression-free survival \\
& Overall survival \\
& Tumour response - RECIST \\
& Duration of response \\
ASEs - NCl-CTC & Haematology and biochemical parameters \\
\hline Notes & - \\
\hline
\end{tabular}

\section{Risk of bias}

\begin{tabular}{lll}
\hline Bias & Authors' judgement & Support for judgement \\
\hline $\begin{array}{l}\text { Random sequence genera- } \\
\text { tion (selection bias) }\end{array}$ & Low risk & $\begin{array}{l}\text { Quote: "Stratified random assignment method, random allocation sequence } \\
\text { generated by central computerised voice response unit" }\end{array}$ \\
& Comment: this was judged as a low risk of bias \\
$\begin{array}{ll}\text { Allocation concealment } \\
\text { (selection bias) }\end{array}$ & Low risk & $\begin{array}{l}\text { Quote: "random allocation sequence generated by central computerised voice } \\
\text { response unit" }\end{array}$ \\
& Comment: this was judged as adequate \\
\hline
\end{tabular}

Blinding (performance Low risk

bias and detection bias)

No blinding but review authors judge that outcome is not likely to be influ-

All outcomes enced by lack of blinding 
Ahn 2012 (Continued)

Comment: this was judged as a low risk of bias

\begin{tabular}{lll}
$\begin{array}{l}\text { Incomplete outcome data } \\
\text { (attrition bias) } \\
\text { All outcomes }\end{array}$ & Low risk & $\begin{array}{l}\text { Exclusions and reasons for withdrawals presented in Figure 1. Missing out- } \\
\text { come data balanced in numbers across interventional groups with similar rea- } \\
\text { sons for missing data across groups. }\end{array}$ \\
& $\begin{array}{l}\text { Data analysed using intention-to-treat analysis } \\
\text { Comment: this was judged as a low risk of bias }\end{array}$ \\
\hline $\begin{array}{l}\text { Selective reporting (re- } \\
\text { porting bias) }\end{array}$ & Low risk & All prespecified outcomes were reported \\
\hline Other bias & Unclear risk & $\begin{array}{l}\text { Funded by Eli Lilly and Company. Authors have received honoraria from Eli Lil- } \\
\text { ly and some authors are current employees or previous employees of Eli Lilly. }\end{array}$ \\
& Comment: this was judged as an unclear risk of bias
\end{tabular}

An 2016

$\begin{array}{ll}\text { Methods } & \text { Design: parallel-group } \\ & \text { Randomisation: yes, method not stated } \\ & \text { Blinding: double-blind } \\ & \text { Withdrawals: not stated }\end{array}$

Participants

Setting: single-centre study, hospital outpatient department

Number eligible: 90

Number enrolled: 90

Number in treatment group: 45

Number in control group: 45

Number of withdrawals (treatment/control): not stated

Number completing trial (treatment/control): not stated

Age range: 57 to 83 years

Sex: $50 \mathrm{M}, 40 \mathrm{~F}$

Ethnicity: East Asian

NSCLC diagnosis: histologic/cytologic diagnosis of non-squamous NSCLC, stage IIIB to IV disease. Presence of EGFR sensitive mutation

Inclusion criteria: at least one measurable lesion, an estimated life expectancy of at least 12 weeks, adequate major organ function

Exclusion criteria: any of the following: myocardial infarction within the previous 3 months, uncontrolled angina pectoris or arrhythmia, brain metastasis, uncontrolled hypertension or diabetes, active infection, pulmonary fibrosis, pleural effusion or ascites requiring drainage, or cerebrovascular disease

Baseline characteristics of treatment/control groups: comparable

Interventions Pemetrexed $500 \mathrm{mg} / \mathrm{m}^{2}$ on day 1


An 2016 (Continued)

PLUS gefitinib $250 \mathrm{mg}$ on day 2 to 16

Cycles repeated every 3 weeks until disease progression

Gefitinib $250 \mathrm{mg}$ on day 2 to 16

PLUS placebo on day 1

Cycles repeated every 3 weeks until disease progression

\begin{tabular}{ll}
\hline Outcomes & Tumour response-RECIST \\
& ASEs - NCI-CTC \\
& Progression-free survival \\
& Overall survival \\
\hline Notes & - \\
\hline
\end{tabular}

\section{Risk of bias}

\begin{tabular}{|c|c|c|}
\hline Bias & Authors' judgement & Support for judgement \\
\hline \multirow[t]{2}{*}{$\begin{array}{l}\text { Random sequence genera- } \\
\text { tion (selection bias) }\end{array}$} & Unclear risk & $\begin{array}{l}\text { Quote: "patients were randomly divided.." but no further information provid- } \\
\text { ed }\end{array}$ \\
\hline & & $\begin{array}{l}\text { Comment: there was insufficient information to permit a clear judgement of } \\
\text { risk of bias }\end{array}$ \\
\hline \multirow{2}{*}{$\begin{array}{l}\text { Allocation concealment } \\
\text { (selection bias) }\end{array}$} & Unclear risk & No information provided \\
\hline & & $\begin{array}{l}\text { Comment: there was insufficient information to permit a clear judgement of } \\
\text { risk of bias }\end{array}$ \\
\hline $\begin{array}{l}\text { Blinding (performance } \\
\text { bias and detection bias) } \\
\text { All outcomes }\end{array}$ & Low risk & Quote: "All investigators and patients were masked to treatment allocation" \\
\hline \multirow{2}{*}{$\begin{array}{l}\text { Incomplete outcome data } \\
\text { (attrition bias) } \\
\text { All outcomes }\end{array}$} & Unclear risk & No information provided \\
\hline & & $\begin{array}{l}\text { Comment: there was insufficient information to permit a clear judgement of } \\
\text { risk of bias }\end{array}$ \\
\hline \multirow{2}{*}{$\begin{array}{l}\text { Selective reporting (re- } \\
\text { porting bias) }\end{array}$} & Low risk & All prespecified outcomes were reported \\
\hline & & Comment: this was judged as a low risk of bias \\
\hline \multirow[t]{2}{*}{ Other bias } & Unclear risk & $\begin{array}{l}\text { There were no declarations of potential conflicts of interest or indication of } \\
\text { funding or support }\end{array}$ \\
\hline & & $\begin{array}{l}\text { Comment: there was insufficient information to permit a clear judgement of } \\
\text { the risk of bias }\end{array}$ \\
\hline
\end{tabular}

\section{Chen 2007}

$\begin{array}{ll}\text { Methods } & \text { Design: parallel-group } \\ & \text { Randomisation: yes, method not stated } \\ & \text { Blinding: nil }\end{array}$


Chen 2007 (Continued)

Withdrawals: stated

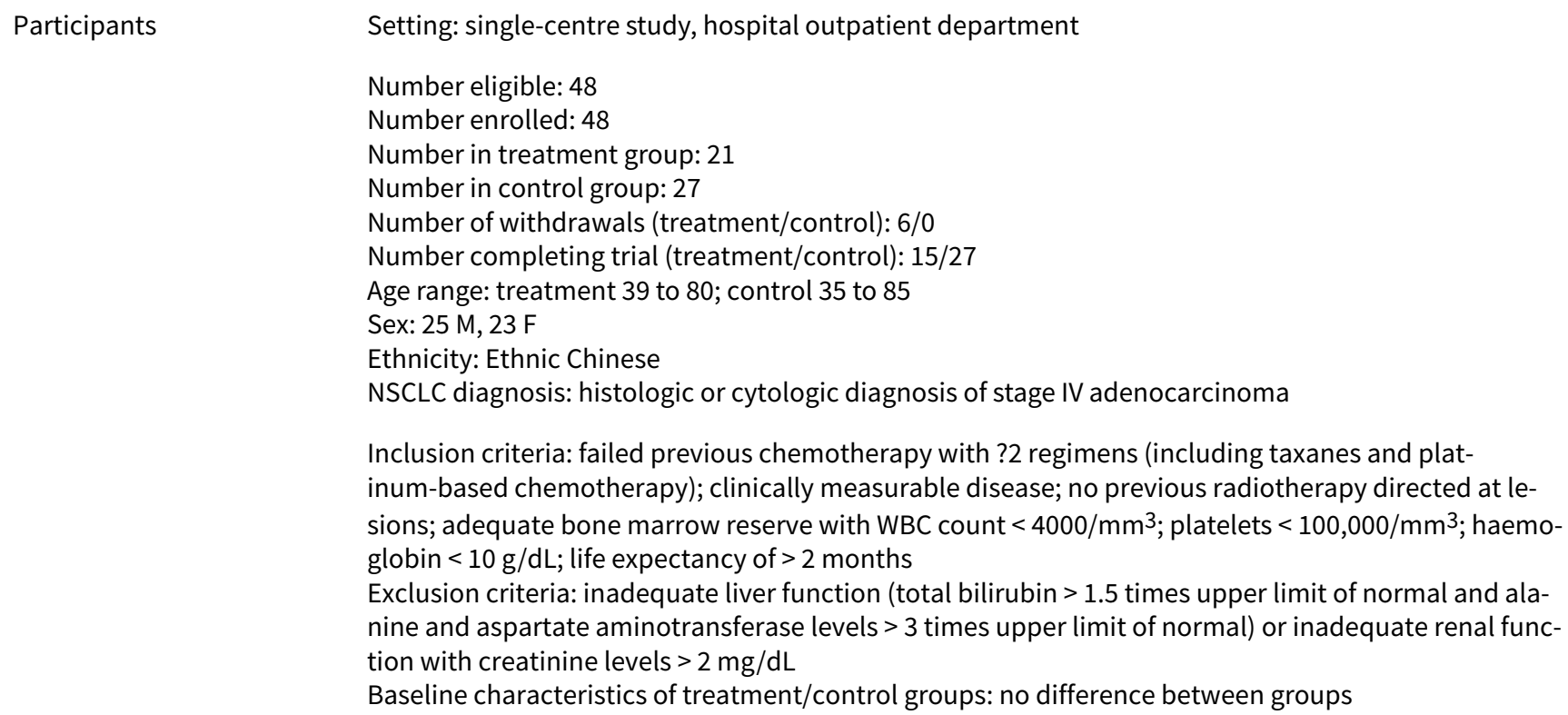

$\begin{array}{ll}\text { Outcomes } & \text { Overall survival } \\ & \text { Time to progression, 1-year progression-free survival } \\ & \text { Tumour response - RECIST } \\ & \text { ASES - NCI-CTC } \\ \text { EGFR FISH examination } & \text { LCS of FACT-L }\end{array}$

\section{Notes}

\section{Risk of bias}

\begin{tabular}{lll}
\hline Bias & Authors' judgement & Support for judgement \\
\hline $\begin{array}{l}\text { Random sequence genera- } \\
\text { tion (selection bias) }\end{array}$ & Unclear risk & $\begin{array}{l}\text { Quote: "Eligible patients were randomized..." but no further information pro- } \\
\text { vided }\end{array}$ \\
\hline $\begin{array}{l}\text { Allocation concealment } \\
\text { (selection bias) }\end{array}$ & Unclear risk & $\begin{array}{l}\text { Comment: there was insufficient information to permit a clear judgement of } \\
\text { risk of bias }\end{array}$ \\
\hline $\begin{array}{l}\text { Blinding (performance } \\
\text { bias and detection bias) } \\
\begin{array}{l}\text { All outcomes } \\
\text { Cow risk }\end{array}\end{array}$ & $\begin{array}{l}\text { Comment: there was insufficient information to permit a clear judgement of } \\
\text { risk of bias }\end{array}$ \\
\hline $\begin{array}{l}\text { Incomplete outcome data } \\
\text { (attrition bias) } \\
\text { All outcomes }\end{array}$ & High risk & $\begin{array}{l}\text { No blinding but review authors judge that outcome is not likely to be influ- } \\
\text { enced by lack of blinding }\end{array}$ \\
\hline
\end{tabular}


Chen 2007 (Continued)

$\begin{array}{ll}\begin{array}{l}\text { Selective reporting (re- } \\ \text { porting bias) }\end{array} & \text { Low risk } \\ & \text { Comment: this was judged as a low risk of bias }\end{array}$

Other bias Unclear risk

There were no declarations of potential conflicts of interest or indication of funding or support

Comment: there was insufficient information to permit a clear judgement of the risk of bias

Chen 2011

\begin{tabular}{|c|c|}
\hline \multirow[t]{5}{*}{ Methods } & Design: parallel-group \\
\hline & Randomisation: yes, method not stated \\
\hline & Blinding: open-label \\
\hline & Withdrawals: stated \\
\hline & Jadad score: 2 \\
\hline \multirow[t]{14}{*}{ Participants } & Setting: single-centre study, hospital outpatient department \\
\hline & Number eligible: 115 \\
\hline & Number enrolled: 115 \\
\hline & Number in treatment group: 58 \\
\hline & Number in control group: 57 \\
\hline & Number of withdrawals (treatment/control): 0/0 \\
\hline & Number completing trial (treatment/control): 58/57 \\
\hline & Age range (treatment/control): 37 to 87 years/30 to 85 years \\
\hline & Sex: 69 M, $45 \mathrm{~F}$ \\
\hline & Ethnicity: Taiwanese \\
\hline & NSCLC diagnosis: histological and cytological diagnosis of adenocarcinoma of the lung \\
\hline & $\begin{array}{l}\text { Inclusion criteria: stage IIIB or IV adenocarcinoma of the lung, age } 18 \text { years or older, failed previous } \\
\text { chemotherapy, WHO PS of } 0 \text { to } 3 \text {, clinically measurable disease, no previous radiotherapy directed at } \\
\text { the measurable lesion(s), adequate bone marrow reserve with a white blood count }>4000 / \mathrm{mm}^{3}\end{array}$ \\
\hline & $\begin{array}{l}\text { Exclusion criteria: previous treatment with } 5 F U \text {-related chemotherapeutic agent, interstitial lung dis- } \\
\text { ease, with inadequate liver function (total bilirubin }>1.5 \text { times and alanine aminotransferase/aspartate } \\
\text { transaminase }>3 \text { times the upper limit normal) or inadequate renal function with creatinine }>2.0 \mathrm{mg} / \\
\text { dl }\end{array}$ \\
\hline & Baseline characteristics of treatment/control groups: comparable \\
\hline \multirow[t]{2}{*}{ Interventions } & Gefitinib 250 mg/day \\
\hline & Gefitinib (250 mg/day) + UFT (tegafur 100 mg + uracil 224 mg) \\
\hline \multirow[t]{2}{*}{ Outcomes } & Progression-free survival \\
\hline & Overall survival \\
\hline
\end{tabular}


Chen 2011 (Continued)

Tumour response - RECIST

ASES - NCl-CTC

Haematology and biochemical parameters

Quality of life (LCS)

\begin{tabular}{|c|c|c|}
\hline Notes & - & \\
\hline \multicolumn{3}{|l|}{ Risk of bias } \\
\hline Bias & Authors' judgement & Support for judgement \\
\hline \multirow{2}{*}{$\begin{array}{l}\text { Random sequence genera- } \\
\text { tion (selection bias) }\end{array}$} & Unclear risk & Randomised but no details provided \\
\hline & & $\begin{array}{l}\text { Comment: there was insufficient detail reported about the method used to } \\
\text { generate the allocation sequence to allow a clear assessment of whether it } \\
\text { would produce comparable groups }\end{array}$ \\
\hline \multirow{2}{*}{$\begin{array}{l}\text { Allocation concealment } \\
\text { (selection bias) }\end{array}$} & Unclear risk & No information provided \\
\hline & & Comment: there was insufficient information to permit a clear judgement \\
\hline \multirow{2}{*}{$\begin{array}{l}\text { Blinding (performance } \\
\text { bias and detection bias) } \\
\text { All outcomes }\end{array}$} & Low risk & $\begin{array}{l}\text { No blinding but review authors judge that outcome is not likely to be influ- } \\
\text { enced by lack of blinding }\end{array}$ \\
\hline & & Comment: this was judged as low risk of bias \\
\hline \multirow{2}{*}{$\begin{array}{l}\text { Incomplete outcome data } \\
\text { (attrition bias) } \\
\text { All outcomes }\end{array}$} & High risk & No information provided \\
\hline & & Comment: this was judged as a high risk of bias \\
\hline \multirow{2}{*}{$\begin{array}{l}\text { Selective reporting (re- } \\
\text { porting bias) }\end{array}$} & Low risk & All prespecified outcomes were reported \\
\hline & & Comment: this was judged as a low risk of bias \\
\hline Other bias & Low risk & $\begin{array}{l}\text { Grants from National Science Council of the Republic of China and Taipei Vet- } \\
\text { erans General Hospital }\end{array}$ \\
\hline
\end{tabular}

Cheng 2016

\begin{tabular}{ll} 
Methods & Design: parallel-group \\
& Randomisation: yes, method stated \\
& Blinding: open-label \\
& Withdrawals: not stated \\
\hline Participants & Setting: multicentre study, hospital outpatient department \\
& Number eligible: 232 \\
& Number enrolled: 195 \\
& Number in treatment group: 129 \\
& Number in control group: 66
\end{tabular}


Number of withdrawals (treatment/control): 106/59

Number completing trial (treatment/control): 23/7

Age range: (treatment/control) 33 to 84 years/41 to 80 years

Sex: $68 \mathrm{M}, 123 \mathrm{~F}$

Ethnicity: East Asian

NSCLC diagnosis: histologic/cytologic diagnosis of non-squamous NSCLC, stage IV or recurrent disease. Presence of activating EGFR mutation

Inclusion criteria: age $\geq 18$ years, ECOG 0 or 1 , measurable disease documented by CT or MRI as defined by RECIST criteria

Exclusion criteria: prior systemic chemotherapy, immunotherapy or biologic therapy, including targeted therapy (e.g. EGFR-TKI) for stage IV or recurrent NSCLC. Receipt of adjuvant or neoadjuvant treatment with pemetrexed or an EGFR-TKI, thoracic radiation therapy within 28 days before enrolment or could not take folic acid, vitamin B12 and dexamethasone

Baseline characteristics of treatment/control groups: comparable

\begin{tabular}{ll}
\hline Interventions & Pemetrexed $500 \mathrm{mg} / \mathrm{m}^{2}$ on day 1 \\
& PLUS gefitinib $250 \mathrm{mg}$ daily \\
Cycles repeated every 3 weeks \\
Gefitinib $250 \mathrm{mg}$ daily \\
\hline
\end{tabular}

\begin{tabular}{|c|c|}
\hline \multirow[t]{8}{*}{ Outcomes } & Progression-free survival \\
\hline & Overall survival \\
\hline & Time to progressive disease (TtPD) \\
\hline & Tumour response - RECIST \\
\hline & Duration of response \\
\hline & ASES - NCl-CTC \\
\hline & Quality of life \\
\hline & Biomarker analysis \\
\hline
\end{tabular}

\begin{tabular}{lll}
\hline Notes & - \\
\hline Risk of bias & & \\
\hline Bias & Authors' judgement & Support for judgement \\
\hline $\begin{array}{l}\text { Random sequence genera- } \\
\text { tion (selection bias) }\end{array}$ & Low risk & $\begin{array}{l}\text { Quote "random assignment was conducted using a computer-generated ran- } \\
\text { dom sequence and an interactive voice-response system." }\end{array}$ \\
\hline $\begin{array}{l}\text { Allocation concealment } \\
\text { (selection bias) }\end{array}$ & Unclear risk & $\begin{array}{l}\text { No information provided } \\
\text { Comment: there was insufficient information to permit a clear judgement of }\end{array}$ \\
\hline
\end{tabular}


Cheng 2016 (Continued)

Blinding (performance bias and detection bias)

All outcomes

Low risk No blinding but review authors judge that outcome is not likely to be influenced by lack of blinding

Comment: this was judged as a low risk of bias
Incomplete outcome data Low risk

(attrition bias)

All outcomes
Exclusions and reasons for withdrawals presented in Figure 1. Missing outcomes balanced in numbers across intervention groups with similar reasons for missing data across groups.

Data analysed using intention-to-treat analysis

Comment: this was judged as low risk of bias

Selective reporting (re- Low risk porting bias)

All prespecified outcomes were reported, except for overall survival

Quote: "At time of PFS analysis, OS data were immature, and therefore, are not presented"

Comment: this was judged as a low risk of bias

\begin{tabular}{|c|c|c|}
\hline Other bias & Unclear risk & $\begin{array}{l}\text { Authors report consultative roles within industry, and other potential financial } \\
\text { conflicts of interest }\end{array}$ \\
\hline & & Comment: this was judged as an unclear risk of bias \\
\hline
\end{tabular}

\section{Crino 2008 INVITE}

$\begin{array}{ll}\text { Methods } & \text { Design: parallel-group } \\ \text { Randomisation: yes, method not stated } \\ \text { Blinding: open-label } \\ \text { Withdrawals: stated }\end{array}$

Participants

Setting: multicentre study, hospital outpatient department

Number eligible: 205

Number enrolled: 196

Number in treatment group: 97

Number in control group: 99

Number of withdrawals (treatment/control): 20/38

Number completing trial (treatment/control): 77/61

Age range: treatment 70 to 89 , control 70 to 86

Sex: M 148, F 48

Ethnicity: white 162, Asian 31, other 3

NSCLC diagnosis: histologically confirmed stage IIIB or stage IV NSCLC

Inclusion criteria: age $>70$ years, at least 1 measurable lesion according to RECIST criteria, histological biopsy and paraffin block from the original tumour or metastatic site, no prior chemotherapy, biologic or immunologic therapy, WHO performance status of 0 to 2, life expectancy of at least 12 weeks 
Crino 2008 INVITE (Continued)

Exclusion criteria: newly diagnosed central nervous system metastases that had not yet been treated, any evidence of clinically active interstitial lung disease, other coexisting malignancies or malignancies discovered within the last 5 years other than basal cell carcinoma or cervical cancer in situ, prior treatment with EGFR inhibitors, treatment with an investigational drug within 30 days

Baseline characteristics of treatment/control groups: comparable

$\begin{array}{ll}\text { Interventions } & \text { Gefitinib } 250 \mathrm{mg} / \text { day } \\ \text { Vinorelbine } 30 \mathrm{mg} / \mathrm{m}^{2} \text { infusion on days } 1 \text { and } 8 \text { of a } 21 \text {-day cycle }\end{array}$

\begin{tabular}{ll}
\hline Outcomes & Overall survival \\
& Progression-free survival (PFS) \\
& Tumour response - RECIST \\
& ASEs - NCI-CTC \\
Quality of life - LCS/FACT-L
\end{tabular}

Notes $-\quad$

\section{Risk of bias}

\begin{tabular}{|c|c|c|}
\hline Bias & Authors' judgement & Support for judgement \\
\hline $\begin{array}{l}\text { Random sequence genera- } \\
\text { tion (selection bias) }\end{array}$ & Low risk & $\begin{array}{l}\text { Quote: "randomly assigned in 1:1 manner" } \\
\text { Comment: this was judged as a low risk of bias }\end{array}$ \\
\hline $\begin{array}{l}\text { Allocation concealment } \\
\text { (selection bias) }\end{array}$ & Unclear risk & $\begin{array}{l}\text { No information provided } \\
\text { Comment: there was insufficient information to permit a clear judgement of } \\
\text { risk of bias }\end{array}$ \\
\hline $\begin{array}{l}\text { Blinding (performance } \\
\text { bias and detection bias) } \\
\text { All outcomes }\end{array}$ & Low risk & $\begin{array}{l}\text { No blinding but review authors judge that outcome is not likely to be influ- } \\
\text { enced by lack of blinding } \\
\text { Comment: this was judged as a low risk of bias }\end{array}$ \\
\hline $\begin{array}{l}\text { Incomplete outcome data } \\
\text { (attrition bias) } \\
\text { All outcomes }\end{array}$ & Low risk & $\begin{array}{l}\text { Exclusions and reasons for withdrawals presented in Figure } 1 . \text { Missing out- } \\
\text { comes balanced in numbers across intervention groups with similar reasons } \\
\text { for missing data across groups. } \\
\text { Data analysed using intention-to-treat analysis } \\
\text { Comment: this was judged as a low risk of bias }\end{array}$ \\
\hline $\begin{array}{l}\text { Selective reporting (re- } \\
\text { porting bias) }\end{array}$ & Low risk & $\begin{array}{l}\text { All prespecified outcomes were reported } \\
\text { Comment: this was judged as a low risk of bias }\end{array}$ \\
\hline Other bias & Unclear risk & $\begin{array}{l}\text { Authors report consultative roles within industry and other potential financial } \\
\text { conflicts of interest } \\
\text { Comment: this was judged as an unclear risk of bias }\end{array}$ \\
\hline
\end{tabular}


Cufer 2006 SIGN

\begin{tabular}{ll}
\hline Methods & Design: parallel-group \\
& Randomisation: yes, method stated \\
& Blinding: open-label \\
& Withdrawals: stated
\end{tabular}

\section{Participants}

Setting: multicentre study, hospital outpatient department

Number eligible: 141

Number enrolled: 141

Number in treatment 1 group: 68

Number in treatment 2 group: 73

Number of withdrawals (treatment $1 /$ treatment 2): $0 / 0$

Number completing trial (treatment 1/treatment 2): 68/73

Age range: treatment 134 to 85 years; treatment 229 to 83 years

Sex: 98 M, $43 \mathrm{~F}$

Ethnicity: 42.6\% Caucasian; 44.0\% Hispanic; 5.0\% Oriental; 1.5\% Black; 7.1\% other

NSCLC diagnosis: histologically or cytologically confirmed advanced (stage IIIb or IV) NSCLC that had progressed on or after 1 previous chemotherapy regimen. Also 1 or more measurable lesion according to RECIST

Inclusion criteria: WHO PS 0 to 2; life expectancy > 12 weeks, age > 18 years, symptomatic (LCS score < 24), capable of understanding the FACT-L questionnaire

Exclusion criteria: previous taxane treatment, treatment with any chemotherapeutic within 30 days prior to study, radiotherapy within 3 weeks prior to study, known cerebral metastasis, any evidence of ongoing interstitial lung disease (ILD), coexisting malignancies, malignancies diagnosed within the last 5 years, with exception of basal cell carcinoma or cervical carcinoma in situ, any unresolved chronic toxicity above grade $2 \mathrm{NCl}$-CTC from previous anti-cancer therapy, laboratory values outside requested limits, psychiatric disorders that may affect completion of FACT-L questionnaire

Baseline characteristics of treatment/control groups: comparable

Treatment 2: docetaxel $75 \mathrm{mg} / \mathrm{m}^{2}$ IV every 3 weeks

\begin{tabular}{ll}
\hline Outcomes & LCS component of FACT-L \\
& Tumour response - RECIST \\
& Overall survival, progression-free survival \\
& ASES - NCI-CTC \\
& - \\
\hline Notes & \\
\hline Risk of bias & Authors' judgement Support for judgement
\end{tabular}


Cufer 2006 SIGN (Continued)

Random sequence genera- Low risk Quote: "sealed randomisation envelopes which were allocated sequentially to tion (selection bias) patients"

Comment: this was judged as low risk of bias

\begin{tabular}{ll}
\hline $\begin{array}{l}\text { Allocation concealment } \\
\text { (selection bias) }\end{array}$ & $\begin{array}{l}\text { Quote: "sealed randomisation envelopes which were allocated sequentially to } \\
\text { patients" }\end{array}$ \\
& Comment: this was judged as low risk of bias
\end{tabular}

Blinding (performance Low risk

bias and detection bias)

No blinding but review authors judge that outcome is not likely to be influ-

All outcomes enced by lack of blinding.

Comment: this was judged as low risk of bias

Incomplete outcome data Low risk
(attrition bias)
All outcomes

Missing outcomes balanced in numbers across intervention groups with similar reasons for missing data across groups. 139/141 completed the trial.

All outcomes

Comment: this was judged as low risk of bias

Selective reporting (re- Unclear risk
porting bias)

All prespecified outcomes were reported. Progression-free survival was not a prespecified outcome but included in results. Quote: "Progression-free survival was not defined as a study variable in the protocol, but as tumour assessments were performed consistently for both treatment arms, it was also estimated."

Comment: this was judged as an unclear risk of bias

\begin{tabular}{ll}
\hline Other bias & $\begin{array}{l}\text { There were no declarations of potential conflicts of interest or indication of } \\
\text { funding or support }\end{array}$ \\
& $\begin{array}{l}\text { Comment: there was insufficient information to permit a clear judgement of } \\
\text { the risk of bias }\end{array}$ \\
\hline
\end{tabular}

\section{Dai 2013}

\begin{tabular}{ll}
\hline Methods & Design: parallel-group \\
Randomisation: yes, method not stated \\
Blinding: open-label \\
Withdrawals: stated \\
\hline Setting: single-centre study, hospital outpatient department \\
Number eligible: 46 \\
Number enrolled: 46 \\
Number in treatment group: 23 \\
Number in control group: 23 \\
Number of withdrawals (treatment/control): $0 / 0$ \\
Number completing trial (treatment/control): $23 / 23$ \\
Age range: (treatment/control): 41 to 74 years/47 to 72 years \\
Sex: $29 \mathrm{M}, 17 \mathrm{~F}$
\end{tabular}


Dai 2013 (Continued)

\section{Ethnicity: East Asian}

NSCLC diagnosis: histologic or pathologically proven diagnosis of nonsquamous NSCLC, stage IIIB to IV disease

Inclusion criteria: age 18 to 75 years, Received prior platinum-based chemotherapy of 4 to 6 cycles and has had progressive disease, at least 1 target lesion, ECOG 0 to 2, adequate bone marrow and organ function

Exclusion criteria: not stated

Baseline characteristics of treatment/control groups: comparable

\begin{tabular}{ll}
\hline Interventions & Gefitinib $250 \mathrm{mg} /$ day \\
& $\begin{array}{l}\text { Pemetrexed } 500 \mathrm{mg} / \mathrm{m}^{2} \text { intravenously, every } 4 \text { weeks until disease progression or unacceptable toxici- } \\
\text { ty }\end{array}$ \\
\hline Outcomes & Tumour response - RECIST \\
Progression-free survival \\
Overall survival \\
Toxicity - CTCAE \\
Quality of life - FACT-L
\end{tabular}

\begin{tabular}{ll}
\hline Notes & - \\
\hline
\end{tabular}

\section{Risk of bias}

Bias Authors' judgement Support for judgement

\begin{tabular}{ll}
\hline $\begin{array}{l}\text { Random sequence genera- } \\
\text { tion (selection bias) }\end{array}$ & Unclear risk \\
& $\begin{array}{l}\text { Quote: "randomized" but random sequence generation not discussed } \\
\text { risk of bias }\end{array}$ \\
\hline
\end{tabular}

\begin{tabular}{ll}
\hline $\begin{array}{l}\text { Allocation concealment } \\
\text { (selection bias) }\end{array}$ & Unclear risk \\
& $\begin{array}{l}\text { No information provided } \\
\text { Comment: there was insufficient information to permit a clear judgement of } \\
\text { risk of }\end{array}$ \\
\hline
\end{tabular}

\begin{tabular}{|c|c|c|}
\hline $\begin{array}{l}\text { Blinding (performance } \\
\text { bias and detection bias) }\end{array}$ & Low risk & $\begin{array}{l}\text { No blinding but review authors judge that outcome is not likely to be influ- } \\
\text { enced by lack of blinding }\end{array}$ \\
\hline
\end{tabular}

All outcomes

Comment: this was judged as low risk of bias

\begin{tabular}{lll}
\hline $\begin{array}{l}\text { Incomplete outcome data } \\
\text { (attrition bias) } \\
\text { All outcomes }\end{array}$ & Low risk & $\begin{array}{l}\text { No missing data } \\
\text { Comment: this was judged as low risk of bias }\end{array}$ \\
\hline $\begin{array}{l}\text { Selective reporting (re- } \\
\text { porting bias) }\end{array}$ & Low risk & All prespecified outcomes were reported \\
& Unclear risk & Comment: this was judged as low risk of bias \\
\hline Other bias & $\begin{array}{l}\text { Comment: there was insufficient information to permit a clear judgement of } \\
\text { risk of bias }\end{array}$ \\
\hline
\end{tabular}


Fukuoka 2003 IDEAL I

$\begin{array}{ll}\text { Methods } & \text { Design: parallel-group } \\ & \text { Randomisation: yes, method not stated } \\ \text { Blinding: double-blind } \\ \text { Withdrawals: stated }\end{array}$

Participants

Setting: multicentre study, hospital outpatient department

Number eligible: 210

Number enrolled: 209

Number in treatment group 1: 103

Number in treatment group 2: 106

Number of withdrawals (treatment $1 /$ treatment 2): $1 / 0$

Number completing trial (treatment 1/treatment 2): 103/105

Age range: treatment 128 to 85 years; treatment 237 to 78 years

Sex: 148 M, $62 \mathrm{~F}$

Ethnicity: 50\% Caucasian, 50\% Japanese

NSCLC diagnosis: histologic or cytologic confirmation of advanced or metastatic NSCLC; stage III or IV not curable with surgery or radiotherapy at study entry

Inclusion criteria: recurrent or refractory disease following 1 or 2 previous chemotherapy regimens (at least 1 containing platinum); at least 1 bi-dimensionally measurable or radiographically assessable lesion, age 18 or older, WHO PS 0 to 2 , life expectancy of 12 weeks or longer

Exclusion criteria: more than 2 previous chemotherapy regimens, systemic anticancer therapy within 21 days, radiotherapy within 14 days before start of treatment; unresolved chronic toxicity higher than in NCI-CTC grade 2; ALT or AST levels greater than 2.5 times upper limit of reference range; serum creatinine levels greater than 1.5 times the upper limit of reference range; neutrophils less than $1.5 \times 109 / \mathrm{L}$ or platelets less than $75 \times 109 / \mathrm{L}$

Baseline characteristics of treatment/control groups: comparable except for sex. Some demographic imbalances between Japanese and non-Japanese populations.

$\begin{array}{ll}\text { Interventions } & \text { Treatment 1: gefitinib } 250 \mathrm{mg} / \text { day } \\ \text { Treatment 2: gefitinib } 500 \mathrm{mg} / \text { day }\end{array}$

\begin{tabular}{ll}
\hline Outcomes & Objective tumour response rate - RECIST \\
& Disease control rate (response + stable disease) \\
& Progression-free survival \\
& Overall survival \\
& FACT-L questionnaire \\
& LCS of FACT-L \\
& ASEs - NCI-CTC
\end{tabular}

Notes -

\section{Risk of bias}

\section{Bias Authors' judgement Support for judgement}

Random sequence genera- Unclear risk tion (selection bias)
Quote: "randomized" but no further information provided

Comment: there was insufficient information to permit a clear judgement of risk of bias

\begin{tabular}{lll}
\hline $\begin{array}{l}\text { Allocation concealment } \\
\text { (selection bias) }\end{array}$ & Unclear risk & No information provided
\end{tabular}


Comment: there was insufficient information to permit a clear judgement of risk of bias

\begin{tabular}{|c|c|c|}
\hline $\begin{array}{l}\text { Blinding (performance } \\
\text { bias and detection bias) } \\
\text { All outcomes }\end{array}$ & Low risk & $\begin{array}{l}\text { Quote: "double-blind", "blinded treatment supplies" } \\
\text { Comment: this was judged as a low risk of bias }\end{array}$ \\
\hline $\begin{array}{l}\text { Incomplete outcome data } \\
\text { (attrition bias) } \\
\text { All outcomes }\end{array}$ & Low risk & $\begin{array}{l}\text { Quote: "1 patient excluded due to protocol violation", otherwise no missing } \\
\text { data } \\
\text { Comment: this was judged as a low risk of bias }\end{array}$ \\
\hline $\begin{array}{l}\text { Selective reporting (re- } \\
\text { porting bias) }\end{array}$ & Low risk & $\begin{array}{l}\text { All prespecified outcomes were reported } \\
\text { Comment: this was judged as a low risk of bias }\end{array}$ \\
\hline Other bias & Unclear risk & $\begin{array}{l}\text { Co-authors are recipients of research grants and honoraria from Astra Zeneca } \\
\text { Comment: this was judged as an unclear risk of bias }\end{array}$ \\
\hline
\end{tabular}

\section{Gaafar 2011 EORTC08021}

\begin{tabular}{ll}
\hline Methods & Design: parallel-group \\
& Randomisation: yes, method stated \\
& Blinding: double-blind, double-dummy \\
Withdrawals: stated
\end{tabular}

\section{Participants}

Setting: multicentre study, hospital outpatient department

Number eligible: 173

Number enrolled: 173

Number in treatment group: 86

Number in control group: 87

Number of withdrawals (treatment/control): 15/9

Number completing trial (treatment/control): 71/78

Age range: 28 to 80 years

Sex: M 133, F 40

Ethnicity: not stated

NSCLC diagnosis: histologically or cytologically confirmed stage IIIB or IV NSCLC (UICC $6^{\text {th }}$ ed)

Inclusion criteria: not amenable to local therapy, non-progressing after prior platinum-based chemotherapy ( 2 to 6 cycles) and without unacceptable toxicity. Age older than 18 years, WHO PS 2 or less, adequate renal, hepatic and haematological function. Patients with brain metastasis were eligible, provided asymptomatic after cranial irradiation.

Exclusion criteria: previous EGFR therapy, symptomatic brain metastasis, other malignancies, pregnancy or breastfeeding and interstitial pulmonary disease.

Baseline characteristics of treatment/control groups: comparable 
Gaafar 2011 EORTC08021 (Continued)
Interventions
Treatment: gefitinib $250 \mathrm{mg}$ daily
Control: placebo

\begin{tabular}{ll}
\hline Outcomes & Overall survival \\
& Time to progression \\
& Tumour response - RECIST \\
ASEs - NCI-CTC \\
Haematology and biochemical parameters
\end{tabular}

Notes -

\section{Risk of bias}

\begin{tabular}{lll}
\hline Bias & Authors' judgement & Support for judgement \\
\hline $\begin{array}{ll}\text { Random sequence genera- } \\
\text { tion (selection bias) }\end{array}$ & Low risk & $\begin{array}{l}\text { Quote: "centralised double blind random assignment using minimisation tech- } \\
\text { nique" }\end{array}$ \\
& & Comment: this was judged as a low risk of bias
\end{tabular}

\begin{tabular}{ll}
\hline $\begin{array}{l}\text { Allocation concealment } \\
\text { (selection bias) }\end{array}$ & Low risk \\
& $\begin{array}{l}\text { Quote: "centralised double blind random assignment using minimisation tech- } \\
\text { nique" }\end{array}$ \\
Comment: this was judged as a low risk of bias
\end{tabular}

\begin{tabular}{lll}
\hline $\begin{array}{l}\text { Blinding (performance } \\
\text { bias and detection bias) } \\
\text { All outcomes }\end{array}$ & Low risk & Double-blind. Quote: "matched daily placebo tablet" \\
\hline $\begin{array}{l}\text { Incomplete outcome data } \\
\text { (attrition bias) }\end{array}$ & Low risk & $\begin{array}{l}\text { Exclusions and reasons for withdrawals presented in Figure } 1 . \text { Missing out- } \\
\text { comes balanced in numbers across intervention groups with similar reasons } \\
\text { for missing data across groups (24/173 lost to follow-up/censored). }\end{array}$ \\
& $\begin{array}{l}\text { Intention-to-treat analysis } \\
\text { Comment: this was judged as a low risk of bias }\end{array}$ \\
\hline
\end{tabular}

\begin{tabular}{lll}
$\begin{array}{l}\text { Selective reporting (re- } \\
\text { porting bias) }\end{array}$ & Low risk & $\begin{array}{l}\text { All prespecified outcomes were reported } \\
\text { Comment: this was judged as a low risk of bias }\end{array}$ \\
\hline Other bias & Low risk & $\begin{array}{l}\text { Funding from EORTC, ILCP, National Cancer Institute, Fonda Cancer (FOCA) } \\
\text { Belgium } \\
\text { Comment: this was judged as a low risk of bias }\end{array}$ \\
\end{tabular}

Giaccone 2004 INTACT I

\begin{tabular}{ll}
\hline Methods & Design: parallel-group \\
& Randomisation: yes, method not stated \\
& Blinding: double-blind \\
& Withdrawals: not stated \\
\hline Participants & Setting: multicentre study, hospital outpatient department \\
\hline
\end{tabular}


Giaccone 2004 INTACT I (Continued)

Number eligible: 1093

Number enrolled: 1093

Number in treatment 1 group: 365

Number in treatment 2 group: 365

Number in control group: 363

Number of withdrawals (treatment $1 /$ treatment $2 /$ control): $3 / 7 / 8$

Number completing trial (treatment 1/treatment 2/control): 362/358/355

Age range: median age 60 years

Sex: $805 \mathrm{M}, 288 \mathrm{~F}$

Ethnicity: 998 white $(90.4 \%)$

NSCLC diagnosis: histologically or cytologically confirmed NSCLC

Inclusion criteria: NSCLC locally advanced stage II disease not curable with surgery or radiotherapy or stage IV disease; aged < 18 years; WHO PS 0 to 2

Exclusion criteria: previously received chemotherapy (prior radiotherapy or surgery allowed); hypersensitive to mannitol, corticosteroids, $\mathrm{H} 2$-antagonists, antihistamines or agents formulated with polyoxyethylated castor oil; had received radiotherapy within the last 2 weeks; had unresolved toxicity from previous radiation therapy or incomplete healing from previous surgery; had pre-existing motor or sensory neurotoxicity ( $\mathrm{NCl}-\mathrm{CTC}<$ grade 2); showed evidence of severe or uncontrolled systemic disease; had recent conditions requiring medication or uncontrolled significant active infections; had absolute neutrophils count $<2000 / \mathrm{mm}^{3}$; WBC $<4000 / \mathrm{mm}^{3}$; platelets $<100000 / \mathrm{mm}^{3}$; serum bilirubin greater than 1.25 times normal upper limit; ALT or AST greater than 2.5 times normal upper limit; creatinine clearance $<60 \mathrm{~mL} / \mathrm{min}$; were pregnant or breastfeeding; other coexisting malignancies or malignancies diagnosed within the last 5 years with the exception of basal cell carcinoma or cervical cancer in situ; had mixed NSCLC plus small cell lung cancer

Baseline characteristics of treatment/control groups: comparable

Regime A: 3-week cycle of IV gemcitabine $1250 \mathrm{mg} / \mathrm{m}^{2}$ for $30 \mathrm{~min}$ of day 1 and day 8; IV Cisplatin $80 \mathrm{mg} /$ $\mathrm{m}^{2}$ after gemcitabine administration on day 1 only

Treatment 1: gefitinib $250 \mathrm{mg} /$ day +6 cycles of regime $A$

Treatment 2: gefitinib $500 \mathrm{mg} /$ day +6 cycles of regime $A$

Control: placebo +6 cycles of regime $A$

\begin{tabular}{ll}
\hline Outcomes & Overall survival \\
& Time to progression \\
& Tumour response - RECIST \\
& ASE - NCI-CTC
\end{tabular}

\section{Notes}

\section{Risk of bias}

\begin{tabular}{lll}
\hline Bias & Authors' judgement & Support for judgement \\
\hline $\begin{array}{l}\text { Random sequence genera- } \\
\text { tion (selection bias) }\end{array}$ & Low risk & $\begin{array}{l}\text { Quote: "randomly assigned to one of three groups.. further stratification by dy- } \\
\text { namic randomisation..." } \\
\text { Comment: this was judged as a low risk of bias }\end{array}$ \\
\hline $\begin{array}{l}\text { Allocation concealment } \\
\text { (selection bias) }\end{array}$ & Unclear risk & $\begin{array}{l}\text { No information provided } \\
\text { Comment: there was insufficient information to permit a clear judgement of } \\
\text { risk of bias }\end{array}$ \\
\hline $\begin{array}{l}\text { Blinding (performance } \\
\text { bias and detection bias) }\end{array}$ & Low risk & $\begin{array}{l}\text { Quote: "double-blind manner" } \\
\text { Comment: this was judged as a low risk of bias }\end{array}$ \\
\hline
\end{tabular}


Giaccone 2004 INTACT I (Continued)

All outcomes

$\begin{array}{lll}\begin{array}{l}\text { Incomplete outcome data } \\ \text { (attrition bias) }\end{array} & \text { High risk } & \text { No information provided } \\ \text { All outcomes } & \text { Comment: this was judged as a high risk of bias }\end{array}$

\begin{tabular}{lll}
\hline $\begin{array}{l}\text { Selective reporting (re- } \\
\text { porting bias) }\end{array}$ & Low risk & $\begin{array}{l}\text { All prespecified outcomes were reported } \\
\text { Comment: this was judged as a low risk of bias }\end{array}$ \\
\hline Other bias & Low risk & Financial conflicts of interest declared \\
& Comment: this was judged as a low risk of bias
\end{tabular}

Goss 2009 INSTEP

$\begin{array}{ll}\text { Methods } & \text { Design: parallel-group } \\ & \text { Randomisation: yes, method not stated } \\ & \text { Blinding: double-blind, double-dummy } \\ & \text { Withdrawals: stated }\end{array}$

Participants

Setting: multicentre study, hospital outpatient department

Number eligible: 220

Number enrolled: 201

Number in treatment group: 100

Number in control group: 101

Number of withdrawals (treatment/control): 26/19

Number completing trial (treatment/control): 100/101

Age range: treatment 43 to 89 , control 42 to 90

Sex: M 122, F 79

Ethnicity: white 193

NSCLC diagnosis: histologically or cytologically confirmed locally advanced or metastatic NSCLC not amenable to curative surgery or radiotherapy

Inclusion criteria: age $>18$ years, chemotherapy-naive, WHO performance of 2 or 3 , measurable disease (RECIST), no prior EGFR inhibitor therapy

Exclusion criteria: untreated, newly diagnosed metastases in the CNS; other coexisting malignancies or malignancies diagnosed within the last 5 years other than basal cell carcinoma or cervical cancer in situ; fewer than 4 weeks since completion of wide-field radiotherapy or persistence of any radiotherapy-related toxicity; unresolved chronic toxicity greater than National Cancer Institute Common Toxicity Criteria for Adverse Events grade 2 from previous anticancer therapy (except alopecia); evidence of clinically active interstitial lung disease; prior treatment with epidermal growth factor receptor inhibitors, biologic or immunological therapy; and treatment with an investigational drug within the prior 30 days.

Baseline characteristics of treatment/control groups: comparable 
Goss 2009 INSTEP (Continued)

Interventions Gefitinib $250 \mathrm{mg}$ /day plus best supportive care

Placebo plus best supportive care

\begin{tabular}{ll}
\hline Outcomes & Overall survival \\
& Progression-free survival (PFS) \\
Tumour response - RECIST \\
ASEs - NCI-CTC \\
Haematology and biochemical parameters \\
Quality of life \\
Pulmonary symptom improvement (PSI) \\
\hline Notes
\end{tabular}

\section{Risk of bias}

\begin{tabular}{|c|c|c|}
\hline Bias & Authors' judgement & Support for judgement \\
\hline \multirow[t]{2}{*}{$\begin{array}{l}\text { Random sequence genera- } \\
\text { tion (selection bias) }\end{array}$} & Low risk & $\begin{array}{l}\text { Quote: "randomly assigned 1:1 according to a randomisation scheme pre- } \\
\text { pared by biostatics group, AstraZeneca" }\end{array}$ \\
\hline & & Comment: this was judged as a low risk of bias \\
\hline \multirow{2}{*}{$\begin{array}{l}\text { Allocation concealment } \\
\text { (selection bias) }\end{array}$} & Low risk & Central allocation \\
\hline & & Comment: this was judged as a low risk of bias \\
\hline \multirow{2}{*}{$\begin{array}{l}\text { Blinding (performance } \\
\text { bias and detection bias) } \\
\text { All outcomes }\end{array}$} & Low risk & $\begin{array}{l}\text { Quote: "double-blind", "gefitinib and placebo tablets physically identical and } \\
\text { presented in identical packaging" }\end{array}$ \\
\hline & & Comment: this was judged as a low risk of bias \\
\hline \multirow{3}{*}{$\begin{array}{l}\text { Incomplete outcome data } \\
\text { (attrition bias) } \\
\text { All outcomes }\end{array}$} & Low risk & $\begin{array}{l}\text { Attrition presented in Figure } 1 \text {. Missing outcomes balanced in numbers across } \\
\text { intervention groups with similar reasons for missing data across groups. }\end{array}$ \\
\hline & & Intention-to-treat analysis performed \\
\hline & & Comment: this was judged as a low risk of bias \\
\hline \multirow{2}{*}{$\begin{array}{l}\text { Selective reporting (re- } \\
\text { porting bias) }\end{array}$} & Low risk & All prespecified outcomes were reported \\
\hline & & Comment: this was judged as a low risk of bias \\
\hline \multirow[t]{2}{*}{ Other bias } & Unclear risk & Co-authors are recipients of research grants and honoraria from industry \\
\hline & & Comment: this was judged as an unclear risk of bias \\
\hline
\end{tabular}

Han 2012 First SIGNAL

\begin{tabular}{ll}
\hline Methods & Design: parallel-group \\
& Randomisation: yes, method not stated \\
& Blinding: open-label \\
\hline
\end{tabular}


Han 2012 First SIGNAL (Continued)

Withdrawals: stated

Jadad score: 2

Participants

Setting: multicentre study, hospital outpatient department

Number eligible: 316

Number enrolled: 313

Number in treatment group: 159

Number in control group: 154

Number of withdrawals (treatment/control): $0 / 4$

Number completing trial (treatment/control): 159/150

Age range: (treatment/control): 32 to 74 years/19 to 74 years

Sex: $35 \mathrm{M}, 174 \mathrm{~F}$

Ethnicity: Asian

NSCLC diagnosis: stage IIIB (ineligible for curative radiotherapy) or IV adenocarcinoma of the lung with measurable or non-measurable disease

Inclusion criteria: stage IIIB or IV adenocarcinoma of the lung. ECOG PS 0 to 2, adequate bone marrow, liver and renal function.

Exclusion criteria: known severe hypersensitivity to gefitinib or any constituents of this product, any evidence of clinically active interstitial lung disease; severe or uncontrolled systemic disease; concomitant use of phenytoin, carbamazepine, rifampin, barbiturate or St John's Wort; non-stable brain metastasis

Baseline characteristics of treatment/control groups: comparable

Interventions Gefitinib $250 \mathrm{mg} /$ day

Gemcitabine $\left(1250 \mathrm{mg} / \mathrm{m}^{2}\right)$ on days 1 and 8 plus cisplatin $\left(75 \mathrm{mg} / \mathrm{m}^{2}\right)$ on day 1 . Cycles repeated every 3 weeks for up to a maximum of 9 cycles as tolerated.

\begin{tabular}{|c|c|c|}
\hline \multirow[t]{5}{*}{ Outcomes } & \multicolumn{2}{|l|}{ Overall survival } \\
\hline & \multicolumn{2}{|c|}{ Progression-free survival } \\
\hline & \multicolumn{2}{|c|}{ Tumour response - RECIST } \\
\hline & \multicolumn{2}{|l|}{ ASES - NCl-CTC } \\
\hline & \multicolumn{2}{|c|}{ Quality of life - EORTC Quality of Life Questionnaire C30 and LC13 } \\
\hline Notes & - & \\
\hline \multicolumn{3}{|l|}{ Risk of bias } \\
\hline Bias & Authors' judgement & Support for judgement \\
\hline \multirow{2}{*}{$\begin{array}{l}\text { Random sequence genera- } \\
\text { tion (selection bias) }\end{array}$} & \multirow[t]{2}{*}{ Unclear risk } & Randomised but no further details provided \\
\hline & & $\begin{array}{l}\text { Comment: there was insufficient information to permit a clear judgement of } \\
\text { risk of bias }\end{array}$ \\
\hline
\end{tabular}


Han 2012 First SIGNAL (Continued)

$\begin{array}{ll}\begin{array}{l}\text { Allocation concealment } \\ \text { (selection bias) }\end{array} & \text { Unclear risk }\end{array} \quad \begin{aligned} & \text { No information provided } \\ & \text { Comment: there was insufficient information to permit a clear judgement of } \\ & \text { risk of bias }\end{aligned}$

\begin{tabular}{ll}
\hline $\begin{array}{l}\text { Blinding (performance } \\
\text { bias and detection bias) }\end{array} \quad$ Low risk & $\begin{array}{l}\text { No blinding but review authors judge that outcome is not likely to be influ- } \\
\text { enced by lack of blinding }\end{array}$
\end{tabular}

All outcomes

Comment: this was judged as a low risk of bias

Incomplete outcome data Low risk

(attrition bias)

All outcomes
Exclusions and reasons for withdrawals presented in Figure 1. Reasons for missing data unlikely to be related to true outcome (4/313 withdrawn, but all from the chemotherapy arm).

Intention-to-treat analysis performed

Comment: this was judged as a low risk of bias

\begin{tabular}{ll}
\hline $\begin{array}{l}\text { Selective reporting (re- } \\
\text { porting bias) }\end{array}$ & Low risk \\
& Comment: this was judged as a low risk of bias
\end{tabular}

Other bias Unclear risk Co-authors are recipients of research grants and honoraria from industry

Comment: this was judged as an unclear risk of bias

\section{Herbst 2004 INTACT II}

\begin{tabular}{ll}
\hline Methods & Design: parallel-group \\
& Randomisation: yes, method not stated \\
& Blinding: double-blind \\
& Withdrawals: not stated
\end{tabular}

\section{Participants}

Setting: multicentre study, hospital outpatient department

Number eligible: 1037

Number enrolled: 1037

Number in treatment 1 group: 345

Number in treatment 2 group: 347

Number in control group: 345

Number of withdrawals (treatment 1 /treatment 2/control): $3 / 5 / 4$

Number completing trial (treatment 1 /treatment 2/control): $342 / 342 / 341$

Age range: treatment 1 median 62 years; treatment 2 median 61 years; control median 63 years

Sex: $619 \mathrm{M}, 418 \mathrm{~F}$

Ethnicity: treatment $188.5 \%$ white, $7.5 \%$ black, $4 \%$ other; treatment $290.4 \%$ white, $4.1 \%$ black, $5.5 \%$ other; control $91.9 \%$ white, $5.2 \%$ black, $2.9 \%$ other NSCLC diagnosis: histologically or cytologically diagnosed NSCLC; unresectable stage III or IV disease

Inclusion criteria: no prior chemotherapy; age < 18 years; WHO PS 0 to 2

Exclusion criteria: presence of mixed NSCLC or small cell lung cancer; brain metastases that were newly diagnosed or had not been treated with surgery or radiation; previously treated CNS metastases or spinal cord compression in presence of clinically stable disease; less than 2 weeks since radiotherapy; unresolved toxicity from prior radiotherapy or incomplete healing from surgery; evidence of severe systemic disease; greater than trace protein or blood on repeat urinalysis; absolute neutrophils count < $2000 / \mu \mathrm{L} ; \mathrm{WBC}<4000 / \mu \mathrm{L}$; platelets < 100,000/ $\mu \mathrm{L}$; serum bilirubin greater than 1.25 times normal upper limit; ALT or AST greater than 2.5 times normal upper limit; serum creatinine greater 1.5 times normal upper limit; pregnancy; breastfeeding; hypersensitive to mannitol, corticosteroids, H2-antagonists, antihistamines or agents formulated with polyoxyethylated castor oil 
Herbst 2004 INTACT II (Continued)

Baseline characteristics of treatment/control groups: comparable

Regime A: IV Paclitaxel $225 \mathrm{mg} / \mathrm{m}^{3}$ over 3 hours on day 1 of 3 week cycle immediately followed by IV
carboplatin AUC of $6 \mathrm{mg} / \mathrm{mL}$ over 15 to 30 min on day 1
Treatment 1: gefitinib $250 \mathrm{mg} /$ day +6 cycles of regime A
Treatment 2: gefitinib $500 \mathrm{mg} /$ day +6 cycles of regime A
Control: placebo +6 cycles of regime A

\begin{tabular}{ll}
\hline Outcomes & Overall survival \\
& Time to progression \\
& Tumour response - RECIST \\
& ASEs - NCI-CTC \\
& Haematology and biochemical parameters \\
\hline
\end{tabular}

Notes

\section{Risk of bias}

\begin{tabular}{|c|c|c|}
\hline Bias & Authors' judgement & Support for judgement \\
\hline \multirow{2}{*}{$\begin{array}{l}\text { Random sequence genera- } \\
\text { tion (selection bias) }\end{array}$} & Unclear risk & Quote: "randomized to receive..." \\
\hline & & $\begin{array}{l}\text { Comment: there was insufficient information to permit a clear judgement of } \\
\text { risk of bias }\end{array}$ \\
\hline \multirow{2}{*}{$\begin{array}{l}\text { Allocation concealment } \\
\text { (selection bias) }\end{array}$} & Unclear risk & No information provided \\
\hline & & $\begin{array}{l}\text { Comment: there was insufficient information to permit a clear judgement of } \\
\text { risk of bias }\end{array}$ \\
\hline \multirow{2}{*}{$\begin{array}{l}\text { Blinding (performance } \\
\text { bias and detection bias) } \\
\text { All outcomes }\end{array}$} & Low risk & "double-blind" with use of placebo tablets \\
\hline & & Comment: this was judged as a low risk of bias \\
\hline \multirow{3}{*}{$\begin{array}{l}\text { Incomplete outcome data } \\
\text { (attrition bias) } \\
\text { All outcomes }\end{array}$} & Unclear risk & No information provided \\
\hline & & Intention-to-treat analysis performed \\
\hline & & $\begin{array}{l}\text { Comment: there was insufficient information to permit a clear judgement of } \\
\text { risk of bias }\end{array}$ \\
\hline \multirow{2}{*}{$\begin{array}{l}\text { Selective reporting (re- } \\
\text { porting bias) }\end{array}$} & Low risk & All prespecified outcomes were reported \\
\hline & & Comment: this was judged as a low risk of bias \\
\hline \multirow[t]{2}{*}{ Other bias } & Low risk & Financial conflicts of interest declared \\
\hline & & Comment: this was judged as a low risk of bias \\
\hline
\end{tabular}

Kelly 2008 SWOG S0023

$\begin{array}{ll}\text { Methods } & \text { Design: parallel-group } \\ & \text { Randomisation: yes, method not stated } \\ & \text { Blinding: not stated }\end{array}$


Kelly 2008 SWOG S0023 (Continued)

$$
\text { Withdrawals: stated }
$$

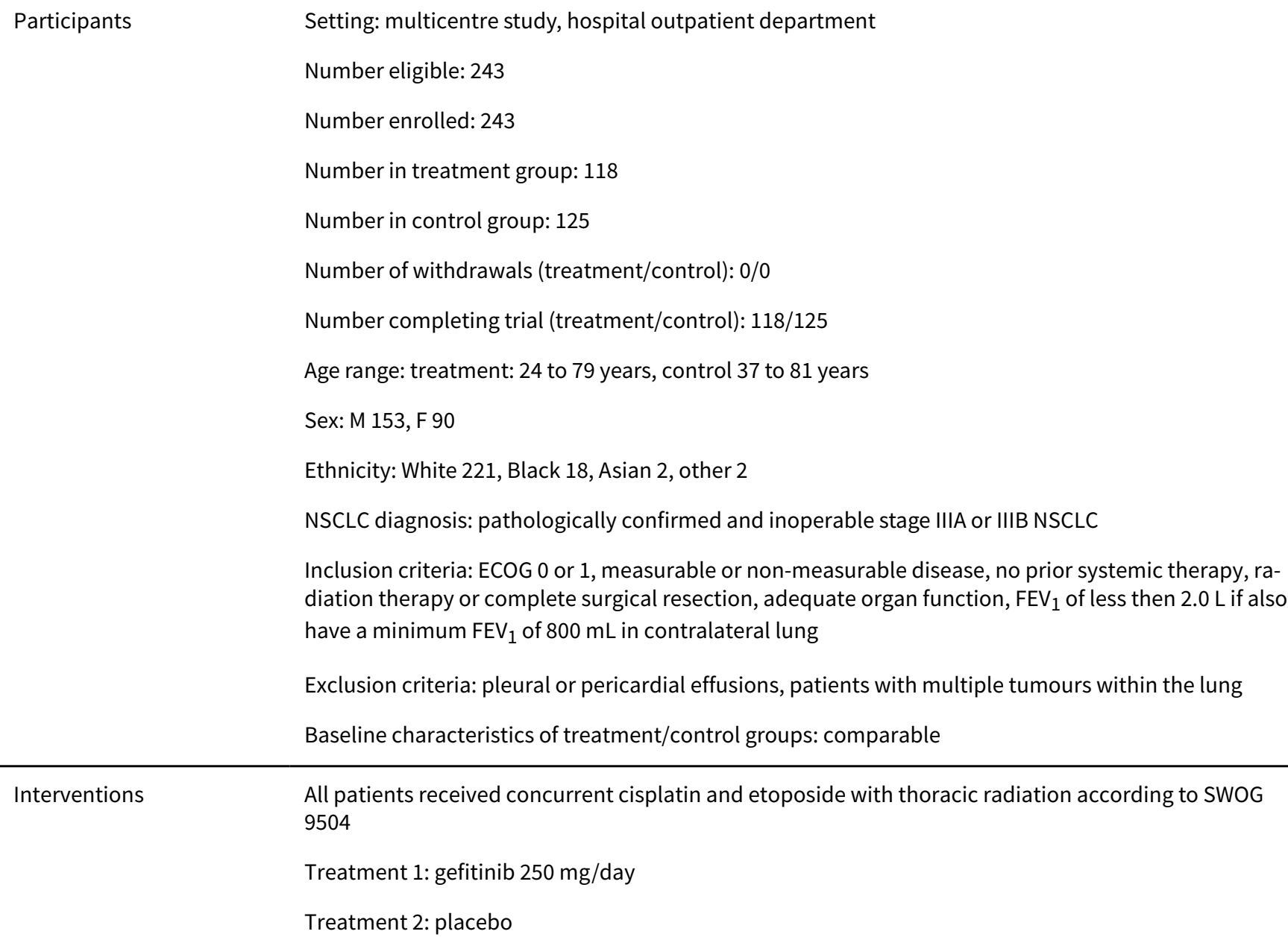

\begin{tabular}{ll}
\hline Outcomes & Overall survival \\
& Progression-free survival (PFS) \\
& ASEs - NCI-CTC \\
\hline Notes & - \\
\hline
\end{tabular}

\section{Risk of bias}

\begin{tabular}{lll}
\hline Bias & Authors' judgement & Support for judgement \\
\hline $\begin{array}{l}\text { Random sequence genera- } \\
\text { tion (selection bias) }\end{array}$ & Unclear risk & $\begin{array}{l}\text { Quote: "Randomised" but no further information given } \\
\text { Comment: there was insufficient information to permit a clear judgement of } \\
\text { risk of bias }\end{array}$ \\
\hline $\begin{array}{l}\text { Allocation concealment } \\
\text { (selection bias) }\end{array}$ & Unclear risk & $\begin{array}{l}\text { No information provided } \\
\text { Comment: there was insufficient information to permit a clear judgement of } \\
\text { risk of bias }\end{array}$ \\
\hline $\begin{array}{l}\text { Blinding (performance } \\
\text { bias and detection bias) }\end{array}$ & Low risk & $\begin{array}{l}\text { No blinding but review authors judge that outcome is not likely to be influ- } \\
\text { enced by lack of blinding }\end{array}$
\end{tabular}


Kelly 2008 SWOG S0023 (Continued)

All outcomes

Incomplete outcome data Low risk

(attrition bias)

All outcomes
Comment: this was judged as a low risk of bias

Exclusions and attrition stated in text. Missing outcomes balanced in numbers across intervention groups with similar reasons for missing data across groups. 115/571 (20\%) eligible patients dropped out before random assignment due to progressive disease and 27 (5\%) dropped out as a result of death from cancer, treatment or other causes.

Comment: this was judged as a low risk of bias

\begin{tabular}{ll}
\hline $\begin{array}{l}\text { Selective reporting (re- } \\
\text { porting bias) }\end{array}$ & Low risk \\
& Comment: this was judged as a low risk of bias
\end{tabular}

Other bias

Unclear risk

Co-authors are recipients of research grants and honoraria from industry

Quote: "Study closed early as unplanned interim analysis rejected alternative hypothesis of improved survival..."

Comment: this was judged as an unclear risk of bias

$\begin{array}{ll}\text { Methods } & \text { Design: parallel-group } \\ & \text { Randomisation: yes, method stated } \\ & \text { Blinding: open-label } \\ \text { Withdrawals: stated }\end{array}$

Participants

Setting: multicentre study, hospital outpatient department

Number eligible: 1607

Number enrolled: 1466

Number in treatment group: 733

Number in control group: 733

Number of withdrawals (treatment/control): 701/711

Number completing trial (treatment/control): 116/107

Age range: treatment 27 to 84 years, control 20 to 84 years

Sex: M 954, F 512

Ethnicity: White 1090, Asian 323, Black 22, other 31

NSCLC diagnosis: histologically or cytologically confirmed locally advanced or metastatic NSCLC

Inclusion criteria: 18 years or older, NSCLC that progressed or recurred after at least 1 previous platinum-based chemotherapy regimen (up to 2 regimens allowed), WHO performance status 0 to 2, measurable or non-measurable disease by Response Evaluation Criteria in Solid Tumours (RECIST), had no previous therapy with EGFR tyrosine kinase inhibitor, absolute neutrophil count $<1.5 \times 109 / \mathrm{L}$, adequate hepatic function

Exclusion criteria: not stated 
Kim 2008 INTEREST (Continued)

Baseline characteristics of treatment/control groups: comparable

Interventions Treatment: gefitinib $(250 \mathrm{mg} /$ day $)$

Control: docetaxel ( $75 \mathrm{mg} / \mathrm{m}^{2}$ in a 1-hour infusion every 3 weeks) with standard premedication

\begin{tabular}{ll}
\hline Outcomes & Overall survival \\
& Progression-free survival (PFS) \\
& Tumour response - RECIST \\
& ASES - NCI-CTC \\
FACT-L, TOI, LCS \\
EGFR gene copy number
\end{tabular}

\section{Notes}

\section{Risk of bias}

\begin{tabular}{|c|c|c|}
\hline Bias & Authors' judgement & Support for judgement \\
\hline $\begin{array}{l}\text { Random sequence genera- } \\
\text { tion (selection bias) }\end{array}$ & Low risk & $\begin{array}{l}\text { Quote: "Use of a centralised registration and randomisation centre, contacted } \\
\text { by telephone, to assign patients to a specific treatment group" } \\
\text { Comment: this was judged as a low risk of bias }\end{array}$ \\
\hline $\begin{array}{l}\text { Allocation concealment } \\
\text { (selection bias) }\end{array}$ & Low risk & $\begin{array}{l}\text { Quote: "Use of a centralised registration and randomisation centre, contacted } \\
\text { by telephone, to assign patients to a specific treatment group" } \\
\text { Comment: this was judged as a low risk of bias }\end{array}$ \\
\hline $\begin{array}{l}\text { Blinding (performance } \\
\text { bias and detection bias) } \\
\text { All outcomes }\end{array}$ & Low risk & $\begin{array}{l}\text { No blinding but review authors judge that outcome is not likely to be influ- } \\
\text { enced by lack of blinding } \\
\text { Comment: this was judged as a low risk of bias }\end{array}$ \\
\hline $\begin{array}{l}\text { Incomplete outcome data } \\
\text { (attrition bias) } \\
\text { All outcomes }\end{array}$ & Low risk & $\begin{array}{l}\text { Exclusions and attrition presented in Figure } 1 \text {. Missing outcome data balanced } \\
\text { in numbers across intervention groups with similar reasons for missing data } \\
\text { across groups. } \\
\text { Comment: this was judged as a low risk of bias }\end{array}$ \\
\hline $\begin{array}{l}\text { Selective reporting (re- } \\
\text { porting bias) }\end{array}$ & Low risk & $\begin{array}{l}\text { All prespecified outcomes were reported } \\
\text { Comment: this was judged as a low risk of bias }\end{array}$ \\
\hline Other bias & Low risk & $\begin{array}{l}\text { Co-authors are recipients of research grants and honoraria from industry. } \\
\text { Study was supported by Astra Zeneca, but principal investigators had unre- } \\
\text { stricted access to the study data and gave assurance for the accuracy and } \\
\text { completeness of the reported analyses. } \\
\text { Comment: this was judged as a low risk of bias }\end{array}$ \\
\hline
\end{tabular}

Kim 2016

Methods Design: parallel-group


Kim 2016 (Continued)

Randomisation: yes, method not stated

Blinding: open-label

Withdrawals: stated

Participants

Setting: single-centre study, hospital outpatient department

Number eligible: 95

Number enrolled: 95

Number in treatment group: 48

Number in control group: 47

Number of withdrawals (treatment/control): not stated

Number completing trial (treatment/control): 0/2

Age range: (treatment/control) 42 to 82 years/31 to 81 years

Sex: $68 \mathrm{M}, 27 \mathrm{~F}$

Ethnicity: East Asian

NSCLC diagnosis: histologically or cytologically proven advanced (stage IIIB or IV) or recurrent NSCLC; disease progression after first-line or second-line chemotherapy; age $\geq 18$ years; ECOG PS $\leq 2$; at least one measurable lesion; adequate bone marrow (absolute neutrophil count $\geq 1500 / \mathrm{mL}$ and platelet count $\geq 100,000 / \mathrm{mL}$ ), normal hepatic (bilirubin $\geq 1.5 \mathrm{ULN}$ and hepatic transaminase $\leq 2.5 \mathrm{ULN}$ ) and renal (serum creatinine $<1.5 \mathrm{mg} / \mathrm{dL}$ ) functions; and an estimated life expectancy of at least 3 months

Patients with brain metastases were eligible if treated with radiotherapy and clinically stable.

Exclusion criteria: patients with chronic diarrhoea of any grade, inflammatory bowel disease, uncontrolled comorbid illness or other malignancies

Baseline characteristics of treatment/control groups: comparable

Cycles to continue until disease progression, unacceptable toxicity or until patient declined further treatment

\begin{tabular}{ll}
\hline Outcomes & Progression-free survival rate at 6 months \\
& Progression-free survival \\
Tumour response - RECIST & ASEs - NCI-CTC \\
& Overall survival
\end{tabular}

Notes Study closed early due to poor accrual

\section{Risk of bias}

Bias Authors' judgement Support for judgement


Kim 2016 (Continued)

Comment: there was insufficient information to permit a clear judgement of risk of bias

\begin{tabular}{|c|c|c|}
\hline $\begin{array}{l}\text { Allocation concealment } \\
\text { (selection bias) }\end{array}$ & Unclear risk & $\begin{array}{l}\text { No information provided } \\
\text { Comment: there was insufficient information to permit a clear judgement of } \\
\text { risk of bias }\end{array}$ \\
\hline
\end{tabular}

\begin{tabular}{lll}
\hline $\begin{array}{l}\text { Blinding (performance } \\
\text { bias and detection bias) } \\
\text { All outcomes }\end{array}$ & Low risk & $\begin{array}{l}\text { Open-label but review authors judge that outcome is not likely to be influ- } \\
\text { enced by lack of blinding } \\
\text { Comment: this was judged as a low risk of bias }\end{array}$ \\
\hline $\begin{array}{l}\text { Incomplete outcome data } \\
\text { (attrition bias) } \\
\text { All outcomes }\end{array}$ & High risk & Withdrawals not stated \\
\hline $\begin{array}{l}\text { Selective reporting (re- } \\
\text { porting bias) }\end{array}$ & Low risk & Comment: this was judged as a high risk of bias \\
\hline $\begin{array}{l}\text { Other bias } \\
\text { Unclear risk }\end{array}$ & $\begin{array}{l}\text { All prespecified outcomes were reported } \\
\text { Comment: this was judged as a low risk of bias }\end{array}$ \\
& $\begin{array}{l}\text { No specific funding was disclosed and authors made no disclosure of conflicts } \\
\text { Comment: this was judged as an unclear risk of bias }\end{array}$
\end{tabular}

\section{Kris 2003 IDEAL II}

\begin{tabular}{ll}
\hline Methods & Design: parallel-group \\
& Randomisation: yes, method not stated \\
& Blinding: double-blind, double-dummy \\
& Withdrawals: stated
\end{tabular}

Setting: multicentre study, hospital outpatient department
Number eligible: 261
Number enrolled: 221
Number in treatment 1 group: 106
Number in treatment 2 group: 115
Number of withdrawals (treatment 1 /treatment 2): $4 / 1$
Number completing trial (treatment 1 /treatment 2 ): $102 / 114$
Age range: treatment 134 to 84 years; treatment 230 to 80 years
Sex: $128 \mathrm{M}, 93 \mathrm{~F}$
Ethnicity: not stated
NSCLC diagnosis: pathological diagnosis of NSCLC, stage IIIB or IV disease extent
Inclusion criteria: treatment with 2 or more regimens containing cisplatin or carboplatin and docetax-
el, given either concurrently or as separate regimens; disease progression or unacceptable toxicity with
last chemotherapy regimen; symptomatic NSCLC as determined by score of 24 of 28 on LCS of FACT-L;
measurable or evaluable indicator lesions, WHO PS 0 to 2
Exclusion criteria: received chemotherapy or irradiation within 14 days; unresolved toxicity greater
than grade 2 from prior chemotherapy; neutrophil count less than $1.5 \times 109 / L ;$ platelet count less than
$75 \times 109 / L ;$ bilirubin level more than 1.25 times the upper limit of normal; creatinine clearance less than
30 mL/min
Baseline characteristics of treatment/control groups: comparable


Kris 2003 IDEAL II (Continued)

Treatment 2: gefitinib $500 \mathrm{mg} /$ day (2 × $250 \mathrm{mg}$ tablets)

\begin{tabular}{|c|c|c|}
\hline Outcomes & \multicolumn{2}{|c|}{$\begin{array}{l}\text { FACT-L } \\
\text { - Time to symptom improvement as measured by FACT-L } \\
\text { - Duration of improvement as measured by FACT-L } \\
\text { Radiographic assessments (PR - } 50 \% \text { decrease in lesion size) } \\
\text { - Duration of radiographic response } \\
\text { - Radiographic response rates } \\
\text { ASEs - NCI-CTC } \\
\text { Overall survival by dose, frequency, severity of ASE }\end{array}$} \\
\hline Notes & - & \\
\hline \multicolumn{3}{|l|}{ Risk of bias } \\
\hline Bias & Authors' judgement & Support for judgement \\
\hline $\begin{array}{l}\text { Random sequence genera- } \\
\text { tion (selection bias) }\end{array}$ & Unclear risk & $\begin{array}{l}\text { Quote: "patients were randomized.." but no further information provided } \\
\text { Comment: there was insufficient information to permit a clear judgement of } \\
\text { risk of bias }\end{array}$ \\
\hline $\begin{array}{l}\text { Allocation concealment } \\
\text { (selection bias) }\end{array}$ & Unclear risk & $\begin{array}{l}\text { No information provided } \\
\text { Comment: there was insufficient information to permit a clear judgement of } \\
\text { risk of bias }\end{array}$ \\
\hline $\begin{array}{l}\text { Blinding (performance } \\
\text { bias and detection bias) } \\
\text { All outcomes }\end{array}$ & Low risk & $\begin{array}{l}\text { No blinding but review authors judge that outcome is not likely to be influ- } \\
\text { enced by lack of blinding } \\
\text { Comment: this was judged as a low risk of bias }\end{array}$ \\
\hline $\begin{array}{l}\text { Incomplete outcome data } \\
\text { (attrition bias) } \\
\text { All outcomes }\end{array}$ & Low risk & $\begin{array}{l}1 / 261 \text { "lost to follow-up" } \\
\text { Comment: this was judged as a low risk of bias }\end{array}$ \\
\hline $\begin{array}{l}\text { Selective reporting (re- } \\
\text { porting bias) }\end{array}$ & Low risk & $\begin{array}{l}\text { All prespecified outcomes were reported } \\
\text { Comment: this was judged as a low risk of bias }\end{array}$ \\
\hline Other bias & Unclear risk & $\begin{array}{l}\text { Research support received from Astra Zeneca } \\
\text { Comment: this was judged as an unclear risk of bias }\end{array}$ \\
\hline
\end{tabular}

\section{Lee 2010 ISTANA}

$\begin{array}{ll}\text { Methods } & \text { Design: parallel-group } \\ & \text { Randomisation: yes, method not stated } \\ & \text { Blinding: double-blind } \\ & \text { Withdrawals: stated }\end{array}$

Setting: multicentre study, hospital outpatient department
Number eligible: 163
Number enrolled: 161


Lee 2010 ISTANA (Continued)

Number in treatment group: 82

Number in control group: 79

Number of withdrawals (treatment/control): $8 / 12$

Number completing trial (treatment/control): 82/79

Age range: treatment 21 to 74 years, control 20 to 73 years

Sex: M 100, F 61

Ethnicity: Korean

NSCLC diagnosis: histologically or cytologically confirmed NSCLC with stage IIB or IV

Inclusion criteria: patients with NSCLC who received only 1 previous platinum-doublet chemotherapy regimen, and who were considered candidates for further chemotherapy. Age 18 years or older, WHO performance status of 0 to 2, progressive or recurrent disease following previous chemotherapy (adjuvant chemotherapy was allowed if full cytotoxic doses of platinum-based doublet therapy was given in patients with early disease having progressed), measurable disease by RECIST, adequate bone marrow, renal and hepatic function

Exclusion criteria: previous docetaxel or any other EGFR-targeted treatment, any evidence of clinically active interstitial lung disease, newly diagnosed central nervous system metastases, or any unresolved chronic toxicity greater than NCI-CTCAE grade 2 from previous anti-cancer therapy

Baseline characteristics of treatment/control groups: comparable

Docetaxel $75 \mathrm{mg} / \mathrm{m}^{2}$ as a 1-hour intravenous infusion on day 1 every 3 weeks

\begin{tabular}{ll}
\hline Outcomes & Overall survival \\
& Progression-free survival (PFS) \\
Tumour response - RECIST \\
ASES - NCI-CTC \\
Quality of life - LCS of FACT-L, the Trial Outcome Index
\end{tabular}

\section{Risk of bias}

\begin{tabular}{lll}
\hline Bias & Authors' judgement & Support for judgement \\
\hline $\begin{array}{l}\text { Random sequence genera- } \\
\text { tion (selection bias) }\end{array}$ & Unclear risk & $\begin{array}{l}\text { Quote: "randomly assigned .. after stratification..." but no further information } \\
\text { provided }\end{array}$ \\
& $\begin{array}{l}\text { Comment: there was insufficient information to permit a clear judgement of } \\
\text { risk of bias }\end{array}$ \\
\hline $\begin{array}{l}\text { Allocation concealment } \\
\text { (selection bias) }\end{array}$ & Unclear risk & $\begin{array}{l}\text { No information provided } \\
\text { Comment: there was insufficient information to permit a clear judgement of } \\
\text { risk of bias }\end{array}$ \\
\hline
\end{tabular}

\begin{tabular}{|c|c|c|}
\hline $\begin{array}{l}\text { Blinding (performance } \\
\text { bias and detection bias) }\end{array}$ & Low risk & $\begin{array}{l}\text { No blinding but review authors judge that outcome is not likely to be influ- } \\
\text { enced by lack of blinding }\end{array}$ \\
\hline
\end{tabular}


Lee 2010 ISTANA (Continued)

Comment: this was judged as a low risk of bias

\section{Incomplete outcome data Low risk} (attrition bias)

All outcomes
Attrition presented in Figure 1. Missing outcome data balanced in numbers across intervention groups with similar reasons for missing data across groups.

\begin{tabular}{lll}
\hline $\begin{array}{l}\text { Selective reporting (re- } \\
\text { porting bias) }\end{array}$ & Low risk & All prespecified outcomes were reported \\
\hline Other bias & Low risk & Quote: "No potential conflicts of interest were disclosed."
\end{tabular}

Li 2010

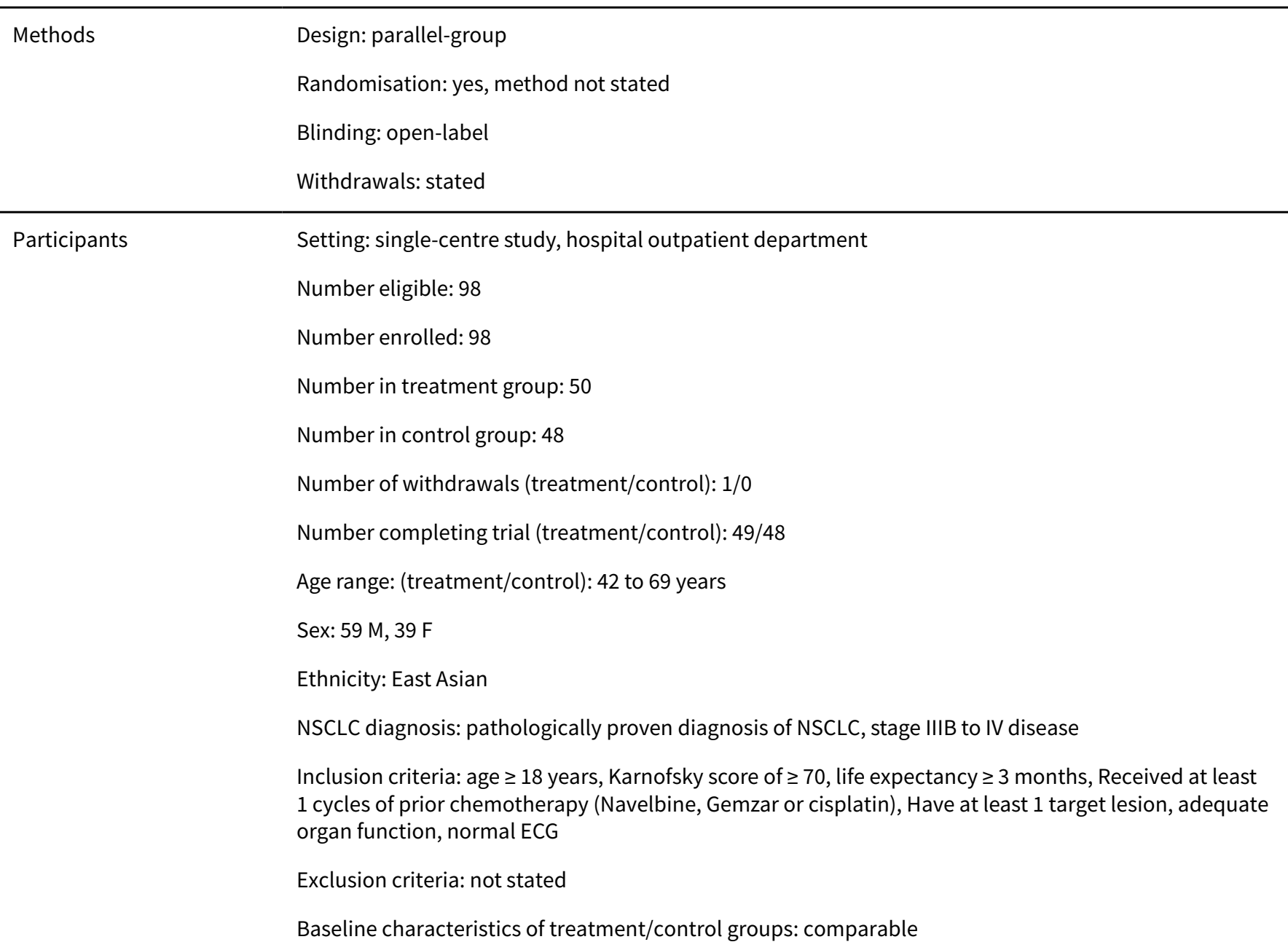

Interventions Gefitinib $250 \mathrm{mg} /$ day

Docetaxel $75 \mathrm{mg} / \mathrm{m}^{2}$ intravenously, every 3 weeks for 2 to 4 cycles or until disease progression or unacceptable toxicity

Outcomes Tumour response - RECIST


Li 2010 (Continued)

$$
\begin{aligned}
& \text { Survival } \\
& \text { Toxicity - CTCAE } \\
& \text { Quality of life - WHO criteria }
\end{aligned}
$$

\begin{tabular}{|c|c|c|}
\hline Bias & Authors' judgement & Support for judgement \\
\hline $\begin{array}{l}\text { Random sequence genera- } \\
\text { tion (selection bias) }\end{array}$ & Unclear risk & $\begin{array}{l}\text { "Randomized" but no further information provided } \\
\text { Comment: there was insufficient information to permit a clear judgement of } \\
\text { risk of bias }\end{array}$ \\
\hline $\begin{array}{l}\text { Allocation concealment } \\
\text { (selection bias) }\end{array}$ & Unclear risk & $\begin{array}{l}\text { No information provided } \\
\text { Comment: there was insufficient information to permit a clear judgement of } \\
\text { risk of bias }\end{array}$ \\
\hline $\begin{array}{l}\text { Blinding (performance } \\
\text { bias and detection bias) } \\
\text { All outcomes }\end{array}$ & Low risk & $\begin{array}{l}\text { No blinding but review authors judge that outcome is not likely to be influ- } \\
\text { enced by lack of blinding } \\
\text { Comment: this was judged as a low risk of bias }\end{array}$ \\
\hline $\begin{array}{l}\text { Incomplete outcome data } \\
\text { (attrition bias) } \\
\text { All outcomes }\end{array}$ & Low risk & $\begin{array}{l}\text { No missing data } \\
\text { Comment: this was judged as low risk of bias }\end{array}$ \\
\hline $\begin{array}{l}\text { Selective reporting (re- } \\
\text { porting bias) }\end{array}$ & Low risk & $\begin{array}{l}\text { All prespecified outcomes were reported } \\
\text { Comment: this was judged as a low risk of bias }\end{array}$ \\
\hline Other bias & Unclear risk & $\begin{array}{l}\text { No information provided } \\
\text { Comment: there was insufficient information to permit a clear judgement of } \\
\text { risk of bias }\end{array}$ \\
\hline
\end{tabular}

Notes -

\section{Risk of bias}

Lou 2014

\begin{tabular}{ll} 
Methods & Design: parallel-group \\
& Randomisation: yes, method not stated \\
& Blinding: open-label \\
& Withdrawals: stated \\
\hline Participants & Setting: single-centre study, hospital outpatient department \\
& Number eligible: 51 \\
& Number enrolled: 51 \\
& Number in treatment group: 25 \\
& Number in control group: 26
\end{tabular}


Lou 2014 (Continued)

Number of withdrawals (treatment/control): 0/0

Number completing trial (treatment/control): 25/26

Age range: (treatment/control): 34 to 73 years/36 to 76 years

Sex: $9 \mathrm{M}, 42 \mathrm{~F}$

Ethnicity: East Asian

NSCLC diagnosis: histologic or pathologically proven diagnosis of NSCLC, stage IIIB to IV disease

Inclusion criteria: age $\geq 18$ years, non-smoker (<100 cigarettes consumed in lifetime) or former light smoker (< 10 pack-year history), received no prior chemotherapy of biological/immunological anti-cancer therapy

Exclusion criteria: not stated

Baseline characteristics of treatment/control groups: comparable

Interventions Gefitinib $250 \mathrm{mg} /$ day

Paclitaxel $200 \mathrm{mg} / \mathrm{m}^{2}$ with carboplatin AUC5 intravenously for 6 cycles or until disease progression

\begin{tabular}{ll}
\hline Outcomes & Progression-free survival \\
& Overall survival \\
& Tumour response - RECIST
\end{tabular}

Notes -

\section{Risk of bias}

\begin{tabular}{|c|c|c|}
\hline Bias & Authors' judgement & Support for judgement \\
\hline $\begin{array}{l}\text { Random sequence genera- } \\
\text { tion (selection bias) }\end{array}$ & Unclear risk & $\begin{array}{l}\text { "Randomized" but no further information provided } \\
\text { Comment: there was insufficient information to permit a clear judgement of } \\
\text { risk of bias }\end{array}$ \\
\hline $\begin{array}{l}\text { Allocation concealment } \\
\text { (selection bias) }\end{array}$ & Unclear risk & $\begin{array}{l}\text { No information provided } \\
\text { Comment: there was insufficient information to permit a clear judgement of } \\
\text { risk of bias }\end{array}$ \\
\hline $\begin{array}{l}\text { Blinding (performance } \\
\text { bias and detection bias) } \\
\text { All outcomes }\end{array}$ & Low risk & $\begin{array}{l}\text { No blinding but review authors judge that outcome is not likely to be influ- } \\
\text { enced by lack of blinding } \\
\text { Comment: this was judged as a low risk of bias }\end{array}$ \\
\hline $\begin{array}{l}\text { Incomplete outcome data } \\
\text { (attrition bias) } \\
\text { All outcomes }\end{array}$ & Low risk & $\begin{array}{l}\text { No missing data } \\
\text { Comment: this was judged as a low risk of bias }\end{array}$ \\
\hline $\begin{array}{l}\text { Selective reporting (re- } \\
\text { porting bias) }\end{array}$ & Low risk & $\begin{array}{l}\text { All prespecified outcomes were reported } \\
\text { Comment: this was judged as a low risk of bias }\end{array}$ \\
\hline Other bias & Unclear risk & No information provided \\
\hline
\end{tabular}


Lou 2014 (Continued)

Comment: there was insufficient information to permit a clear judgement of risk of bias

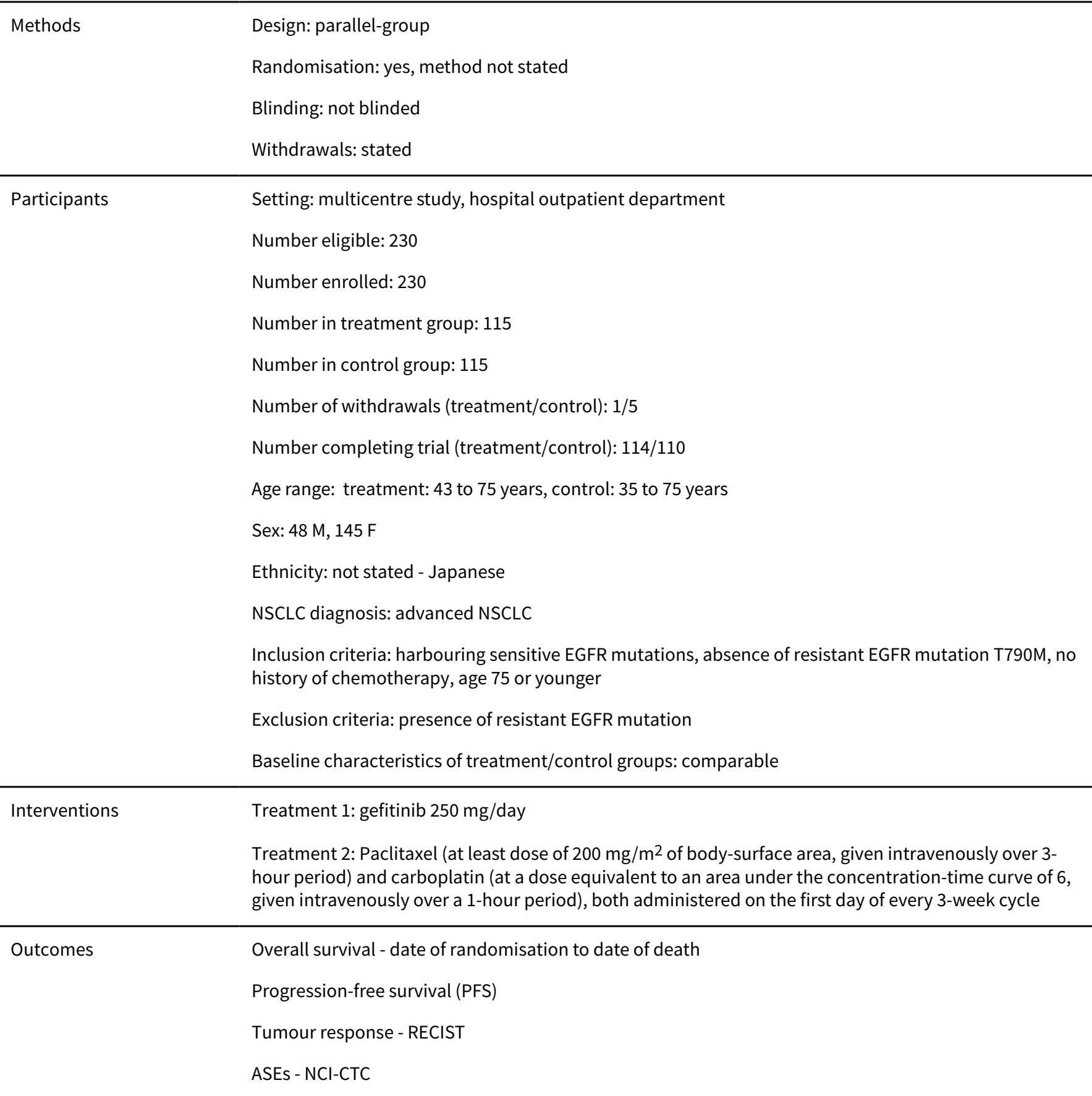

\section{Risk of bias}


Maemondo 2010 NEJ002 (Continued)

$\begin{array}{ll}\begin{array}{l}\text { Random sequence genera- } \\ \text { tion (selection bias) }\end{array} & \text { Unclear risk } \\ & \begin{array}{l}\text { Comment: there was insufficient information to permit a clear judgement of } \\ \text { risk of bias }\end{array}\end{array}$

\begin{tabular}{ll}
\hline $\begin{array}{l}\text { Allocation concealment } \\
\text { (selection bias) }\end{array}$ & Unclear risk \\
& $\begin{array}{l}\text { No information provided } \\
\text { Comment: there was insufficient information to permit a clear judgement of } \\
\text { risk of bias }\end{array}$ \\
\hline
\end{tabular}

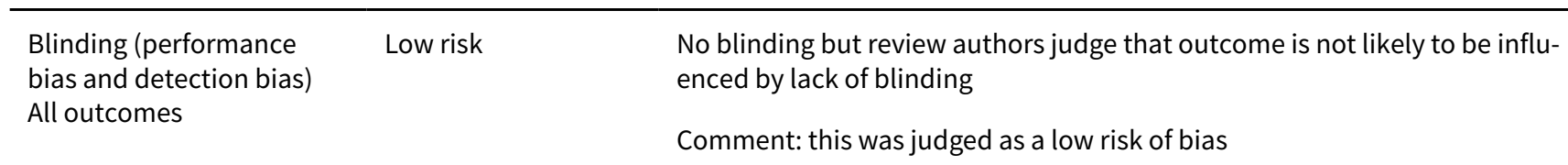

\begin{tabular}{|c|c|c|}
\hline $\begin{array}{l}\text { Incomplete outcome data } \\
\text { (attrition bias) } \\
\text { All outcomes }\end{array}$ & Low risk & $\begin{array}{l}\text { Exclusions presented in Figure } 1 \text {, attrition stated in text. Reasons for missing } \\
\text { data unlikely to be related to true outcome. } 224 / 230 \text { patients included in PFS } \\
\text { population, } 227 / 230 \text { patients included in safety population. } \\
\text { Intention-to-treat analysis performed } \\
\text { Comment: this was judged as a low risk of bias }\end{array}$ \\
\hline $\begin{array}{l}\text { Selective reporting (re- } \\
\text { porting bias) }\end{array}$ & Low risk & $\begin{array}{l}\text { All prespecified outcomes were reported } \\
\text { Comment: this was judged as a low risk of bias }\end{array}$ \\
\hline Other bias & Low risk & $\begin{array}{l}\text { Quote: "In the planned interim analysis of data, PFS was significantly longer } \\
\text { in the gefitinib group than in standard-chemotherapy group resulting in early } \\
\text { termination of the study" } \\
\text { Funded by Japan Society for Promotion and Science and Japanese Founda- } \\
\text { tion for Multidisciplinary Treatment of Cancer and Tokyo Cooperative Oncolo- } \\
\text { gy Group } \\
\text { Comment: this was judged as an unclear risk of bias }\end{array}$ \\
\hline
\end{tabular}

\section{Maruyama 2008 V-15-32}

$\begin{array}{ll}\text { Methods } & \text { Design: parallel-group } \\ & \text { Randomisation: yes, method stated } \\ & \text { Blinding: open-label } \\ & \text { Withdrawals: stated }\end{array}$

\footnotetext{
Participants

Setting: multicentre study, hospital outpatient department

Number eligible: 511

Number enrolled: 489

Number in treatment group: 245

Number in control group: 244

Number of withdrawals (treatment/control): 233/241

Number completing trial (treatment/control): 12/3
} 
Maruyama 2008 V-15-32 (Continued)

Age range: $<64$ years $=275,>65$ years $=216$

Sex: M 302, F 187

Ethnicity: Japanese

NSCLC diagnosis: histologically or cytologically confirmed NSCLC (stage IIIB/IV)

Inclusion criteria: age 20 years or older, pretreated locally advanced/metastatic (stage IIIB/IV) NSCLC, or recurrent NSCLC, NSCLC not amenable to curative surgery or radiotherapy or postoperative recurrent NSCLC, failure of prior treatment with 1 or 2 chemotherapy regimens ( $>1$ platinum based regimen), life expectancy of 3 months or greater, WHO PS score 0 to 2, measurable disease by RECIST, WBC count of 4.0 to $12.0 \times 10^{9}$ cells/L, neutrophil count $<2.0 \times 10^{9}$ cells/L, platelet count $>100 \times 10^{9}$ cells/L, serum bilirubin $<1.5 \times 10^{9}$ cells/L, ALT or AST $<2.5 \times$ upper limit of reference range, serum creatinine < $1.5 \mathrm{mg} / \mathrm{dL}$, arterial oxygen tension $>70$ torr.

Exclusion criteria: received last chemotherapy within 4 weeks before enrolment, received prior treatment with a docetaxel-containing regimen or any anti-EGFR therapy, an allergy or suspected allergy to gefitinib or docetaxel, other coexisting malignancies diagnosed within the last 5 years, with exceptions, any unresolved chronic toxicity greater than $\mathrm{NCl}$-CTC grade 2 from previous anticancer therapy, any evidence of severe or uncontrolled systemic disease, as judged by investigator, current status of pregnancy or breastfeeding, treatment with a non-approved or investigational drug within 30 drugs before enrolment, intracerebral metastases, significant malabsorption syndrome, past history of or concurrent interstitial lung disease, idiopathic pulmonary fibrosis or pneumoconiosis, or radiation pneumonia or drug-induced pneumonia, that required corticosteroids, fever with suspected infection or treatment with systemic corticosteroids for $>4$ weeks

Baseline characteristics of treatment/control groups: comparable

Interventions Gefitinib $250 \mathrm{mg} /$ day

Docetaxel every 3 weeks as a 1-hour intravenous infusion of $60 \mathrm{mg} / \mathrm{m}^{2}$

\begin{tabular}{|c|c|c|}
\hline \multirow[t]{4}{*}{ Outcomes } & \multicolumn{2}{|l|}{ Overall survival } \\
\hline & \multicolumn{2}{|c|}{ Progression-free survival (PFS) } \\
\hline & \multicolumn{2}{|c|}{ Tumour response - RECIST } \\
\hline & \multicolumn{2}{|l|}{ ASES - NCI-CTC } \\
\hline Notes & \multicolumn{2}{|l|}{-} \\
\hline \multicolumn{3}{|l|}{ Risk of bias } \\
\hline Bias & Authors' judgement & Support for judgement \\
\hline \multirow{2}{*}{$\begin{array}{l}\text { Random sequence genera- } \\
\text { tion (selection bias) }\end{array}$} & Low risk & Quote: "randomly assigned by using stratification..." \\
\hline & & Comment: this was judged as a low risk of bias \\
\hline \multirow{2}{*}{$\begin{array}{l}\text { Allocation concealment } \\
\text { (selection bias) }\end{array}$} & Unclear risk & No information provided \\
\hline & & $\begin{array}{l}\text { Comment: there was insufficient information to permit a clear judgement of } \\
\text { risk of bias }\end{array}$ \\
\hline \multirow{2}{*}{$\begin{array}{l}\text { Blinding (performance } \\
\text { bias and detection bias) } \\
\text { All outcomes }\end{array}$} & Low risk & $\begin{array}{l}\text { No blinding but review authors judge that outcome is not likely to be influ- } \\
\text { enced by lack of blinding }\end{array}$ \\
\hline & & Comment: this was judged as a low risk of bias \\
\hline
\end{tabular}


Maruyama 2008 V-15-32 (Continued)

Incomplete outcome data Low risk (attrition bias)

Attrition and exclusions presented in Figure 1. Missing outcome data balanced All outcomes in numbers across intervention groups with similar reasons for missing data across groups. 483/489 patients analysed for safety, 387/489 (79\%) analysed for response (balanced between treatment arms)

Intention-to-treat analysis performed

Comment: this was judged as a low risk of bias

\begin{tabular}{lll}
\hline $\begin{array}{l}\text { Selective reporting (re- } \\
\text { porting bias) }\end{array}$ & Low risk & $\begin{array}{l}\text { All prespecified outcomes were reported } \\
\text { Comment: this was judged as a low risk of bias }\end{array}$ \\
\hline Other bias & Low risk & Co-authors have received honoraria from industry \\
& Comment: this was judged as a low risk of bias
\end{tabular}

Mitsudomi 2010 WJTOG3405

$\begin{array}{ll}\text { Methods } & \text { Design: parallel-group } \\ & \text { Randomisation: yes, method stated } \\ & \text { Blinding: open-label } \\ & \text { Withdrawals: stated }\end{array}$

Participants

Setting: multicentre study, hospital outpatient department

Number eligible: 177

Number enrolled: 177

Number in treatment group: 88

Number in control group: 89

Number of withdrawals (treatment/control): 50/30

Number completing trial (treatment/control): 30/59

Age range: treatment: 34 to 73 years, control: 41 to 75 years

Sex: M 53, F 119

Ethnicity: Japanese

NSCLC diagnosis: histologically or cytologically confirmed NSCLC (stage IIIB/IV) harbouring an activating mutation of EGFR gene (either exon 19 deletion or L858R in exon 21)

Inclusion criteria: aged 75 or younger, WHO performance status 0 to 1 , had measurable or non-measurable disease according to RECIST, adequate organ function. Patients with postoperative recurrence, treated with adjuvant therapy other than cisplatin plus docetaxel, were included when interval between end of adjuvant chemotherapy and registration exceeded 6 months for platinum-doublet therapy and more than 1 month for oral tegafur plus uracil therapy.

Exclusion criteria: received previous drug therapy that had targeted the EGFR, a history of interstitial lung disease, severe drug allergy, active infection or other serious disease condition, symptomatic brain metastases, poorly controlled pleural effusion, pericardial effusion or ascites necessitating drainage, active double cancer, or severe hypersensitivity to drugs containing poly solvate 80 , pregnancy or lactation. 
Mitsudomi 2010 WJTOG3405 (Continued)

Baseline characteristics of treatment/control groups: comparable

Interventions
Gefitinib $250 \mathrm{mg} / \mathrm{day}$
$\begin{aligned} & \text { Docetaxel } 60 \mathrm{mg} / \mathrm{m}^{2} \text {, administered intravenously over a 1-hour period, followed by cisplatin } 80 \mathrm{mg} / \mathrm{m}^{2}, \\ & \text { administered intravenously over a 90-min period with adequate hydration, in cycles of once every } 21 \\ & \text { days for } 3 \text { to } 6 \text { cycles }\end{aligned}$

\begin{tabular}{ll}
\hline Outcomes & Progression-free survival (PFS) \\
& Overall survival \\
& Tumour response - RECIST \\
& Disease control rate \\
& ASEs - NCI-CTC
\end{tabular}

Mutation-type-specific survival

\begin{tabular}{ll} 
Notes $\quad-$ \\
\hline
\end{tabular}

\section{Risk of bias}

\begin{tabular}{lll}
\hline Bias & Authors' judgement & Support for judgement \\
\hline $\begin{array}{l}\text { Random sequence genera- } \\
\text { tion (selection bias) }\end{array}$ & Low risk & $\begin{array}{l}\text { Quote: "randomly assigned in 1:1 ratio" } \\
\text { Comment: this was judged as a low risk of bias }\end{array}$ \\
\hline $\begin{array}{l}\text { Allocation concealment } \\
\text { (selection bias) }\end{array}$ & Low risk & $\begin{array}{l}\text { Quote: "Patients were allocated at the WJOG data centre to each treatment } \\
\text { group using a desktop computer programmed for the minimisation method." }\end{array}$ \\
& Comment: this was judged as a low risk of bias \\
\hline
\end{tabular}

$\begin{array}{ll}\text { Blinding (performance } & \text { Low risk } \\ \text { bias and detection bias) } & \text { No blinding but review authors judge that outcome is not likely to be influ- } \\ \text { All outcomes } & \text { enced by lack of blinding }\end{array}$

All outcomes

Comment: this was judged as a low risk of bias

\begin{tabular}{lll}
$\begin{array}{l}\text { Incomplete outcome data } \\
\text { (attrition bias) } \\
\text { All outcomes }\end{array}$ & Low risk & $\begin{array}{l}\text { Exclusions and attrition presented in Figure 1. Reasons for missing data unlike- } \\
\text { ly to be related to true outcome. } 5 / 177 \text { withdrawn. } \\
\text { Comment: this was judged as a low risk of bias }\end{array}$ \\
\hline $\begin{array}{l}\text { Selective reporting (re- } \\
\text { porting bias) }\end{array}$ & Low risk & All prespecified outcomes were reported, except for overall survival. \\
& Quote: "data for overall survival were immature, with follow-up still ongoing" \\
& Comment: this was judged as a low risk of bias
\end{tabular}

\begin{tabular}{ll}
\hline Other bias & Trial designed and conducted independently of any pharmaceutical company \\
& Author conflicts of interest declared \\
& $\begin{array}{l}\text { Trial closed early as results of contemporary studies showing improved PFS in } \\
\text { EGFR mutation positive NSCLC. Further trial accrual was felt to be futile and } \\
\text { unethical. } \\
\text { Comment: this was judged as low risk of bias }\end{array}$ \\
\hline
\end{tabular}




$\begin{array}{ll}\text { Methods } & \text { Design: parallel-group } \\ & \text { Randomisation: yes, method stated } \\ & \text { Blinding: not blinded } \\ & \text { Withdrawals: stated }\end{array}$

Participants

Setting: multicentre study, hospital outpatient department

Number eligible: 1329

Number enrolled: 1217

Number in treatment group: 609

Number in control group: 608

Number of withdrawals (treatment/control): 12/28

Number completing trial (treatment/control): 597/580

Age range: treatment: 24 to 84 years, control: 25 to 84 years

Sex: M 252, F 965

Ethnicity: Chinese 618, Japanese 233, other East Asian 363, other 3

NSCLC diagnosis: histologically or cytologically confirmed stage IIIB or IV NSCLC with histological features of adenocarcinoma

Inclusion criteria: 18 years or older, non-smoker or former light smokers (those who had stopped smoking at least 15 years previously and had a total of ?10 pack-years of smoking), no previous chemotherapy or biologic or immunologic therapy, WHO PS 0 to 2, measurable disease according to RECIST criteria with at least 1 measurable lesion, not previously irradiated, adjuvant chemotherapy permitted if not platinum-based and completed $>6$ months previously, absolute neutrophil count $>2.0 \times 10^{9}$ and adequate hepatic function

Exclusion criteria: not stated

Baseline characteristics of treatment/control groups: comparable

Interventions Treatment: gefitinib $250 \mathrm{mg} /$ day

Control: Paclitaxel ( $200 \mathrm{mg} / \mathrm{m}^{2}$ of body-surface area, administered intravenously over a 3-hour period on the first day of the cycle) followed immediately by carboplatin (at a dose calculated to produce an area under the curve of 5.0 to 6.0 per $\mathrm{mL}$ per min, administered intravenously over a period of 15 to 60 $\min )$

\begin{tabular}{ll}
\hline Outcomes & Overall survival \\
& Progression-free survival (PFS) \\
& Tumour response - RECIST \\
& ASEs - NCI-CTC \\
& Quality of life - FACT-L, TOI, LCS score of FACT-L
\end{tabular}

Notes $-$ 
Mok 2009 IPASS (Continued)

Risk of bias

\begin{tabular}{|c|c|c|}
\hline Bias & Authors' judgement & Support for judgement \\
\hline $\begin{array}{l}\text { Random sequence genera- } \\
\text { tion (selection bias) }\end{array}$ & Low risk & $\begin{array}{l}\text { Quote: "randomisation was performed with the use of dynamic balancing..." } \\
\text { Comment: this was judged as a low risk of bias }\end{array}$ \\
\hline $\begin{array}{l}\text { Allocation concealment } \\
\text { (selection bias) }\end{array}$ & Unclear risk & $\begin{array}{l}\text { No information provided } \\
\text { Comment: there was insufficient information to permit a clear judgement of } \\
\text { risk of bias }\end{array}$ \\
\hline $\begin{array}{l}\text { Blinding (performance } \\
\text { bias and detection bias) } \\
\text { All outcomes }\end{array}$ & Low risk & $\begin{array}{l}\text { No blinding but review authors judge that outcome is not likely to be influ- } \\
\text { enced by lack of blinding } \\
\text { Comment: this was judged as a low risk of bias }\end{array}$ \\
\hline $\begin{array}{l}\text { Incomplete outcome data } \\
\text { (attrition bias) } \\
\text { All outcomes }\end{array}$ & Low risk & $\begin{array}{l}\text { Exclusions and attrition presented in Figure } 1 \text {. Missing outcome data balanced } \\
\text { in numbers across intervention groups with similar reasons for missing data } \\
\text { across groups. } 1159 / 1217(95 \%) \text { included in analysis } \\
\text { Intention-to-treat analysis performed } \\
\text { Comment: this was judged as a low risk of bias }\end{array}$ \\
\hline $\begin{array}{l}\text { Selective reporting (re- } \\
\text { porting bias) }\end{array}$ & Low risk & $\begin{array}{l}\text { All prespecified outcomes were reported } \\
\text { Comment: this was judged as a low risk of bias }\end{array}$ \\
\hline Other bias & Unclear risk & $\begin{array}{l}\text { Funding from the Chinese Lung Cancer Research Foundation. Co-authors re- } \\
\text { ceived consulting fees and grant support from industry. } \\
\text { Comment: this was judged as an unclear risk of bias }\end{array}$ \\
\hline
\end{tabular}

Morere 2010 IFCT-0301

$\begin{array}{ll}\text { Methods } & \text { Design: parallel-group } \\ \text { Randomisation: yes, method stated } \\ \text { Blinding: double-blind } \\ \text { Withdrawals: stated }\end{array}$

\title{
Participants
}

\author{
Setting: multicentre study, hospital outpatient department \\ Number eligible: 128 \\ Number enrolled: 85 \\ Number in treatment group: 43 \\ Number in control group: 42 \\ Number of withdrawals (treatment/control): 43/41 \\ Number completing trial (treatment/control): 0/0 \\ Age range: treatment 45 to 79 years, control 30 to 79 years
}


Morere 2010 IFCT-0301 (Continued)

\section{Sex: M 71, F 14}

Ethnicity: not stated

NSCLC diagnosis: stage IIIb/IV NSCLC

Inclusion criteria: age 18 to 80 , NSCLC with measurable disease, ECOG PS 2 or 3 , adequate organ function

Exclusion criteria: prior chemotherapy, prior EGFR therapy or prior thoracic radiotherapy

Baseline characteristics of treatment/control groups: comparable

\begin{tabular}{ll}
\hline Interventions & Gefitinib $250 \mathrm{mg}$ daily \\
& Docetaxel $75 \mathrm{mg} / \mathrm{m}^{2}$ day 1 every 3 weeks \\
\hline Outcomes & Overall survival \\
& Time to progression \\
& Tumour response - RECIST \\
& ASEs - NCI-CTC \\
\hline Notes & -
\end{tabular}

\section{Risk of bias}

\begin{tabular}{|c|c|c|}
\hline Bias & Authors' judgement & Support for judgement \\
\hline $\begin{array}{l}\text { Random sequence genera- } \\
\text { tion (selection bias) }\end{array}$ & Low risk & $\begin{array}{l}\text { Quote: "random assignment was block stratified..." } \\
\text { Comment: this was judged as a low risk of bias }\end{array}$ \\
\hline $\begin{array}{l}\text { Allocation concealment } \\
\text { (selection bias) }\end{array}$ & Unclear risk & $\begin{array}{l}\text { No information provided } \\
\text { Comment: there was insufficient information to permit a clear judgement of } \\
\text { risk of bias }\end{array}$ \\
\hline $\begin{array}{l}\text { Blinding (performance } \\
\text { bias and detection bias) } \\
\text { All outcomes }\end{array}$ & Low risk & $\begin{array}{l}\text { No blinding but review authors judge that outcome is not likely to be influ- } \\
\text { enced by lack of blinding } \\
\text { Comment: this was judged as a low risk of bias }\end{array}$ \\
\hline $\begin{array}{l}\text { Incomplete outcome data } \\
\text { (attrition bias) } \\
\text { All outcomes }\end{array}$ & Low risk & $\begin{array}{l}\text { Exclusions and attrition presented in Figure } 1 . \text { Missing outcome data balanced } \\
\text { in numbers across intervention groups with similar reasons for missing data } \\
\text { across groups. } \\
\text { Comment: this was judged as a low risk of bias }\end{array}$ \\
\hline $\begin{array}{l}\text { Selective reporting (re- } \\
\text { porting bias) }\end{array}$ & Low risk & $\begin{array}{l}\text { All prespecified outcomes were reported } \\
\text { Comment: this was judged as a low risk of bias }\end{array}$ \\
\hline Other bias & Low risk & $\begin{array}{l}\text { Co-authors have received honoraria from industry } \\
\text { Comment: this was judged as a low risk of bias }\end{array}$ \\
\hline
\end{tabular}


Soria 2015 IMPRESS

\begin{tabular}{ll}
\hline Methods & Design: parallel-group \\
& Randomisation: yes, method stated \\
& Blinding: placebo-controlled \\
& Withdrawals: stated
\end{tabular}

Participants

Setting: multicentre study, hospital outpatient department

Number eligible: 287

Number enrolled: 265

Number in treatment group: 133

Number in control group: 132

Number of withdrawals (treatment/control): 1/0

Number completing trial (treatment/control): 23/18

Age range: (treatment/control) 33 to 79 years/35 to 79 years

Sex: $94 \mathrm{M}, 171 \mathrm{~F}$

Ethnicity: East Asian 78\%; Spanish/French/German/Italian/Russia 22\%

NSCLC diagnosis: histologic/cytologic diagnosis of NSCLC, stage IIIB to IV disease, chemotherapy-naive

Inclusion criteria: age $\geq 18$ years; chemotherapy-naive advanced NSCLC and an activating EGFR mutation as confirmed by local testing, who had achieved a complete or partial response for longer than 4 months, or durable stable disease for at least 6 months on first-line gefitinib and had subsequently developed radiological disease progression. Life expectancy of $>12$ months, and a WHO PS of 0 or 1.

Exclusion criteria: NSCLC of predominately squamous cell histology, a history of interstitial lung disease, any other coexisting malignancies diagnosed within the past 5 years (excluding basal cell carcinoma, cervical cancer in situ, or completely resected intramucosal gastric cancer) or treatment with another investigational drug 4 weeks of less before random allocation

Baseline characteristics of treatment/control groups: comparable

Interventions

Gefitinib $250 \mathrm{mg}$ daily PLUS cisplatin $75 \mathrm{mg} / \mathrm{m}^{2}$ and pemetrexed $500 \mathrm{mg} / \mathrm{m}^{2}$ on day 1 of cycle

Placebo PLUS cisplatin $75 \mathrm{mg} / \mathrm{m}^{2}$ and pemetrexed $500 \mathrm{mg} / \mathrm{m}^{2}$ on day 1 of cycle

\begin{tabular}{ll}
\hline Outcomes & Progression-free survival \\
& Tumour response - RECIST \\
& Overall survival \\
& ASEs - NCI-CTC \\
& Health-related quality of life - FACT-L, LCS, TOI \\
\hline Notes & - \\
\hline Risk of bias & Authors' judgement Support for judgement \\
\hline Bias &
\end{tabular}


Soria 2015 IMPRESS (Continued)
Random sequence genera- Low risk
Use of "central block randomisation to allocate patients (1:1)..." tion (selection bias)
Comment: this was judged as a low risk of bias

\begin{tabular}{lll}
\hline $\begin{array}{l}\text { Allocation concealment } \\
\text { (selection bias) }\end{array}$ & Low risk & $\begin{array}{l}\text { Patients were assigned a unique enrolment num } \\
\text { response system } \\
\text { Comment: this was judged as a low risk of bias }\end{array}$ \\
\hline $\begin{array}{l}\text { Blinding (performance } \\
\text { bias and detection bias) } \\
\text { All outcomes }\end{array}$ & Low risk & Placebo-controlled with identical packaging \\
\hline
\end{tabular}

\begin{tabular}{|c|c|c|}
\hline $\begin{array}{l}\text { Incomplete outcome data } \\
\text { (attrition bias) } \\
\text { All outcomes }\end{array}$ & Low risk & $\begin{array}{l}\text { Withdrawals stated in Figure } 1 \\
\text { Missing outcome data balanced in numbers across intervention groups with } \\
\text { similar reasons for missing data across groups } \\
\text { Comment: this was judged as a low risk of bias }\end{array}$ \\
\hline $\begin{array}{l}\text { Selective reporting (re- } \\
\text { porting bias) }\end{array}$ & Low risk & $\begin{array}{l}\text { All prespecified outcomes were reported } \\
\text { Comment: this was judged as a low risk of bias }\end{array}$ \\
\hline Other bias & Unclear risk & $\begin{array}{l}\text { Authors have received honoraria, consultant and advisor fees from industry } \\
\text { Study funded by Astra Zeneca, who co-ordinated the trial, managed the data- } \\
\text { base and undertook analyses } \\
\text { Comment: this was judged as an unclear risk of bias }\end{array}$ \\
\hline
\end{tabular}

Sun 2012 KCSG-LU08-01

\begin{tabular}{ll}
\hline Methods & Design: parallel-group \\
& Randomisation: yes, method not stated \\
& Blinding: open-label \\
Withdrawals: stated
\end{tabular}

\title{
Participants
}

\author{
Setting: multicentre study, hospital outpatient department \\ Number eligible: 147 \\ Number enrolled: 141 \\ Number in treatment group: 71 \\ Number in control group: 70 \\ Number of withdrawals (treatment/control): $3 / 3$ \\ Number completing trial (treatment/control): 68/67 \\ Age range: (treatment/control): 40 to 77 years/30 to 78 years \\ Sex: $20 \mathrm{M}, 115 \mathrm{~F}$ \\ Ethnicity: Asian
}


Sun 2012 KCSG-LU08-01 (Continued)

NSCLC diagnosis: histologically or cytologically confirmed pulmonary adenocarcinoma

Inclusion criteria: histologically or cytologically confirmed pulmonary adenocarcinoma that progressed after just 1 previous platinum-based chemotherapy regimen for advanced disease, never-smoker, 18 years or older, ECOG PS 0 to 2, measurable or evaluable disease, adequate bone marrow, renal and hepatic function

Exclusion criteria: prior EGFR TKI or pemetrexed treatment and symptomatic or uncontrolled brain metastases

Baseline characteristics of treatment/control groups: comparable

Gefitinib $250 \mathrm{mg} /$ day
Pemetrexed $500 \mathrm{mg} / \mathrm{m}^{2}$ on day 1 of a 21 -day cycle
Cycles repeated until disease progression, unacceptable toxicity, or until patient or investigator re-
quested therapy discontinuation

\begin{tabular}{ll}
\hline Outcomes & Tumour response - RECIST \\
Overall survival & Progression-free survival \\
ASEs - NCI-CTC \\
Haematology and biochemical parameters \\
Quality of life - EORTC Quality of Life Questionnaire C30 (EORTC QLQ-C30)
\end{tabular}

Notes -

\section{Risk of bias}

\begin{tabular}{|c|c|c|}
\hline Bias & Authors' judgement & Support for judgement \\
\hline $\begin{array}{l}\text { Random sequence genera- } \\
\text { tion (selection bias) }\end{array}$ & Low risk & $\begin{array}{l}\text { Quote: "consecutively assigned to either arm according to a predefined com- } \\
\text { puter-generated randomisation scheme developed by statisticians" } \\
\text { Comment: this was judged as a low risk of bias }\end{array}$ \\
\hline $\begin{array}{l}\text { Allocation concealment } \\
\text { (selection bias) }\end{array}$ & Low risk & $\begin{array}{l}\text { Quote: "consecutively assigned to either arm according to a predefined com- } \\
\text { puter-generated randomisation scheme developed by statisticians" } \\
\text { Comment: this was judged as a low risk of bias }\end{array}$ \\
\hline $\begin{array}{l}\text { Blinding (performance } \\
\text { bias and detection bias) } \\
\text { All outcomes }\end{array}$ & Low risk & $\begin{array}{l}\text { No blinding but review authors judge that outcome is not likely to be influ- } \\
\text { enced by lack of blinding } \\
\text { Comment: this was judged as a low risk of bias }\end{array}$ \\
\hline $\begin{array}{l}\text { Incomplete outcome data } \\
\text { (attrition bias) } \\
\text { All outcomes }\end{array}$ & Low risk & $\begin{array}{l}\text { Exclusions and attrition presented in Figure } 1 . \text { Missing outcome data balanced } \\
\text { in numbers across intervention groups with similar reasons for missing data } \\
\text { across groups. } 135 / 141 \text { patients analysed for efficacy. } \\
\text { Comment: this was judged as a low risk of bias }\end{array}$ \\
\hline $\begin{array}{l}\text { Selective reporting (re- } \\
\text { porting bias) }\end{array}$ & Low risk & $\begin{array}{l}\text { All prespecified outcomes were reported } \\
\text { Comment: this was judged as a low risk of bias }\end{array}$ \\
\hline
\end{tabular}


Sun 2012 KCSG-LU08-01 (Continued)

$\begin{array}{ll}\text { Other bias } & \begin{array}{l}\text { No specific funding was disclosed and authors made no disclosure of conflicts } \\ \text { of interest }\end{array} \\ \text { Comment: this was judged as an unclear risk of bias }\end{array}$

\section{Takeda 2010 WJTOG0203}

$\begin{array}{ll}\text { Methods } & \text { Design: parallel-group } \\ & \text { Randomisation: yes, method stated } \\ & \text { Blinding: double-blind } \\ & \text { Withdrawals: stated }\end{array}$

Participants

Setting: multicentre study, hospital outpatient department

Number eligible: 604

Number enrolled: 603

Number in treatment group: 302

Number in control group: 301

Number of withdrawals (treatment/control): $4 / 4$

Number completing trial (treatment/control): 298/297

Age range: treatment 25 to 74 years; control 35 to 74 years

Sex: M 383, F 215

Ethnicity: Japanese

NSCLC diagnosis: histologically or cytologically confirmed stage IIIB (with malignant pleural effusion or contralateral hilar lymph node metastases) or stage IV NSCLC

Inclusion criteria: NSCLC who had not previously received any chemotherapy, patients who had recurrence after complete surgical resection were permitted, ECOG performance status 0 to 1 , adequate organ function as indicated as WBC count $>4000 / \mu \mathrm{L}$, absolute neutrophil count $>2000 / \mu \mathrm{L}$, haemoglobin $>9.5 \mathrm{~g} / \mathrm{dL}, \mathrm{AST} / \mathrm{ALT}<2.5$ times the upper limit of normal, total bilirubin $<1.5 \mathrm{mg} / \mathrm{dL}$, serum creatinine $<$ $1.2 \mathrm{mg} / \mathrm{dL}, \mathrm{PaO}_{2}$ in arterial blood $>70 \mathrm{mmHg}$. Asymptomatic brain metastases were allowed provided they had been irradiated and were clinically and radiologically stable.

Exclusion criteria: patients treated with either adjuvant or neoadjuvant chemotherapy. Radiologically or clinically apparent interstitial pneumonitis or pulmonary fibrosis.

Baseline characteristics of treatment/control groups: comparable

Interventions Arm A: platinum doublet chemotherapy - up to 6 cycles

Arm B: 3 cycles of chemotherapy followed by gefitinib $250 \mathrm{~g}$ /day orally until disease progression

\begin{tabular}{ll}
\hline Outcomes & Overall survival \\
& Progression-free survival (PFS) \\
& Tumour response - RECIST \\
& Quality of life - FACT-L
\end{tabular}


Takeda 2010 WJTOG0203 (Continued)

Notes

\section{Risk of bias}

Bias Authors' judgement Support for judgement

Random sequence genera- Unclear risk
tion (selection bias)

"Randomised" but no further information provided

Comment: there was insufficient information to permit a clear judgement of risk of bias

\begin{tabular}{ll}
\hline $\begin{array}{l}\text { Allocation concealment } \\
\text { (selection bias) }\end{array}$ & Unclear risk \\
& $\begin{array}{l}\text { No information provided } \\
\text { Comment: there was insufficient information to permit a clear judgement of } \\
\text { risk of bias }\end{array}$ \\
\hline
\end{tabular}

$\begin{array}{ll}\text { Blinding (performance } & \text { Low risk } \\ \text { bias and detection bias) } & \text { No blinding but review authors judge that outcome is not likely to be influ- } \\ \text { enced by lack of blinding }\end{array}$

All outcomes

Comment: this was judged as a low risk of bias

\begin{tabular}{|c|c|c|}
\hline $\begin{array}{l}\text { Incomplete outcome data } \\
\text { (attrition bias) } \\
\text { All outcomes }\end{array}$ & Low risk & $\begin{array}{l}\text { Exclusions presented in Figure } 1 \text {; withdrawals were stated in text. Missing out } \\
\text { come data balanced in numbers across intervention groups with similar rea- } \\
\text { sons for missing data across groups. } 595 / 604 \text { included in analysis. }\end{array}$ \\
\hline
\end{tabular}

All outcomes sons for missing data across groups. 595/604 included in analysis.

Comment: this was judged as a low risk of bias

\begin{tabular}{lll}
\hline $\begin{array}{l}\text { Selective reporting (re- } \\
\text { porting bias) }\end{array}$ & Low risk & $\begin{array}{l}\text { All prespecified outcomes were reported } \\
\text { Comment: this was judged as a low risk of bias }\end{array}$ \\
\hline Other bias & Low risk & Co-authors have received honoraria from industry \\
& Comment: this was judged as a low risk of bias \\
\hline
\end{tabular}

Thatcher 2005 ISEL

\begin{tabular}{ll}
\hline Methods & Design: parallel-group \\
& Randomisation: yes, method not stated \\
& Blinding: double-blind, double-dummy \\
& Withdrawals: stated \\
\hline Participants & Setting: multicentre study, hospital outpatient department \\
& Number eligible: 1836 \\
& Number enrolled: 1692 \\
& Number in treatment group: 1126 \\
& Number in control group: 562 \\
& Number of withdrawals (treatment/control): $818 / 451$ \\
& Number completing trial (treatment/control): $308 / 111$ \\
& Age range: treatment 28 to 90 years, control 31 to 87 years \\
& Sex: 1139 M, $553 \mathrm{~F}$ \\
& Ethnicity: 1274 Caucasian; 342 Asian; 14 Black; 62 other \\
& NSCLC diagnosis: histologically or cytologically proven NSCLC \\
& Inclusion criteria: NSCLC not curable with surgery or radiotherapy; previously received 1 or 2 \\
& chemotherapy regimens; refractory to (recurrent or progressive disease within 90 days of chemother-
\end{tabular}


Thatcher 2005 ISEL (Continued)

apy) or intolerant of latest chemotherapy regimen; younger than 70 years; received at least 1 previous platinum-based chemotherapy regimen; WHO PS 0 to 2; life expectancy of at least 8 weeks

Exclusion criteria: presence of small cell lung cancer alone or with NSCLC; administration of last dose of single-agent chemotherapy within the previous 21 days; untreated or clinically unstable newly diagnosed metastasis in central nervous system; less than 1 week since completion of previous radiotherapy or persistence of any radiotherapy-related toxic effects; unresolved chronic toxic effects from previous anticancer therapy; known severe hypersensitivity to gefitinib or any tablet excipients; inability to swallow tablets; other coexisting malignant disease (apart from basal cell carcinoma); absolute neutrophils count less than $1.0 \times 109 / \mathrm{L}$; platelet count less than $100 \times 109 / \mathrm{L}$; serum bilirubin concentration more than 3 times upper limit of normal; AST or AST concentration more than $5 x$ upper limit of normal; more than 2 previous chemotherapy regimens for NSCLC; previous treatment with an experimental agent of which the main mechanism of action is inhibition of epidermal growth receptor or its associated tyrosine kinase; concomitant use of phenytoin, carbamazepine, rifampicin, barbiturates, St John's wort; severe or uncontrolled systemic disease; clinically active interstitial lung disease (except uncomplicated lymphangitic carcinomatosis); pregnancy; breastfeeding

Baseline characteristics of treatment/control groups: comparable

\begin{tabular}{ll}
\hline Interventions & Gefitinib $250 \mathrm{mg} /$ day \\
& Placebo \\
\hline Outcomes & Overall survival \\
& Time to treatment failure \\
& Tumour progression - RECIST \\
& FACT-L \\
& LCS of FACT-L \\
& ASES - NCI-CTC \\
\hline Notes & - \\
\hline
\end{tabular}

\section{Risk of bias}

Bias Authors' judgement Support for judgement

\begin{tabular}{lll}
\hline $\begin{array}{l}\text { Random sequence genera- } \\
\text { tion (selection bias) }\end{array}$ & Low risk & $\begin{array}{l}\text { Quote: "randomisation done by a minimisation method" } \\
\text { Comment: this was judged as a low risk of bias }\end{array}$ \\
\hline $\begin{array}{l}\text { Allocation concealment } \\
\text { (selection bias) }\end{array}$ & Low risk & Quote: "central registration and randomisation centre" \\
\hline $\begin{array}{l}\text { Blinding (performance } \\
\text { bias and detection bias) } \\
\begin{array}{l}\text { All outcomes } \\
\text { Comment: this was judged as a low risk of bias }\end{array}\end{array}$ & Low risk & Quote: "double-blind", "physically identical tablets and packaging" \\
\hline
\end{tabular}

\begin{tabular}{|c|c|c|}
\hline $\begin{array}{l}\text { Incomplete outcome data } \\
\text { (attrition bias) } \\
\text { All outcomes }\end{array}$ & Low risk & $\begin{array}{l}\text { Quote: " } 818 / 1126 \text { in treatment group and } 451 / 562 \text { in placebo group discontin- } \\
\text { ued". Missing outcomes balanced in numbers across intervention groups with } \\
\text { similar reasons for missing data across groups. }\end{array}$ \\
\hline
\end{tabular}

Comment: this was judged as a low risk of bias

\begin{tabular}{lll}
\hline $\begin{array}{l}\text { Selective reporting (re- } \\
\text { porting bias) }\end{array}$ & Low risk & $\begin{array}{l}\text { All prespecified outcomes were reported } \\
\text { Comment: this was judged as a low risk of bias }\end{array}$ \\
\hline Other bias & Low risk & Co-authors have received honoraria from industry \\
& Comment: this was judged as a low risk of bias \\
\hline
\end{tabular}


Design: parallel-group

Randomisation: yes, method not stated

Blinding: open-label

Withdrawals: not stated

Participants

Setting: single-centre study, hospital outpatient department

Number eligible: 188

Number enrolled: 188

Number in treatment group: 94

Number in control group: 94

Number of withdrawals (treatment/control): not stated

Number completing trial (treatment/control): not stated

Age range: (treatment/control): 60 to 82 years

Sex: $98 \mathrm{M}, 90 \mathrm{~F}$

Ethnicity: East Asian

NSCLC diagnosis: histologic/cytologic diagnosis of NSCLC, stage IIIB to IV disease

Inclusion criteria: stage IIIB to IV NSCLC, inoperable due to medical reasons or rejecting surgery, or the patients accepting 4 to 8 cycles of first-line chemotherapy and achieving complete remission, partial response or stability. KPS $\geq 60$, no other disease interfering patients to complete the treatment; no brain metastases, with good compliance

Exclusion criteria: not stated

Baseline characteristics of treatment/control groups: comparable

\begin{tabular}{ll}
\hline Interventions & Pemetrexed $500 \mathrm{mg} / \mathrm{m}^{2}$ day 1 to 3 \\
& Gefitinib $250 \mathrm{mg} /$ daily \\
\hline Outcomes & Tumour response - RECIST \\
& ASEs $-\mathrm{NCl}-\mathrm{CTC}$ \\
\hline Notes & - \\
\hline
\end{tabular}

\section{Risk of bias}

\begin{tabular}{lll}
\hline Bias & Authors' judgement & Support for judgement \\
\hline $\begin{array}{l}\text { Random sequence genera- } \\
\text { tion (selection bias) }\end{array}$ & Unclear risk & $\begin{array}{l}\text { "...randomized" } \\
\text { Comment: there was insufficient information to permit a clear judgement of } \\
\text { risk of bias }\end{array}$ \\
\hline $\begin{array}{l}\text { Allocation concealment } \\
\text { (selection bias) }\end{array}$ & Unclear risk & No information provided \\
\hline
\end{tabular}


Comment: there was insufficient information to permit a clear judgement of risk of bias

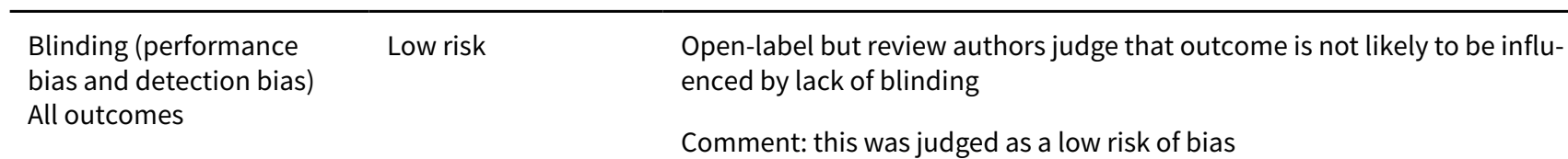

\begin{tabular}{lll}
\hline $\begin{array}{l}\text { Incomplete outcome data } \\
\text { (attrition bias) }\end{array}$ & High risk & Withdrawals not stated \\
All outcomes & Comment: this was judged as a high risk of bias \\
\hline $\begin{array}{l}\text { Selective reporting (re- } \\
\text { porting bias) }\end{array}$ & High risk & $\begin{array}{l}\text { "survival time" was a prespecified outcome but not reported in methods; rea- } \\
\text { son for this is unclear }\end{array}$ \\
& Comment: this was judged as a high risk of bias
\end{tabular}

\begin{tabular}{ll}
\hline Other bias & Low risk \\
& Comment: this was judged as a low risk of bias \\
\hline
\end{tabular}

Xue 2015

\begin{tabular}{ll}
\hline Methods & Design: parallel-group \\
& Randomisation: yes, method not stated \\
& Blinding: open-label \\
Withdrawals: stated
\end{tabular}

Participants

\author{
Setting: multicentre study, hospital outpatient department \\ Number eligible: 155 \\ Number enrolled: 100 \\ Number in treatment group: 48 \\ Number in control group: 48 \\ Number of withdrawals (treatment/control): $2 / 2$ \\ Number completing trial (treatment/control): $8 / 10$ \\ Age range: (treatment/control) 33 to 83 years/32 to 83 years \\ Sex: $43 \mathrm{M}, 53 \mathrm{~F}$ \\ Ethnicity: East Asian
}

NSCLC diagnosis: histologic/cytologic diagnosis of NSCLC, stage IIIB to IV disease

Inclusion criteria: advanced, refractory or recurrent NSCLC after at least 1 previous regimen; achievement of stable disease after 1 month of gefitinib $250 \mathrm{mg}$ daily therapy; measurable lesions by RECIST criteria; ECOG PS 0 to 2; satisfactory renal, haematological and cardiac function. Stable brain metastases were allowed.

Exclusion criteria: previous EGFR TKI therapy, pregnancy, breastfeeding, or unable to take oral medications 
Xue 2015 (Continued)

Baseline characteristics of treatment/control groups: comparable

\begin{tabular}{|c|c|c|}
\hline Interventions & \multicolumn{2}{|l|}{$\begin{array}{l}\text { Gefitinib } 500 \text { mg/day } \\
\text { Gefitinib } 250 \text { mg/day }\end{array}$} \\
\hline Outcomes & $\begin{array}{l}\text { Tumour response - R } \\
\text { Progression-free survi } \\
\text { Overall survival } \\
\text { ASEs - NCI-CTC }\end{array}$ & al \\
\hline Notes & \multicolumn{2}{|l|}{-} \\
\hline \multicolumn{3}{|l|}{ Risk of bias } \\
\hline Bias & Authors' judgement & Support for judgement \\
\hline $\begin{array}{l}\text { Random sequence genera- } \\
\text { tion (selection bias) }\end{array}$ & Unclear risk & $\begin{array}{l}\text { "...randomized " } \\
\text { Comment: there was insufficient information to permit a clear judgement of } \\
\text { risk of bias }\end{array}$ \\
\hline $\begin{array}{l}\text { Allocation concealment } \\
\text { (selection bias) }\end{array}$ & Unclear risk & $\begin{array}{l}\text { No information provided } \\
\text { Comment: there was insufficient information to permit a clear judgement of } \\
\text { risk of bias }\end{array}$ \\
\hline $\begin{array}{l}\text { Blinding (performance } \\
\text { bias and detection bias) } \\
\text { All outcomes }\end{array}$ & Low risk & $\begin{array}{l}\text { Open-label but review authors judge that outcome is not likely to be influ- } \\
\text { enced by lack of blinding } \\
\text { Comment: this was judged as a low risk of bias }\end{array}$ \\
\hline $\begin{array}{l}\text { Incomplete outcome data } \\
\text { (attrition bias) } \\
\text { All outcomes }\end{array}$ & Low risk & $\begin{array}{l}\text { Withdrawals stated with reasons such as "consent not given" provided } \\
\text { Comment: this was judged as a low risk of bias }\end{array}$ \\
\hline $\begin{array}{l}\text { Selective reporting (re- } \\
\text { porting bias) }\end{array}$ & Low risk & $\begin{array}{l}\text { All prespecified outcomes were reported } \\
\text { Comment: this was judged as a low risk of bias }\end{array}$ \\
\hline Other bias & Low risk & $\begin{array}{l}\text { Study supported by Wu Jieping Medical Foundation Project grant and National } \\
\text { funding programmes. One author has declared having received research sup- } \\
\text { port from industry. } \\
\text { Comment: this was judged as a low risk of bias }\end{array}$ \\
\hline
\end{tabular}

\section{Yang 2014}

$\begin{array}{ll}\text { Methods } & \text { Design: parallel-group } \\ \text { Randomisation: yes, method stated } \\ \text { Blinding: open-label } \\ \text { Withdrawals: stated }\end{array}$


Yang 2014 (Continued)

Participants
Setting: multicentre study, hospital outpatient department

Number eligible: 253

Number enrolled: 236

Number in treatment group: 118

Number in control group: 118

Number of withdrawals (treatment/control): 4/0

Number completing trial (treatment/control): 12/46

Age range: treatment 24 to 81 years; control 31 to 79 years

Sex: 59 M, $177 \mathrm{~F}$

Ethnicity: East Asian

NSCLC diagnosis: histologic/cytologic diagnosis of non-squamous NSCLC, stage IIIB to IV disease

Inclusion criteria: chemotherapy-naive patients of East Asian ethnicity and unknown EGFR mutation status. Stage IIIB to IV non-squamous NSCLC. Age $\geq 18$ years, "light ex smokers" or "never smokers" measurable disease by RECIST version 1.0, ECOG PS 0 or 1

Exclusion criteria: known EGFR status before study entry, documented brain metastasis (previously treated stable brain metastases were allowed), clinically significant third space fluid collections, inability to interrupt aspirin or other non-steroidal anti-inflammatory agents (except aspirin at a dose of 1300 mg daily for a 5-day period) and concomitant use of CYP3A4 inducers

Baseline characteristics of treatment/control groups: comparable

Interventions

$\underline{P C / G e f i t i n i b ~ a r m ~}$

Pemetrexed $\left(500 \mathrm{mg} / \mathrm{m}^{2}\right)+$ cisplatin $\left(75 \mathrm{mg} / \mathrm{m}^{2}\right)$ on day 1 of 21 -day cycle. Maximum of 6 cycles.

Then non-progressing patients received gefitinib $250 \mathrm{mg}$ daily as maintenance

Gefitinib arm

Gefitinib $250 \mathrm{mg}$ daily as maintenance

\section{Outcomes}

Progression-free survival

Overall survival

Tumour response - RECIST

Time to progressive disease (TtPD)

Duration of response (DoR)

ASES - NCl-CTC

Association between EGFR mutation status and clinical outcomes

\section{Notes}

\section{Risk of bias}

Bias Authors' judgement Support for judgement


Yang 2014 (Continued)

Random sequence genera- Low risk tion (selection bias)
"... randomisation was controlled by a centrally located computerised voice response unit using a computer-generated random sequence and an interactive voice response system..."

Comment: this was judged as a low risk of bias

\begin{tabular}{|c|c|c|}
\hline $\begin{array}{l}\text { Allocation concealment } \\
\text { (selection bias) }\end{array}$ & Low risk & $\begin{array}{l}\text { External computer generated random sequence } \\
\text { Comment: this was judged as a low risk of bias }\end{array}$ \\
\hline $\begin{array}{l}\text { Blinding (performance } \\
\text { bias and detection bias) } \\
\text { All outcomes }\end{array}$ & Low risk & $\begin{array}{l}\text { Open-label but review authors judge that outcome is not likely to be influ- } \\
\text { enced by lack of blinding } \\
\text { Comment: this was judged as a low risk of bias }\end{array}$ \\
\hline $\begin{array}{l}\text { Incomplete outcome data } \\
\text { (attrition bias) } \\
\text { All outcomes }\end{array}$ & Low risk & $\begin{array}{l}\text { Withdrawals presented in Figure } 1.58 \text { patients completed the study, with bal- } \\
\text { anced numbers between both arms. } \\
\text { Comment: this was judged as a low risk of bias }\end{array}$ \\
\hline $\begin{array}{l}\text { Selective reporting (re- } \\
\text { porting bias) }\end{array}$ & Low risk & $\begin{array}{l}\text { All prespecified outcomes were reported } \\
\text { Comment: this was judged as a low risk of bias }\end{array}$ \\
\hline Other bias & Unclear risk & $\begin{array}{l}\text { Authors have declared paid consultancies, honorarium and research funding } \\
\text { from industry } \\
\text { Comment: this was judged as an unclear risk of bias }\end{array}$ \\
\hline
\end{tabular}

Yu 2014

$\begin{array}{ll}\text { Methods } & \text { Design: parallel-group } \\ & \text { Randomisation: yes, method not stated } \\ & \text { Blinding: open-label } \\ & \text { Withdrawals: stated }\end{array}$

\section{Participants}

Setting: single-centre study, hospital outpatient department

Number eligible: 120

Number enrolled: 117

Number in treatment group: 58

Number in control group: 59

Number of withdrawals (treatment/control): 6/2

Number completing trial (treatment/control): 27/27

Age range: treatmnet 36 to 72 years;control 33 to 70 years

Sex: 58 M, $59 \mathrm{~F}$

Ethnicity: East Asian

NSCLC diagnosis: histologic/cytologic diagnosis of advanced or recurrent non-squamous NSCLC, stage IIIB to IV disease 
Yu 2014 (Continued)

Inclusion criteria: $\geq 18$ years, stage IIIB to IV non-squamous NSCLC ECOG PS 0 to 1 ; measurable disease according to RECIST, adequate haematological hepatic and renal functions, life expectancy of $>12$ weeks

Exclusion criteria: received previous systemic anticancer treatment or had severe drug allergy, or another serious disease or condition, uncontrolled brain metastases, uncontrolled pleural effusion and/ or pericardial effusion, or second malignancy, pregnancy or lactation. Baseline characteristics of treatment/control groups: comparable

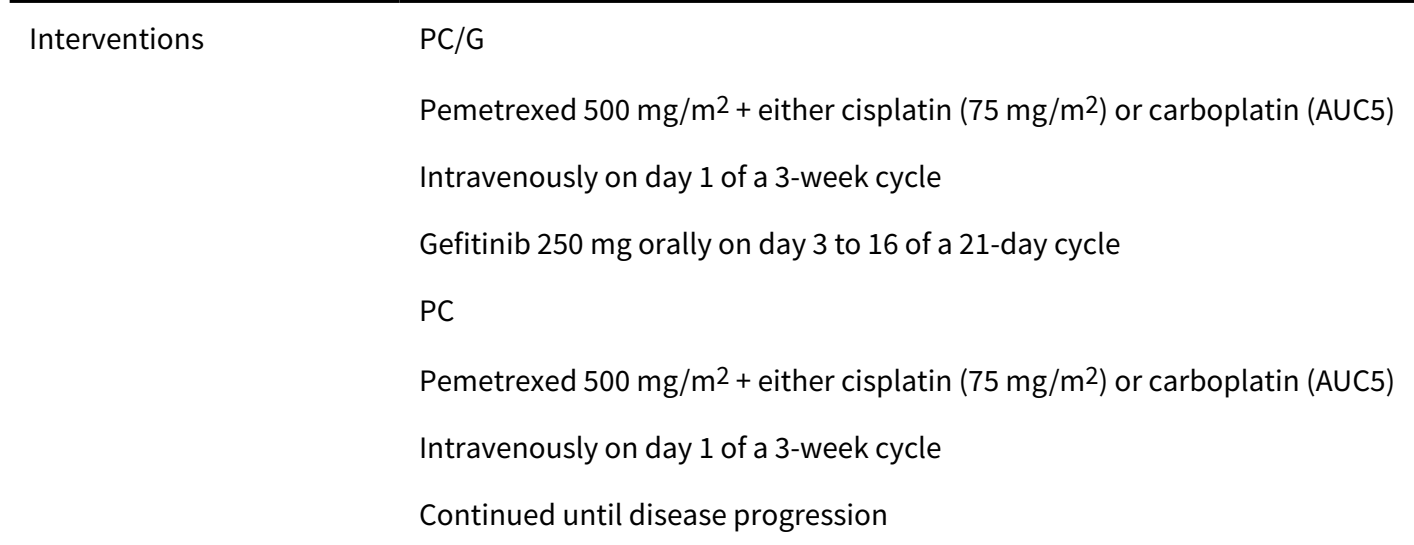

\begin{tabular}{ll}
\hline Outcomes & Non-progression rate (NPR) \\
Tumour response-RECIST \\
Progression-free survival \\
Overall survival \\
ASEs - NCI-CTC
\end{tabular}

\section{Notes}

\section{Risk of bias}

\begin{tabular}{|c|c|c|}
\hline Bias & Authors' judgement & Support for judgement \\
\hline $\begin{array}{l}\text { Random sequence genera- } \\
\text { tion (selection bias) }\end{array}$ & Unclear risk & $\begin{array}{l}\text { "...randomized in 1:1 ratio" and stratified by smoking status, EGFR genotype } \\
\text { Comment: this was judged as an unclear risk of bias }\end{array}$ \\
\hline $\begin{array}{l}\text { Allocation concealment } \\
\text { (selection bias) }\end{array}$ & Unclear risk & $\begin{array}{l}\text { No information provided } \\
\text { Comment: there was insufficient information to permit a clear judgement of } \\
\text { risk of bias }\end{array}$ \\
\hline $\begin{array}{l}\text { Blinding (performance } \\
\text { bias and detection bias) } \\
\text { All outcomes }\end{array}$ & Low risk & $\begin{array}{l}\text { No blinding but review authors judge that outcome is not likely to be influ- } \\
\text { enced by lack of blinding } \\
\text { Comment: this was judged as a low risk of bias }\end{array}$ \\
\hline $\begin{array}{l}\text { Incomplete outcome data } \\
\text { (attrition bias) } \\
\text { All outcomes }\end{array}$ & Low risk & $\begin{array}{l}\text { Withdrawals stated in text } \\
\text { Comment: this was judged as a low risk of bias }\end{array}$ \\
\hline $\begin{array}{l}\text { Selective reporting (re- } \\
\text { porting bias) }\end{array}$ & Low risk & $\begin{array}{l}\text { All prespecified outcomes were reported } \\
\text { Comment: this was judged as a low risk of bias }\end{array}$ \\
\hline
\end{tabular}


Yu 2014 (Continued)

Other bias Low risk Authors declared no competing conflicts of interest

$\begin{array}{ll}\text { Methods } & \text { Design: parallel-group } \\ & \text { Randomisation: yes, method stated } \\ & \text { Blinding: double-blind } \\ & \text { Withdrawals: stated }\end{array}$

Participants

Setting: multicentre study, hospital outpatient department

Number eligible: 298

Number enrolled: 296

Number in treatment group: 148

Number in control group: 148

Number of withdrawals (treatment/control): 81/95

Number completing trial (treatment/control): 67/53

Age range: treatment 31 to 79 years; control 20 to 75 years

Sex: $175 \mathrm{M}, 121 \mathrm{~F}$

Ethnicity: East Asian (Chinese)

NSCLC diagnosis: histologically or cytologically confirmed stage IIIB or IV NSCLC

Inclusion criteria: stage IIIB or IV NSCLC, 18 years or older, life expectancy of $>12$ weeks, WHO PS 0 to 2 , completed 4 cycles of first-line platinum doublet chemotherapy without disease progression and acceptable toxic effects

Exclusion criteria: patients with known EGFR status to avoid selection bias. Prior exposure to monoclonal antibodies or small molecule inhibitors against EGFR receptors (e.g. gefitinib, erlotinib, C225). Participation in another clinical study or received treatment with a non-approved agent within 42 days before Day 1 of study treatment. Serum bilirubin $>3 \times$ ULRR, Aspartate aminotransferase (AST/SGOT) or alanine aminotransferase (ALT/SGPT) $\geq 2.5 \times$ ULN if no demonstrable liver metastases (or $>5 x$ in presence of liver metastases). Any unresolved chronic toxicity greater than common toxicity criteria (CT$\mathrm{CAE}$ ) grade 2 from previous anticancer therapy excluding peripheral neuropathy. Patients with previously diagnosed and treated CNS metastases or spinal cord compression may be considered if they are clinically stable and have been discontinued from steroid therapy for at least 4 weeks prior to first dose of study medication. Any evidence of clinically active interstitial lung disease (patients with chronic, stable, radiographic changes who are asymptomatic need not be excluded). Pre-existing idiopathic pulmonary fibrosis evidence by CT scan at baseline. Patients who have undergone complete tumour resection after responding to platinum-based chemotherapy. As judged by the investigator, any evidence of severe or uncontrolled systemic disease (e.g. unstable or uncompensated respiratory, cardiac, hepatic or renal disease). Treatment with any systemic anticancer therapies other than the prescribed protocol chemotherapy regimen (refer to Inclusion criterion). Exception: palliative radiotherapy for symptom relief of lesions present at diagnosis will be allowed; however, palliative wide field radiotherapy to the lung must be completed at least 4 weeks before day 1 with no persistence of any radiotherapy-related toxicity. Other co-existing malignancies or malignancies diagnosed within the last 5 years with the exception of basal cell carcinoma or cervical cancer in situ. Pregnancy or breastfeeding (women of child bearing potential). Concomitant use of phenytoin, carbamazepine, rifampicin, barbiturates or St. John's wort. Previous bone marrow transplant. Whole blood transfusion within 120 days 
Zhang 2012 INFORM (Continued)

of the date of genetic sample collection. Known biomarker status of one or more of the following: tumour EGFR gene copy number, tumour EGFR gene mutation status, tumour EGFR protein expression.

Baseline characteristics of treatment/control groups: comparable

\begin{tabular}{ll}
\hline Interventions & $\begin{array}{l}\text { Gefitinib } 250 \mathrm{mg} / \text { day } \\
\text { Placebo (oral) }\end{array}$ \\
\hline Outcomes & Progression-free survival \\
& Overall survival \\
& Time to progression \\
& Tumour response - RECIST \\
& ASEs - NCl-CTC \\
Haematology and biochemical parameters & Quality of life (FACT-L)
\end{tabular}

Notes - -

\section{Risk of bias}

\begin{tabular}{lll}
\hline Bias & Authors' judgement & Support for judgement \\
\hline $\begin{array}{ll}\text { Random sequence genera- } \\
\text { tion (selection bias) }\end{array}$ & Low risk & $\begin{array}{l}\text { Quote: "randomisation was done centrally by a third-party randomisation cen- } \\
\text { tre that had no other role in the study", "Randomization was performed using } \\
\text { dynamic balancing..." }\end{array}$ \\
& \\
& Comment: this was judged as a low risk of bias
\end{tabular}

\begin{tabular}{lll}
\hline $\begin{array}{l}\text { Allocation concealment } \\
\text { (selection bias) }\end{array}$ & Low risk & $\begin{array}{l}\text { Quote: "randomisation was done centrally by a third-party randomisation cen- } \\
\text { tre that had no other role in the study" } \\
\text { Comment: this was judged as a low risk of bias }\end{array}$ \\
\hline $\begin{array}{l}\text { Blinding (performance } \\
\text { bias and detection bias) }\end{array}$ & Low risk & $\begin{array}{l}\text { Quote: "active and placebo drugs were identical in form and packaging to en- } \\
\text { sure blinding" }\end{array}$ \\
& Comment: this was judged as a low risk of bias
\end{tabular}

\begin{tabular}{|c|c|c|}
\hline $\begin{array}{l}\text { Incomplete outcome data } \\
\text { (attrition bias) } \\
\text { All outcomes }\end{array}$ & Low risk & $\begin{array}{l}\text { Exclusions and attrition presented in Figure } 1 \text {. Missing outcomes balanced } \\
\text { in numbers across intervention groups with similar reasons for missing data } \\
\text { across groups. All } 296 \text { patients were available for analysis. } \\
\text { Comment: this was judged as a low risk of bias }\end{array}$ \\
\hline $\begin{array}{l}\text { Selective reporting (re- } \\
\text { porting bias) }\end{array}$ & Low risk & $\begin{array}{l}\text { All prespecified outcomes were reported } \\
\text { Comment: this was judged as a low risk of bias }\end{array}$ \\
\hline Other bias & Unclear risk & $\begin{array}{l}\text { Funding for study from Astra Zeneca. Co-authors have received research sup- } \\
\text { port from industry. } \\
\text { Comment: this was judged as an unclear risk of bias }\end{array}$ \\
\hline
\end{tabular}

\section{ALT: alanine transaminase}


ASE: adverse side effects

AST: aspartate transaminase

AUC: area under curve

CNS: central nervous system

$\mathrm{CT}$ : computerised tomography

CTCAE: Common Toxicity Criteria for Adverse Events

ECG: electrocardiogram

ECOG: Eastern Cooperative Oncology Group

ECOG PS: ECOG Performance Status

EGFR: epidermal growth factor receptor

EORTC: European Organisation for Research and Treatment of Cancer

$F$ : female

FACT-L: Functional Assessment of Cancer Therapy-Lung

$\mathrm{FEV}_{1}$ : forced expiratory volume in one second

ILCP: Italian Lung Cancer Project

IV: intravenous

KPS: Karnofsky Performance Status

LCS: lung cancer subscale

M: male

MRI: magnetic resonance imaging

$\mathrm{NCl}$-CTC: National Cancer Institute Common Toxicity Criteria

NSCLC: non-small cell lung cancer

PFS: progression-free survival

PR: partial response

RECIST: Response Evaluation Criteria in Solid Tumours

SGOT: serum glutamic-oxaloacetic transaminase

SGPT: serum glutamic-pyruvic transaminase

TKI: tyrosine kinase inhibitor

TOI: Trial Outcome Index

UFT: tegafur + uracil

UICC: Union for International Cancer Control

ULN: upper limit of normal

ULRR: upper limit of the reference range

WBC: white blood cell

WHO: World Health Organization

WHO PS: WHO Performance Status

Characteristics of excluded studies [ordered by study ID]

\begin{tabular}{ll}
\hline Study & Reason for exclusion \\
\hline Choi 2015 & Recruited only EGFR-mutation negative patients \\
\hline Kim 2012 & Gefitinib versus other EGFR TKI \\
\hline Lee 2009 & Open-label, non-randomised study \\
\hline Manegold 2005 & No direct comparison arm \\
\hline Natale 2009 & Cross-over study \\
\hline Shi 2013 ICOGEN & Gefitinib versus other EGFR TKI \\
\hline Sugawara 2015 & Gefitinib + chemotherapy (sequential) versus gefitinib + chemotherapy (alternating) \\
\hline Urata 2016 & Gefitinib versus other EGFR TKI \\
\hline Zhou 2014 CTONG 0806 & Recruited only EGFR-mutation negative patients \\
\hline
\end{tabular}


EGFR: epidermal growth factor receptor

TKI: tyrosine kinase inhibitor

Characteristics of ongoing studies [ordered by study ID]

Bhatnagar 2012

Trial name or title

platinum-based chemotherapy

\begin{tabular}{ll}
\hline Methods & Randomised \\
\hline Participants & $\begin{array}{l}\text { 30 patients with locally advanced or metastatic NSCLC previously treated with cisplatin-based } \\
\text { chemotherapy, who had progressive or recurrent disease and ECOG performance score } 0 \text { to } 2\end{array}$ \\
\hline Interventions & Gefitinib $250 \mathrm{mg} /$ day versus docetaxel $75 \mathrm{mg} / \mathrm{m}^{2}$ every 3 weeks \\
\hline Outcomes & Tumour response \\
\hline Starting date & Adverse events \\
\hline Contact information & Not known \\
\hline Notes & Not known \\
\hline
\end{tabular}

\section{Gaafar 2010}

\begin{tabular}{ll}
\hline Trial name or title & A double-blind, randomized, placebo-controlled phase III intergroup study of gefitinib (G) in pa- \\
tients (pts) with advanced NSCLC, non-progressing after first-line platinum-based chemotherapy \\
(EORTC 08021-ILCP 01/03)
\end{tabular}

\begin{tabular}{ll}
\hline Methods & Randomised \\
\hline Participants & Advanced NSCLC \\
\hline Interventions & Gefitinib 250 mg daily versus placebo \\
\hline Outcomes & Overall survival \\
& Progression-free survival \\
& Toxicity \\
\hline Starting date & Not known \\
\hline Contact information & Not known \\
\hline Notes & - \\
\hline
\end{tabular}

\section{Hong 2010}

Trial name or title

Randomized phase II study of pemetrexed versus gefitinib for patients with previously treated nonsmall cell lung cancer 
Hong 2010 (Continued)

Methods Randomised

\begin{tabular}{ll}
\hline Participants & $\begin{array}{l}\text { Patients with histologically or cytologically confirmed advanced (stage IIIB or IV) or recurrent NS- } \\
\text { CLC were eligible if they were; age }>18 \text { years, with measurable lesion, previously treated, an East- } \\
\text { ern Cooperative Oncology Group (ECOG) Performance Status (PS) 0 to 2, and with adequate organ } \\
\text { function }\end{array}$ \\
\hline Interventions & $\begin{array}{l}500 \mathrm{mg} / \mathrm{m}^{2} \text { of pemetrexed intravenously every } 3 \text { weeks with vitamin supplementation versus gefi- } \\
\text { tinib } 250 \mathrm{mg} / \text { day until disease progression, intolerable toxicity or withdrawal of consent }\end{array}$ \\
\hline Outcomes & Tumour response \\
& PFS \\
OS & Toxicity \\
\hline Starting date & Not known \\
\hline Notes & Not known \\
\hline
\end{tabular}

\section{Laurie 2000}

Trial name or title

Pilot trial of ZD1839 (Iressa-TM-), an oral inhibitor of epidermal growth factor receptor (EGFR) tyrosine kinase, in combination with carboplatin $(C)$ and paclitaxel $(P)$ in previously untreated advanced non-small cell lung cancer

\begin{tabular}{ll}
\hline Methods & Not known \\
\hline Participants & Not known \\
\hline Interventions & Not known \\
\hline Outcomes & Not known \\
\hline Starting date & Not known \\
\hline Contact information & Not known \\
\hline Notes & - \\
\hline
\end{tabular}

\section{Lee 2013}

Trial name or title

Randomized phase Il study comparing paclitaxel/carboplatin intercalated with gefitinib to paclitaxel/carboplatin alone for chemotherapy-naive non-small cell lung cancer patients either with history of smoking or with wild-type EGFR

\begin{tabular}{ll}
\hline Methods & Randomised \\
\hline Participants & Chemotherapy-naive advanced NSCLC patients with good ECOG PS of 0 or 1 \\
\hline
\end{tabular}


Lee 2013 (Continued)

Interventions
PCG arm: P $175 \mathrm{mg} / \mathrm{m}^{2}$ and C AUC 5 intravenously on day 1 intercalated with $\mathrm{G} 250 \mathrm{mg}$ orally on days 2 through 15 every 3 weeks for 4 cycles followed by G 250 mg orally until progressive disease

PC arm: P $175 \mathrm{mg} / \mathrm{m}^{2}$ and C AUC 5 on day 1 every 3 weeks for 4 cycles only without maintenance therapy

\begin{tabular}{ll}
\hline Outcomes & Tumour response \\
& PFS \\
& OS \\
& Toxicity \\
\hline Starting date & Not known \\
\hline Contact information & Not known \\
\hline Notes & - \\
\hline
\end{tabular}

\section{Liang 2010}

Trial name or title

First-line treatment (txt) with pemetrexed-cisplatin (PC), followed sequentially by gefitinib $(G)$ or pemetrexed, in Asian, never-smoker (n/smkr) patients (pts) with advanced NSCLC: an open-label, randomized phase II trial

\begin{tabular}{ll}
\hline Methods & Randomised \\
\hline Participants & Advanced NSCLC \\
& Asian, chemotherapy-naive, non-smoker \\
\hline Interventions & First-line PC + TXT followed by gefitinib 250 mg daily versus placebo \\
\hline Outcomes & Progression-free survival \\
& Response rate \\
& Toxicities \\
\hline Starting date & February 2007 \\
\hline Contact information & Not known \\
\hline Notes & - \\
\hline
\end{tabular}

\section{Nokihara 2006}

Trial name or title

A randomized phase Il study of sequential carboplatin/paclitaxel (CP) and gefitinib (G) in chemotherapy-naive patients with advanced non-small-cell lung cancer (NSCLC): preliminary results 
Nokihara 2006 (Continued)

\begin{tabular}{ll} 
Participants & Not known \\
\hline Interventions & Not known \\
\hline Outcomes & Not known \\
\hline Starting date & Not known \\
\hline Contact information & Not known \\
\hline Notes & -
\end{tabular}

\section{Puri 2013}

$\begin{array}{ll}\text { Trial name or title } & \begin{array}{l}\text { A randomized phase } 2 \text { trial of pemetrexed }(P) \text { and gefitinib }(G) \text { versus } G \text { as first-line treatment for } \\ \text { patients with stage IV non-squamous (NS) non-small cell lung cancer (NSCLC) with activating epi- } \\ \text { dermal growth factor receptor (EGFR) mutations }\end{array}\end{array}$

\begin{tabular}{ll}
\hline Methods & Randomised \\
\hline Participants & $\begin{array}{l}\text { Stage IV NS NSCLC, an Eastern Cooperative Oncology Group performance status (ECOG PS) of 0 to 1 } \\
\text { and an activating EGFR mutation }\end{array}$ \\
\hline Interventions & Gefitinib versus pemetrexed \\
\hline Outcomes & PFS \\
& Time to progressive disease \\
& OS \\
& ORR \\
& DCR \\
& Adverse events \\
\hline Starting date & Not known \\
\hline Contact information & Not known \\
\hline Notes & - \\
\hline
\end{tabular}

AUC: Area under curve

C: carboplatin

DCR: disease control rate

ECOG: Eastern Cooperative Oncology Group

ECOG PS: ECOG Performance Status

EGFR: epidermal growth factor receptor

G: gefitinib

NSCLC: non-small cell lung cancer

ORR: overall response rate

OS: overall survival

$P$ : paclitaxel

PC: pemetrexed-cisplatin

PFS: progression-free survival 
TXT: first-line treatment

\section{DATA AND ANALYSES}

\section{Comparison 1. Gefitinib versus placebo}

\begin{tabular}{|c|c|c|c|c|}
\hline Outcome or subgroup title & No. of studies & $\begin{array}{l}\text { No. of partici- } \\
\text { pants }\end{array}$ & Statistical method & Effect size \\
\hline 1 HR Overall survival & 4 & & Hazard Ratio (Random, 95\% Cl) & Subtotals only \\
\hline $1.1 \mathrm{G}(250)$ vs $\mathrm{P}=1$ st line & 1 & & Hazard Ratio (Random, 95\% Cl) & $0.84[0.62,1.14]$ \\
\hline $1.2 \mathrm{G}(250)$ vs $\mathrm{P}=2 \mathrm{nd}$ line & 1 & & Hazard Ratio (Random, 95\% Cl) & $0.89[0.79,1.01]$ \\
\hline $\begin{array}{l}1.3 \mathrm{G}(500) \text { vs } \mathrm{P}=\text { Mainte- } \\
\text { nance }\end{array}$ & 2 & & Hazard Ratio (Random, 95\% Cl) & $1.14[0.61,2.14]$ \\
\hline $\begin{array}{l}2 \text { HR Progression-free sur- } \\
\text { vival }\end{array}$ & 4 & & Hazard Ratio (Random, 95\% Cl) & Subtotals only \\
\hline $2.1 \mathrm{G}(250)$ vs $\mathrm{P}=1$ st line & 1 & & Hazard Ratio (Random, 95\% Cl) & $0.82[0.60,1.12]$ \\
\hline 2.2 G(250) vs $P=2$ nd line & 1 & & Hazard Ratio (Random, 95\% Cl) & $0.82[0.75,0.90]$ \\
\hline $\begin{array}{l}2.3 \mathrm{G}(500) \text { vs } \mathrm{P}=\text { Mainte- } \\
\text { nance }\end{array}$ & 2 & & Hazard Ratio (Random, 95\% Cl) & $0.70[0.53,0.91]$ \\
\hline 31 -year survival rate & 2 & & Risk Ratio (M-H, Fixed, 95\% Cl) & Subtotals only \\
\hline $3.1 \mathrm{G}(250)$ vs $\mathrm{P}=2 \mathrm{nd}$ line & 1 & 1439 & Risk Ratio (M-H, Fixed, 95\% Cl) & $1.28[1.05,1.57]$ \\
\hline $\begin{array}{l}3.2 \mathrm{G}(500) \text { vs } \mathrm{P}=\text { Mainte- } \\
\text { nance }\end{array}$ & 1 & 243 & Risk Ratio (M-H, Fixed, 95\% Cl) & $0.90[0.78,1.04]$ \\
\hline 4 Skin rash & 3 & 2060 & Risk Ratio (M-H, Fixed, 95\% Cl) & $7.92[1.46,43.03]$ \\
\hline $4.1 \mathrm{G}(250)$ vs $\mathrm{P}=1$ st line & 1 & 201 & Risk Ratio (M-H, Fixed, 95\% Cl) & $0.0[0.0,0.0]$ \\
\hline 4.2 G(250) vs $P=2$ nd line & 1 & 1688 & Risk Ratio (M-H, Fixed, 95\% Cl) & $8.98[1.20,67.13]$ \\
\hline $\begin{array}{l}4.3 \mathrm{G}(250) \text { vs } \mathrm{P}=\text { Mainte- } \\
\text { nance }\end{array}$ & 1 & 171 & Risk Ratio (M-H, Fixed, 95\% Cl) & $5.06[0.25,103.82]$ \\
\hline 5 Pruritus & 2 & 1889 & Risk Ratio (M-H, Fixed, 95\% Cl) & $2.00[0.22,17.82]$ \\
\hline $5.1 \mathrm{G}(250)$ vs $\mathrm{P}=1$ st line & 1 & 201 & Risk Ratio (M-H, Fixed, 95\% Cl) & $0.0[0.0,0.0]$ \\
\hline $5.2 \mathrm{G}(250)$ vs $\mathrm{P}=2$ nd line & 1 & 1688 & Risk Ratio (M-H, Fixed, 95\% Cl) & $2.00[0.22,17.82]$ \\
\hline 6 Diarrhoea & 3 & 2060 & Risk Ratio (M-H, Fixed, 95\% Cl) & $2.48[1.15,5.35]$ \\
\hline $6.1 \mathrm{G}(250)$ vs $\mathrm{P}=1$ st line & 1 & 201 & Risk Ratio (M-H, Fixed, 95\% Cl) & $1.01[0.21,4.89]$ \\
\hline $6.2 \mathrm{G}(250)$ vs $\mathrm{P}=2 \mathrm{nd}$ line & 1 & 1688 & Risk Ratio (M-H, Fixed, 95\% Cl) & $3.09[1.21,7.91]$ \\
\hline
\end{tabular}




\begin{tabular}{|c|c|c|c|c|}
\hline Outcome or subgroup title & No. of studies & $\begin{array}{l}\text { No. of partici- } \\
\text { pants }\end{array}$ & Statistical method & Effect size \\
\hline $\begin{array}{l}6.3 \mathrm{G}(250) \text { vs } \mathrm{P}=\text { Mainte- } \\
\text { nance }\end{array}$ & 1 & 171 & Risk Ratio (M-H, Fixed, 95\% Cl) & $3.03[0.13,73.47]$ \\
\hline 7 Constipation & 1 & 201 & Risk Ratio (M-H, Fixed, 95\% Cl) & $1.01[0.06,15.93]$ \\
\hline $7.1 \mathrm{G}(250)$ vs $\mathrm{P}=1$ st line & 1 & 201 & Risk Ratio (M-H, Fixed, 95\% Cl) & $1.01[0.06,15.93]$ \\
\hline 8 Nausea & 2 & 1889 & Risk Ratio (M-H, Random, 95\% Cl) & $0.65[0.03,12.44]$ \\
\hline $8.1 \mathrm{G}(250)$ vs $\mathrm{P}=1$ st line & 1 & 201 & Risk Ratio (M-H, Random, 95\% Cl) & $0.11[0.01,2.06]$ \\
\hline $8.2 \mathrm{G}(250)$ vs $\mathrm{P}=2 \mathrm{nd}$ line & 1 & 1688 & Risk Ratio (M-H, Random, 95\% Cl) & $2.25[0.49,10.36]$ \\
\hline 9 Vomiting & 2 & 1859 & Risk Ratio (M-H, Fixed, 95\% Cl) & $3.21[0.83,12.38]$ \\
\hline $9.1 \mathrm{G}(250)$ vs $\mathrm{P}=2$ nd line & 1 & 1688 & Risk Ratio (M-H, Fixed, 95\% Cl) & $3.24[0.73,14.33]$ \\
\hline $\begin{array}{l}9.2 \mathrm{G}(250) \text { vs } \mathrm{P}=\text { Mainte- } \\
\text { nance }\end{array}$ & 1 & 171 & Risk Ratio (M-H, Fixed, 95\% Cl) & $3.03[0.13,73.47]$ \\
\hline 10 Anorexia & 3 & 2060 & Risk Ratio (M-H, Fixed, 95\% Cl) & $1.22[0.64,2.33]$ \\
\hline $10.1 \mathrm{G}(250)$ vs $\mathrm{P}=1$ st line & 1 & 201 & Risk Ratio (M-H, Fixed, 95\% Cl) & $5.05[0.25,103.87]$ \\
\hline $10.2 \mathrm{G}(250)$ vs $\mathrm{P}=2 \mathrm{nd}$ line & 1 & 1688 & Risk Ratio (M-H, Fixed, 95\% Cl) & $1.18[0.59,2.37]$ \\
\hline $\begin{array}{l}10.3 \mathrm{G}(250) \text { vs } \mathrm{P}=\text { Mainte- } \\
\text { nance }\end{array}$ & 1 & 171 & Risk Ratio (M-H, Fixed, 95\% Cl) & $0.34[0.01,8.16]$ \\
\hline 11 Fatigue & 2 & & Risk Ratio (M-H, Fixed, 95\% Cl) & Subtotals only \\
\hline $11.1 \mathrm{G}(250)$ vs $\mathrm{P}=1$ st line & 1 & 201 & Risk Ratio (M-H, Fixed, 95\% Cl) & $0.76[0.27,2.10]$ \\
\hline $\begin{array}{l}11.2 \mathrm{G}(250) \text { vs } \mathrm{P}=\text { Mainte- } \\
\text { nance }\end{array}$ & 1 & 171 & Risk Ratio (M-H, Fixed, 95\% Cl) & $4.05[0.46,35.47]$ \\
\hline 12 Asthenia & 1 & & Risk Ratio (M-H, Fixed, 95\% Cl) & Subtotals only \\
\hline 12.1 $\mathrm{G}(250)$ vs $\mathrm{P}=2$ nd line & 1 & 1688 & Risk Ratio (M-H, Fixed, 95\% Cl) & $1.20[0.66,2.17]$ \\
\hline $\begin{array}{l}13 \text { Respiratory tract infec- } \\
\text { tion }\end{array}$ & 2 & 1889 & Risk Ratio (M-H, Random, 95\% Cl) & $0.53[0.07,3.83]$ \\
\hline $13.1 \mathrm{G}(250)$ vs $\mathrm{P}=1$ st line & 1 & 201 & Risk Ratio (M-H, Random, 95\% Cl) & $0.11[0.01,2.06]$ \\
\hline 13.2 G(250) vs $P=2$ nd line & 1 & 1688 & Risk Ratio (M-H, Random, 95\% Cl) & $1.00[0.54,1.84]$ \\
\hline 14 Dyspnoea & 3 & 2060 & Risk Ratio (M-H, Random, 95\% Cl) & $0.98[0.59,1.63]$ \\
\hline 14.1 G(250) vs $P=1$ st line & 1 & 201 & Risk Ratio (M-H, Random, 95\% Cl) & $1.85[0.71,4.81]$ \\
\hline 14.2 G(250) vs $P=2$ nd line & 1 & 1688 & Risk Ratio (M-H, Random, 95\% Cl) & $0.83[0.49,1.42]$ \\
\hline
\end{tabular}




\begin{tabular}{|c|c|c|c|c|}
\hline Outcome or subgroup title & No. of studies & $\begin{array}{l}\text { No. of partici- } \\
\text { pants }\end{array}$ & Statistical method & Effect size \\
\hline $\begin{array}{l}14.3 \mathrm{G}(250) \text { vs } \mathrm{P}=\text { Mainte- } \\
\text { nance }\end{array}$ & 1 & 171 & Risk Ratio (M-H, Random, 95\% Cl) & $0.67[0.20,2.31]$ \\
\hline 15 Anaemia & 1 & 201 & Risk Ratio (M-H, Fixed, 95\% Cl) & $7.07[0.37,135.12]$ \\
\hline $15.1 \mathrm{G}(250)$ vs $\mathrm{P}=1$ st line & 1 & 201 & Risk Ratio (M-H, Fixed, 95\% Cl) & $7.07[0.37,135.12]$ \\
\hline 16 Abdominal pain & 1 & 201 & Risk Ratio (M-H, Fixed, 95\% Cl) & $0.51[0.05,5.48]$ \\
\hline $16.1 \mathrm{G}(250)$ vs $\mathrm{P}=1$ st line & 1 & 201 & Risk Ratio (M-H, Fixed, 95\% Cl) & $0.51[0.05,5.48]$ \\
\hline 17 Increased ALT & 1 & 171 & Risk Ratio (M-H, Fixed, 95\% Cl) & $9.11[1.18,70.32]$ \\
\hline $\begin{array}{l}17.1 \mathrm{G}(250) \text { vs } \mathrm{P}=\text { Mainte- } \\
\text { nance }\end{array}$ & 1 & 171 & Risk Ratio (M-H, Fixed, 95\% Cl) & $9.11[1.18,70.32]$ \\
\hline 18 Increased AST & 1 & 171 & Risk Ratio (M-H, Fixed, 95\% Cl) & $7.08[0.89,56.34]$ \\
\hline $\begin{array}{l}18.1 \mathrm{G}(250) \text { vs } \mathrm{P}=\text { Mainte- } \\
\text { nance }\end{array}$ & 1 & 171 & Risk Ratio (M-H, Fixed, 95\% Cl) & $7.08[0.89,56.34]$ \\
\hline 19 Neutropenia & 1 & 171 & Risk Ratio (M-H, Fixed, 95\% Cl) & $3.03[0.13,73.47]$ \\
\hline $\begin{array}{l}19.1 \mathrm{G}(250) \text { vs } \mathrm{P}=\text { Mainte- } \\
\text { nance }\end{array}$ & 1 & 171 & Risk Ratio (M-H, Fixed, 95\% Cl) & $3.03[0.13,73.47]$ \\
\hline 20 Anaemia & 1 & 171 & Risk Ratio (M-H, Fixed, 95\% Cl) & $0.20[0.01,4.15]$ \\
\hline $\begin{array}{l}20.1 \mathrm{G}(250) \text { vs } \mathrm{P}=\text { Mainte- } \\
\text { nance }\end{array}$ & 1 & 171 & Risk Ratio (M-H, Fixed, 95\% Cl) & $0.20[0.01,4.15]$ \\
\hline 21 Thrombocytopaenia & 1 & 171 & Risk Ratio (M-H, Fixed, 95\% Cl) & $3.03[0.13,73.47]$ \\
\hline $\begin{array}{l}21.1 \mathrm{G}(250) \text { vs } \mathrm{P}=\text { Mainte- } \\
\text { nance }\end{array}$ & 1 & 171 & Risk Ratio (M-H, Fixed, 95\% Cl) & $3.03[0.13,73.47]$ \\
\hline 22 Overall response rate & 3 & & Risk Ratio (M-H, Fixed, 95\% Cl) & Subtotals only \\
\hline $22.1 \mathrm{G}(250)$ vs $\mathrm{P}=1$ st line & 1 & 201 & Risk Ratio (M-H, Fixed, 95\% Cl) & $6.06[0.74,49.43]$ \\
\hline 22.2 $\mathrm{G}(250)$ vs $P=2$ nd line & 1 & 1439 & Risk Ratio (M-H, Fixed, 95\% Cl) & $6.42[2.82,14.64]$ \\
\hline $\begin{array}{l}22.3 \mathrm{G}(250) \text { vs } \mathrm{P}=\text { Mainte- } \\
\text { nance }\end{array}$ & 1 & 173 & Risk Ratio (M-H, Fixed, 95\% Cl) & $10.12[1.32,77.33]$ \\
\hline 23 Disease control rate & 3 & & Risk Ratio (M-H, Fixed, 95\% Cl) & Subtotals only \\
\hline $23.1 \mathrm{G}(250)$ vs $\mathrm{P}=1$ st line & 1 & 201 & Risk Ratio (M-H, Fixed, 95\% Cl) & $1.36[0.86,2.16]$ \\
\hline $23.2 \mathrm{G}(250)$ vs $\mathrm{P}=2 \mathrm{nd}$ line & 1 & 1439 & Risk Ratio (M-H, Fixed, 95\% Cl) & $1.24[1.06,1.44]$ \\
\hline $\begin{array}{l}23.3 \mathrm{G}(250) \text { vs } \mathrm{P}=\text { Mainte- } \\
\text { nance }\end{array}$ & 1 & 173 & Risk Ratio (M-H, Fixed, 95\% Cl) & $1.21[1.00,1.46]$ \\
\hline
\end{tabular}


Analysis 1.1. Comparison 1 Gefitinib versus placebo, Outcome 1 HR Overall survival.

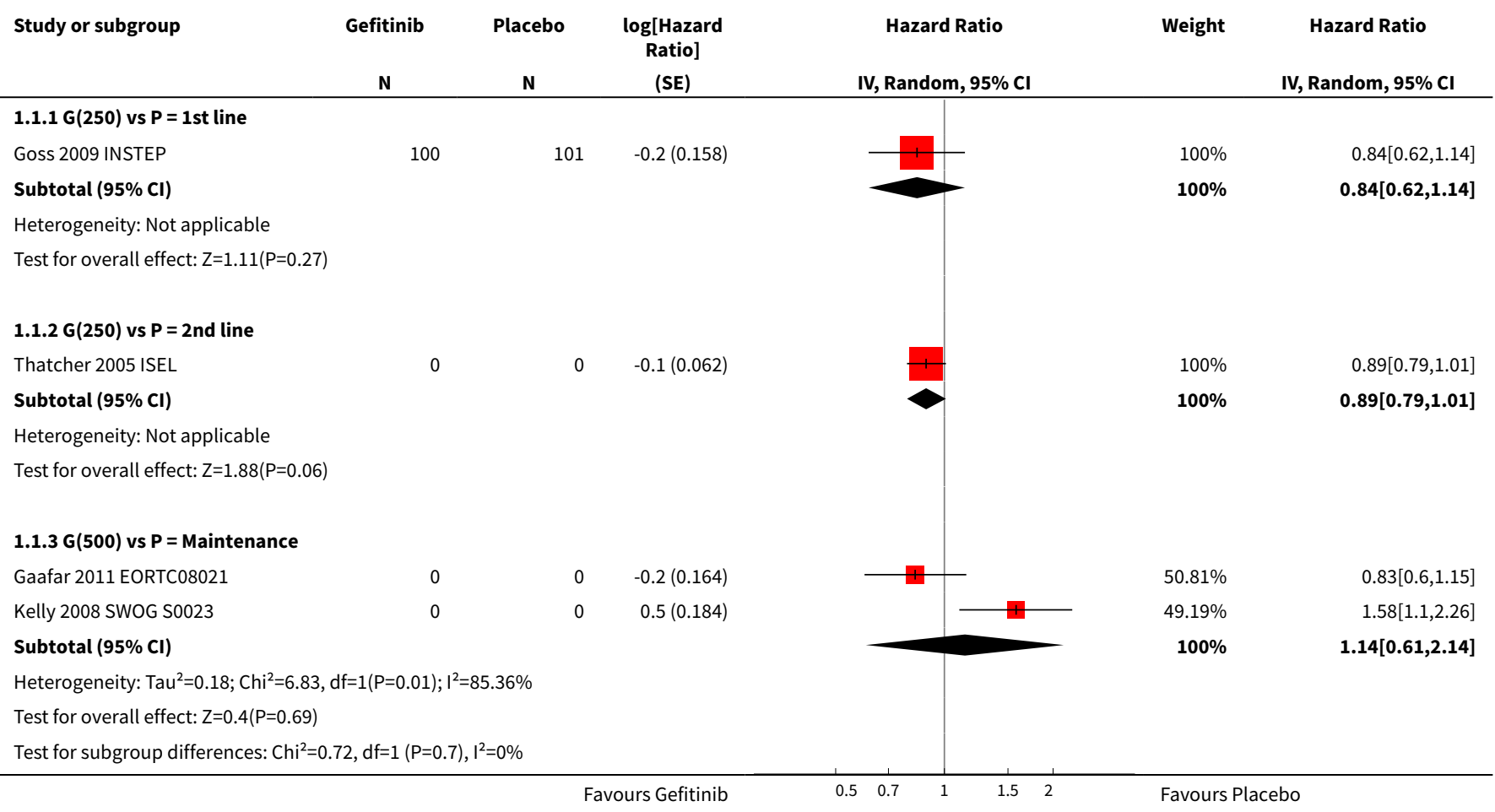

Analysis 1.2. Comparison 1 Gefitinib versus placebo, Outcome 2 HR Progression-free survival.

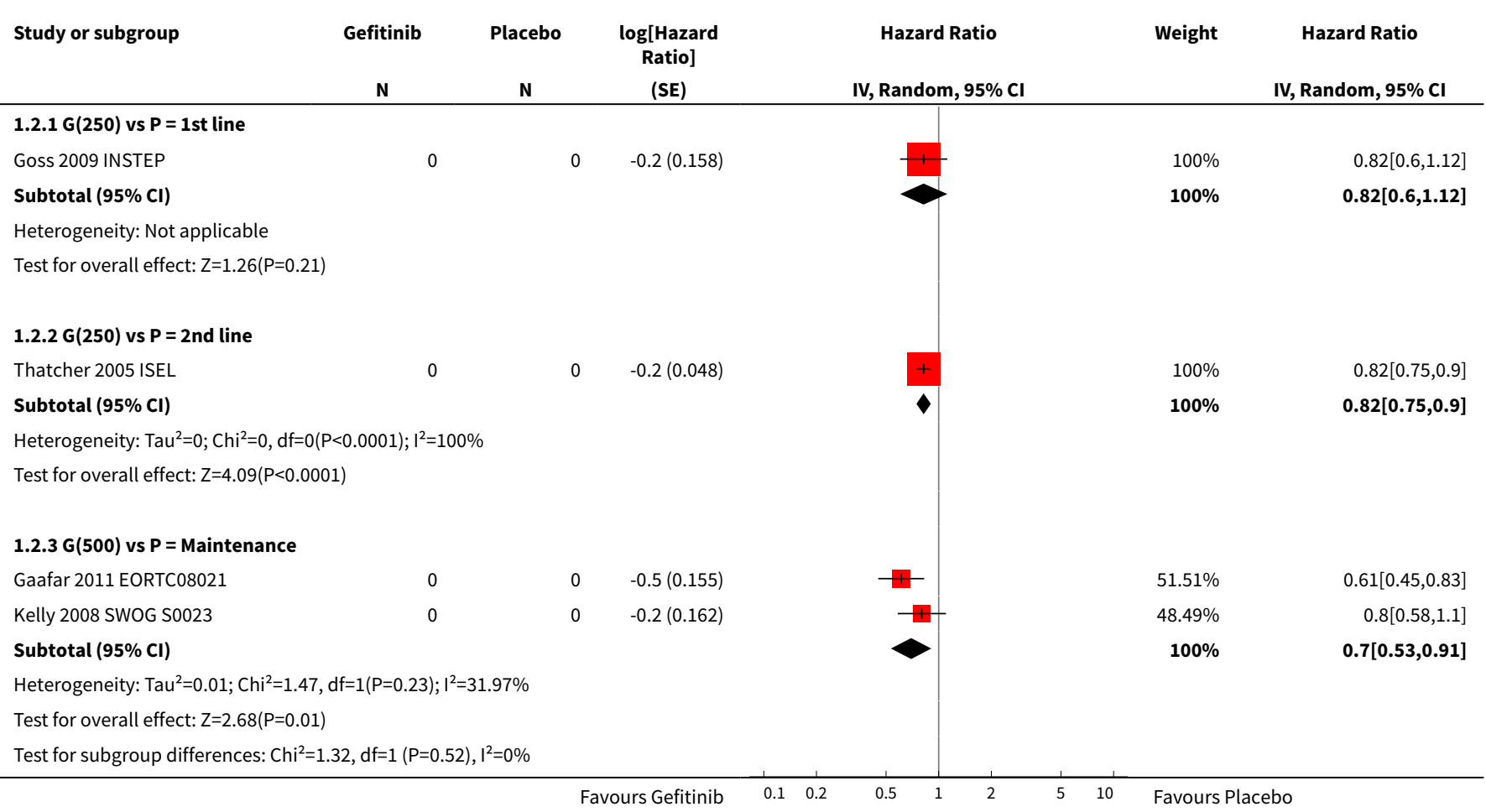


Analysis 1.3. Comparison 1 Gefitinib versus placebo, Outcome 3 1-year survival rate.

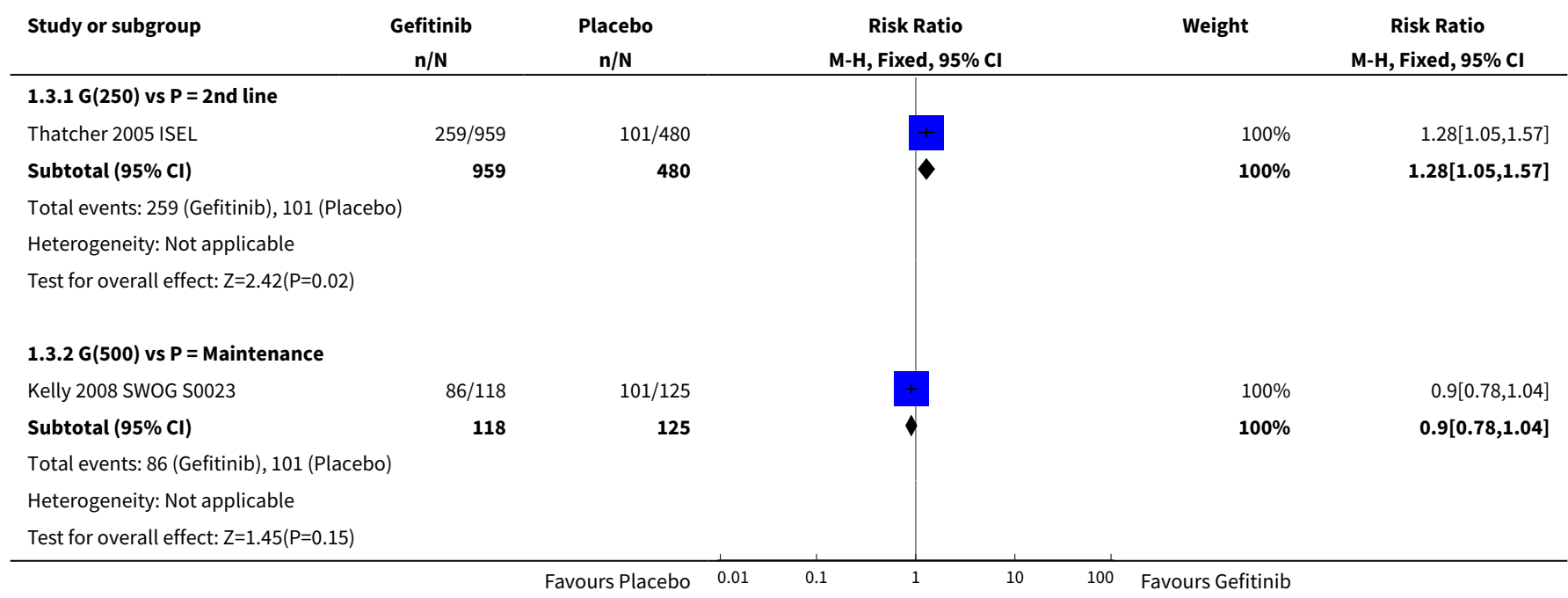

Analysis 1.4. Comparison 1 Gefitinib versus placebo, Outcome 4 Skin rash.

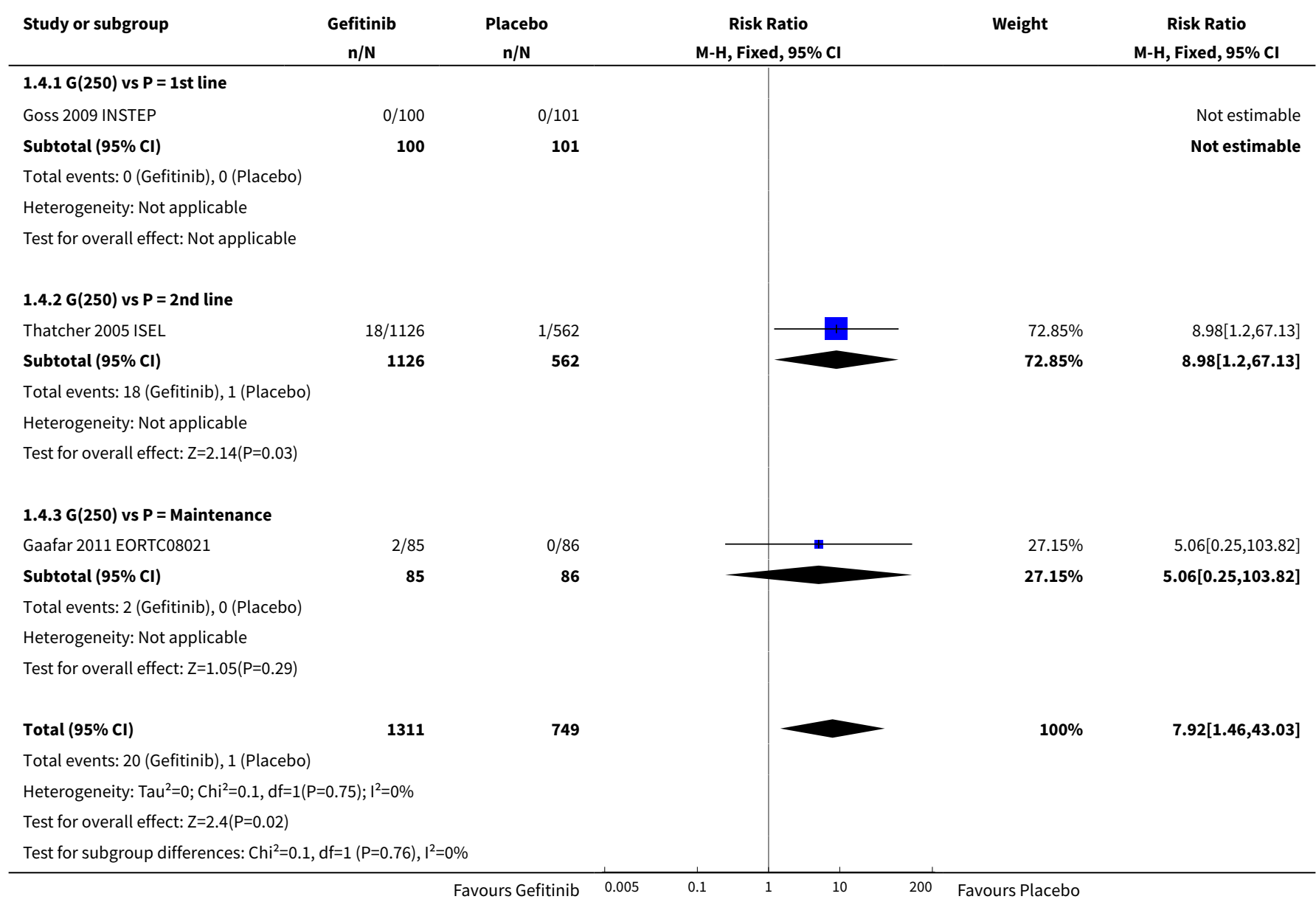


Analysis 1.5. Comparison 1 Gefitinib versus placebo, Outcome 5 Pruritus.

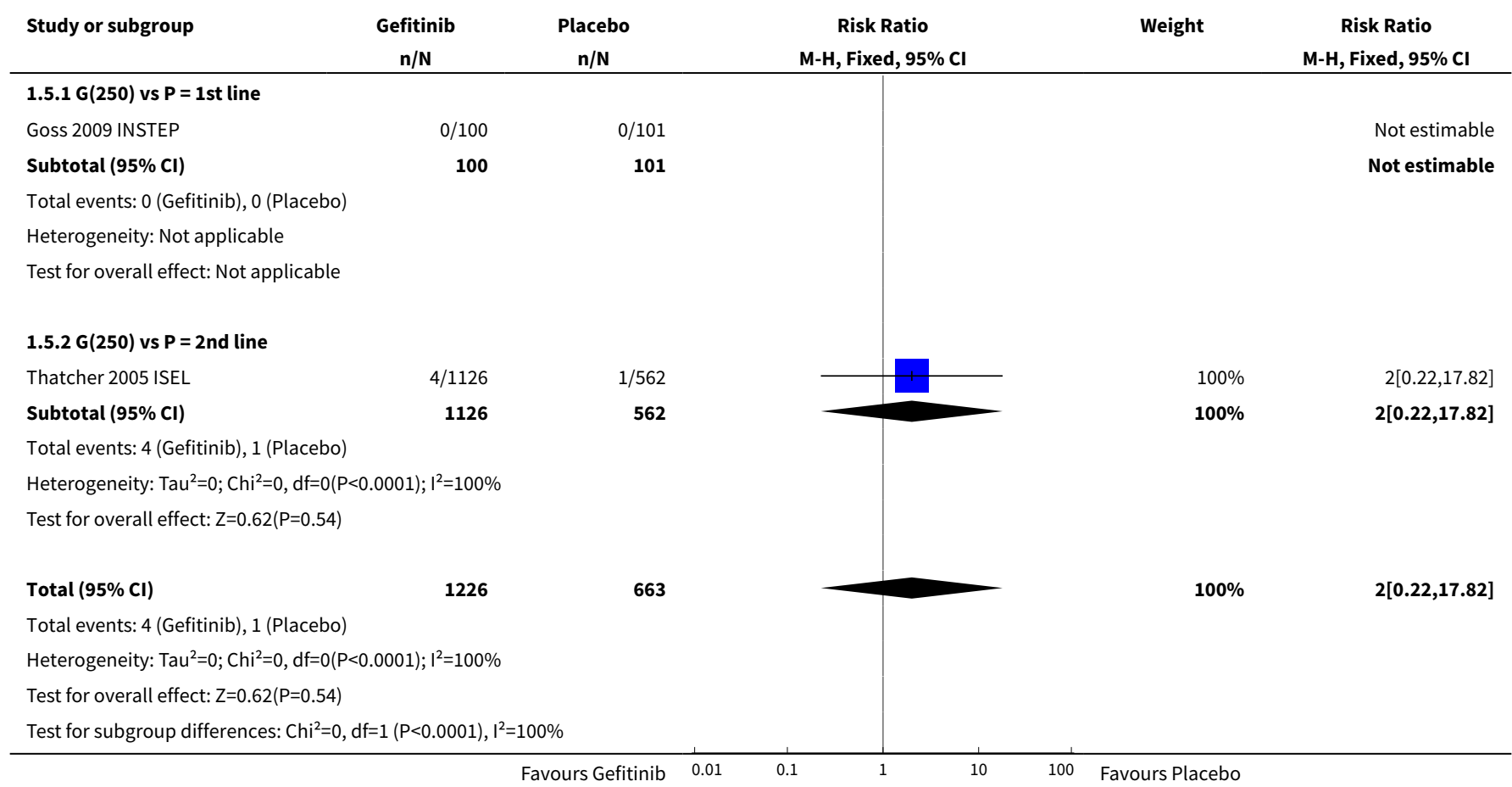

Analysis 1.6. Comparison 1 Gefitinib versus placebo, Outcome 6 Diarrhoea.

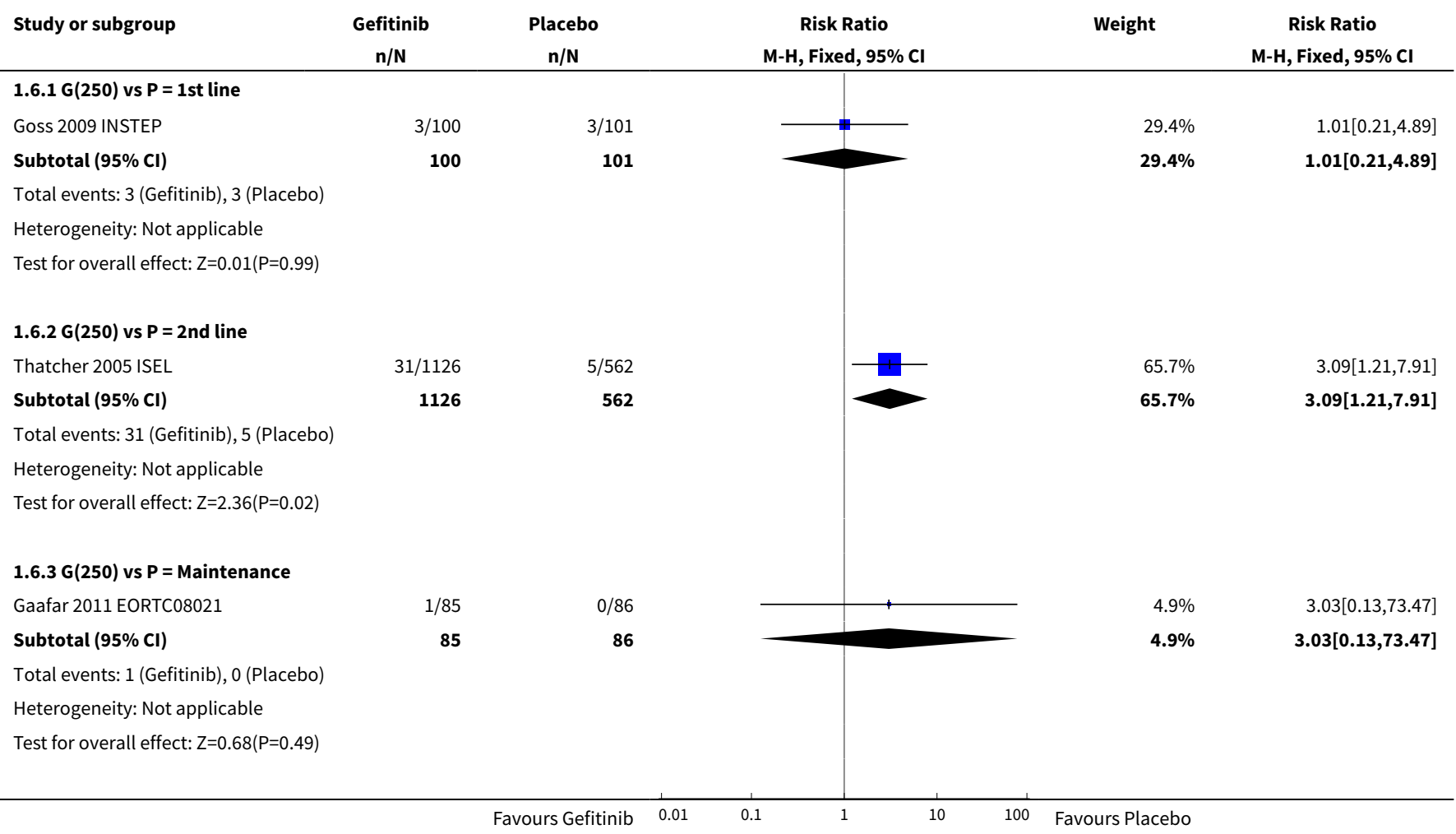




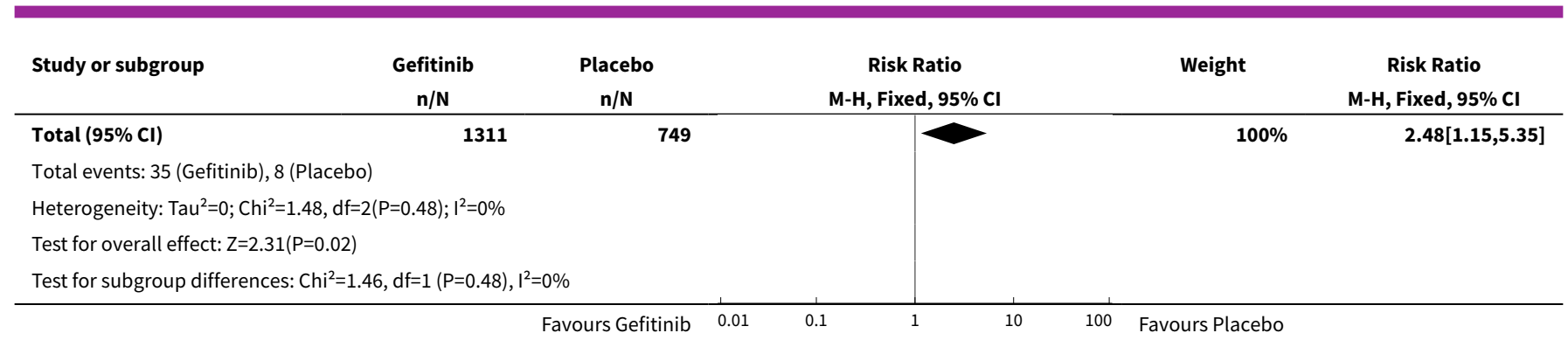

Analysis 1.7. Comparison 1 Gefitinib versus placebo, Outcome 7 Constipation.

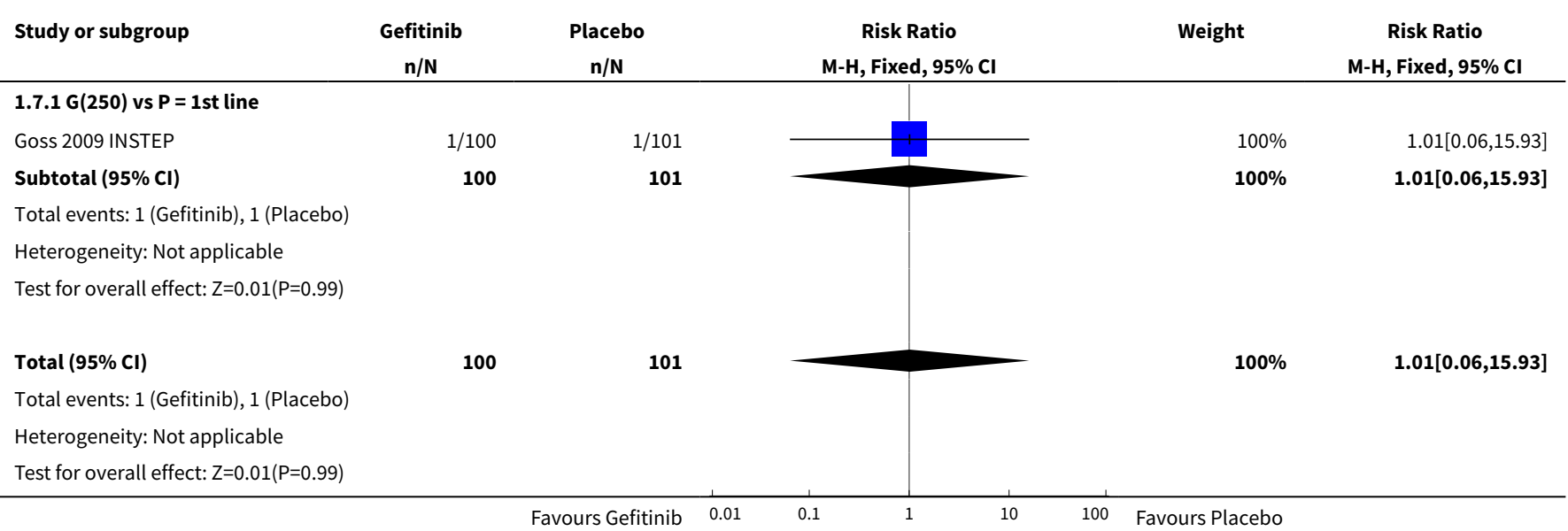

Analysis 1.8. Comparison 1 Gefitinib versus placebo, Outcome 8 Nausea.

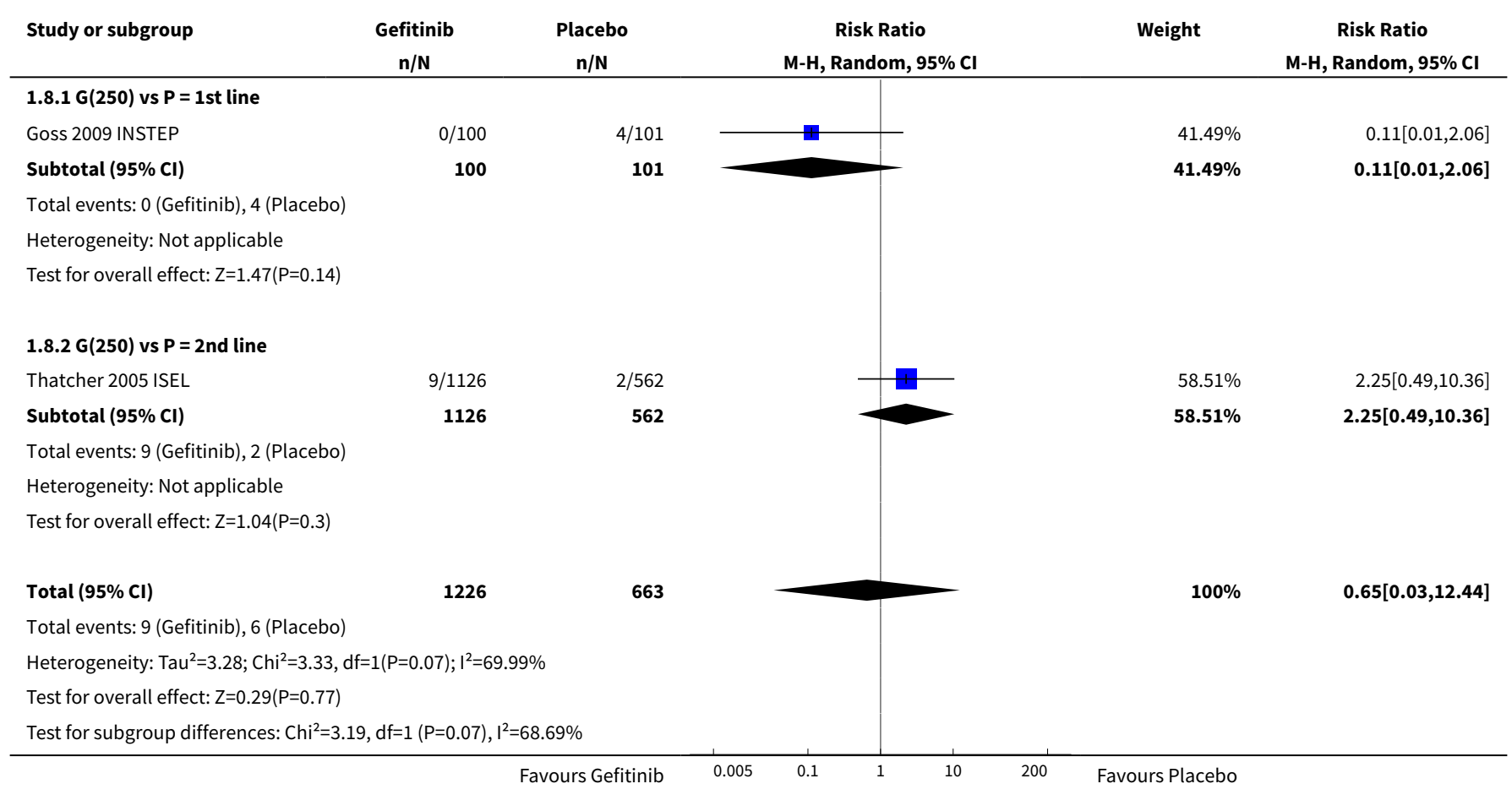


Analysis 1.9. Comparison 1 Gefitinib versus placebo, Outcome 9 Vomiting.

\begin{tabular}{|c|c|c|c|c|c|}
\hline Study or subgroup & $\begin{array}{c}\text { Gefitinib } \\
\text { n/N }\end{array}$ & $\begin{array}{c}\text { Placebo } \\
\mathrm{n} / \mathrm{N}\end{array}$ & $\begin{array}{c}\text { Risk Ratio } \\
\text { M-H, Fixed, } 95 \% \mathrm{Cl} \\
\end{array}$ & Weight & $\begin{array}{c}\text { Risk Ratio } \\
\text { M-H, Fixed, } 95 \% \mathrm{CI}\end{array}$ \\
\hline \multicolumn{6}{|l|}{ 1.9.1 G(250) vs $P=2$ nd line } \\
\hline Thatcher 2005 ISEL & $13 / 1126$ & $2 / 562$ & & $84.3 \%$ & $3.24[0.73,14.33]$ \\
\hline Subtotal $(95 \% \mathrm{Cl})$ & 1126 & 562 & & $84.3 \%$ & $3.24[0.73,14.33]$ \\
\hline \multicolumn{6}{|c|}{ Total events: 13 (Gefitinib), 2 (Placebo) } \\
\hline \multicolumn{6}{|c|}{ Heterogeneity: Not applicable } \\
\hline \multicolumn{6}{|c|}{ Test for overall effect: $Z=1.55(P=0.12)$} \\
\hline \multicolumn{6}{|c|}{ 1.9.2 G(250) vs $P=$ Maintenance } \\
\hline Gaafar 2011 EORTC08021 & $1 / 85$ & $0 / 86$ & & $15.7 \%$ & $3.03[0.13,73.47]$ \\
\hline Subtotal $(95 \% \mathrm{Cl})$ & 85 & 86 & & $15.7 \%$ & $3.03[0.13,73.47]$ \\
\hline \multicolumn{6}{|c|}{ Total events: 1 (Gefitinib), 0 (Placebo) } \\
\hline \multicolumn{6}{|c|}{ Heterogeneity: Not applicable } \\
\hline \multicolumn{6}{|c|}{ Test for overall effect: $Z=0.68(P=0.49)$} \\
\hline Total $(95 \% \mathrm{Cl})$ & 1211 & 648 & & $100 \%$ & $3.21[0.83,12.38]$ \\
\hline \multicolumn{6}{|c|}{ Total events: 14 (Gefitinib), 2 (Placebo) } \\
\hline \multicolumn{6}{|c|}{ Heterogeneity: $\mathrm{Tau}^{2}=0 ; \mathrm{Chi}^{2}=0, \mathrm{df}=1(\mathrm{P}=0.97) ; \mathrm{I}^{2}=0 \%$} \\
\hline \multicolumn{6}{|c|}{ Test for overall effect: $Z=1.69(P=0.09)$} \\
\hline Test for subgroup differenc & $f=1(P=0.97), I^{2}=$ & & & & \\
\hline
\end{tabular}

Analysis 1.10. Comparison 1 Gefitinib versus placebo, Outcome 10 Anorexia.

\begin{tabular}{|c|c|c|c|c|c|}
\hline Study or subgroup & $\begin{array}{c}\text { Gefitinib } \\
\mathrm{n} / \mathrm{N}\end{array}$ & $\begin{array}{l}\text { Placebo } \\
n / N\end{array}$ & $\begin{array}{c}\text { Risk Ratio } \\
\text { M-H, Fixed, } 95 \% \mathrm{Cl}\end{array}$ & Weight & $\begin{array}{c}\text { Risk Ratio } \\
\text { M-H, Fixed, } 95 \% \mathrm{Cl}\end{array}$ \\
\hline \multicolumn{6}{|c|}{$1.10 .1 \mathrm{G}(250)$ vs $P=1$ st line } \\
\hline Goss 2009 INSTEP & $2 / 100$ & $0 / 101$ & & $2.99 \%$ & $5.05[0.25,103.87]$ \\
\hline Subtotal $(95 \% \mathrm{Cl})$ & 100 & 101 & 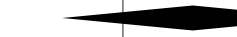 & $2.99 \%$ & $5.05[0.25,103.87]$ \\
\hline \multicolumn{6}{|c|}{ Total events: 2 (Gefitinib), 0 (Placebo) } \\
\hline \multicolumn{6}{|c|}{ Heterogeneity: Not applicable } \\
\hline \multicolumn{6}{|c|}{ Test for overall effect: $Z=1.05(P=0.29)$} \\
\hline \multicolumn{6}{|c|}{$1.10 .2 \mathrm{G}(250)$ vs $P=2$ nd line } \\
\hline Thatcher 2005 ISEL & $26 / 1126$ & $11 / 562$ & & $88.07 \%$ & $1.18[0.59,2.37]$ \\
\hline Subtotal $(95 \% \mathrm{Cl})$ & 1126 & 562 & & $88.07 \%$ & $1.18[0.59,2.37]$ \\
\hline \multicolumn{6}{|c|}{ Total events: 26 (Gefitinib), 11 (Placebo) } \\
\hline \multicolumn{6}{|c|}{ Heterogeneity: Not applicable } \\
\hline \multicolumn{6}{|c|}{ Test for overall effect: $Z=0.46(P=0.64)$} \\
\hline \multicolumn{6}{|c|}{ 1.10.3 G(250) vs $P=$ Maintenance } \\
\hline Gaafar 2011 EORTC08021 & $0 / 85$ & $1 / 86$ & & $8.95 \%$ & $0.34[0.01,8.16]$ \\
\hline Subtotal $(95 \% \mathrm{Cl})$ & 85 & 86 & & $8.95 \%$ & $0.34[0.01,8.16]$ \\
\hline \multicolumn{6}{|c|}{ Total events: 0 (Gefitinib), 1 (Placebo) } \\
\hline \multicolumn{6}{|c|}{ Heterogeneity: Not applicable } \\
\hline Test for overall effect: $Z=0$. & & & & & \\
\hline
\end{tabular}




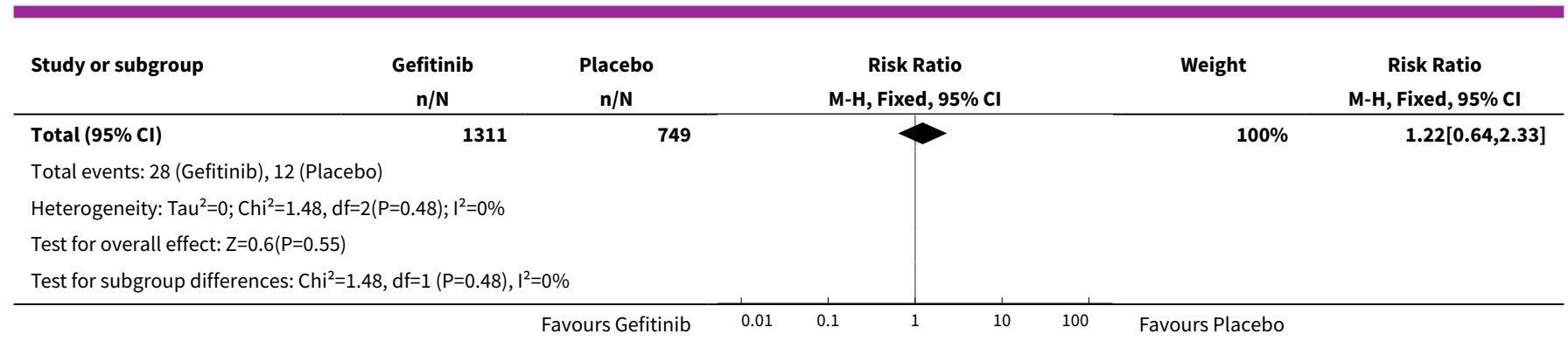

Analysis 1.11. Comparison 1 Gefitinib versus placebo, Outcome 11 Fatigue.

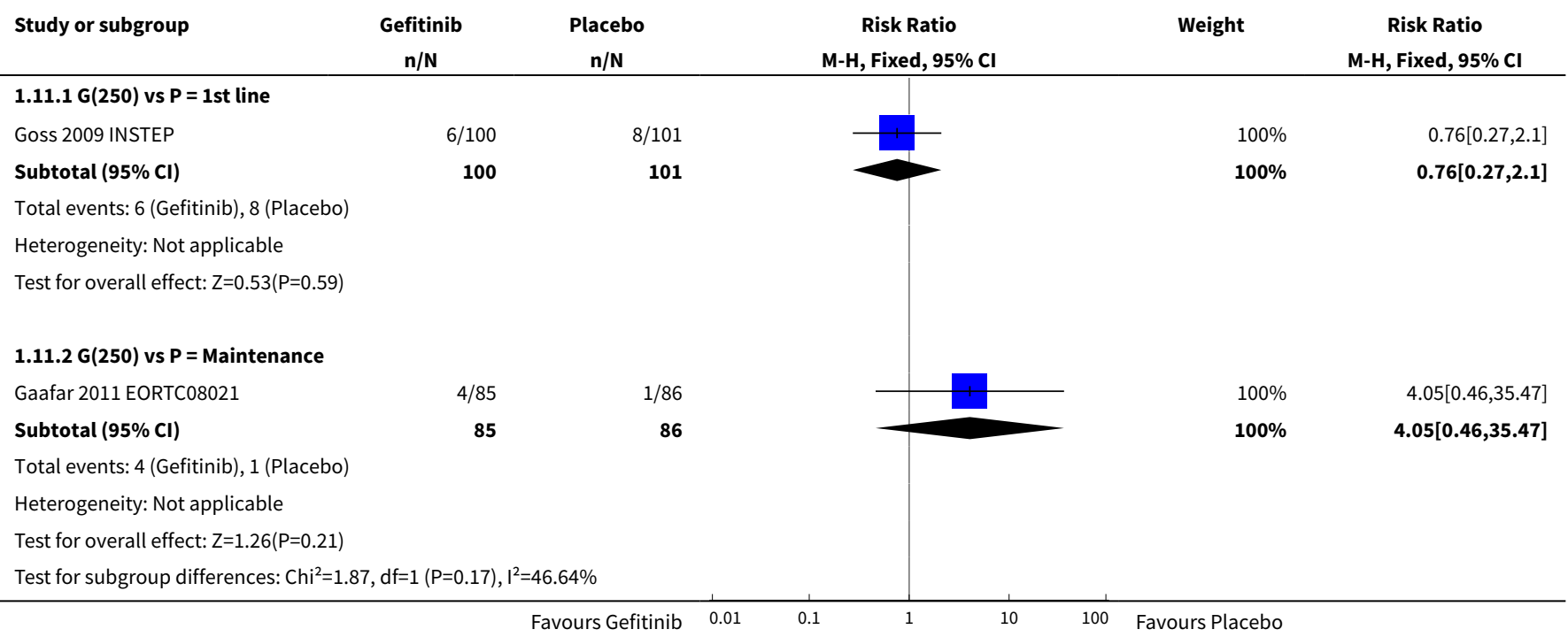

Analysis 1.12. Comparison 1 Gefitinib versus placebo, Outcome 12 Asthenia.

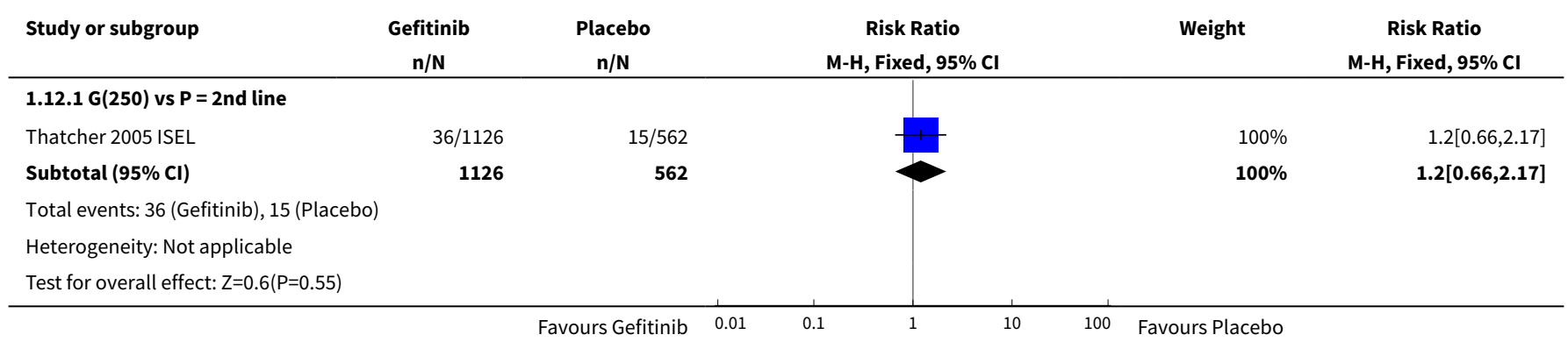

Analysis 1.13. Comparison 1 Gefitinib versus placebo, Outcome 13 Respiratory tract infection.

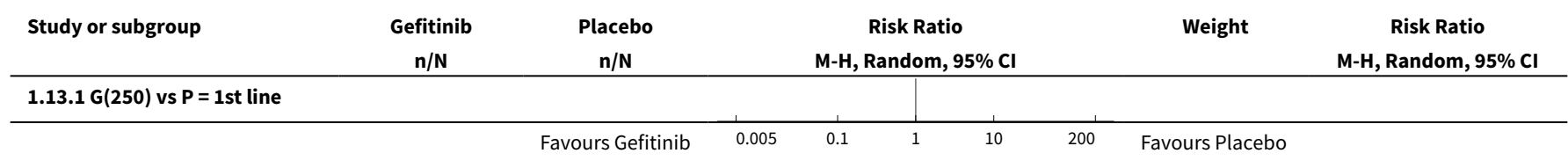




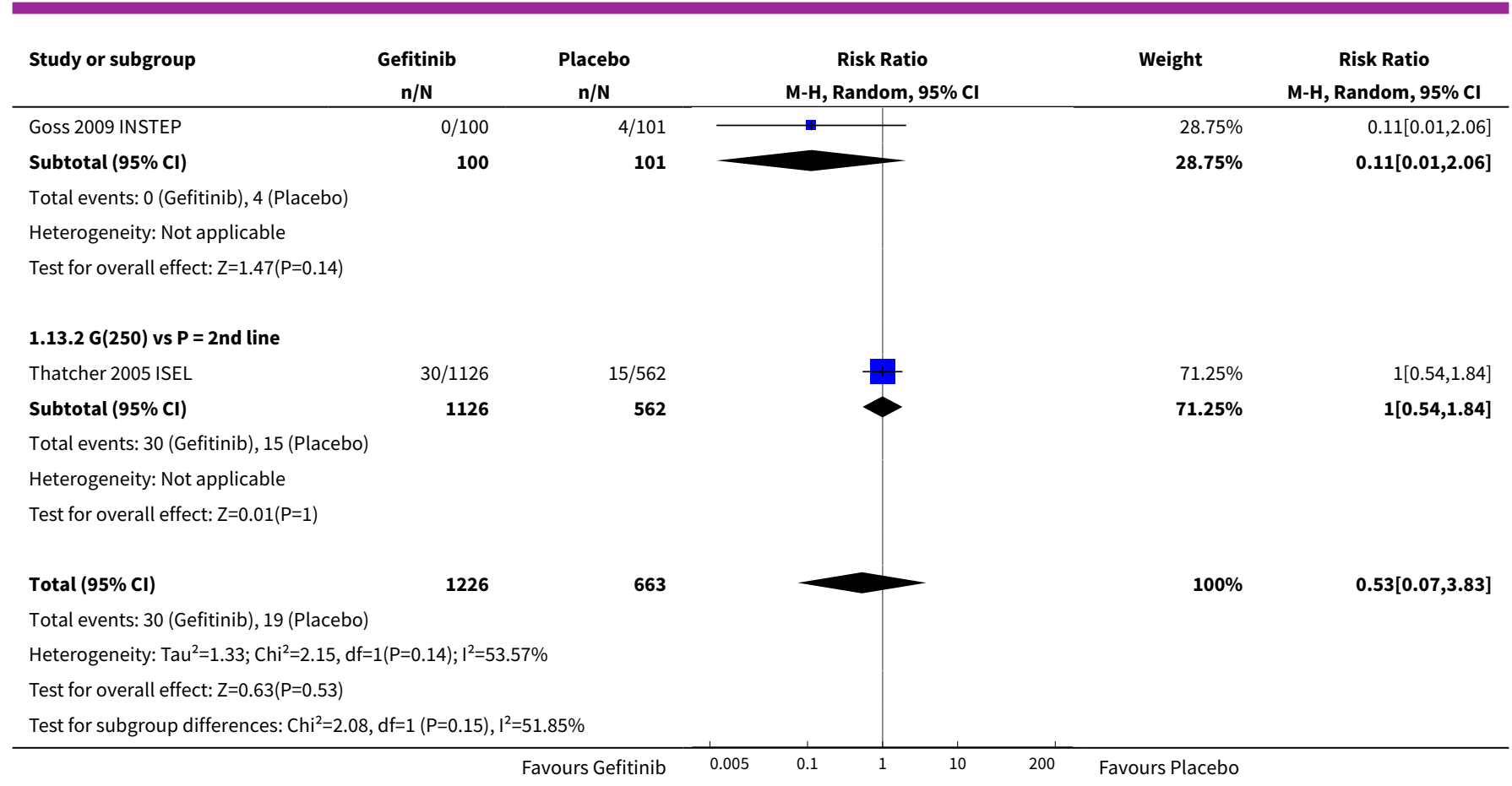

Analysis 1.14. Comparison 1 Gefitinib versus placebo, Outcome 14 Dyspnoea.

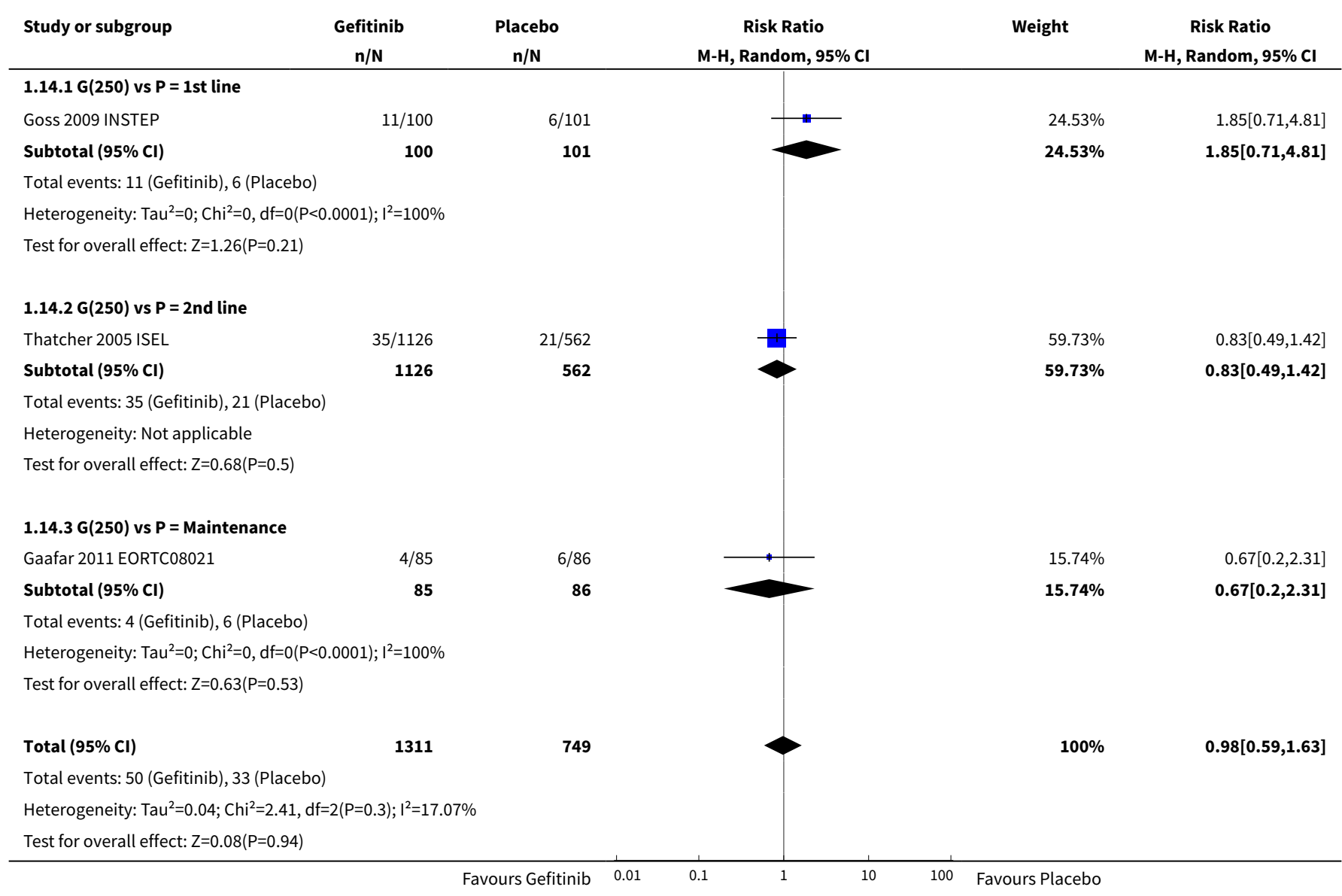




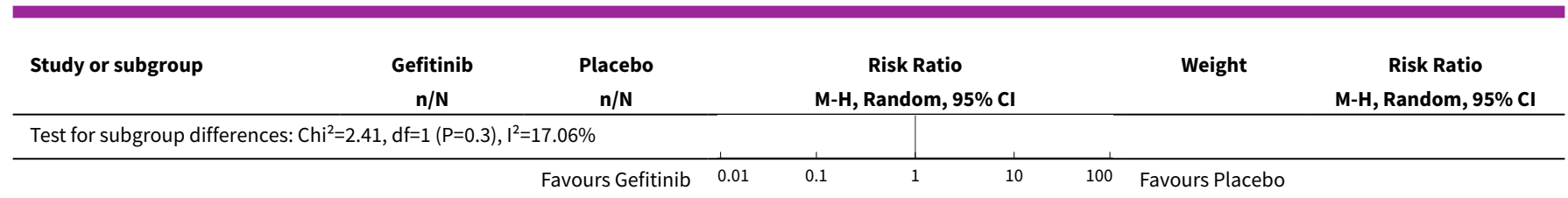

Analysis 1.15. Comparison 1 Gefitinib versus placebo, Outcome 15 Anaemia.

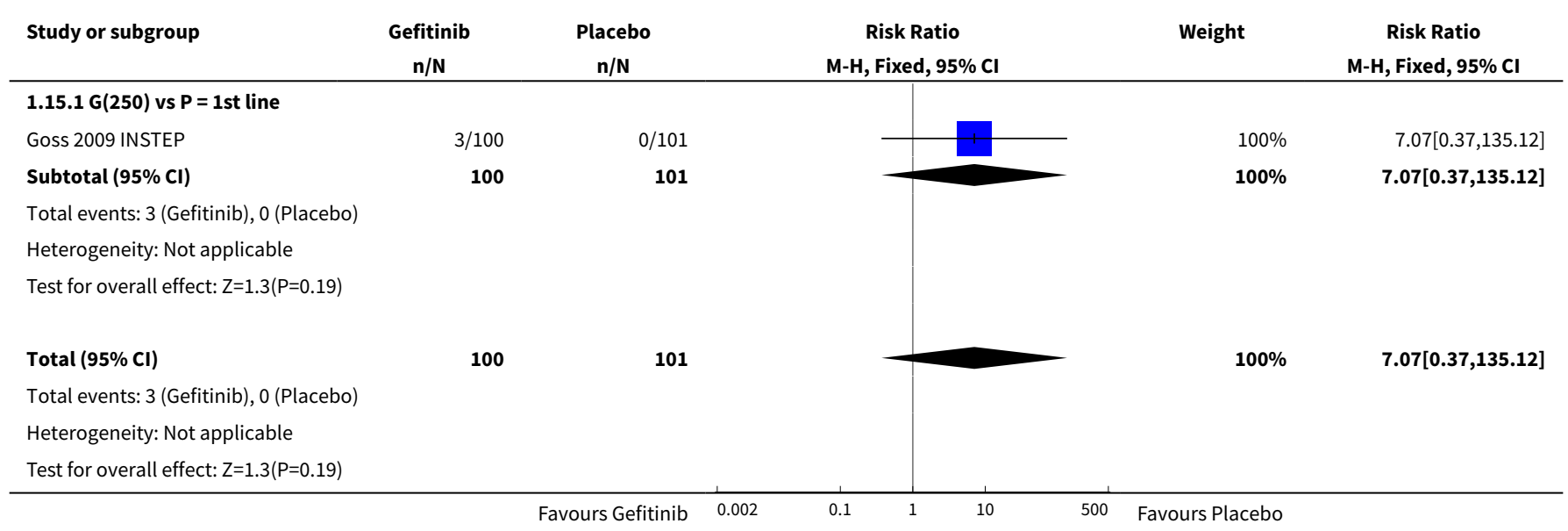

Analysis 1.16. Comparison 1 Gefitinib versus placebo, Outcome 16 Abdominal pain.

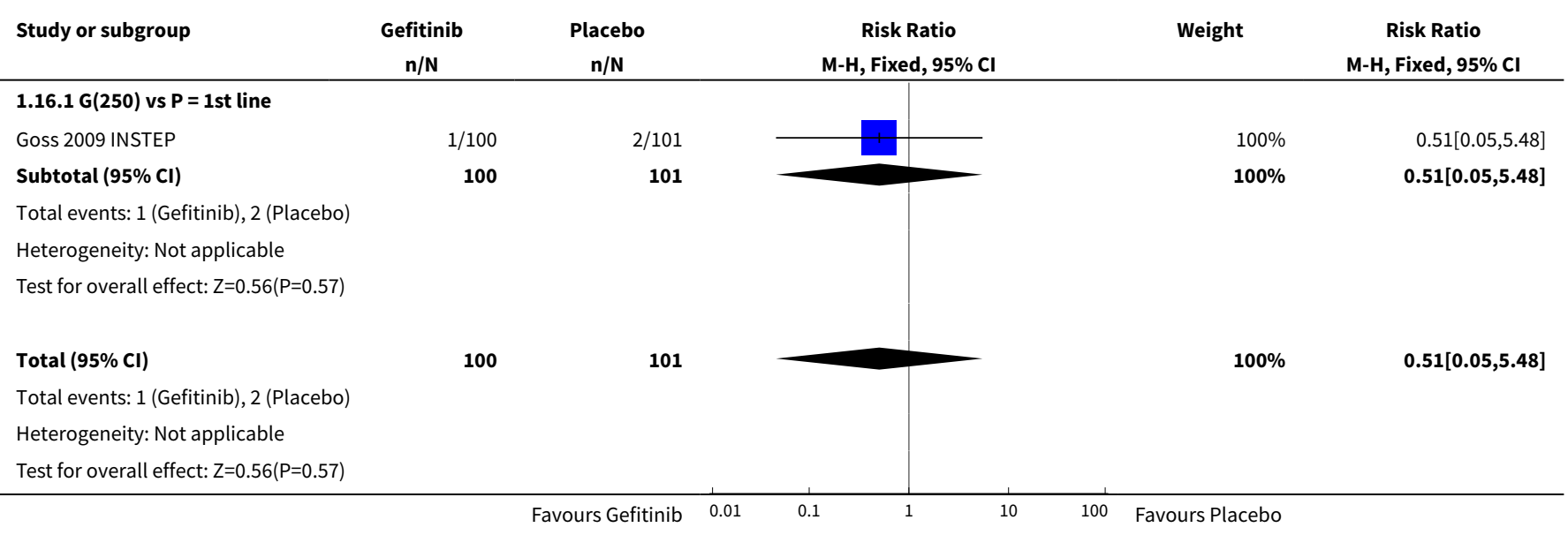

Analysis 1.17. Comparison 1 Gefitinib versus placebo, Outcome 17 Increased ALT.

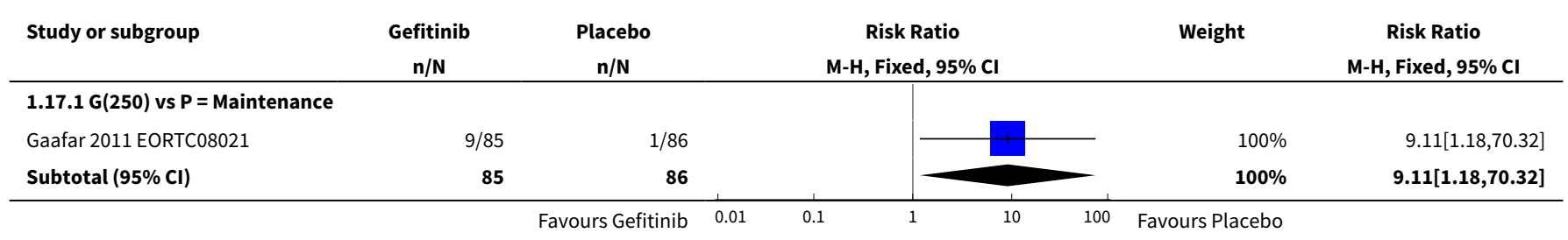




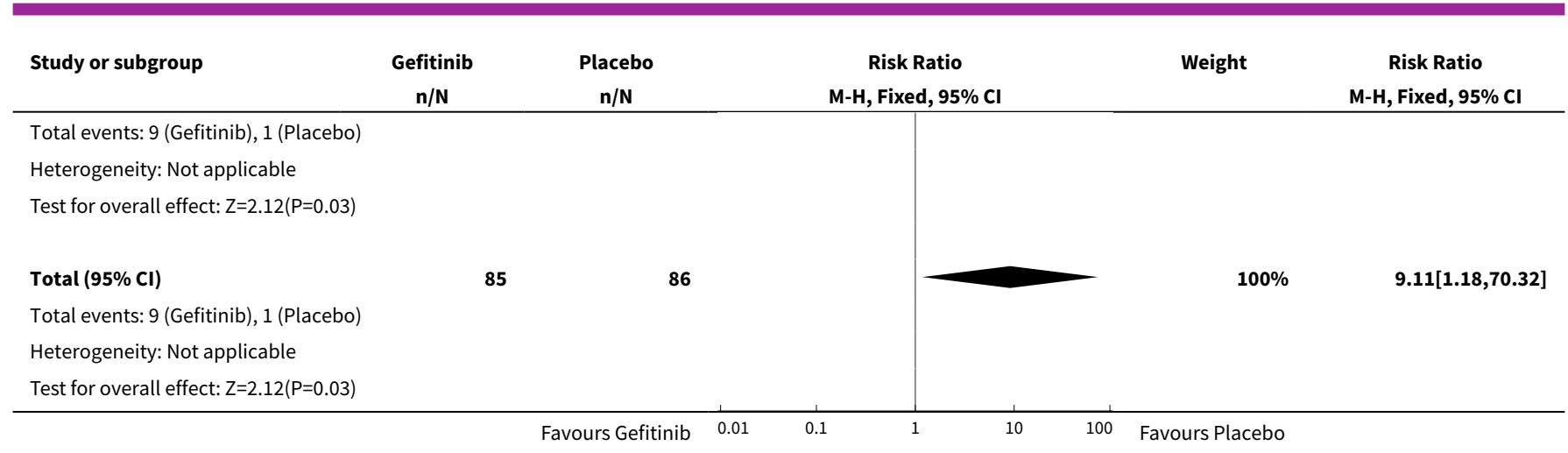

Analysis 1.18. Comparison 1 Gefitinib versus placebo, Outcome 18 Increased AST.

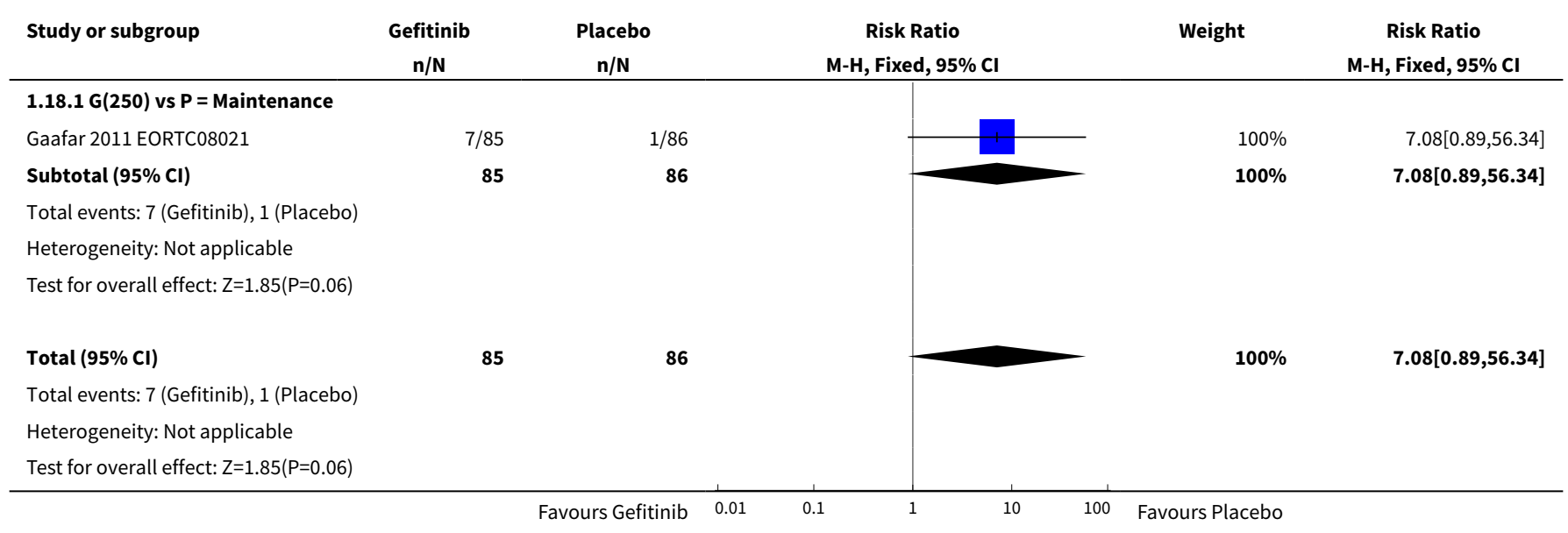

Analysis 1.19. Comparison 1 Gefitinib versus placebo, Outcome 19 Neutropenia.

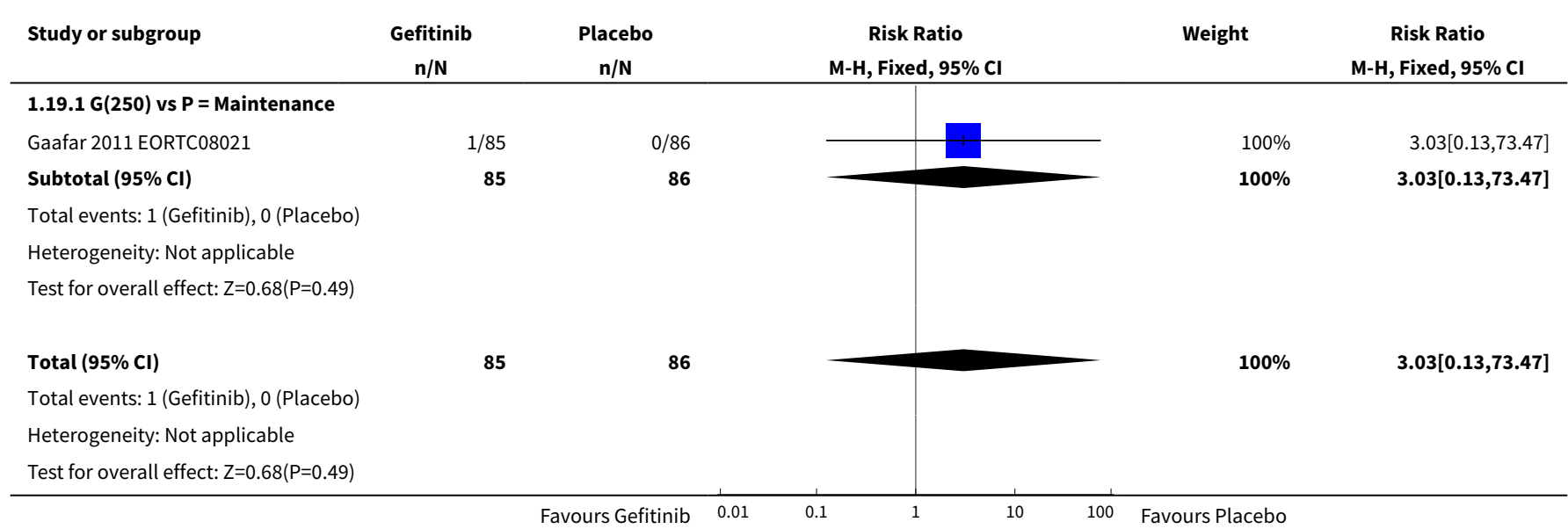


Analysis 1.20. Comparison 1 Gefitinib versus placebo, Outcome 20 Anaemia.

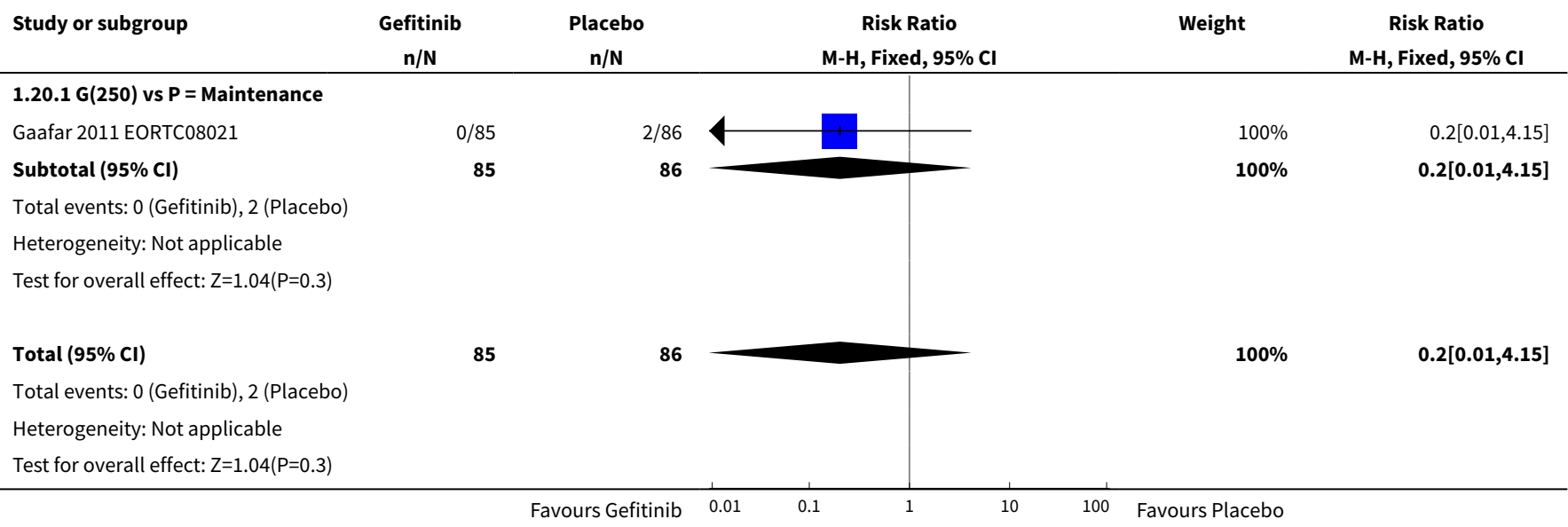

Analysis 1.21. Comparison 1 Gefitinib versus placebo, Outcome 21 Thrombocytopaenia.

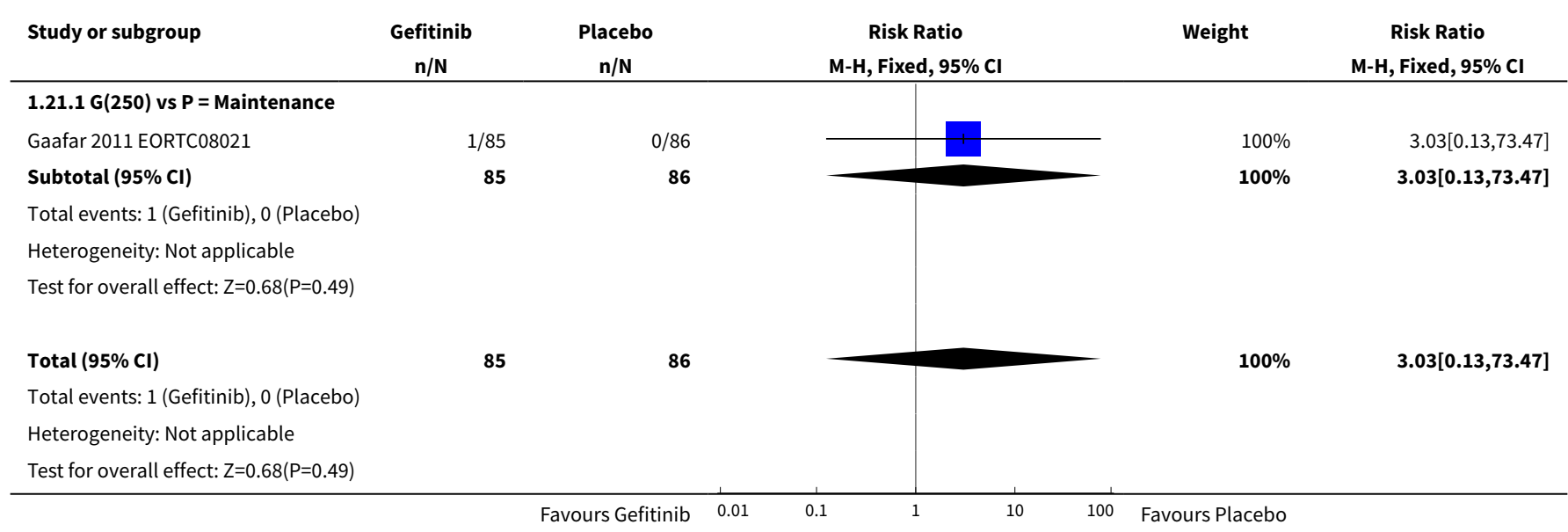

Analysis 1.22. Comparison 1 Gefitinib versus placebo, Outcome 22 Overall response rate.

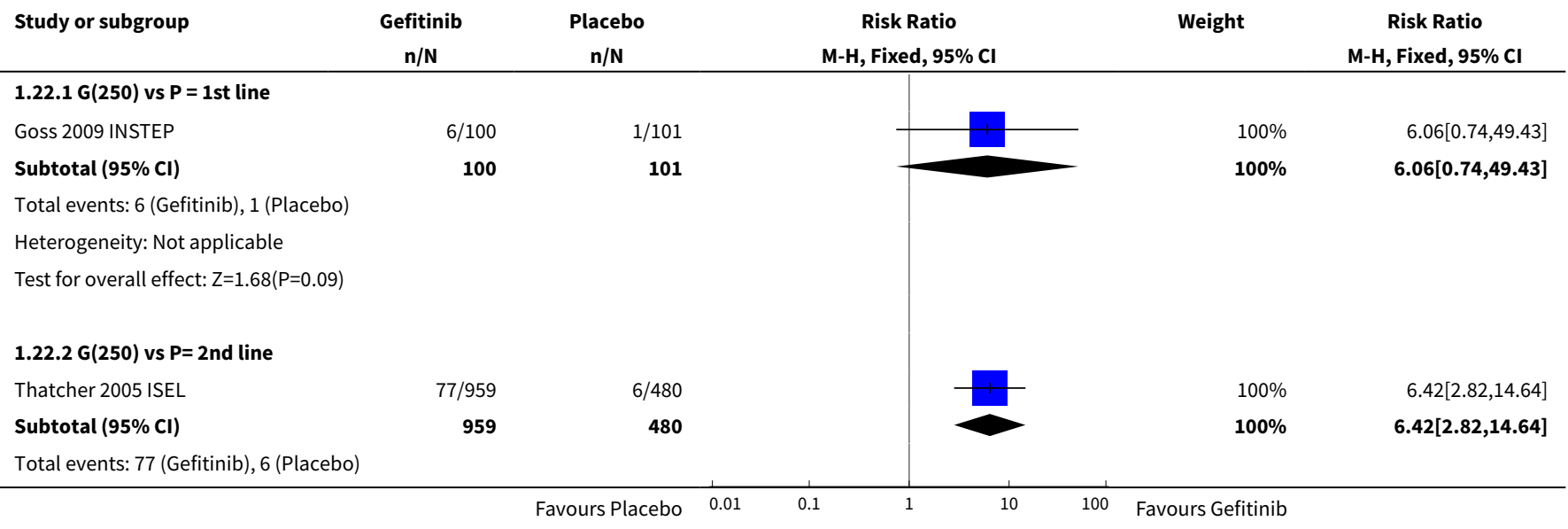




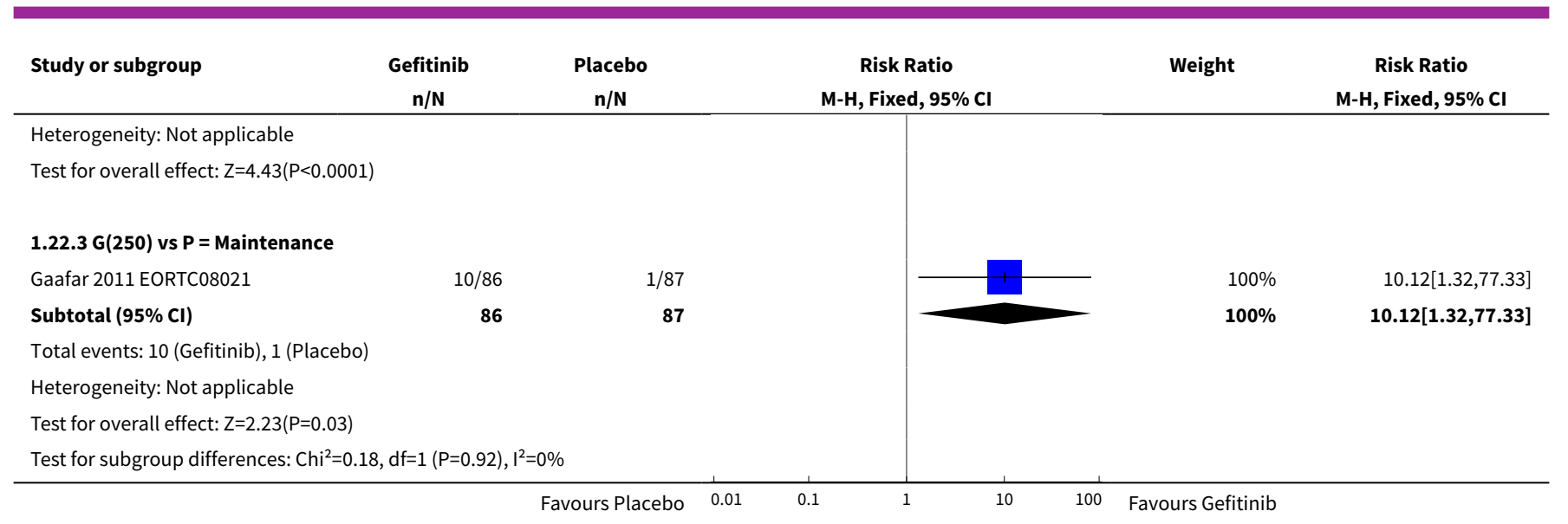

Analysis 1.23. Comparison 1 Gefitinib versus placebo, Outcome 23 Disease control rate.

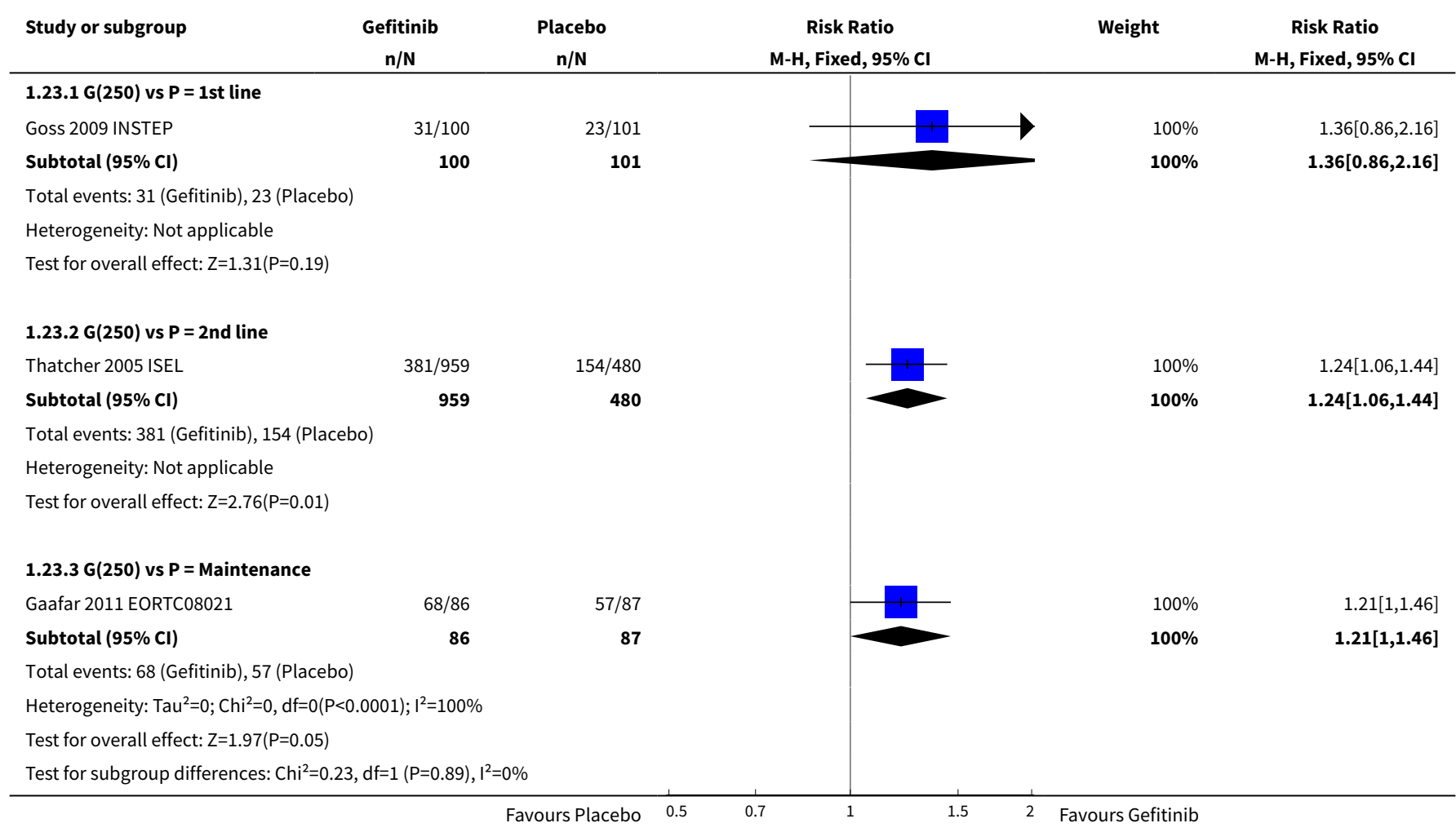

Comparison 2. Gefitinib versus placebo (Asian subgroup)

\begin{tabular}{lllll}
\hline Outcome or subgroup title & No. of studies & $\begin{array}{l}\text { No. of partici- } \\
\text { pants }\end{array}$ & Statistical method & Effect size \\
\hline 1 HR Overall survival & 2 & & Hazard Ratio (Fixed, 95\% Cl) & Subtotals only \\
\hline $1.1 \mathrm{G}(250)$ vs $\mathrm{P}=$ 2nd line & 1 & Hazard Ratio (Fixed, 95\% Cl) & $0.66[0.48,0.91]$ \\
\hline
\end{tabular}




\begin{tabular}{lllll}
\hline Outcome or subgroup title & No. of studies & $\begin{array}{l}\text { No. of partici- } \\
\text { pants }\end{array}$ & Statistical method & Effect size \\
\hline $1.2 \mathrm{G}(250)$ vs P = Maintenance & 1 & & Hazard Ratio (Fixed, 95\% Cl) & $0.88[0.68,1.14]$ \\
\hline 2 HR Progression-free survival & 2 & Hazard Ratio (Fixed, 95\% Cl) & Subtotals only \\
\hline $2.1 \mathrm{G}(250)$ vs P = 2nd line & 1 & Hazard Ratio (Fixed, 95\% Cl) & $0.69[0.52,0.91]$ \\
\hline $2.2 \mathrm{G}(250)$ vs P = Maintenance & 1 & Hazard Ratio (Fixed, 95\% Cl) & $0.42[0.33,0.54]$ \\
\hline 31 -year survival rate & 1 & Risk Ratio (M-H, Fixed, 95\% Cl) & Subtotals only \\
\hline $3.1 \mathrm{G}(250)$ vs P = 2nd line & 1 & Risk Ratio (M-H, Fixed, 95\% Cl) & $1.75[1.20,2.55]$ \\
\hline 4 Overall response rate & 2 & 342 & Risk Ratio (M-H, Random, 95\% Cl) & Subtotals only \\
\hline $4.1 \mathrm{G}(250)$ vs P = 2nd line & 1 & Risk Ratio (M-H, Random, 95\% Cl) & $6.03[1.46,24.91]$ \\
\hline $4.2 \mathrm{G}(250)$ vs P = Maintenance & 1 & 306 & Risk Ratio (M-H, Random, 95\% Cl) & $35.00[4.86,252.15]$ \\
\hline
\end{tabular}

Analysis 2.1. Comparison 2 Gefitinib versus placebo (Asian subgroup), Outcome 1 HR Overall survival.

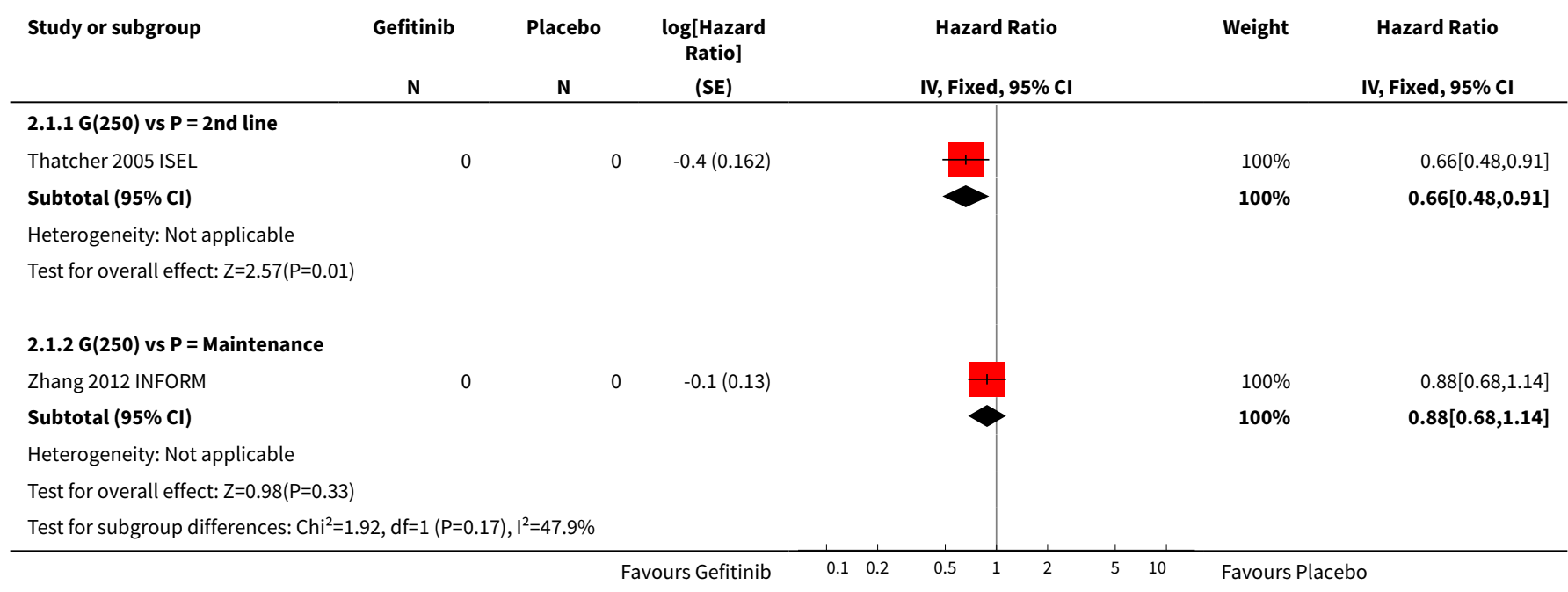

Analysis 2.2. Comparison 2 Gefitinib versus placebo (Asian subgroup), Outcome 2 HR Progression-free survival.

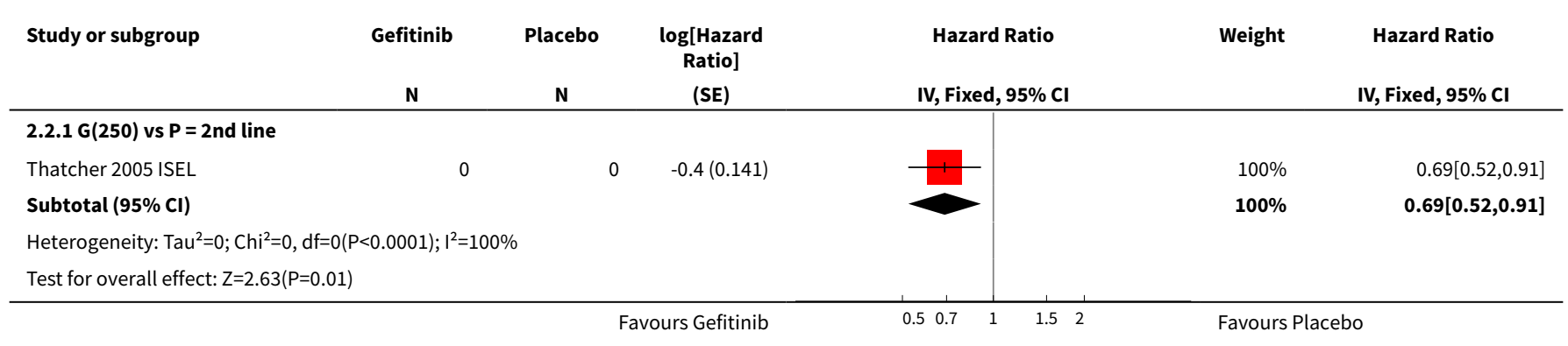




\begin{tabular}{|c|c|c|c|c|c|c|}
\hline Study or subgroup & $\begin{array}{c}\text { Gefitinib } \\
\text { N }\end{array}$ & $\begin{array}{c}\text { Placebo } \\
\text { N }\end{array}$ & $\begin{array}{c}\log [\text { Hazard } \\
\text { Ratio] } \\
\text { (SE) }\end{array}$ & Hazard Ratio & Weight & $\begin{array}{c}\text { Hazard Ratio } \\
\text { IV, Fixed, } 95 \% \mathrm{CI}\end{array}$ \\
\hline \multicolumn{7}{|c|}{ 2.2.2 G(250) vs $P=$ Maintenance } \\
\hline Zhang 2012 INFORM & 0 & 0 & $-0.9(0.129)$ & - & $100 \%$ & $0.42[0.33,0.54]$ \\
\hline Subtotal $(95 \% \mathrm{Cl})$ & & & & & $100 \%$ & $0.42[0.33,0.54]$ \\
\hline \multicolumn{7}{|c|}{ Heterogeneity: Not applicable } \\
\hline \multicolumn{7}{|c|}{ Test for overall effect: $Z=6.72(P<0.0001)$} \\
\hline \multicolumn{7}{|c|}{ Test for subgroup differences: $\mathrm{Chi}^{2}=6.73, \mathrm{df}=1(\mathrm{P}=0.01), \mathrm{I}^{2}=85.14 \%$} \\
\hline
\end{tabular}

\section{Analysis 2.3. Comparison 2 Gefitinib versus placebo (Asian subgroup), Outcome 3 1-year survival rate.}

\begin{tabular}{|c|c|c|c|c|c|}
\hline Study or subgroup & $\begin{array}{c}\text { Gefitinib } \\
n / N\end{array}$ & $\begin{array}{c}\text { Placebo } \\
\mathbf{n} / \mathbf{N}\end{array}$ & $\begin{array}{c}\text { Risk Ratio } \\
\text { M-H, Fixed, 95\% Cl }\end{array}$ & Weight & $\begin{array}{c}\text { Risk Ratio } \\
\text { M-H, Fixed, 95\% Cl }\end{array}$ \\
\hline \multicolumn{6}{|c|}{ 2.3.1 G(250) vs $P=2$ nd line } \\
\hline Thatcher 2005 ISEL & $96 / 235$ & $25 / 107$ & & $100 \%$ & $1.75[1.2,2.55]$ \\
\hline Subtotal $(95 \% \mathrm{CI})$ & 235 & 107 & & $100 \%$ & $1.75[1.2,2.55]$ \\
\hline \multicolumn{6}{|c|}{ Total events: 96 (Gefitinib), 25 (Placebo) } \\
\hline \multicolumn{6}{|c|}{ Heterogeneity: Not applicable } \\
\hline
\end{tabular}

\section{Analysis 2.4. Comparison 2 Gefitinib versus placebo (Asian subgroup), Outcome 4 Overall response rate.}

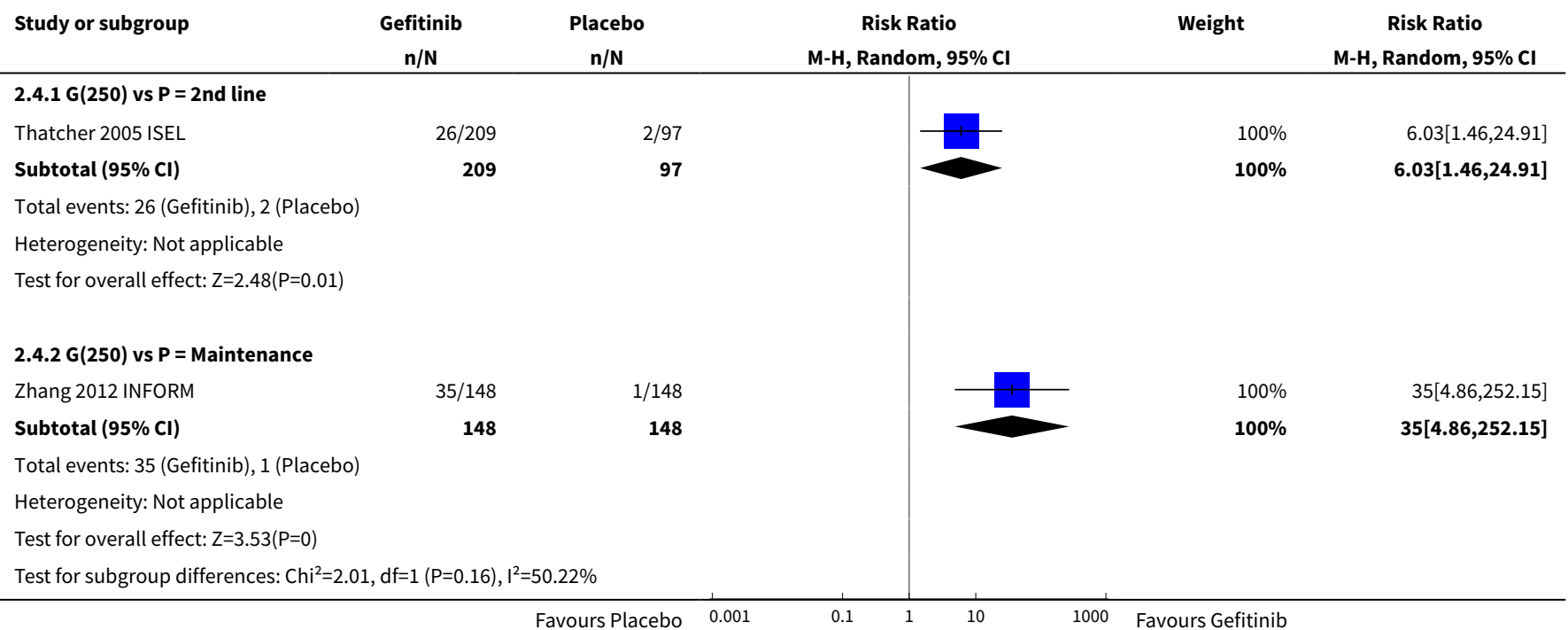


Comparison 3. Gefitinib versus placebo (biomarker subgroup)

\begin{tabular}{lllll}
\hline Outcome or subgroup title & No. of studies & $\begin{array}{l}\text { No. of partici- } \\
\text { pants }\end{array}$ & Statistical method & Effect size \\
\hline 1 HR Overall survival & 1 & Hazard Ratio (Fixed, 95\% Cl) & Subtotals only \\
\hline $1.1 \mathrm{G}(250)$ vs P = Maintenance & 1 & Hazard Ratio (Fixed, 95\% Cl) & $0.39[0.15,0.98]$ \\
\hline 2 HR Progression-free survival & 1 & Hazard Ratio (Fixed, 95\% Cl) & Subtotals only \\
\hline $2.1 \mathrm{G}(250)$ vs P = Maintenance & 1 & Hazard Ratio (Fixed, 95\% Cl) & $0.17[0.07,0.41]$ \\
\hline
\end{tabular}

Analysis 3.1. Comparison 3 Gefitinib versus placebo (biomarker subgroup), Outcome 1 HR Overall survival.

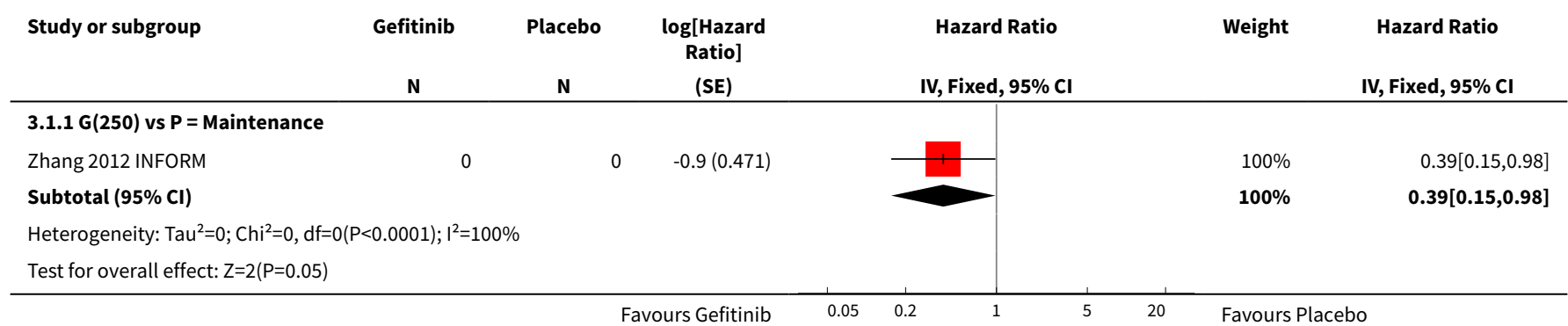

Analysis 3.2. Comparison 3 Gefitinib versus placebo (biomarker subgroup), Outcome 2 HR Progression-free survival.

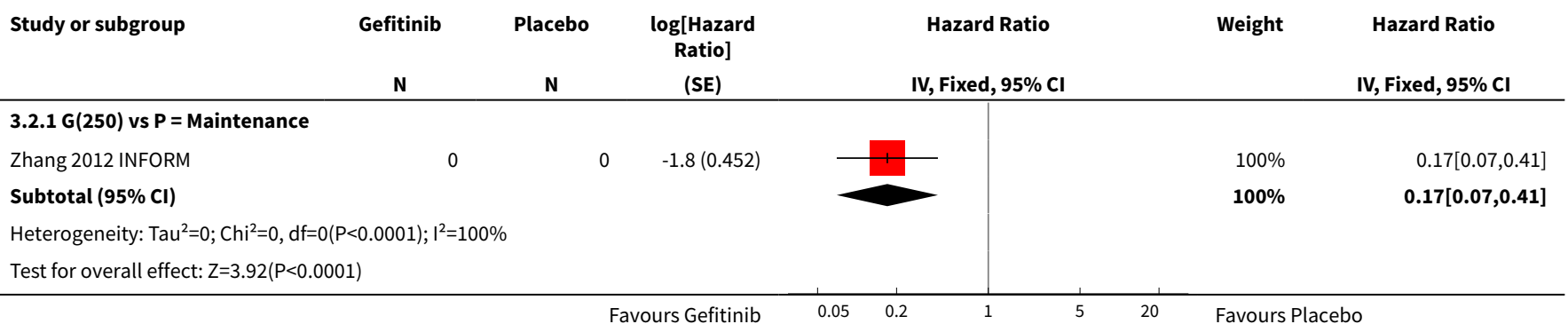

\section{Comparison 4. Gefitinib versus chemotherapy}

\begin{tabular}{lllll}
\hline Outcome or subgroup title & No. of studies & $\begin{array}{l}\text { No. of partici- } \\
\text { pants }\end{array}$ & Statistical method & Effect size \\
\hline 1 HR Overall survival & 2 & Hazard Ratio (Fixed, 95\% Cl) & Subtotals only \\
\hline 1.1 G vs vinorelbine = 1st line & 1 & Hazard Ratio (Fixed, 95\% Cl) & $0.98[0.66,1.46]$ \\
\hline 1.2 G vs docetaxel = 2nd line & 1 & Hazard Ratio (Fixed, 95\% Cl) & $1.02[0.91,1.15]$ \\
\hline
\end{tabular}




\begin{tabular}{|c|c|c|c|c|}
\hline Outcome or subgroup title & No. of studies & $\begin{array}{l}\text { No. of partici- } \\
\text { pants }\end{array}$ & Statistical method & Effect size \\
\hline $\begin{array}{l}2 \text { HR Progression-free sur- } \\
\text { vival }\end{array}$ & 2 & & Hazard Ratio (Fixed, 95\% Cl) & Subtotals only \\
\hline $2.1 \mathrm{G}$ vs vinorelbine $=1 \mathrm{st}$ line & 1 & & Hazard Ratio (Fixed, 95\% Cl) & $1.19[0.86,1.65]$ \\
\hline $2.2 \mathrm{G}$ vs docetaxel $=2 \mathrm{nd}$ line & 1 & & Hazard Ratio (Fixed, 95\% Cl) & $1.04[0.92,1.17]$ \\
\hline 31 -year survival rate & 3 & 1741 & Risk Ratio (M-H, Fixed, 95\% Cl) & $0.94[0.82,1.08]$ \\
\hline $3.1 \mathrm{G}$ vs vinorelbine $=1$ st line & 1 & 190 & Risk Ratio (M-H, Fixed, 95\% Cl) & $1.02[0.69,1.52]$ \\
\hline $3.2 \mathrm{G}$ vs docetaxel = 1 st line & 1 & 85 & Risk Ratio (M-H, Fixed, 95\% Cl) & $0.39[0.08,1.90]$ \\
\hline $3.3 \mathrm{G}$ vs docetaxel $=2 \mathrm{nd}$ line & 1 & 1466 & Risk Ratio (M-H, Fixed, 95\% Cl) & $0.94[0.82,1.09]$ \\
\hline 4 Skin rash & 4 & 1858 & Risk Ratio (M-H, Fixed, 95\% Cl) & $2.40[1.08,5.31]$ \\
\hline $4.1 \mathrm{G}$ vs vinorelbine $=1$ st line & 1 & 190 & Risk Ratio (M-H, Fixed, 95\% Cl) & $5.11[0.25,104.94]$ \\
\hline $4.2 \mathrm{G}$ vs docetaxel = 1 st line & 1 & 85 & Risk Ratio (M-H, Fixed, 95\% Cl) & $0.49[0.05,5.19]$ \\
\hline $4.3 \mathrm{G}$ vs docetaxel $=2 \mathrm{nd}$ line & 2 & 1583 & Risk Ratio (M-H, Fixed, 95\% Cl) & $2.82[1.11,7.13]$ \\
\hline 5 Constipation & 3 & 1719 & Risk Ratio (M-H, Fixed, 95\% Cl) & $0.41[0.17,0.97]$ \\
\hline $5.1 \mathrm{G}$ vs vinorelbine $=1$ st line & 1 & 190 & Risk Ratio (M-H, Fixed, 95\% Cl) & $0.20[0.01,4.20]$ \\
\hline $5.2 \mathrm{G}$ vs docetaxel = 1 st line & 1 & 85 & Risk Ratio (M-H, Fixed, 95\% Cl) & $0.33[0.01,7.78]$ \\
\hline $5.3 \mathrm{G}$ vs docetaxel $=2 \mathrm{nd}$ line & 1 & 1444 & Risk Ratio (M-H, Fixed, 95\% Cl) & $0.45[0.17,1.18]$ \\
\hline 6 Fatigue & 2 & 275 & Risk Ratio (M-H, Fixed, 95\% Cl) & $0.16[0.03,0.88]$ \\
\hline $6.1 \mathrm{G}$ vs vinorelbine $=1$ st line & 1 & 190 & Risk Ratio (M-H, Fixed, 95\% Cl) & $0.07[0.00,1.18]$ \\
\hline $6.2 \mathrm{G}$ vs docetaxel = 1st line & 1 & 85 & Risk Ratio (M-H, Fixed, 95\% Cl) & $0.49[0.05,5.19]$ \\
\hline 7 Asthenia & 3 & 1773 & Risk Ratio (M-H, Fixed, 95\% Cl) & $0.51[0.35,0.75]$ \\
\hline $7.1 \mathrm{G}$ vs vinorelbine $=1 \mathrm{st}$ line & 1 & 190 & Risk Ratio (M-H, Fixed, 95\% Cl) & $0.15[0.01,2.79]$ \\
\hline $7.2 \mathrm{G}$ vs docetaxel $=2 \mathrm{nd}$ line & 2 & 1583 & Risk Ratio (M-H, Fixed, 95\% Cl) & $0.53[0.36,0.78]$ \\
\hline 8 Neurotoxicity & 2 & 1529 & Risk Ratio (M-H, Fixed, 95\% Cl) & $0.07[0.01,0.34]$ \\
\hline $8.1 \mathrm{G}$ vs docetaxel = 1st line & 1 & 85 & Risk Ratio (M-H, Fixed, 95\% Cl) & $0.09[0.01,1.56]$ \\
\hline $8.2 \mathrm{G}$ vs docetaxel $=2$ nd line & 1 & 1444 & Risk Ratio (M-H, Fixed, 95\% Cl) & $0.06[0.01,0.43]$ \\
\hline 9 Neutropenia & 4 & 1857 & Risk Ratio (M-H, Fixed, 95\% Cl) & $0.04[0.02,0.06]$ \\
\hline $9.1 \mathrm{G}$ vs vinorelbine $=1 \mathrm{st}$ line & 1 & 190 & Risk Ratio (M-H, Fixed, 95\% Cl) & $0.03[0.00,0.43]$ \\
\hline $9.2 \mathrm{G}$ vs docetaxel = 1 st line & 1 & 85 & Risk Ratio (M-H, Fixed, 95\% Cl) & $0.15[0.04,0.63]$ \\
\hline
\end{tabular}




\begin{tabular}{|c|c|c|c|c|}
\hline Outcome or subgroup title & No. of studies & $\begin{array}{l}\text { No. of partici- } \\
\text { pants }\end{array}$ & Statistical method & Effect size \\
\hline $9.3 \mathrm{G}$ vs docetaxel $=2$ nd line & 2 & 1582 & Risk Ratio (M-H, Fixed, 95\% Cl) & $0.04[0.02,0.06]$ \\
\hline 10 Leukopenia & 2 & 324 & Risk Ratio (M-H, Fixed, 95\% Cl) & $0.03[0.00,0.22]$ \\
\hline $\begin{array}{l}10.1 \mathrm{G} \text { vs vinorelbine }=1 \text { st } \\
\text { line }\end{array}$ & 1 & 190 & Risk Ratio (M-H, Fixed, 95\% Cl) & $0.07[0.00,1.18]$ \\
\hline $10.2 \mathrm{G}$ vs docetaxel $=2 \mathrm{nd}$ line & 1 & 134 & Risk Ratio (M-H, Fixed, 95\% Cl) & $0.02[0.00,0.32]$ \\
\hline 11 Febrile neutropenia & 3 & 1768 & Risk Ratio (M-H, Fixed, 95\% Cl) & $0.12[0.06,0.23]$ \\
\hline $\begin{array}{l}11.1 \mathrm{G} \text { vs vinorelbine }=1 \text { st } \\
\text { line }\end{array}$ & 1 & 190 & Risk Ratio (M-H, Fixed, 95\% Cl) & $0.07[0.00,1.18]$ \\
\hline $11.2 \mathrm{G}$ vs docetaxel $=2$ nd line & 2 & 1578 & Risk Ratio (M-H, Fixed, 95\% Cl) & $0.13[0.06,0.24]$ \\
\hline 12 Pruritus & 1 & 139 & Risk Ratio (M-H, Fixed, 95\% Cl) & $5.22[0.26,106.74]$ \\
\hline $12.1 \mathrm{G}$ vs docetaxel $=2 \mathrm{nd}$ line & 1 & 139 & Risk Ratio (M-H, Fixed, 95\% Cl) & $5.22[0.26,106.74]$ \\
\hline 13 Diarrhoea & 4 & 1858 & Risk Ratio (M-H, Fixed, 95\% Cl) & $0.81[0.48,1.34]$ \\
\hline $\begin{array}{l}13.1 \mathrm{G} \text { vs vinorelbine }=1 \text { st } \\
\text { line }\end{array}$ & 1 & 190 & Risk Ratio (M-H, Fixed, 95\% Cl) & $1.02[0.26,3.96]$ \\
\hline 13.2 G vs docetaxel = 1st line & 1 & 85 & Risk Ratio (M-H, Fixed, 95\% Cl) & $0.98[0.14,6.62]$ \\
\hline $13.3 \mathrm{G}$ vs docetaxel $=2$ nd line & 2 & 1583 & Risk Ratio (M-H, Fixed, 95\% Cl) & $0.76[0.43,1.35]$ \\
\hline 14 Vomiting & 2 & 1583 & Risk Ratio (M-H, Fixed, 95\% Cl) & $0.55[0.19,1.63]$ \\
\hline 14.1 G vs docetaxel $=2$ nd line & 2 & 1583 & Risk Ratio (M-H, Fixed, 95\% Cl) & $0.55[0.19,1.63]$ \\
\hline 15 Anorexia & 3 & 1719 & Risk Ratio (M-H, Fixed, 95\% Cl) & $1.43[0.61,3.32]$ \\
\hline $\begin{array}{l}15.1 \mathrm{G} \text { vs vinorelbine = 1st } \\
\text { line }\end{array}$ & 1 & 190 & Risk Ratio (M-H, Fixed, 95\% Cl) & $1.02[0.15,7.10]$ \\
\hline $15.2 \mathrm{G}$ vs docetaxel $=1$ st line & 1 & 85 & Risk Ratio (M-H, Fixed, 95\% Cl) & $0.0[0.0,0.0]$ \\
\hline $15.3 \mathrm{G}$ vs docetaxel $=2$ nd line & 1 & 1444 & Risk Ratio (M-H, Fixed, 95\% Cl) & $1.54[0.60,3.95]$ \\
\hline 16 Stomatitis & 1 & 1444 & Risk Ratio (M-H, Fixed, 95\% Cl) & $0.14[0.01,2.71]$ \\
\hline $16.1 \mathrm{G}$ vs docetaxel $=2 \mathrm{nd}$ line & 1 & 1444 & Risk Ratio (M-H, Fixed, 95\% Cl) & $0.14[0.01,2.71]$ \\
\hline 17 Arthralgia/myalgia & 2 & 1529 & Risk Ratio (M-H, Fixed, 95\% Cl) & $0.25[0.03,2.19]$ \\
\hline $17.1 \mathrm{G}$ vs docetaxel = 1st line & 1 & 85 & Risk Ratio (M-H, Fixed, 95\% Cl) & $0.0[0.0,0.0]$ \\
\hline 17.2 G vs docetaxel = 2nd line & 1 & 1444 & Risk Ratio (M-H, Fixed, 95\% Cl) & $0.25[0.03,2.19]$ \\
\hline 18 Peripheral oedema & 2 & 1634 & Risk Ratio (M-H, Fixed, 95\% Cl) & $0.09[0.00,1.61]$ \\
\hline
\end{tabular}




\begin{tabular}{|c|c|c|c|c|}
\hline Outcome or subgroup title & No. of studies & $\begin{array}{l}\text { No. of partici- } \\
\text { pants }\end{array}$ & Statistical method & Effect size \\
\hline $\begin{array}{l}18.1 \mathrm{G} \text { vs vinorelbine }=1 \text { st } \\
\text { line }\end{array}$ & 1 & 190 & Risk Ratio (M-H, Fixed, 95\% Cl) & $0.0[0.0,0.0]$ \\
\hline 18.2 G vs docetaxel = 2nd line & 1 & 1444 & Risk Ratio (M-H, Fixed, 95\% Cl) & $0.09[0.00,1.61]$ \\
\hline 19 Respiratory tract infection & 1 & 1444 & Risk Ratio (M-H, Fixed, 95\% Cl) & $0.90[0.52,1.57]$ \\
\hline 19.1 G vs docetaxel = 2nd line & 1 & 1444 & Risk Ratio (M-H, Fixed, 95\% Cl) & $0.90[0.52,1.57]$ \\
\hline 20 Dyspnoea & 3 & 1773 & Risk Ratio (M-H, Fixed, 95\% Cl) & $0.82[0.57,1.16]$ \\
\hline $\begin{array}{l}20.1 \mathrm{G} \text { vs vinorelbine }=1 \text { st } \\
\text { line }\end{array}$ & 1 & 190 & Risk Ratio (M-H, Fixed, 95\% Cl) & $0.26[0.03,2.24]$ \\
\hline $20.2 \mathrm{G}$ vs docetaxel $=2 \mathrm{nd}$ line & 2 & 1583 & Risk Ratio (M-H, Fixed, 95\% Cl) & $0.85[0.59,1.22]$ \\
\hline 21 Cough & 2 & 1583 & Risk Ratio (M-H, Fixed, 95\% Cl) & $1.18[0.36,3.84]$ \\
\hline $21.1 \mathrm{G}$ vs docetaxel $=2 \mathrm{nd}$ line & 2 & 1583 & Risk Ratio (M-H, Fixed, 95\% Cl) & $1.18[0.36,3.84]$ \\
\hline 22 Anaemia & 4 & 1853 & Risk Ratio (M-H, Fixed, 95\% Cl) & $0.70[0.36,1.36]$ \\
\hline $\begin{array}{l}22.1 \mathrm{G} \text { vs vinorelbine = 1st } \\
\text { line }\end{array}$ & 1 & 190 & Risk Ratio (M-H, Fixed, 95\% Cl) & $0.34[0.01,8.25]$ \\
\hline $22.2 \mathrm{G}$ vs docetaxel = 1st line & 1 & 85 & Risk Ratio (M-H, Fixed, 95\% Cl) & $0.14[0.01,2.62]$ \\
\hline $22.3 \mathrm{G}$ vs docetaxel $=2$ nd line & 2 & 1578 & Risk Ratio (M-H, Fixed, 95\% Cl) & $0.86[0.42,1.75]$ \\
\hline 23 Thrombocytopenia & 2 & 219 & Risk Ratio (M-H, Fixed, 95\% Cl) & $3.0[0.12,72.35]$ \\
\hline $23.1 \mathrm{G}$ vs docetaxel = 1st line & 1 & 85 & Risk Ratio (M-H, Fixed, 95\% Cl) & $0.0[0.0,0.0]$ \\
\hline $23.2 \mathrm{G}$ vs docetaxel $=2 \mathrm{nd}$ line & 1 & 134 & Risk Ratio (M-H, Fixed, 95\% Cl) & $3.0[0.12,72.35]$ \\
\hline 24 Hypokalaemia & 1 & 190 & Risk Ratio (M-H, Fixed, 95\% Cl) & $1.02[0.06,16.09]$ \\
\hline $\begin{array}{l}24.1 \mathrm{G} \text { vs vinorelbine = 1st } \\
\text { line }\end{array}$ & 1 & 190 & Risk Ratio (M-H, Fixed, 95\% Cl) & $1.02[0.06,16.09]$ \\
\hline 25 Pyrexia & 3 & 1773 & Risk Ratio (M-H, Fixed, 95\% Cl) & $0.59[0.14,2.47]$ \\
\hline $\begin{array}{l}25.1 \mathrm{G} \text { vs vinorelbine = 1st } \\
\text { line }\end{array}$ & 1 & 190 & Risk Ratio (M-H, Fixed, 95\% Cl) & $1.02[0.06,16.09]$ \\
\hline $25.2 \mathrm{G}$ vs docetaxel = 2 nd line & 2 & 1583 & Risk Ratio (M-H, Fixed, 95\% Cl) & $0.49[0.09,2.67]$ \\
\hline 26 Overall response rate & 2 & & Risk Ratio (M-H, Fixed, 95\% Cl) & Subtotals only \\
\hline $26.1 \mathrm{G}$ vs docetaxel = 2nd line & 2 & 1607 & Risk Ratio (M-H, Fixed, 95\% Cl) & $1.16[0.85,1.59]$ \\
\hline 27 Disease control rate & 2 & & Risk Ratio (M-H, Fixed, 95\% Cl) & Subtotals only \\
\hline $27.1 \mathrm{G}$ vs docetaxel = 1st line & 1 & 190 & Risk Ratio (M-H, Fixed, 95\% Cl) & $0.82[0.61,1.10]$ \\
\hline
\end{tabular}




\begin{tabular}{|c|c|c|c|c|}
\hline Outcome or subgroup title & No. of studies & $\begin{array}{l}\text { No. of partici- } \\
\text { pants }\end{array}$ & Statistical method & Effect size \\
\hline $27.2 \mathrm{G}$ vs docetaxel $=2$ nd line & 1 & 141 & Risk Ratio (M-H, Fixed, 95\% Cl) & $1.07[0.82,1.40]$ \\
\hline $\begin{array}{l}28 \text { FACT-L QOL improvement } \\
\text { rate }\end{array}$ & 2 & 1656 & Mean Difference (IV, Fixed, 95\% CI) & $10.50[9.55,11.45]$ \\
\hline $\begin{array}{l}28.1 \mathrm{G} \text { vs vinorelbine }=1 \mathrm{st} \\
\text { line }\end{array}$ & 1 & 190 & Mean Difference (IV, Fixed, 95\% CI) & $13.4[8.25,18.55]$ \\
\hline 28.2 G vs docetaxel = 2nd line & 1 & 1466 & Mean Difference (IV, Fixed, 95\% CI) & $10.40[9.43,11.37]$ \\
\hline $\begin{array}{l}29 \text { LCS QOL improvement } \\
\text { rate }\end{array}$ & 2 & 1656 & Mean Difference (IV, Fixed, 95\% Cl) & $3.63[3.08,4.19]$ \\
\hline $\begin{array}{l}29.1 \mathrm{G} \text { vs vinorelbine = 1st } \\
\text { line }\end{array}$ & 1 & 190 & Mean Difference (IV, Fixed, 95\% CI) & $3.80[2.42,5.18]$ \\
\hline 29.2 G vs docetaxel = 2nd line & 1 & 1466 & Mean Difference (IV, Fixed, 95\% CI) & $3.60[2.99,4.21]$ \\
\hline $\begin{array}{l}30 \mathrm{TOI} \text { QOL improvement } \\
\text { rate }\end{array}$ & 2 & 1656 & $\begin{array}{l}\text { Mean Difference (IV, Random, 95\% } \\
\mathrm{Cl} \text { ) }\end{array}$ & $9.87[1.26,18.48]$ \\
\hline $\begin{array}{l}30.1 \mathrm{G} \text { vs vinorelbine }=1 \mathrm{st} \\
\text { line }\end{array}$ & 1 & 190 & $\begin{array}{l}\text { Mean Difference (IV, Random, 95\% } \\
\text { Cl) }\end{array}$ & $16.60[4.61,28.59]$ \\
\hline $30.2 \mathrm{G}$ vs docetaxel $=2 \mathrm{nd}$ line & 1 & 1466 & $\begin{array}{l}\text { Mean Difference (IV, Random, 95\% } \\
\text { CI) }\end{array}$ & $7.0[5.97,8.03]$ \\
\hline 31 PSI QOL improvement rate & 1 & 190 & Mean Difference (IV, Fixed, 95\% CI) & $5.60[3.55,7.65]$ \\
\hline $\begin{array}{l}31.1 \mathrm{G} \text { vs vinorelbine }=1 \mathrm{st} \\
\text { line }\end{array}$ & 1 & 190 & Mean Difference (IV, Fixed, 95\% Cl) & $5.60[3.55,7.65]$ \\
\hline
\end{tabular}

Analysis 4.1. Comparison 4 Gefitinib versus chemotherapy, Outcome 1 HR Overall survival.

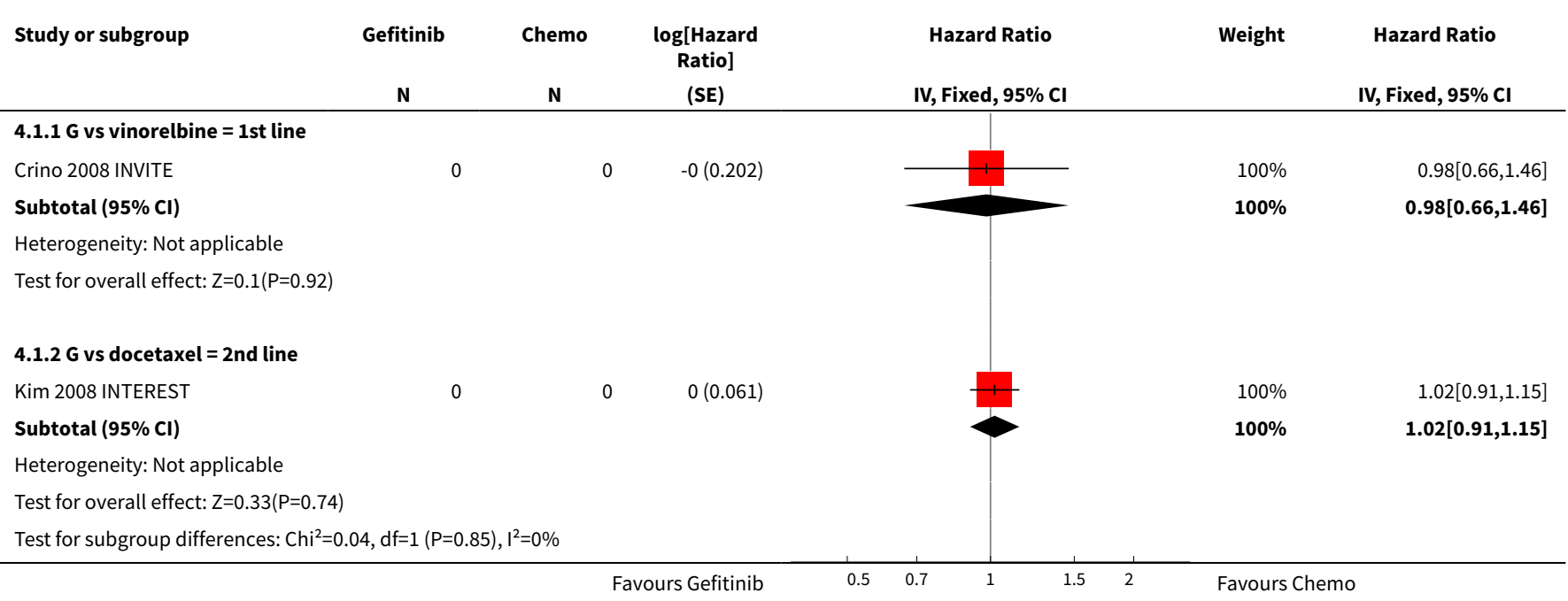


Analysis 4.2. Comparison 4 Gefitinib versus chemotherapy, Outcome 2 HR Progression-free survival.

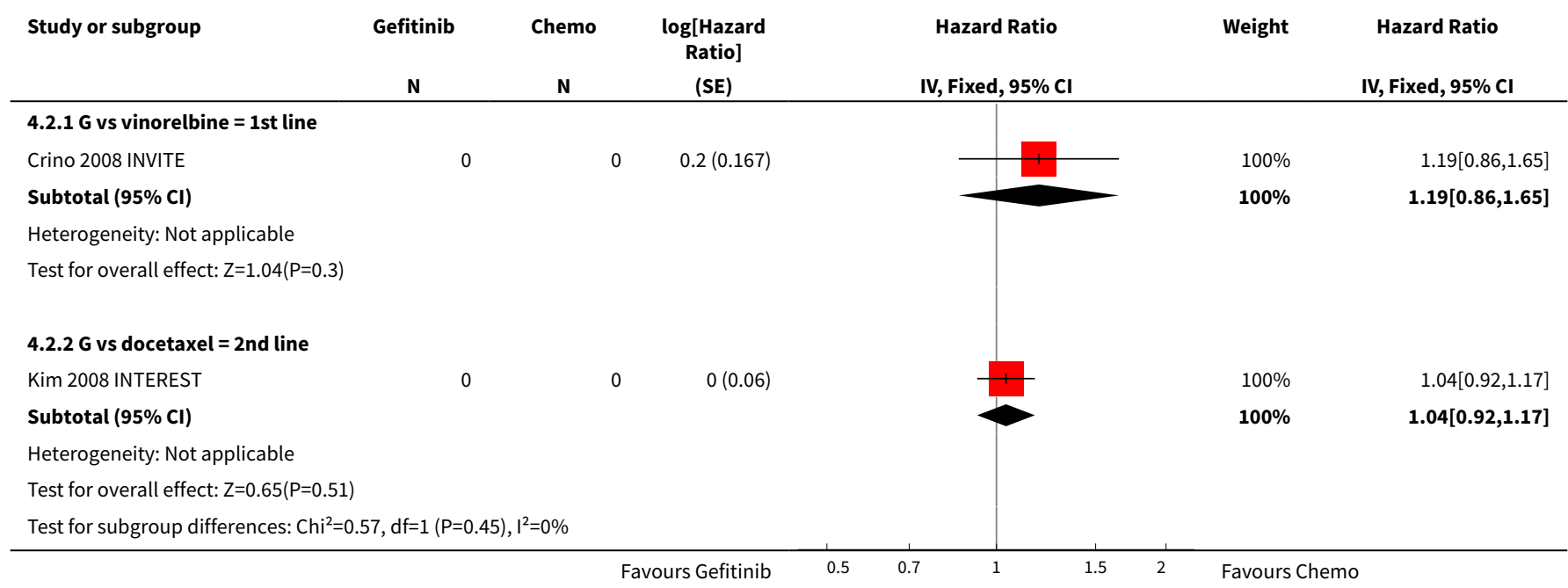

Analysis 4.3. Comparison 4 Gefitinib versus chemotherapy, Outcome 3 1-year survival rate.

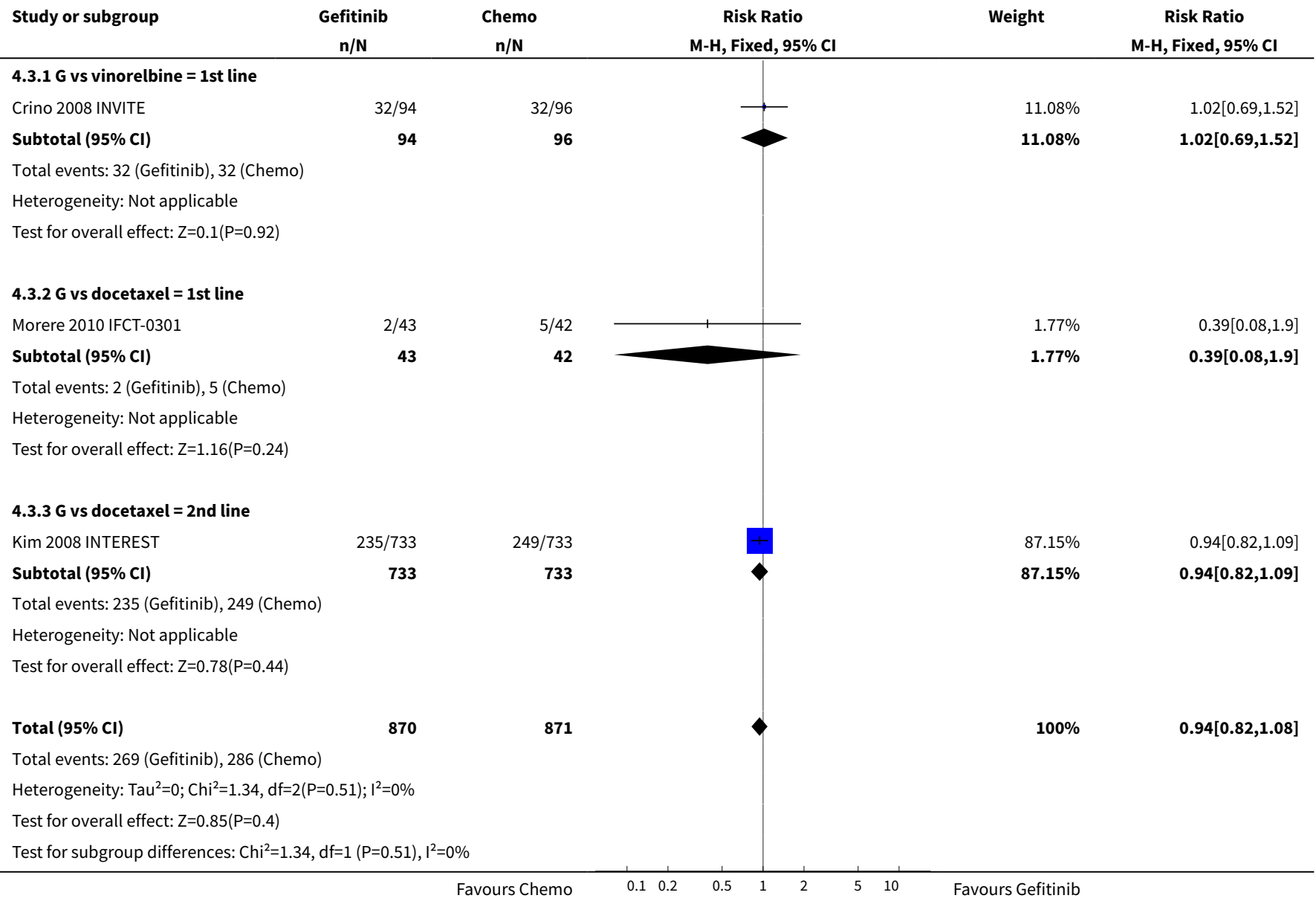


Analysis 4.4. Comparison 4 Gefitinib versus chemotherapy, Outcome 4 Skin rash.

\begin{tabular}{|c|c|c|c|c|c|}
\hline Study or subgroup & $\begin{array}{c}\text { Gefitinib } \\
\mathrm{n} / \mathrm{N}\end{array}$ & $\begin{array}{c}\text { Chemo } \\
\mathrm{n} / \mathrm{N}\end{array}$ & $\begin{array}{c}\text { Risk Ratio } \\
\text { M-H, Fixed, } 95 \% \mathrm{Cl} \\
\end{array}$ & Weight & $\begin{array}{c}\text { Risk Ratio } \\
\text { M-H, Fixed, } 95 \% \mathrm{Cl} \\
\end{array}$ \\
\hline \multicolumn{6}{|c|}{ 4.4.1 $\mathrm{G}$ vs vinorelbine $=1$ st line } \\
\hline Crino 2008 INVITE & $2 / 94$ & $0 / 96$ & & $5.81 \%$ & $5.11[0.25,104.94]$ \\
\hline Subtotal $(95 \% \mathrm{Cl})$ & 94 & 96 & - & $5.81 \%$ & $5.11[0.25,104.94]$ \\
\hline \multicolumn{6}{|c|}{ Total events: 2 (Gefitinib), 0 (Chemo) } \\
\hline \multicolumn{6}{|c|}{ Heterogeneity: Not applicable } \\
\hline \multicolumn{6}{|c|}{ Test for overall effect: $Z=1.06(P=0.29)$} \\
\hline \multicolumn{6}{|c|}{ 4.4.2 G vs docetaxel = 1st line } \\
\hline Morere 2010 IFCT-0301 & $1 / 43$ & $2 / 42$ & "- & $23.77 \%$ & $0.49[0.05,5.19]$ \\
\hline Subtotal $(95 \% \mathrm{Cl})$ & 43 & 42 & & $23.77 \%$ & $0.49[0.05,5.19]$ \\
\hline \multicolumn{6}{|c|}{ Total events: 1 (Gefitinib), 2 (Chemo) } \\
\hline \multicolumn{6}{|c|}{ Heterogeneity: Not applicable } \\
\hline \multicolumn{6}{|c|}{ Test for overall effect: $Z=0.59(P=0.55)$} \\
\hline \multicolumn{6}{|c|}{ 4.4.3 $\mathrm{G}$ vs docetaxel $=2$ nd line } \\
\hline Cufer 2006 SIGN & $2 / 68$ & $2 / 71$ & & $22.98 \%$ & $1.04[0.15,7.2]$ \\
\hline Kim 2008 INTEREST & $15 / 729$ & $4 / 715$ & -1 & $47.44 \%$ & $3.68[1.23,11.03]$ \\
\hline Subtotal $(95 \% \mathrm{Cl})$ & 797 & 786 & 4 & $70.42 \%$ & $2.82[1.11,7.13]$ \\
\hline \multicolumn{6}{|c|}{ Total events: 17 (Gefitinib), 6 (Chemo) } \\
\hline \multicolumn{6}{|c|}{ Heterogeneity: Tau $^{2}=0 ; \mathrm{Chi}^{2}=1.24, \mathrm{df}=1(\mathrm{P}=0.27) ; I^{2}=19.42 \%$} \\
\hline \multicolumn{6}{|c|}{ Test for overall effect: $Z=2.19(P=0.03)$} \\
\hline Total $(95 \% \mathrm{Cl})$ & 934 & 924 & $\infty$ & $100 \%$ & $2.4[1.08,5.31]$ \\
\hline \multicolumn{6}{|c|}{ Total events: 20 (Gefitinib), 8 (Chemo) } \\
\hline \multicolumn{6}{|c|}{ Heterogeneity: $\operatorname{Tau}^{2}=0 ; \mathrm{Chi}^{2}=3.28, \mathrm{df}=3(\mathrm{P}=0.35) ; \mathrm{I}^{2}=8.46 \%$} \\
\hline \multicolumn{6}{|c|}{ Test for overall effect: $Z=2.16(P=0.03)$} \\
\hline Test for subgroup differe & $d f=1(P=0.35), 1^{2}$ & & & & \\
\hline
\end{tabular}

Analysis 4.5. Comparison 4 Gefitinib versus chemotherapy, Outcome 5 Constipation.

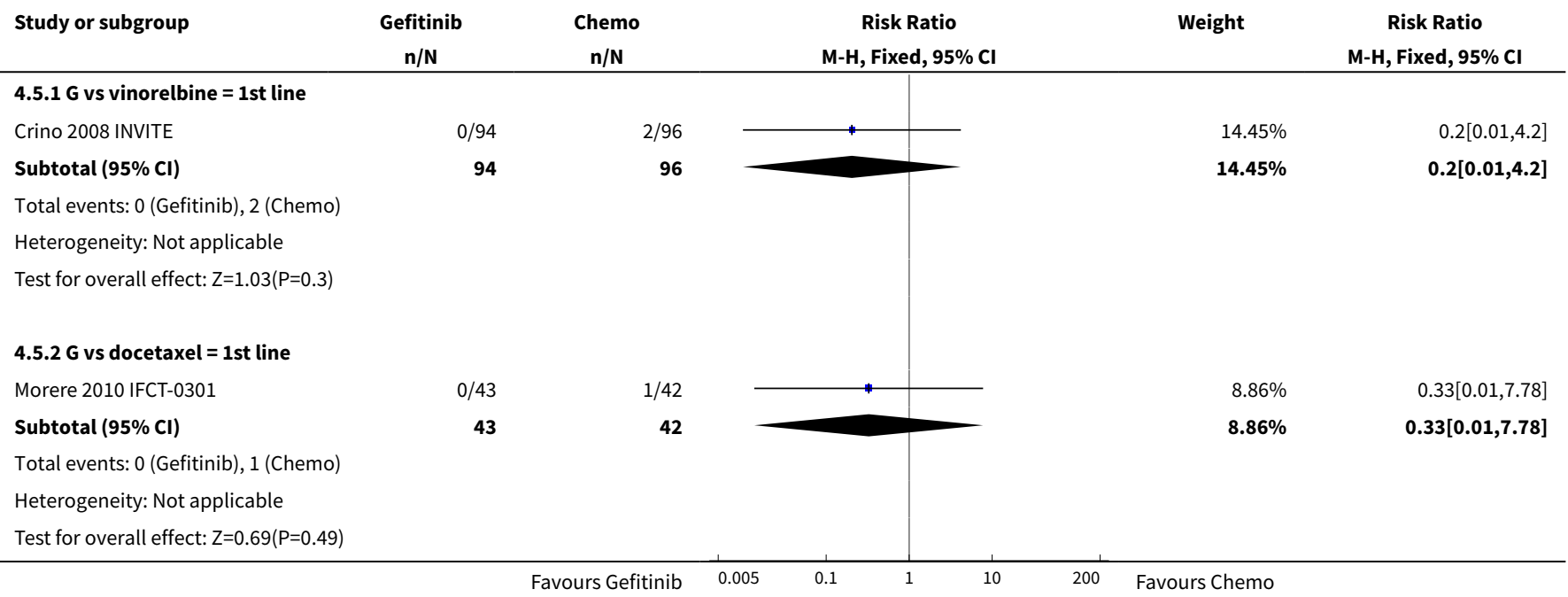




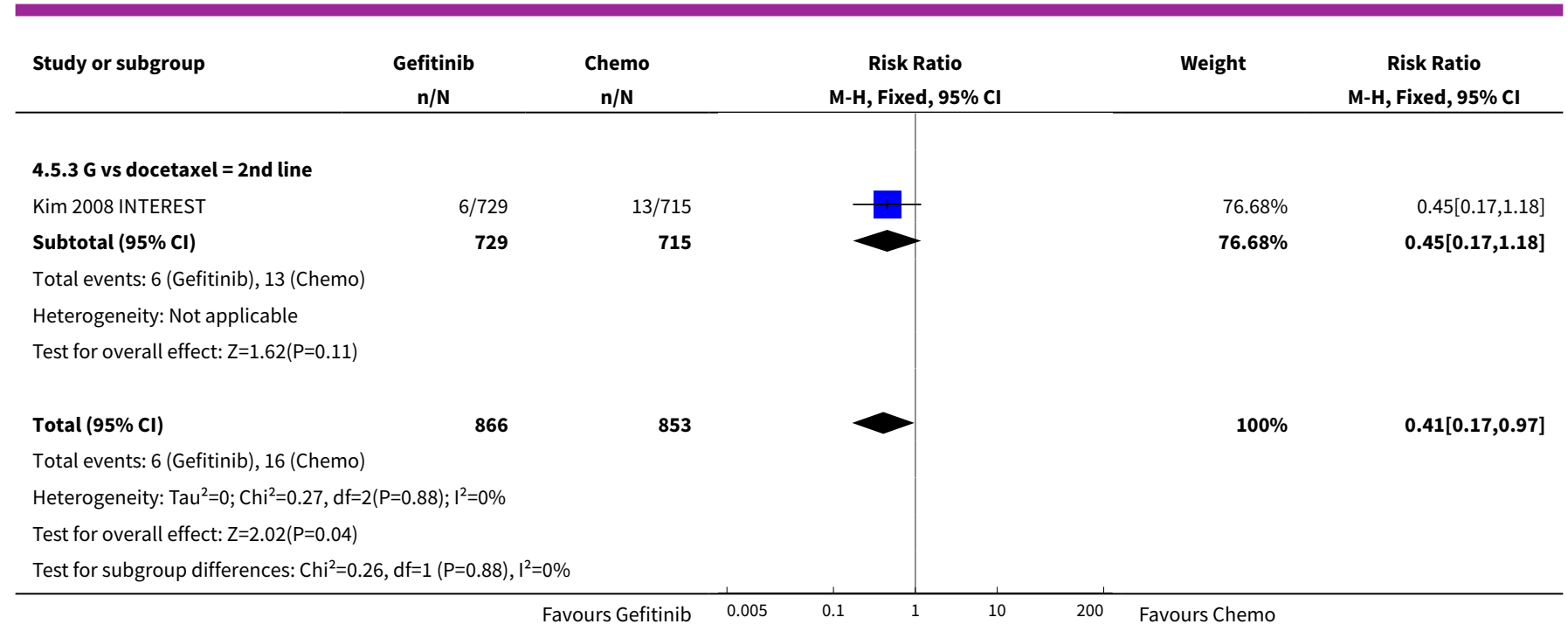

Analysis 4.6. Comparison 4 Gefitinib versus chemotherapy, Outcome 6 Fatigue.

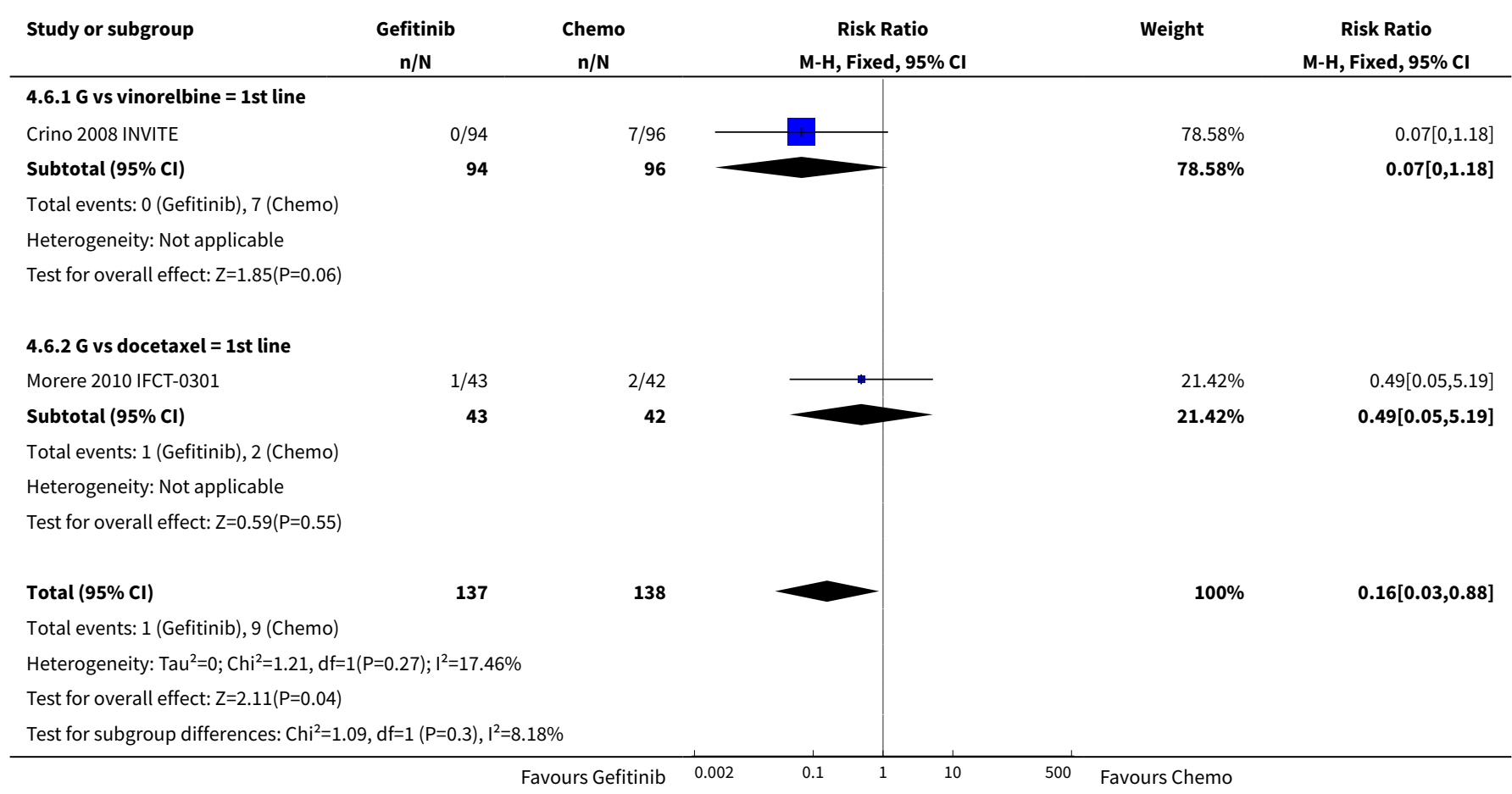

Analysis 4.7. Comparison 4 Gefitinib versus chemotherapy, Outcome 7 Asthenia.

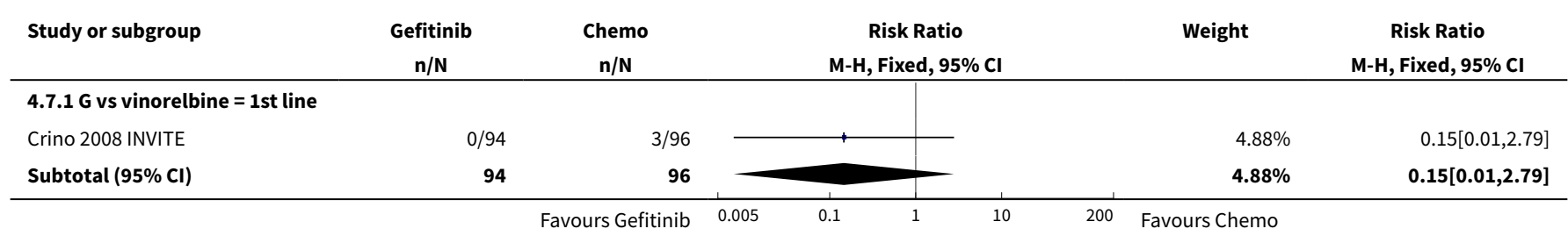




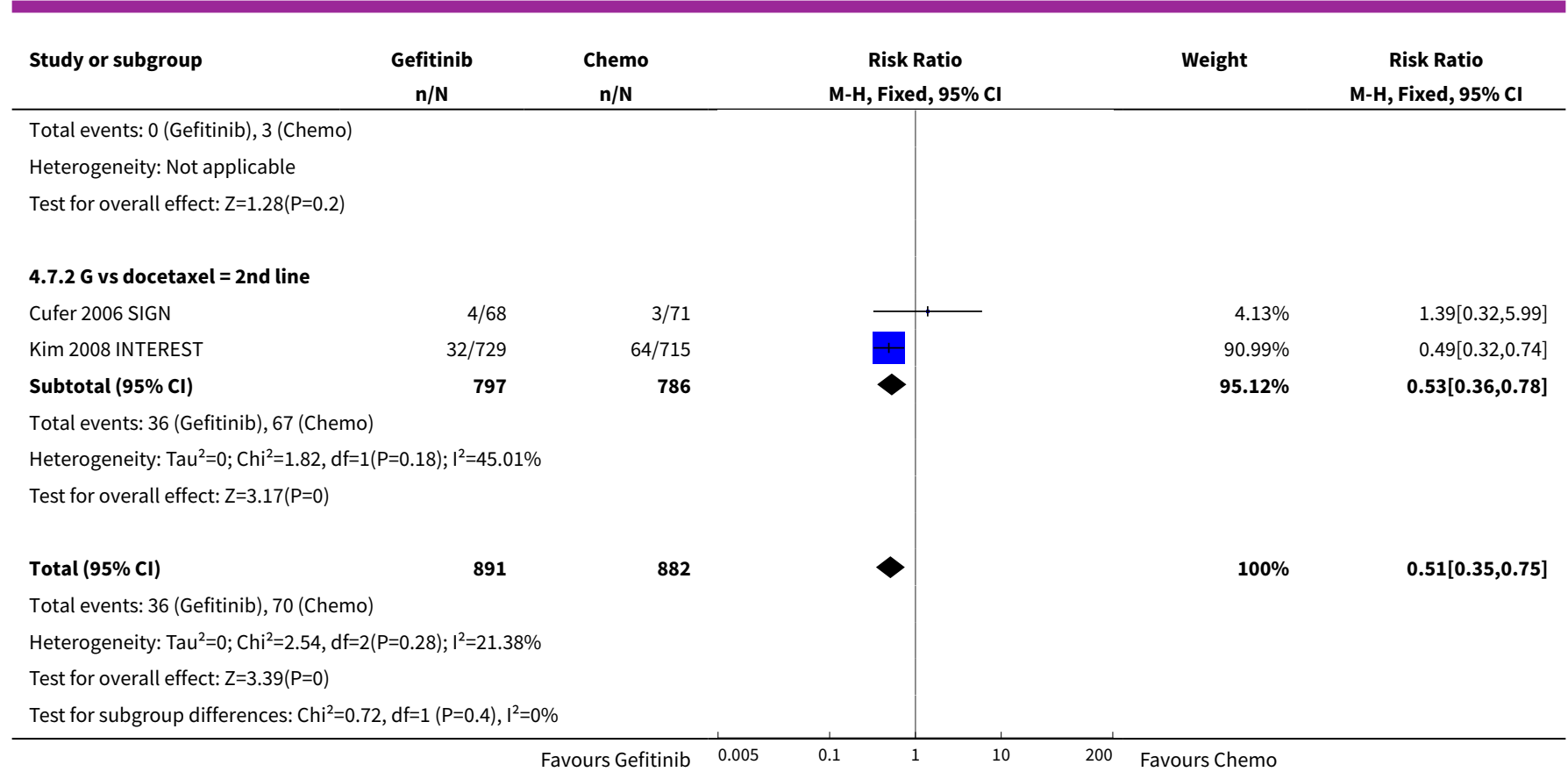

\section{Analysis 4.8. Comparison 4 Gefitinib versus chemotherapy, Outcome 8 Neurotoxicity.}

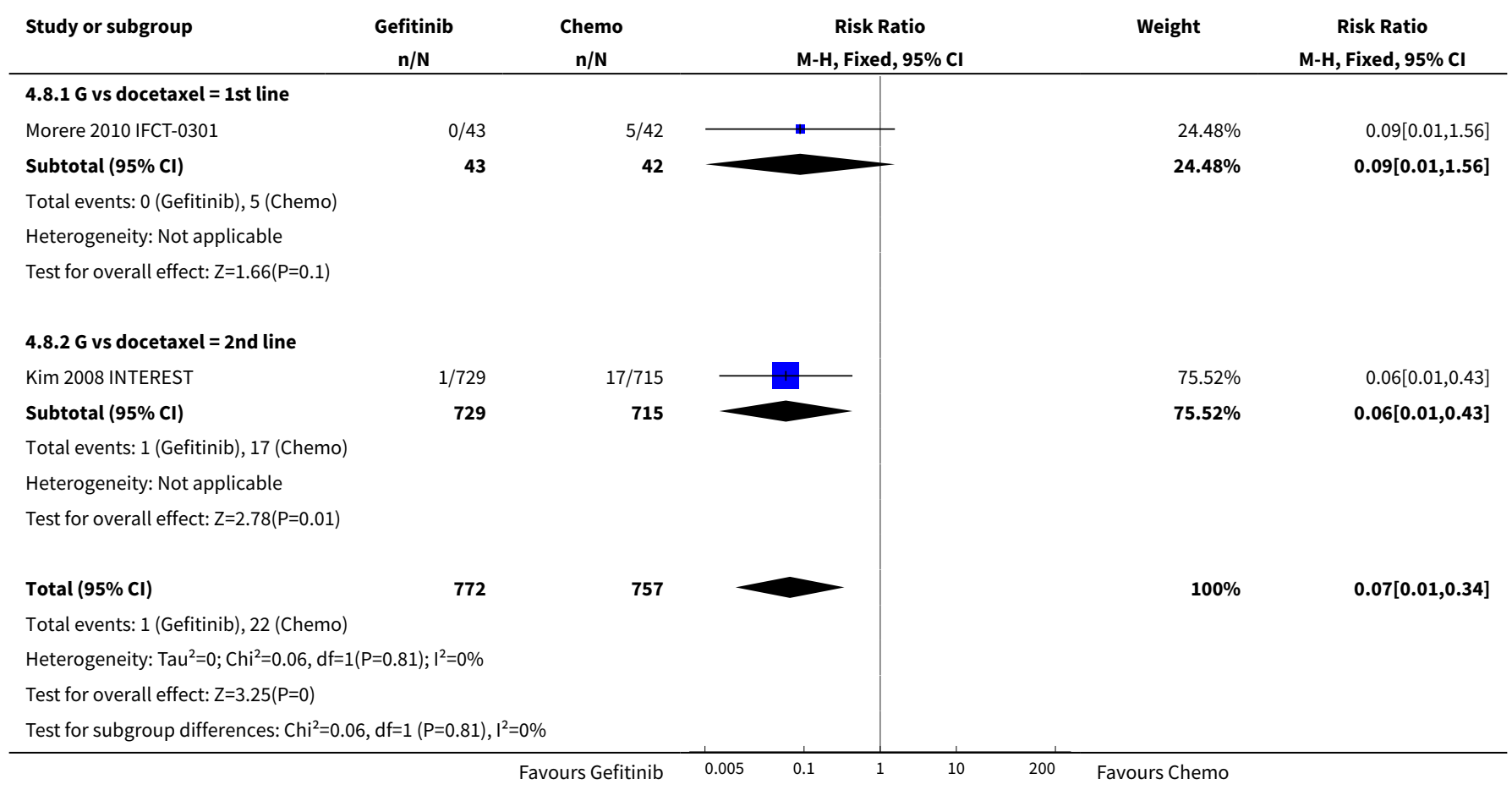


Analysis 4.9. Comparison 4 Gefitinib versus chemotherapy, Outcome 9 Neutropenia.

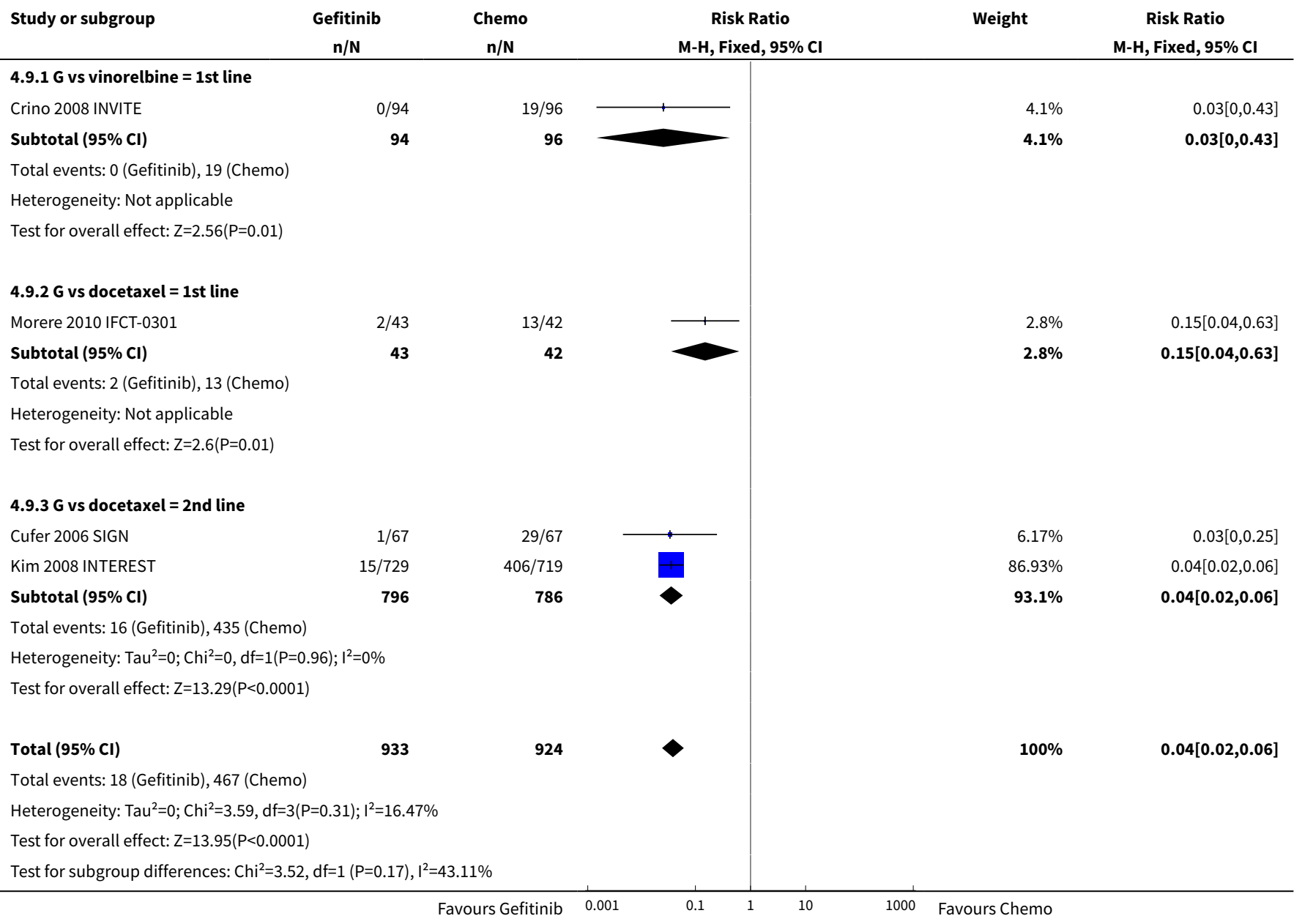

Analysis 4.10. Comparison 4 Gefitinib versus chemotherapy, Outcome 10 Leukopenia.

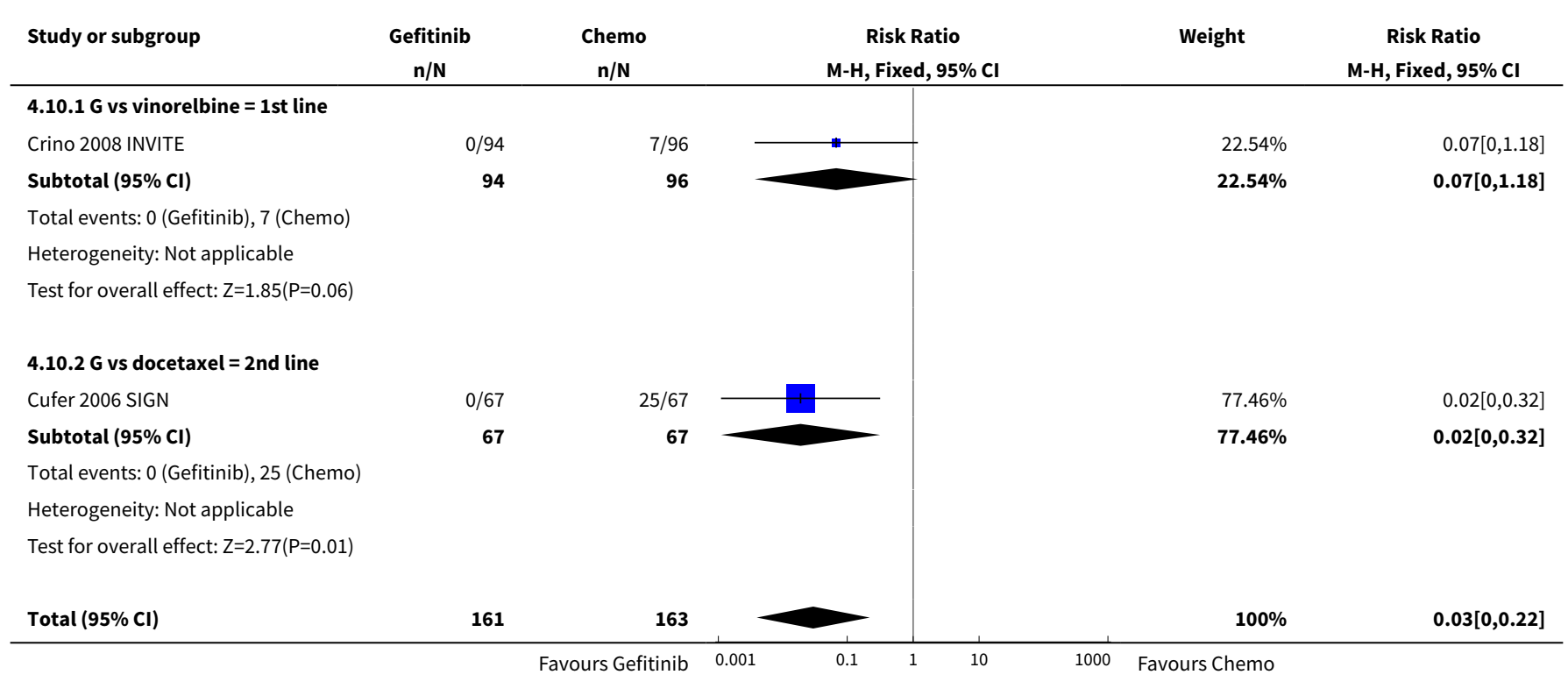




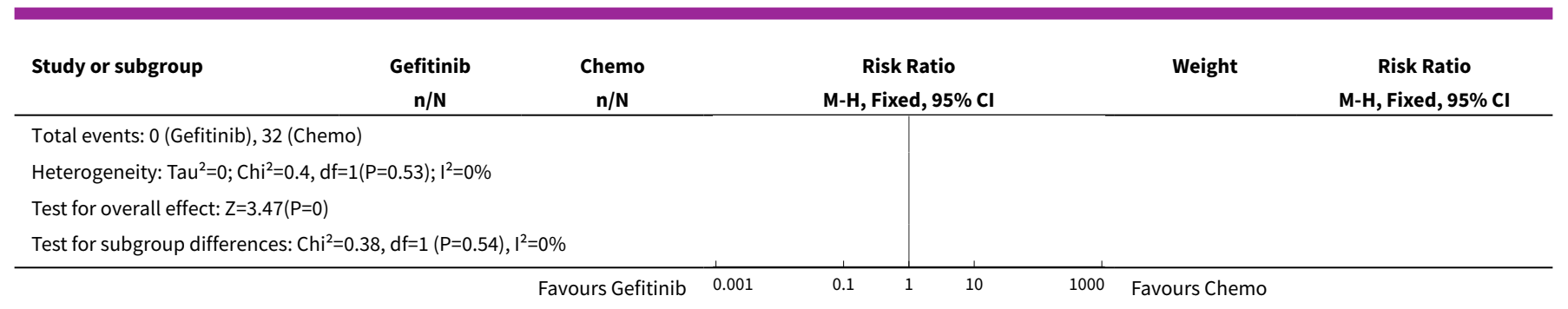

Analysis 4.11. Comparison 4 Gefitinib versus chemotherapy, Outcome 11 Febrile neutropenia.

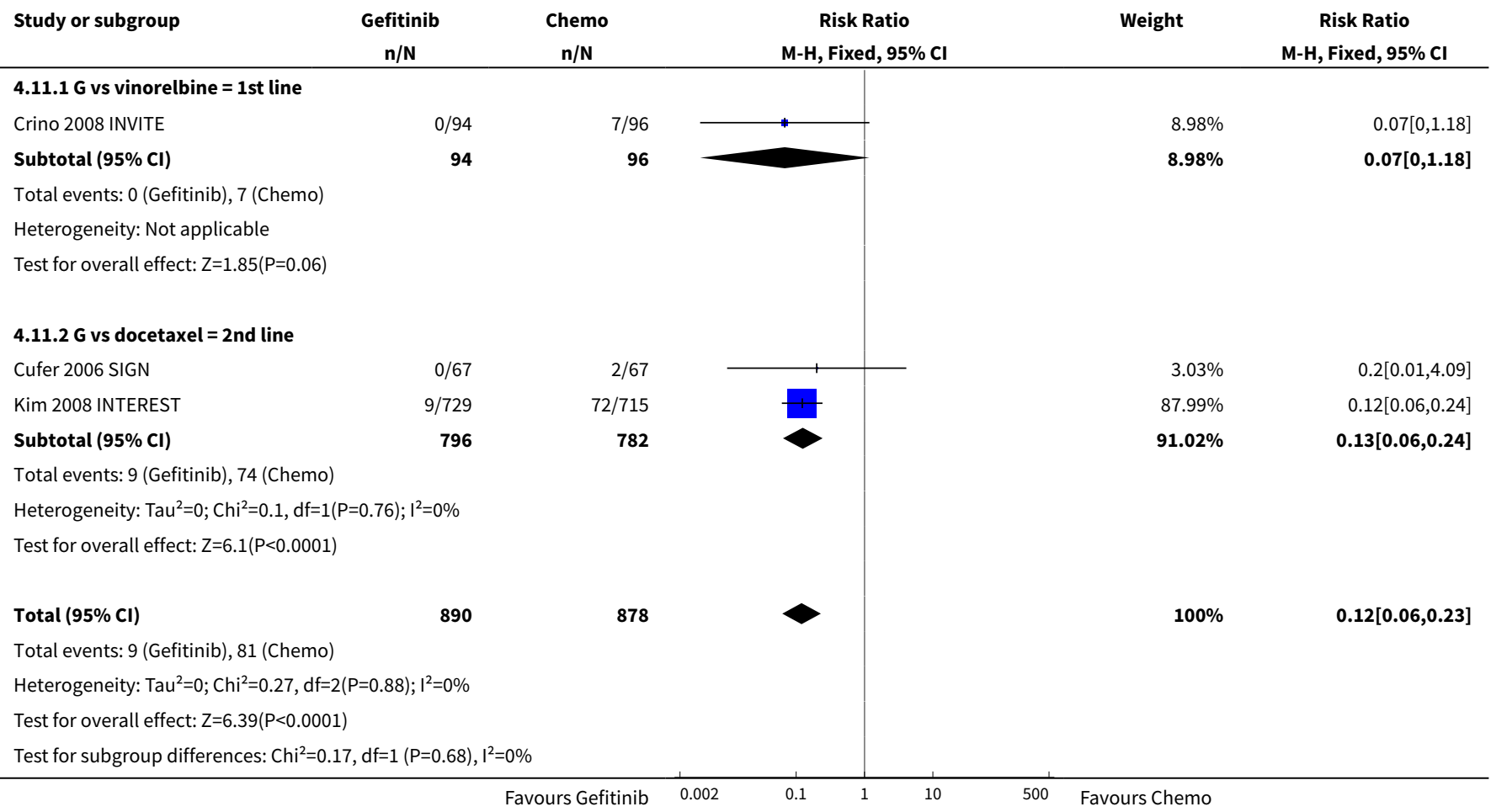

Analysis 4.12. Comparison 4 Gefitinib versus chemotherapy, Outcome 12 Pruritus.

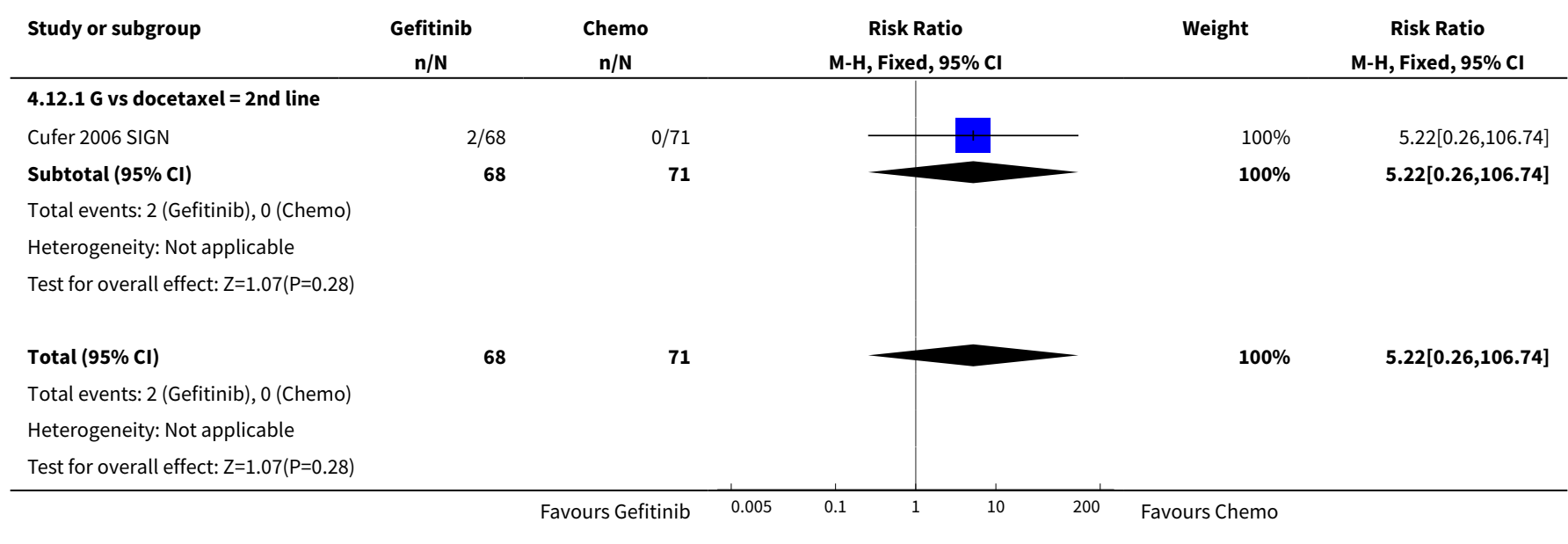


Analysis 4.13. Comparison 4 Gefitinib versus chemotherapy, Outcome 13 Diarrhoea.

\begin{tabular}{|c|c|c|c|c|c|}
\hline Study or subgroup & $\begin{array}{c}\text { Gefitinib } \\
\text { n/N }\end{array}$ & $\begin{array}{c}\text { Chemo } \\
n / N\end{array}$ & $\begin{array}{c}\text { Risk Ratio } \\
\text { M-H, Fixed, } 95 \% \mathrm{CI}\end{array}$ & Weight & $\begin{array}{c}\text { Risk Ratio } \\
\text { M-H, Fixed, } 95 \% \mathrm{Cl} \\
\end{array}$ \\
\hline \multicolumn{6}{|c|}{ 4.13.1 G vs vinorelbine $=1$ st line } \\
\hline Crino 2008 INVITE & $4 / 94$ & $4 / 96$ & & $12.33 \%$ & $1.02[0.26,3.96]$ \\
\hline Subtotal $(95 \% \mathrm{Cl})$ & 94 & 96 & & $12.33 \%$ & $1.02[0.26,3.96]$ \\
\hline \multicolumn{6}{|c|}{ Total events: 4 (Gefitinib), 4 (Chemo) } \\
\hline \multicolumn{6}{|c|}{ Heterogeneity: Not applicable } \\
\hline \multicolumn{6}{|c|}{ Test for overall effect: $Z=0.03(P=0.98)$} \\
\hline \multicolumn{6}{|c|}{ 4.13.2 G vs docetaxel $=1$ st line } \\
\hline Morere 2010 IFCT-0301 & $2 / 43$ & $2 / 42$ & & $6.3 \%$ & $0.98[0.14,6.62]$ \\
\hline Subtotal $(95 \% \mathrm{Cl})$ & 43 & 42 & & $6.3 \%$ & $0.98[0.14,6.62]$ \\
\hline \multicolumn{6}{|c|}{ Total events: 2 (Gefitinib), 2 (Chemo) } \\
\hline \multicolumn{6}{|c|}{ Heterogeneity: Not applicable } \\
\hline \multicolumn{6}{|c|}{ Test for overall effect: $Z=0.02(P=0.98)$} \\
\hline \multicolumn{6}{|c|}{ 4.13.3 G vs docetaxel $=2$ nd line } \\
\hline Cufer 2006 SIGN & $2 / 68$ & $4 / 71$ & - & $12.19 \%$ & $0.52[0.1,2.76]$ \\
\hline Kim 2008 INTEREST & $18 / 729$ & $22 / 715$ & & $69.18 \%$ & $0.8[0.43,1.48]$ \\
\hline Subtotal $(95 \% \mathrm{Cl})$ & 797 & 786 & & $81.37 \%$ & $0.76[0.43,1.35]$ \\
\hline \multicolumn{6}{|c|}{ Total events: 20 (Gefitinib), 26 (Chemo) } \\
\hline \multicolumn{6}{|c|}{ Heterogeneity: $\operatorname{Tau}^{2}=0 ; \mathrm{Chi}^{2}=0.23, \mathrm{df}=1(\mathrm{P}=0.63) ; I^{2}=0 \%$} \\
\hline \multicolumn{6}{|c|}{ Test for overall effect: $Z=0.93(P=0.35)$} \\
\hline Total $(95 \% \mathrm{Cl})$ & 934 & 924 & & $100 \%$ & $0.81[0.48,1.34]$ \\
\hline \multicolumn{6}{|c|}{ Total events: 26 (Gefitinib), 32 (Chemo) } \\
\hline \multicolumn{6}{|c|}{ Heterogeneity: $\mathrm{Tau}^{2}=0 ; \mathrm{Chi}^{2}=0.42, \mathrm{df}=3(\mathrm{P}=0.94) ; I^{2}=0 \%$} \\
\hline \multicolumn{6}{|c|}{ Test for overall effect: $Z=0.83(P=0.41)$} \\
\hline Test for subgroup differ & $d f=1(P=0.91)$ & & & & \\
\hline
\end{tabular}

Analysis 4.14. Comparison 4 Gefitinib versus chemotherapy, Outcome 14 Vomiting.

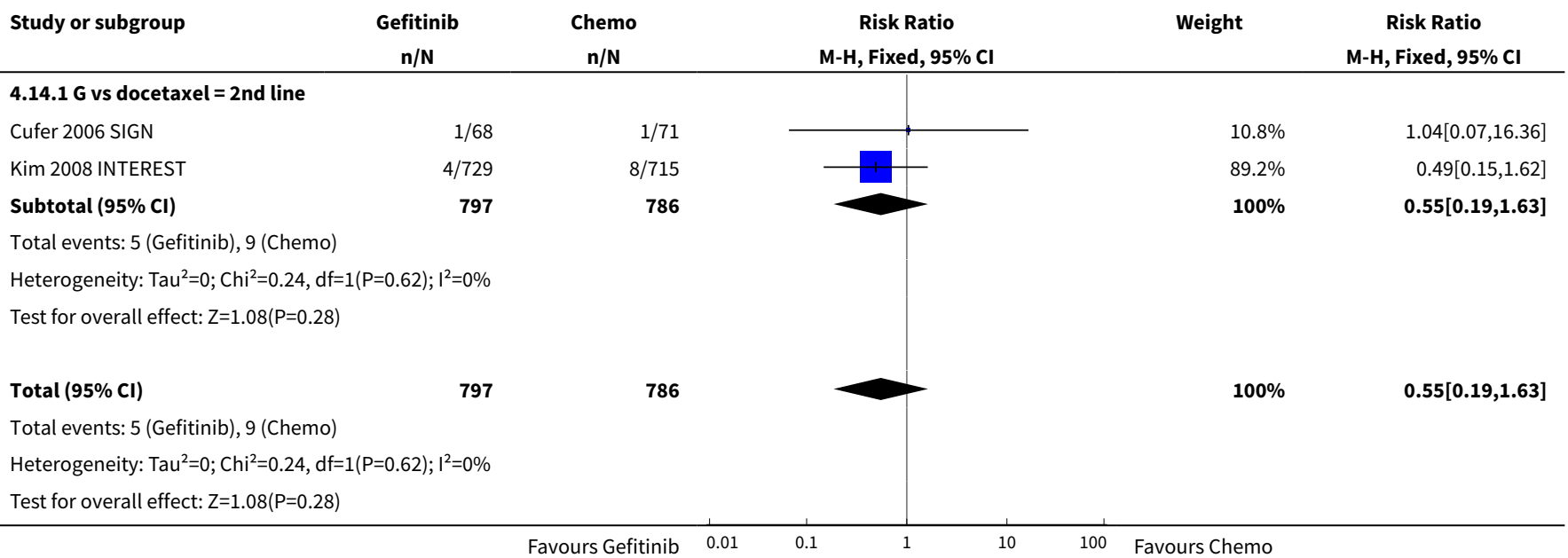


Analysis 4.15. Comparison 4 Gefitinib versus chemotherapy, Outcome 15 Anorexia.

\begin{tabular}{|c|c|c|c|c|c|}
\hline Study or subgroup & $\begin{array}{c}\text { Gefitinib } \\
\text { n/N }\end{array}$ & $\begin{array}{c}\text { Chemo } \\
n / N\end{array}$ & $\begin{array}{c}\text { Risk Ratio } \\
\text { M-H, Fixed, } 95 \% \mathrm{CI}\end{array}$ & Weight & $\begin{array}{c}\text { Risk Ratio } \\
\text { M-H, Fixed, } 95 \% \mathrm{Cl} \\
\end{array}$ \\
\hline \multicolumn{6}{|c|}{ 4.15.1 G vs vinorelbine $=1$ st line } \\
\hline Crino 2008 INVITE & $2 / 94$ & $2 / 96$ & & $21.87 \%$ & $1.02[0.15,7.1]$ \\
\hline Subtotal $(95 \% \mathrm{Cl})$ & 94 & 96 & & $21.87 \%$ & $1.02[0.15,7.1]$ \\
\hline \multicolumn{6}{|c|}{ Total events: 2 (Gefitinib), 2 (Chemo) } \\
\hline \multicolumn{6}{|c|}{ Heterogeneity: Not applicable } \\
\hline \multicolumn{6}{|c|}{ Test for overall effect: $Z=0.02(P=0.98)$} \\
\hline \multicolumn{6}{|c|}{ 4.15.2 G vs docetaxel $=1$ st line } \\
\hline Morere 2010 IFCT-0301 & $0 / 43$ & $0 / 42$ & & & Not estimable \\
\hline Subtotal (95\% Cl) & 43 & 42 & & & Not estimable \\
\hline \multicolumn{6}{|c|}{ Total events: 0 (Gefitinib), 0 (Chemo) } \\
\hline \multicolumn{6}{|c|}{ Heterogeneity: Not applicable } \\
\hline \multicolumn{6}{|c|}{ Test for overall effect: Not applicable } \\
\hline \multicolumn{6}{|c|}{ 4.15.3 G vs docetaxel $=2$ nd line } \\
\hline Kim 2008 INTEREST & $11 / 729$ & $7 / 715$ & & $78.13 \%$ & $1.54[0.6,3.95]$ \\
\hline Subtotal $(95 \% \mathrm{Cl})$ & 729 & 715 & & $78.13 \%$ & $1.54[0.6,3.95]$ \\
\hline \multicolumn{6}{|c|}{ Total events: 11 (Gefitinib), 7 (Chemo) } \\
\hline \multicolumn{6}{|c|}{ Heterogeneity: Not applicable } \\
\hline \multicolumn{6}{|c|}{ Test for overall effect: $Z=0.9(P=0.37)$} \\
\hline Total $(95 \% \mathrm{Cl})$ & 866 & 853 & & $100 \%$ & $1.43[0.61,3.32]$ \\
\hline \multicolumn{6}{|c|}{ Total events: 13 (Gefitinib), 9 (Chemo) } \\
\hline \multicolumn{6}{|c|}{ Heterogeneity: Tau $^{2}=0 ; \mathrm{Chi}^{2}=0.14, \mathrm{df}=1(\mathrm{P}=0.71) ; \mathrm{I}^{2}=0 \%$} \\
\hline \multicolumn{6}{|c|}{ Test for overall effect: $\mathrm{Z}=0.83(\mathrm{P}=0.41)$} \\
\hline Test for subgroup differe &,$d f=1(P=0.71)$ & & & & \\
\hline
\end{tabular}

Analysis 4.16. Comparison 4 Gefitinib versus chemotherapy, Outcome 16 Stomatitis.

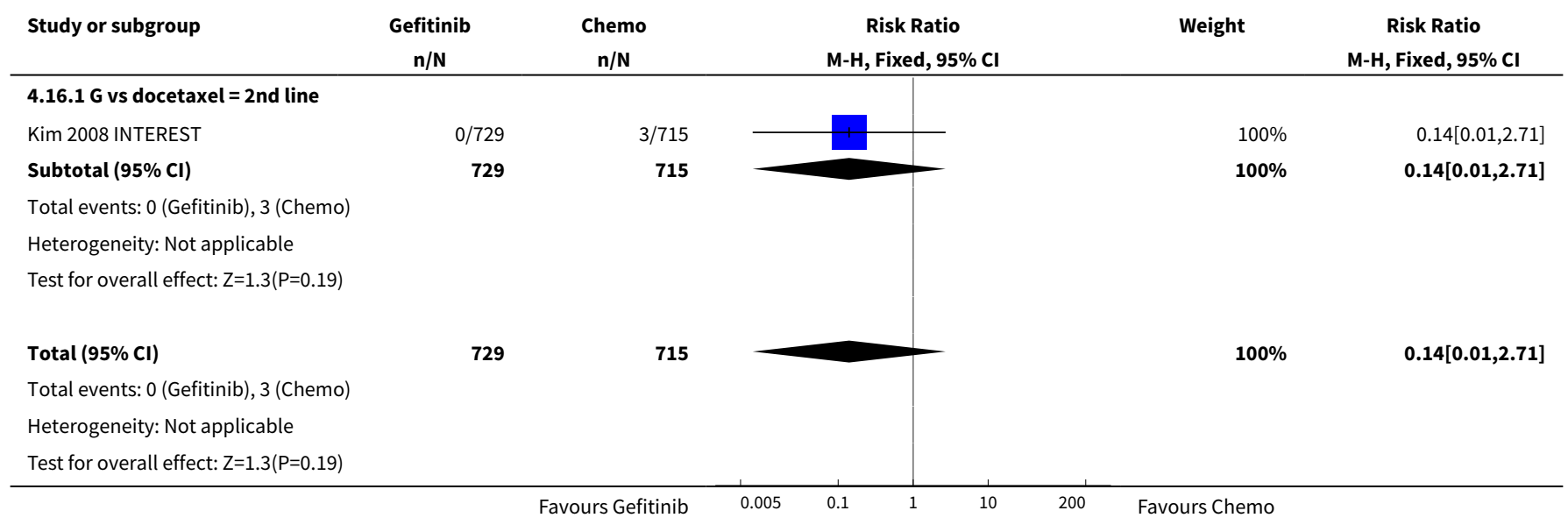


Analysis 4.17. Comparison 4 Gefitinib versus chemotherapy, Outcome 17 Arthralgia/myalgia.

\begin{tabular}{|c|c|c|c|c|c|}
\hline Study or subgroup & $\begin{array}{c}\text { Gefitinib } \\
\text { n/N }\end{array}$ & $\begin{array}{c}\text { Chemo } \\
n / N\end{array}$ & $\begin{array}{c}\text { Risk Ratio } \\
\text { M-H, Fixed, 95\% Cl }\end{array}$ & Weight & $\begin{array}{c}\text { Risk Ratio } \\
\text { M-H, Fixed, 95\% Cl }\end{array}$ \\
\hline \multicolumn{6}{|c|}{ 4.17.1 G vs docetaxel = 1st line } \\
\hline Morere 2010 IFCT-0301 & $0 / 43$ & $0 / 42$ & & & Not estimable \\
\hline Subtotal $(95 \% \mathrm{CI})$ & 43 & 42 & & & Not estimable \\
\hline \multicolumn{6}{|c|}{ Total events: 0 (Gefitinib), 0 (Chemo) } \\
\hline \multicolumn{6}{|c|}{ Heterogeneity: Not applicable } \\
\hline \multicolumn{6}{|c|}{ 4.17.2 G vs docetaxel = 2 nd line } \\
\hline Kim 2008 INTEREST & $1 / 729$ & $4 / 715$ & - & $100 \%$ & $0.25[0.03,2.19]$ \\
\hline Subtotal $(95 \% \mathrm{Cl})$ & 729 & 715 & & $100 \%$ & $0.25[0.03,2.19]$ \\
\hline \multicolumn{6}{|c|}{ Total events: 1 (Gefitinib), 4 (Chemo) } \\
\hline \multicolumn{6}{|c|}{ Heterogeneity: Not applicable } \\
\hline \multicolumn{6}{|c|}{ Test for overall effect: $Z=1.26(P=0.21)$} \\
\hline Total $(95 \% \mathrm{Cl})$ & 772 & 757 & & $100 \%$ & $0.25[0.03,2.19]$ \\
\hline \multicolumn{6}{|c|}{ Total events: 1 (Gefitinib), 4 (Chemo) } \\
\hline \multicolumn{6}{|c|}{ Heterogeneity: Not applicable } \\
\hline \multicolumn{6}{|c|}{ Test for overall effect: $Z=1.26(P=0.21)$} \\
\hline Test for subgroup differ & cable & & & & \\
\hline
\end{tabular}

\section{Analysis 4.18. Comparison 4 Gefitinib versus chemotherapy, Outcome 18 Peripheral oedema.}

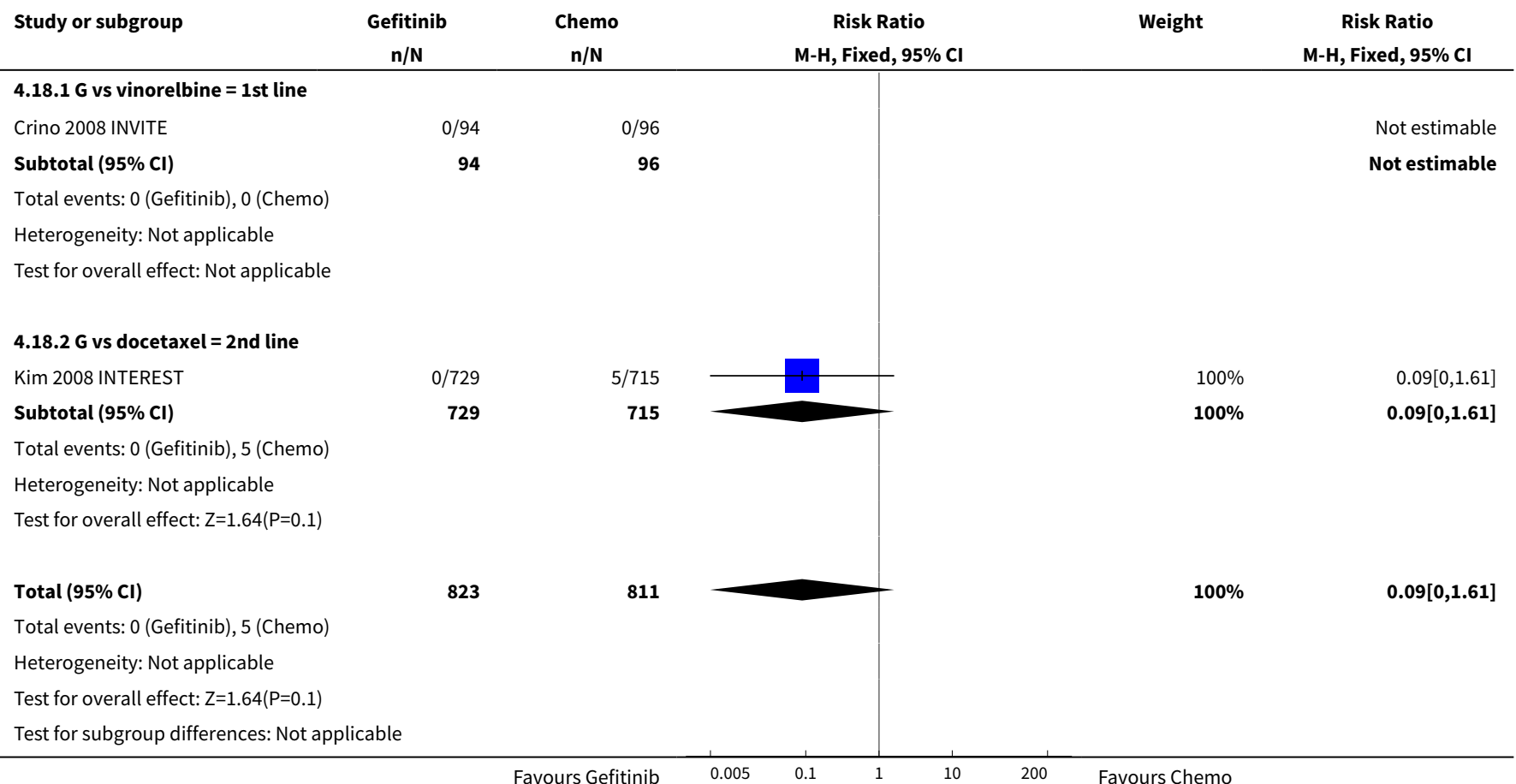


Analysis 4.19. Comparison 4 Gefitinib versus chemotherapy, Outcome 19 Respiratory tract infection.

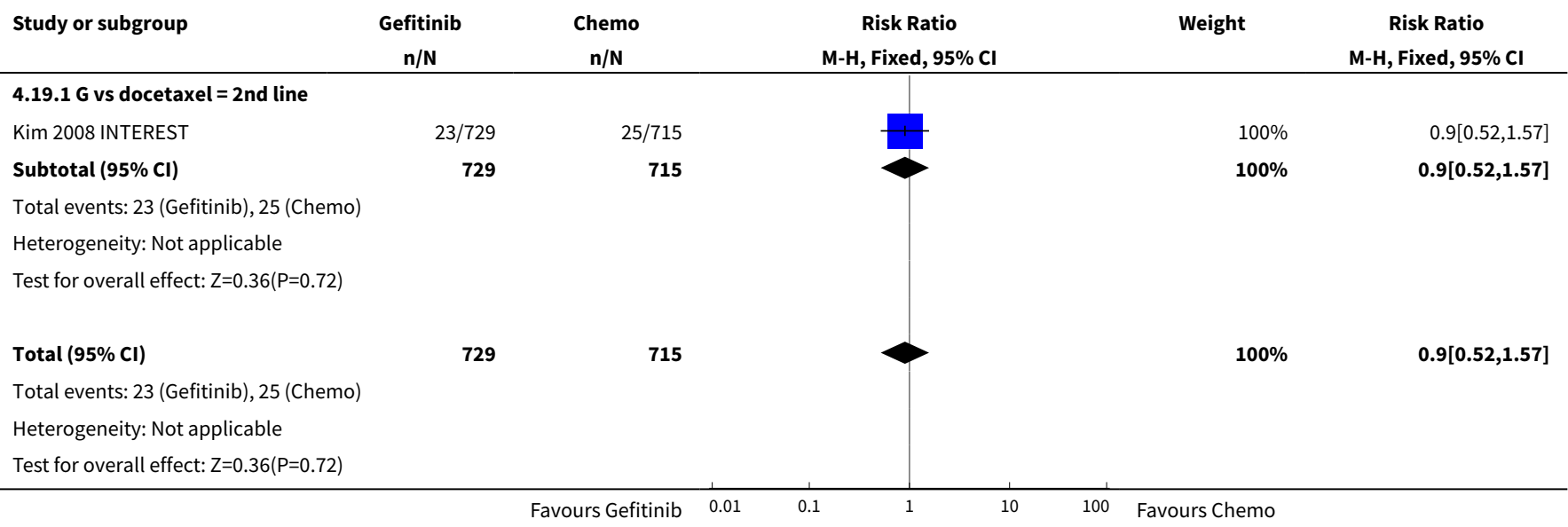

Analysis 4.20. Comparison 4 Gefitinib versus chemotherapy, Outcome 20 Dyspnoea.

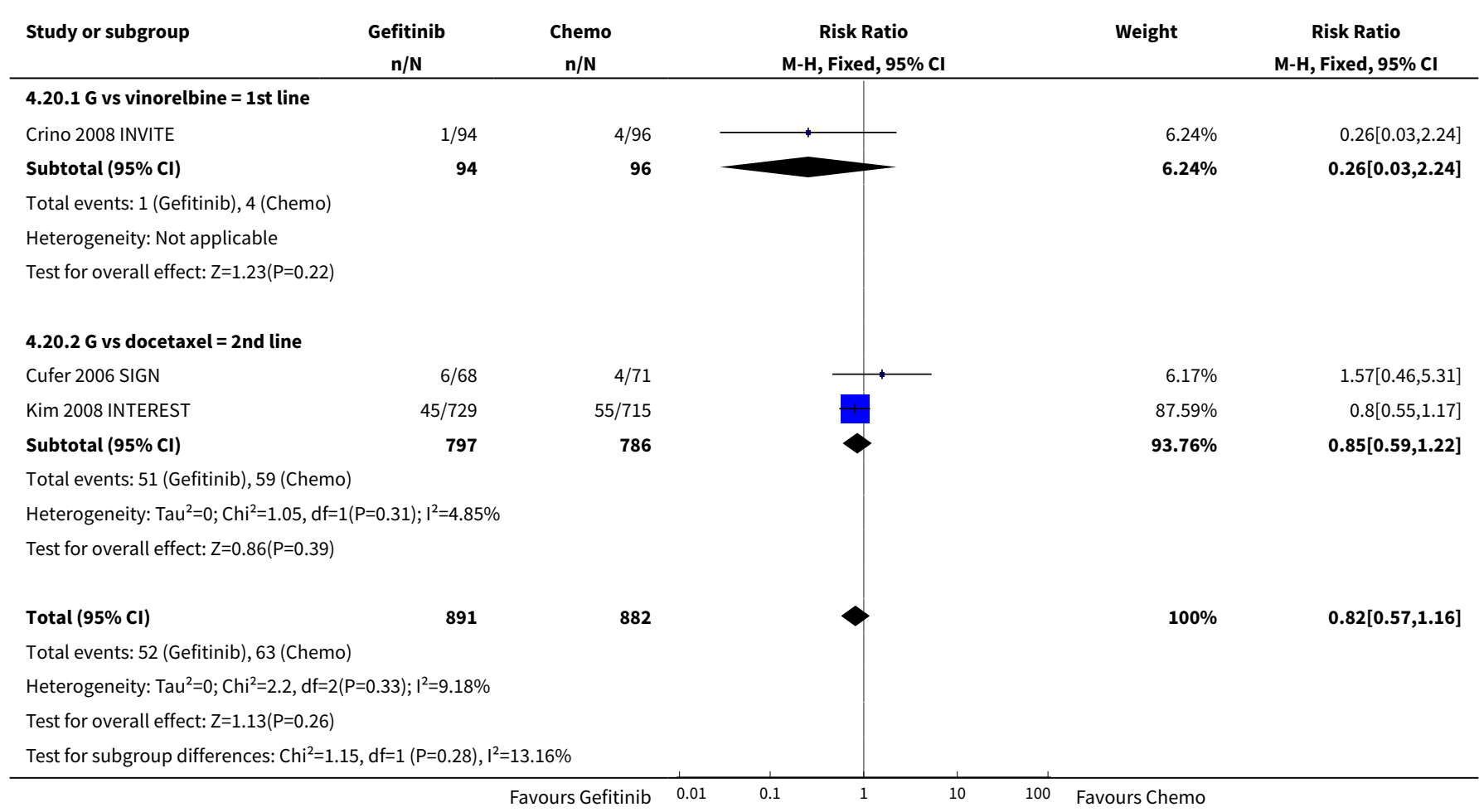

Analysis 4.21. Comparison 4 Gefitinib versus chemotherapy, Outcome 21 Cough.

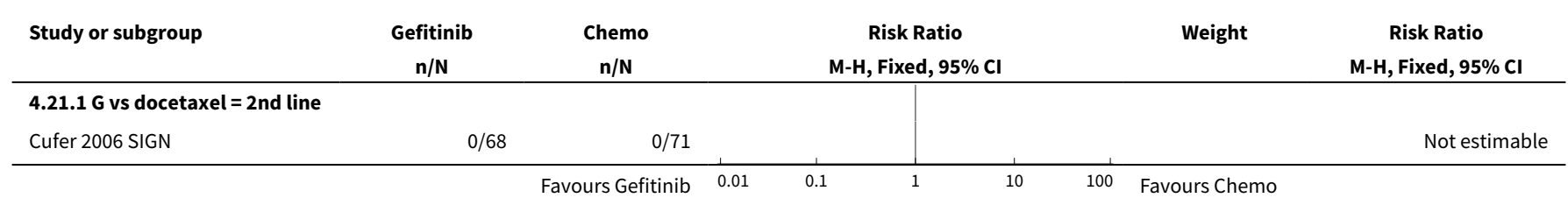




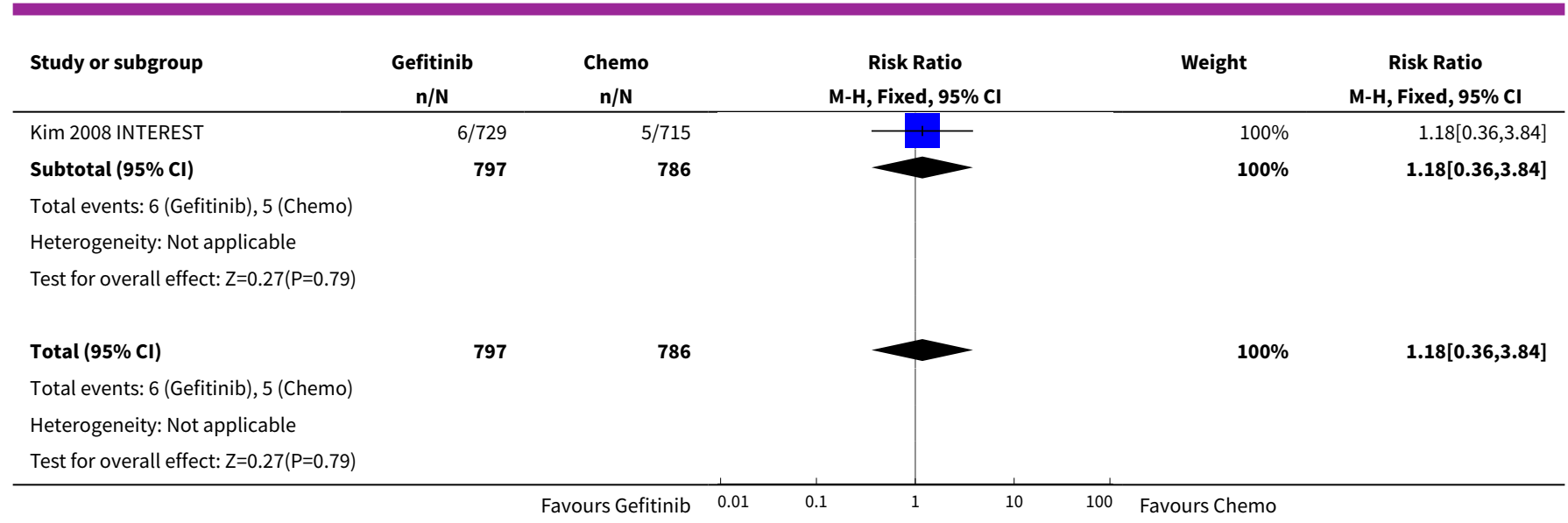

Analysis 4.22. Comparison 4 Gefitinib versus chemotherapy, Outcome 22 Anaemia.

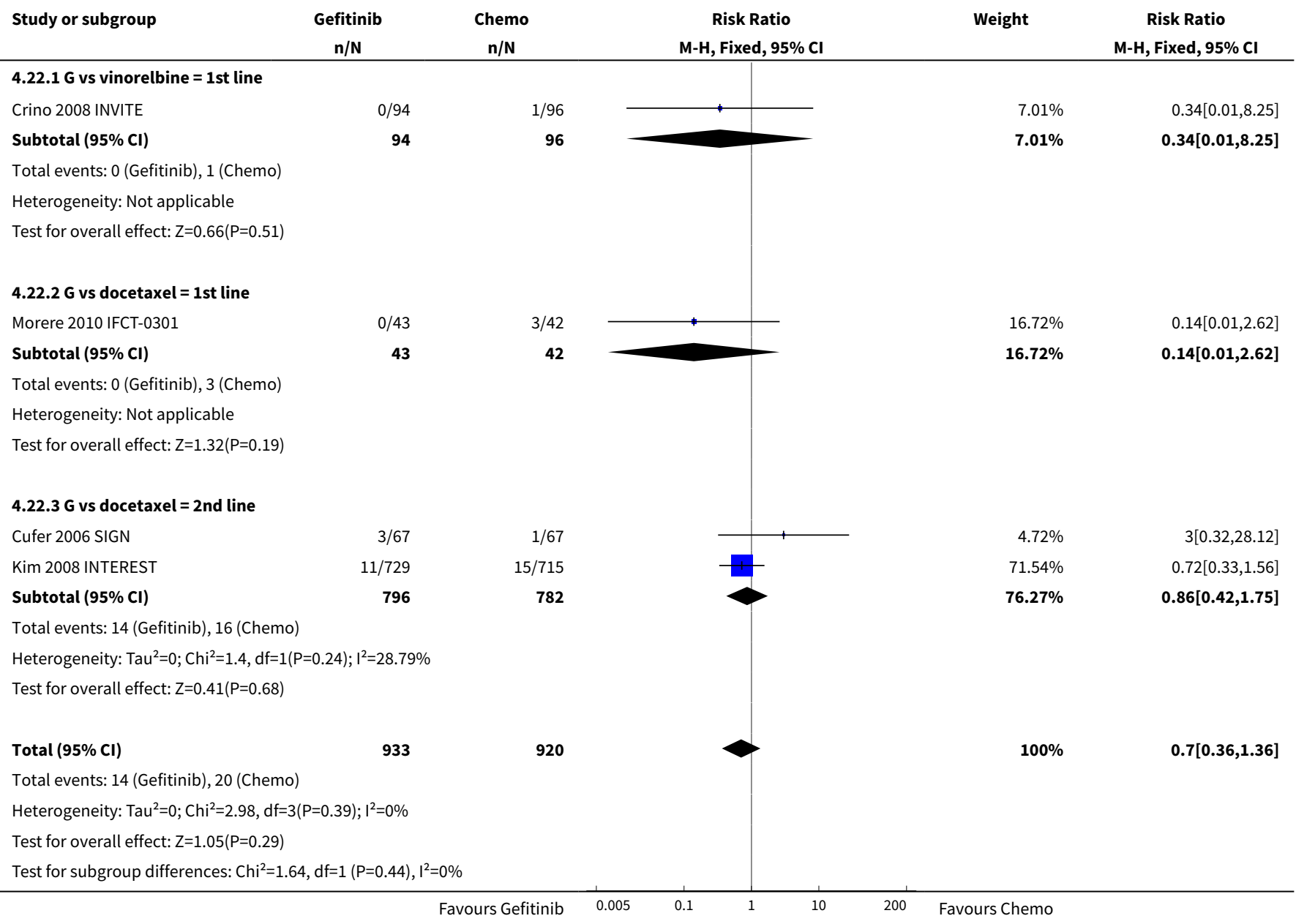


Analysis 4.23. Comparison 4 Gefitinib versus chemotherapy, Outcome 23 Thrombocytopenia.

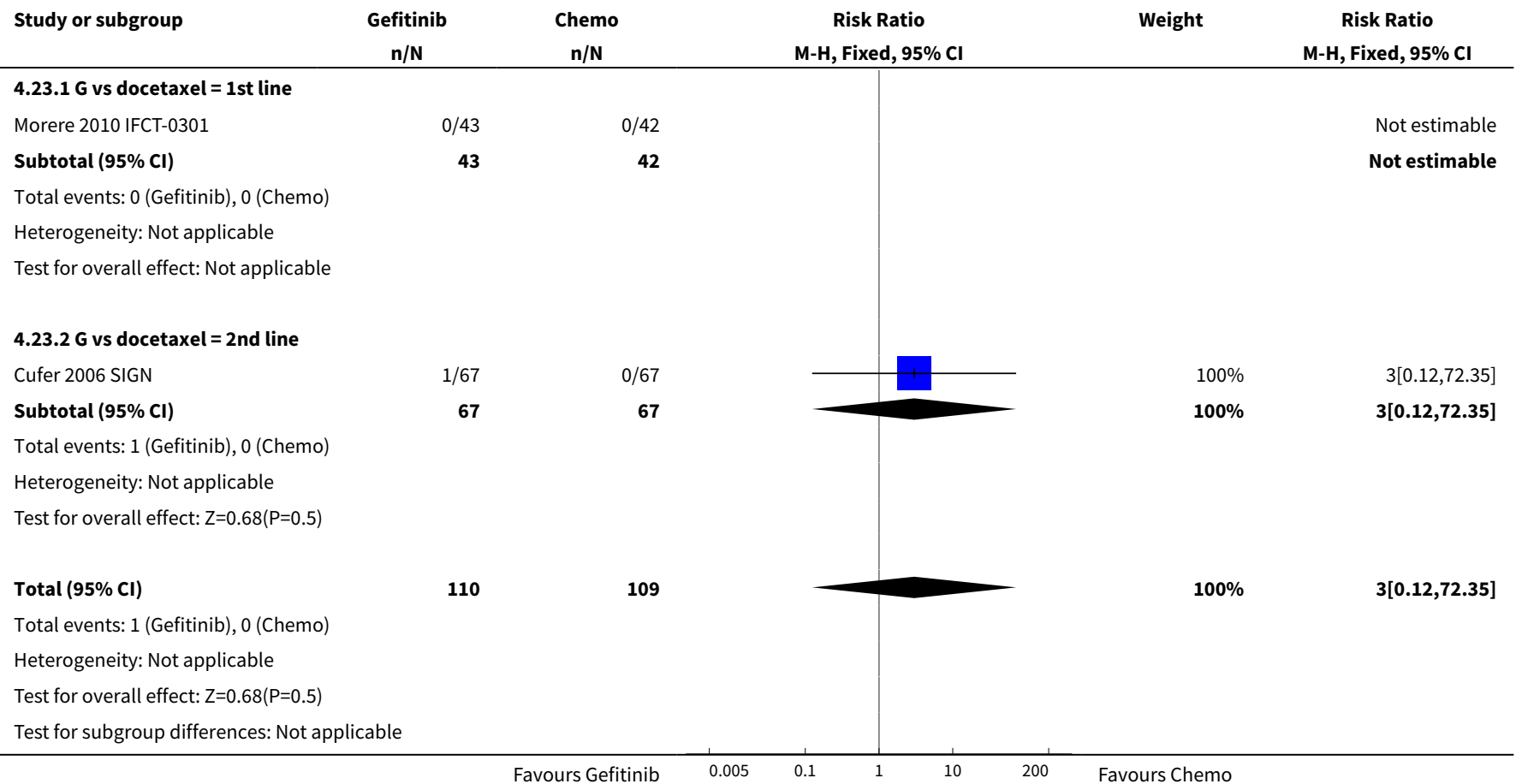

\section{Analysis 4.24. Comparison 4 Gefitinib versus chemotherapy, Outcome 24 Hypokalaemia.}

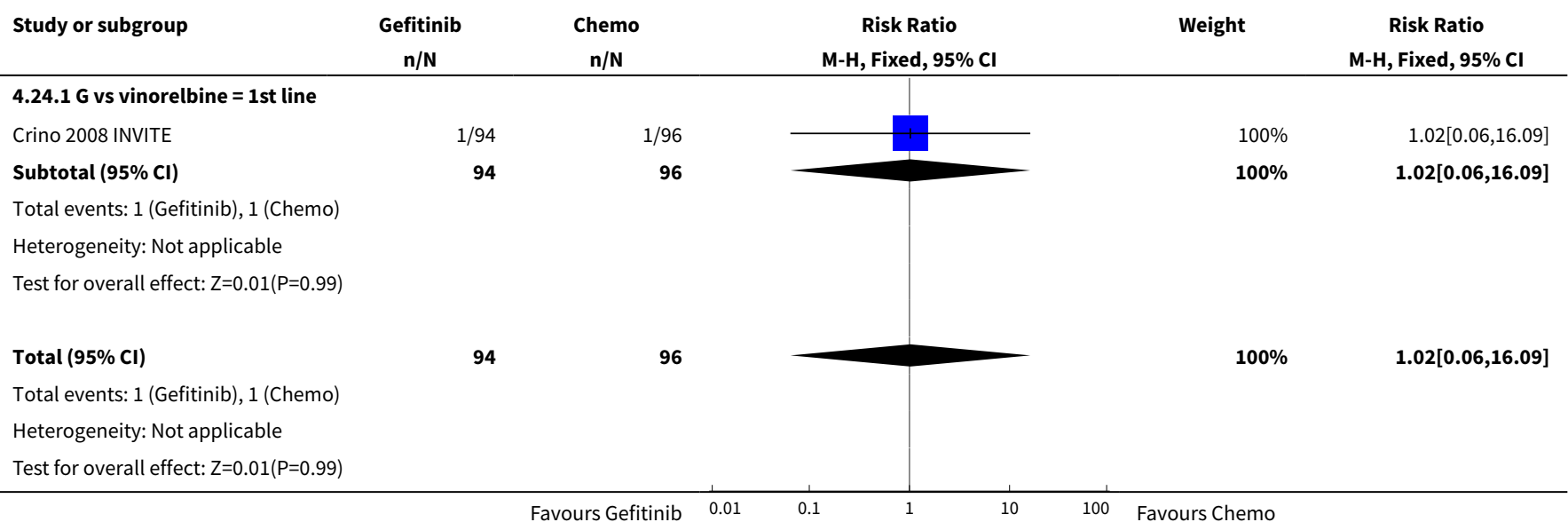

Analysis 4.25. Comparison 4 Gefitinib versus chemotherapy, Outcome 25 Pyrexia.

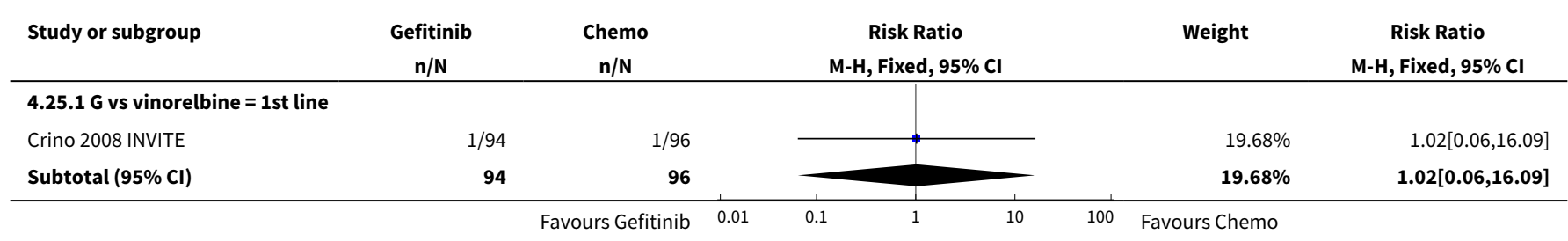




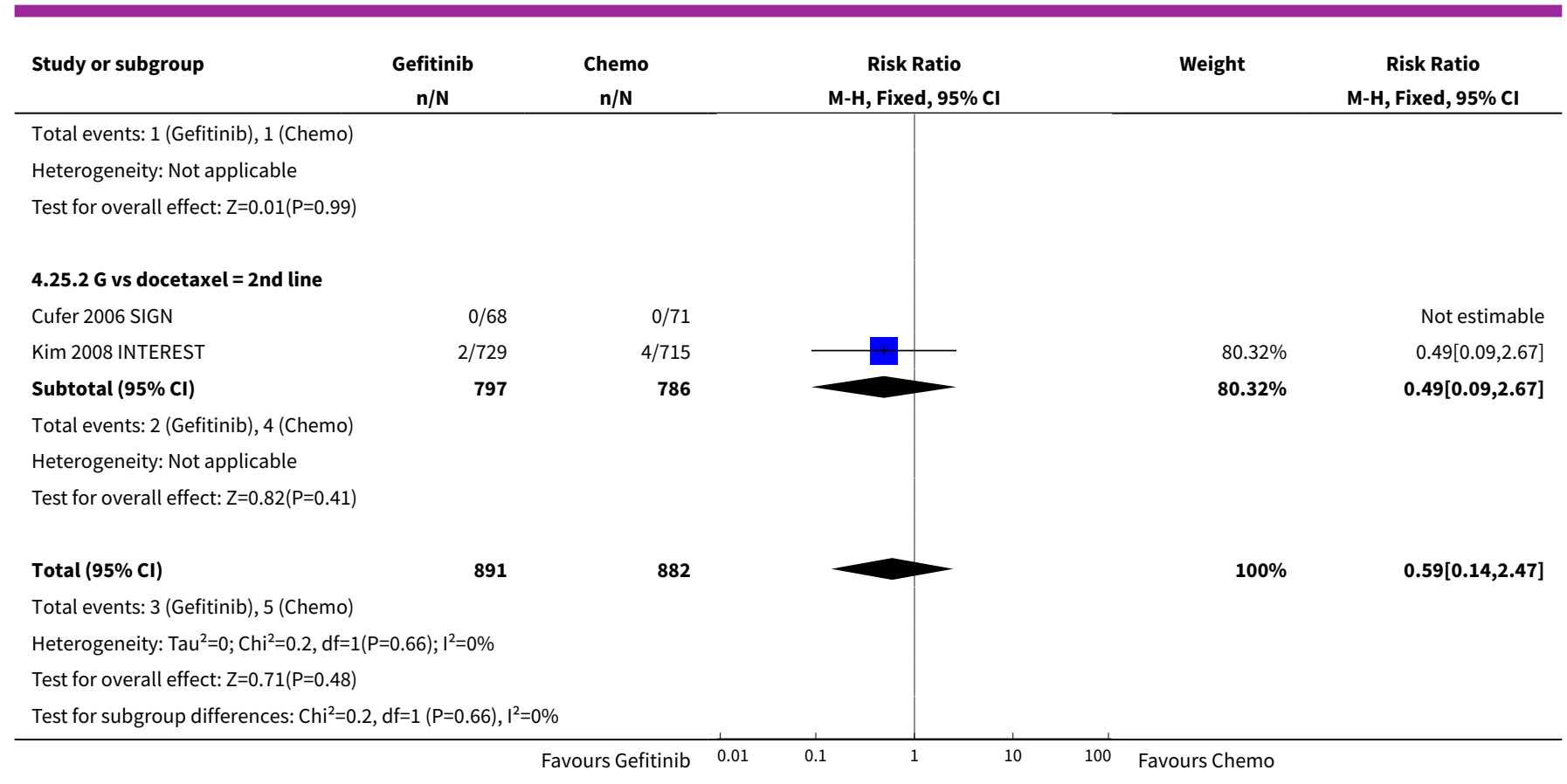

Analysis 4.26. Comparison 4 Gefitinib versus chemotherapy, Outcome 26 Overall response rate.

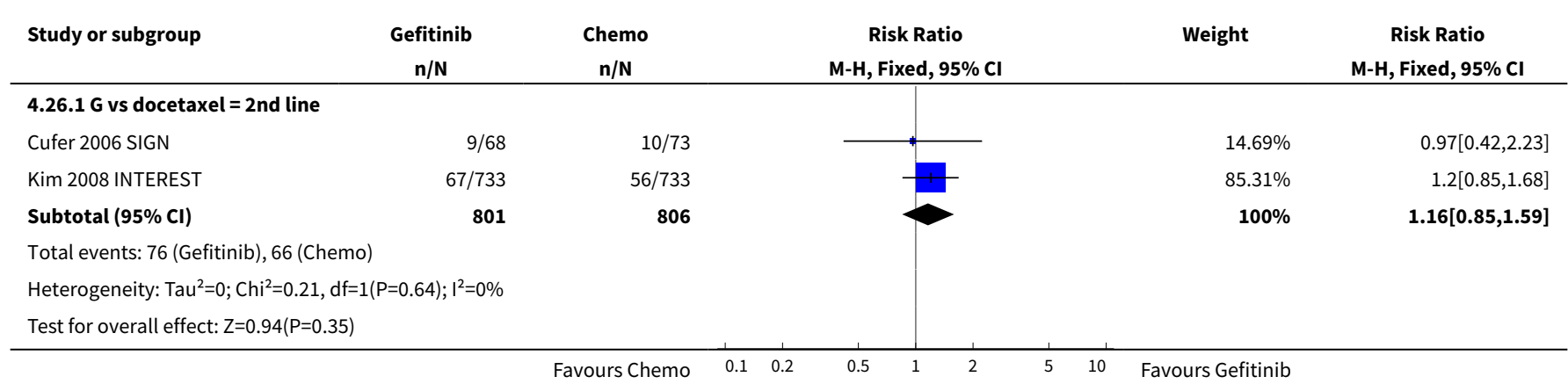

Analysis 4.27. Comparison 4 Gefitinib versus chemotherapy, Outcome 27 Disease control rate.

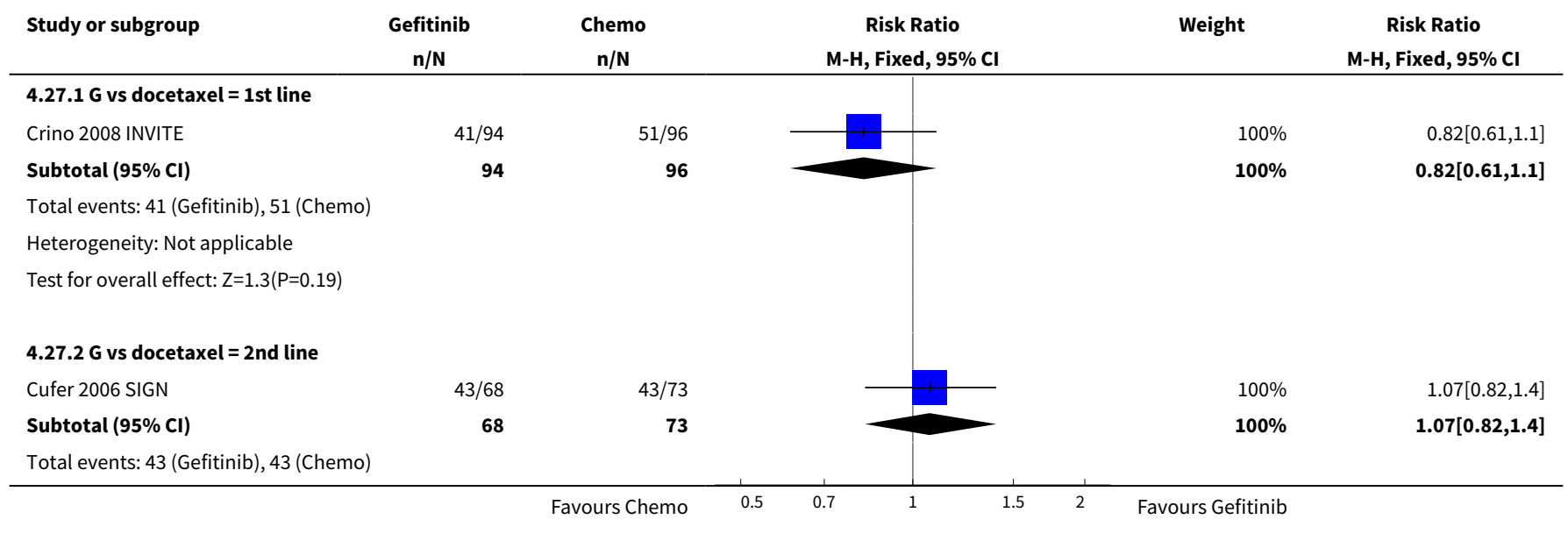




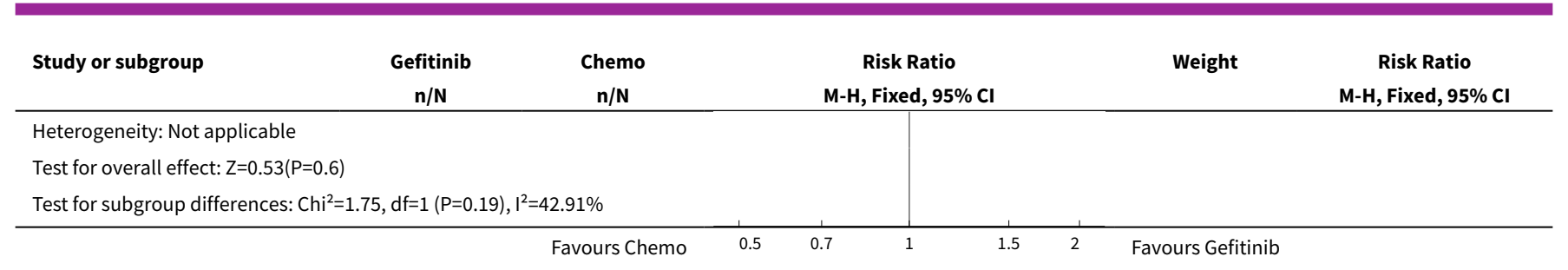

\section{Analysis 4.28. Comparison 4 Gefitinib versus chemotherapy, Outcome 28 FACT-L QOL improvement rate.}

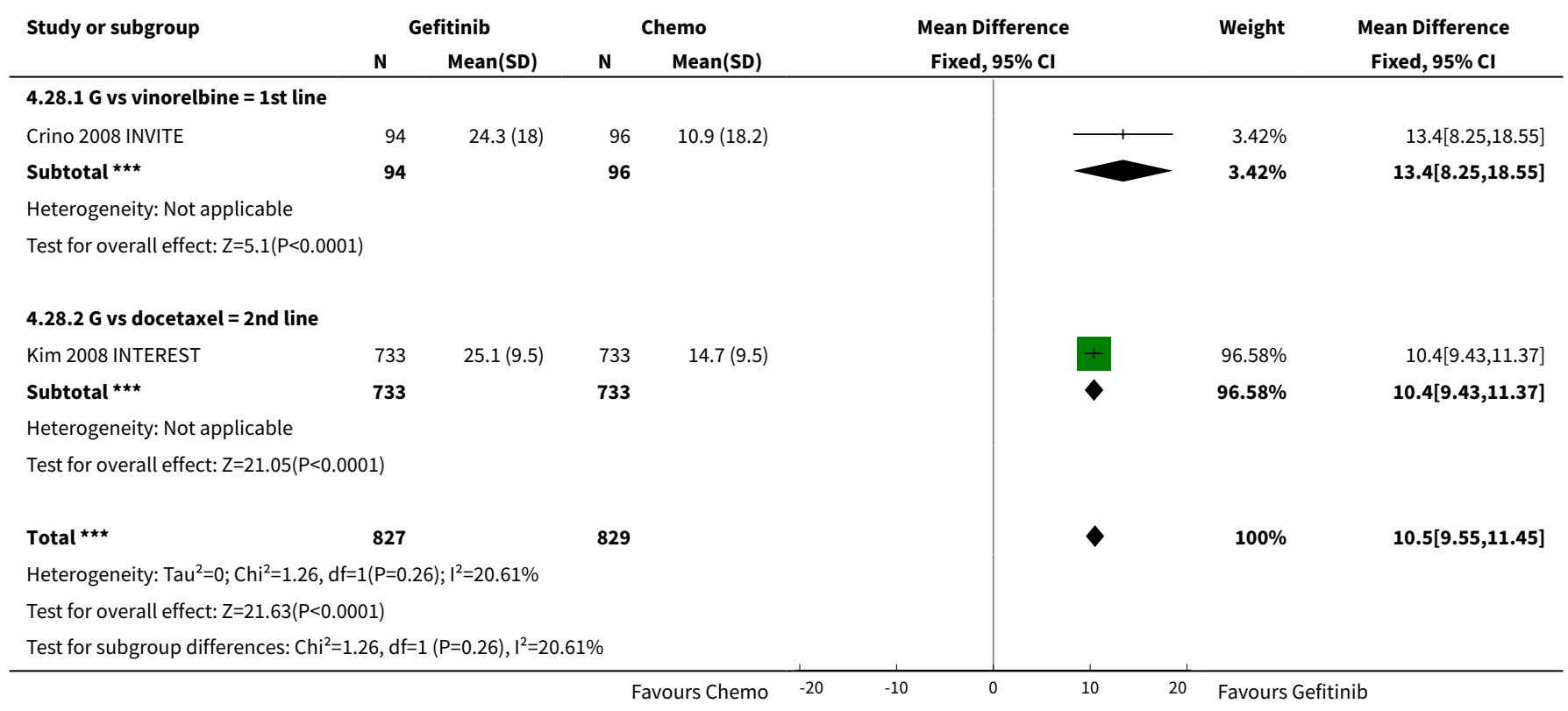

Analysis 4.29. Comparison 4 Gefitinib versus chemotherapy, Outcome 29 LCS QOL improvement rate.

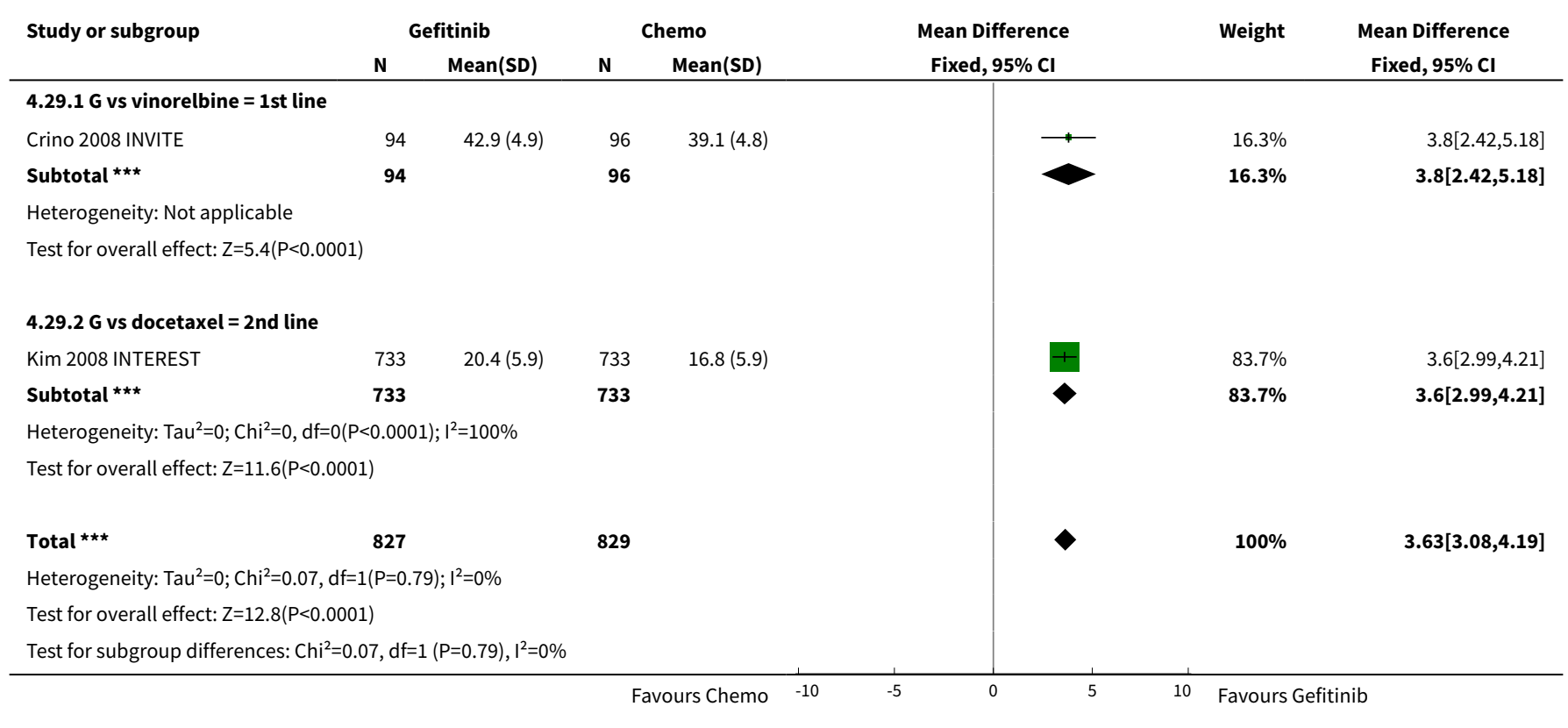


Analysis 4.30. Comparison 4 Gefitinib versus chemotherapy, Outcome 30 TOI QOL improvement rate.

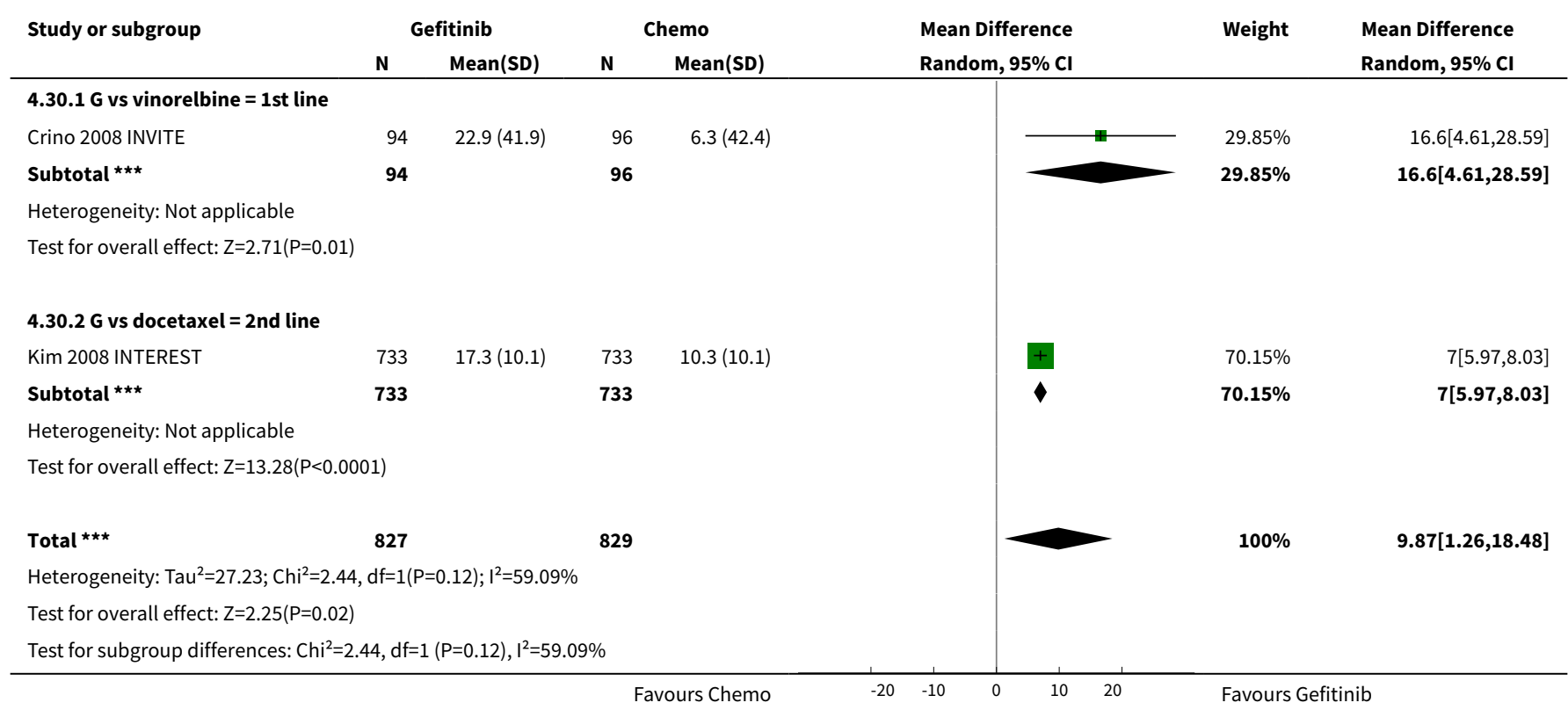

Analysis 4.31. Comparison 4 Gefitinib versus chemotherapy, Outcome 31 PSI QOL improvement rate.

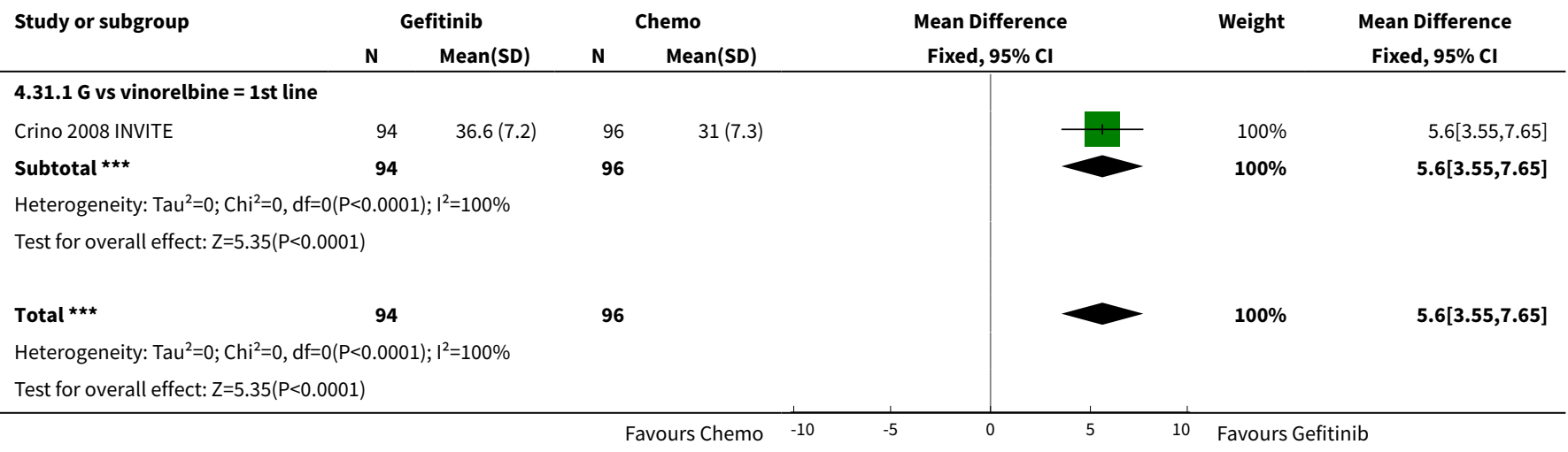

\section{Comparison 5. Gefitinib versus chemotherapy (Asian subgroup)}

\begin{tabular}{lllll}
\hline $\begin{array}{l}\text { Outcome or subgroup } \\
\text { title }\end{array}$ & No. of studies & $\begin{array}{l}\text { No. of partici- } \\
\text { pants }\end{array}$ & Statistical method & Effect size \\
\hline $\begin{array}{l}1 \text { HR Overall survival }= \\
\text { 1st line }\end{array}$ & 4 & Hazard Ratio (Random, 95\% Cl) & $0.94[0.82,1.06]$ \\
\hline $\begin{array}{l}1.1 \text { G vs carboplatin }+ \\
\text { paclitaxel }\end{array}$ & 2 & Hazard Ratio (Random, 95\% Cl) & $1.09[0.64,1.84]$
\end{tabular}




\begin{tabular}{|c|c|c|c|c|}
\hline $\begin{array}{l}\text { Outcome or subgroup } \\
\text { title }\end{array}$ & No. of studies & $\begin{array}{l}\text { No. of partici- } \\
\text { pants }\end{array}$ & Statistical method & Effect size \\
\hline $\begin{array}{l}1.2 \mathrm{G} \text { vs gemcitabine + } \\
\text { cisplatin }\end{array}$ & 1 & & Hazard Ratio (Random, 95\% Cl) & $0.93[0.72,1.21]$ \\
\hline $\begin{array}{l}1.3 \mathrm{G} \text { vs pemetrexed + } \\
\text { cisplatin }\end{array}$ & 1 & & Hazard Ratio (Random, 95\% Cl) & $0.94[0.68,1.30]$ \\
\hline $\begin{array}{l}2 \mathrm{HR} \text { Overall survival = } \\
2 \text { nd line }\end{array}$ & 3 & & Hazard Ratio (Random, 95\% Cl) & $0.94[0.79,1.12]$ \\
\hline $2.1 \mathrm{G}$ vs docetaxel & 2 & & Hazard Ratio (Random, 95\% Cl) & $0.97[0.80,1.17]$ \\
\hline $2.2 \mathrm{G}$ vs pemetrexed & 1 & & Hazard Ratio (Random, 95\% Cl) & $0.80[0.50,1.28]$ \\
\hline $\begin{array}{l}3 \text { HR Overall survival = } \\
\text { Maintenance }\end{array}$ & 1 & & Hazard Ratio (Random, 95\% Cl) & $2.15[0.83,5.55]$ \\
\hline $3.1 \mathrm{G}$ vs pemetrexed & 1 & & Hazard Ratio (Random, 95\% Cl) & $2.15[0.83,5.55]$ \\
\hline $\begin{array}{l}4 \text { HR Progression-free } \\
\text { survival = 1st line }\end{array}$ & 5 & & Hazard Ratio (Random, 95\% Cl) & $0.65[0.43,0.98]$ \\
\hline $\begin{array}{l}4.1 \mathrm{G} \text { vs carboplatin + } \\
\text { paclitaxel }\end{array}$ & 2 & & Hazard Ratio (Random, 95\% Cl) & $0.48[0.20,1.15]$ \\
\hline $\begin{array}{l}4.2 \mathrm{G} \text { vs cisplatin + doc- } \\
\text { etaxel }\end{array}$ & 1 & & Hazard Ratio (Random, 95\% Cl) & $0.49[0.34,0.71]$ \\
\hline $\begin{array}{l}4.3 \mathrm{G} \text { vs gemcitabine + } \\
\text { cisplatin }\end{array}$ & 1 & & Hazard Ratio (Random, 95\% Cl) & $1.20[0.95,1.52]$ \\
\hline $\begin{array}{l}4.4 \mathrm{G} \text { vs pemetrexed + } \\
\text { cisplatin }\end{array}$ & 1 & & Hazard Ratio (Random, 95\% Cl) & $0.85[0.64,1.14]$ \\
\hline $\begin{array}{l}5 \text { HR Progression-free } \\
\text { survival = } 2 \text { nd line }\end{array}$ & 3 & & Hazard Ratio (Random, 95\% Cl) & $0.71[0.57,0.88]$ \\
\hline $5.1 \mathrm{G}$ vs docetaxel & 2 & & Hazard Ratio (Random, 95\% Cl) & $0.78[0.65,0.94]$ \\
\hline $5.2 \mathrm{G}$ vs pemetrexed & 1 & & Hazard Ratio (Random, 95\% Cl) & $0.54[0.37,0.79]$ \\
\hline $\begin{array}{l}6 \text { HR Progression-free } \\
\text { survival = Maintenance }\end{array}$ & 1 & & Hazard Ratio (Random, 95\% Cl) & $0.53[0.27,1.04]$ \\
\hline $6.1 \mathrm{G}$ vs pemetrexed & 1 & & Hazard Ratio (Random, 95\% Cl) & $0.53[0.27,1.04]$ \\
\hline 7 1-year survival rate & 7 & & Risk Ratio (M-H, Fixed, 95\% Cl) & Subtotals only \\
\hline 7.1 1st line & 3 & 1754 & Risk Ratio (M-H, Fixed, 95\% Cl) & $1.03[0.97,1.09]$ \\
\hline 7.2 2nd line & 3 & 681 & Risk Ratio (M-H, Fixed, 95\% Cl) & $0.94[0.81,1.11]$ \\
\hline 7.3 Maintenance & 1 & 70 & Risk Ratio (M-H, Fixed, 95\% Cl) & $0.79[0.65,0.98]$ \\
\hline 8 Nausea & 10 & 2898 & Risk Ratio (M-H, Fixed, 95\% Cl) & $0.34[0.17,0.64]$ \\
\hline
\end{tabular}




\begin{tabular}{|c|c|c|c|c|}
\hline $\begin{array}{l}\text { Outcome or subgroup } \\
\text { title }\end{array}$ & No. of studies & $\begin{array}{l}\text { No. of partici- } \\
\text { pants }\end{array}$ & Statistical method & Effect size \\
\hline 8.1 1st line & 4 & 1912 & Risk Ratio (M-H, Fixed, 95\% Cl) & $0.19[0.06,0.54]$ \\
\hline 8.2 2nd line & 5 & 916 & Risk Ratio (M-H, Fixed, 95\% Cl) & $0.59[0.22,1.60]$ \\
\hline 8.3 Maintenance & 1 & 70 & Risk Ratio (M-H, Fixed, 95\% Cl) & $0.53[0.09,2.98]$ \\
\hline 9 Vomiting & 6 & 2447 & Risk Ratio (M-H, Random, 95\% Cl) & $0.19[0.05,0.77]$ \\
\hline 9.1 1st line & 3 & 1737 & Risk Ratio (M-H, Random, 95\% Cl) & $0.08[0.02,0.29]$ \\
\hline 9.2 2nd line & 2 & 640 & Risk Ratio (M-H, Random, 95\% Cl) & $1.31[0.30,5.77]$ \\
\hline 9.3 Maintenance & 1 & 70 & Risk Ratio (M-H, Random, 95\% Cl) & $0.20[0.02,1.69]$ \\
\hline 10 Anorexia & 10 & 2950 & Risk Ratio (M-H, Fixed, 95\% Cl) & $0.36[0.27,0.49]$ \\
\hline 10.1 1st line & 4 & 1964 & Risk Ratio (M-H, Fixed, 95\% Cl) & $0.32[0.23,0.45]$ \\
\hline 10.2 2nd line & 5 & 916 & Risk Ratio (M-H, Fixed, 95\% Cl) & $0.53[0.27,1.02]$ \\
\hline 10.3 Maintenance & 1 & 70 & Risk Ratio (M-H, Fixed, 95\% Cl) & $0.79[0.05,12.20]$ \\
\hline 11 Fatigue & 10 & 1960 & Risk Ratio (M-H, Fixed, 95\% Cl) & $0.32[0.22,0.46]$ \\
\hline 11.1 1st line & 4 & 943 & Risk Ratio (M-H, Fixed, 95\% Cl) & $0.26[0.17,0.40]$ \\
\hline 11.2 2nd line & 4 & 759 & Risk Ratio (M-H, Fixed, 95\% Cl) & $0.26[0.06,1.03]$ \\
\hline 11.3 Maintenance & 2 & 258 & Risk Ratio (M-H, Fixed, 95\% Cl) & $1.09[0.41,2.89]$ \\
\hline 12 Arthralgia/myalgia & 4 & 2063 & Risk Ratio (M-H, Fixed, 95\% Cl) & $0.14[0.03,0.61]$ \\
\hline 12.1 1st line & 2 & 1423 & Risk Ratio (M-H, Fixed, 95\% Cl) & $0.14[0.03,0.61]$ \\
\hline 12.2 2nd line & 2 & 640 & Risk Ratio (M-H, Fixed, 95\% Cl) & $0.0[0.0,0.0]$ \\
\hline 13 Asthenia & 4 & 1755 & Risk Ratio (M-H, Fixed, 95\% Cl) & $0.22[0.08,0.58]$ \\
\hline 13.1 st line & 3 & 1598 & Risk Ratio (M-H, Fixed, 95\% Cl) & $0.21[0.07,0.61]$ \\
\hline 13.2 2nd line & 1 & 157 & Risk Ratio (M-H, Fixed, 95\% Cl) & $0.31[0.03,2.94]$ \\
\hline 14 Neurotoxicity & 4 & 1797 & Risk Ratio (M-H, Fixed, 95\% Cl) & $0.07[0.02,0.24]$ \\
\hline 14.1 1st line & 2 & 1505 & Risk Ratio (M-H, Fixed, 95\% Cl) & $0.07[0.02,0.24]$ \\
\hline 14.2 2nd line & 2 & 292 & Risk Ratio (M-H, Fixed, 95\% Cl) & $0.0[0.0,0.0]$ \\
\hline 15 Neutropenia & 10 & 3061 & Risk Ratio (M-H, Random, 95\% Cl) & $0.11[0.05,0.27]$ \\
\hline 15.1 1st line & 5 & 2139 & Risk Ratio (M-H, Random, 95\% Cl) & $0.05[0.03,0.07]$ \\
\hline 15.2 2nd line & 3 & 664 & Risk Ratio (M-H, Random, 95\% Cl) & $0.12[0.08,0.18]$ \\
\hline
\end{tabular}




\begin{tabular}{|c|c|c|c|c|}
\hline $\begin{array}{l}\text { Outcome or subgroup } \\
\text { title }\end{array}$ & No. of studies & $\begin{array}{l}\text { No. of partici- } \\
\text { pants }\end{array}$ & Statistical method & Effect size \\
\hline 15.3 Maintenance & 2 & 258 & Risk Ratio (M-H, Random, 95\% Cl) & $1.20[0.49,2.96]$ \\
\hline 16 Anaemia & 9 & 2538 & Risk Ratio (M-H, Fixed, 95\% Cl) & $0.18[0.12,0.29]$ \\
\hline 16.1 1st line & 5 & 2139 & Risk Ratio (M-H, Fixed, 95\% Cl) & $0.16[0.10,0.26]$ \\
\hline 16.2 2nd line & 2 & 141 & Risk Ratio (M-H, Fixed, 95\% Cl) & $0.20[0.02,1.61]$ \\
\hline 16.3 Maintenance & 2 & 258 & Risk Ratio (M-H, Fixed, 95\% Cl) & $1.36[0.24,7.87]$ \\
\hline 17 Leukopenia & 4 & 2086 & Risk Ratio (M-H, Random, 95\% Cl) & $0.07[0.02,0.23]$ \\
\hline 17.1 1st line & 3 & 1603 & Risk Ratio (M-H, Random, 95\% Cl) & $0.04[0.02,0.08]$ \\
\hline 17.2 2nd line & 1 & 483 & Risk Ratio (M-H, Random, 95\% Cl) & $0.16[0.09,0.26]$ \\
\hline 18 Thrombocytopenia & 7 & 1070 & Risk Ratio (M-H, Fixed, 95\% Cl) & $0.32[0.14,0.72]$ \\
\hline 18.1 1st line & 2 & 536 & Risk Ratio (M-H, Fixed, 95\% Cl) & $0.14[0.04,0.51]$ \\
\hline 18.2 2nd line & 3 & 276 & Risk Ratio (M-H, Fixed, 95\% Cl) & $0.25[0.03,2.15]$ \\
\hline 18.3 Maintenance & 2 & 258 & Risk Ratio (M-H, Fixed, 95\% Cl) & $3.63[0.42,31.44]$ \\
\hline 19 Febrile neutropenia & 2 & 1679 & Risk Ratio (M-H, Fixed, 95\% Cl) & $0.09[0.03,0.28]$ \\
\hline 19.1 1st line & 1 & 1196 & Risk Ratio (M-H, Fixed, 95\% Cl) & $0.06[0.01,0.43]$ \\
\hline 19.2 2nd line & 1 & 483 & Risk Ratio (M-H, Fixed, 95\% Cl) & $0.12[0.03,0.49]$ \\
\hline 20 Skin rash & 10 & 3174 & Risk Ratio (M-H, Random, 95\% Cl) & $3.11[1.28,7.55]$ \\
\hline 20.1 1st line & 5 & 2141 & Risk Ratio (M-H, Random, 95\% Cl) & $5.09[2.21,11.72]$ \\
\hline 20.2 2nd line & 3 & 775 & Risk Ratio (M-H, Random, 95\% Cl) & $2.54[0.46,13.95]$ \\
\hline 20.3 Maintenance & 2 & 258 & Risk Ratio (M-H, Random, 95\% Cl) & $0.91[0.24,3.44]$ \\
\hline 21 Diarrhoea & 10 & 3055 & Risk Ratio (M-H, Fixed, 95\% Cl) & $2.79[1.57,4.94]$ \\
\hline 21.1 1st line & 5 & 2139 & Risk Ratio (M-H, Fixed, 95\% Cl) & $2.74[1.43,5.27]$ \\
\hline 21.2 2nd line & 5 & 916 & Risk Ratio (M-H, Fixed, 95\% Cl) & $2.93[0.88,9.73]$ \\
\hline 22 Increased ALT & 7 & 1542 & Risk Ratio (M-H, Fixed, 95\% Cl) & $10.03[5.23,19.26]$ \\
\hline 22.1 1st line & 4 & 943 & Risk Ratio (M-H, Fixed, 95\% Cl) & $11.66[5.13,26.49]$ \\
\hline 22.2 2nd line & 2 & 529 & Risk Ratio (M-H, Fixed, 95\% Cl) & $13.22[3.18,54.99]$ \\
\hline 22.3 Maintenance & 1 & 70 & Risk Ratio (M-H, Fixed, 95\% Cl) & $0.27[0.01,6.33]$ \\
\hline 23 Increased AST & 4 & 762 & Risk Ratio (M-H, Fixed, 95\% Cl) & $7.73[2.78,21.46]$ \\
\hline
\end{tabular}




\begin{tabular}{|c|c|c|c|c|}
\hline $\begin{array}{l}\text { Outcome or subgroup } \\
\text { title }\end{array}$ & No. of studies & $\begin{array}{l}\text { No. of partici- } \\
\text { pants }\end{array}$ & Statistical method & Effect size \\
\hline 23.1 1st line & 3 & 716 & Risk Ratio (M-H, Fixed, 95\% Cl) & $7.73[2.78,21.46]$ \\
\hline 23.2 2nd line & 1 & 46 & Risk Ratio (M-H, Fixed, 95\% Cl) & $0.0[0.0,0.0]$ \\
\hline 24 Overall response rate & 14 & & Risk Ratio (M-H, Random, 95\% Cl) & Subtotals only \\
\hline 24.1 1st line & 6 & 2158 & Risk Ratio (M-H, Random, 95\% Cl) & $1.43[1.13,1.82]$ \\
\hline 24.2 2nd line & 6 & 921 & Risk Ratio (M-H, Random, 95\% Cl) & $1.43[0.92,2.22]$ \\
\hline 24.3 Maintenance & 2 & 258 & Risk Ratio (M-H, Random, 95\% Cl) & $0.88[0.41,1.87]$ \\
\hline 25 Stable disease & 9 & & Risk Ratio (M-H, Random, 95\% Cl) & Subtotals only \\
\hline 25.1 1st line & 5 & 941 & Risk Ratio (M-H, Random, 95\% Cl) & $0.47[0.34,0.64]$ \\
\hline 25.2 2nd line & 2 & 143 & Risk Ratio (M-H, Random, 95\% Cl) & $1.08[0.64,1.82]$ \\
\hline 25.3 Maintenance & 2 & 258 & Risk Ratio (M-H, Random, 95\% Cl) & $0.64[0.44,0.93]$ \\
\hline 26 Disease control rate & 9 & & Risk Ratio (M-H, Random, 95\% Cl) & Subtotals only \\
\hline 26.1 1st line & 5 & 1848 & Risk Ratio (M-H, Random, 95\% Cl) & $0.99[0.86,1.13]$ \\
\hline 26.2 2nd line & 3 & 528 & Risk Ratio (M-H, Random, 95\% Cl) & $0.99[0.78,1.25]$ \\
\hline 26.3 Maintenance & 1 & 188 & Risk Ratio (M-H, Random, 95\% Cl) & $0.65[0.49,0.85]$ \\
\hline $\begin{array}{l}27 \text { FACT-L QOL improve- } \\
\text { ment rate }\end{array}$ & 3 & 1670 & Mean Difference (IV, Fixed, 95\% CI) & $9.50[7.95,11.05]$ \\
\hline 27.1 1st line & 1 & 1151 & Mean Difference (IV, Fixed, 95\% CI) & $0.0[0.0,0.0]$ \\
\hline 27.2 2nd line & 2 & 519 & Mean Difference (IV, Fixed, 95\% CI) & $9.50[7.95,11.05]$ \\
\hline $\begin{array}{l}28 \text { LCS QOL improve- } \\
\text { ment rate }\end{array}$ & 3 & 1748 & Mean Difference (IV, Fixed, 95\% CI) & $2.30[1.53,3.07]$ \\
\hline 28.1 1st line & 1 & 1151 & Mean Difference (IV, Fixed, 95\% CI) & $0.0[0.0,0.0]$ \\
\hline 28.2 2nd line & 2 & 597 & Mean Difference (IV, Fixed, 95\% CI) & $2.30[1.53,3.07]$ \\
\hline $\begin{array}{l}29 \text { TOI QOL improve- } \\
\text { ment rate }\end{array}$ & 3 & 1670 & Mean Difference (IV, Fixed, 95\% CI) & $11.8[9.17,14.43]$ \\
\hline 29.1 1st line & 1 & 1151 & Mean Difference (IV, Fixed, 95\% CI) & $0.0[0.0,0.0]$ \\
\hline 29.2 2nd line & 2 & 519 & Mean Difference (IV, Fixed, 95\% CI) & $11.8[9.17,14.43]$ \\
\hline
\end{tabular}


Analysis 5.1. Comparison 5 Gefitinib versus chemotherapy (Asian subgroup), Outcome $1 \mathrm{HR}$ Overall survival = 1st line.

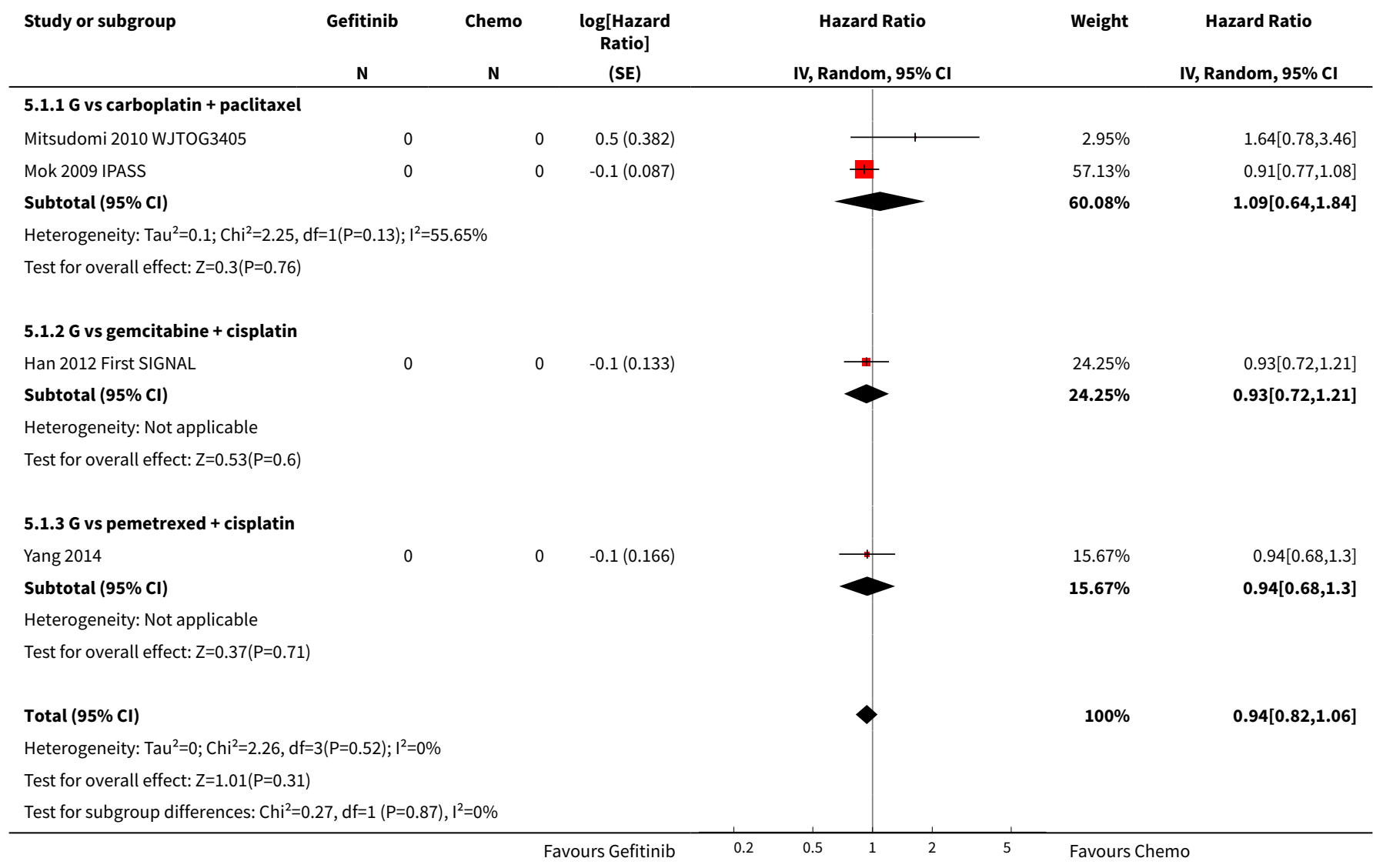

Analysis 5.2. Comparison 5 Gefitinib versus chemotherapy (Asian subgroup), Outcome 2 HR Overall survival $=2$ nd line.

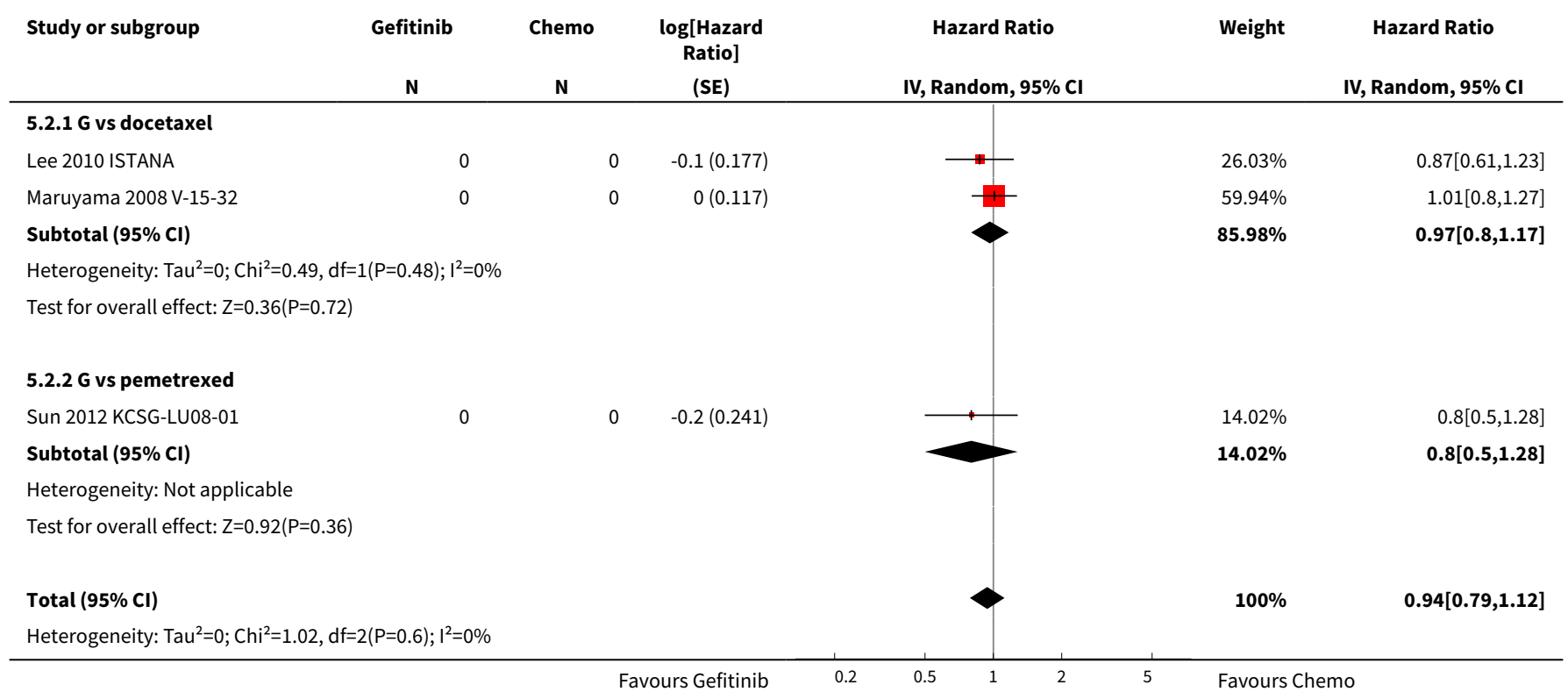




\begin{tabular}{|c|c|c|c|c|c|c|c|c|}
\hline \multirow[t]{2}{*}{ Study or subgroup } & \multirow{2}{*}{$\begin{array}{c}\text { Gefitinib } \\
\text { N }\end{array}$} & \multirow{2}{*}{$\begin{array}{c}\text { Chemo } \\
\text { N }\end{array}$} & \multirow{2}{*}{$\begin{array}{c}\log [\text { Hazard } \\
\text { Ratio }] \\
\text { (SE) }\end{array}$} & \multicolumn{3}{|c|}{ Hazard Ratio } & \multirow[t]{2}{*}{ Weight } & \multirow{2}{*}{$\begin{array}{c}\text { Hazard Ratio } \\
\text { IV, Random, } 95 \% \mathrm{CI}\end{array}$} \\
\hline & & & & & \multicolumn{2}{|c|}{ IV, Random, $95 \% \mathrm{CI}$} & & \\
\hline \multicolumn{9}{|c|}{ Test for overall effect: $Z=0.68(P=0.5)$} \\
\hline \multicolumn{9}{|c|}{ Test for subgroup differences: $\mathrm{Chi}^{2}=0.52, \mathrm{df}=1(\mathrm{P}=0.47), \mathrm{I}^{2}=0 \%$} \\
\hline & & & ours Gefitinib & 0.2 & 0.5 & 2 & Favours & \\
\hline
\end{tabular}

Analysis 5.3. Comparison 5 Gefitinib versus chemotherapy (Asian subgroup), Outcome 3 HR Overall survival = Maintenance.

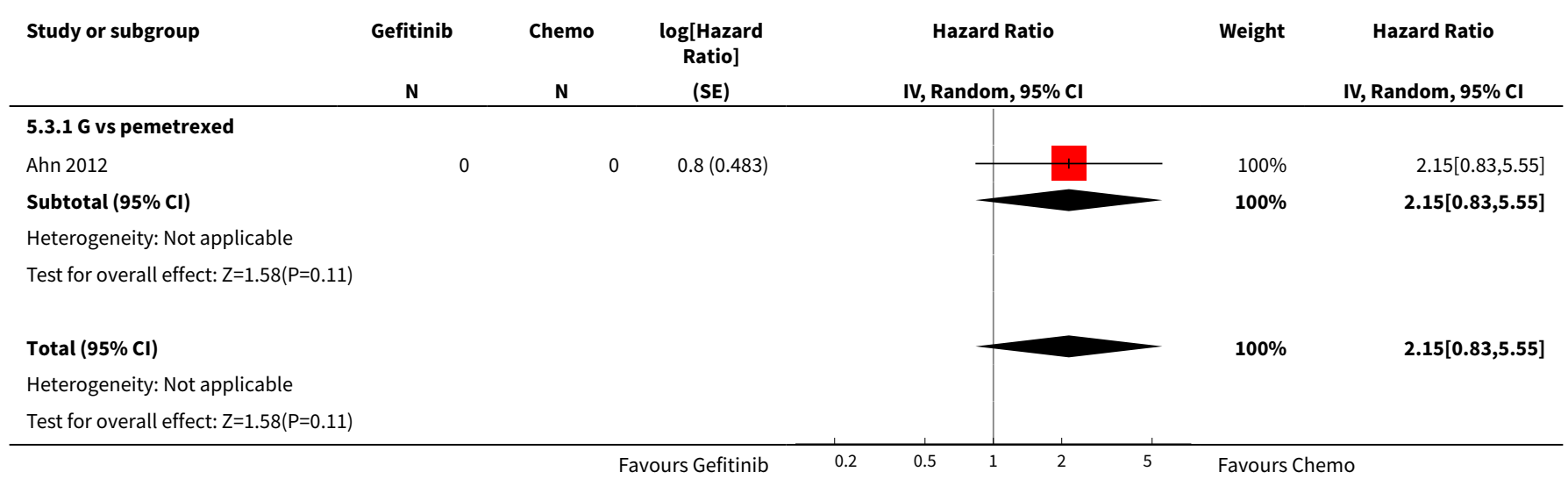

\section{Analysis 5.4. Comparison 5 Gefitinib versus chemotherapy (Asian subgroup), Outcome 4 HR Progression-free survival = 1st line.}

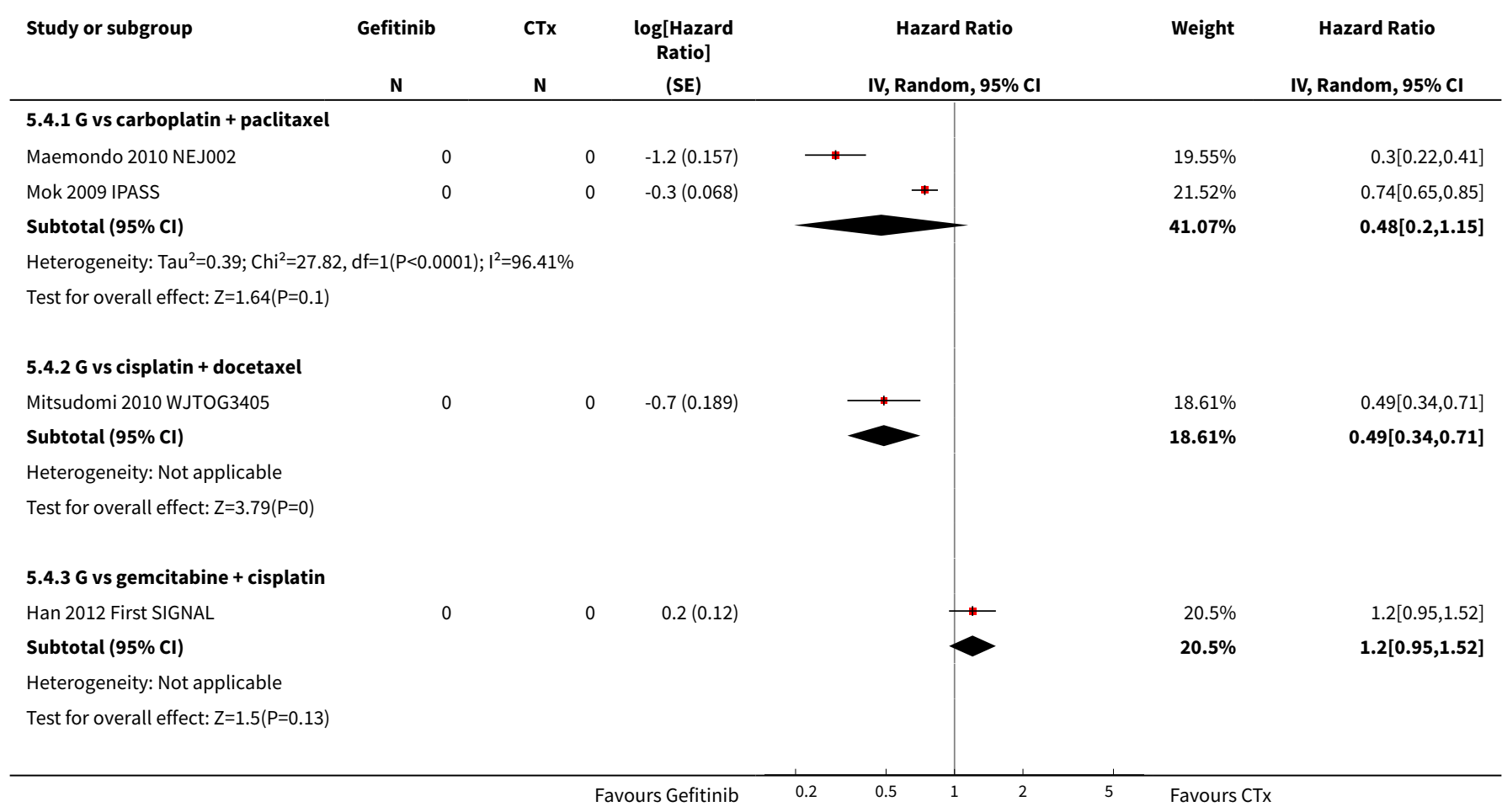




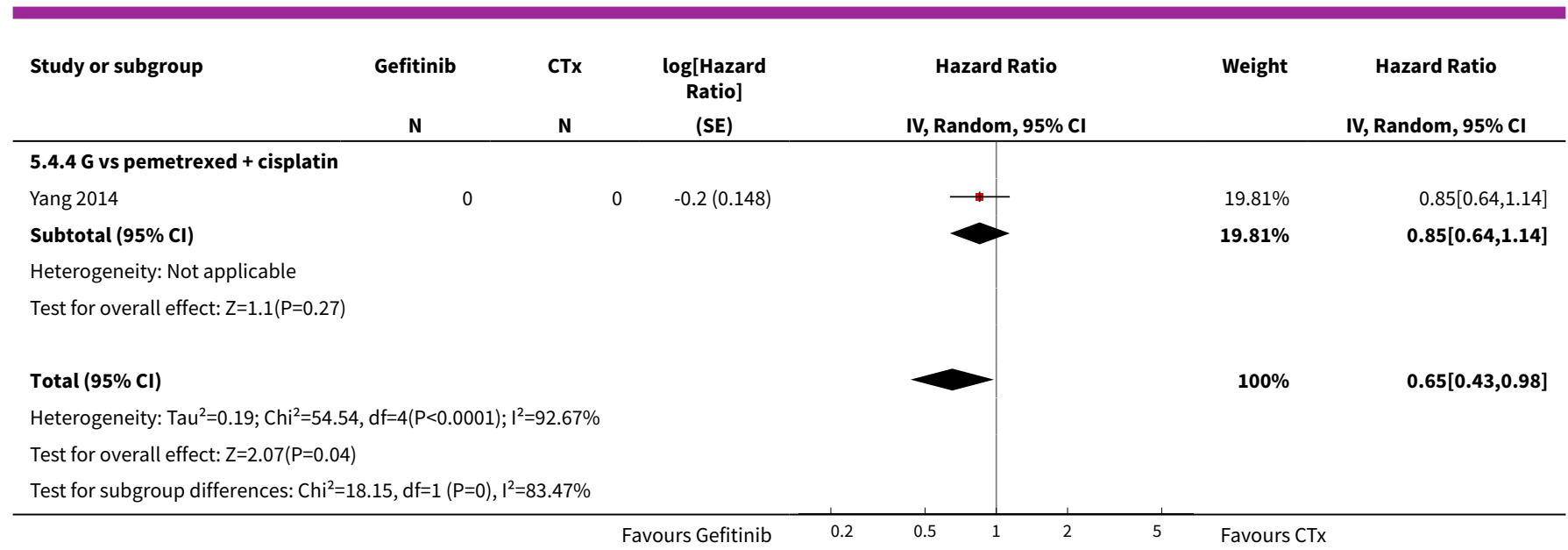

\section{Analysis 5.5. Comparison 5 Gefitinib versus chemotherapy (Asian subgroup), Outcome 5 HR Progression-free survival = 2nd line.}

\begin{tabular}{|c|c|c|c|c|c|c|}
\hline \multirow[t]{2}{*}{ Study or subgroup } & \multirow{2}{*}{$\begin{array}{c}\text { Gefitinib } \\
\text { N }\end{array}$} & \multirow{2}{*}{$\begin{array}{c}\text { Chemo } \\
\text { N }\end{array}$} & \multirow{2}{*}{$\begin{array}{c}\log [\text { Hazard } \\
\text { Ratio }] \\
\text { (SE) }\end{array}$} & \multirow{2}{*}{$\begin{array}{c}\text { Hazard Ratio } \\
\text { IV, Random, } 95 \% \text { CI }\end{array}$} & \multirow[t]{2}{*}{ Weight } & \multirow{2}{*}{$\begin{array}{c}\text { Hazard Ratio } \\
\text { IV, Random, 95\% CI }\end{array}$} \\
\hline & & & & & & \\
\hline \multicolumn{7}{|l|}{ 5.5.1 G vs docetaxel } \\
\hline Lee 2010 ISTANA & 0 & 0 & $-0.3(0.156)$ & 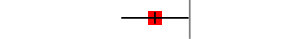 & $31.49 \%$ & $0.73[0.54,0.99]$ \\
\hline Maruyama $2008 \mathrm{~V}-15-32$ & 0 & 0 & $-0.2(0.114)$ & +- & $44.48 \%$ & $0.81[0.65,1.01]$ \\
\hline Subtotal $(95 \% \mathrm{Cl})$ & & & & & $75.97 \%$ & $0.78[0.65,0.94]$ \\
\hline \multicolumn{7}{|c|}{ Test for overall effect: $Z=2.69(P=0.01)$} \\
\hline \multicolumn{7}{|l|}{$5.5 .2 \mathrm{G}$ vs pemetrexed } \\
\hline Sun 2012 KCSG-LU08-01 & 0 & 0 & $-0.6(0.192)$ & $\longrightarrow$ & $24.03 \%$ & $0.54[0.37,0.79]$ \\
\hline Subtotal $(95 \% \mathrm{Cl})$ & & & & & $24.03 \%$ & $0.54[0.37,0.79]$ \\
\hline \multicolumn{7}{|c|}{ Heterogeneity: Not applicable } \\
\hline Total $(95 \% \mathrm{Cl})$ & & & & & $100 \%$ & $0.71[0.57,0.88]$ \\
\hline \multicolumn{7}{|c|}{ Heterogeneity: $\mathrm{Tau}^{2}=0.01 ; \mathrm{Chi}^{2}=3.31, \mathrm{df}=2(\mathrm{P}=0.19) ; \mathrm{I}^{2}=39.61 \%$} \\
\hline \multicolumn{7}{|c|}{ Test for overall effect: $Z=3.06(P=0)$} \\
\hline Test for subgroup differer & $2, d f=1(P=0$ & ${ }^{2}=66.83 \%$ & & & & \\
\hline
\end{tabular}

Analysis 5.6. Comparison 5 Gefitinib versus chemotherapy (Asian subgroup), Outcome 6 HR Progression-free survival = Maintenance.

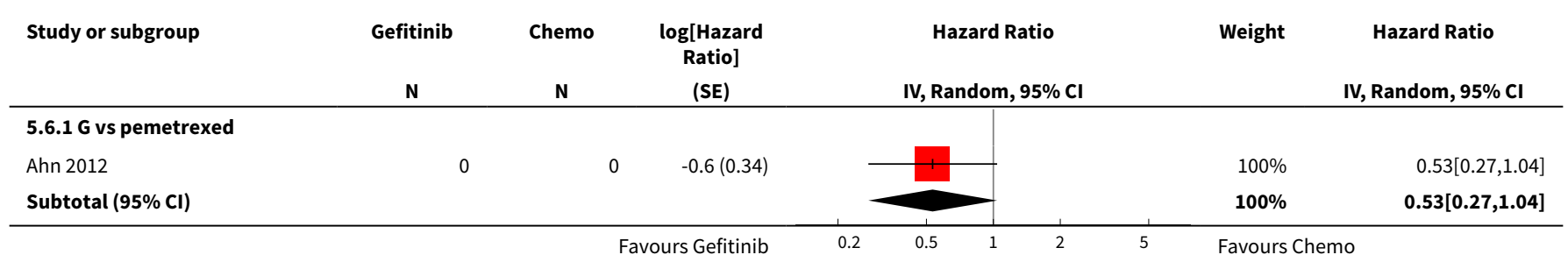




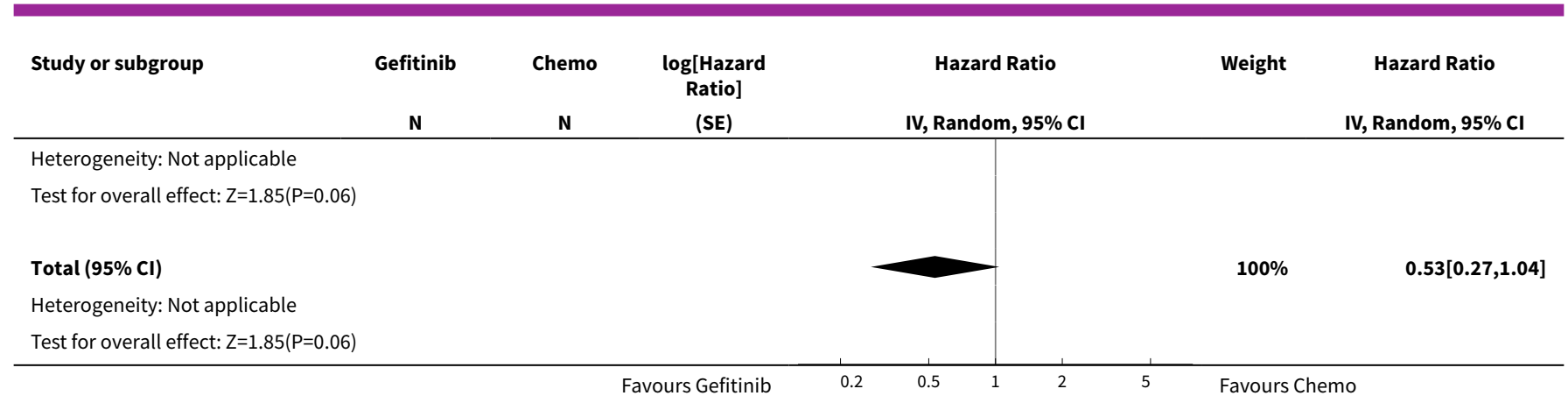

Analysis 5.7. Comparison 5 Gefitinib versus chemotherapy (Asian subgroup), Outcome 7 1-year survival rate.

\begin{tabular}{|c|c|c|c|c|c|}
\hline Study or subgroup & $\begin{array}{c}\text { Gefitinib } \\
n / N\end{array}$ & $\begin{array}{c}\text { Chemo } \\
n / N\end{array}$ & $\begin{array}{c}\text { Risk Ratio } \\
\text { M-H, Fixed, 95\% Cl }\end{array}$ & Weight & $\begin{array}{c}\text { Risk Ratio } \\
\text { M-H, Fixed, 95\% Cl }\end{array}$ \\
\hline \multicolumn{6}{|l|}{ 5.7.1 1st line } \\
\hline Han 2012 First SIGNAL & $118 / 159$ & $114 / 150$ & & $19.28 \%$ & $0.98[0.86,1.11]$ \\
\hline Maemondo 2010 NEJ002 & $97 / 114$ & $99 / 114$ & $\rightarrow$ & $16.27 \%$ & $0.98[0.88,1.09]$ \\
\hline Mok 2009 IPASS & $416 / 609$ & $392 / 608$ & & $64.46 \%$ & $1.06[0.98,1.15]$ \\
\hline Subtotal $(95 \% \mathrm{CI})$ & 882 & 872 & & $100 \%$ & $1.03[0.97,1.09]$ \\
\hline \multicolumn{6}{|c|}{ Heterogeneity: $\operatorname{Tau}^{2}=0 ; \mathrm{Chi}^{2}=2.03, \mathrm{df}=2(\mathrm{P}=0.36) ; \mathrm{I}^{2}=1.24 \%$} \\
\hline \multicolumn{6}{|c|}{ Test for overall effect: $Z=0.98(P=0.33)$} \\
\hline \multicolumn{6}{|l|}{ 5.7.2 2nd line } \\
\hline Kim 2016 & $20 / 48$ & $17 / 47$ & & $10.47 \%$ & $1.15[0.69,1.91]$ \\
\hline Li 2010 & $18 / 49$ & $15 / 48$ & & $9.24 \%$ & $1.18[0.67,2.05]$ \\
\hline Subtotal $(95 \% \mathrm{Cl})$ & 341 & 340 & & $100 \%$ & $0.94[0.81,1.11]$ \\
\hline \multicolumn{6}{|c|}{ Total events: 155 (Gefitinib), 164 (Chemo) } \\
\hline \multicolumn{6}{|c|}{ Heterogeneity: Tau $^{2}=0 ; \mathrm{Chi}^{2}=1.62, \mathrm{df}=2(\mathrm{P}=0.44) ; \mathrm{I}^{2}=0 \%$} \\
\hline \multicolumn{6}{|c|}{ Test for overall effect: $Z=0.71(P=0.48)$} \\
\hline \multicolumn{6}{|l|}{ 5.7.3 Maintenance } \\
\hline Ahn 2012 & $29 / 39$ & $29 / 31$ & & $100 \%$ & $0.79[0.65,0.98]$ \\
\hline Subtotal $(95 \% \mathrm{Cl})$ & 39 & 31 & & $100 \%$ & $0.79[0.65,0.98]$ \\
\hline \multicolumn{6}{|c|}{ Total events: 29 (Gefitinib), 29 (Chemo) } \\
\hline \multicolumn{6}{|c|}{ Heterogeneity: Not applicable } \\
\hline \multicolumn{6}{|c|}{ Test for overall effect: $Z=2.18(P=0.03)$} \\
\hline Test for subgroup differer &,$d f=1(P=0.04)$, & $1 \%$ & & & \\
\hline
\end{tabular}

Analysis 5.8. Comparison 5 Gefitinib versus chemotherapy (Asian subgroup), Outcome 8 Nausea.

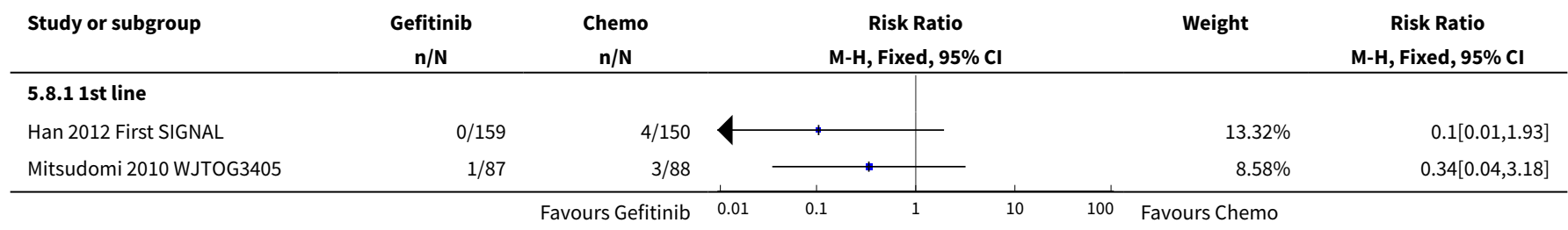




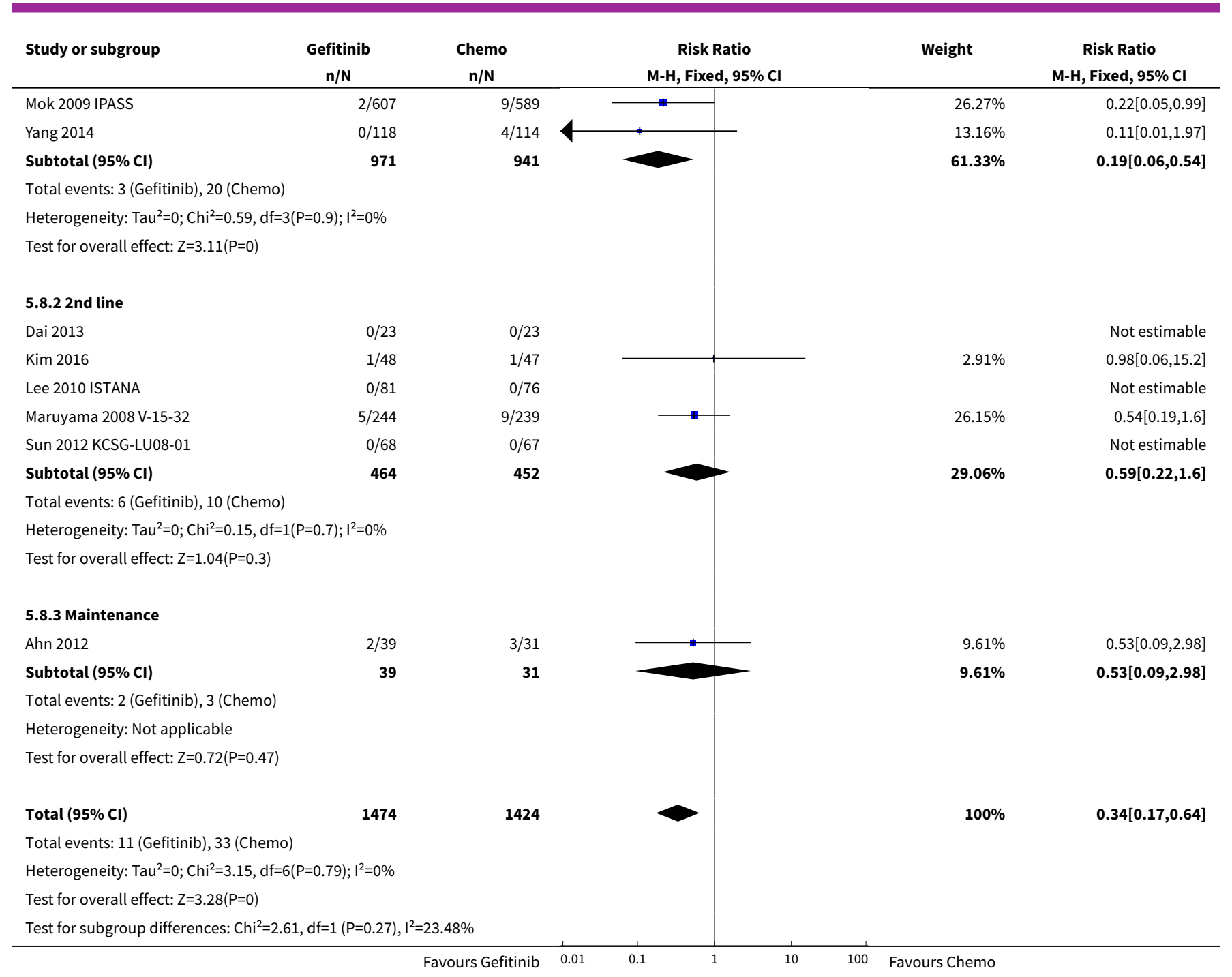

\section{Analysis 5.9. Comparison 5 Gefitinib versus chemotherapy (Asian subgroup), Outcome 9 Vomiting.}

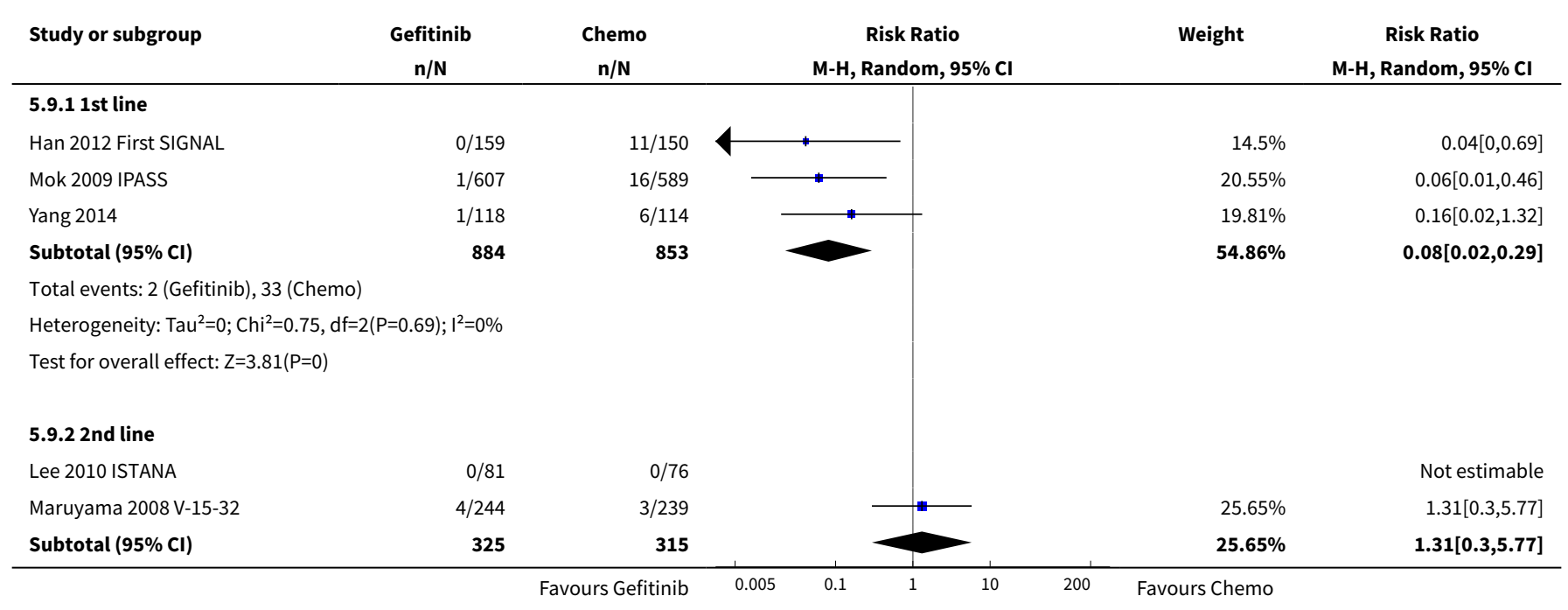




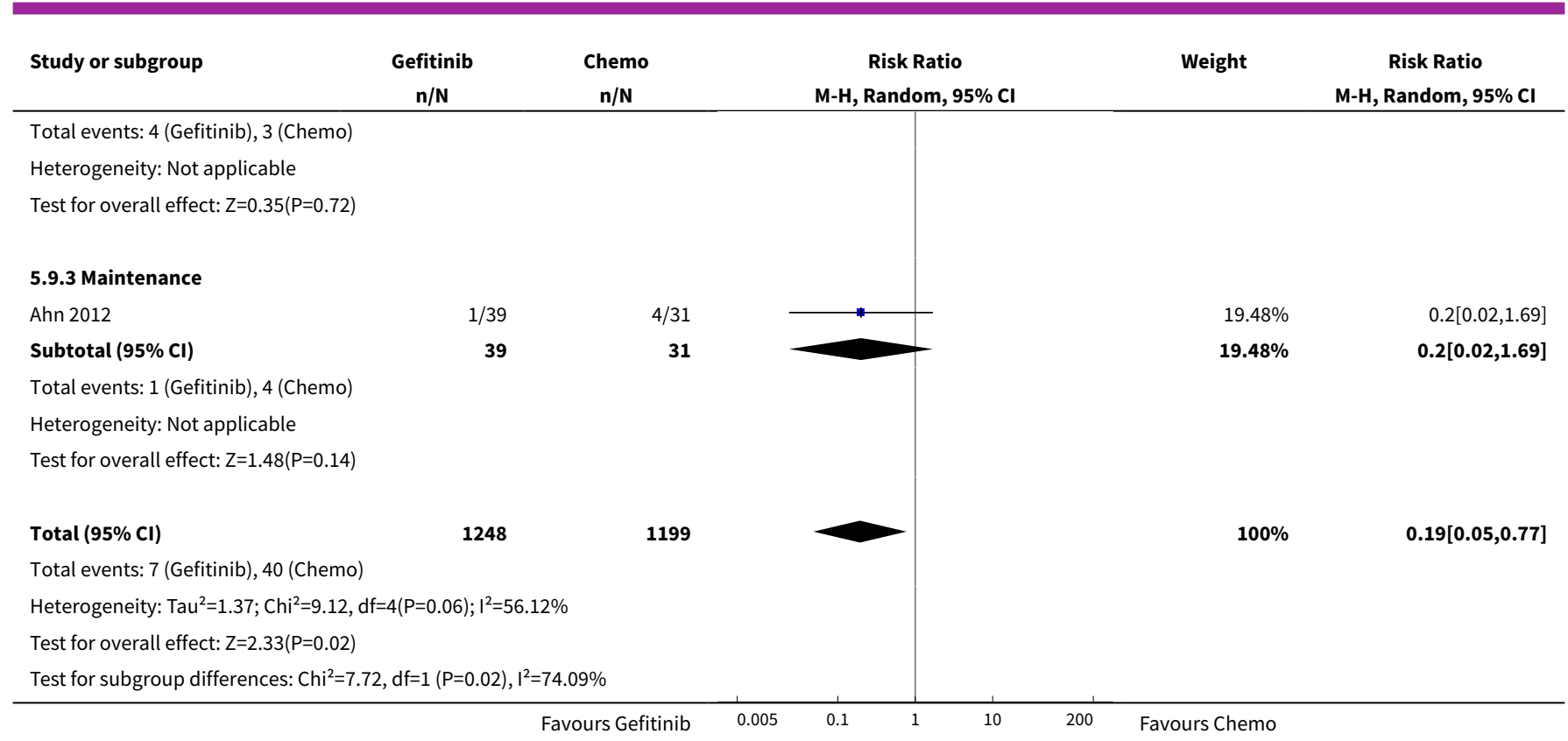

Analysis 5.10. Comparison 5 Gefitinib versus chemotherapy (Asian subgroup), Outcome 10 Anorexia.

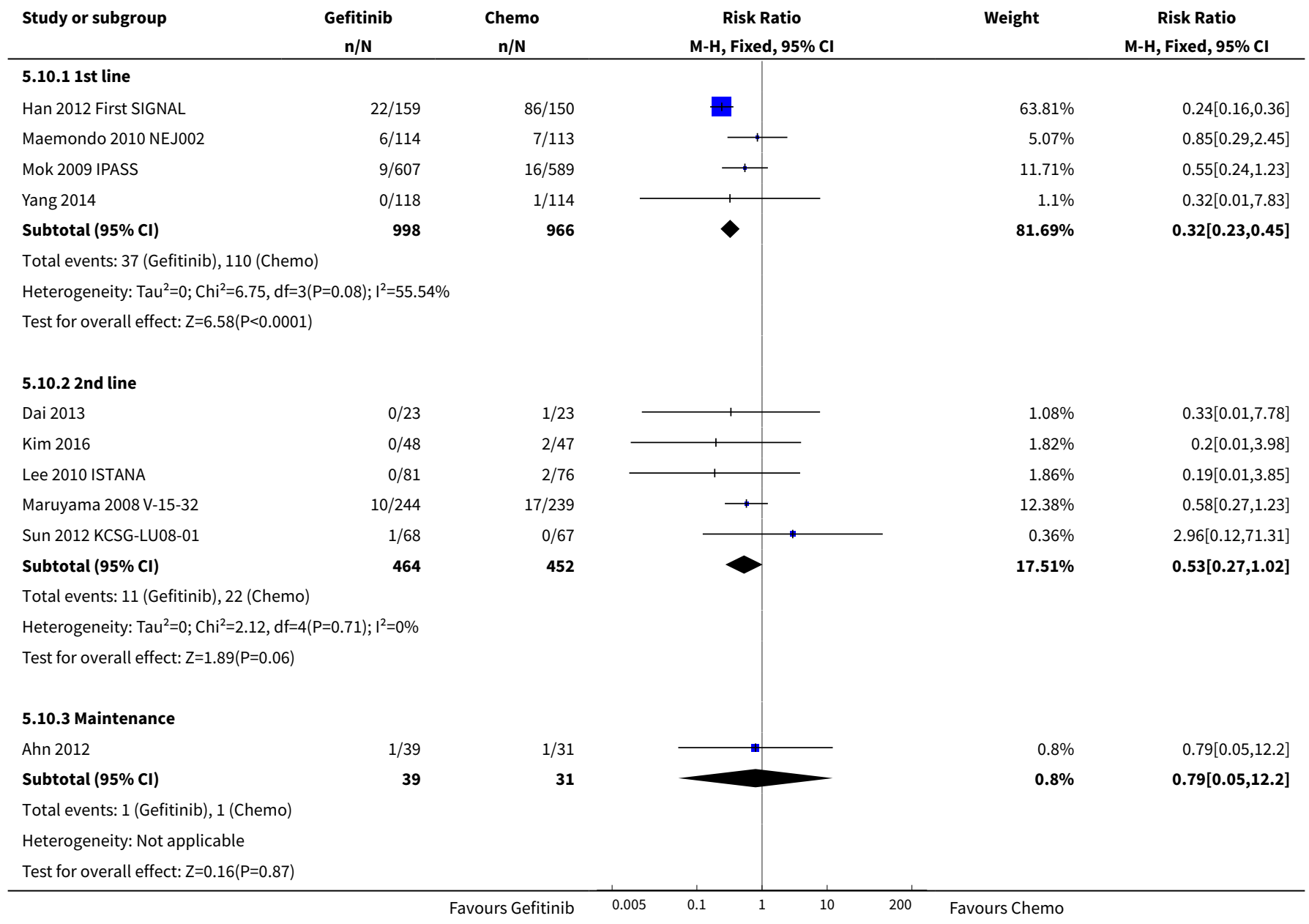




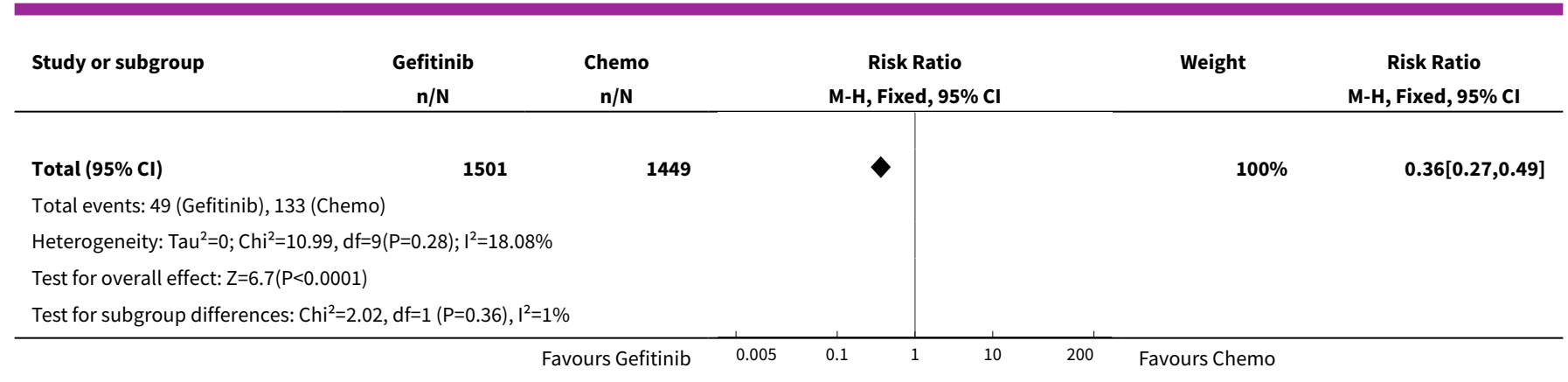

Analysis 5.11. Comparison 5 Gefitinib versus chemotherapy (Asian subgroup), Outcome 11 Fatigue.

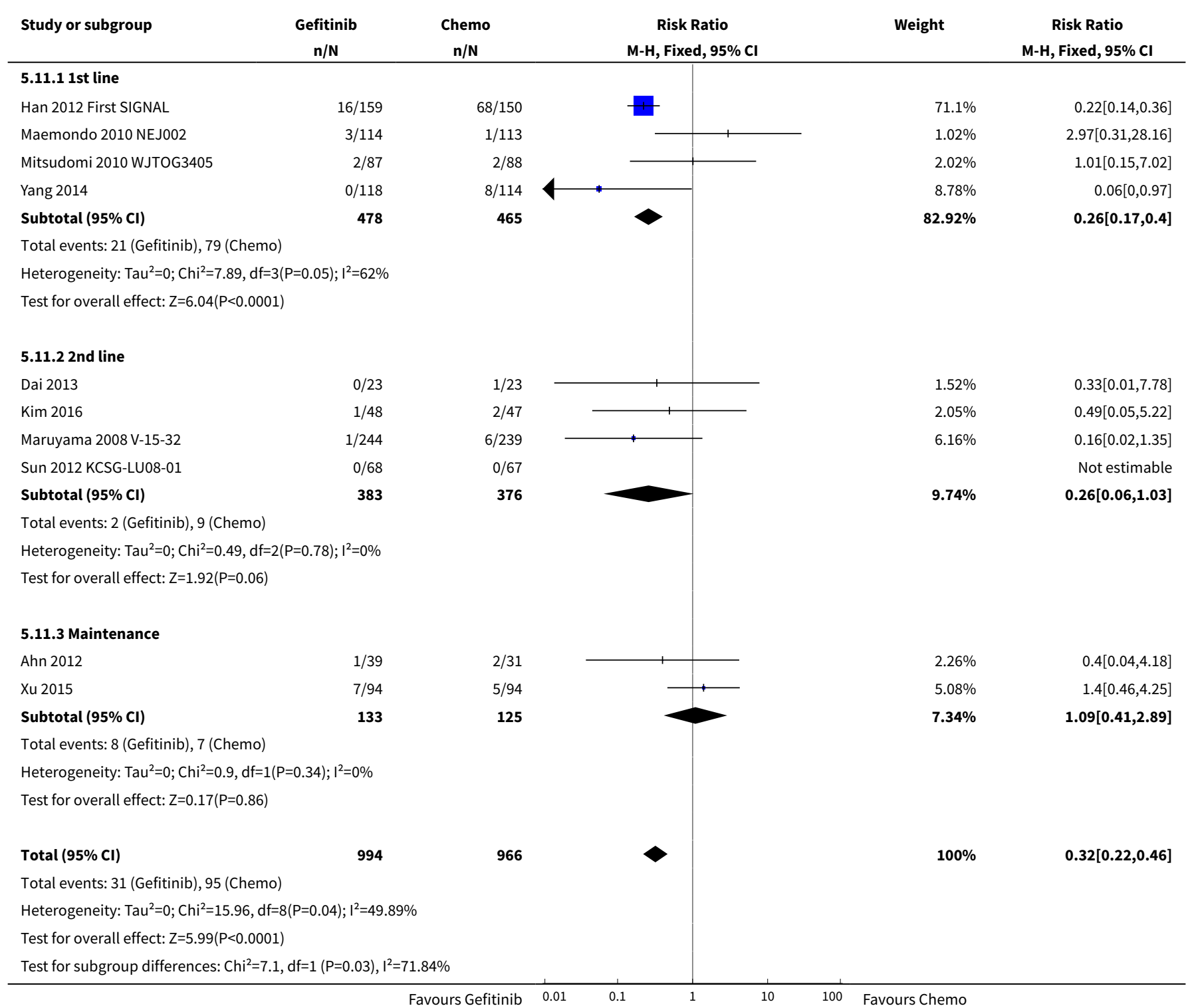


Analysis 5.12. Comparison 5 Gefitinib versus chemotherapy (Asian subgroup), Outcome 12 Arthralgia/myalgia.

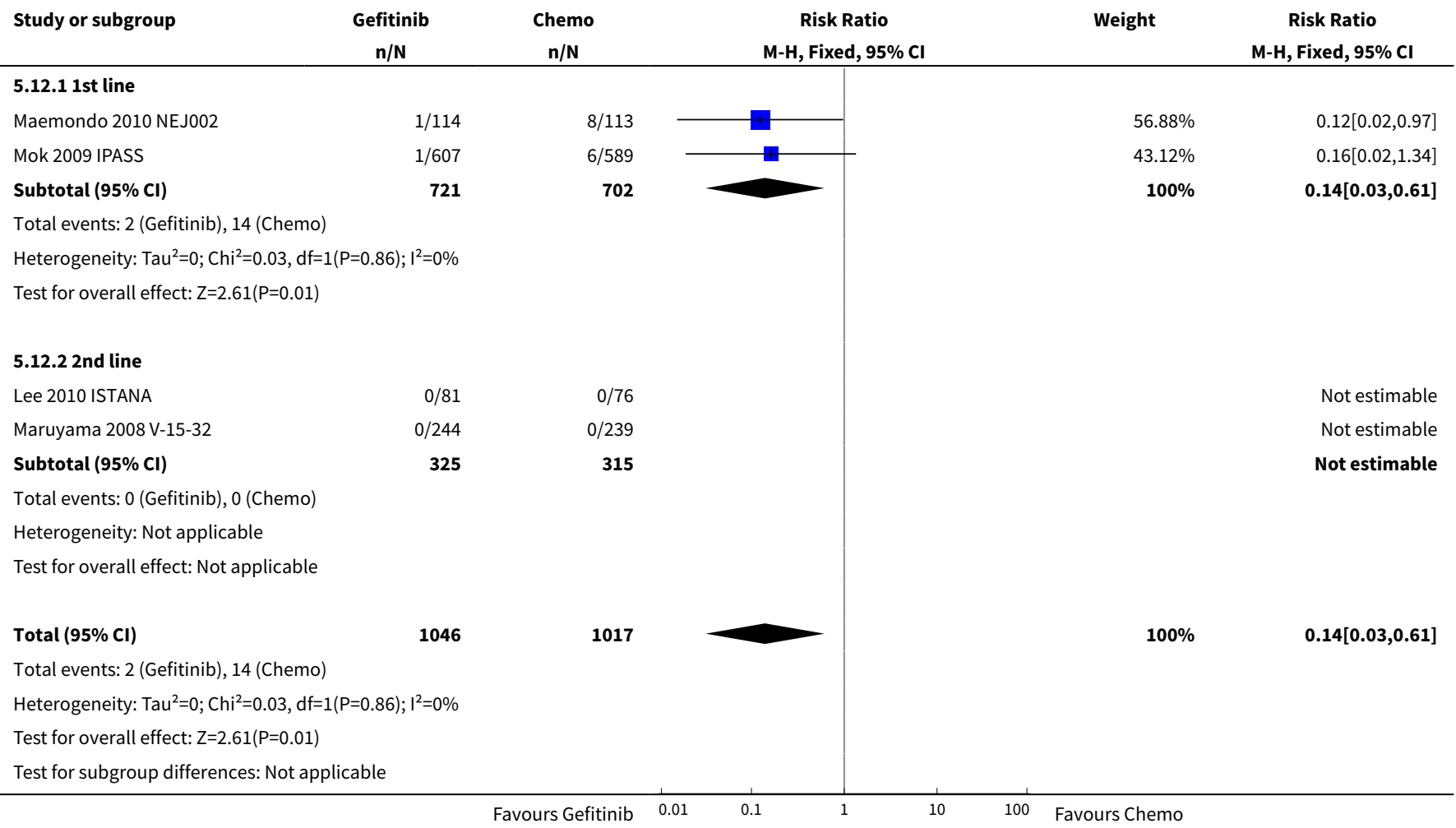

\section{Analysis 5.13. Comparison 5 Gefitinib versus chemotherapy (Asian subgroup), Outcome 13 Asthenia.}

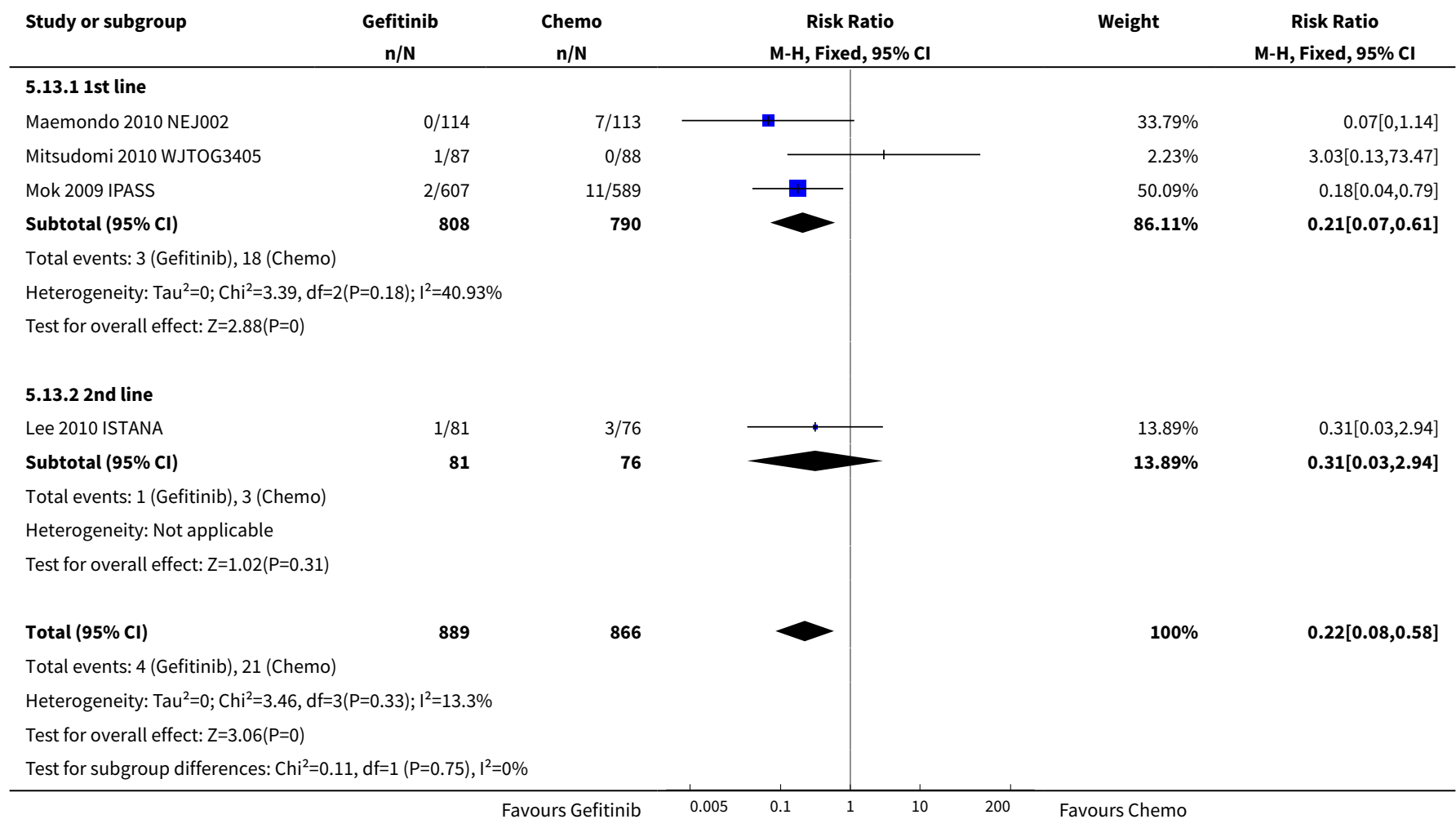


Analysis 5.14. Comparison 5 Gefitinib versus chemotherapy (Asian subgroup), Outcome 14 Neurotoxicity.

\begin{tabular}{|c|c|c|c|c|c|}
\hline Study or subgroup & $\begin{array}{c}\text { Gefitinib } \\
\mathrm{n} / \mathrm{N}\end{array}$ & $\begin{array}{c}\text { Chemo } \\
n / N\end{array}$ & $\begin{array}{c}\text { Risk Ratio } \\
\text { M-H, Fixed, } 95 \% \mathrm{Cl}\end{array}$ & Weight & $\begin{array}{c}\text { Risk Ratio } \\
\text { M-H, Fixed, } 95 \% \mathrm{Cl}\end{array}$ \\
\hline \multicolumn{6}{|l|}{ 5.14.1 1st line } \\
\hline Han 2012 First SIGNAL & $0 / 159$ & $6 / 150$ & & $18.51 \%$ & $0.07[0,1.28]$ \\
\hline Mok 2009 IPASS & $2 / 607$ & $29 / 589$ & & $81.49 \%$ & $0.07[0.02,0.28]$ \\
\hline Subtotal $(95 \% \mathrm{Cl})$ & 766 & 739 & & $100 \%$ & $0.07[0.02,0.24]$ \\
\hline \multicolumn{6}{|c|}{ Total events: 2 (Gefitinib), 35 (Chemo) } \\
\hline \multicolumn{6}{|c|}{ Heterogeneity: $\operatorname{Tau}^{2}=0 ; \mathrm{Chi}^{2}=0, \mathrm{df}=1(\mathrm{P}=0.96) ; \mathrm{I}^{2}=0 \%$} \\
\hline \multicolumn{6}{|c|}{ Test for overall effect: $Z=4.12(P<0.0001)$} \\
\hline \multicolumn{6}{|l|}{ 5.14.2 2nd line } \\
\hline Lee 2010 ISTANA & $0 / 81$ & $0 / 76$ & & & Not estimable \\
\hline Sun 2012 KCSG-LU08-01 & $0 / 68$ & $0 / 67$ & & & Not estimable \\
\hline Subtotal $(95 \% \mathrm{Cl})$ & 149 & 143 & & & Not estimable \\
\hline \multicolumn{6}{|c|}{ Total events: 0 (Gefitinib), 0 (Chemo) } \\
\hline \multicolumn{6}{|c|}{ Heterogeneity: Not applicable } \\
\hline \multicolumn{6}{|c|}{ Test for overall effect: Not applicable } \\
\hline Total $(95 \% \mathrm{Cl})$ & 915 & 882 & & $100 \%$ & $0.07[0.02,0.24]$ \\
\hline \multicolumn{6}{|c|}{ Total events: 2 (Gefitinib), 35 (Chemo) } \\
\hline \multicolumn{6}{|c|}{ Heterogeneity: $\operatorname{Tau}^{2}=0 ; \mathrm{Chi}^{2}=0, \mathrm{df}=1(\mathrm{P}=0.96) ; \mathrm{I}^{2}=0 \%$} \\
\hline \multicolumn{6}{|c|}{ Test for overall effect: $Z=4.12(P<0.0001)$} \\
\hline Test for subgroup differe & icable & & & & \\
\hline
\end{tabular}

\section{Analysis 5.15. Comparison 5 Gefitinib versus chemotherapy (Asian subgroup), Outcome 15 Neutropenia.}

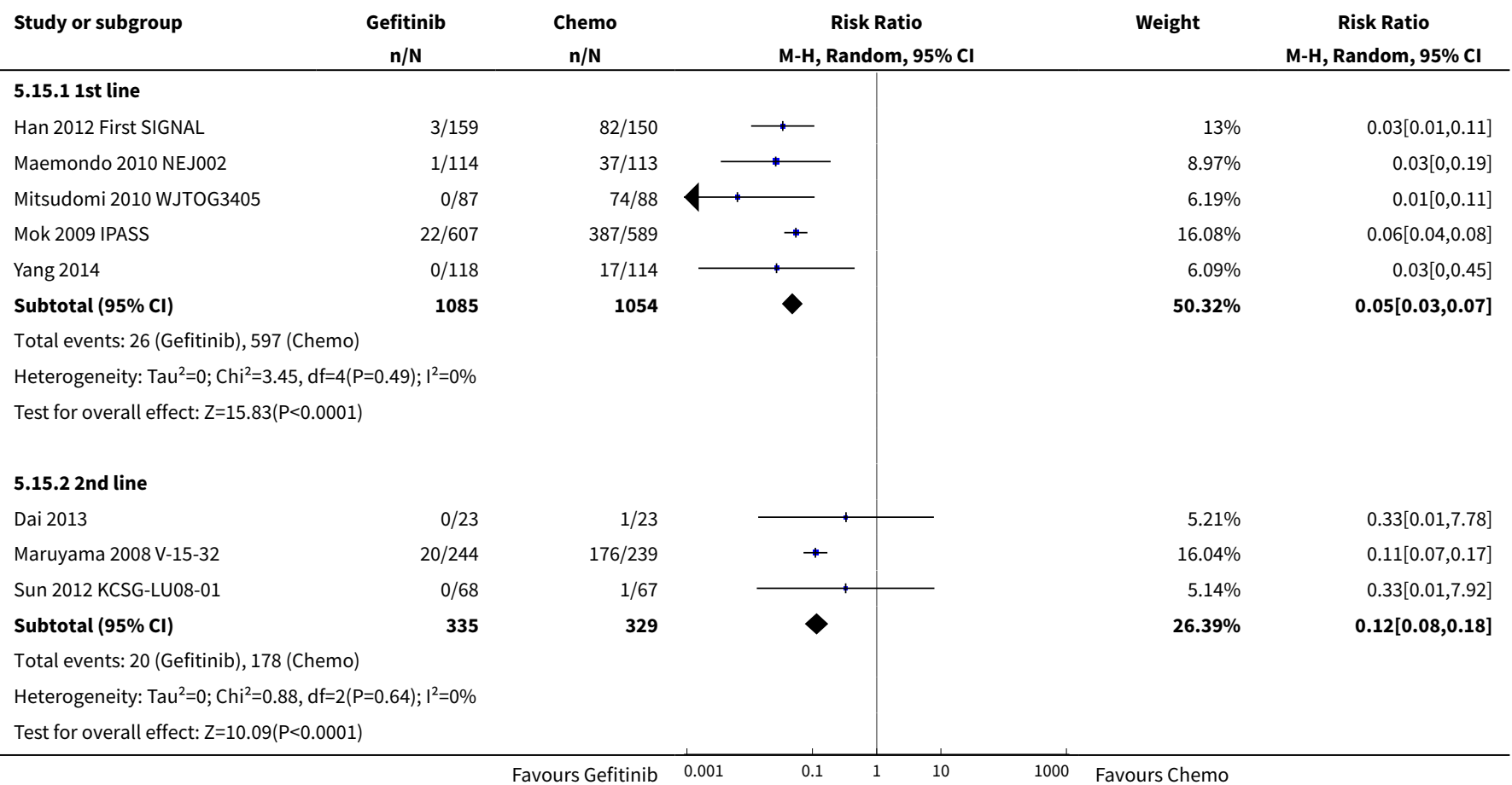




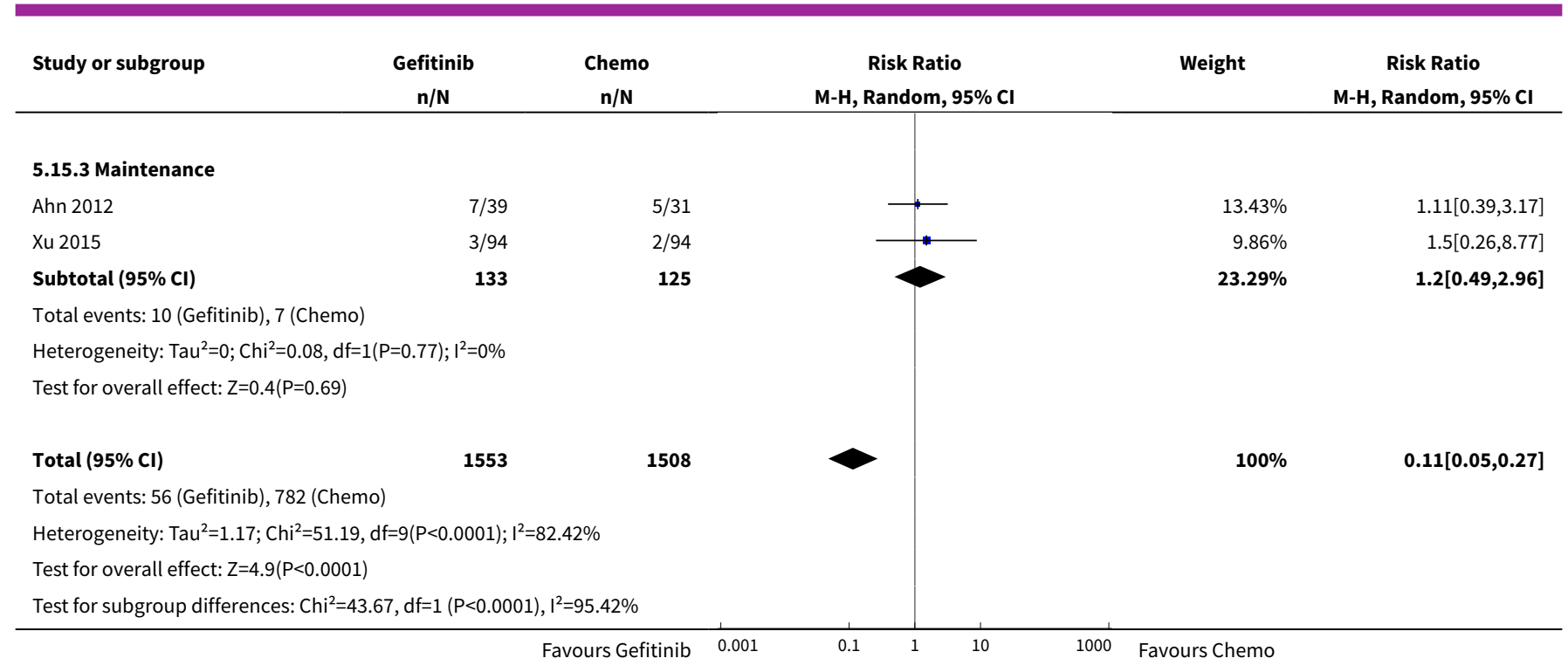

\section{Analysis 5.16. Comparison 5 Gefitinib versus chemotherapy (Asian subgroup), Outcome 16 Anaemia.}

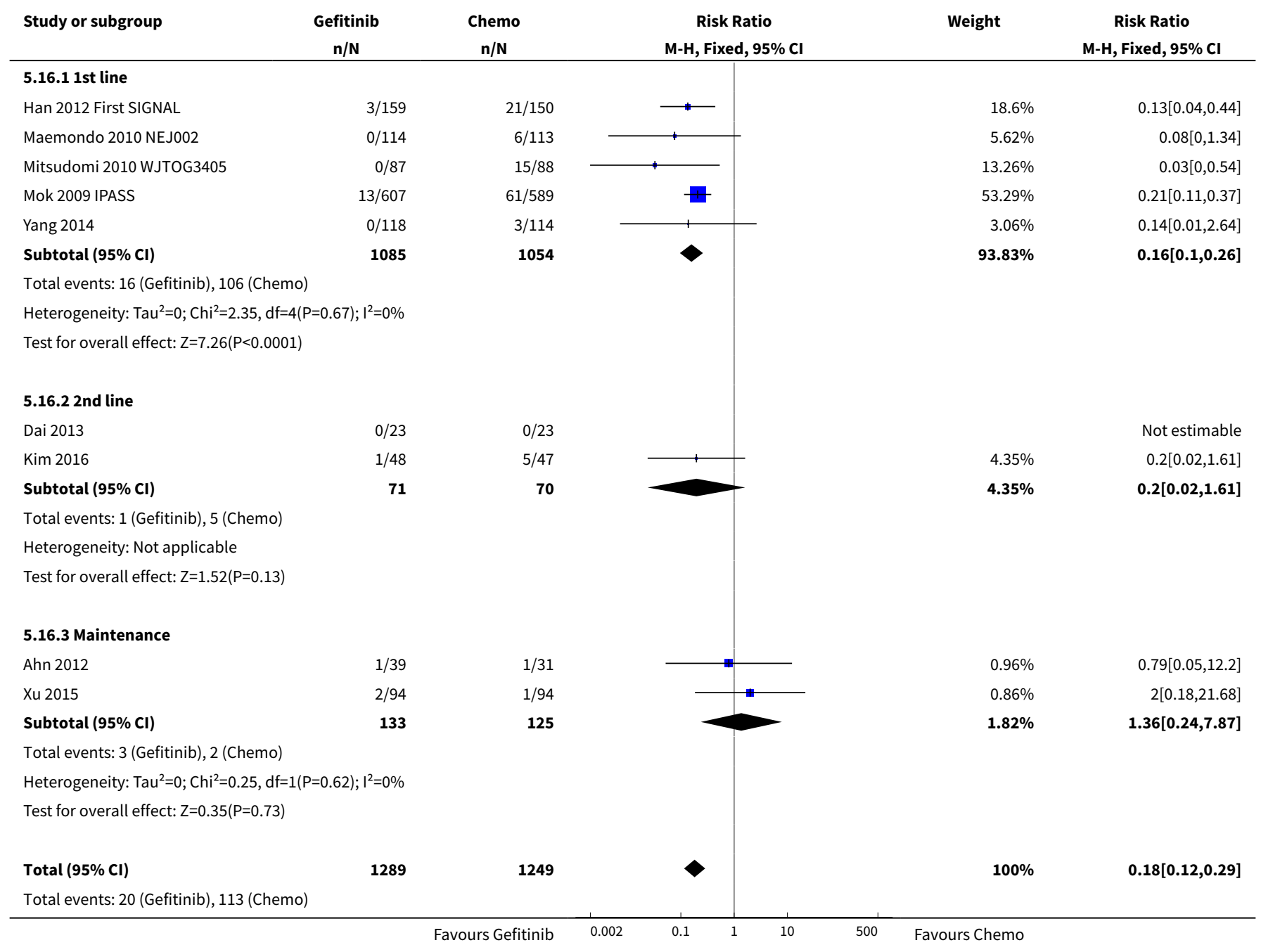




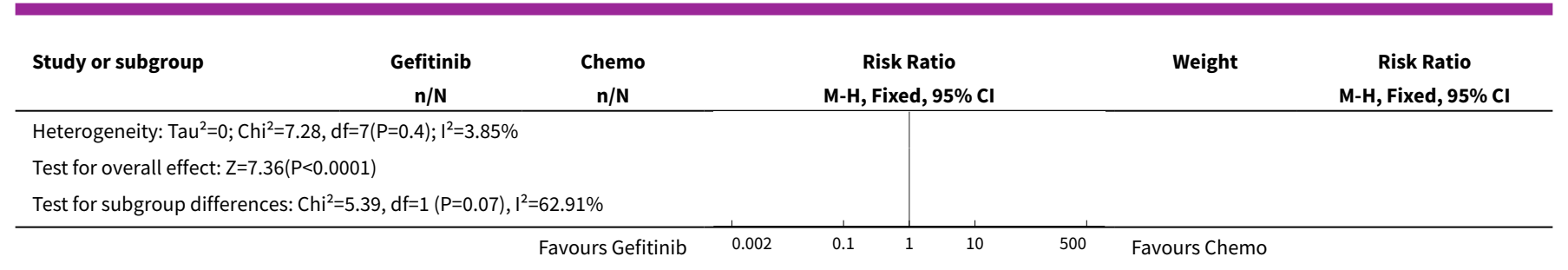

\section{Analysis 5.17. Comparison 5 Gefitinib versus chemotherapy (Asian subgroup), Outcome 17 Leukopenia.}

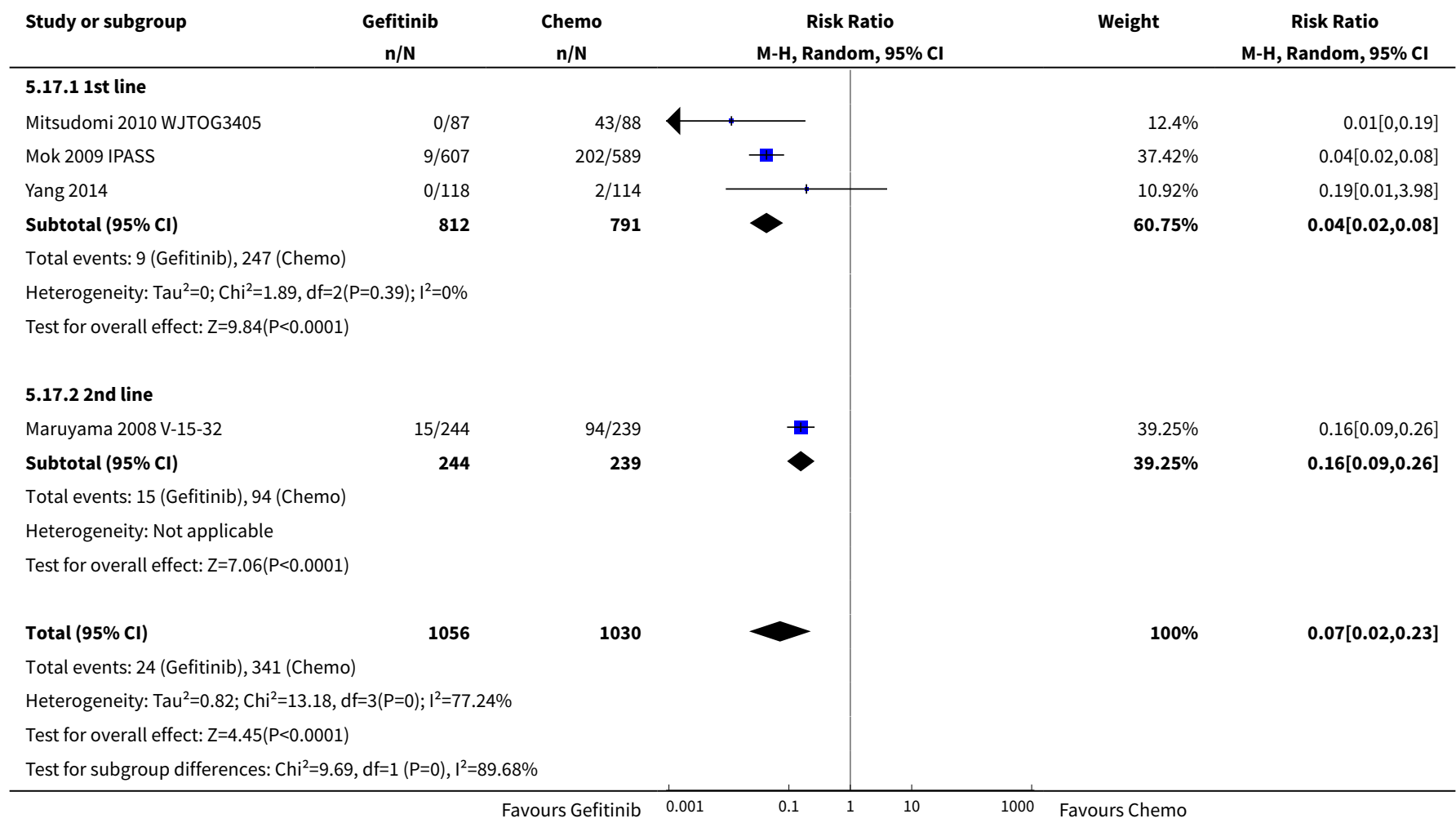

Analysis 5.18. Comparison 5 Gefitinib versus chemotherapy (Asian subgroup), Outcome 18 Thrombocytopenia.

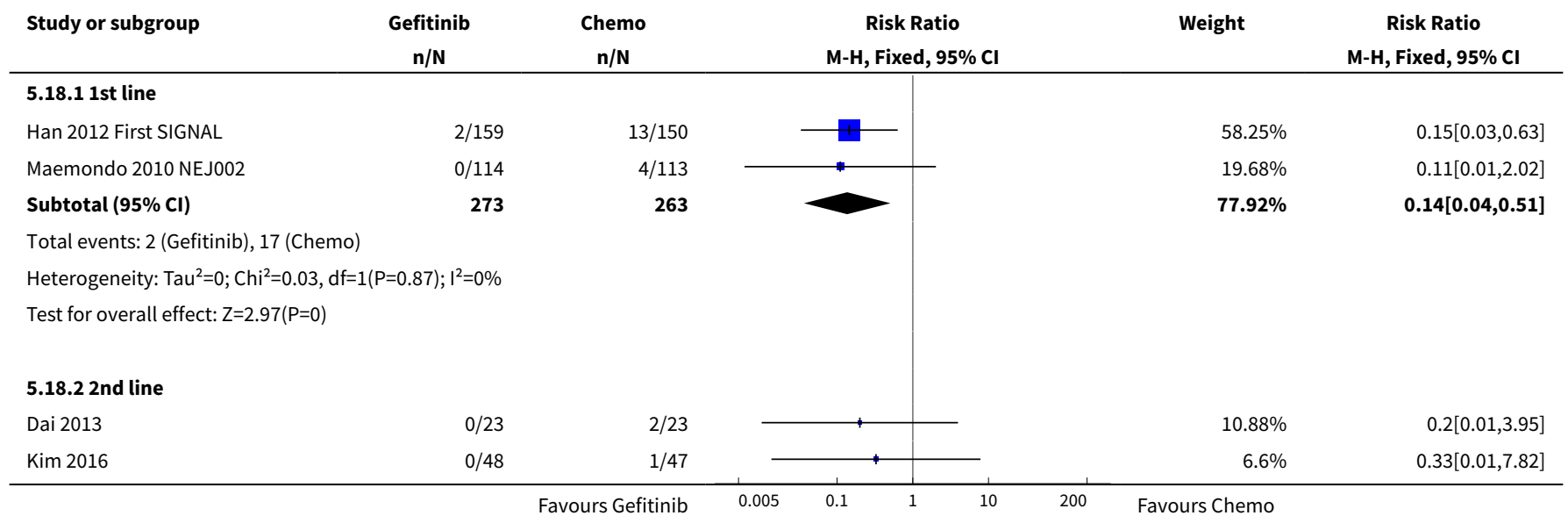




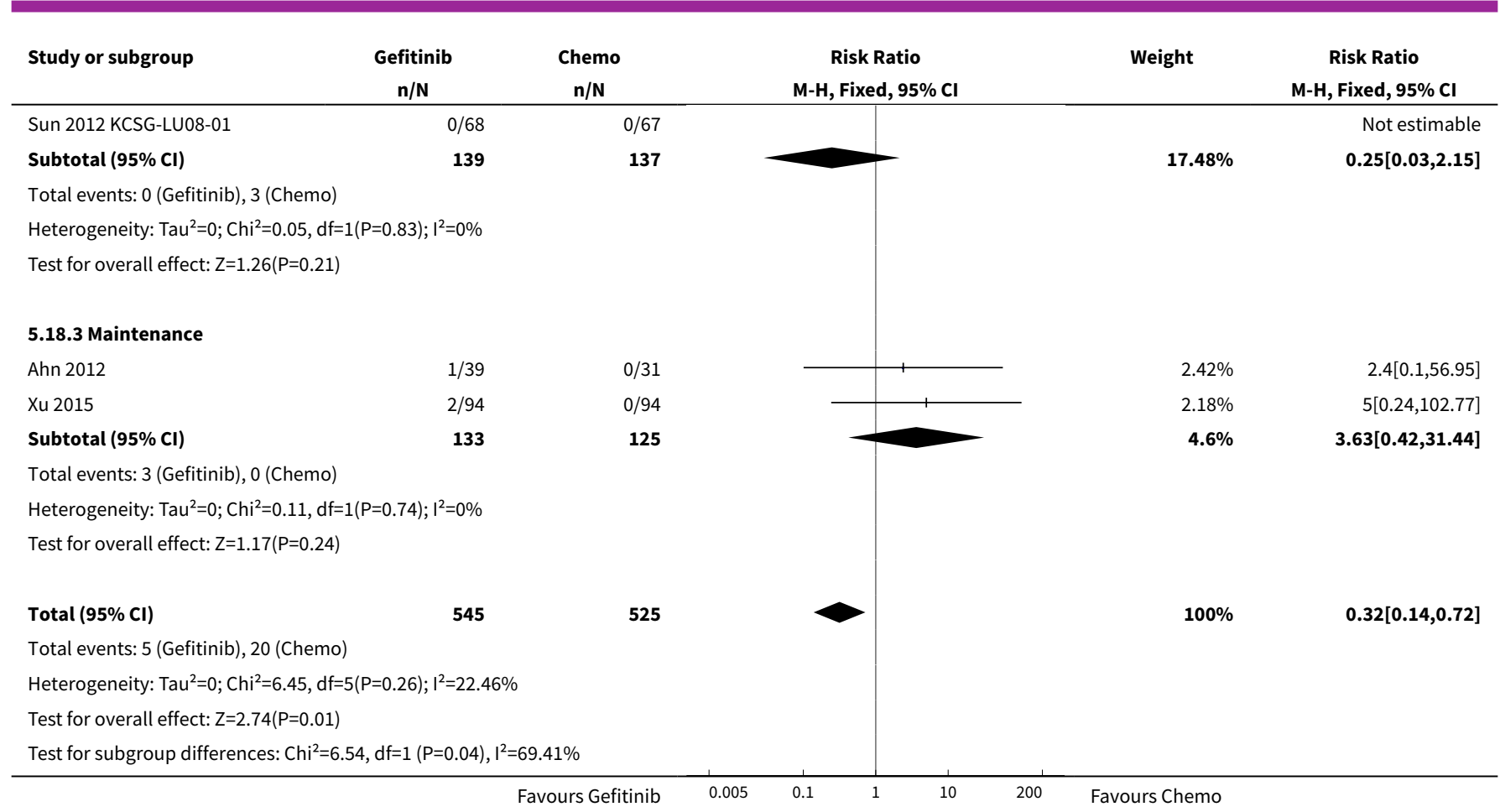

Analysis 5.19. Comparison 5 Gefitinib versus chemotherapy (Asian subgroup), Outcome 19 Febrile neutropenia.

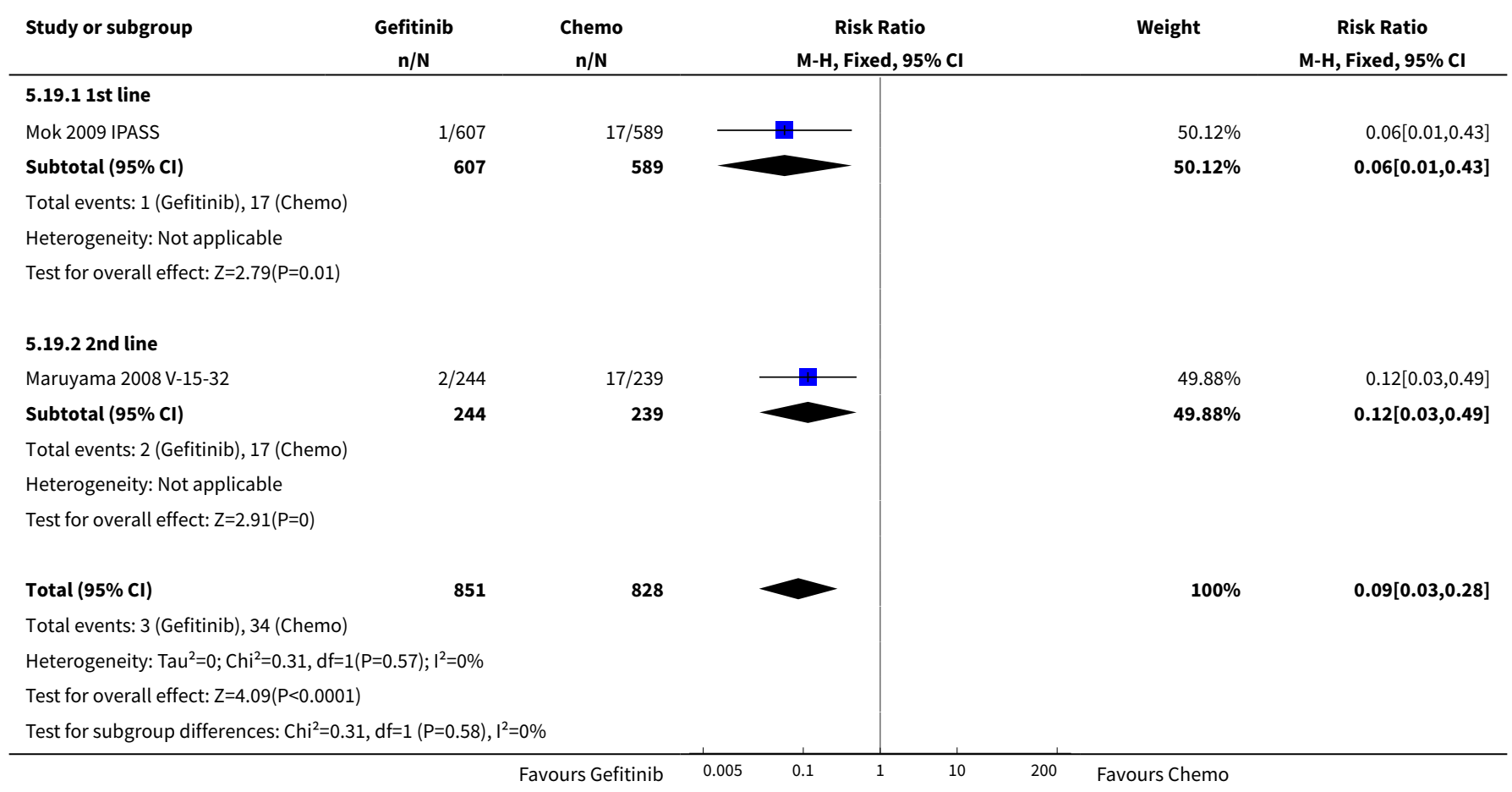


Analysis 5.20. Comparison 5 Gefitinib versus chemotherapy (Asian subgroup), Outcome 20 Skin rash.

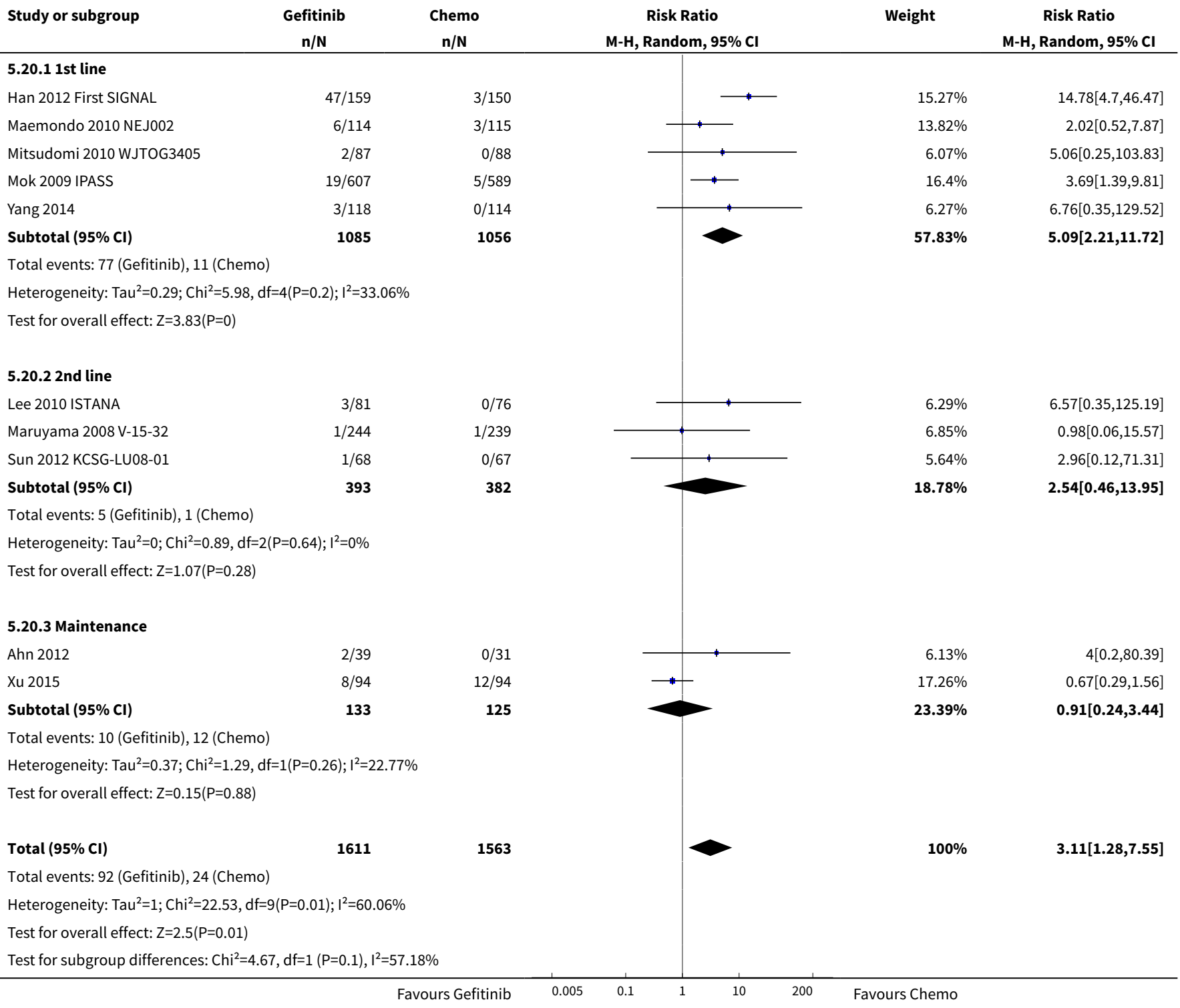

Analysis 5.21. Comparison 5 Gefitinib versus chemotherapy (Asian subgroup), Outcome 21 Diarrhoea.

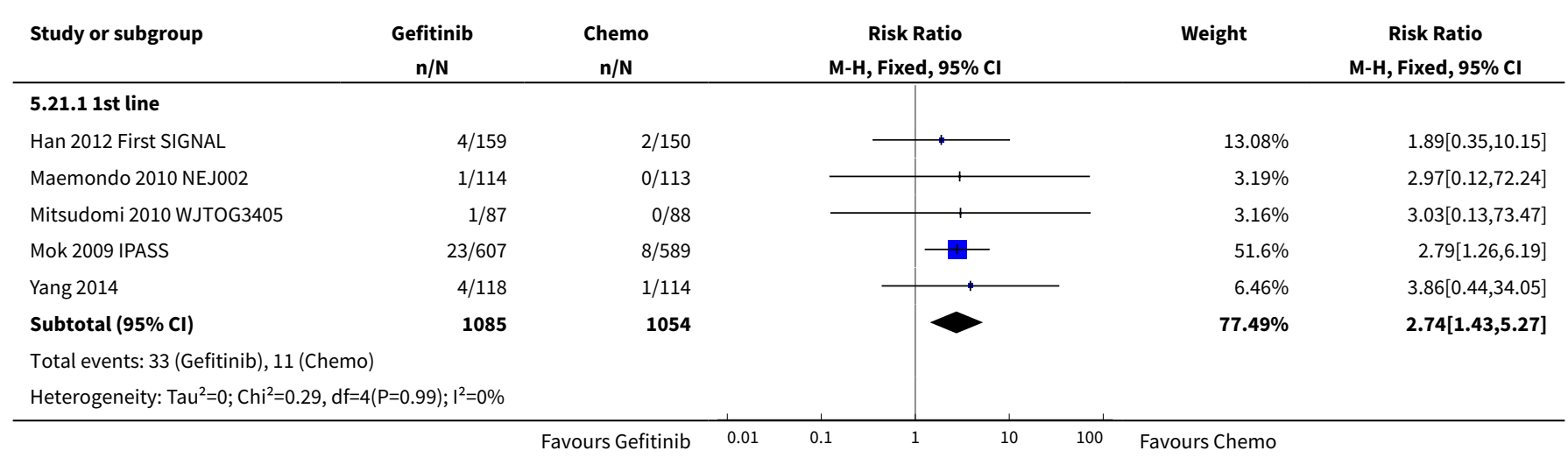




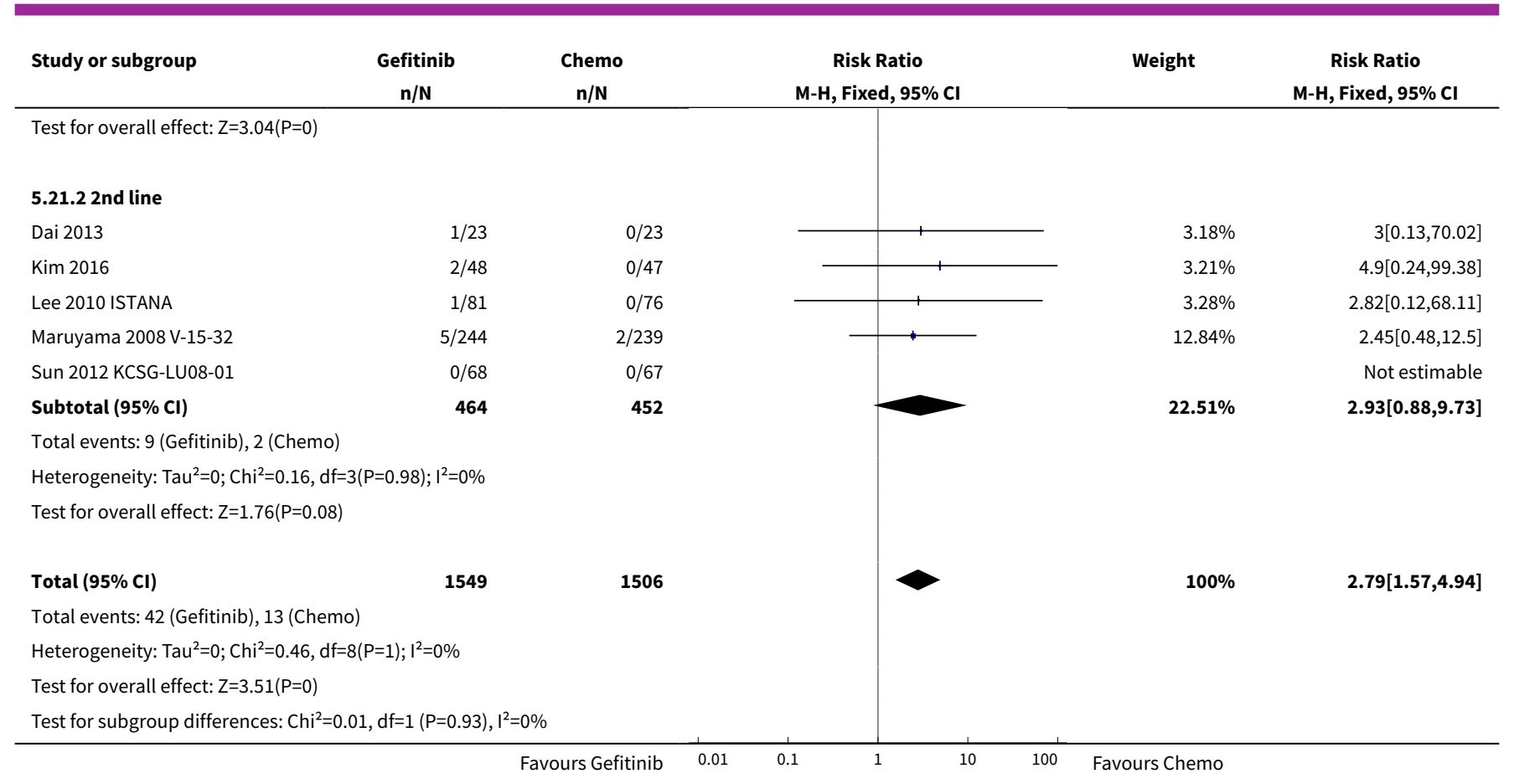

Analysis 5.22. Comparison 5 Gefitinib versus chemotherapy (Asian subgroup), Outcome 22 Increased ALT.

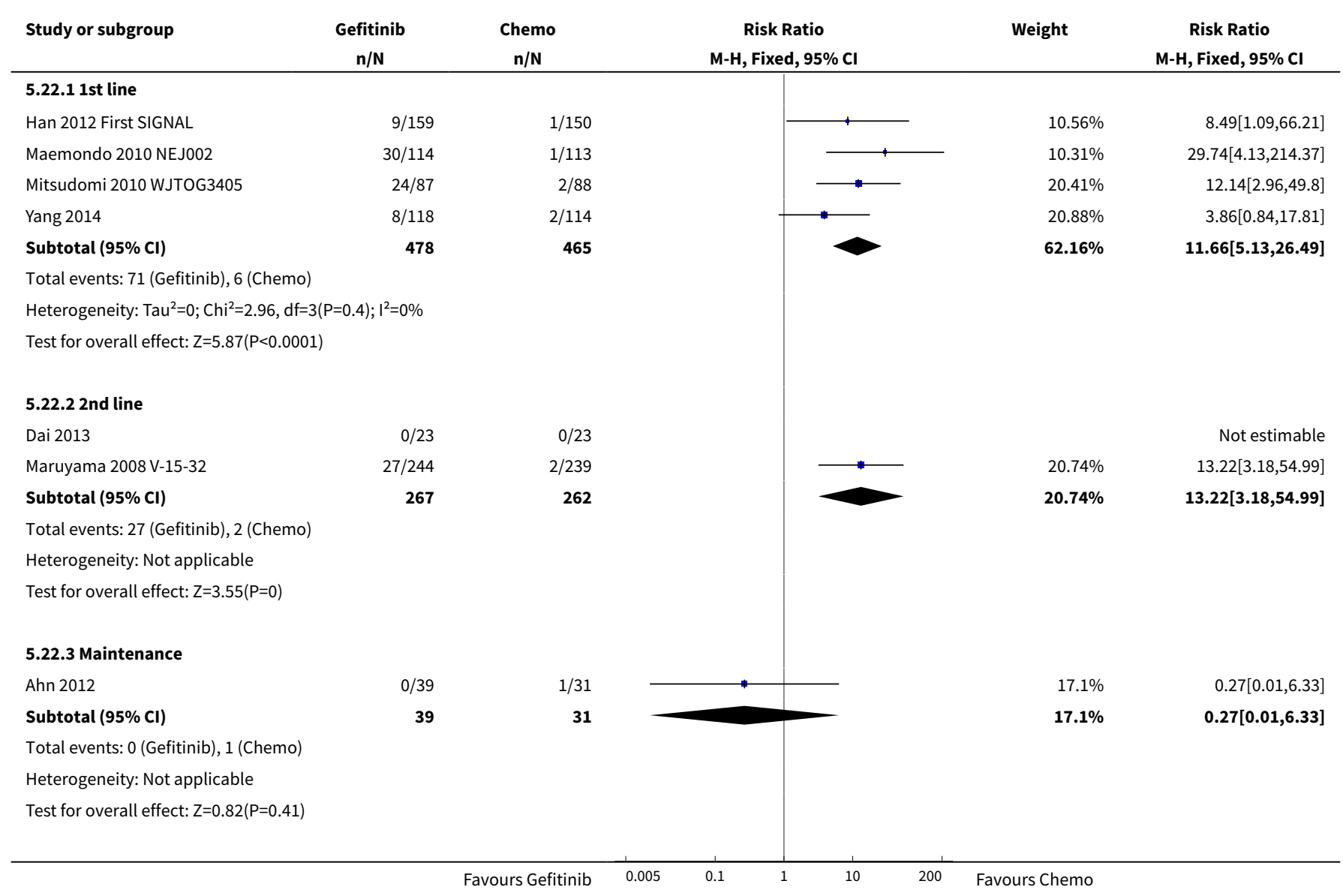




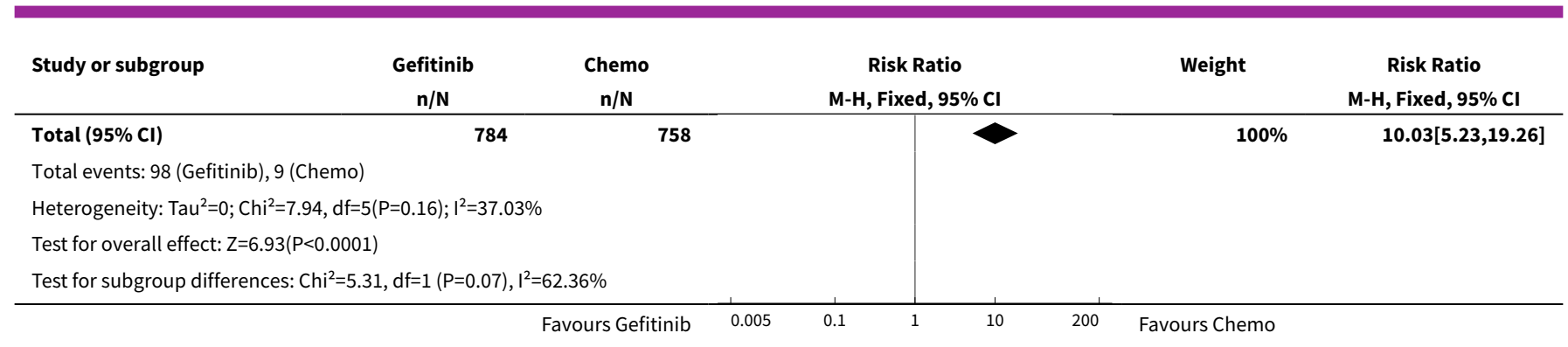

Analysis 5.23. Comparison 5 Gefitinib versus chemotherapy (Asian subgroup), Outcome 23 Increased AST.

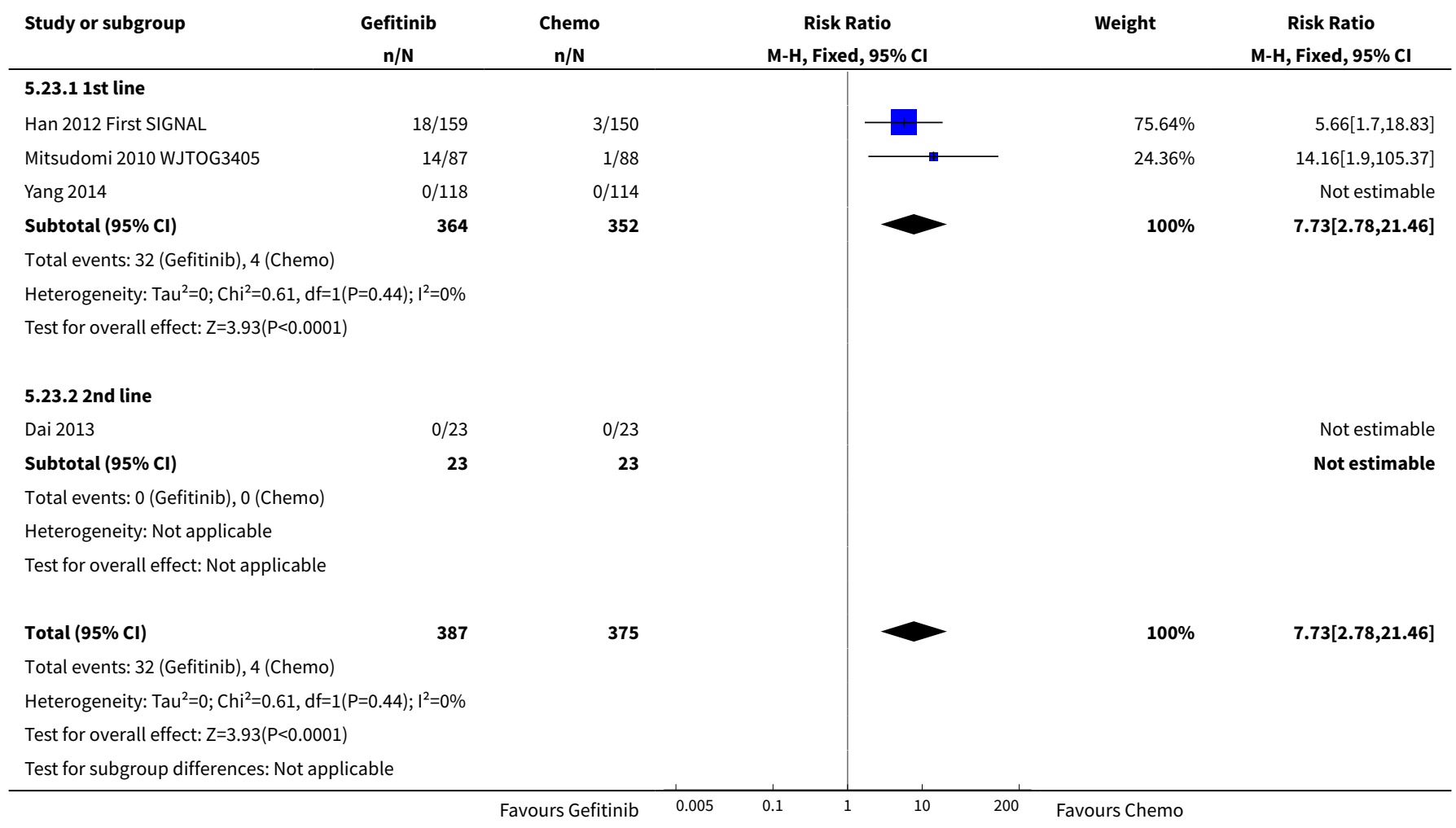

Analysis 5.24. Comparison 5 Gefitinib versus chemotherapy (Asian subgroup), Outcome 24 Overall response rate.

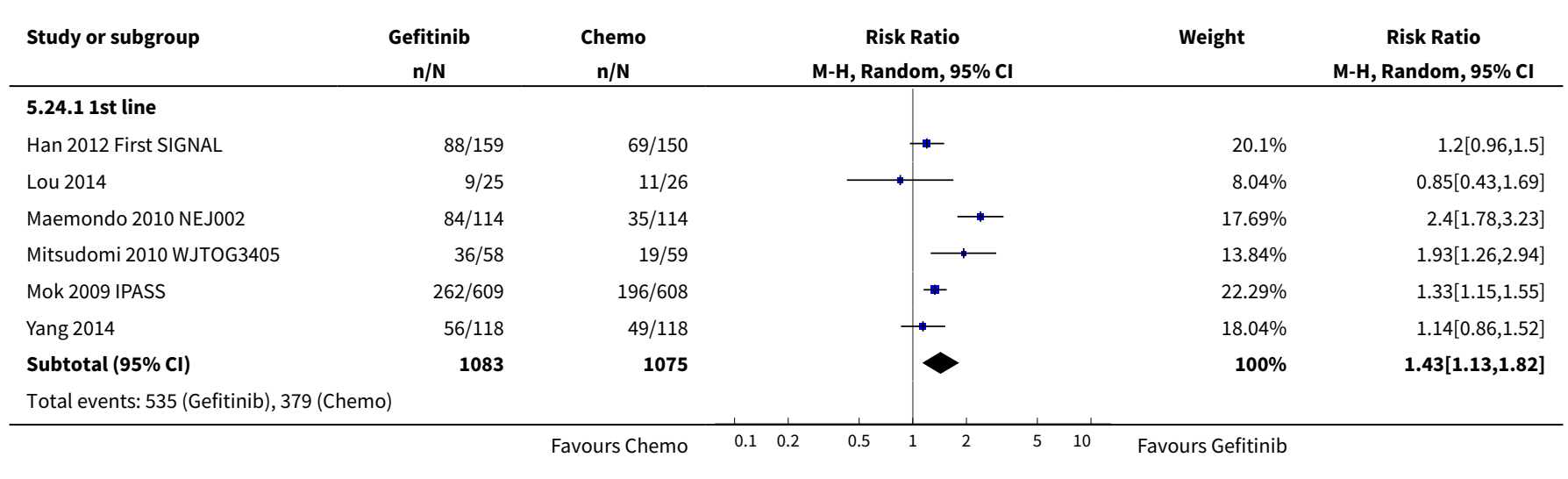




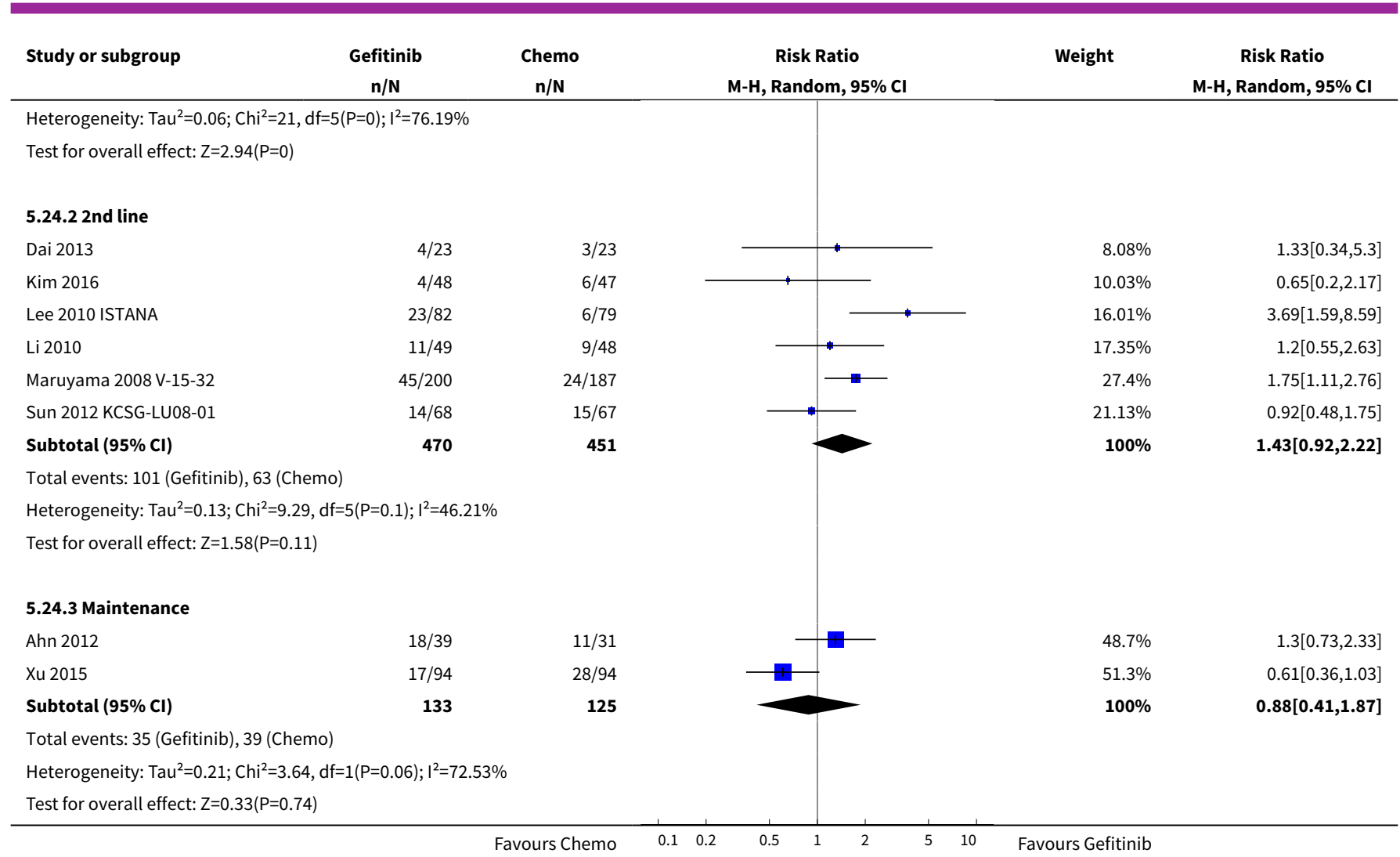

\section{Analysis 5.25. Comparison 5 Gefitinib versus chemotherapy (Asian subgroup), Outcome 25 Stable disease.}

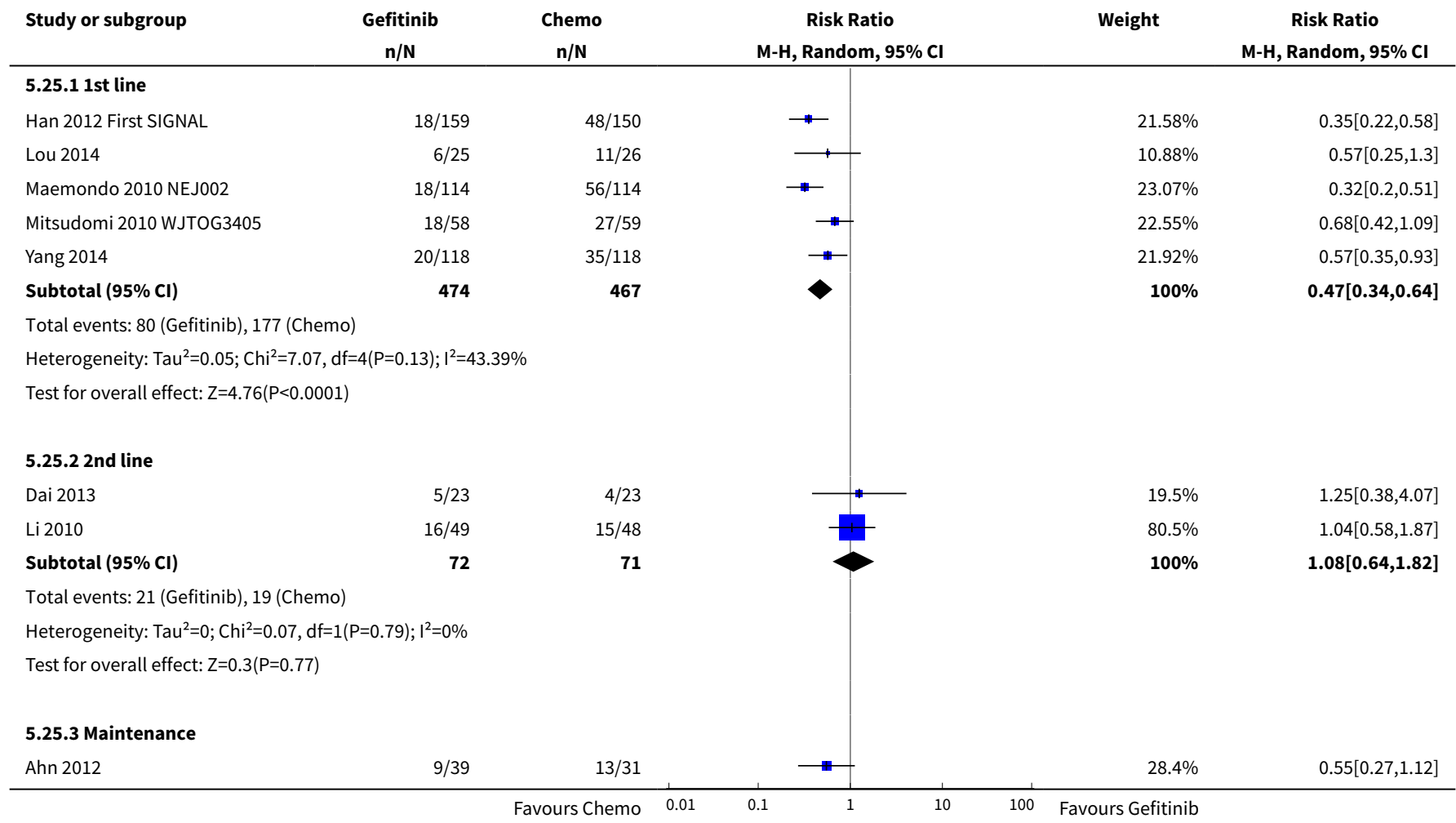




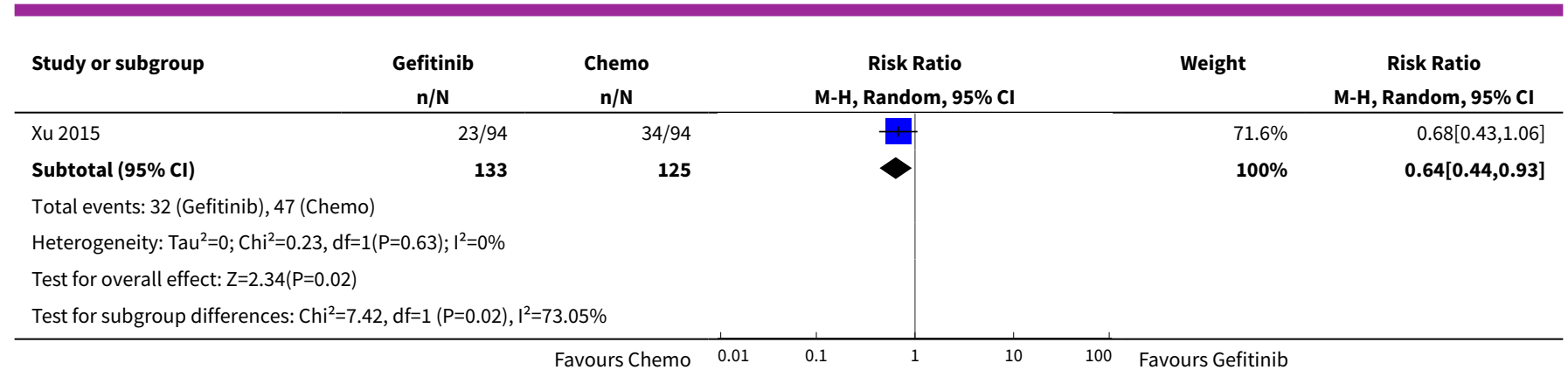

Analysis 5.26. Comparison 5 Gefitinib versus chemotherapy (Asian subgroup), Outcome 26 Disease control rate.

\begin{tabular}{|c|c|c|c|c|c|}
\hline Study or subgroup & $\begin{array}{c}\text { Gefitinib } \\
n / N\end{array}$ & $\begin{array}{c}\text { Chemo } \\
n / N\end{array}$ & $\begin{array}{c}\text { Risk Ratio } \\
\text { M-H, Random, 95\% Cl }\end{array}$ & Weight & $\begin{array}{c}\text { Risk Ratio } \\
\text { M-H, Random, 95\% Cl }\end{array}$ \\
\hline \multicolumn{6}{|l|}{ 5.26.1 1st line } \\
\hline Lou 2014 & $15 / 25$ & $22 / 26$ & & $9.55 \%$ & $0.71[0.49,1.02]$ \\
\hline Maemondo 2010 NEJ002 & $102 / 114$ & $91 / 113$ & 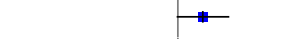 & $23.82 \%$ & $1.11[0.99,1.24]$ \\
\hline Mitsudomi 2010 WJTOG3405 & $54 / 58$ & $46 / 59$ & $\longrightarrow$ & $20.86 \%$ & $1.19[1.03,1.39]$ \\
\hline Mok 2009 IPASS & $444 / 609$ & $482 / 608$ & $\rightarrow$ & $26.59 \%$ & $0.92[0.86,0.98]$ \\
\hline Subtotal $(95 \% \mathrm{CI})$ & 924 & 924 & & $100 \%$ & $0.99[0.86,1.13]$ \\
\hline \multicolumn{6}{|c|}{ Total events: 691 (Gefitinib), 725 (Chemo) } \\
\hline \multicolumn{6}{|c|}{ Heterogeneity: $\operatorname{Tau}^{2}=0.02 ; \mathrm{Chi}^{2}=19.96, \mathrm{df}=4(\mathrm{P}=0) ; \mathrm{I}^{2}=79.96 \%$} \\
\hline \multicolumn{6}{|c|}{ Test for overall effect: $\mathrm{Z}=0.18(\mathrm{P}=0.86)$} \\
\hline \multicolumn{6}{|l|}{ 5.26.2 2nd line } \\
\hline Kim 2016 & $17 / 48$ & $21 / 47$ & & $22.1 \%$ & $0.79[0.48,1.3]$ \\
\hline Maruyama 2008 V-15-32 & $68 / 200$ & $62 / 187$ & & $69.39 \%$ & $1.03[0.77,1.36]$ \\
\hline Subtotal $(95 \% \mathrm{Cl})$ & 271 & 257 & & $100 \%$ & $0.99[0.78,1.25]$ \\
\hline \multicolumn{6}{|c|}{ Total events: 94 (Gefitinib), 90 (Chemo) } \\
\hline \multicolumn{6}{|c|}{ Heterogeneity: $\operatorname{Tau}^{2}=0 ; \mathrm{Chi}^{2}=1.24, \mathrm{df}=2(\mathrm{P}=0.54) ; \mathrm{I}^{2}=0 \%$} \\
\hline \multicolumn{6}{|c|}{ Test for overall effect: $Z=0.1(P=0.92)$} \\
\hline \multicolumn{6}{|l|}{ 5.26.3 Maintenance } \\
\hline Xu 2015 & $40 / 94$ & $62 / 94$ & & $100 \%$ & $0.65[0.49,0.85]$ \\
\hline Subtotal $(95 \% \mathrm{Cl})$ & 94 & 94 & & $100 \%$ & $0.65[0.49,0.85]$ \\
\hline \multicolumn{6}{|c|}{ Total events: 40 (Gefitinib), 62 (Chemo) } \\
\hline \multicolumn{6}{|c|}{ Heterogeneity: Not applicable } \\
\hline \multicolumn{6}{|c|}{ Test for overall effect: $Z=3.11(P=0)$} \\
\hline
\end{tabular}

Favours Chemo

Favours Gefitinib

Analysis 5.27. Comparison 5 Gefitinib versus chemotherapy (Asian subgroup), Outcome 27 FACT-L QOL improvement rate.

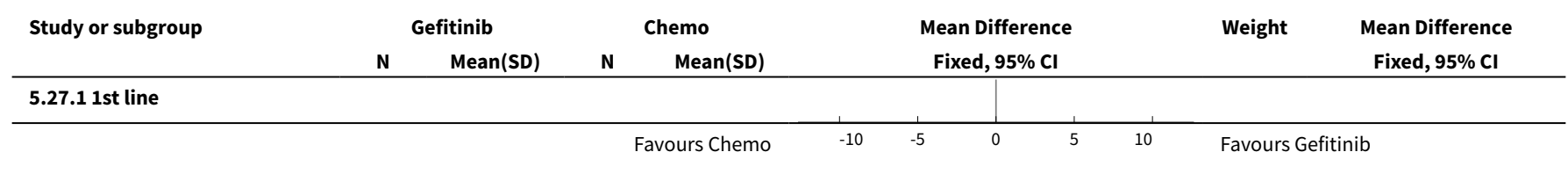




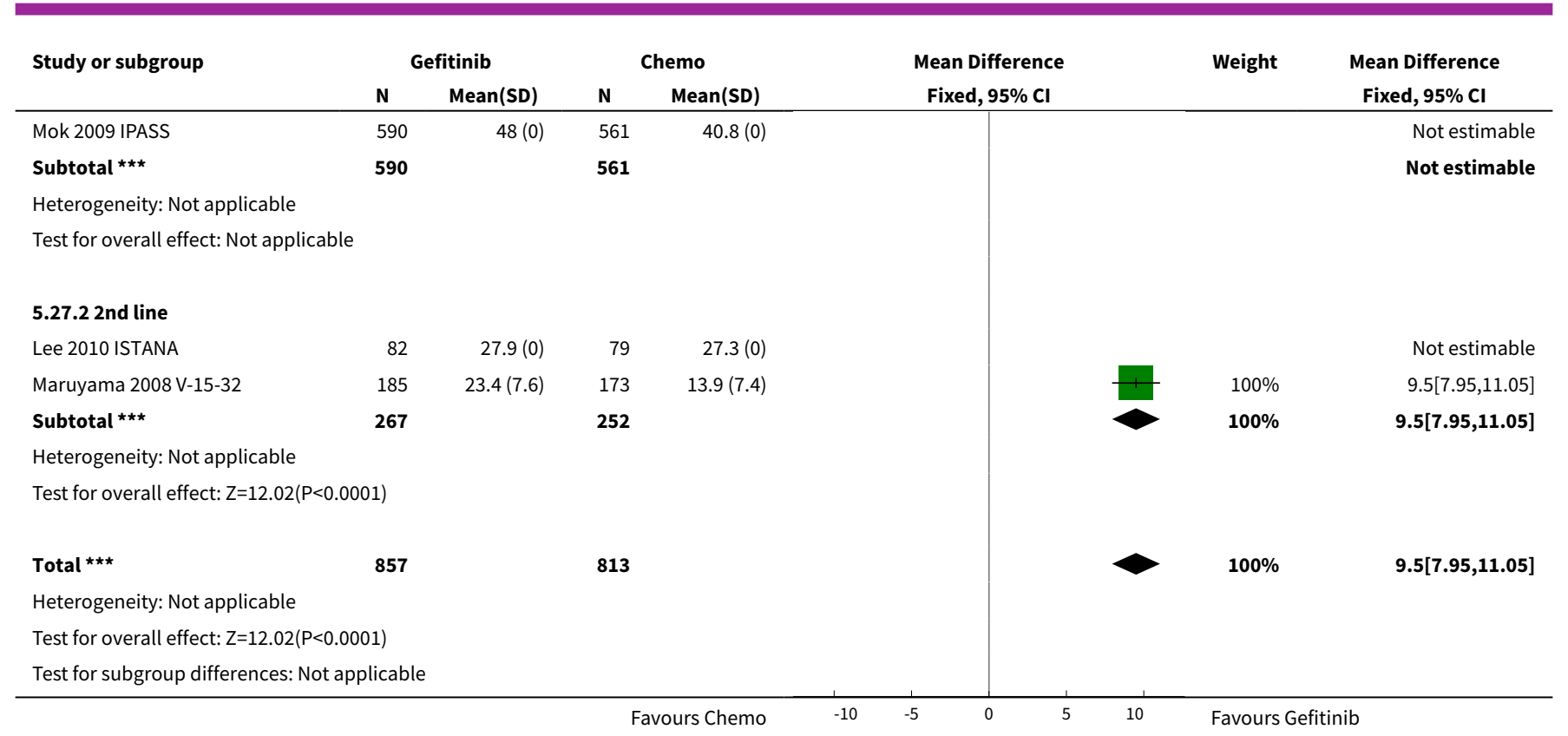

\section{Analysis 5.28. Comparison 5 Gefitinib versus chemotherapy} (Asian subgroup), Outcome 28 LCS QOL improvement rate.

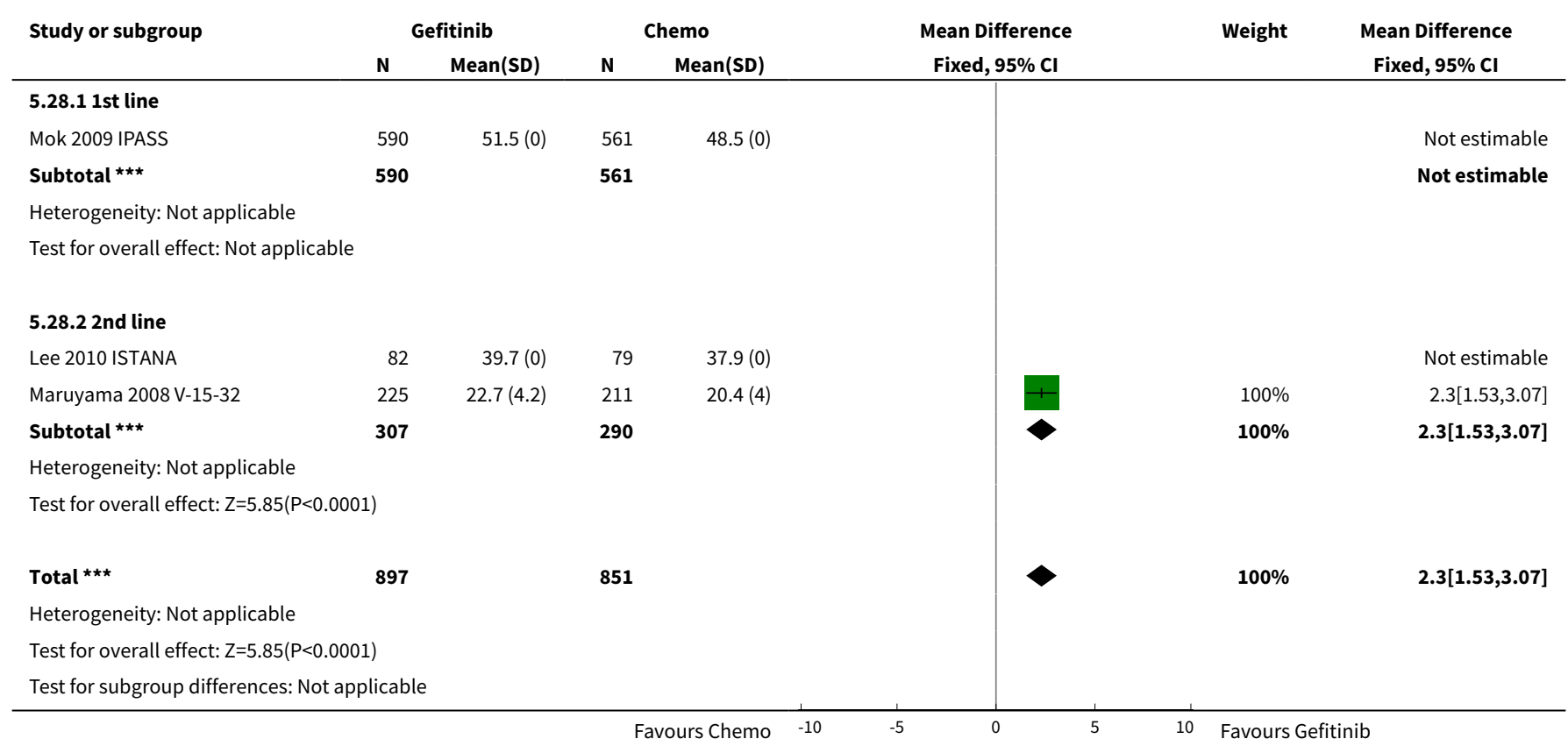


Analysis 5.29. Comparison 5 Gefitinib versus chemotherapy (Asian subgroup), Outcome 29 TOI QOL improvement rate.

\begin{tabular}{|c|c|c|c|c|c|c|c|}
\hline \multirow[t]{2}{*}{ Study or subgroup } & \multicolumn{2}{|c|}{ Gefitinib } & \multicolumn{2}{|c|}{ Chemo } & \multirow{2}{*}{$\begin{array}{c}\text { Mean Difference } \\
\text { Fixed, } 95 \% \mathrm{Cl} \\
\end{array}$} & \multirow[t]{2}{*}{ Weight } & \multirow{2}{*}{$\begin{array}{c}\text { Mean Difference } \\
\text { Fixed, } 95 \% \mathrm{Cl} \\
\end{array}$} \\
\hline & $\mathbf{N}$ & $\operatorname{Mean}(\mathrm{SD})$ & $\mathbf{N}$ & Mean(SD) & & & \\
\hline \multicolumn{8}{|l|}{ 5.29.1 1st line } \\
\hline Mok 2009 IPASS & 590 & $46.4(0)$ & 561 & $32.8(0)$ & & & Not estimable \\
\hline 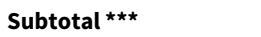 & 590 & & 561 & & & & Not estimable \\
\hline \multicolumn{8}{|c|}{ Heterogeneity: Not applicable } \\
\hline \multicolumn{8}{|c|}{ Test for overall effect: Not applicable } \\
\hline \multicolumn{8}{|l|}{ 5.29.2 2nd line } \\
\hline Maruyama 2008 V-15-32 & 185 & $20.5(12.9)$ & 173 & $8.7(12.5)$ & & $100 \%$ & $11.8[9.17,14.43]$ \\
\hline Lee 2010 ISTANA & 82 & $26.5(0)$ & 79 & $13.6(0)$ & & & Not estimable \\
\hline 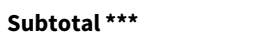 & 267 & & 252 & & & $100 \%$ & $11.8[9.17,14.43]$ \\
\hline \multicolumn{8}{|c|}{ Heterogeneity: Not applicable } \\
\hline \multicolumn{8}{|c|}{ Test for overall effect: $Z=8.79(P<0.0001)$} \\
\hline Total $* \star \star$ & 857 & & 813 & & & $100 \%$ & $11.8[9.17,14.43]$ \\
\hline \multicolumn{8}{|c|}{ Heterogeneity: Not applicable } \\
\hline \multicolumn{8}{|c|}{ Test for overall effect: $Z=8.79(P<0.0001)$} \\
\hline Test for subgroup differer & olicable & & & & & & \\
\hline
\end{tabular}

\section{Comparison 6. Gefitinib versus chemotherapy (EGFR mutation)}

\begin{tabular}{|c|c|c|c|c|}
\hline Outcome or subgroup title & No. of studies & $\begin{array}{l}\text { No. of partici- } \\
\text { pants }\end{array}$ & Statistical method & Effect size \\
\hline $1 \mathrm{HR}$ Overall survival $=1$ st line & 5 & & Hazard Ratio (Fixed, 95\% Cl) & $0.97[0.77,1.21]$ \\
\hline 1.1 Biomarker driven selection & 2 & & Hazard Ratio (Fixed, 95\% Cl) & $0.98[0.72,1.33]$ \\
\hline $\begin{array}{l}1.2 \text { Clinical feature driven selec- } \\
\text { tion }\end{array}$ & 3 & & Hazard Ratio (Fixed, 95\% Cl) & $0.95[0.68,1.33]$ \\
\hline $2 \mathrm{HR}$ Overall survival $=2 \mathrm{nd}$ line & 1 & & Hazard Ratio (Fixed, 95\% Cl) & $0.83[0.41,1.66]$ \\
\hline $2.1 \mathrm{G}$ vs docetaxel & 1 & & Hazard Ratio (Fixed, 95\% Cl) & $0.83[0.41,1.66]$ \\
\hline $\begin{array}{l}3 \text { HR Progression-free survival = } \\
1 \text { st line }\end{array}$ & 5 & & $\begin{array}{l}\text { Hazard Ratio (Random, 95\% } \\
\mathrm{Cl} \text { ) }\end{array}$ & $0.47[0.36,0.61]$ \\
\hline 3.1 Biomarker driven selection & 2 & & $\begin{array}{l}\text { Hazard Ratio (Random, 95\% } \\
\mathrm{Cl} \text { ) }\end{array}$ & $0.39[0.26,0.59]$ \\
\hline $\begin{array}{l}3.2 \text { Clinical feature driven selec- } \\
\text { tion }\end{array}$ & 3 & & $\begin{array}{l}\text { Hazard Ratio (Random, 95\% } \\
\mathrm{Cl} \text { ) }\end{array}$ & $0.53[0.41,0.70]$ \\
\hline $\begin{array}{l}4 \mathrm{HR} \text { Progression-free survival = } \\
2 \text { nd line }\end{array}$ & 2 & & Hazard Ratio (Fixed, 95\% Cl) & $0.24[0.12,0.47]$ \\
\hline 4.1 G vs docetaxel & 1 & & Hazard Ratio (Fixed, 95\% Cl) & $0.16[0.05,0.50]$ \\
\hline
\end{tabular}




\begin{tabular}{|c|c|c|c|c|}
\hline Outcome or subgroup title & No. of studies & $\begin{array}{l}\text { No. of partici- } \\
\text { pants }\end{array}$ & Statistical method & Effect size \\
\hline $4.2 \mathrm{G}$ vs pemetrexed & 1 & & Hazard Ratio (Fixed, 95\% Cl) & $0.30[0.13,0.70]$ \\
\hline 5 Overall response rate & 7 & 758 & $\begin{array}{l}\text { Risk Ratio (M-H, Random, 95\% } \\
\mathrm{Cl} \text { ) }\end{array}$ & $1.71[1.34,2.19]$ \\
\hline $\begin{array}{l}\text { 5.1 First-line biomarker driven se- } \\
\text { lection }\end{array}$ & 2 & 347 & $\begin{array}{l}\text { Risk Ratio (M-H, Random, 95\% } \\
\mathrm{Cl} \text { ) }\end{array}$ & $2.23[1.75,2.85]$ \\
\hline $\begin{array}{l}5.2 \text { First-line, clinical feature dri- } \\
\text { ven selection }\end{array}$ & 3 & 353 & $\begin{array}{l}\text { Risk Ratio (M-H, Random, 95\% } \\
\mathrm{Cl} \text { ) }\end{array}$ & $1.45[1.05,1.99]$ \\
\hline 5.3 2nd line & 2 & 58 & $\begin{array}{l}\text { Risk Ratio (M-H, Random, 95\% } \\
\mathrm{Cl} \text { ) }\end{array}$ & $1.65[0.88,3.09]$ \\
\hline 6 Stable disease & 3 & 397 & $\begin{array}{l}\text { Risk Ratio (M-H, Random, 95\% } \\
\mathrm{Cl} \text { ) }\end{array}$ & $0.52[0.28,0.97]$ \\
\hline $\begin{array}{l}\text { 6.1 First-line, biomarker driven } \\
\text { selection }\end{array}$ & 2 & 347 & $\begin{array}{l}\text { Risk Ratio (M-H, Random, 95\% } \\
\mathrm{Cl} \text { ) }\end{array}$ & $0.47[0.22,0.98]$ \\
\hline $\begin{array}{l}6.2 \text { First-line, clinical feature dri- } \\
\text { ven selection }\end{array}$ & 1 & 50 & $\begin{array}{l}\text { Risk Ratio (M-H, Random, 95\% } \\
\mathrm{Cl} \text { ) }\end{array}$ & $0.87[0.26,2.85]$ \\
\hline 7 Disease control rate & 5 & 2001 & $\begin{array}{l}\text { Risk Ratio (M-H, Random, 95\% } \\
\mathrm{Cl} \text { ) }\end{array}$ & $1.05[0.93,1.19]$ \\
\hline $\begin{array}{l}\text { 7.1 First-line, biomarker driven } \\
\text { selection }\end{array}$ & 2 & 347 & $\begin{array}{l}\text { Risk Ratio (M-H, Random, 95\% } \\
\mathrm{Cl} \text { ) }\end{array}$ & $1.15[1.05,1.26]$ \\
\hline $\begin{array}{l}\text { 7.2 First-line, clinical feature dri- } \\
\text { ven selection }\end{array}$ & 2 & 1267 & $\begin{array}{l}\text { Risk Ratio (M-H, Random, 95\% } \\
\mathrm{Cl} \text { ) }\end{array}$ & $0.93[0.87,0.99]$ \\
\hline 7.3 Second-line & 1 & 387 & $\begin{array}{l}\text { Risk Ratio (M-H, Random, 95\% } \\
\mathrm{Cl} \text { ) }\end{array}$ & $1.03[0.77,1.36]$ \\
\hline
\end{tabular}

\section{Analysis 6.1. Comparison 6 Gefitinib versus chemotherapy (EGFR mutation), Outcome 1 HR Overall survival = 1st line.}

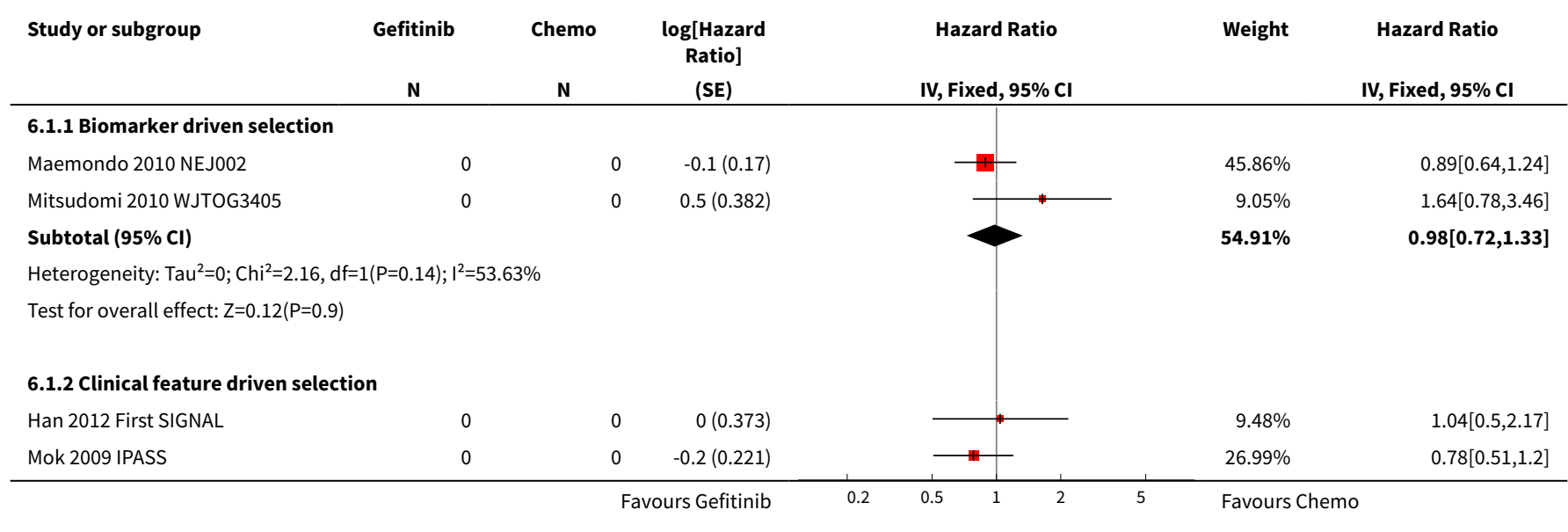




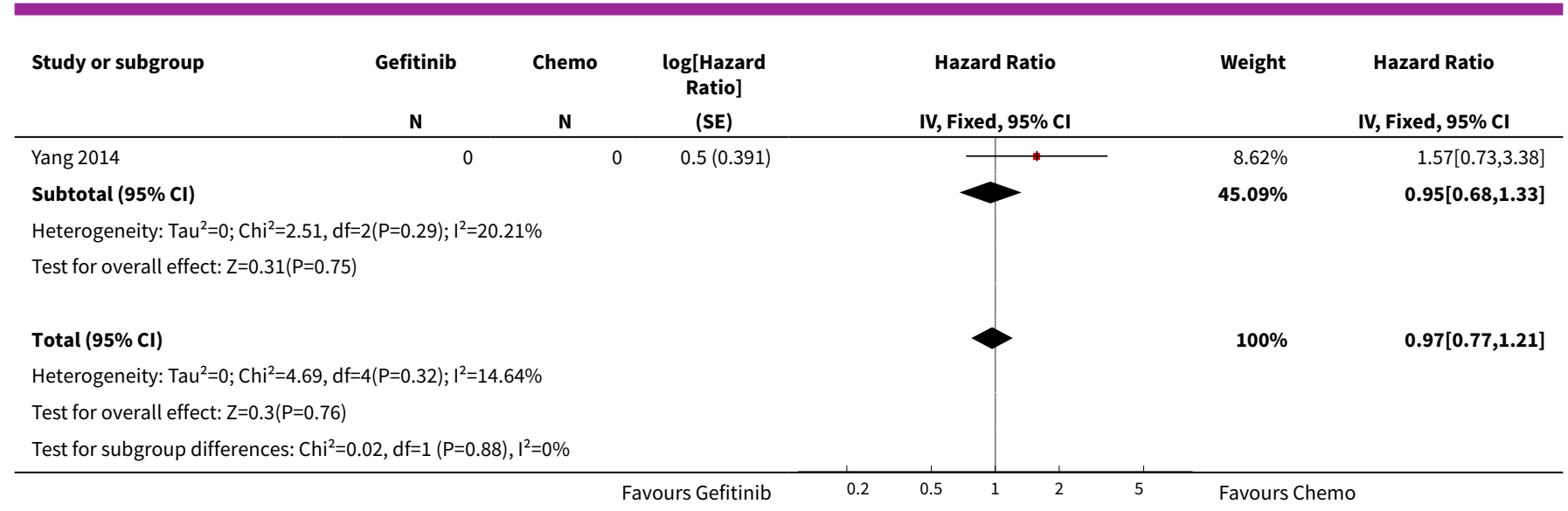

Analysis 6.2. Comparison 6 Gefitinib versus chemotherapy (EGFR mutation), Outcome 2 HR Overall survival $=2$ nd line.

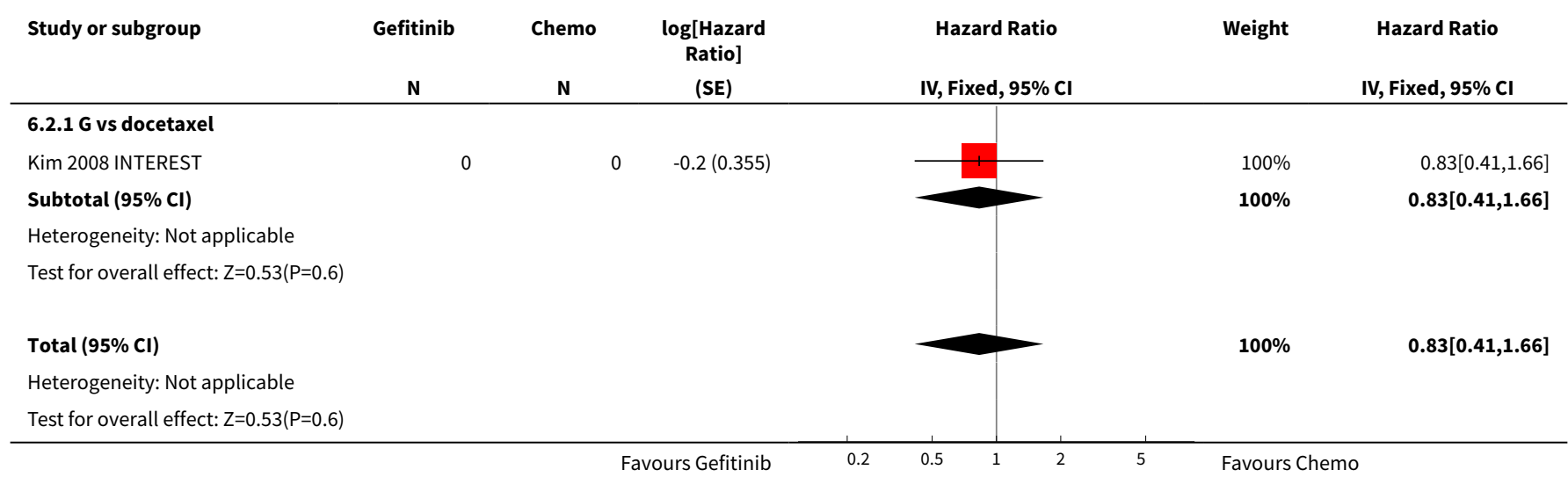

\section{Analysis 6.3. Comparison 6 Gefitinib versus chemotherapy (EGFR mutation), Outcome 3 HR Progression-free survival = 1st line.}

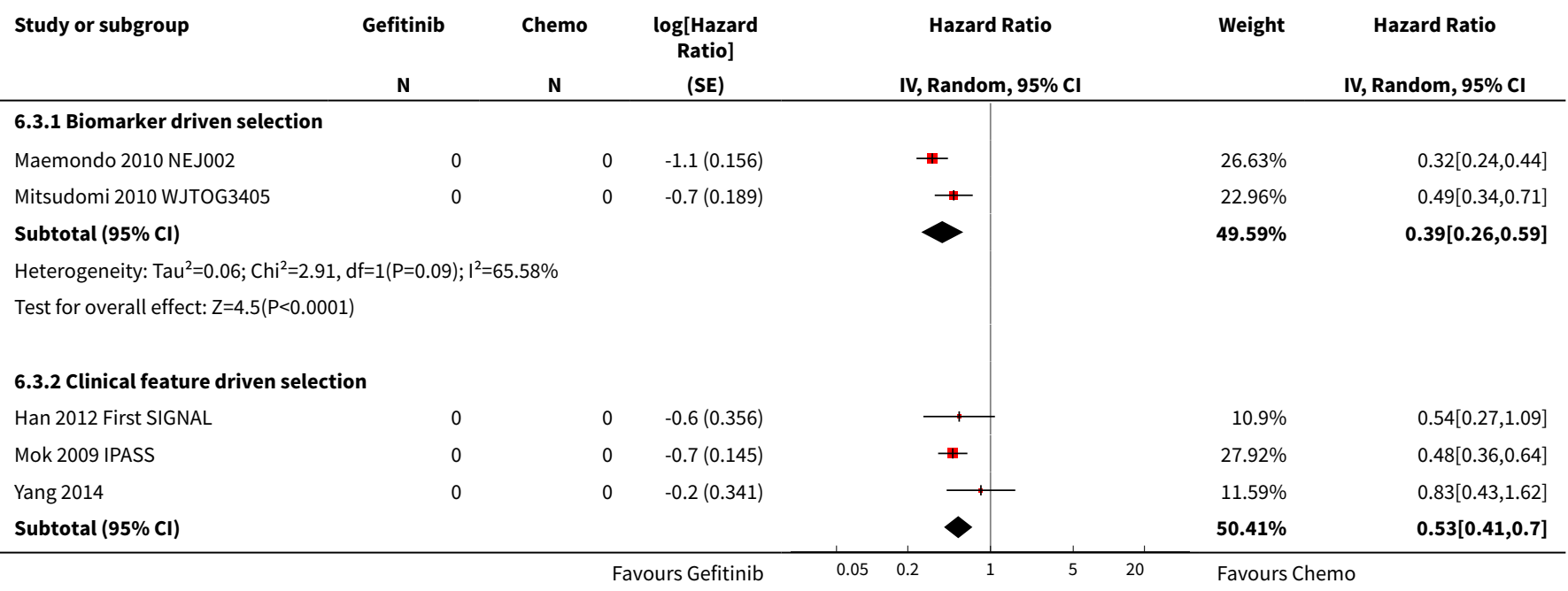




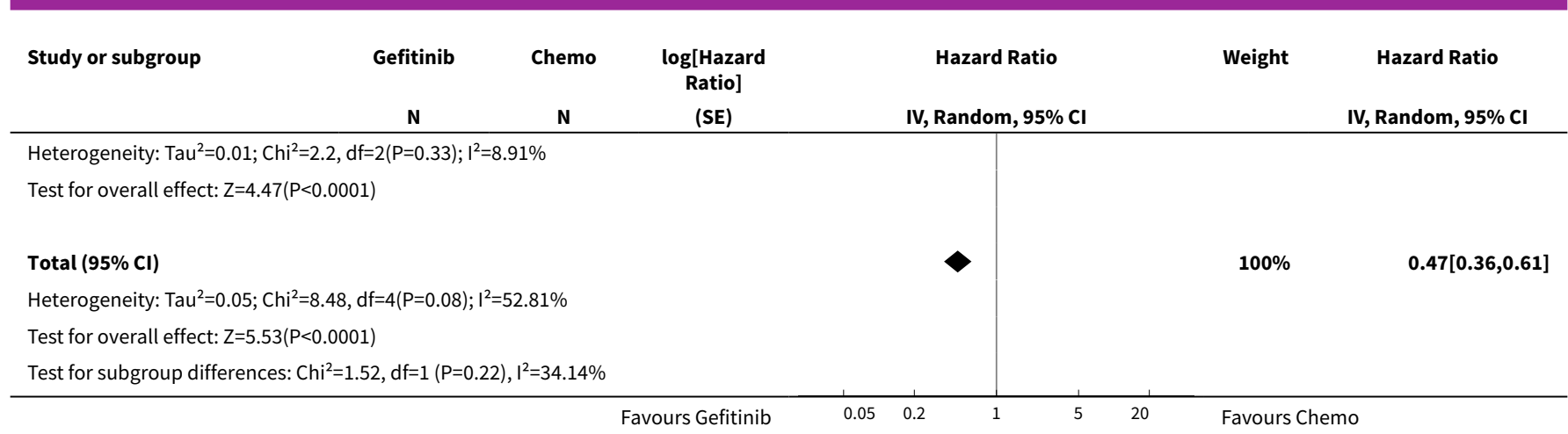

\section{Analysis 6.4. Comparison 6 Gefitinib versus chemotherapy (EGFR} mutation), Outcome 4 HR Progression-free survival = 2nd line.

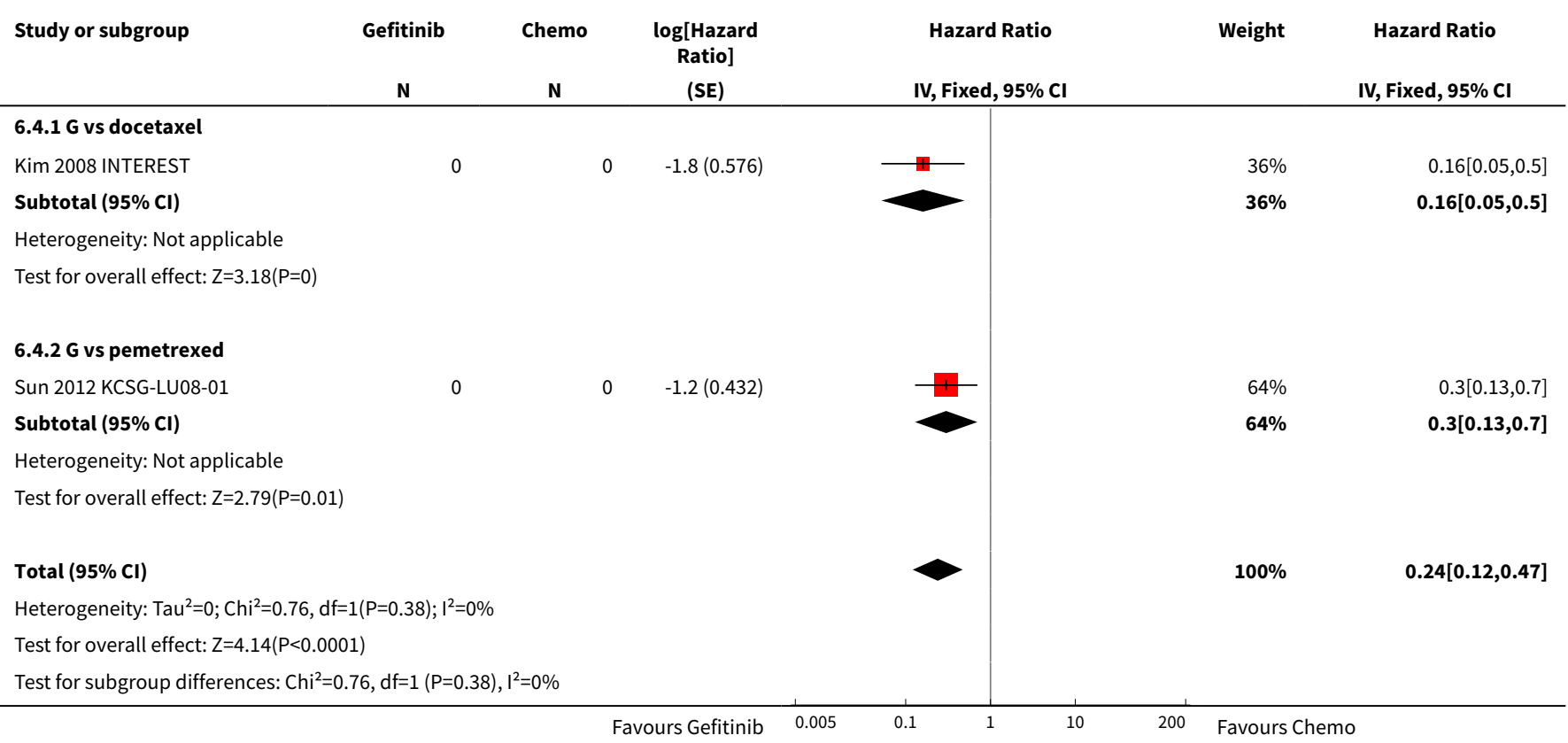

\section{Analysis 6.5. Comparison 6 Gefitinib versus chemotherapy (EGFR mutation), Outcome 5 Overall response rate.}

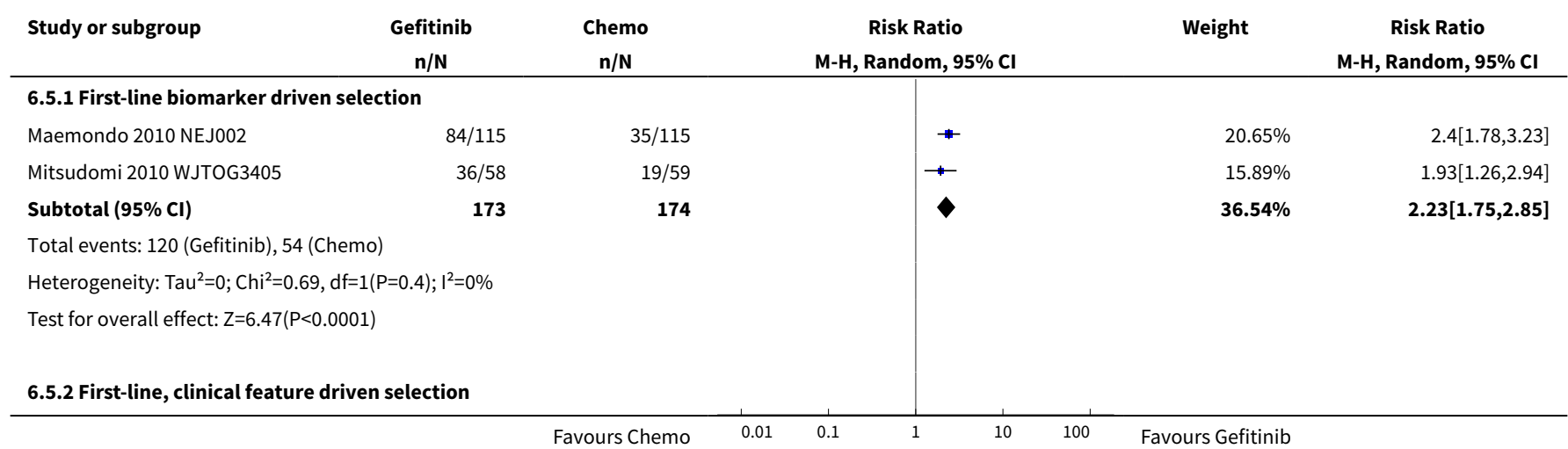




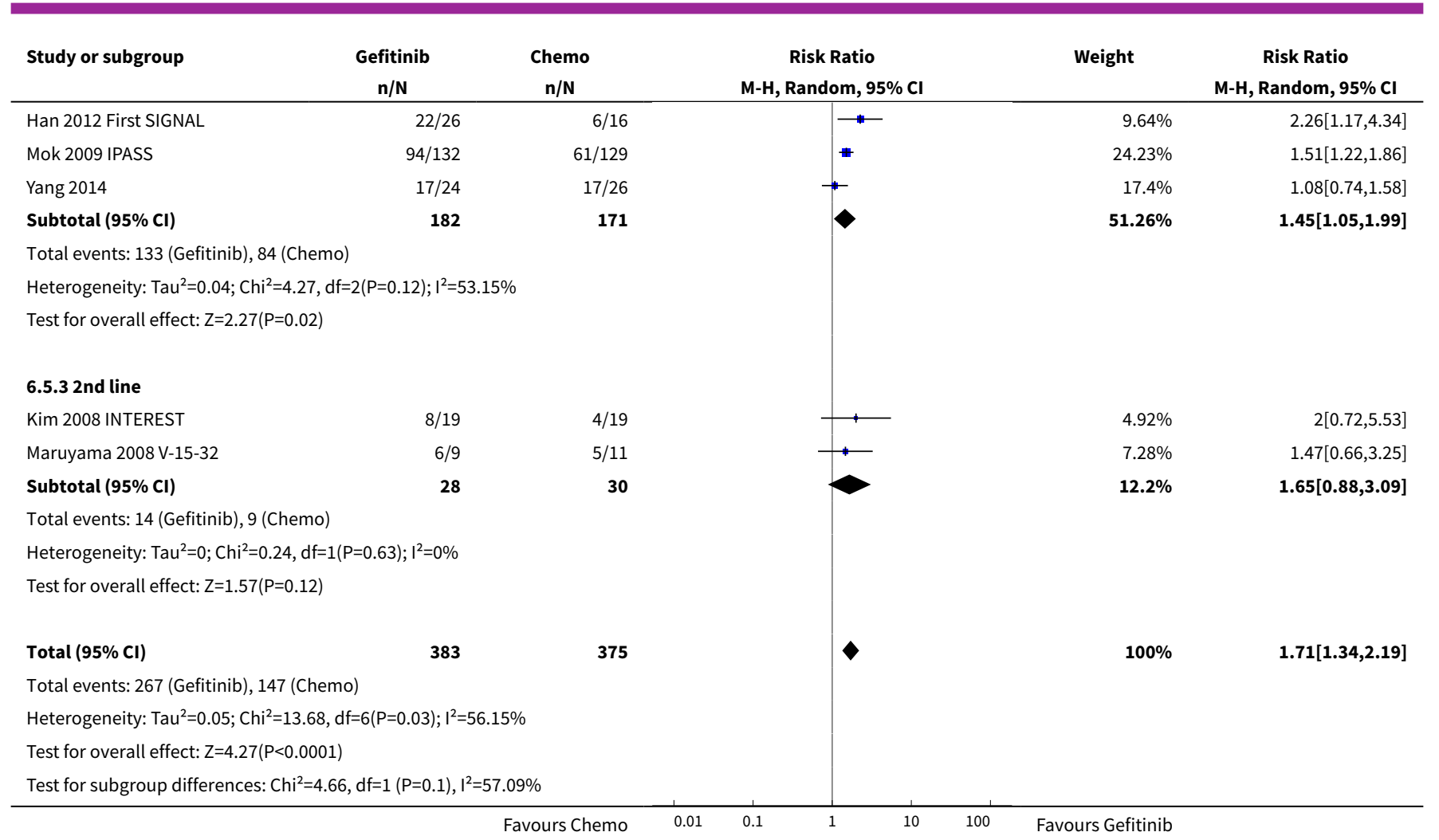

Analysis 6.6. Comparison 6 Gefitinib versus chemotherapy (EGFR mutation), Outcome 6 Stable disease.

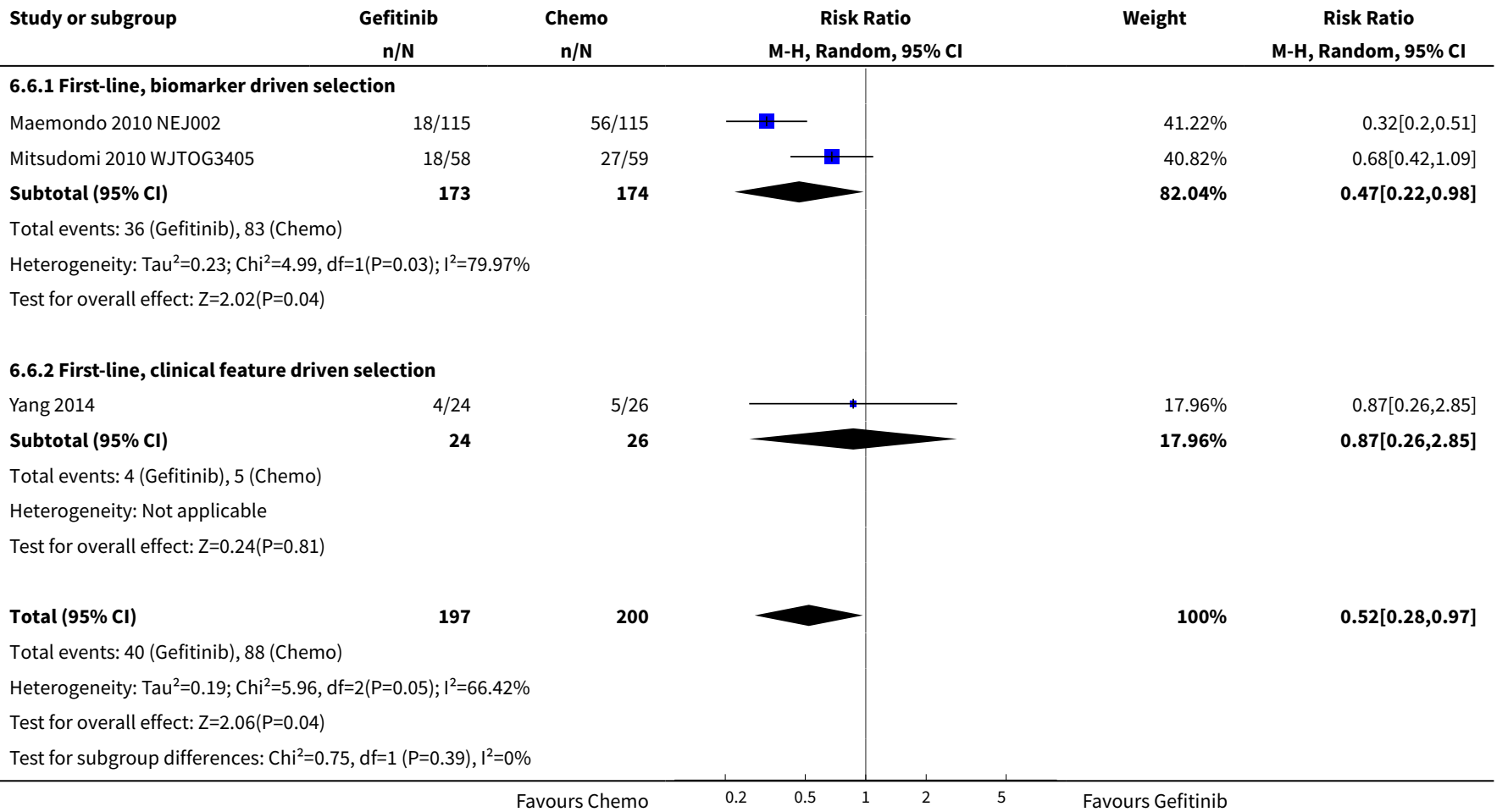


Analysis 6.7. Comparison 6 Gefitinib versus chemotherapy (EGFR mutation), Outcome 7 Disease control rate.

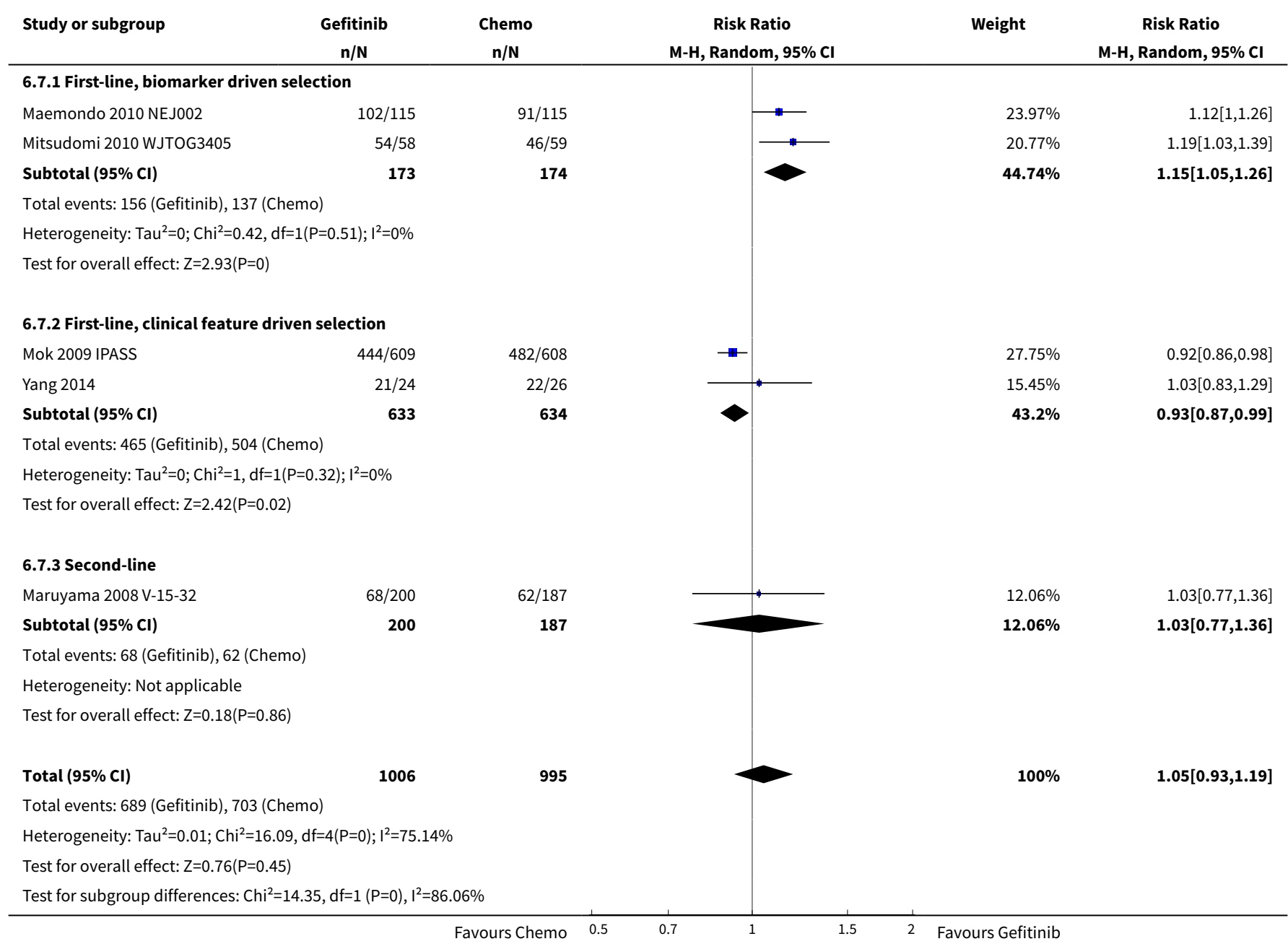

\section{Comparison 7. Gefitinib $250 \mathrm{mg}$ versus gefitinib $500 \mathrm{mg}$}

\begin{tabular}{lllll}
\hline $\begin{array}{l}\text { Outcome or sub- } \\
\text { group title }\end{array}$ & No. of studies & $\begin{array}{l}\text { No. of partici- } \\
\text { pants }\end{array}$ & Statistical method & Effect size \\
\hline 1 1-year survival rate & 2 & 424 & Risk Ratio (M-H, Fixed, 95\% Cl) & $0.83[0.61,1.11]$ \\
\hline 1.1 2nd line & 2 & 424 & Risk Ratio (M-H, Fixed, 95\% Cl) & $0.83[0.61,1.11]$ \\
\hline 2 Skin rash & 2 & 290 & Risk Ratio (M-H, Fixed, 95\% Cl) & $8.13[1.51,43.72]$ \\
\hline 2.1 2nd line & 1 & Risk Ratio (M-H, Fixed, 95\% Cl) & $6.80[0.85,54.32]$ \\
\hline 2.2 Maintenance & 1 & 209 & Risk Ratio (M-H, Fixed, 95\% Cl) & $10.41[0.61,176.21]$ \\
\hline 3 Acne & 1 & 81 & Risk Ratio (M-H, Fixed, 95\% Cl) & $4.86[0.24,100.02]$ \\
\hline 3.1 2nd line & 1 & 209 & Risk Ratio (M-H, Fixed, 95\% Cl) & $4.86[0.24,100.02]$ \\
\hline
\end{tabular}




\begin{tabular}{|c|c|c|c|c|}
\hline $\begin{array}{l}\text { Outcome or sub- } \\
\text { group title }\end{array}$ & No. of studies & $\begin{array}{l}\text { No. of partici- } \\
\text { pants }\end{array}$ & Statistical method & Effect size \\
\hline 4 Pruritus & 1 & 209 & Risk Ratio (M-H, Fixed, 95\% Cl) & $2.92[0.12,70.77]$ \\
\hline 4.1 2nd line & 1 & 209 & Risk Ratio (M-H, Fixed, 95\% Cl) & $2.92[0.12,70.77]$ \\
\hline 5 Diarrhoea & 3 & 521 & Risk Ratio (M-H, Fixed, 95\% Cl) & $8.36[1.58,44.34]$ \\
\hline 5.1 2nd line & 3 & 521 & Risk Ratio (M-H, Fixed, 95\% Cl) & $8.36[1.58,44.34]$ \\
\hline 6 Nausea & 1 & 209 & Risk Ratio (M-H, Fixed, 95\% Cl) & $0.97[0.06,15.33]$ \\
\hline 6.1 2nd line & 1 & 209 & Risk Ratio (M-H, Fixed, 95\% Cl) & $0.97[0.06,15.33]$ \\
\hline 7 Vomiting & 1 & 209 & Risk Ratio (M-H, Fixed, 95\% Cl) & $0.0[0.0,0.0]$ \\
\hline 7.1 2nd line & 1 & 209 & Risk Ratio (M-H, Fixed, 95\% Cl) & $0.0[0.0,0.0]$ \\
\hline 8 Anorexia & 1 & 209 & Risk Ratio (M-H, Fixed, 95\% Cl) & $2.92[0.12,70.77]$ \\
\hline 8.1 2nd line & 1 & 209 & Risk Ratio (M-H, Fixed, 95\% CI) & $2.92[0.12,70.77]$ \\
\hline 9 Asthenia & 1 & 209 & Risk Ratio (M-H, Fixed, 95\% Cl) & $2.92[0.12,70.77]$ \\
\hline 9.1 2nd line & 1 & 209 & Risk Ratio (M-H, Fixed, 95\% Cl) & $2.92[0.12,70.77]$ \\
\hline $\begin{array}{l}10 \text { Overall response } \\
\text { rate }\end{array}$ & 3 & & Risk Ratio (M-H, Fixed, 95\% Cl) & Subtotals only \\
\hline 10.1 2nd line & 2 & 424 & Risk Ratio (M-H, Fixed, 95\% Cl) & $0.92[0.58,1.46]$ \\
\hline 10.2 Maintenance & 1 & 96 & Risk Ratio (M-H, Fixed, 95\% Cl) & $1.0[0.35,2.88]$ \\
\hline 11 Partial response & 1 & 216 & Risk Ratio (M-H, Fixed, 95\% CI) & $0.75[0.34,1.65]$ \\
\hline 11.12nd line & 1 & 216 & Risk Ratio (M-H, Fixed, 95\% Cl) & $0.75[0.34,1.65]$ \\
\hline $\begin{array}{l}12 \text { FACT-L Symptom } \\
\text { improvement rate }\end{array}$ & 2 & 356 & Mean Difference (IV, Fixed, 95\% CI) & $3.70[-7.28,14.69]$ \\
\hline 12.12nd line & 2 & 356 & Mean Difference (IV, Fixed, 95\% CI) & $3.70[-7.28,14.69]$ \\
\hline $\begin{array}{l}13 \text { TOI QOL improve- } \\
\text { ment rate }\end{array}$ & 2 & 424 & Mean Difference (IV, Fixed, 95\% CI) & $7.38[-2.30,17.05]$ \\
\hline 13.1 2nd line & 2 & 424 & Mean Difference (IV, Fixed, 95\% CI) & $7.38[-2.30,17.05]$ \\
\hline
\end{tabular}

Analysis 7.1. Comparison 7 Gefitinib $250 \mathrm{mg}$ versus gefitinib $500 \mathrm{mg}$, Outcome 1 1-year survival rate.

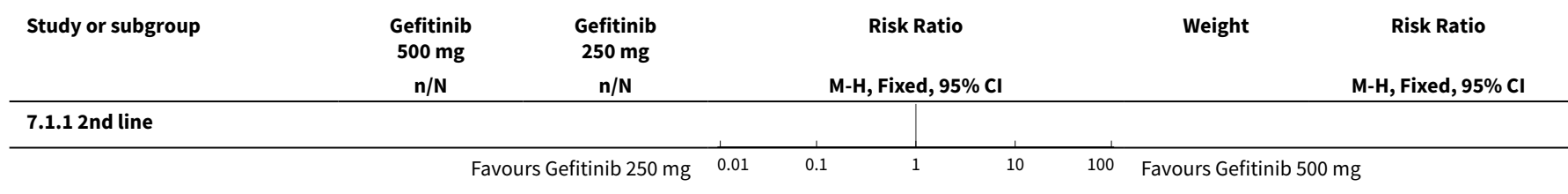




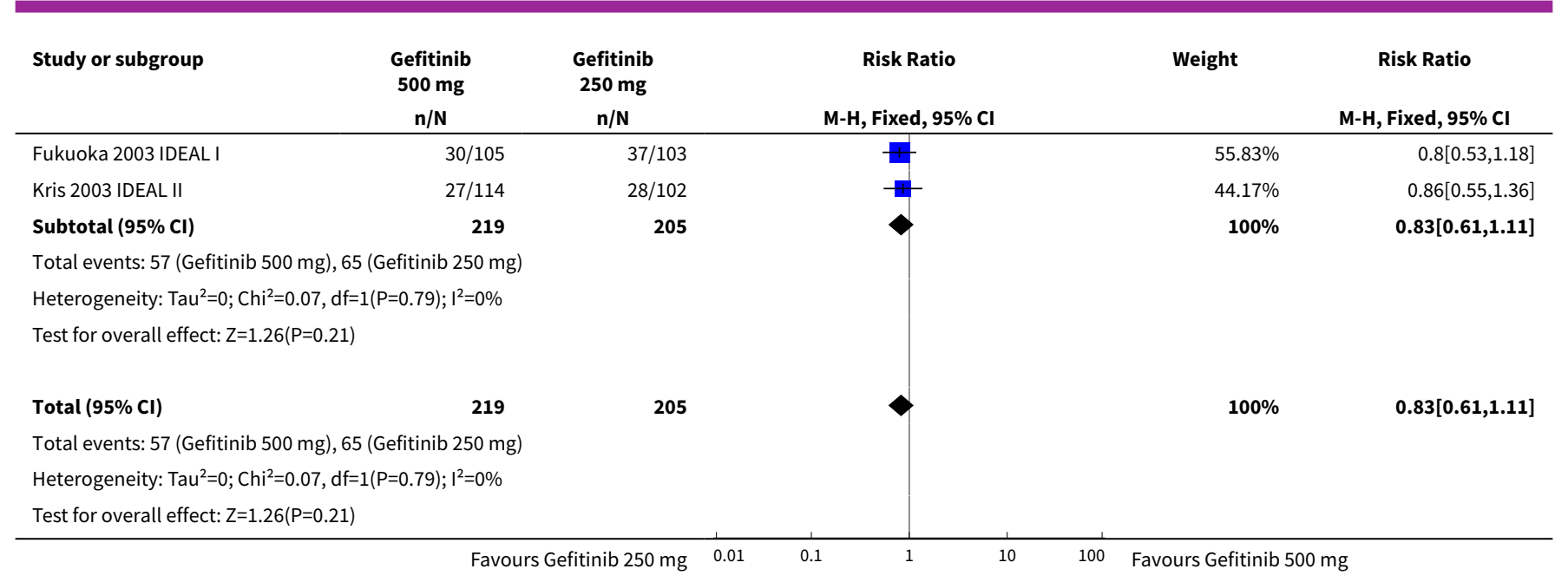

Analysis 7.2. Comparison 7 Gefitinib $250 \mathrm{mg}$ versus gefitinib $500 \mathrm{mg}$, Outcome 2 Skin rash.

\begin{tabular}{ccccc} 
Study or subgroup & Gefitinib & Gefitinib & Risk Ratio & Weight \\
& $500 \mathrm{mg}$ & $250 \mathrm{mg}$ & $\mathrm{M}-\mathrm{H}$, Fixed, $95 \% \mathrm{Cl}$ & $\mathrm{M}-\mathrm{H}$, Fixed, $95 \% \mathrm{Cl}$ \\
\hline
\end{tabular}

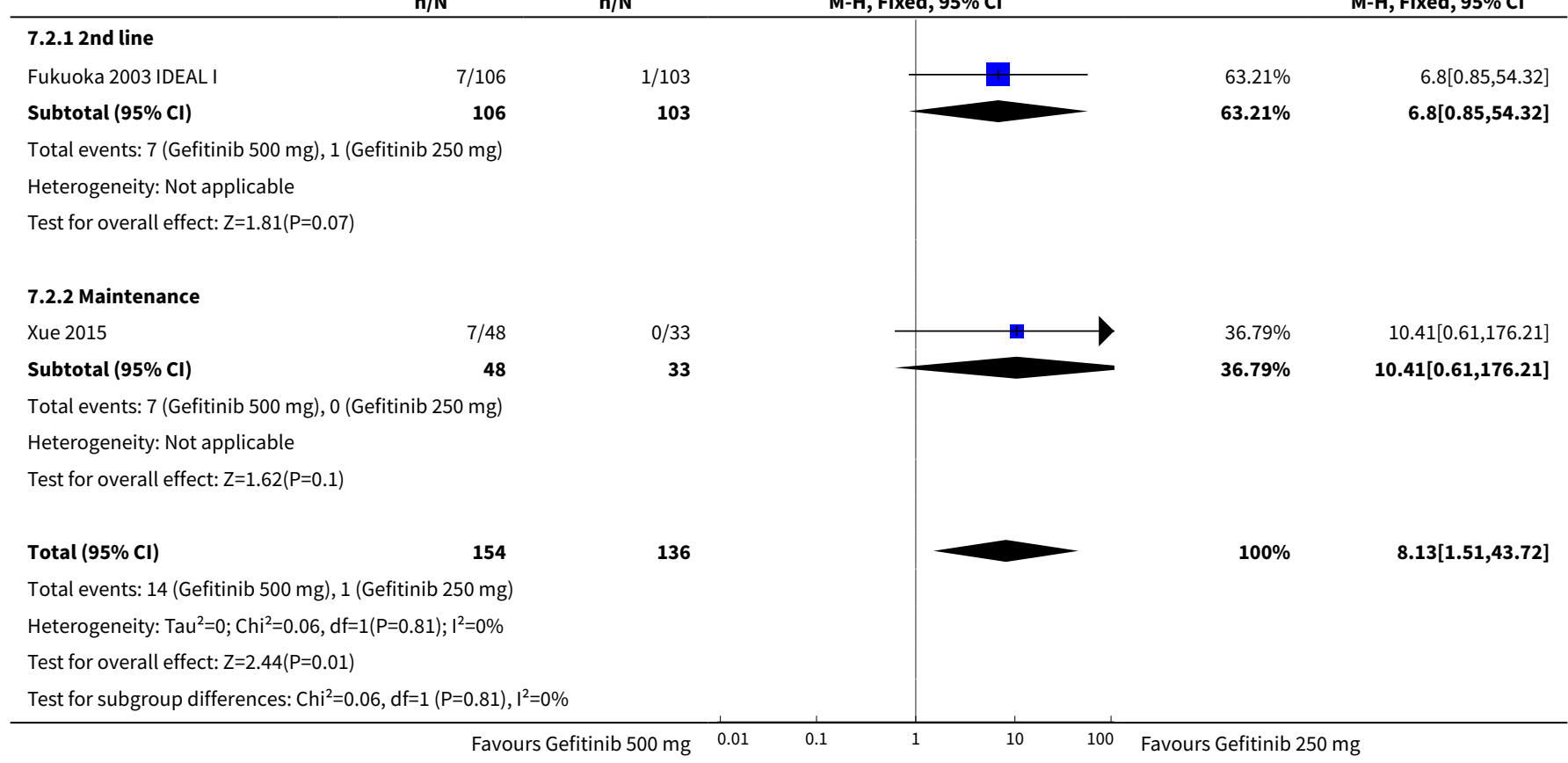

Analysis 7.3. Comparison 7 Gefitinib $250 \mathrm{mg}$ versus gefitinib $500 \mathrm{mg}$, Outcome 3 Acne.

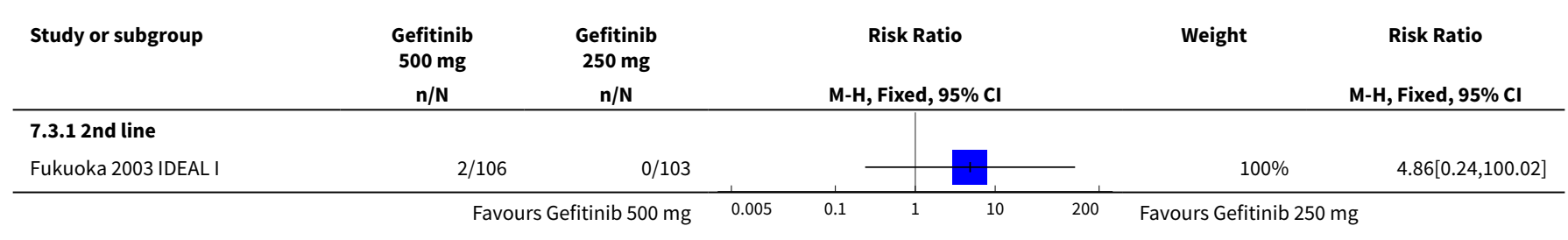




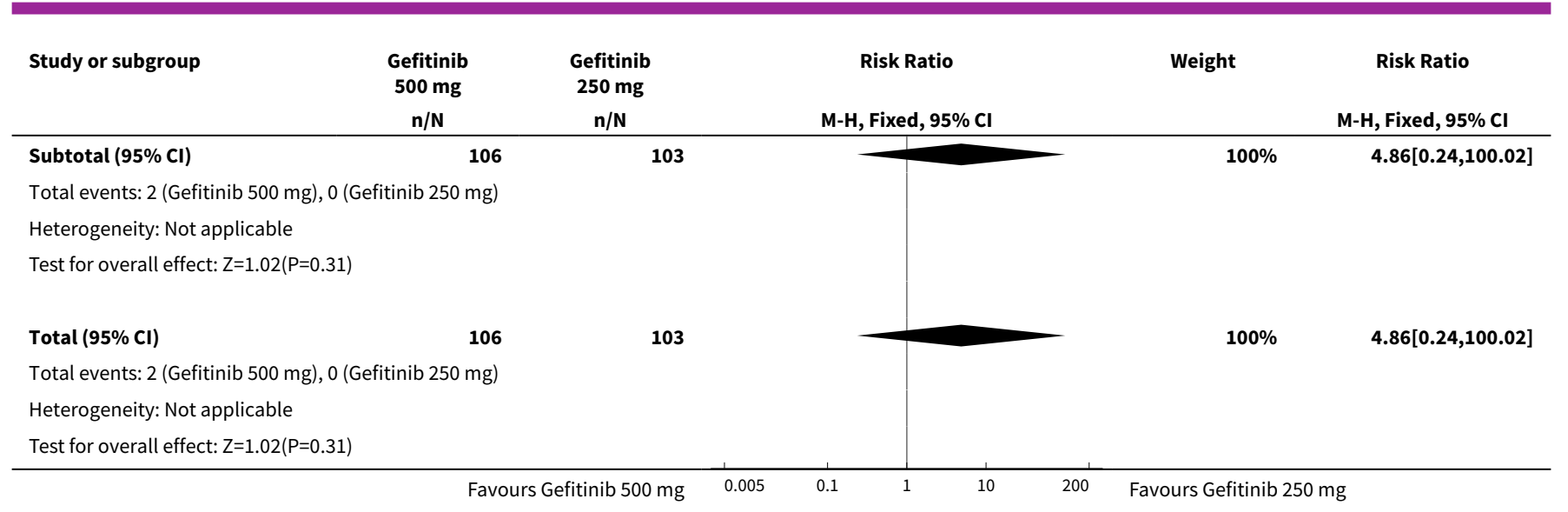

Analysis 7.4. Comparison 7 Gefitinib 250 mg versus gefitinib $500 \mathrm{mg}$, Outcome 4 Pruritus.

\begin{tabular}{|c|c|c|c|c|c|}
\hline Study or subgroup & $\begin{array}{c}\text { Gefitinib } \\
500 \mathrm{mg} \\
\mathrm{n} / \mathrm{N}\end{array}$ & $\begin{array}{c}\text { Gefitinib } \\
250 \mathrm{mg} \\
\mathrm{n} / \mathrm{N}\end{array}$ & $\begin{array}{c}\text { Risk Ratio } \\
\text { M-H, Fixed, 95\% Cl }\end{array}$ & Weight & $\begin{array}{c}\text { Risk Ratio } \\
\text { M-H, Fixed, } 95 \% \mathrm{Cl} \\
\end{array}$ \\
\hline \multicolumn{6}{|l|}{ 7.4.1 2nd line } \\
\hline Fukuoka 2003 IDEAL I & $1 / 106$ & $0 / 103$ & & $100 \%$ & $2.92[0.12,70.77]$ \\
\hline Subtotal $(95 \% \mathrm{Cl})$ & 106 & 103 & & $100 \%$ & $2.92[0.12,70.77]$ \\
\hline \multicolumn{6}{|c|}{ Total events: 1 (Gefitinib 500 mg), 0 (Gefitinib 250 mg) } \\
\hline \multicolumn{6}{|c|}{ Test for overall effect: $Z=0.66(P=0.51)$} \\
\hline Total $(95 \% \mathrm{Cl})$ & 106 & 103 & & $100 \%$ & $2.92[0.12,70.77]$ \\
\hline \multicolumn{6}{|c|}{ Total events: 1 (Gefitinib 500 mg), 0 (Gefitinib 250 mg) } \\
\hline \multicolumn{6}{|c|}{ Heterogeneity: Not applicable } \\
\hline \multicolumn{6}{|c|}{ Test for overall effect: $Z=0.66(P=0.51)$} \\
\hline
\end{tabular}

\section{Analysis 7.5. Comparison 7 Gefitinib 250 mg versus gefitinib $500 \mathrm{mg}$, Outcome 5 Diarrhoea.}

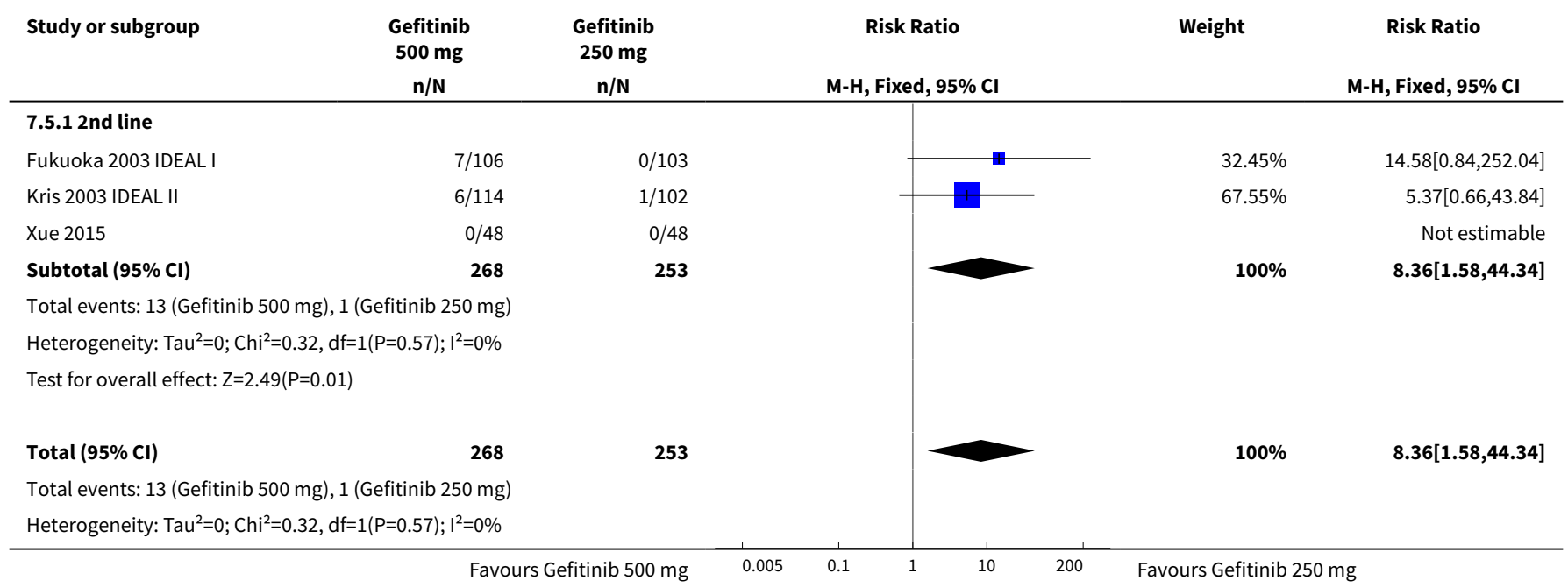




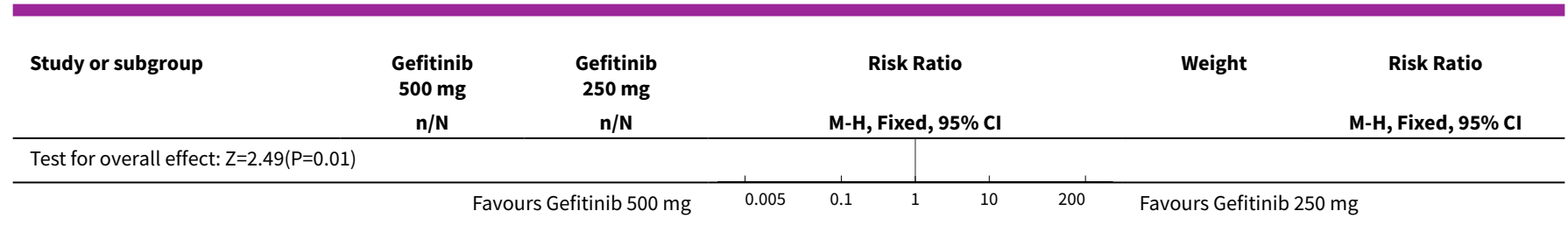

Analysis 7.6. Comparison 7 Gefitinib $250 \mathrm{mg}$ versus gefitinib $500 \mathrm{mg}$, Outcome 6 Nausea.

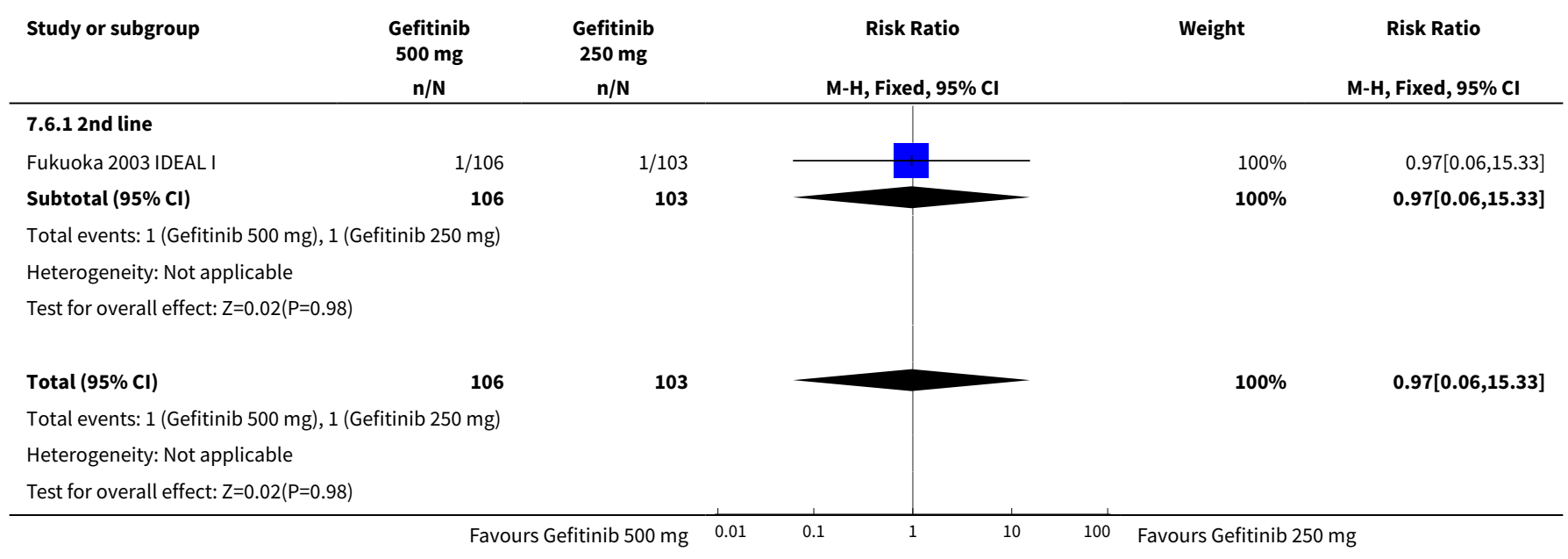

Analysis 7.7. Comparison 7 Gefitinib $250 \mathrm{mg}$ versus gefitinib $500 \mathrm{mg}$, Outcome 7 Vomiting.

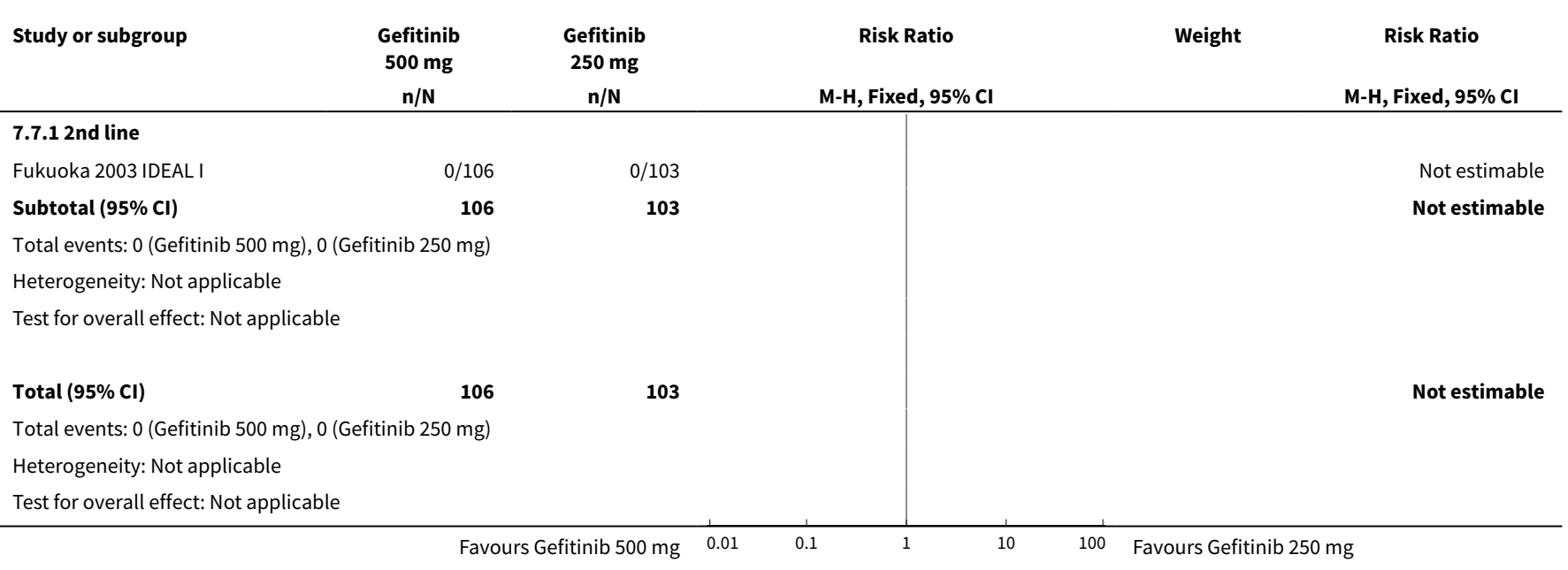


Analysis 7.8. Comparison 7 Gefitinib 250 mg versus gefitinib 500 mg, Outcome 8 Anorexia.

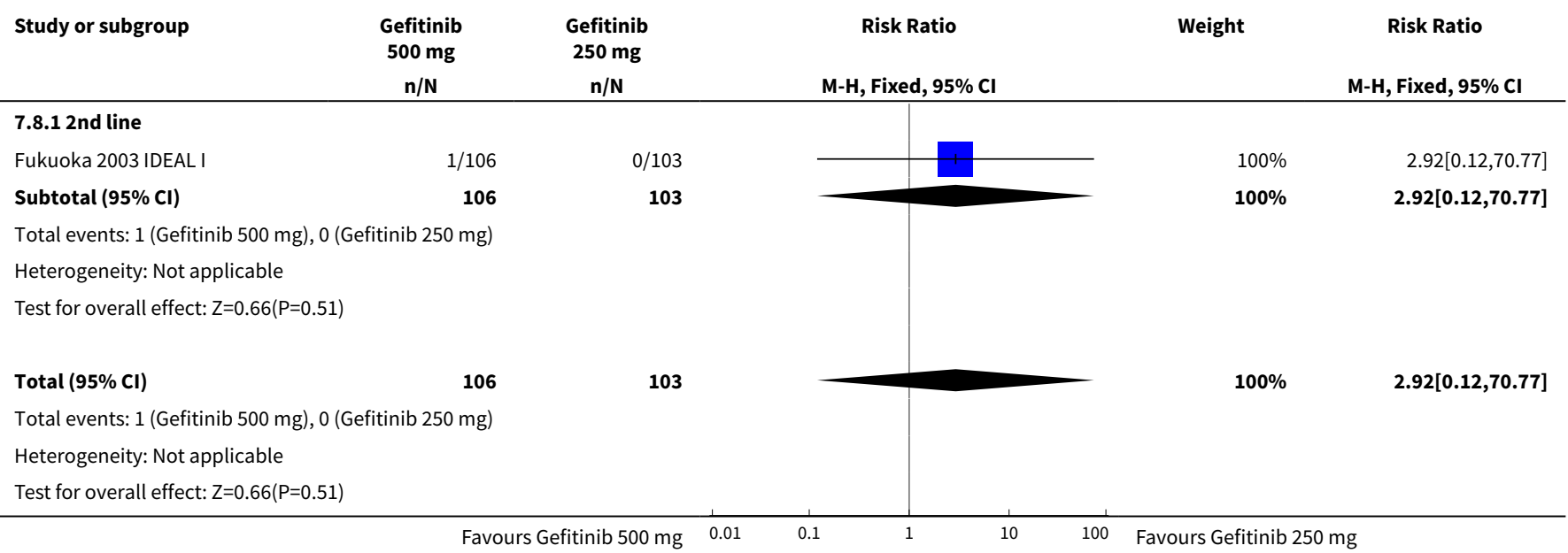

Analysis 7.9. Comparison 7 Gefitinib $250 \mathrm{mg}$ versus gefitinib $500 \mathrm{mg}$, Outcome 9 Asthenia.

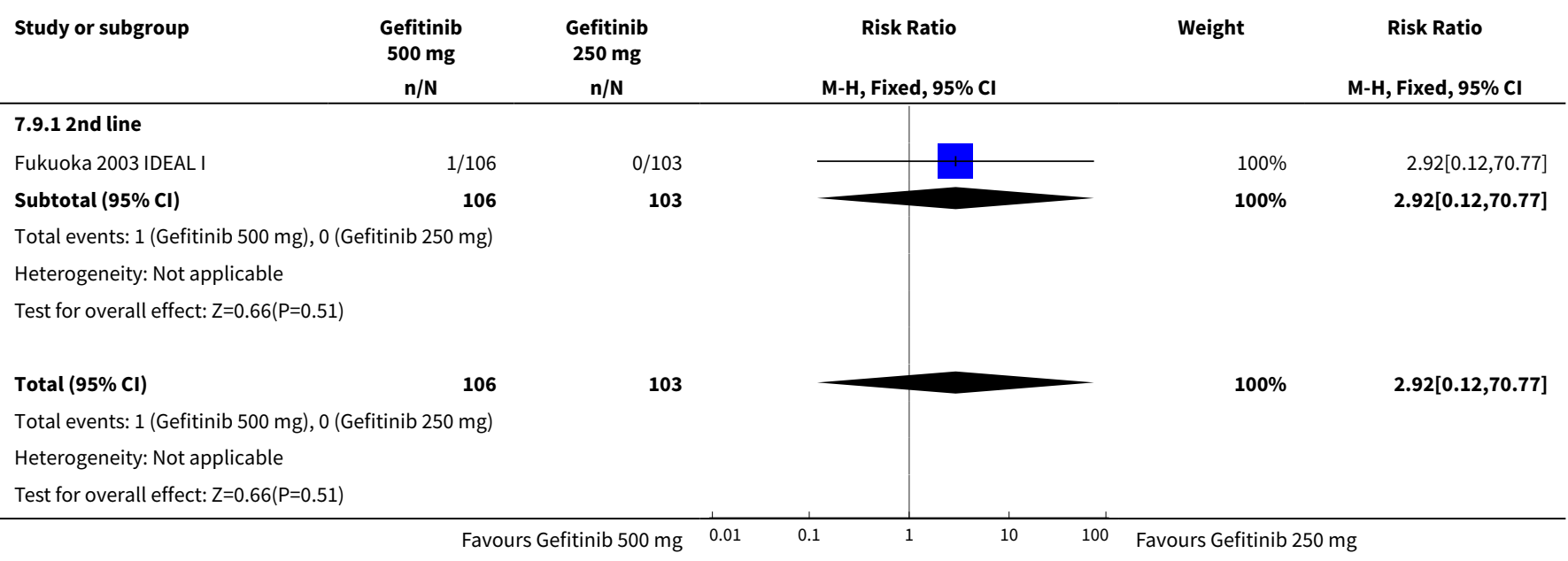

Analysis 7.10. Comparison 7 Gefitinib $250 \mathrm{mg}$ versus gefitinib $500 \mathrm{mg}$, Outcome 10 Overall response rate.

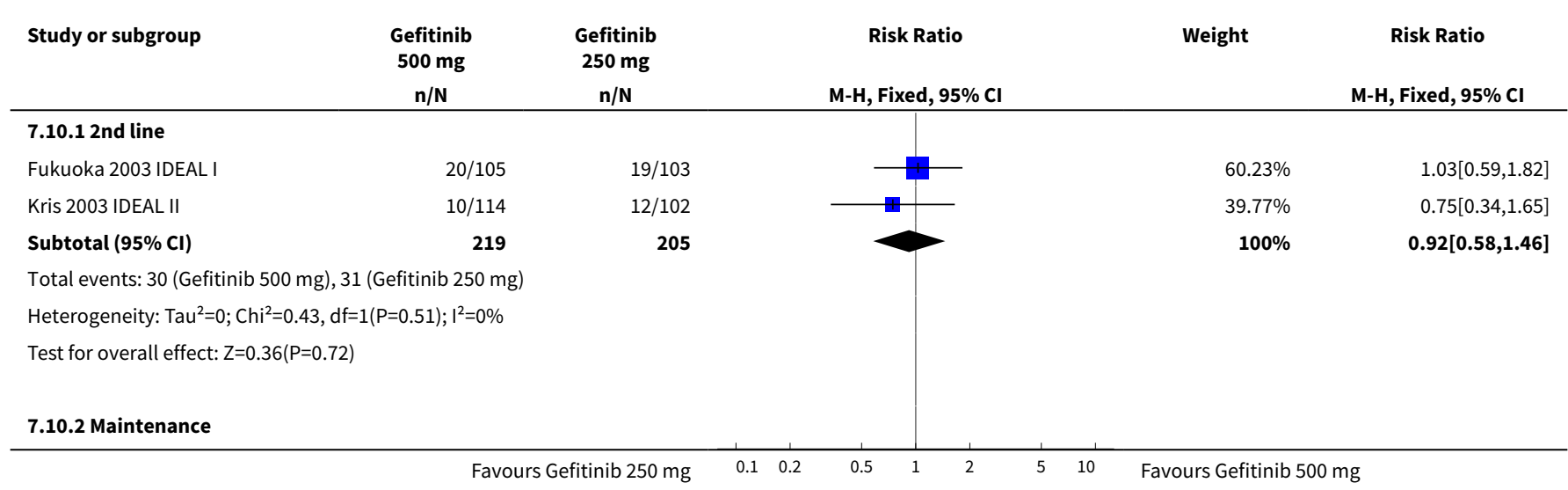




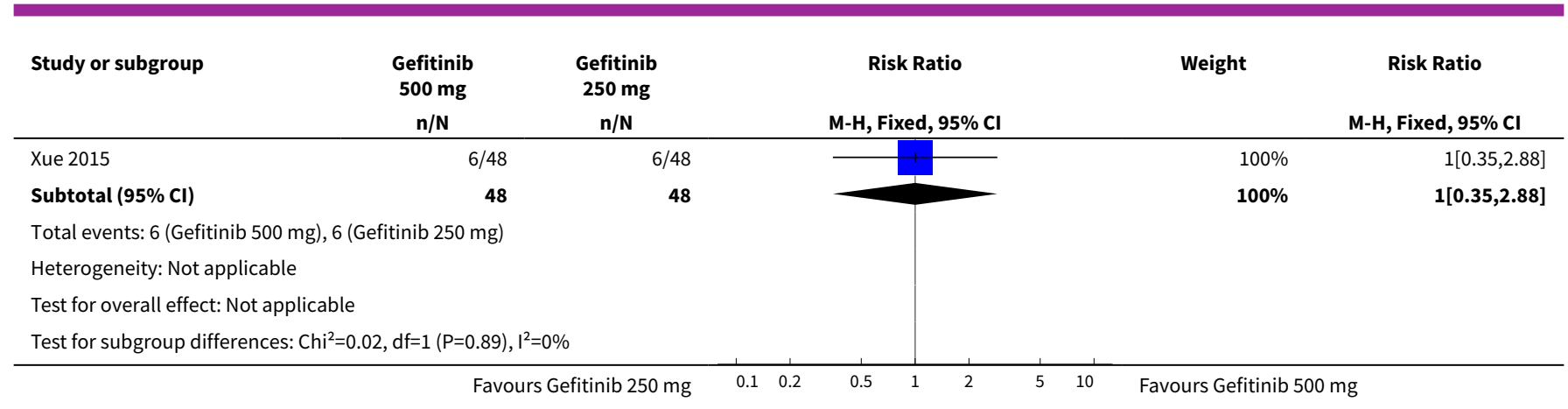

Analysis 7.11. Comparison 7 Gefitinib $250 \mathrm{mg}$ versus gefitinib $500 \mathrm{mg}$, Outcome 11 Partial response.

\begin{tabular}{|c|c|c|c|c|c|}
\hline Study or subgroup & $\begin{array}{c}\text { Gefitinib } \\
500 \mathrm{mg} \\
\mathrm{n} / \mathrm{N}\end{array}$ & $\begin{array}{c}\text { Gefitinib } \\
250 \mathrm{mg} \\
\mathrm{n} / \mathrm{N} \\
\end{array}$ & M-H, Fixed, $95 \% \mathrm{Cl}$ & Weight & $\begin{array}{c}\text { Risk Ratio } \\
\text { M-H, Fixed, } 95 \% \mathrm{Cl}\end{array}$ \\
\hline \multicolumn{6}{|l|}{ 7.11.1 2nd line } \\
\hline Kris 2003 IDEAL II & $10 / 114$ & $12 / 102$ & - & $100 \%$ & $0.75[0.34,1.65]$ \\
\hline Subtotal $(95 \% \mathrm{Cl})$ & 114 & 102 & & $100 \%$ & $0.75[0.34,1.65]$ \\
\hline \multicolumn{6}{|c|}{ Total events: 10 (Gefitinib $500 \mathrm{mg}$ ), 12 (Gefitinib $250 \mathrm{mg}$ ) } \\
\hline \multicolumn{6}{|c|}{ Test for overall effect: $Z=0.72(P=0.47)$} \\
\hline Total $(95 \% \mathrm{Cl})$ & 114 & 102 & & $100 \%$ & $0.75[0.34,1.65]$ \\
\hline \multicolumn{6}{|c|}{ Total events: 10 (Gefitinib $500 \mathrm{mg}$ ), 12 (Gefitinib $250 \mathrm{mg}$ ) } \\
\hline \multicolumn{6}{|c|}{ Heterogeneity: $\mathrm{Tau}^{2}=0 ; \mathrm{Chi}^{2}=0, \mathrm{df}=0(\mathrm{P}<0.0001) ; \mathrm{I}^{2}=100 \%$} \\
\hline \multicolumn{6}{|c|}{ Test for overall effect: $Z=0.72(P=0.47)$} \\
\hline
\end{tabular}

\section{Analysis 7.12. Comparison 7 Gefitinib $250 \mathrm{mg}$ versus gefitinib $500 \mathrm{mg}$, Outcome 12 FACT-L Symptom improvement rate.}

\begin{tabular}{|c|c|c|c|c|c|c|c|}
\hline \multirow[t]{2}{*}{ Study or subgroup } & \multicolumn{2}{|c|}{ Gefitinib 250 mg } & \multicolumn{2}{|c|}{ Gefitinib 500 mg } & \multirow{2}{*}{$\begin{array}{c}\text { Mean Difference } \\
\text { Fixed, } 95 \% \mathrm{Cl}\end{array}$} & \multirow[t]{2}{*}{ Weight } & \multirow{2}{*}{$\begin{array}{c}\text { Mean Difference } \\
\text { Fixed, } 95 \% \mathrm{Cl}\end{array}$} \\
\hline & $\mathbf{N}$ & Mean(SD) & $\mathbf{N}$ & Mean(SD) & & & \\
\hline \multicolumn{8}{|l|}{ 7.12.1 2nd line } \\
\hline Fukuoka 2003 IDEAL I & 67 & $40.3(51.2)$ & 73 & $37(50.4)$ & 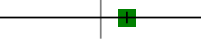 & $42.57 \%$ & $3.3[-13.54,20.14]$ \\
\hline Kris 2003 IDEAL II & 102 & $44(51.5)$ & 114 & $40(57.2)$ & & $57.43 \%$ & $4[-10.5,18.5]$ \\
\hline Subtotal $\star \star \star ~$ & 169 & & 187 & & & $100 \%$ & $3.7[-7.28,14.69]$ \\
\hline \multicolumn{8}{|c|}{ Heterogeneity: $\mathrm{Tau}^{2}=0 ; \mathrm{Chi}^{2}=0, \mathrm{df}=1(\mathrm{P}=0.95) ; \mathrm{I}^{2}=0 \%$} \\
\hline \multicolumn{8}{|c|}{ Test for overall effect: $Z=0.66(P=0.51)$} \\
\hline Total $\star \star \star ~$ & 169 & & 187 & & & $100 \%$ & $3.7[-7.28,14.69]$ \\
\hline \multicolumn{8}{|c|}{ Heterogeneity: $\mathrm{Tau}^{2}=0 ; \mathrm{Chi}^{2}=0, \mathrm{df}=1(\mathrm{P}=0.95) ; \mathrm{I}^{2}=0 \%$} \\
\hline Test for overall effect: 2 & & & & & & & \\
\hline
\end{tabular}


Analysis 7.13. Comparison 7 Gefitinib $250 \mathrm{mg}$ versus gefitinib $500 \mathrm{mg}$, Outcome 13 TOI QOL improvement rate.

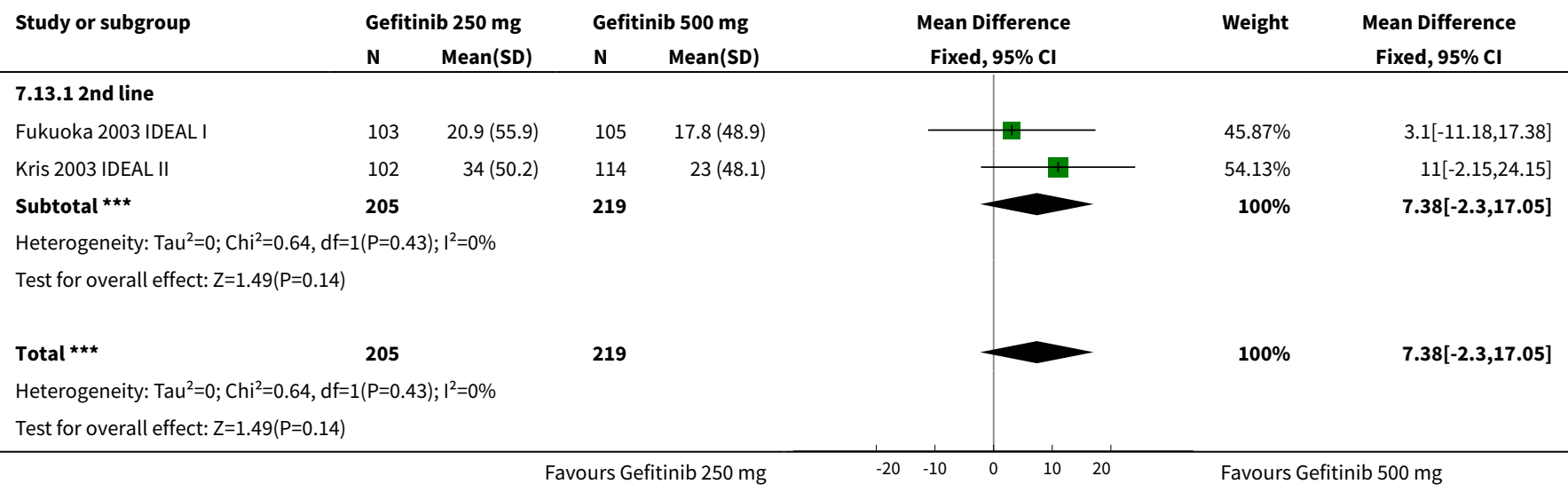

\section{Comparison 8. Gefitinib versus gefitinib + chemotherapy}

\begin{tabular}{|c|c|c|c|c|}
\hline $\begin{array}{l}\text { Outcome or sub- } \\
\text { group title }\end{array}$ & No. of studies & $\begin{array}{l}\text { No. of partici- } \\
\text { pants }\end{array}$ & Statistical method & Effect size \\
\hline $\begin{array}{l}1 \text { HR Progres- } \\
\text { sion-free survival }\end{array}$ & 2 & & Hazard Ratio (Random, 95\% Cl) & Subtotals only \\
\hline 1.1 1st line & 1 & & Hazard Ratio (Random, 95\% Cl) & $0.69[0.49,0.96]$ \\
\hline 1.2 2nd line & 1 & & Hazard Ratio (Random, 95\% Cl) & $0.65[0.43,0.97]$ \\
\hline 21 -year survival rate & 2 & 163 & Risk Ratio (M-H, Fixed, 95\% Cl) & $1.15[0.92,1.43]$ \\
\hline 2.1 2nd line & 2 & 163 & Risk Ratio (M-H, Fixed, 95\% Cl) & $1.15[0.92,1.43]$ \\
\hline $\begin{array}{l}\text { 31-year progres- } \\
\text { sion-free survival }\end{array}$ & 2 & 163 & Risk Ratio (M-H, Fixed, 95\% Cl) & $2.29[1.38,3.80]$ \\
\hline 3.1 2nd line & 2 & 163 & Risk Ratio (M-H, Fixed, 95\% Cl) & $2.29[1.38,3.80]$ \\
\hline 4 Skin rash & 3 & 329 & Risk Ratio (M-H, Fixed, 95\% Cl) & $1.34[0.39,4.57]$ \\
\hline 4.1 1st line & 2 & 281 & Risk Ratio (M-H, Fixed, 95\% Cl) & $1.01[0.23,4.51]$ \\
\hline 4.2 2nd line & 1 & 48 & Risk Ratio (M-H, Fixed, 95\% Cl) & $2.57[0.25,26.47]$ \\
\hline 5 Diarrhoea & 3 & 329 & Risk Ratio (M-H, Fixed, 95\% Cl) & $1.16[0.21,6.34]$ \\
\hline 5.1 1st line & 2 & 281 & Risk Ratio (M-H, Fixed, 95\% Cl) & $1.16[0.21,6.34]$ \\
\hline 5.2 2nd line & 1 & 48 & Risk Ratio (M-H, Fixed, 95\% Cl) & $0.0[0.0,0.0]$ \\
\hline 6 Constipation & 1 & 48 & Risk Ratio (M-H, Fixed, 95\% Cl) & $0.42[0.02,9.92]$ \\
\hline 6.1 2nd line & 1 & 48 & Risk Ratio (M-H, Fixed, 95\% Cl) & $0.42[0.02,9.92]$ \\
\hline 7 Fatigue & 3 & 329 & Risk Ratio (M-H, Fixed, 95\% Cl) & $2.68[0.60,11.90]$ \\
\hline
\end{tabular}




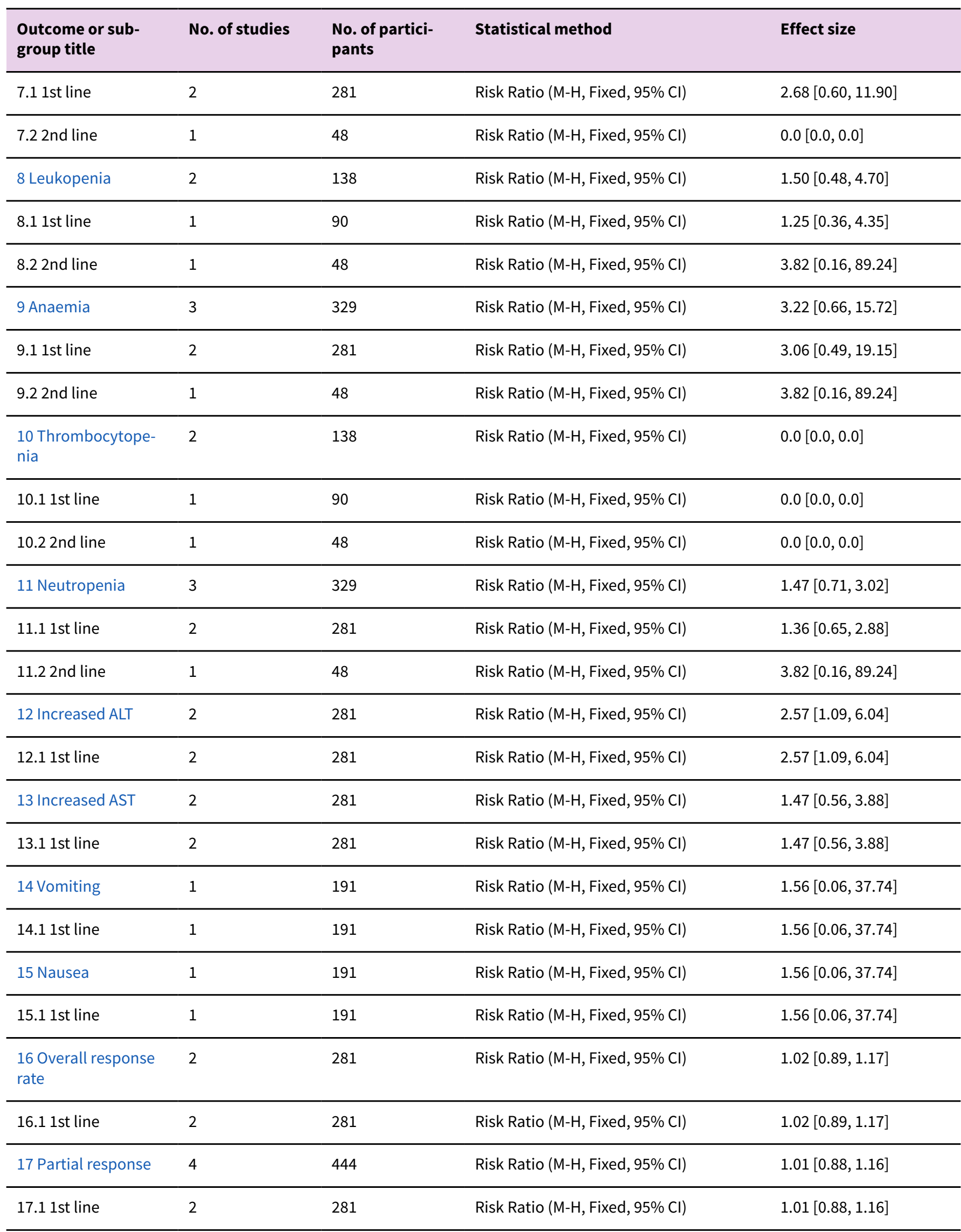




\begin{tabular}{lllll}
\hline $\begin{array}{l}\text { Outcome or sub- } \\
\text { group title }\end{array}$ & No. of studies & $\begin{array}{l}\text { No. of partici- } \\
\text { pants }\end{array}$ & Statistical method & Effect size \\
\hline 17.2 2nd line & 2 & 163 & Risk Ratio (M-H, Fixed, 95\% Cl) & $1.02[0.71,1.47]$ \\
\hline 18 Stable disease & 4 & 444 & Risk Ratio (M-H, Fixed, 95\% Cl) & $0.97[0.69,1.37]$ \\
\hline 18.1 1st line & 2 & 281 & Risk Ratio (M-H, Fixed, 95\% Cl) & $0.67[0.39,1.16]$ \\
\hline 18.2 2nd line & 2 & 163 & Risk Ratio (M-H, Fixed, 95\% Cl) & $1.30[0.84,2.03]$ \\
\hline
\end{tabular}

Analysis 8.1. Comparison 8 Gefitinib versus gefitinib + chemotherapy, Outcome 1 HR Progression-free survival.

\begin{tabular}{|c|c|c|c|c|c|c|}
\hline Study or subgroup & G + Chemo & Gefitinib & $\begin{array}{c}\log [\text { Hazard } \\
\text { Ratio }] \\
\text { (SE) }\end{array}$ & IV, Random, 95\% CI & Weight & $\begin{array}{c}\text { Hazard Ratio } \\
\text { IV, Random, } 95 \% \mathrm{CI}\end{array}$ \\
\hline \multicolumn{7}{|l|}{ 8.1.1 1st line } \\
\hline Cheng 2016 & 0 & 0 & $-0.4(0.17)$ & & $100 \%$ & $0.69[0.49,0.96]$ \\
\hline Subtotal $(95 \% \mathrm{Cl})$ & & & & & $100 \%$ & $0.69[0.49,0.96]$ \\
\hline \multicolumn{7}{|c|}{ Heterogeneity: Not applicable } \\
\hline \multicolumn{7}{|l|}{ 8.1.2 2nd line } \\
\hline Chen 2011 & 0 & 0 & $-0.4(0.205)$ & & $100 \%$ & $0.65[0.43,0.97]$ \\
\hline Subtotal $(95 \% \mathrm{Cl})$ & & & & & $100 \%$ & $0.65[0.43,0.97]$ \\
\hline \multicolumn{7}{|c|}{ Heterogeneity: Not applicable } \\
\hline \multicolumn{7}{|c|}{ Test for overall effect: $Z=2.1(P=0.04)$} \\
\hline
\end{tabular}

\section{Analysis 8.2. Comparison 8 Gefitinib versus gefitinib + chemotherapy, Outcome 2 1-year survival rate.}

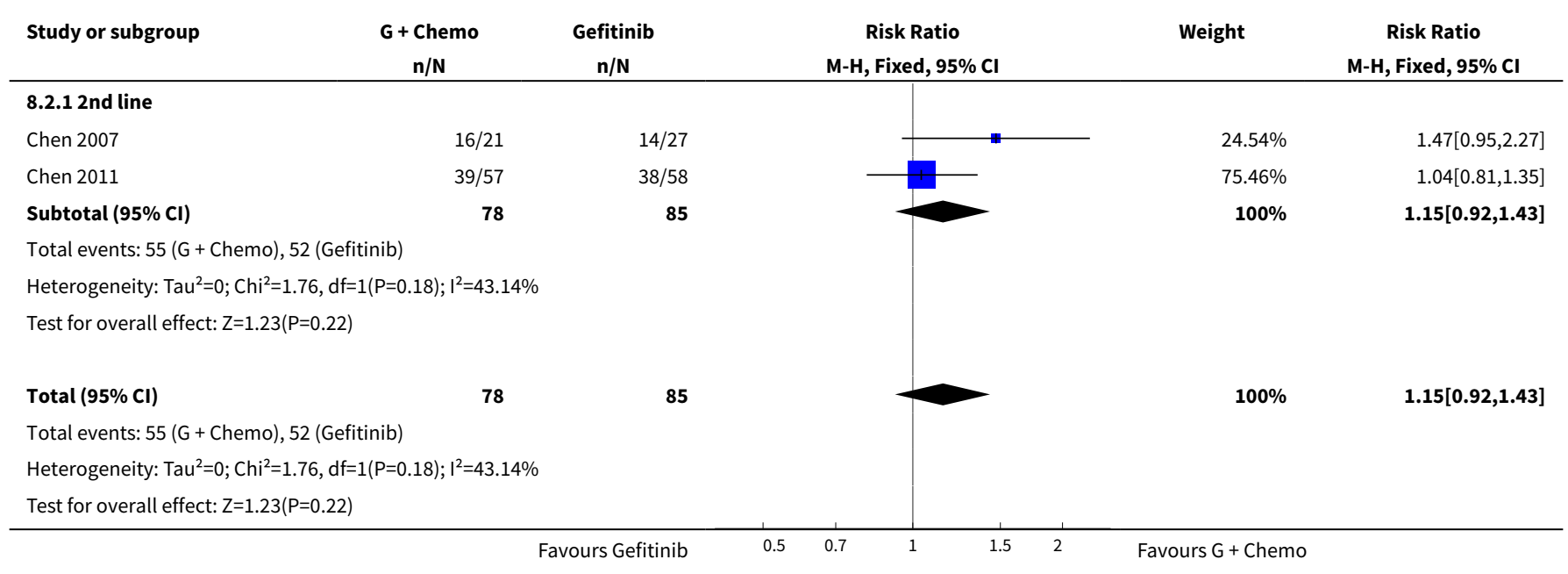


Analysis 8.3. Comparison 8 Gefitinib versus gefitinib + chemotherapy, Outcome 3 1-year progression-free survival.

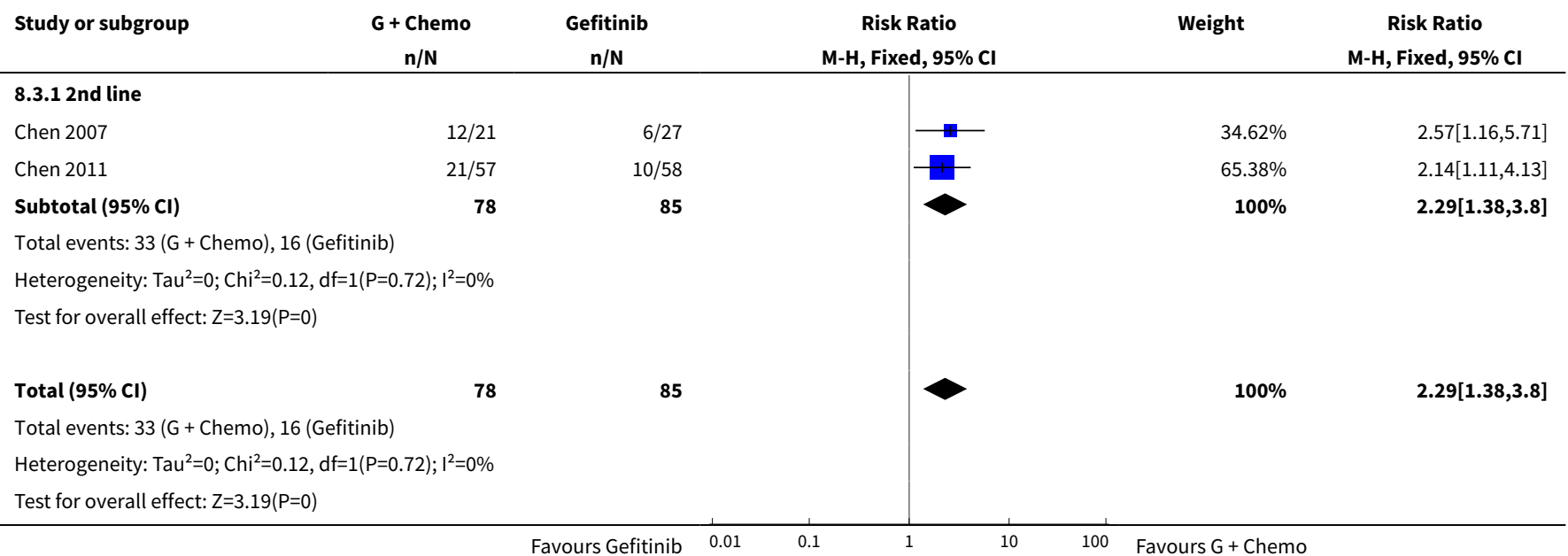

Analysis 8.4. Comparison 8 Gefitinib versus gefitinib + chemotherapy, Outcome 4 Skin rash.

\begin{tabular}{|c|c|c|c|c|c|}
\hline Study or subgroup & $\begin{array}{c}\text { G + Chemo } \\
n / N\end{array}$ & $\begin{array}{c}\text { Gefitinib } \\
n / N\end{array}$ & $\begin{array}{c}\text { Risk Ratio } \\
\text { M-H, Fixed, } 95 \% \mathrm{Cl}\end{array}$ & Weight & $\begin{array}{c}\text { Risk Ratio } \\
\text { M-H, Fixed, } 95 \% \mathrm{Cl}\end{array}$ \\
\hline \multicolumn{6}{|l|}{ 8.4.1 1st line } \\
\hline An 2016 & $2 / 45$ & $2 / 45$ & & $47.68 \%$ & $1[0.15,6.79]$ \\
\hline Cheng 2016 & $2 / 126$ & $1 / 65$ & & $31.46 \%$ & $1.03[0.1,11.17]$ \\
\hline Subtotal $(95 \% \mathrm{Cl})$ & 171 & 110 & & $79.14 \%$ & $1.01[0.23,4.51]$ \\
\hline \multicolumn{6}{|c|}{ Total events: 4 (G + Chemo), 3 (Gefitinib) } \\
\hline \multicolumn{6}{|c|}{ Heterogeneity: $\operatorname{Tau}^{2}=0 ; \mathrm{Chi}^{2}=0, \mathrm{df}=1(\mathrm{P}=0.98) ; \mathrm{I}^{2}=0 \%$} \\
\hline \multicolumn{6}{|c|}{ Test for overall effect: $Z=0.02(P=0.99)$} \\
\hline \multicolumn{6}{|l|}{ 8.4.2 2nd line } \\
\hline Chen 2007 & $2 / 21$ & $1 / 27$ & $\rightarrow$ & $20.86 \%$ & $2.57[0.25,26.47]$ \\
\hline Subtotal $(95 \% \mathrm{Cl})$ & 21 & 27 & & $20.86 \%$ & $2.57[0.25,26.47]$ \\
\hline \multicolumn{6}{|c|}{ Total events: 2 (G + Chemo), 1 (Gefitinib) } \\
\hline \multicolumn{6}{|c|}{ Heterogeneity: Not applicable } \\
\hline \multicolumn{6}{|c|}{ Test for overall effect: $Z=0.79(P=0.43)$} \\
\hline Total $(95 \% \mathrm{Cl})$ & 192 & 137 & & $100 \%$ & $1.34[0.39,4.57]$ \\
\hline \multicolumn{6}{|c|}{ Total events: 6 (G + Chemo), 4 (Gefitinib) } \\
\hline \multicolumn{6}{|c|}{ Heterogeneity: $\operatorname{Tau}^{2}=0 ; \mathrm{Chi}^{2}=0.44, \mathrm{df}=2(\mathrm{P}=0.8) ; \mathrm{I}^{2}=0 \%$} \\
\hline \multicolumn{6}{|c|}{ Test for overall effect: $Z=0.46(P=0.64)$} \\
\hline \multicolumn{6}{|c|}{ Test for subgroup differences: $\mathrm{Chi}^{2}=0.44, \mathrm{df}=1(\mathrm{P}=0.51), \mathrm{I}^{2}=0 \%$} \\
\hline
\end{tabular}

Analysis 8.5. Comparison 8 Gefitinib versus gefitinib + chemotherapy, Outcome 5 Diarrhoea.

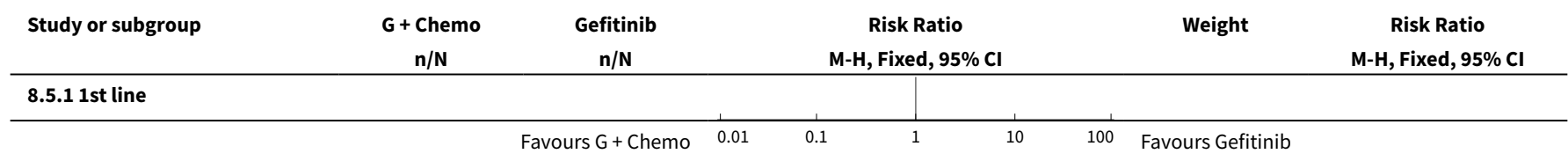




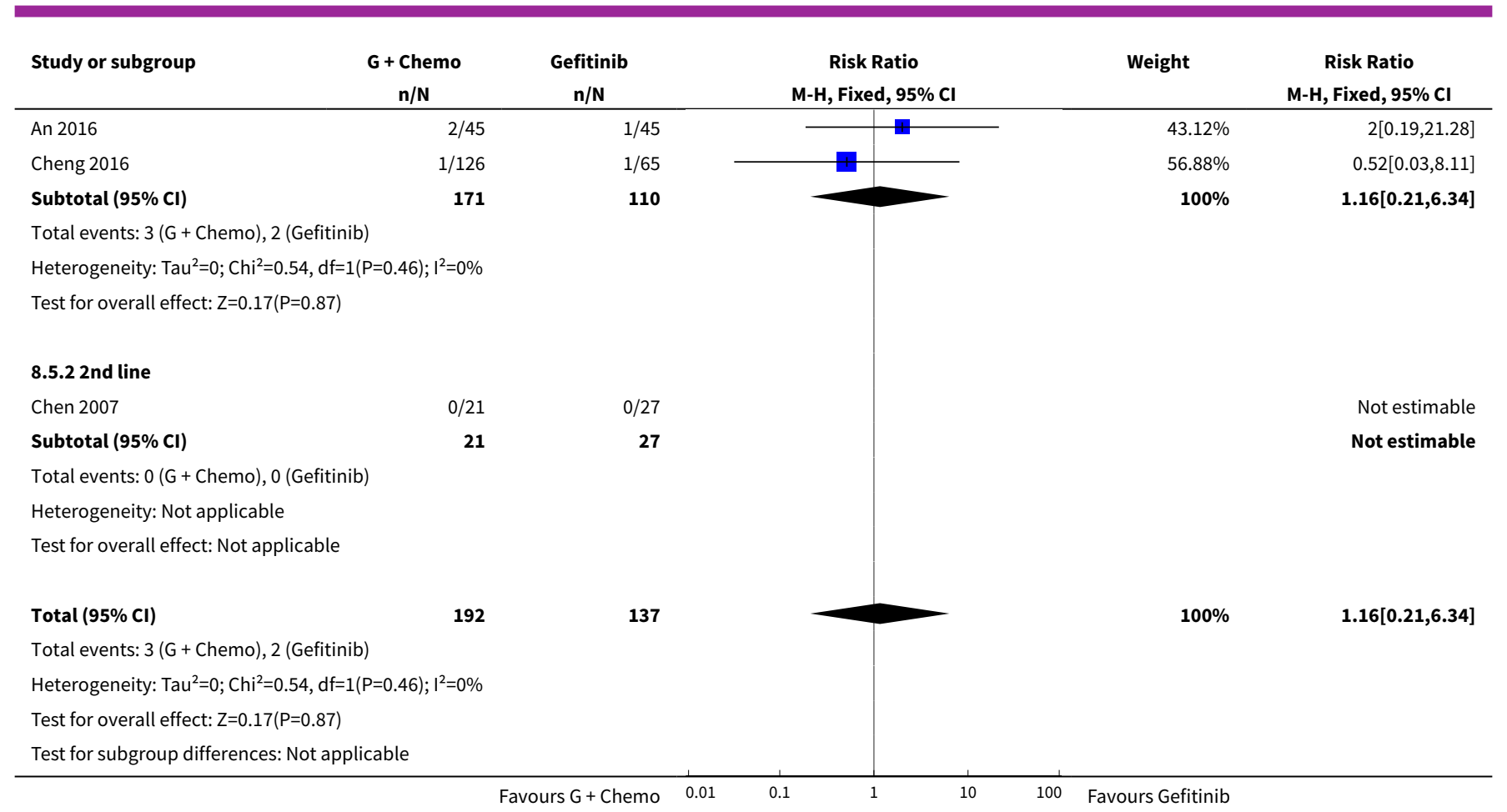

Analysis 8.6. Comparison 8 Gefitinib versus gefitinib + chemotherapy, Outcome 6 Constipation.

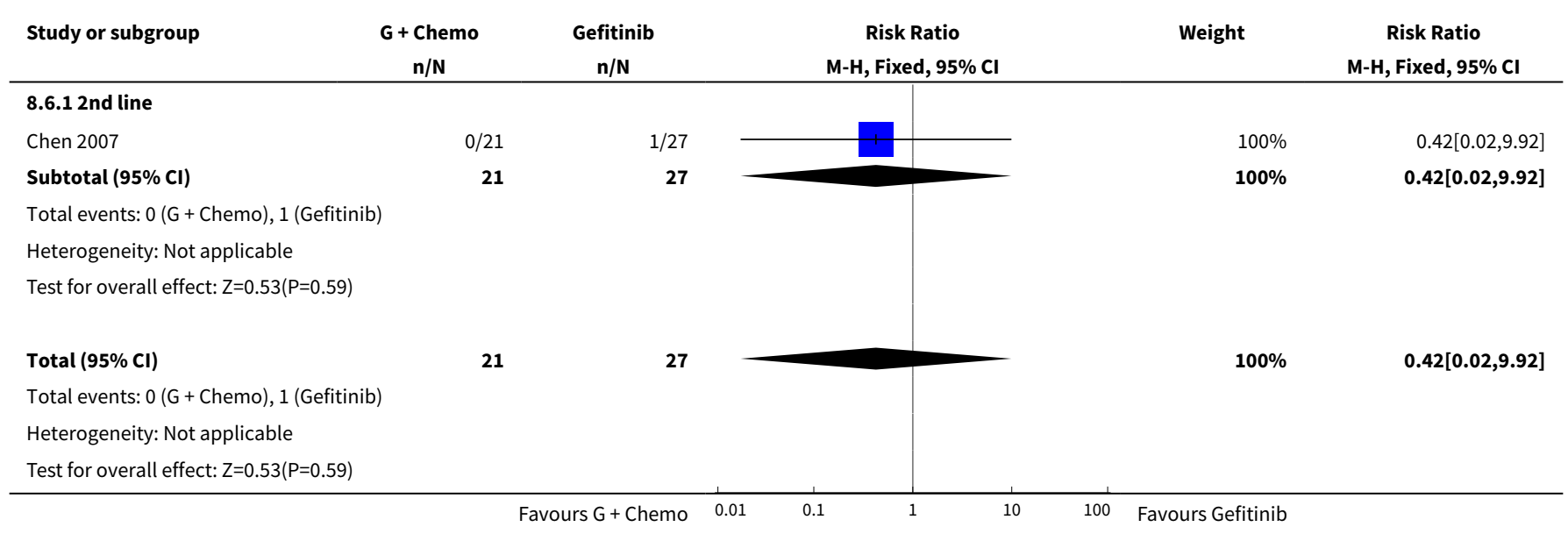

Analysis 8.7. Comparison 8 Gefitinib versus gefitinib + chemotherapy, Outcome 7 Fatigue.

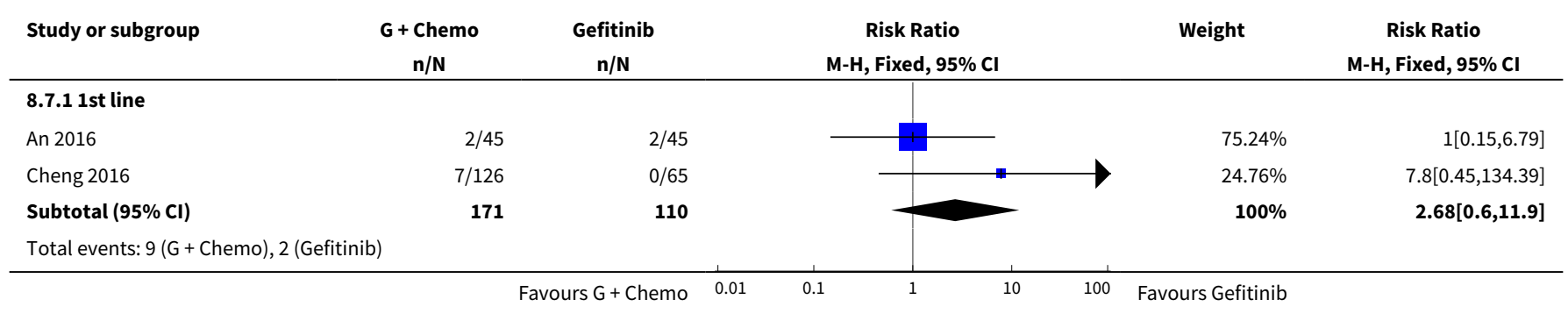




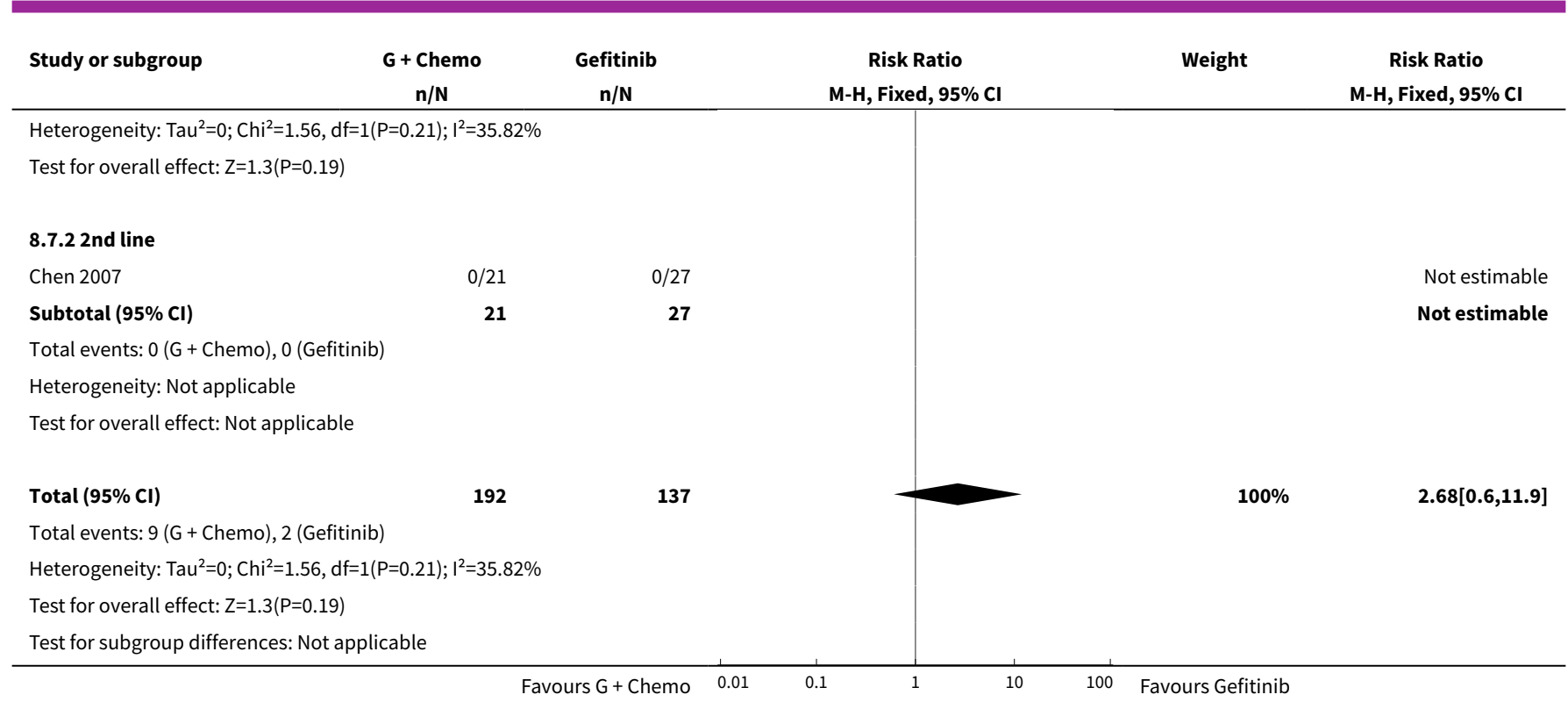

Analysis 8.8. Comparison 8 Gefitinib versus gefitinib + chemotherapy, Outcome 8 Leukopenia.

\begin{tabular}{|c|c|c|c|c|c|}
\hline Study or subgroup & $\begin{array}{c}\text { G + Chemo } \\
n / N \\
\end{array}$ & $\begin{array}{c}\text { Gefitinib } \\
n / N\end{array}$ & $\begin{array}{c}\text { Risk Ratio } \\
\text { M-H, Fixed, 95\% Cl }\end{array}$ & Weight & $\begin{array}{c}\text { Risk Ratio } \\
\text { M-H, Fixed, 95\% Cl }\end{array}$ \\
\hline \multicolumn{6}{|l|}{ 8.8.1 1st line } \\
\hline An 2016 & $5 / 45$ & $4 / 45$ & & $90.09 \%$ & $1.25[0.36,4.35]$ \\
\hline Subtotal $(95 \% \mathrm{CI})$ & 45 & 45 & & $90.09 \%$ & $1.25[0.36,4.35]$ \\
\hline \multicolumn{6}{|c|}{ Total events: 5 (G + Chemo), 4 (Gefitinib) } \\
\hline \multicolumn{6}{|c|}{ Heterogeneity: Not applicable } \\
\hline \multicolumn{6}{|c|}{ Test for overall effect: $\mathrm{Z}=0.35(\mathrm{P}=0.73)$} \\
\hline \multicolumn{6}{|l|}{ 8.8.2 2nd line } \\
\hline Chen 2007 & $1 / 21$ & $0 / 27$ & $\rightarrow$ & $9.91 \%$ & $3.82[0.16,89.24]$ \\
\hline Subtotal $(95 \% \mathrm{Cl})$ & 21 & 27 & & $9.91 \%$ & $3.82[0.16,89.24]$ \\
\hline \multicolumn{6}{|c|}{ Total events: 1 (G + Chemo), 0 (Gefitinib) } \\
\hline \multicolumn{6}{|c|}{ Heterogeneity: Not applicable } \\
\hline \multicolumn{6}{|c|}{ Test for overall effect: $Z=0.83(P=0.4)$} \\
\hline Total $(95 \% \mathrm{Cl})$ & 66 & 72 & & $100 \%$ & $1.5[0.48,4.7]$ \\
\hline \multicolumn{6}{|c|}{ Total events: 6 (G + Chemo), 4 (Gefitinib) } \\
\hline \multicolumn{6}{|c|}{ Heterogeneity: $\operatorname{Tau}^{2}=0 ; \mathrm{Chi}^{2}=0.42, \mathrm{df}=1(\mathrm{P}=0.52) ; \mathrm{I}^{2}=0 \%$} \\
\hline \multicolumn{6}{|c|}{ Test for overall effect: $Z=0.7(P=0.48)$} \\
\hline Test for subgroup dif & $2, \mathrm{df}=1(P=0.52)$ & & & & \\
\hline
\end{tabular}

Analysis 8.9. Comparison 8 Gefitinib versus gefitinib + chemotherapy, Outcome 9 Anaemia.

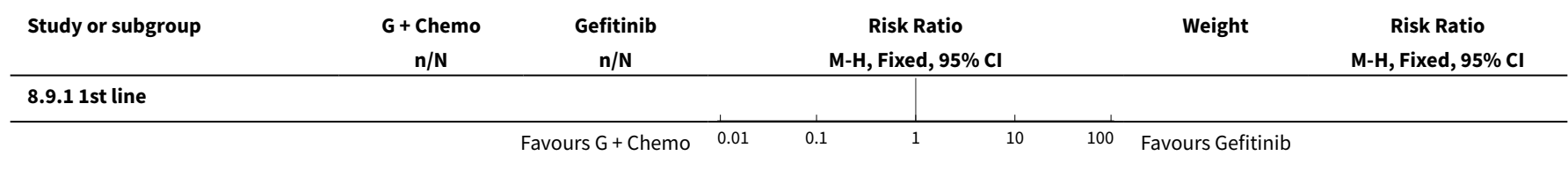




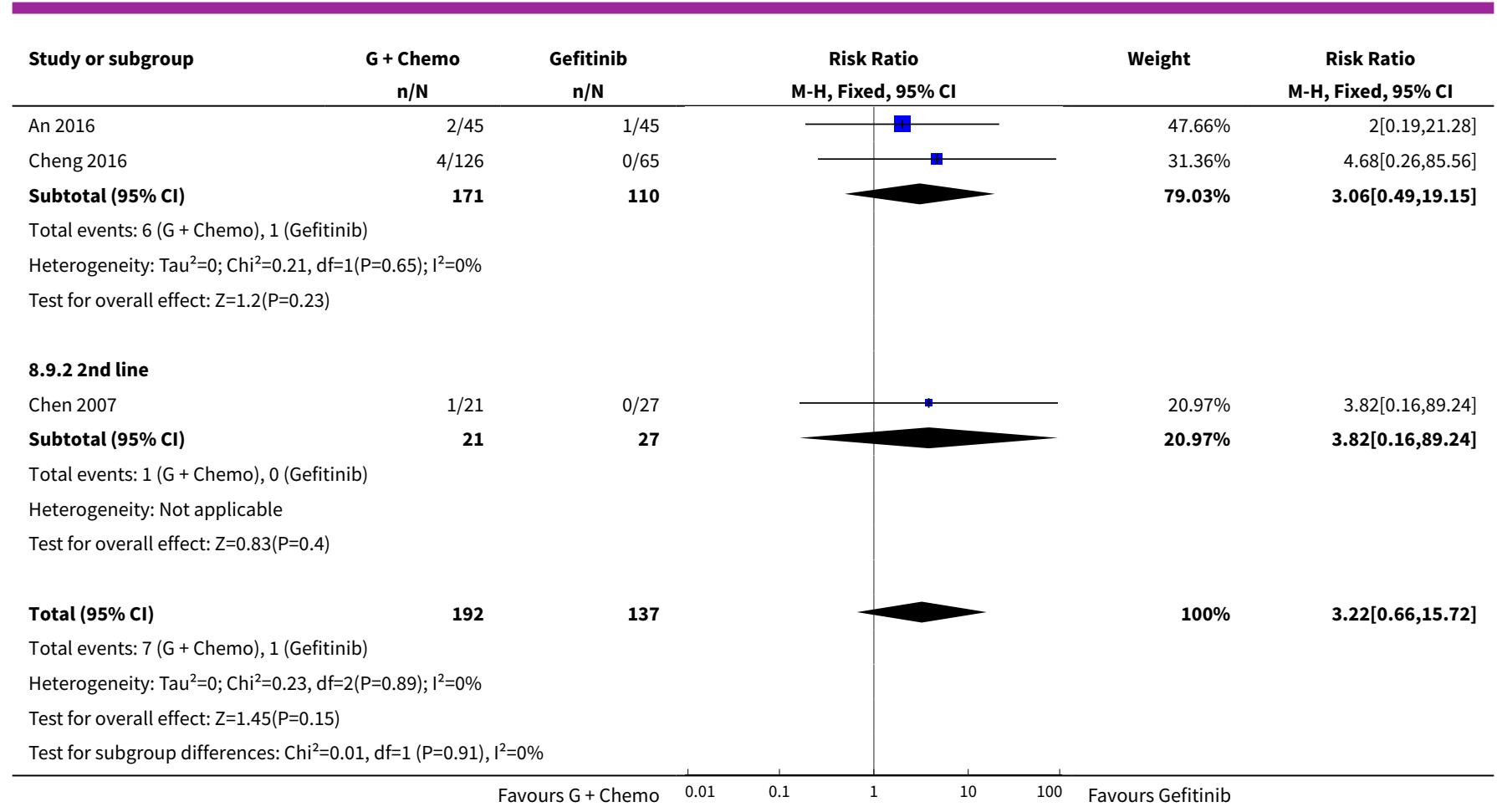

Analysis 8.10. Comparison 8 Gefitinib versus gefitinib + chemotherapy, Outcome 10 Thrombocytopenia.

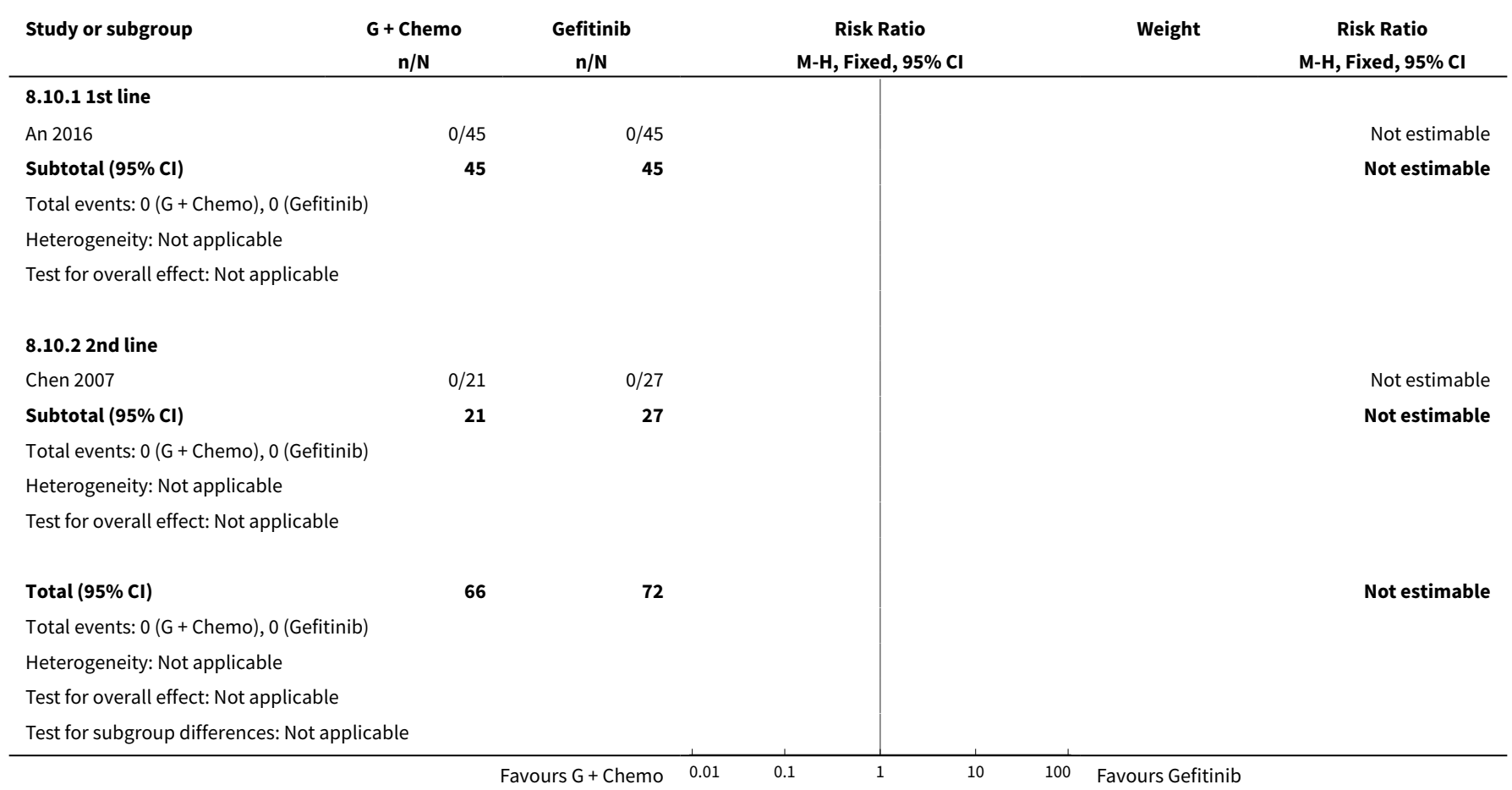


Analysis 8.11. Comparison 8 Gefitinib versus gefitinib + chemotherapy, Outcome 11 Neutropenia.

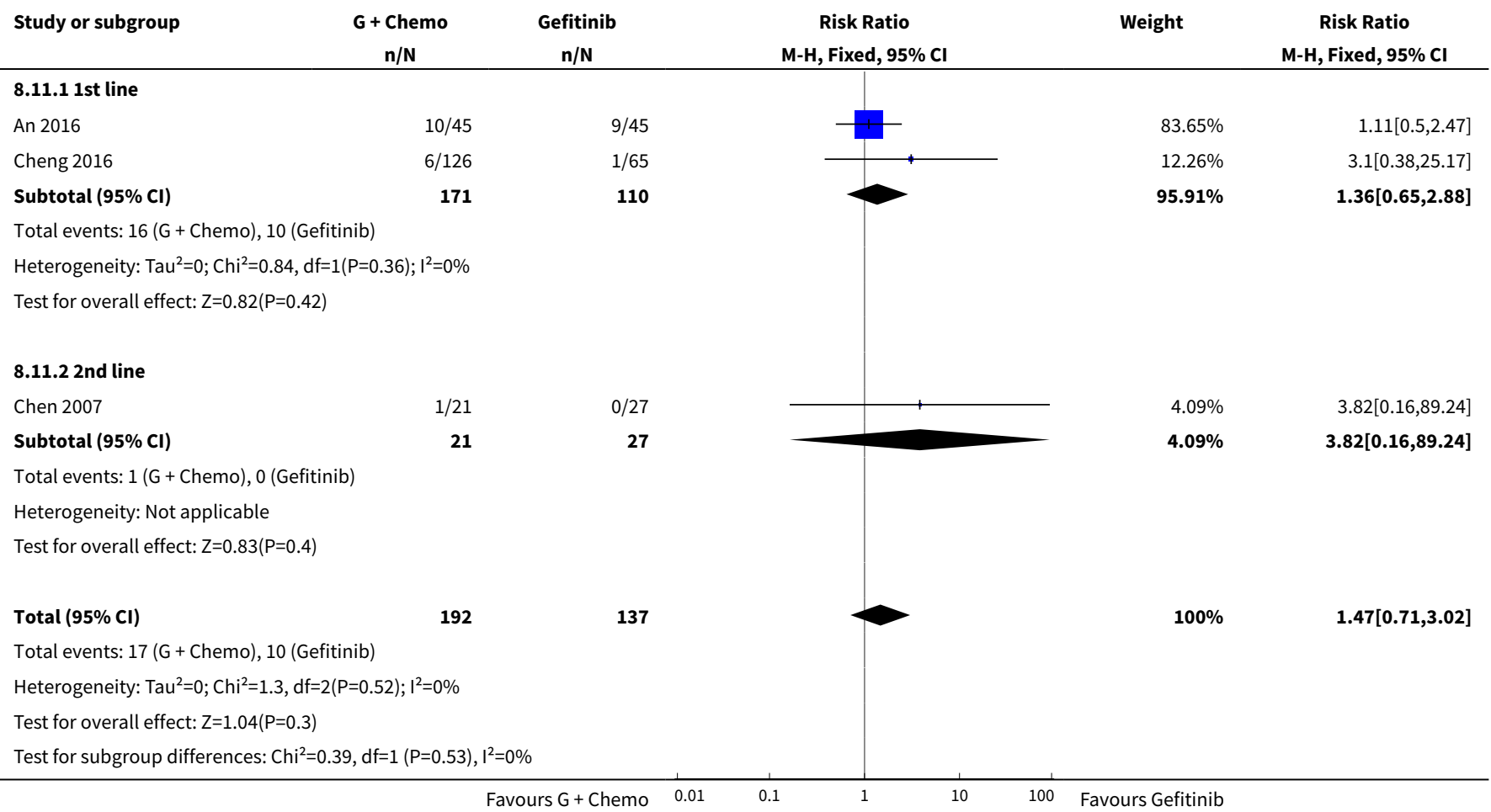

Analysis 8.12. Comparison 8 Gefitinib versus gefitinib + chemotherapy, Outcome 12 Increased ALT.

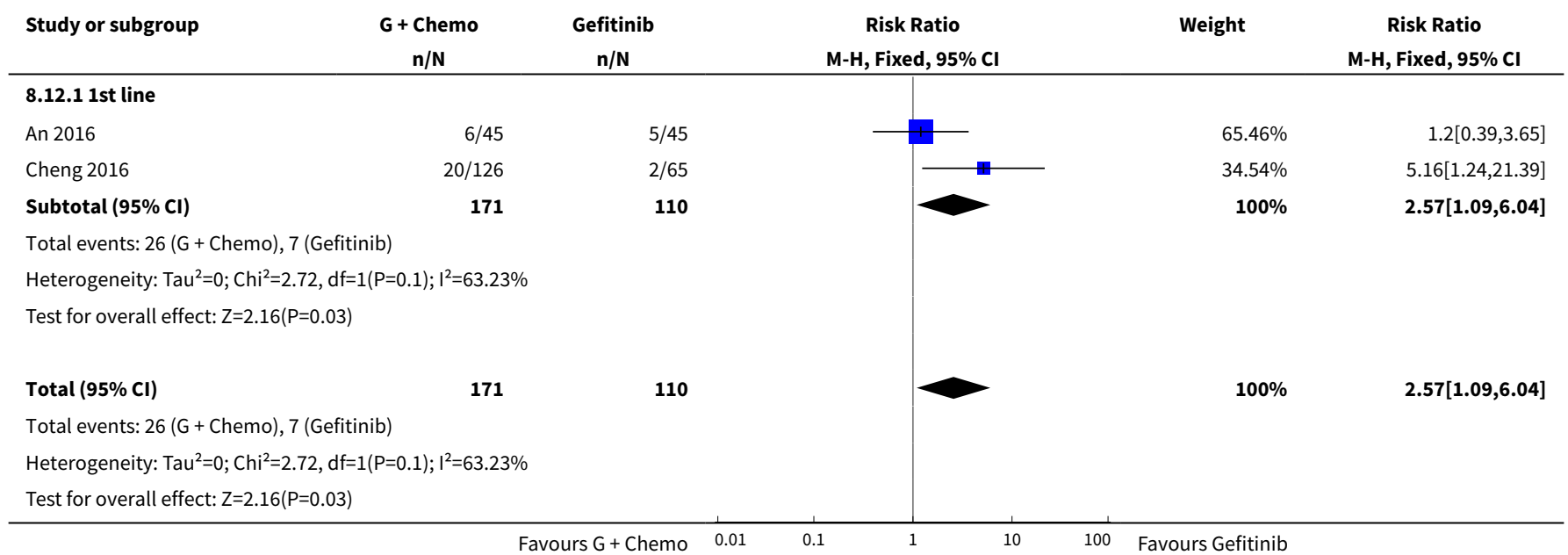

Analysis 8.13. Comparison 8 Gefitinib versus gefitinib + chemotherapy, Outcome 13 Increased AST.

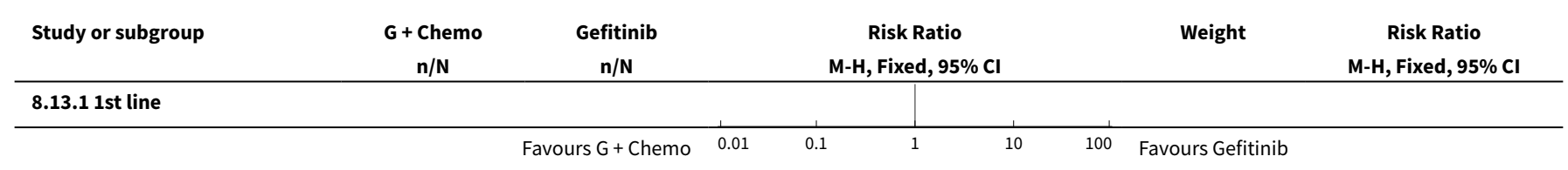




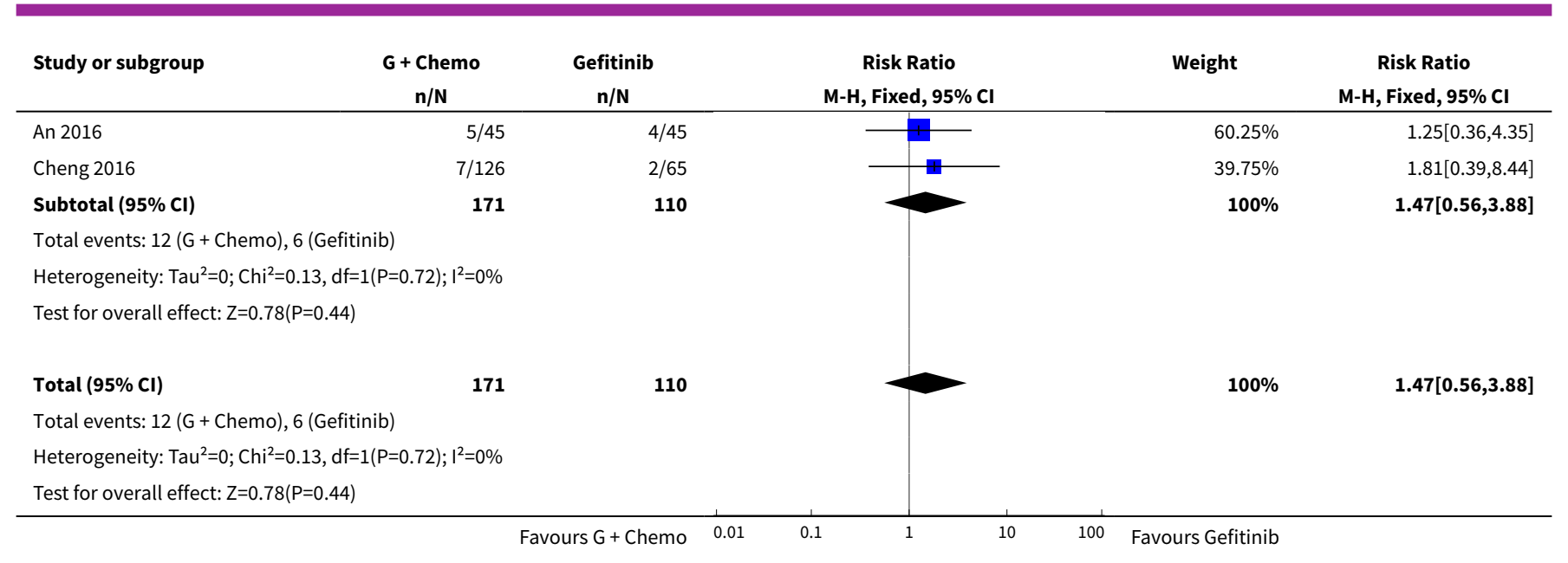

Analysis 8.14. Comparison 8 Gefitinib versus gefitinib + chemotherapy, Outcome 14 Vomiting.

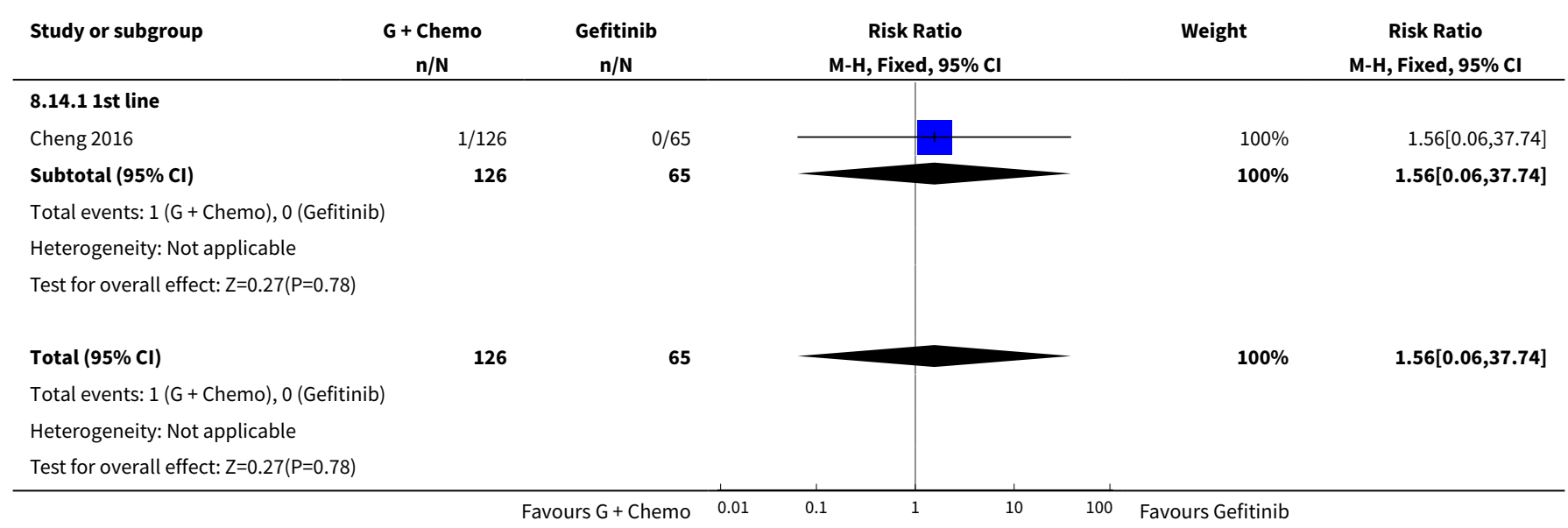

Analysis 8.15. Comparison 8 Gefitinib versus gefitinib + chemotherapy, Outcome 15 Nausea.

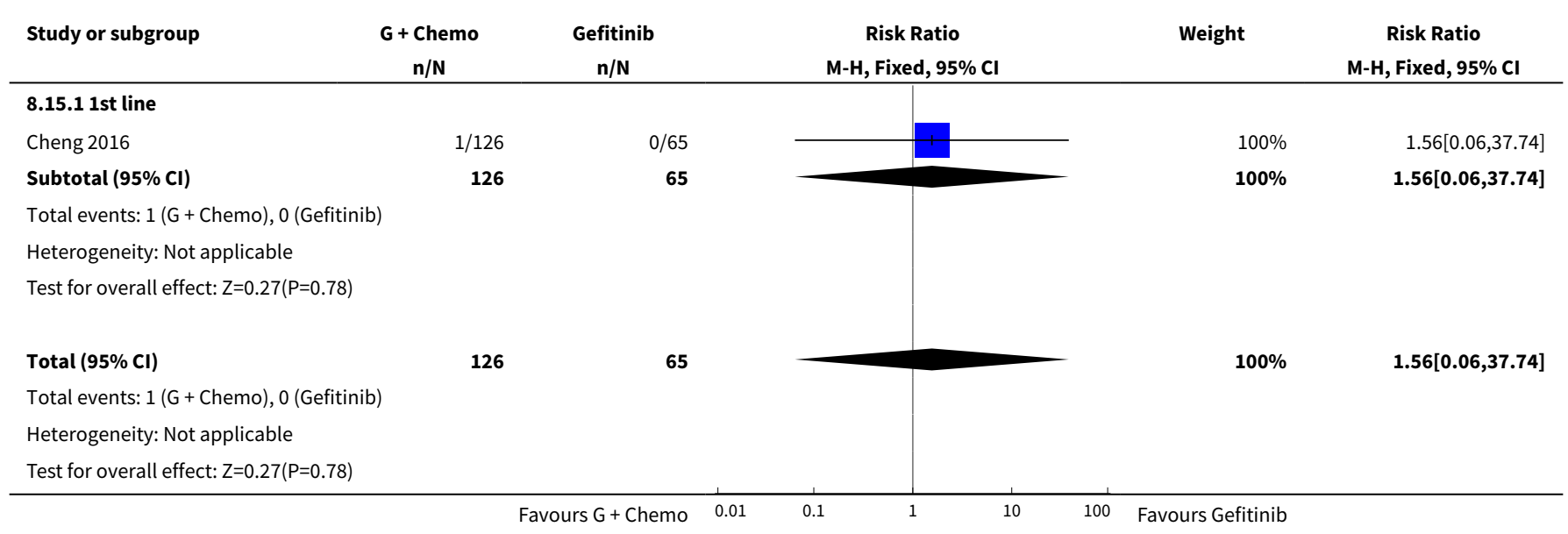


Analysis 8.16. Comparison 8 Gefitinib versus gefitinib + chemotherapy, Outcome 16 Overall response rate.

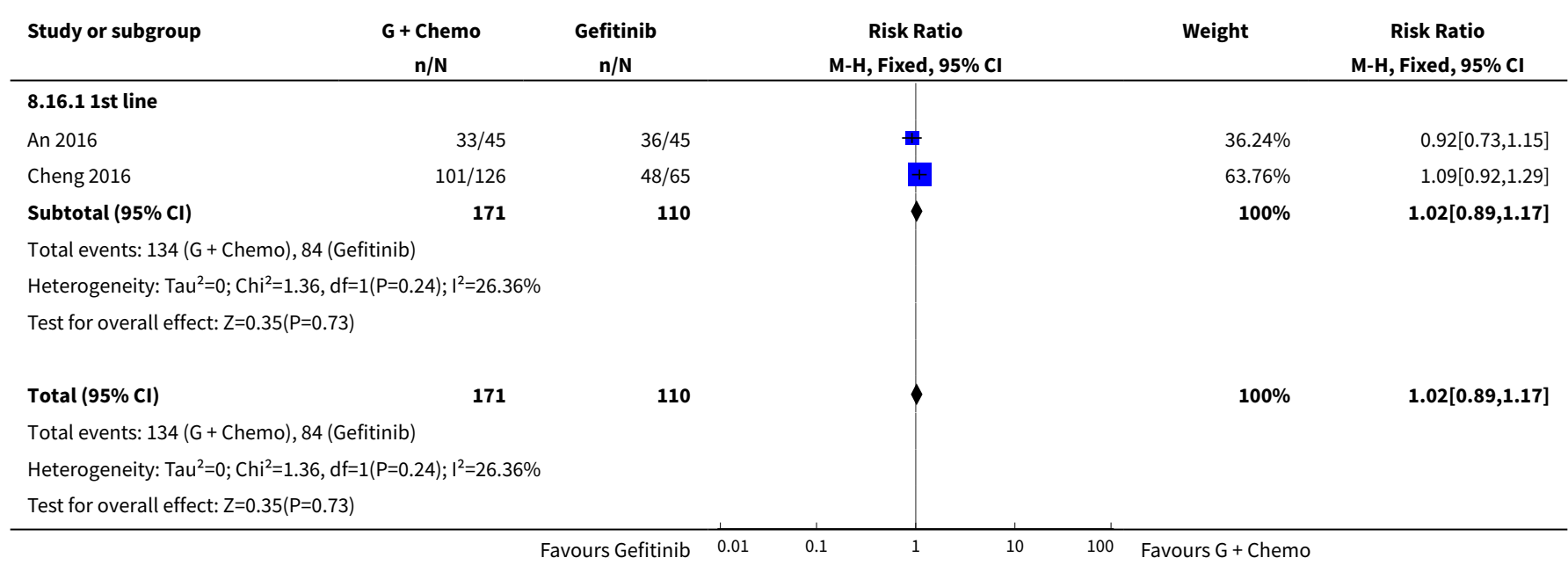

Analysis 8.17. Comparison 8 Gefitinib versus gefitinib + chemotherapy, Outcome 17 Partial response.

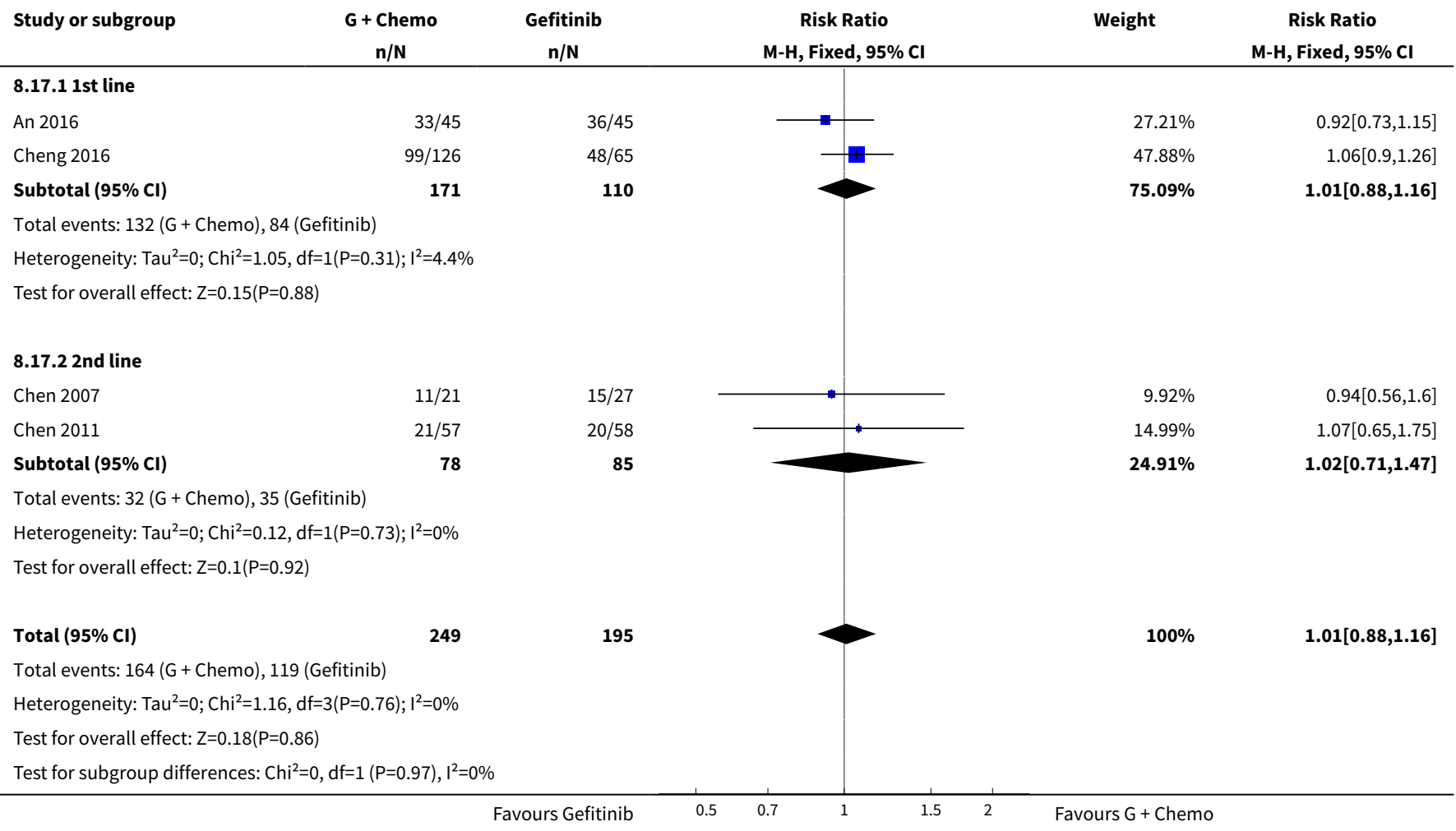


Analysis 8.18. Comparison 8 Gefitinib versus gefitinib + chemotherapy, Outcome 18 Stable disease.

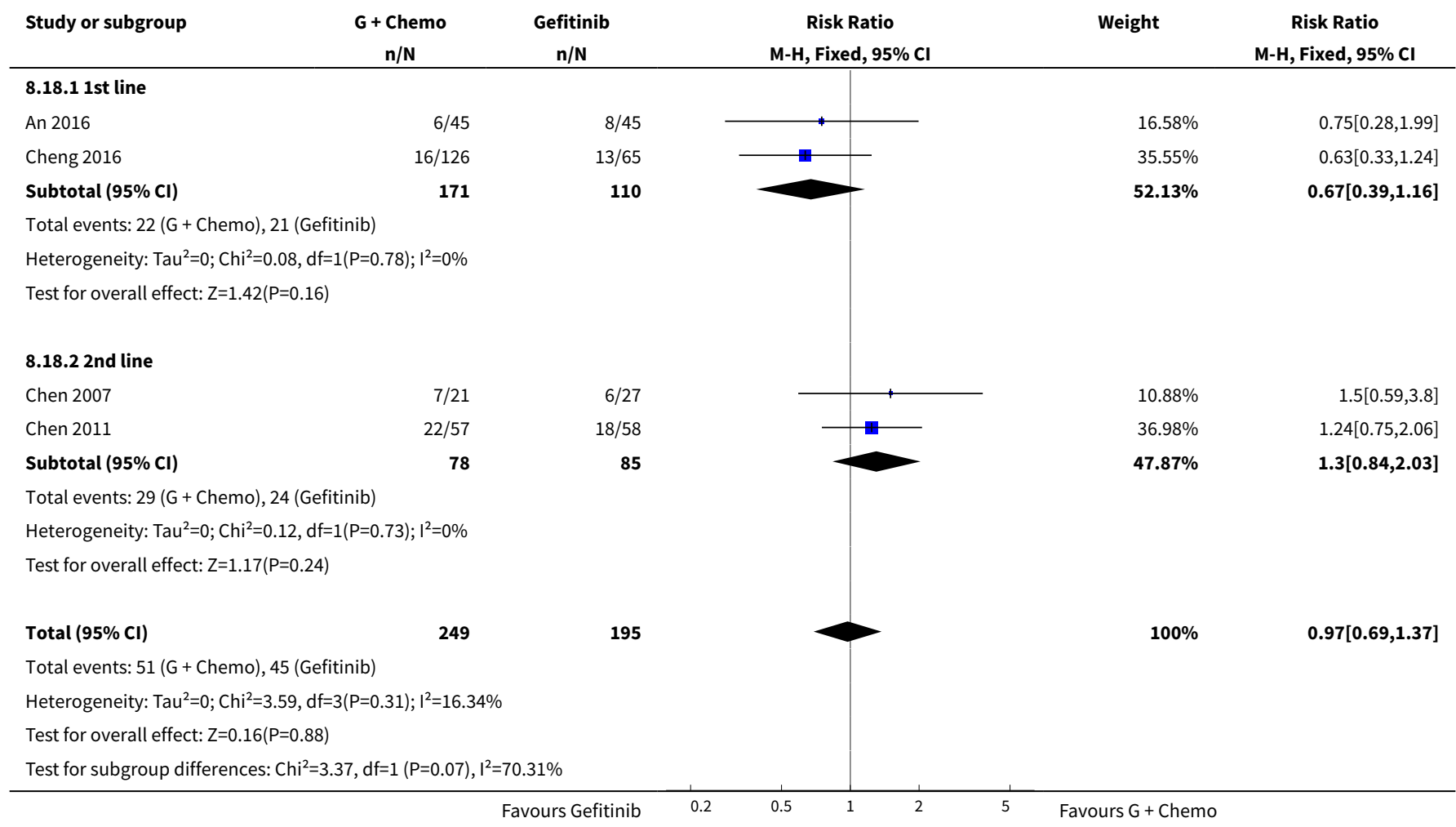

\section{Comparison 9. Gefitinib + chemotherapy versus chemotherapy}

\begin{tabular}{|c|c|c|c|c|}
\hline $\begin{array}{l}\text { Outcome or sub- } \\
\text { group title }\end{array}$ & No. of studies & $\begin{array}{l}\text { No. of partici- } \\
\text { pants }\end{array}$ & Statistical method & Effect size \\
\hline 1 HR Overall survival & 3 & & Hazard Ratio (Fixed, 95\% Cl) & Subtotals only \\
\hline 1.1 1st line [Asian] & 2 & & Hazard Ratio (Fixed, 95\% Cl) & $0.86[0.72,1.02]$ \\
\hline 1.2 2nd line [EGFRm] & 1 & & Hazard Ratio (Fixed, 95\% Cl) & $1.62[1.05,2.50]$ \\
\hline $\begin{array}{l}2 \text { HR Progression-free } \\
\text { survival }\end{array}$ & 3 & & Hazard Ratio (Fixed, 95\% Cl) & Subtotals only \\
\hline 2.1 1st line [Asian] & 2 & & Hazard Ratio (Fixed, 95\% Cl) & $0.69[0.62,0.77]$ \\
\hline 2.2 2nd line [EGFRm] & 1 & & Hazard Ratio (Fixed, 95\% Cl) & $0.86[0.65,1.13]$ \\
\hline 3 1-year survival rate & 2 & 1411 & Risk Ratio (M-H, Fixed, 95\% Cl) & $0.95[0.84,1.08]$ \\
\hline 3.1 1st line & 2 & 1411 & Risk Ratio (M-H, Fixed, 95\% Cl) & $0.95[0.84,1.08]$ \\
\hline 4 Skin rash & 5 & 2379 & Risk Ratio (M-H, Fixed, 95\% Cl) & $2.98[1.54,5.77]$ \\
\hline 4.1 1st line & 2 & 1400 & Risk Ratio (M-H, Fixed, 95\% Cl) & $2.64[1.23,5.63]$ \\
\hline 4.2 1st line [Asian] & 2 & 715 & Risk Ratio (M-H, Fixed, 95\% Cl) & $4.23[1.08,16.54]$ \\
\hline
\end{tabular}




\begin{tabular}{|c|c|c|c|c|}
\hline $\begin{array}{l}\text { Outcome or sub- } \\
\text { group title }\end{array}$ & No. of studies & $\begin{array}{l}\text { No. of partici- } \\
\text { pants }\end{array}$ & Statistical method & Effect size \\
\hline 4.3 2nd line [EGFRm] & 1 & 264 & Risk Ratio (M-H, Fixed, 95\% Cl) & $0.0[0.0,0.0]$ \\
\hline 5 Acne & 3 & 1664 & Risk Ratio (M-H, Fixed, 95\% Cl) & $4.95[1.09,22.51]$ \\
\hline 5.1 1st line & 2 & 1400 & Risk Ratio (M-H, Fixed, 95\% Cl) & $5.59[0.99,31.60]$ \\
\hline 5.2 2nd line [EGFRm] & 1 & 264 & Risk Ratio (M-H, Fixed, 95\% Cl) & $3.0[0.12,72.98]$ \\
\hline 6 Diarrhoea & 5 & 2379 & Risk Ratio (M-H, Random, 95\% Cl) & $2.04[1.17,3.58]$ \\
\hline 6.1 1st line & 2 & 1400 & Risk Ratio (M-H, Random, 95\% Cl) & $2.44[1.17,5.09]$ \\
\hline 6.2 1st line [Asian] & 2 & 715 & Risk Ratio (M-H, Random, 95\% Cl) & $0.97[0.32,2.92]$ \\
\hline 6.3 2nd line [EGFRm] & 1 & 264 & Risk Ratio (M-H, Random, 95\% Cl) & $3.0[0.32,28.47]$ \\
\hline 7 Pruritus & 2 & 1400 & Risk Ratio (M-H, Fixed, 95\% Cl) & $1.99[0.18,21.89]$ \\
\hline 7.1 1st line & 2 & 1400 & Risk Ratio (M-H, Fixed, 95\% Cl) & $1.99[0.18,21.89]$ \\
\hline 8 Vomiting & 5 & 2379 & Risk Ratio (M-H, Fixed, 95\% Cl) & $1.24[0.81,1.89]$ \\
\hline 8.1 1st line & 2 & 1400 & Risk Ratio (M-H, Fixed, 95\% Cl) & $1.05[0.53,2.06]$ \\
\hline 8.2 1st line [Asian] & 2 & 715 & Risk Ratio (M-H, Fixed, 95\% Cl) & $1.28[0.70,2.32]$ \\
\hline 8.3 2nd line [EGFRm] & 1 & 264 & Risk Ratio (M-H, Fixed, 95\% Cl) & $2.0[0.51,7.83]$ \\
\hline 9 Nausea & 5 & 2379 & Risk Ratio (M-H, Fixed, 95\% Cl) & $0.82[0.58,1.17]$ \\
\hline 9.1 1st line & 2 & 1400 & Risk Ratio (M-H, Fixed, 95\% Cl) & $1.06[0.51,2.18]$ \\
\hline 9.2 1st line [Asian] & 2 & 715 & Risk Ratio (M-H, Fixed, 95\% Cl) & $0.74[0.48,1.14]$ \\
\hline 9.3 2nd line [EGFRm] & 1 & 264 & Risk Ratio (M-H, Fixed, 95\% Cl) & $0.83[0.26,2.66]$ \\
\hline 10 Anorexia & 5 & 2379 & Risk Ratio (M-H, Fixed, 95\% Cl) & $0.82[0.55,1.20]$ \\
\hline 10.1 1st line & 2 & 1400 & Risk Ratio (M-H, Fixed, 95\% Cl) & $1.98[0.36,10.76]$ \\
\hline 10.2 1st line [Asian] & 2 & 715 & Risk Ratio (M-H, Fixed, 95\% Cl) & $0.80[0.53,1.20]$ \\
\hline 10.3 2nd line [EGFRm] & 1 & 264 & Risk Ratio (M-H, Fixed, 95\% Cl) & $0.33[0.04,3.16]$ \\
\hline 11 Asthenia & 3 & 1664 & Risk Ratio (M-H, Random, 95\% Cl) & $0.80[0.21,2.99]$ \\
\hline 11.1 st line & 2 & 1400 & Risk Ratio (M-H, Random, 95\% Cl) & $0.90[0.10,7.76]$ \\
\hline 11.2 2nd line [EGFRm] & 1 & 264 & Risk Ratio (M-H, Random, 95\% Cl) & $0.5[0.09,2.68]$ \\
\hline 12 Dyspnoea & 2 & 947 & Risk Ratio (M-H, Fixed, 95\% Cl) & $1.00[0.25,3.96]$ \\
\hline 12.1 1st line & 1 & 683 & Risk Ratio (M-H, Fixed, 95\% Cl) & $1.99[0.18,21.89]$ \\
\hline
\end{tabular}




\begin{tabular}{|c|c|c|c|c|}
\hline $\begin{array}{l}\text { Outcome or sub- } \\
\text { group title }\end{array}$ & No. of studies & $\begin{array}{l}\text { No. of partici- } \\
\text { pants }\end{array}$ & Statistical method & Effect size \\
\hline 12.2 2nd line [EGFRm] & 1 & 264 & Risk Ratio (M-H, Fixed, 95\% Cl) & $0.67[0.11,3.93]$ \\
\hline 13 Anaemia & 3 & 979 & Risk Ratio (M-H, Fixed, 95\% CI) & $0.74[0.53,1.03]$ \\
\hline 13.1 1st line [Asian] & 2 & 715 & Risk Ratio (M-H, Fixed, 95\% Cl) & $0.63[0.44,0.90]$ \\
\hline 13.2 2nd line [EGFRm] & 1 & 264 & Risk Ratio (M-H, Fixed, 95\% Cl) & $2.2[0.79,6.16]$ \\
\hline 14 Neutropenia & 5 & 2379 & Risk Ratio (M-H, Fixed, 95\% Cl) & $0.97[0.87,1.08]$ \\
\hline 14.1 1st line & 2 & 1400 & Risk Ratio (M-H, Fixed, 95\% CI) & $1.18[0.77,1.80]$ \\
\hline 14.2 1st line [Asian] & 2 & 715 & Risk Ratio (M-H, Fixed, 95\% Cl) & $0.93[0.84,1.03]$ \\
\hline 14.3 2nd line [EGFRm] & 1 & 264 & Risk Ratio (M-H, Fixed, 95\% Cl) & $1.29[0.49,3.35]$ \\
\hline 15 Leukopenia & 4 & 2262 & Risk Ratio (M-H, Fixed, 95\% Cl) & $1.08[0.89,1.31]$ \\
\hline 15.1 1st line & 2 & 1400 & Risk Ratio (M-H, Fixed, 95\% Cl) & $1.17[0.61,2.26]$ \\
\hline 15.21 st line [Asian] & 1 & 598 & Risk Ratio (M-H, Fixed, 95\% Cl) & $1.06[0.87,1.30]$ \\
\hline 15.3 2nd line [EGFRm] & 1 & 264 & Risk Ratio (M-H, Fixed, 95\% Cl) & $1.0[0.21,4.86]$ \\
\hline $\begin{array}{l}16 \text { Overall response } \\
\text { rate }\end{array}$ & 5 & 2314 & Risk Ratio (M-H, Fixed, 95\% Cl) & $1.08[0.97,1.20]$ \\
\hline 16.1 1st line & 2 & 1343 & Risk Ratio (M-H, Fixed, 95\% Cl) & $1.07[0.94,1.22]$ \\
\hline 16.2 1st line [Asian] & 2 & 706 & Risk Ratio (M-H, Fixed, 95\% Cl) & $1.14[0.93,1.40]$ \\
\hline 16.3 2nd line [EGFRm] & 1 & 265 & Risk Ratio (M-H, Fixed, 95\% Cl) & $0.93[0.66,1.31]$ \\
\hline
\end{tabular}

Analysis 9.1. Comparison 9 Gefitinib + chemotherapy versus chemotherapy, Outcome 1 HR Overall survival.

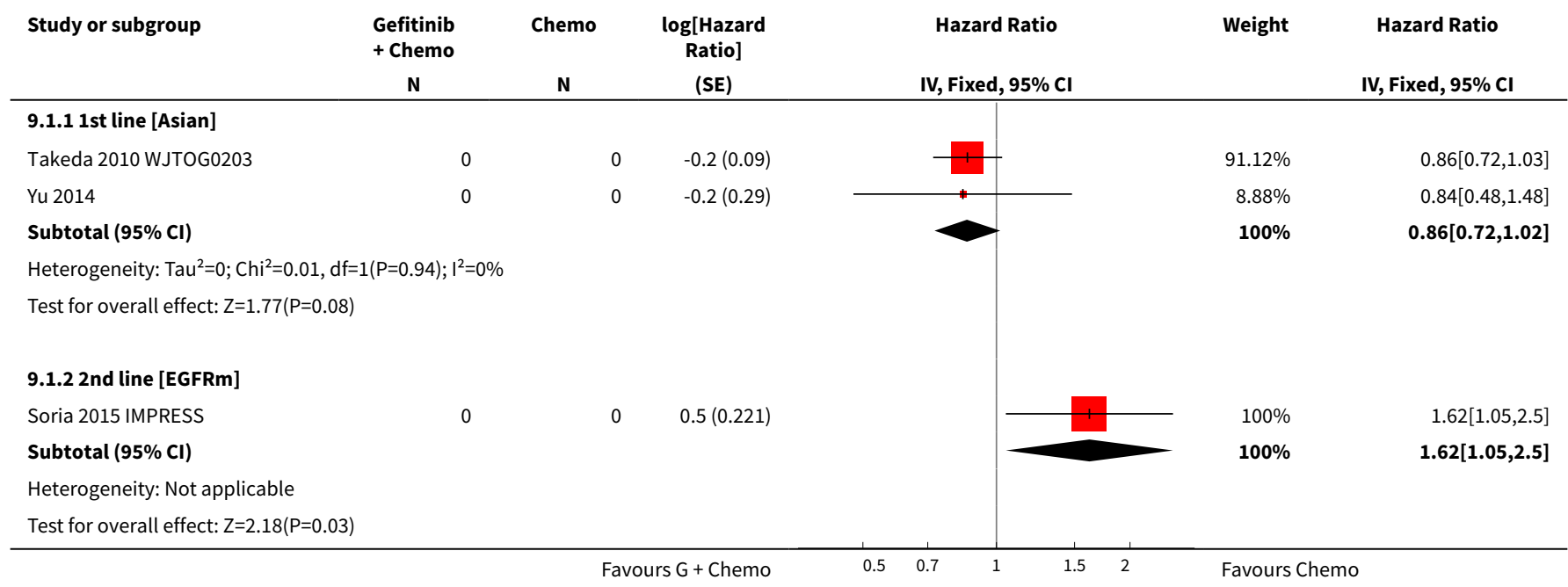




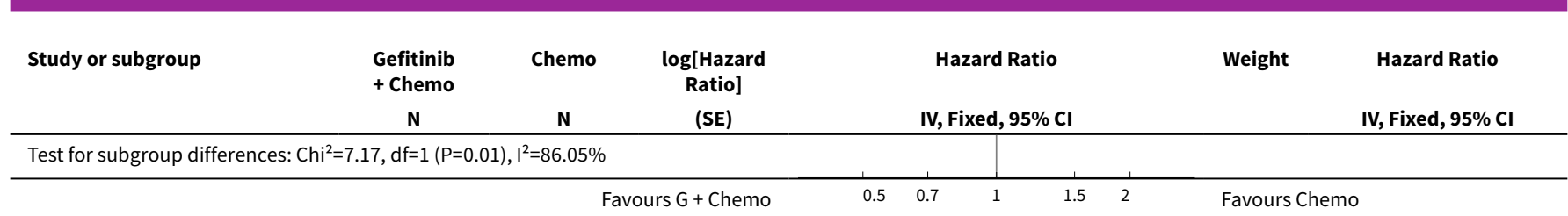

\section{Analysis 9.2. Comparison 9 Gefitinib + chemotherapy versus chemotherapy, Outcome 2 HR Progression-free survival.}

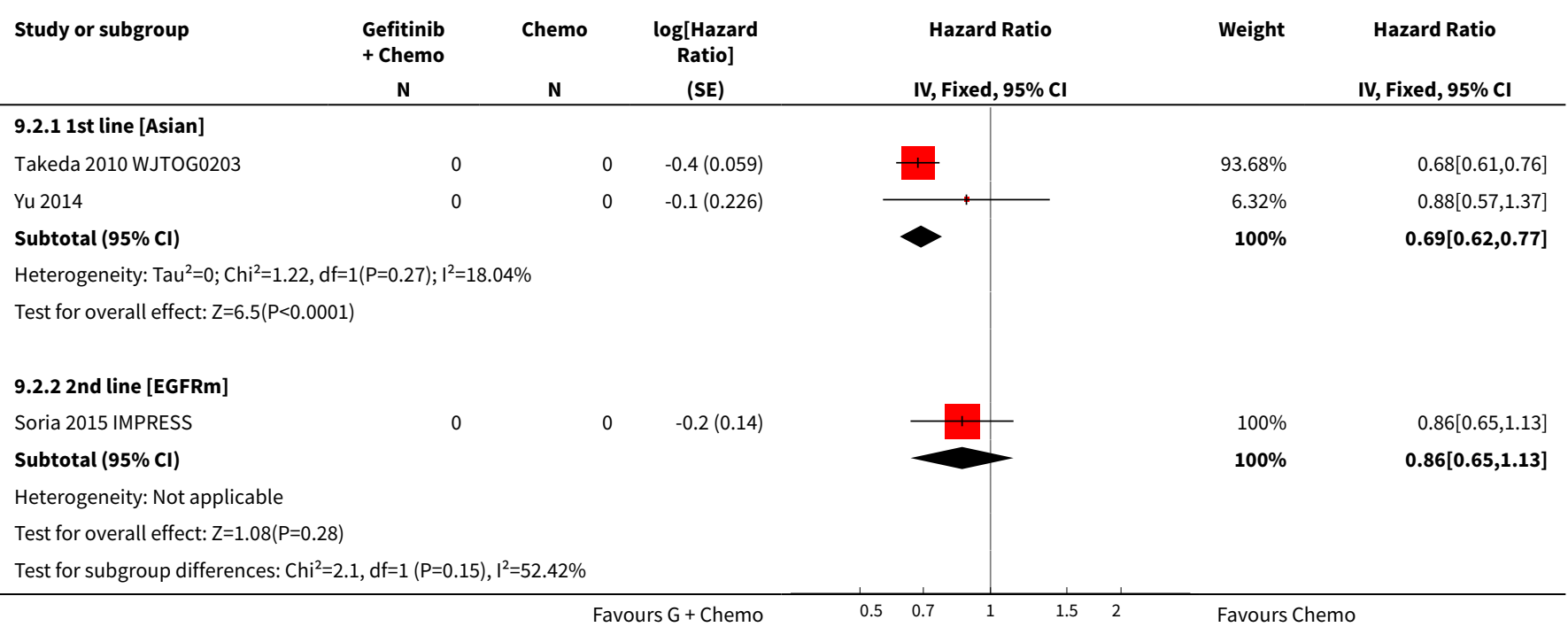

Analysis 9.3. Comparison 9 Gefitinib + chemotherapy versus chemotherapy, Outcome 3 1-year survival rate.

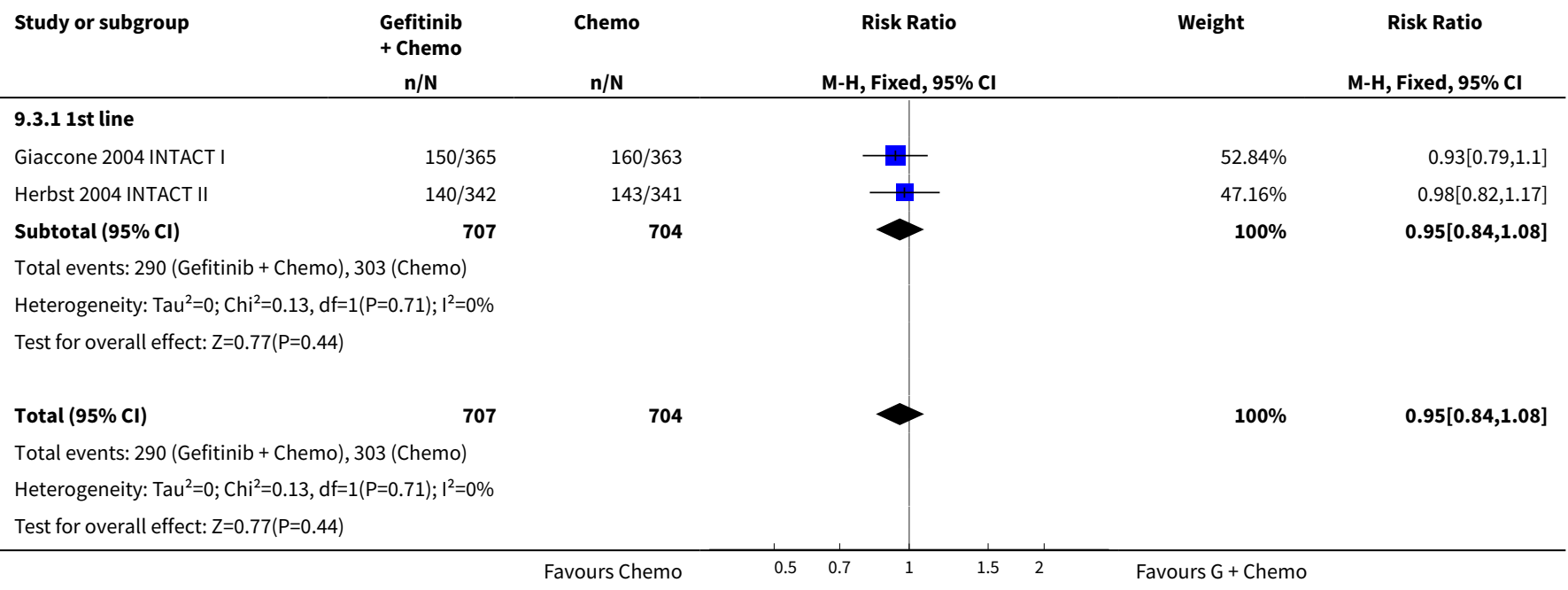


Analysis 9.4. Comparison 9 Gefitinib + chemotherapy versus chemotherapy, Outcome 4 Skin rash.

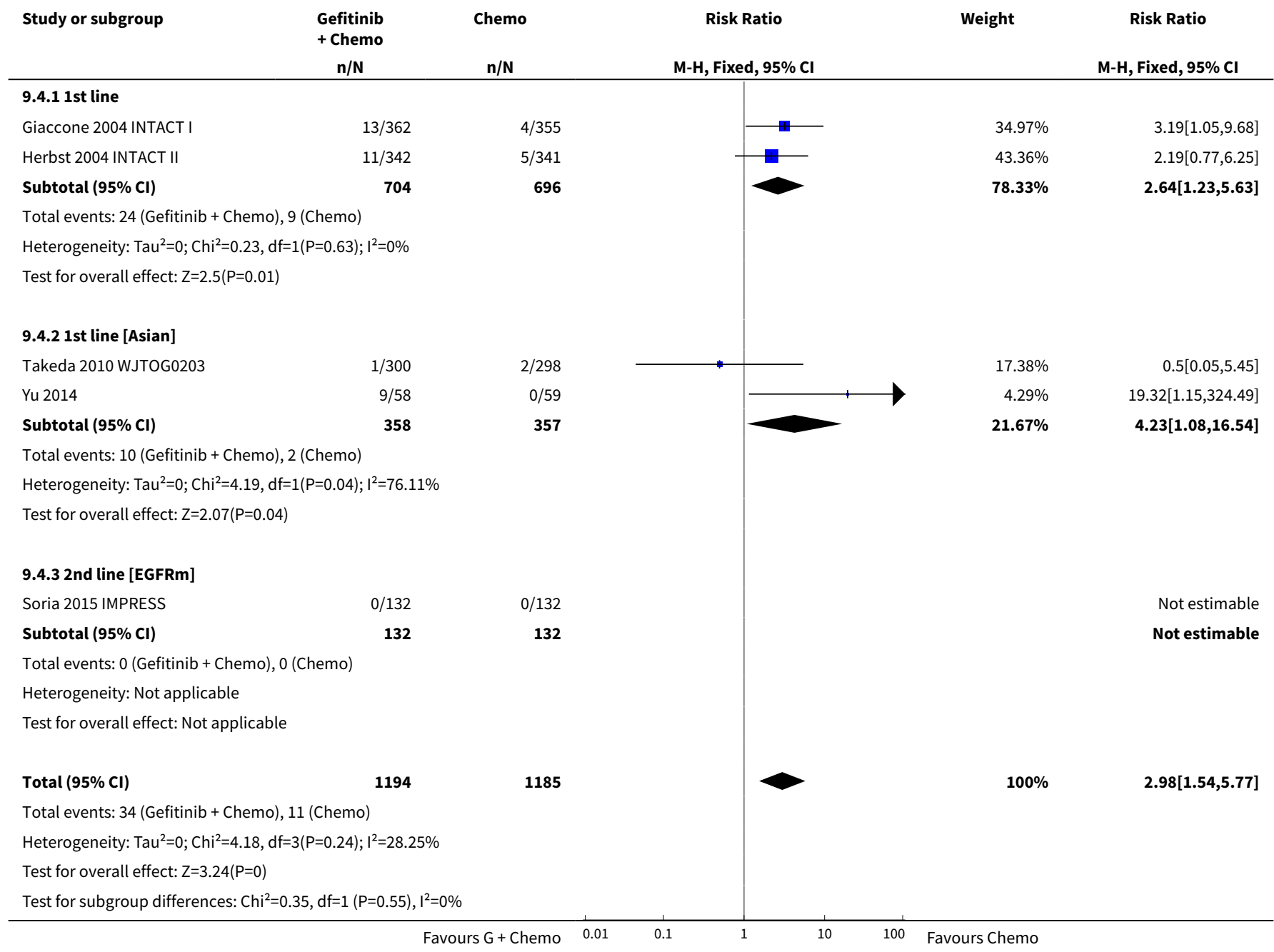

Analysis 9.5. Comparison 9 Gefitinib + chemotherapy versus chemotherapy, Outcome 5 Acne.

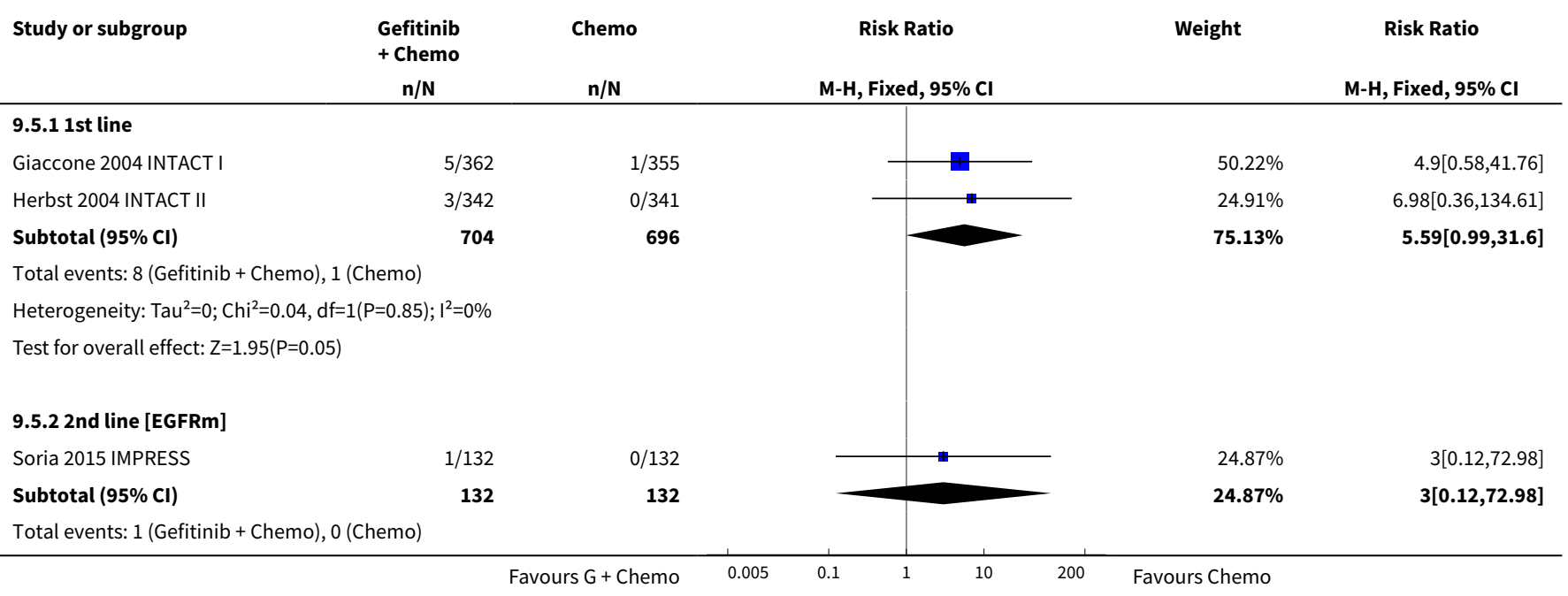




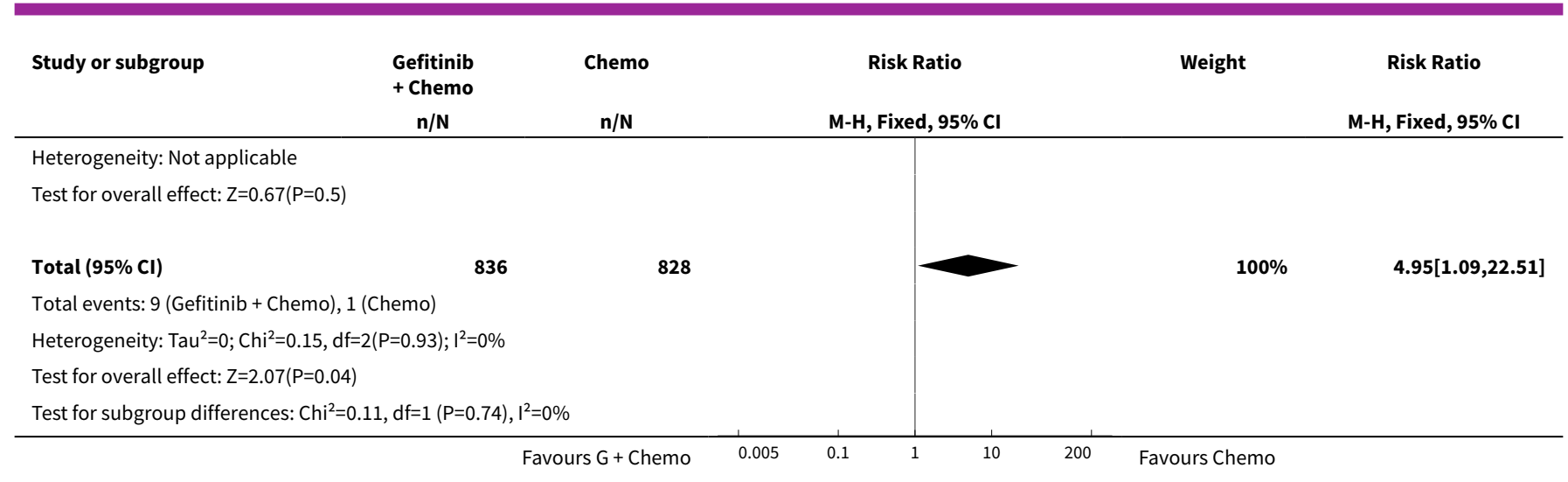

\section{Analysis 9.6. Comparison 9 Gefitinib + chemotherapy versus chemotherapy, Outcome 6 Diarrhoea.}

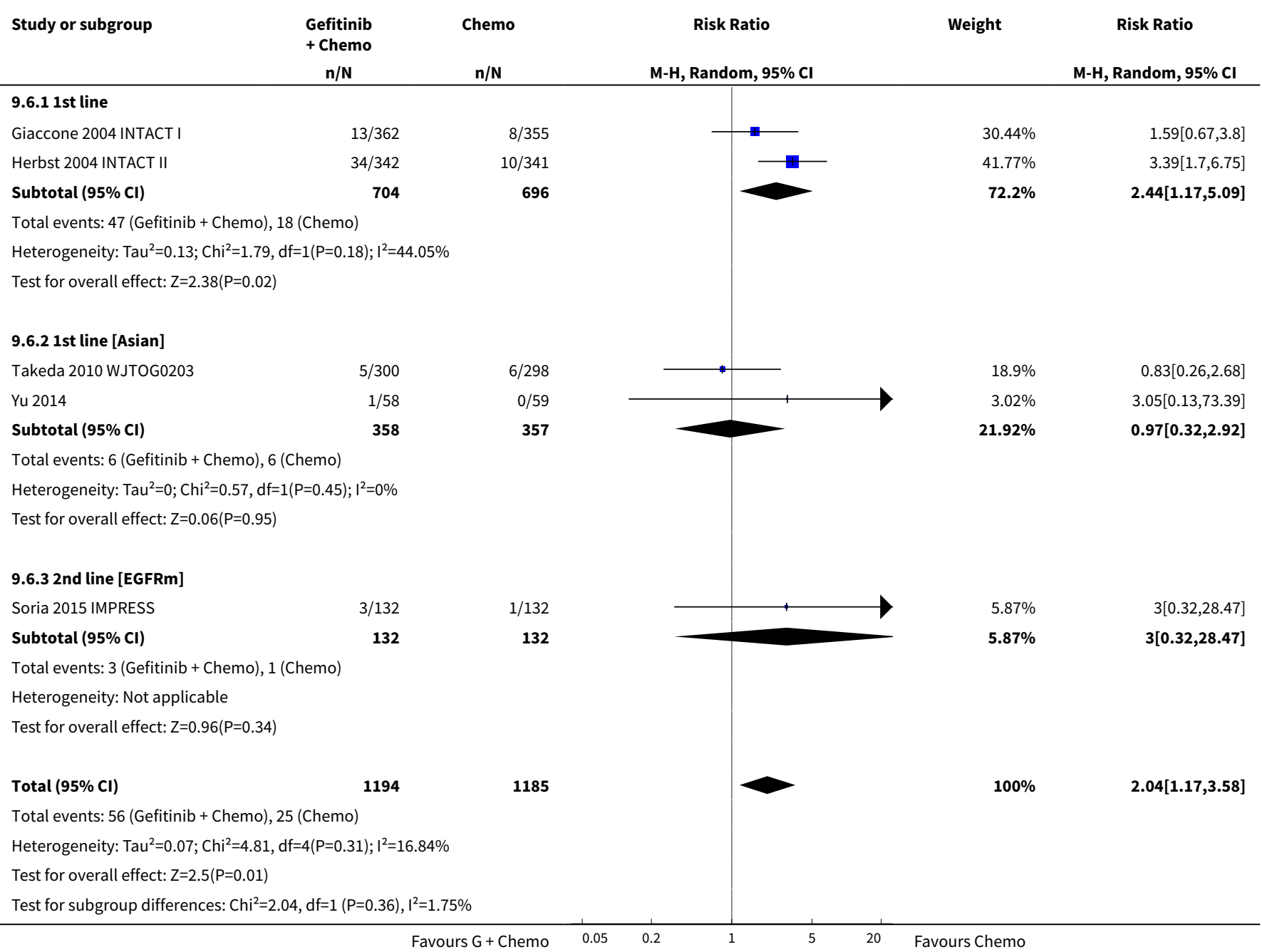


Analysis 9.7. Comparison 9 Gefitinib + chemotherapy versus chemotherapy, Outcome 7 Pruritus.

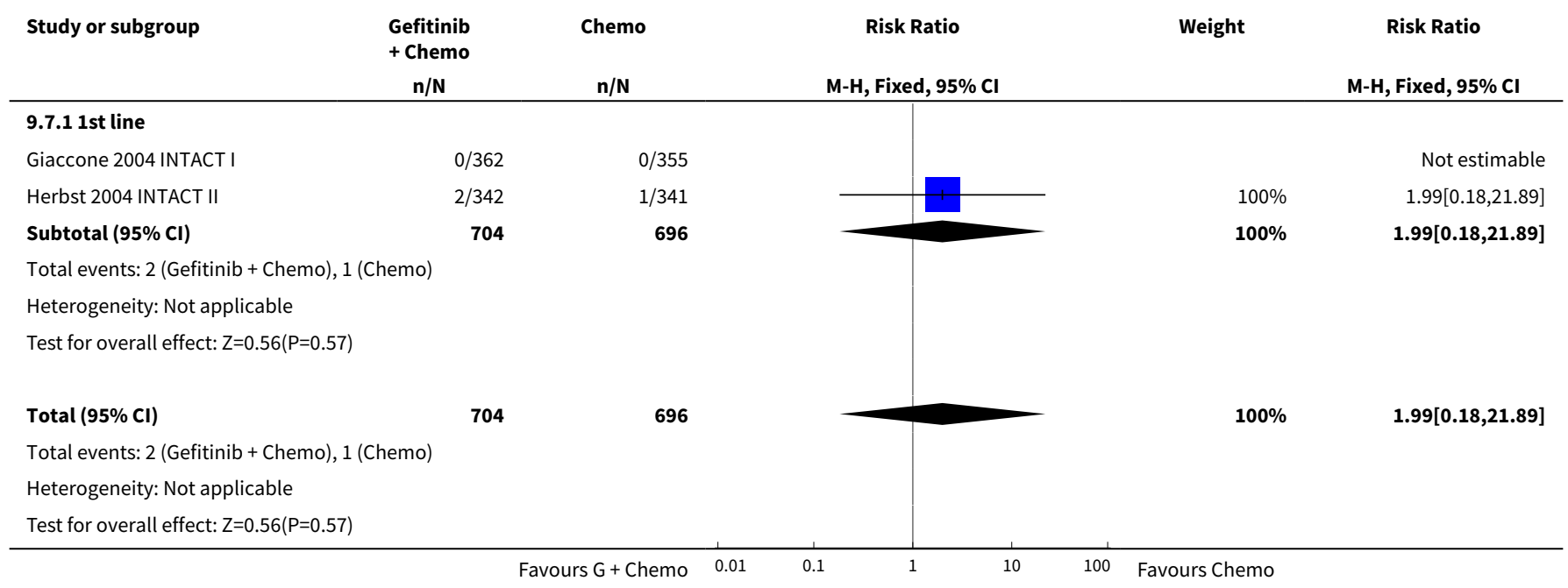

Analysis 9.8. Comparison 9 Gefitinib + chemotherapy versus chemotherapy, Outcome 8 Vomiting.

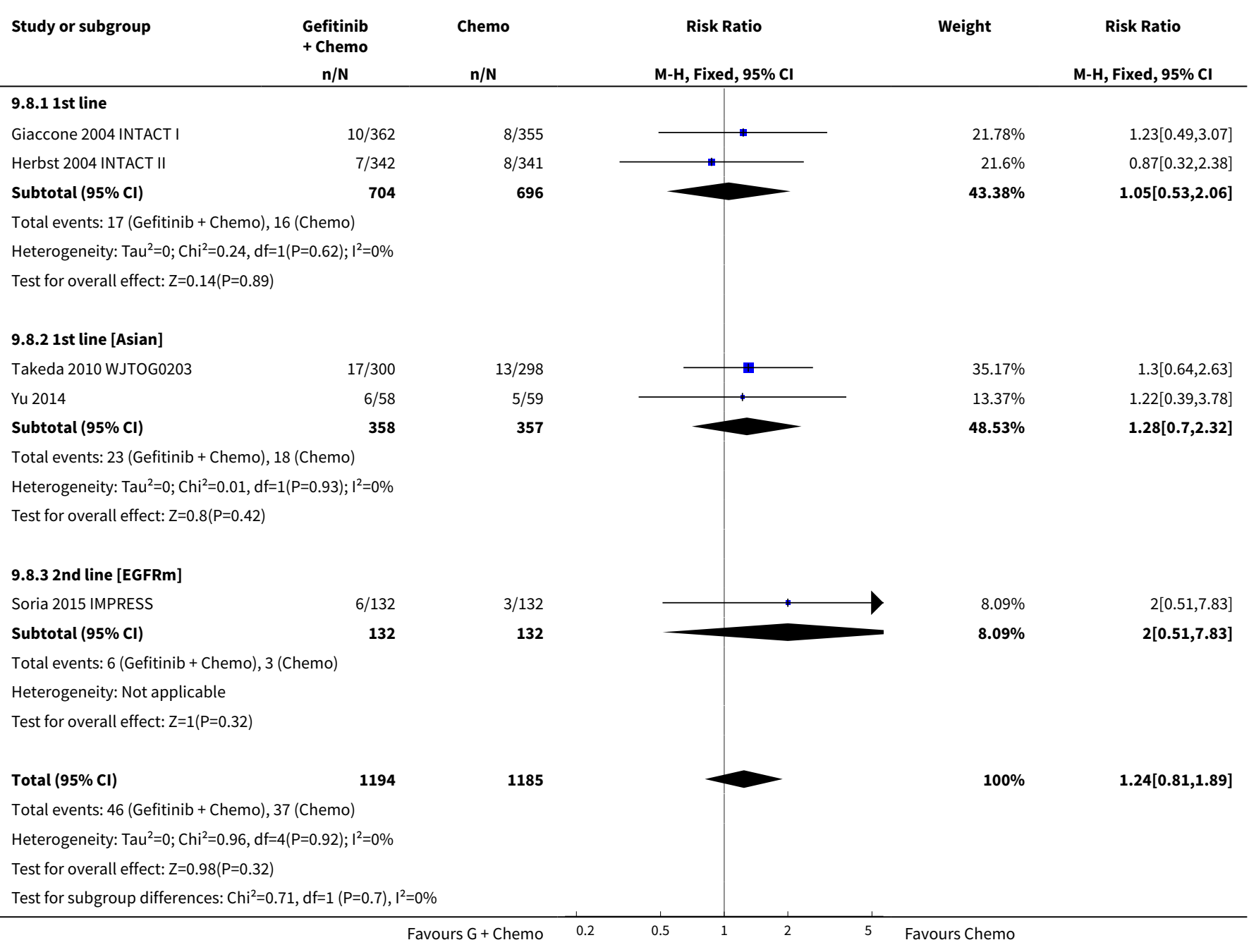


Analysis 9.9. Comparison 9 Gefitinib + chemotherapy versus chemotherapy, Outcome 9 Nausea.

\begin{tabular}{|c|c|c|c|c|c|}
\hline Study or subgroup & $\begin{array}{c}\text { Gefitinib } \\
+ \text { Chemo } \\
n / N\end{array}$ & $\begin{array}{c}\text { Chemo } \\
\mathrm{n} / \mathrm{N} \\
\end{array}$ & $\begin{array}{c}\text { Risk Ratio } \\
\text { M-H, Fixed, 95\% Cl }\end{array}$ & Weight & $\begin{array}{c}\text { Risk Ratio } \\
\text { M-H, Fixed, 95\% Cl }\end{array}$ \\
\hline \multicolumn{6}{|l|}{ 9.9.1 1st line } \\
\hline Giaccone 2004 INTACT I & $9 / 362$ & $7 / 355$ & ! & $11.19 \%$ & $1.26[0.47,3.35]$ \\
\hline Herbst 2004 INTACT II & $6 / 342$ & $7 / 341$ & & $11.1 \%$ & $0.85[0.29,2.52]$ \\
\hline Subtotal $(95 \% \mathrm{Cl})$ & 704 & 696 & & $22.29 \%$ & $1.06[0.51,2.18]$ \\
\hline \multicolumn{6}{|c|}{ Total events: 15 (Gefitinib + Chemo), 14 (Chemo) } \\
\hline \multicolumn{6}{|c|}{ Heterogeneity: $\mathrm{Tau}^{2}=0 ; \mathrm{Chi}^{2}=0.27, \mathrm{df}=1(\mathrm{P}=0.6) ; \mathrm{I}^{2}=0 \%$} \\
\hline \multicolumn{6}{|c|}{ Test for overall effect: $Z=0.15(P=0.88)$} \\
\hline \multicolumn{6}{|l|}{ 9.9.2 1st line [Asian] } \\
\hline Takeda 2010 WJTOG0203 & $29 / 300$ & $38 / 298$ & - & $60.36 \%$ & $0.76[0.48,1.2]$ \\
\hline Yu 2014 & $3 / 58$ & $5 / 59$ & & $7.85 \%$ & $0.61[0.15,2.44]$ \\
\hline Subtotal $(95 \% \mathrm{Cl})$ & 358 & 357 & & $68.21 \%$ & $0.74[0.48,1.14]$ \\
\hline \multicolumn{6}{|c|}{ Total events: 32 (Gefitinib + Chemo), 43 (Chemo) } \\
\hline \multicolumn{6}{|c|}{ Heterogeneity: $\mathrm{Tau}^{2}=0 ; \mathrm{Chi}^{2}=0.08, \mathrm{df}=1(\mathrm{P}=0.77) ; \mathrm{I}^{2}=0 \%$} \\
\hline \multicolumn{6}{|c|}{ Test for overall effect: $Z=1.36(P=0.17)$} \\
\hline \multicolumn{6}{|l|}{ 9.9.3 2nd line [EGFRm] } \\
\hline Soria 2015 IMPRESS & $5 / 132$ & $6 / 132$ & & $9.5 \%$ & $0.83[0.26,2.66]$ \\
\hline Subtotal $(95 \% \mathrm{Cl})$ & 132 & 132 & & $9.5 \%$ & $0.83[0.26,2.66]$ \\
\hline \multicolumn{6}{|c|}{ Total events: 5 (Gefitinib + Chemo), 6 (Chemo) } \\
\hline \multicolumn{6}{|c|}{ Heterogeneity: Not applicable } \\
\hline \multicolumn{6}{|c|}{ Test for overall effect: $\mathrm{Z}=0.31(\mathrm{P}=0.76)$} \\
\hline Total $(95 \% \mathrm{Cl})$ & 1194 & 1185 & & $100 \%$ & $0.82[0.58,1.17]$ \\
\hline \multicolumn{6}{|c|}{ Total events: 52 (Gefitinib + Chemo), 63 (Chemo) } \\
\hline \multicolumn{6}{|c|}{ Heterogeneity: $\mathrm{Tau}^{2}=0 ; \mathrm{Chi}^{2}=1.04, \mathrm{df}=4(\mathrm{P}=0.9) ; I^{2}=0 \%$} \\
\hline \multicolumn{6}{|c|}{ Test for overall effect: $Z=1.1(P=0.27)$} \\
\hline Test for subgroup differen & , $d f=1(P=0.71)$, & & & & \\
\hline
\end{tabular}

\section{Analysis 9.10. Comparison 9 Gefitinib + chemotherapy versus chemotherapy, Outcome 10 Anorexia.}

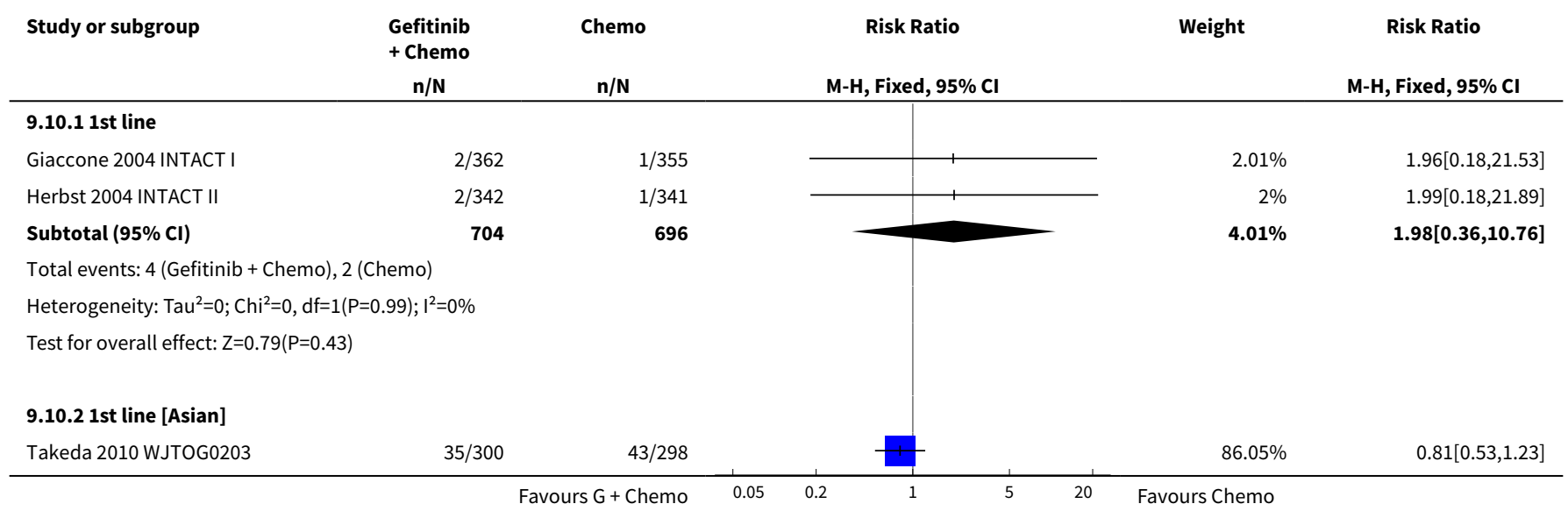




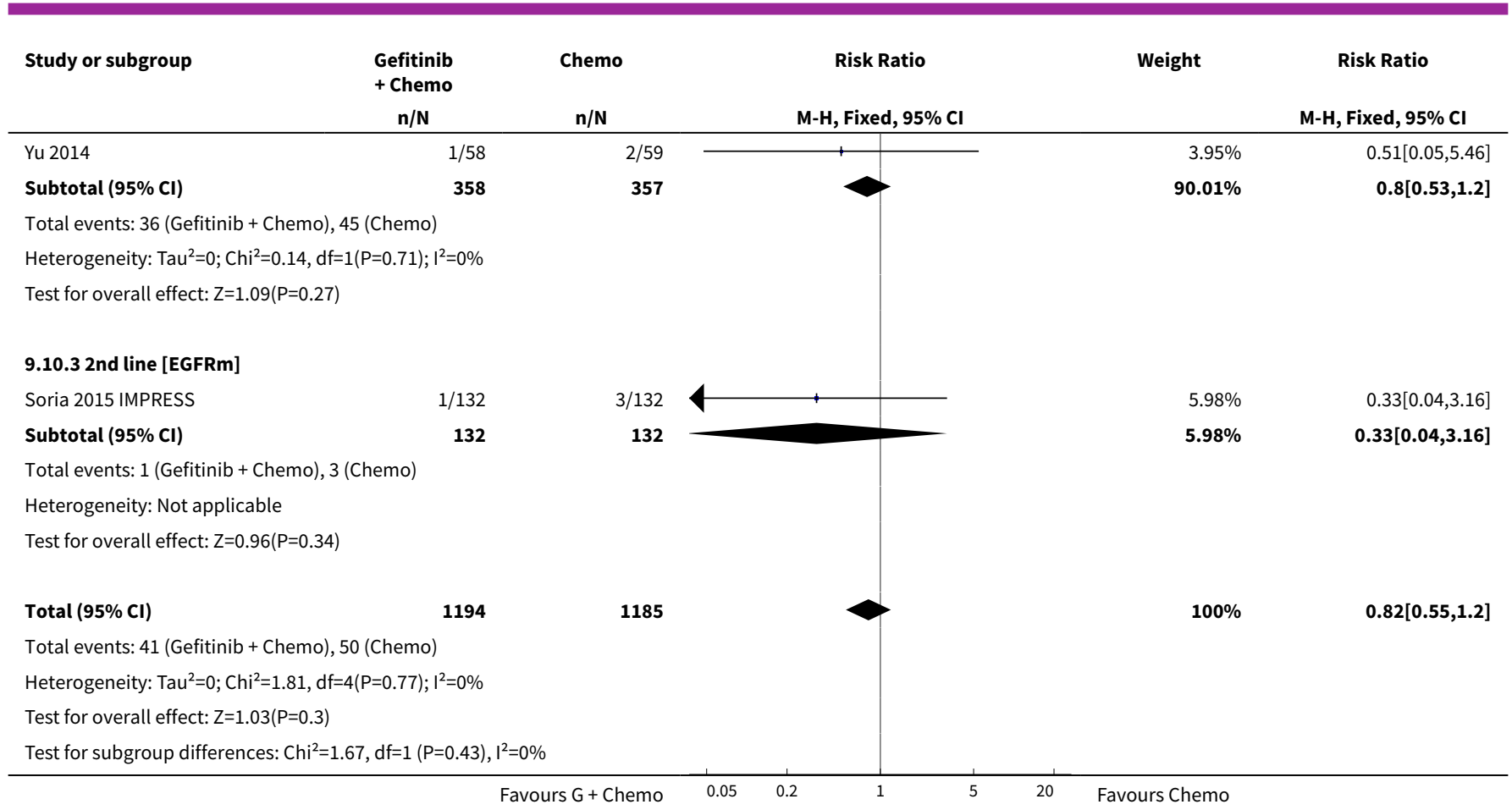

Analysis 9.11. Comparison 9 Gefitinib + chemotherapy versus chemotherapy, Outcome 11 Asthenia.

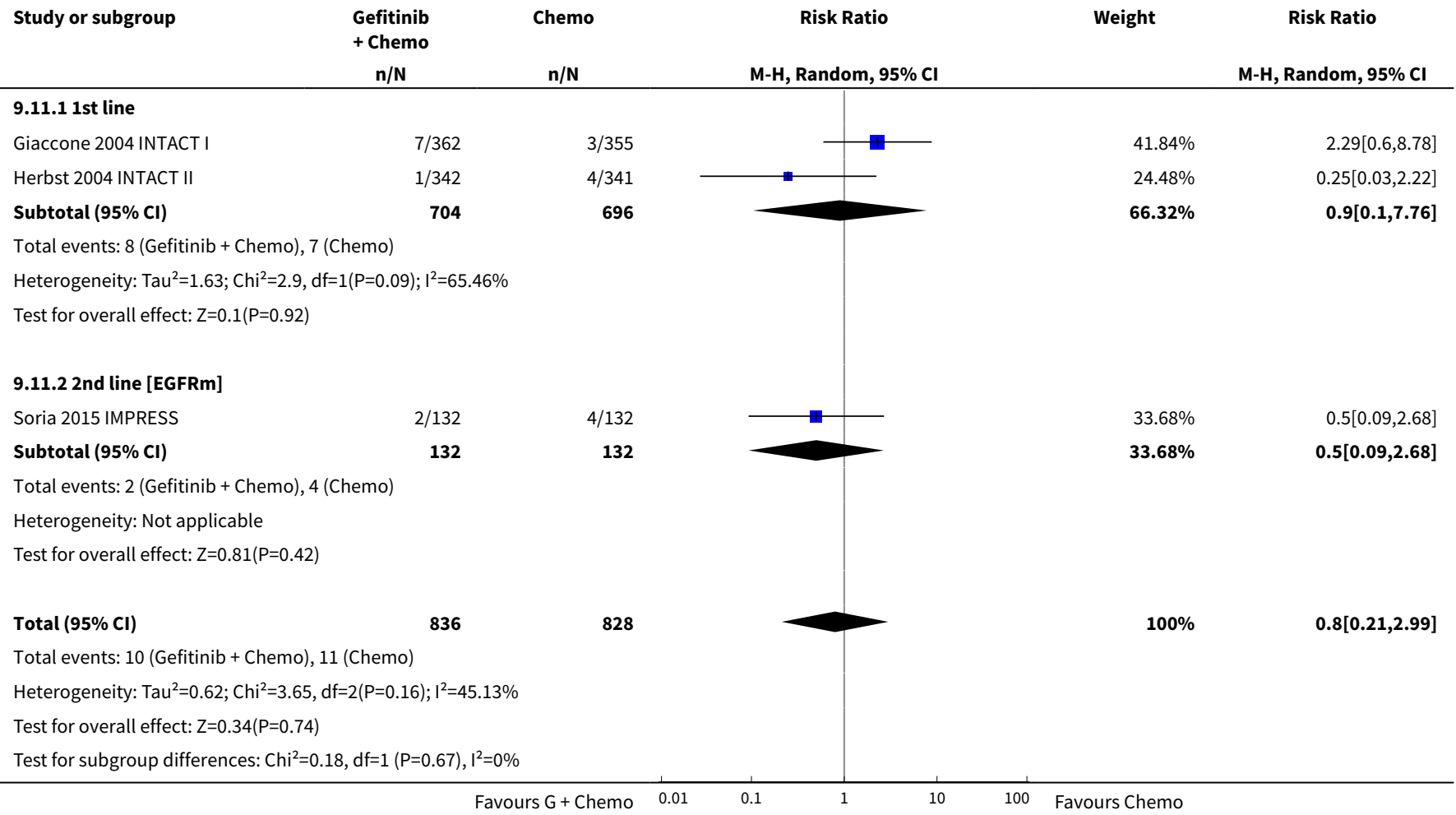


Analysis 9.12. Comparison 9 Gefitinib + chemotherapy versus chemotherapy, Outcome 12 Dyspnoea.

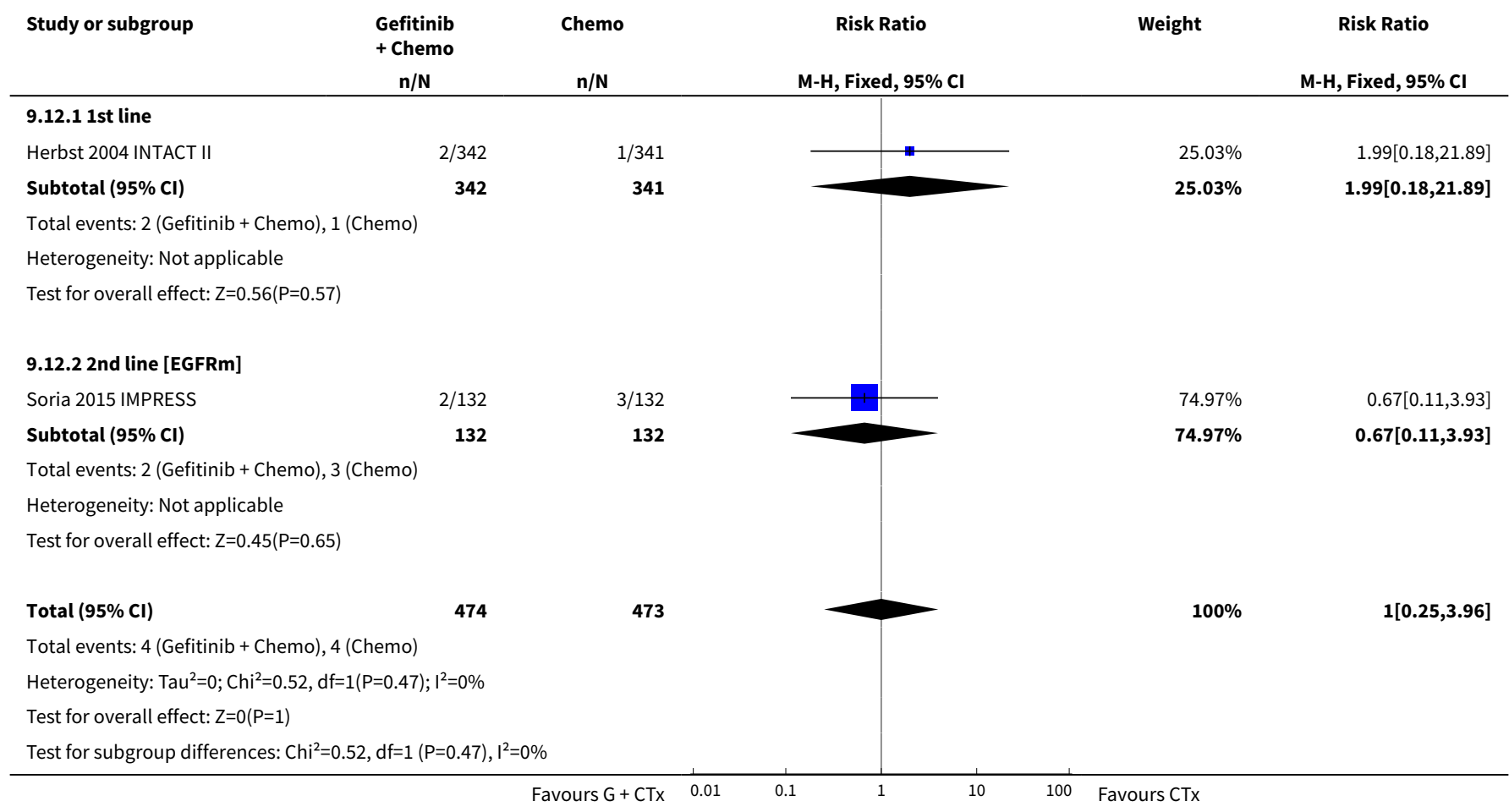

Analysis 9.13. Comparison 9 Gefitinib + chemotherapy versus chemotherapy, Outcome 13 Anaemia.

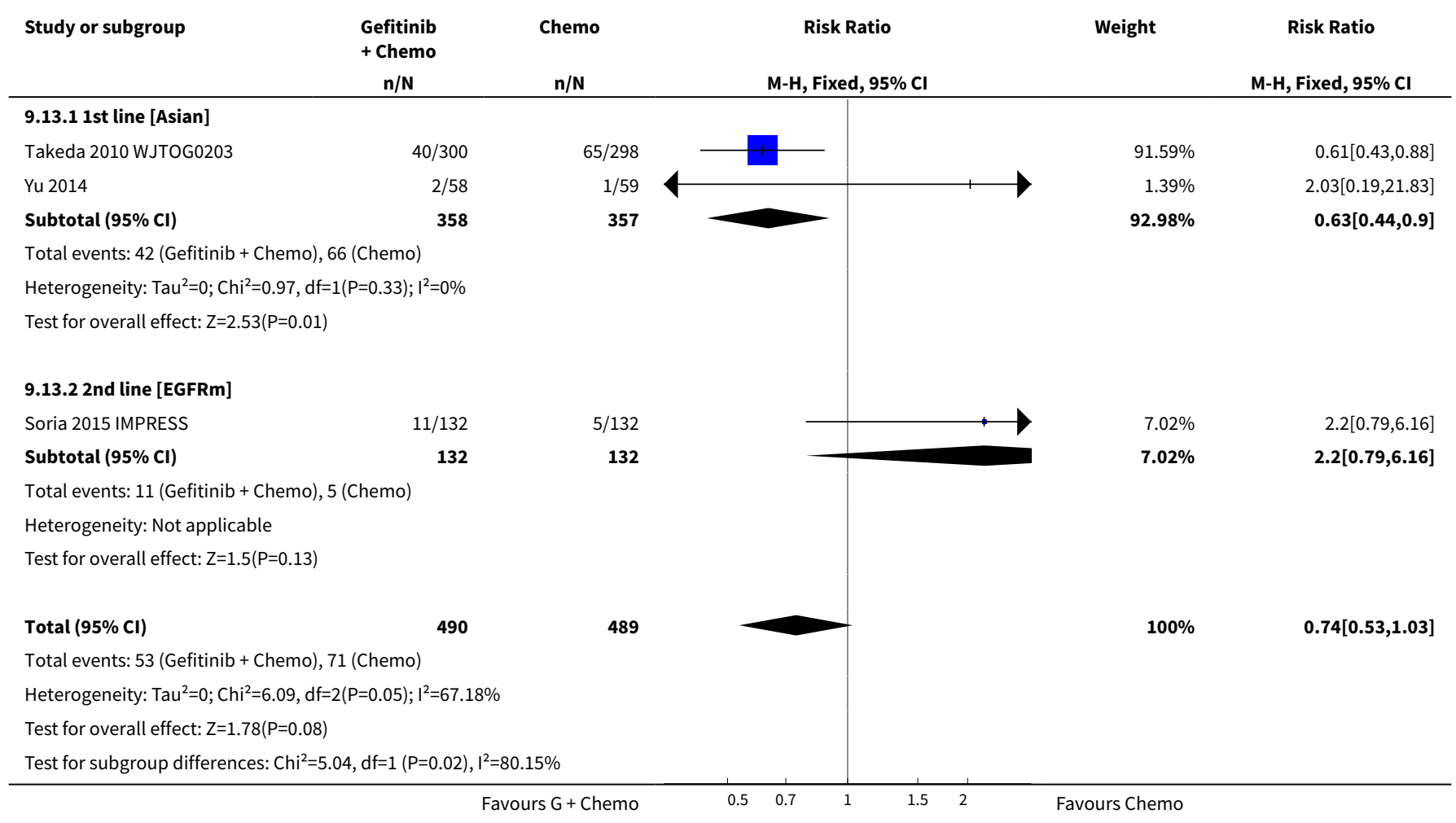


Analysis 9.14. Comparison 9 Gefitinib + chemotherapy versus chemotherapy, Outcome 14 Neutropenia.

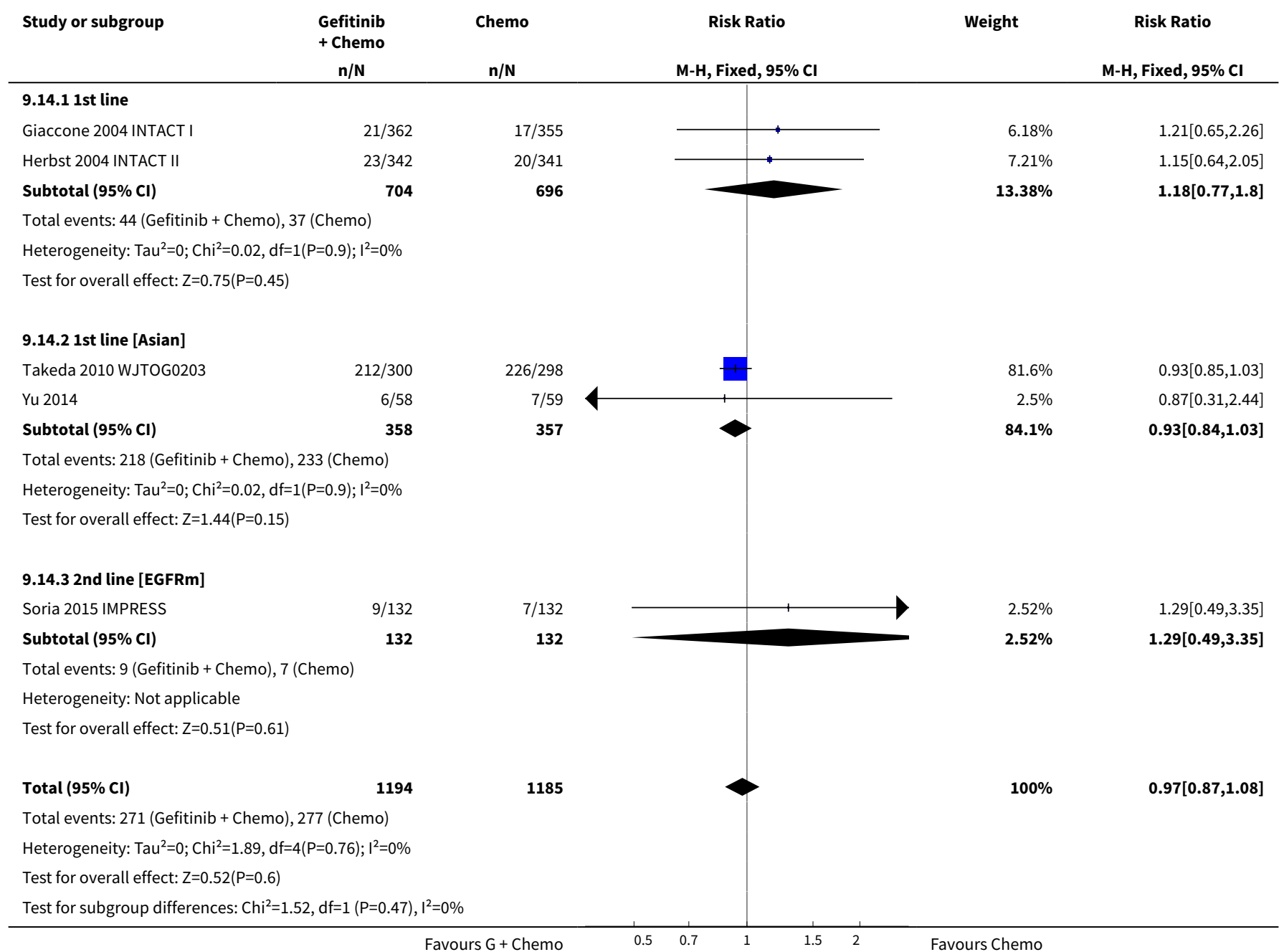

Analysis 9.15. Comparison 9 Gefitinib + chemotherapy versus chemotherapy, Outcome 15 Leukopenia.

\begin{tabular}{|c|c|c|c|c|c|}
\hline Study or subgroup & $\begin{array}{c}\text { Gefitinib } \\
+ \text { Chemo } \\
n / N \\
\end{array}$ & $\mathrm{n} / \mathrm{N}$ & M-H, Fixed, $95 \% \mathrm{Cl}$ & Weight & $\begin{array}{c}\text { Risk Ratio } \\
\text { M-H, Fixed, } 95 \% \text { Cl }\end{array}$ \\
\hline \multicolumn{6}{|l|}{ 9.15.1 1st line } \\
\hline Giaccone 2004 INTACT I & $12 / 362$ & $9 / 355$ & . & $6.97 \%$ & $1.31[0.56,3.06]$ \\
\hline Herbst 2004 INTACT II & $7 / 342$ & $7 / 341$ & & $5.37 \%$ & $1[0.35,2.81]$ \\
\hline Subtotal $(95 \% \mathrm{CI})$ & 704 & 696 & & $12.34 \%$ & $1.17[0.61,2.26]$ \\
\hline \multicolumn{6}{|c|}{ Heterogeneity: $\operatorname{Tau}^{2}=0 ; \mathrm{Chi}^{2}=0.16, \mathrm{df}=1(\mathrm{P}=0.69) ; \mathrm{I}^{2}=0 \%$} \\
\hline \multicolumn{6}{|c|}{ Test for overall effect: $Z=0.47(P=0.64)$} \\
\hline \multicolumn{6}{|l|}{ 9.15.2 1st line [Asian] } \\
\hline Takeda 2010 WJTOG0203 & $119 / 300$ & $111 / 298$ & - & $85.36 \%$ & $1.06[0.87,1.3]$ \\
\hline
\end{tabular}




\begin{tabular}{|c|c|c|c|c|c|}
\hline Study or subgroup & $\begin{array}{c}\text { Gefitinib } \\
+ \text { Chemo } \\
n / N \\
\end{array}$ & $\begin{array}{c}\text { Chemo } \\
\text { n/N }\end{array}$ & $\begin{array}{c}\text { Risk Ratio } \\
\text { M-H, Fixed, 95\% Cl }\end{array}$ & Weight & $\begin{array}{c}\text { Risk Ratio } \\
\text { M-H, Fixed, } 95 \% \mathrm{Cl} \\
\end{array}$ \\
\hline Subtotal $(95 \% \mathrm{Cl})$ & 300 & 298 & & $85.36 \%$ & $1.06[0.87,1.3]$ \\
\hline \multicolumn{6}{|c|}{ Total events: 119 (Gefitinib + Chemo), 111 (Chemo) } \\
\hline \multicolumn{6}{|c|}{ Heterogeneity: Not applicable } \\
\hline \multicolumn{6}{|c|}{ 9.15.3 2nd line [EGFRm] } \\
\hline Soria 2015 IMPRESS & $3 / 132$ & $3 / 132$ & & $2.3 \%$ & $1[0.21,4.86]$ \\
\hline Subtotal $(95 \% \mathrm{Cl})$ & 132 & 132 & & $2.3 \%$ & $1[0.21,4.86]$ \\
\hline \multicolumn{6}{|c|}{ Total events: 3 (Gefitinib + Chemo), 3 (Chemo) } \\
\hline \multicolumn{6}{|c|}{ Heterogeneity: Not applicable } \\
\hline \multicolumn{6}{|c|}{ Test for overall effect: Not applicable } \\
\hline Total $(95 \% \mathrm{Cl})$ & 1136 & 1126 & & $100 \%$ & $1.08[0.89,1.31]$ \\
\hline \multicolumn{6}{|c|}{ Total events: 141 (Gefitinib + Chemo), 130 (Chemo) } \\
\hline \multicolumn{6}{|c|}{ Heterogeneity: $\mathrm{Tau}^{2}=0 ; \mathrm{Chi}^{2}=0.24, \mathrm{df}=3(\mathrm{P}=0.97) ; \mathrm{I}^{2}=0 \%$} \\
\hline \multicolumn{6}{|c|}{ Test for overall effect: $\mathrm{Z}=0.74(\mathrm{P}=0.46)$} \\
\hline Test for subgroup dif & $\mathrm{df}=1(\mathrm{P}=0.96)$, & & & & \\
\hline
\end{tabular}

Analysis 9.16. Comparison 9 Gefitinib + chemotherapy versus chemotherapy, Outcome 16 Overall response rate.

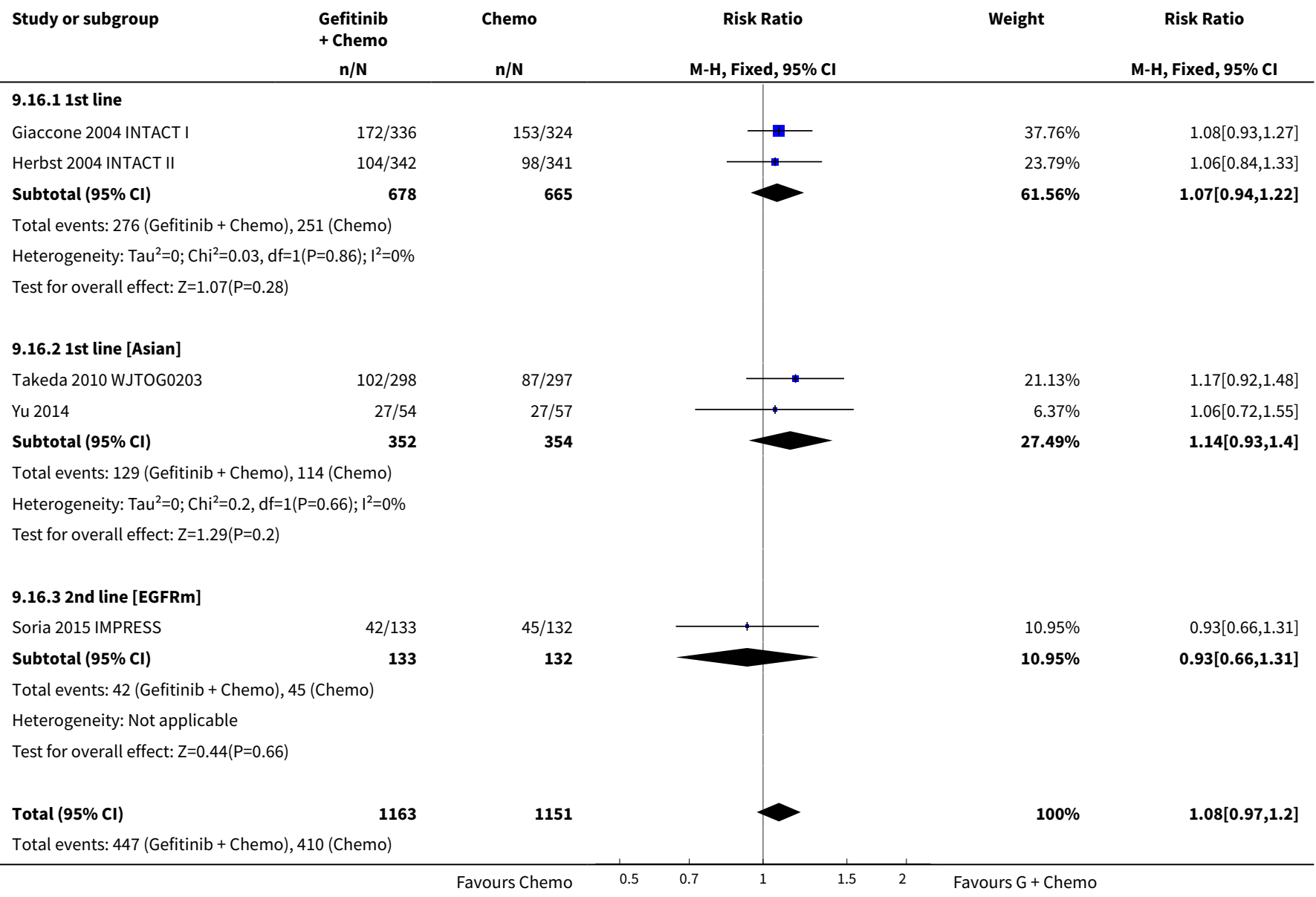




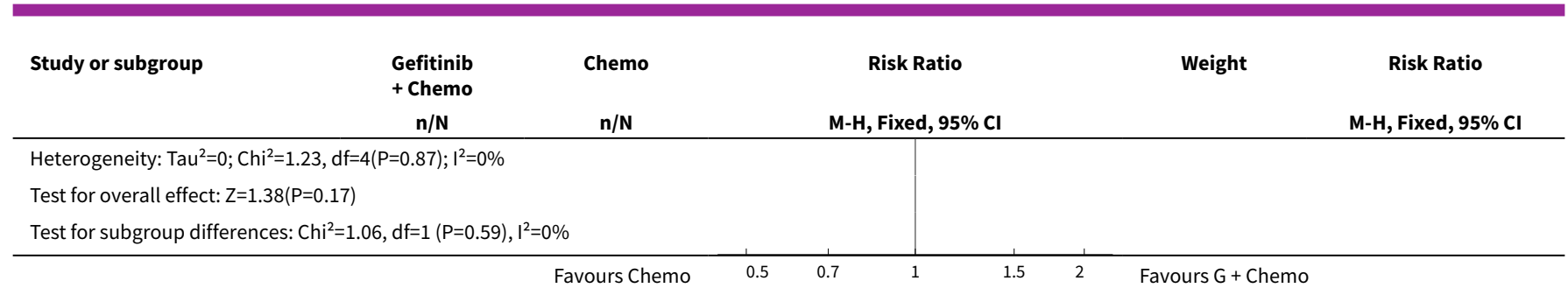




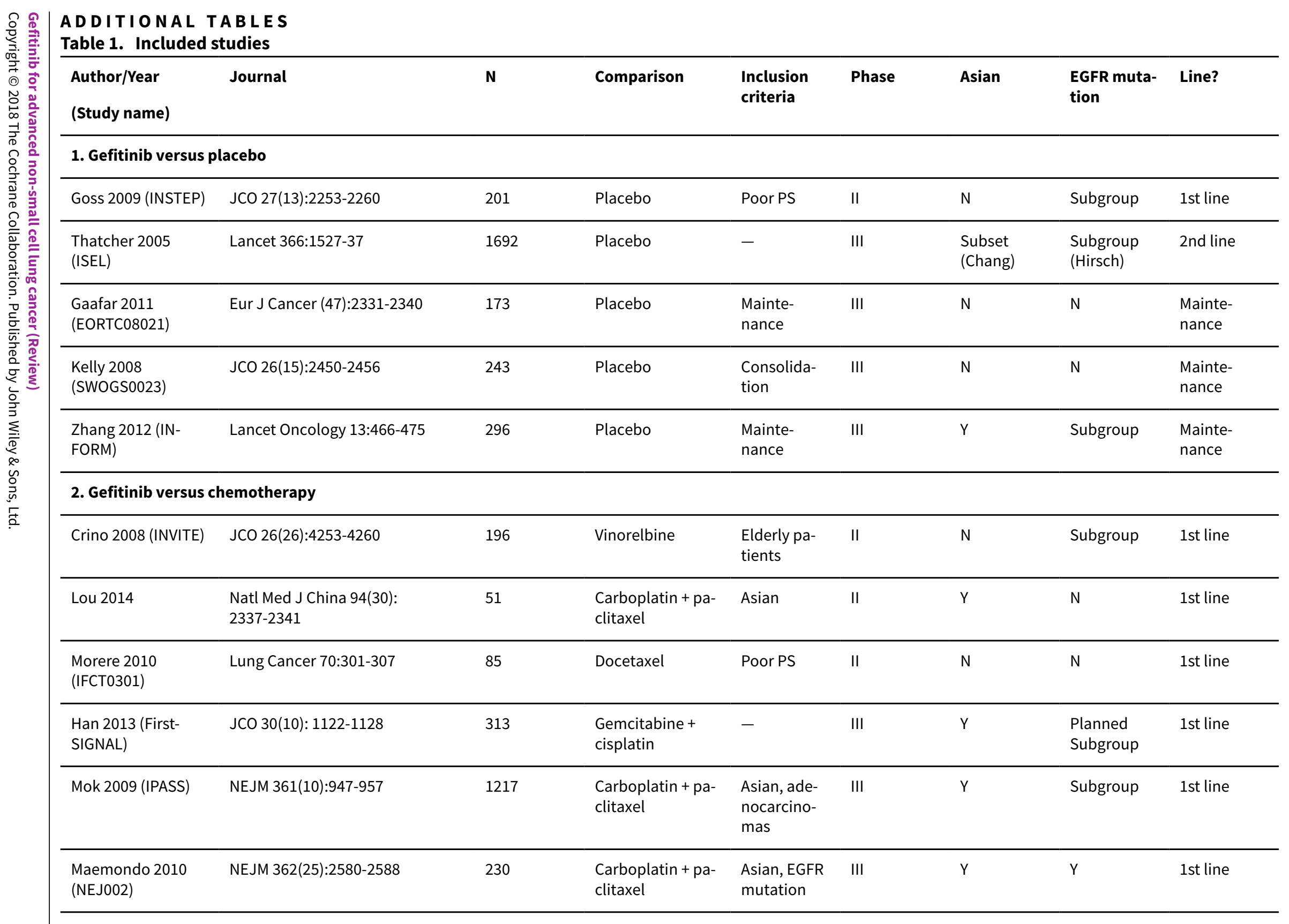




\begin{tabular}{|c|c|c|c|c|c|c|c|c|}
\hline $\begin{array}{l}\text { Mitsudomi } 2010 \\
\text { (WJTOG3405) }\end{array}$ & Lancet Oncol 11:121-128 & 177 & $\begin{array}{l}\text { Cisplatin + doc- } \\
\text { etaxel }\end{array}$ & $\begin{array}{l}\text { Asian, EGFR } \\
\text { mutation }\end{array}$ & III & Y & Y & 1st line \\
\hline Yang 2014 & Eur J Cancer 50:2219-2230 & 236 & $\begin{array}{l}\text { Pemetrexed + cis- } \\
\text { platin }\end{array}$ & Asian & III & $\mathrm{Y}$ & Subgroup & $\begin{array}{l}\text { 1st line + } \\
\text { mainte- } \\
\text { nance }\end{array}$ \\
\hline Cufer 2006 (SIGN) & Anti-cancer Drugs 14:401-409 & 141 & Docetaxel & Open-label & II & $\mathrm{N}$ & $\mathrm{N}$ & 2nd line \\
\hline Dai 2013 & Chin J Lung Cancer 16(8):405-410 & 46 & Pemetrexed & Asian & II & $\mathrm{Y}$ & $\mathrm{N}$ & 2nd line \\
\hline Kim 2016 & Cancer Res Treat 48(1):80-87 & 95 & Pemetrexed & Asian & II & Y & $\mathrm{N}$ & 2nd/3rd line \\
\hline Li 2010 & Chinese J Clin Onc 37:16-18 & 98 & Docetaxel & Asian & II & $\mathrm{Y}$ & $\mathrm{N}$ & 2nd line \\
\hline $\begin{array}{l}\text { Kim } 2008 \text { (IN- } \\
\text { TEREST) }\end{array}$ & Lancet 372:1809-1818 & 1466 & Docetaxel & - & III & $\mathrm{N}$ & $\begin{array}{l}\text { Subgroup } \\
\text { (Doulliard) }\end{array}$ & 2nd line \\
\hline Lee 2010 (ISTANA) & Clin Cancer Res 16(4):1307-1314 & 161 & Docetaxel & Asian & III & $\mathrm{Y}$ & $\mathrm{N}$ & 2nd/3rd line \\
\hline $\begin{array}{l}\text { Maruyama } 2008 \\
(\mathrm{~V}-15-32)\end{array}$ & JCO 26(26):4244-4252 & 489 & Docetaxel & Asian & III & Y & Subgroup & 2nd/3rd line \\
\hline $\begin{array}{l}\text { Sun } 2012 \text { (KSCG- } \\
\text { LU08-01) }\end{array}$ & Cancer 118:6234-6242 & 141 & Pemetrexed & $\begin{array}{l}\text { Adenocarci- } \\
\text { noma, non- } \\
\text { smoker }\end{array}$ & III & $\mathrm{Y}$ & Subgroup & 2nd line \\
\hline Ahn 2012 & Lung Cancer 77:346-352 & 73 & Pemetrexed & $\begin{array}{l}\text { Asian, nev- } \\
\text { er-smokers }\end{array}$ & II & Y & $\mathrm{N}$ & $\begin{array}{l}\text { Mainte- } \\
\text { nance }\end{array}$ \\
\hline Xu 2015 & Int J Clin Exp Med 8(4):6242-6246 & 188 & Pemetrexed & Asian & II & $\mathrm{Y}$ & $\mathrm{N}$ & $\begin{array}{l}\text { Mainte- } \\
\text { nance }\end{array}$ \\
\hline \multicolumn{9}{|c|}{ 3. Gefitinib $250 \mathrm{mg}$ versus gefitinib $500 \mathrm{mg}$} \\
\hline $\begin{array}{l}\text { Fukuoka } 2003 \\
\text { (IDEAL I) }\end{array}$ & JCO 21(12):2237-2246 & 210 & G250 versus $\mathrm{G} 500$ & - & II & $\mathrm{N}$ & $\mathrm{N}$ & $2 \mathrm{rd} / 3 \mathrm{rd}$ line \\
\hline Kris 2003 (IDEAL II) & JAMA 290(16):2149-2158 & 216 & G250 versus $\mathrm{G} 500$ & - & II & $\mathrm{N}$ & $\mathrm{N}$ & 3rd line \\
\hline Xue 2015 & Int J Clin Exp Med 8(4):6242-6246 & 188 & G250 versus G500 & Asian & II & $\mathrm{Y}$ & $\mathrm{N}$ & $\begin{array}{l}\text { Mainte- } \\
\text { nance }\end{array}$ \\
\hline
\end{tabular}


Table 1. Included studies (Continued)

4. Gefitinib versus gefitinib + chemotherapy

\begin{tabular}{|c|c|c|c|c|c|c|c|c|}
\hline An 2016 & Pathol Oncol Res 22:763-768 & 90 & $\begin{array}{l}\text { Gefitinib + Peme- } \\
\text { trexed }\end{array}$ & $\begin{array}{l}\text { Asian, EGFR } \\
\text { mutation }\end{array}$ & II & Y & Y & 1st line \\
\hline Cheng 2016 & JCO 34(27): 3258-3266 & 191 & $\begin{array}{l}\text { Gefitinib + Peme- } \\
\text { trexed }\end{array}$ & $\begin{array}{l}\text { Asian, EGFR } \\
\text { mutation }\end{array}$ & II & Y & $\mathrm{Y}$ & 1st line \\
\hline Chen 2007 & Cancer 109:1821-8 & 48 & $\begin{array}{l}\text { Gefitinib + Vi- } \\
\text { norelbine }\end{array}$ & $\begin{array}{l}\text { Adenocarci- } \\
\text { noma }\end{array}$ & II & $\mathrm{N}$ & Subgroup & 3rd line \\
\hline \multicolumn{9}{|c|}{ 5. Gefitinib + chemotherapy versus chemotherapy } \\
\hline $\begin{array}{l}\text { Giaccone } 2004 \text { (IN- } \\
\text { TACT I) }\end{array}$ & JCO 22(5):777-784 & 1093 & $\begin{array}{l}\text { Gemcitabine + } \\
\text { Cisplatin }\end{array}$ & - & III & $\mathrm{N}$ & $\mathrm{N}$ & 1st line \\
\hline $\begin{array}{l}\text { Herbst } 2004 \\
\text { (INTACT II) }\end{array}$ & JCO 22(5):785-794 & 1037 & $\begin{array}{l}\text { Carboplatin + pa- } \\
\text { clitaxel }\end{array}$ & - & III & $\mathrm{N}$ & $\mathrm{N}$ & 1st line \\
\hline $\begin{array}{l}\text { Takeda } 2010 \\
\text { (WTOG0203) }\end{array}$ & JCO 28(5):753-760 & 604 & Platinum doublet & - & III & Y & $\mathrm{N}$ & 1st line \\
\hline Yu 2014 & $\begin{array}{l}\text { Cancer Biology \& Therapy } \\
\text { 15:832-839 }\end{array}$ & 117 & $\begin{array}{l}\text { Pemetrexed + } \\
\text { platinum }\end{array}$ & Asian & II & Y & $\mathrm{N}$ & 1st line \\
\hline $\begin{array}{l}\text { Soria } 2015 \text { (IM- } \\
\text { PRESS) }\end{array}$ & Lancet Oncology 16:990-98 & 265 & $\begin{array}{l}\text { Pemetrexed + cis- } \\
\text { platin }\end{array}$ & $\begin{array}{l}\text { EGFR muta- } \\
\text { tion positive }\end{array}$ & III & $\mathrm{N}$ & Y & 2nd line \\
\hline
\end{tabular}

EGFR: epidermal growth factor receptor

$\mathrm{N}$ : number of patients included

PS: performance status

Journals:

Cancer Res Treat: Cancer Research and Treatment

Chin J Lung Cancer: Chinese Journal of Lung Cancer

Chinese J Clin Onc: Chinese Journal of Clinical Oncology

Clin Cancer Res: Clinical Cancer Research

Eur J Cancer: European Journal of Cancer

Int J Clin Exp Med: International Journal of Clinical and Experimental Medicine

J Thor Oncol: Journal of Thoracic Oncology 


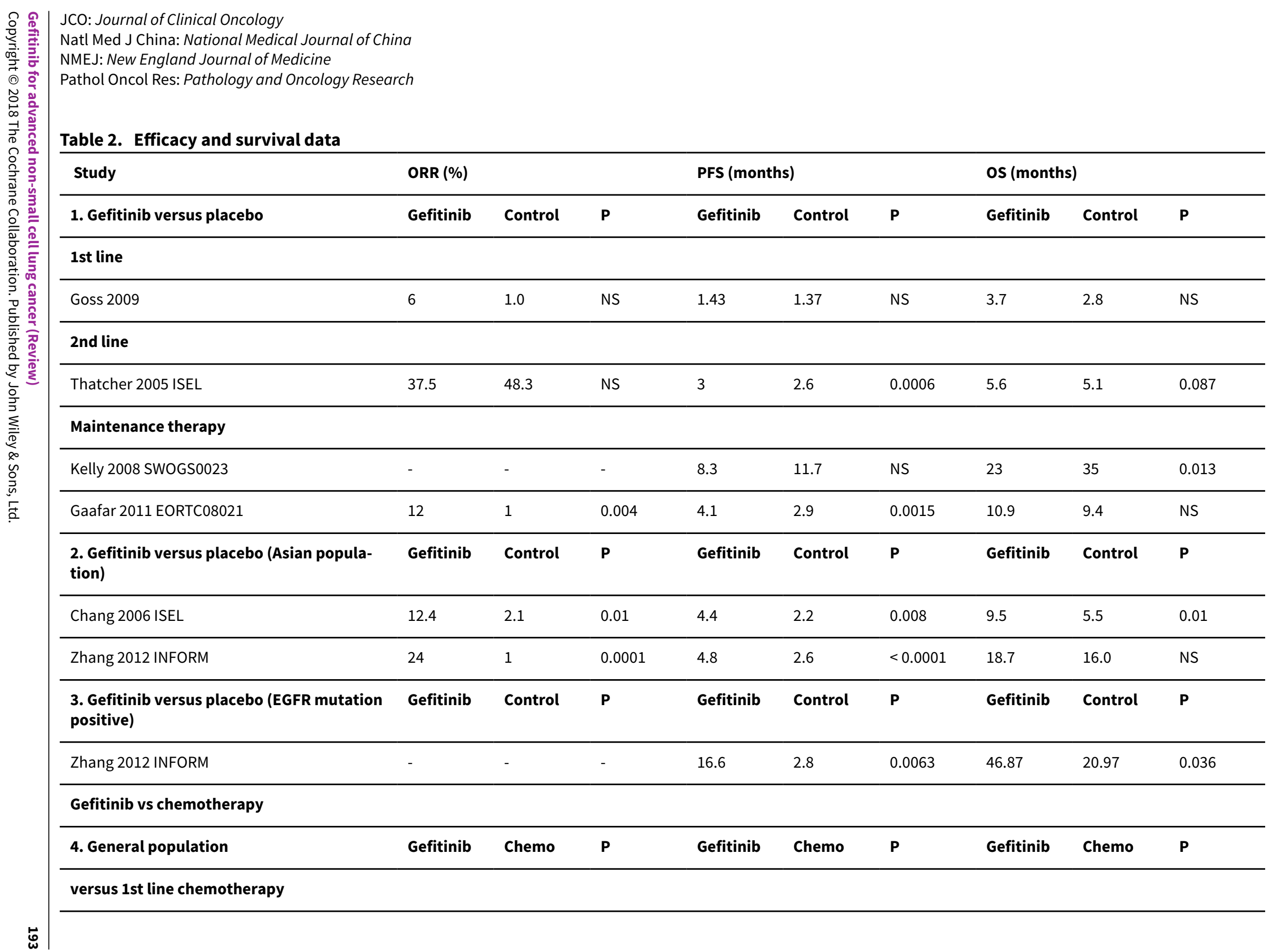




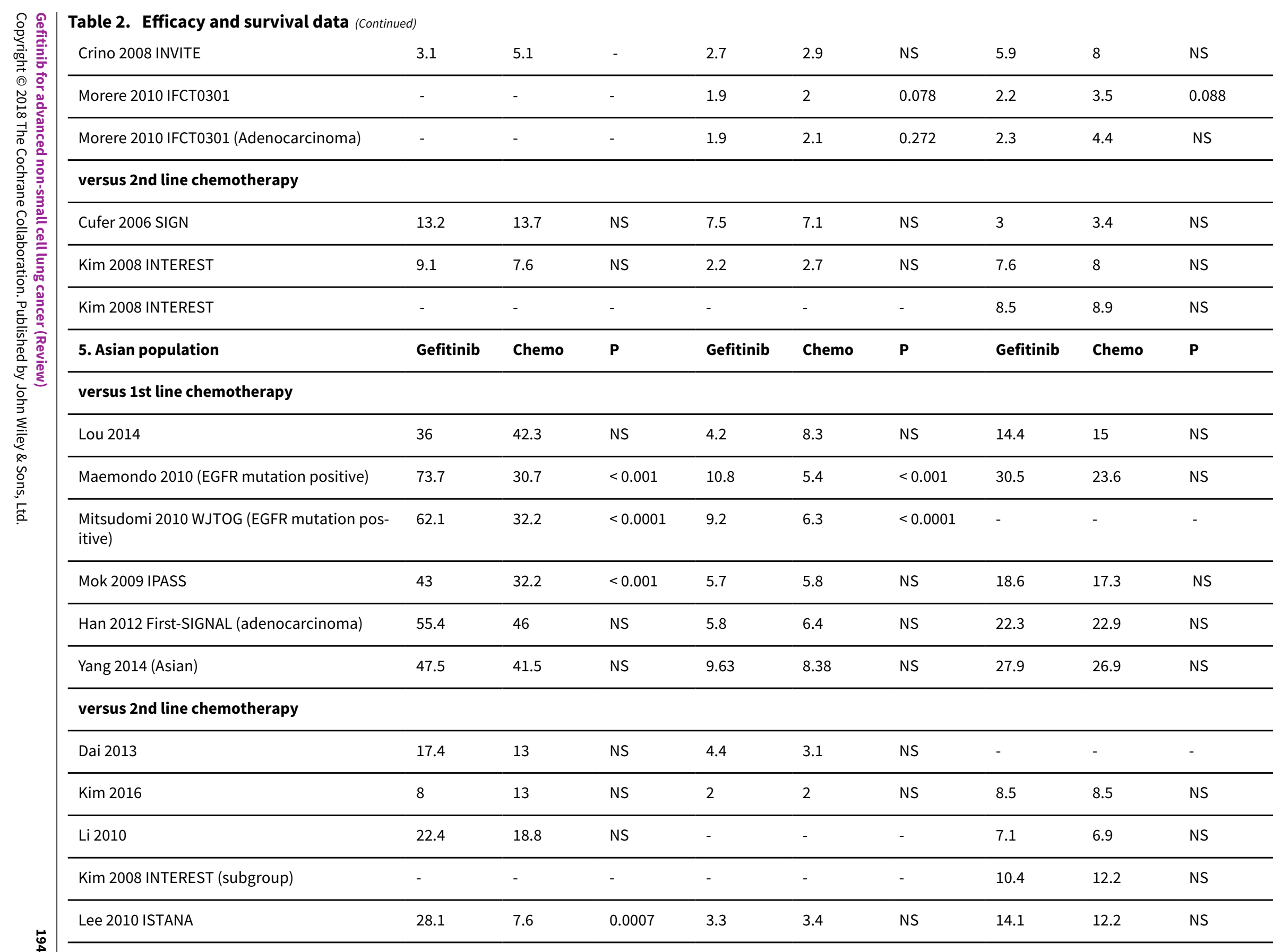




\begin{tabular}{|c|c|c|c|c|c|c|c|c|c|}
\hline Maruyama 2008 V-15-32 & 22.5 & 12.8 & 0.009 & 2 & 2 & NS & 11.5 & 14 & NS \\
\hline $\begin{array}{l}\text { Sun } 2012 \text { KCSG-LU08-01 (adenocarcinoma, } \\
\text { subgroup) }\end{array}$ & 58.8 & 22.4 & $<0.001$ & 9.0 & 3.0 & 0.0006 & 22.2 & 18.9 & NS \\
\hline \multicolumn{10}{|l|}{ versus maintenance therapy } \\
\hline Ahn 2012 (Asian) & 46 & 35 & NS & 9.95 & 6.83 & NS & - & - & - \\
\hline Xu 2015 (Asian) & 18.1 & 29.8 & NS & - & - & - & - & - & - \\
\hline 6. EGFR mutation positive & Gefitinib & Chemo & $\mathbf{P}$ & Gefitinib & Chemo & $\mathbf{P}$ & Gefitinib & Chemo & $\mathbf{P}$ \\
\hline \multicolumn{10}{|l|}{ versus 1st line chemotherapy } \\
\hline Maemondo 2010 (EGFR mutation positive) & 73.7 & 30.7 & $<0.001$ & 10.8 & 5.4 & $<0.001$ & 30.5 & 23.6 & NS \\
\hline $\begin{array}{l}\text { Mitsudomi } 2010 \text { WJTOG (EGFR mutation pos- } \\
\text { itive) }\end{array}$ & 62.1 & 32.2 & $<0.0001$ & 9.2 & 6.3 & $<0.0001$ & - & - & - \\
\hline Mok 2009 IPASS (subgroup) & 71.2 & 47.3 & $<0.001$ & - & - & - & - & - & - \\
\hline Han 2012 First-SIGNAL (subgroup) & 84.6 & 37.5 & 0.002 & - & - & - & - & - & - \\
\hline Yang 2014 (subgroup) & 70.8 & 65.4 & NS & 16.62 & 12.91 & NS & 45.7 & 32.4 & 0.255 \\
\hline \multicolumn{10}{|l|}{ versus 2 nd line chemotherapy } \\
\hline INTEREST Doulliard 2010 (subgroup) & 42.1 & 21.1 & 0.04 & 7 & 4.1 & 0.001 & 14.2 & 16.6 & NS \\
\hline Maruyama 2008 (subgroup) & 67 & 46 & - & - & - & - & - & - & - \\
\hline Sun 2012 KCSG-LU08-01 (subgroup) & - & - & - & 15.7 & 2.9 & 0.005 & - & - & - \\
\hline 7. Gefitinib $250 \mathrm{mg}$ versus gefitinib $500 \mathrm{mg}$ & $250 \mathrm{mg}$ & $500 \mathrm{mg}$ & $\mathbf{P}$ & $250 \mathrm{mg}$ & $500 \mathrm{mg}$ & $\mathbf{P}$ & $250 \mathrm{mg}$ & $500 \mathrm{mg}$ & $\mathbf{P}$ \\
\hline \multicolumn{10}{|l|}{ 2nd+ line } \\
\hline Fukuoka 2003 & 18.4 & 19 & NS & 2.7 & 2.8 & NS & 7.6 & 8 & NS \\
\hline Kris 2004 & 12 & 9 & NS & - & - & - & 7 & 6 & NS \\
\hline
\end{tabular}




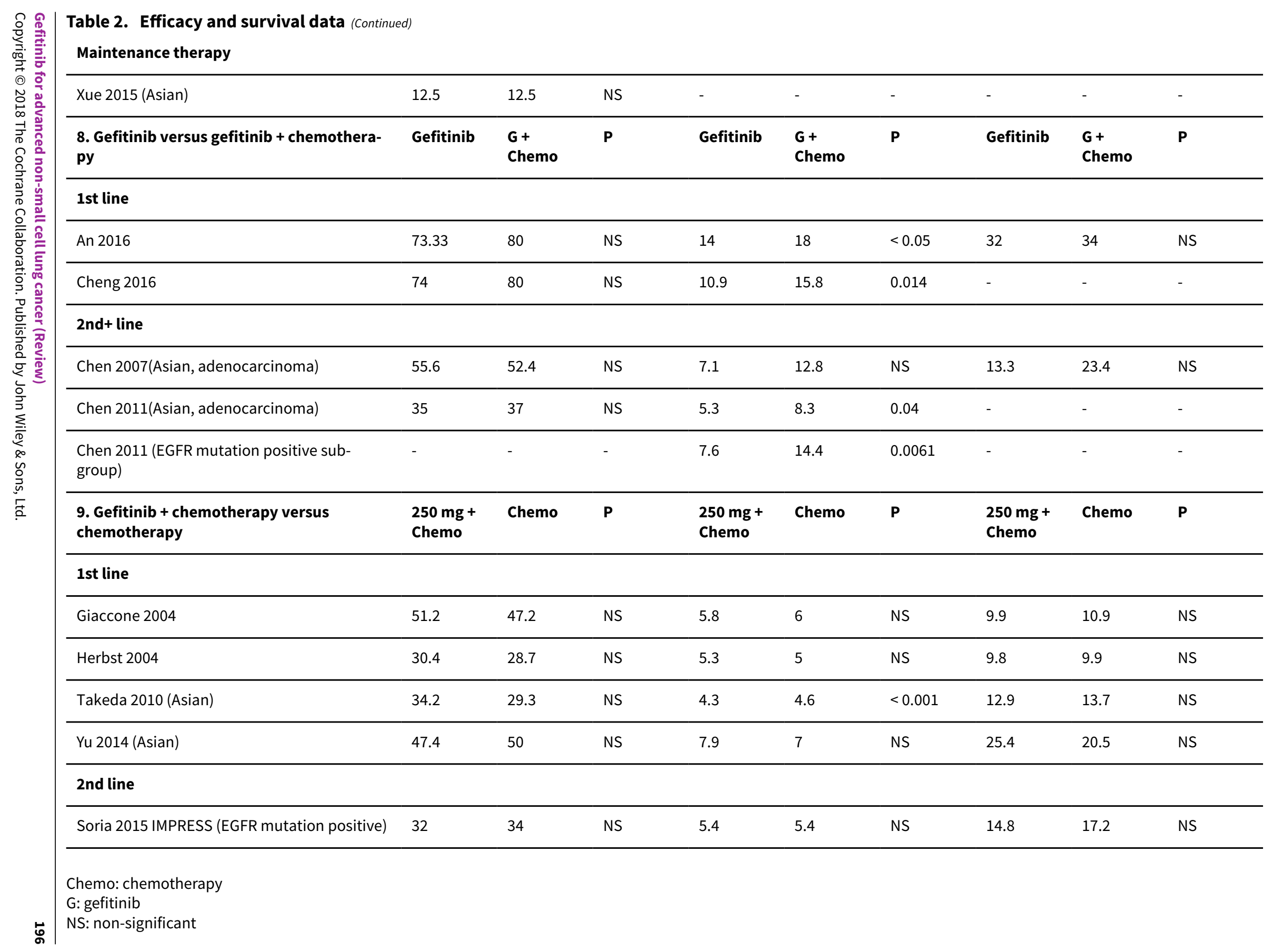



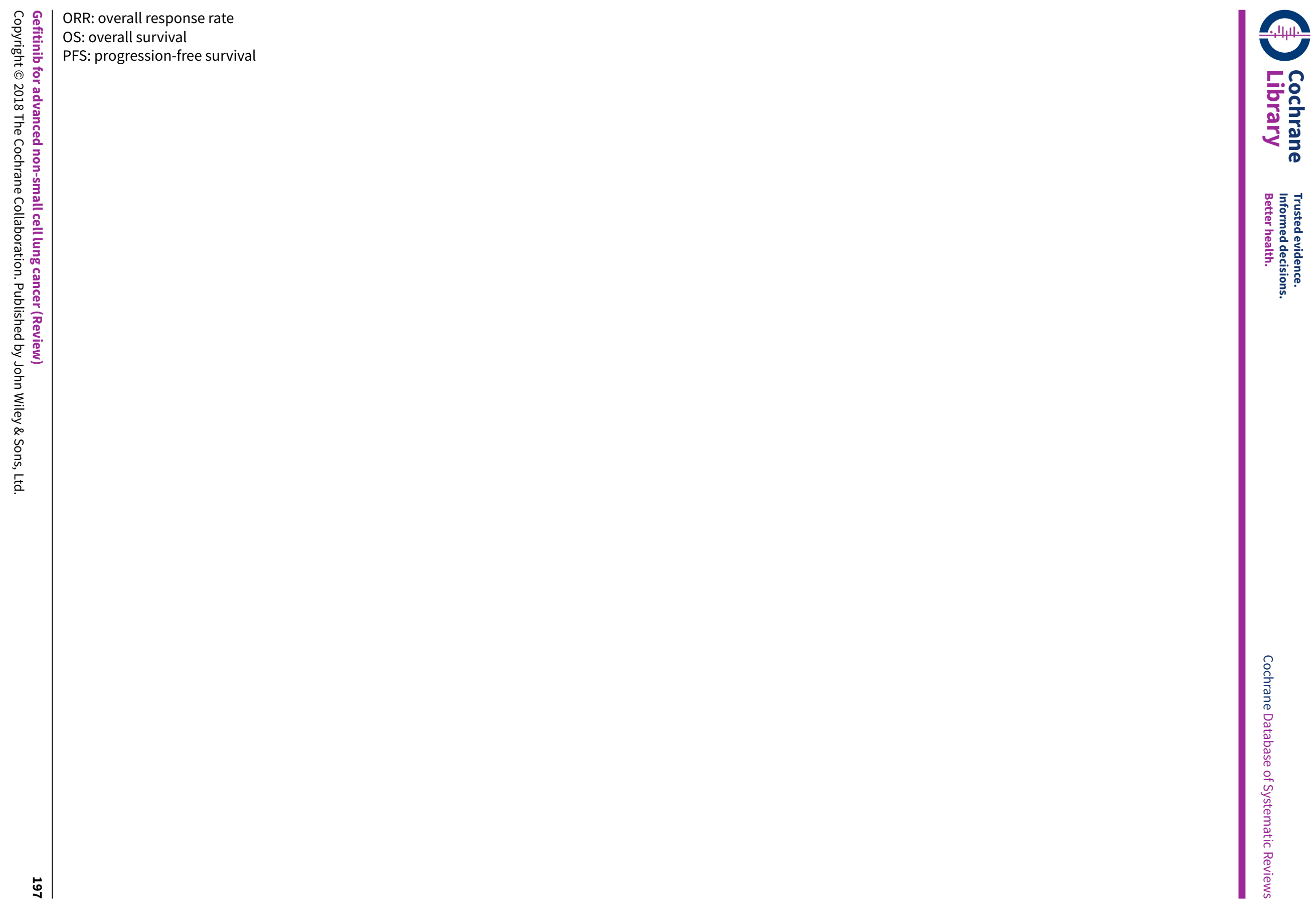


\section{APPEN DICES}

\section{Appendix 1. CENTRAL search strategy (Cochrane Library 2017, Issue 2)}

\#1 MeSH descriptor: [Lung Neoplasms] explode all trees 5740

\#2 MeSH descriptor: [Carcinoma, Non-Small-Cell Lung] explode all trees 2918

\#3 (lung or pulmon^) and (neoplas* or cancer or carcinoma* or tumor or tumour) 17027

\#4 \#1 or \#2 or \#3 17106

\#5 gefitinib or zd 1839 or zd1839 or iressa 490

\#6 \#4 and \#5 360

\section{Appendix 2. MEDLINE search strategy (PubMed; 17 February 2017)}

\#11 Add Search \#9 AND \#10 3906 00:07:34

\#10 Add Search (randomized controlled trial[pt] OR controlled clinical trial[pt] OR randomized[tiab] OR placebo[tiab] OR drug therapy[sh] OR randomly[tiab] OR trial[tiab] OR groups[tiab]) NOT (animals [mh] NOT humans [mh]) 3415417 00:06:59

\#9 Add Search \#5 AND \#8 5006 00:02:59

\#8 Add Search \#6 OR \#7 11742 00:02:47

\#7 Add Search gefitinib[tw] OR ZD1839[tw] OR ZD 1839[tw] OR Iressa[tw] 5828 00:02:34

\#6 Add Search "Receptor, Epidermal Growth Factor/antagonists and inhibitors"[Mesh] 7886 00:01:43

\#5 Add Search \#1 OR \#2 OR \#3 OR \#4 208140 00:01:13

\#4 Add Search NSCLC[tiab] 28799 00:00:30

\#3 Add Search Non Small Cell[tiab] 45118 00:00:14

\#2 Add Search "Carcinoma, Non-Small-Cell Lung"[MeSH] 39657 23:59:42

\#1 Add Search Lung Neoplasms[MeSH] 196596 23:59:14

\section{Appendix 3. Embase search strategy (Ovid; 1980 to 2017 Week 08)}

1 exp lung cancer/ $(275,340)$

2 exp lung non small cell cancer/ $(102,369)$

3 non small cell.ti,ab. $(66,846)$

4 NSCLC.ti,ab. $(49,669)$

51 or 2 or 3 or $4(286,738)$

$6 \exp$ GEFITINIB/ $(19,445)$

7 gefitinib.mp. $(19,987)$

8 (ZD1839 or ZD 1839 or iressa).mp. $(4,876)$

96 or 7 or $8(20,033)$

105 and $9(11,699)$

11 random:.tw. or placebo:.mp. or double-blind:.mp. $(699,255)$

1210 and $11(1,437)$ 


\section{CONTRIBUTIONS OF AUTHORS}

All authors contributed to the design and methodology of this review. Esther Sim assessed the trials for inclusion, extracted data on included trials, entered data to RevMan, undertook the analysis and wrote the review. Ian Yang independently assessed the trials for inclusion, independently extracted data from included trials, checked the analysis and contributed to writing the review. Rayleen Bowman, Kwun Fong and Richard Wood-Baker critically commented on the review and provided advice for improving the review.

\section{DECLARATIONS OF INTEREST}

Esther HA Sim (ES): none known

Ian A Yang (IY): none known

Rayleen V Bowman (RB) has received pharmaceutical company sponsored items, meals and travel expenses associated with attendance at scientific meetings including Australian Lung Cancer Conference and Thoracic Society of Australia and New Zealand.

RB is a current member of the Lung Foundation (Australia)'s Lung Cancer Consultative Group, which receives financial sponsorship from a number of pharmaceutical companies.

Kwun M Fong (KF) was an investigator for a clinical trial of gefitinib for lung cancer (Astra Zeneca international trial) - funding received by the Hospital funds the clinical trial and the employment of a trials nurse.

KF's laboratory has also undertaken contract research for a clinical study looking at immunohistochemistry of certain proteins in lung cancer for Novartis - funding received will go to the Project and employment of Research staff for the Project.

KF was previously offered an honorarium from a pharmaceutical company for attending an one-off Advisory Board Meeting; this was not accepted and asked to be given to a charity.

KF has received occasional pens, pads and minor stationery from industry. KF has occasionally attended/spoken at meetings organised by pharmaceutical companies where meals/travel costs would be sponsored.

KF has organised the Queensland Lung Cancer Interest Group Meeting (two to three meetings per year, a teleconference meeting, which is supported by Eli Lilly. KF has/is also involved in organising and attending professional meetings including those run by the Thoracic Society of Australia and New Zealand, Asia-Pacific Society of Respirology, Australian Lung Cancer Conference, IASLC, where some sponsorship is usually provided by industry.

KF is involved with the Lung Foundation (Australia)'s Lung Cancer Cooperative Group (not-for-profit, public benevolent institution) (http://www.lungnet.org/www.lungnet.org.au) and its activities, which includes promotion of Cochrane Reviews. The LFA receives support from pharmaceutical companies. KF was Chair of the Australian Lung Cancer trials Group, which receives some support funding from pharmaceutical companies.

Richard Wood-Baker (RWB): none known

\section{SOURCES OF SUPPORT}

\section{Internal sources}

- No sources of support supplied

\section{External sources}

- The Lung Foundation (Australia)/Lung Cancer Consultative Group Cochrane Review Scholarship (ES), Australia.

- Lung Foundation (Australia) Lung Consultative Group (IY, KF, RB), Australia.

- National Health and Medical Research Council (IY, KF, RB, RWB), Australia.

\section{DIFFERENCES BETWEEN PROTOCOLAND REVIEW}

The text of the protocol section of the review has been updated to included new subheadings.

We have added toxicity to the list of our primary outcomes.

We have included three 'Summary of findings' tables giving overall survival and progression-free survival for gefitinib compared to chemotherapy for first-line treatment of advanced NSCLC, gefitinib compared to chemotherapy for second-line treatment of advanced NSCLC and the toxicity of gefitinib compared to chemotherapy for advanced NSCLC. 


\section{N D X TERMS}

\section{Medical Subject Headings (MeSH)}

Antineoplastic Agents [adverse effects] [*therapeutic use]; Carcinoma, Non-Small-Cell Lung [ ${ }^{\star}$ drug therapy] [ethnology] [genetics]; Disease-Free Survival; Gefitinib; Genes, erbB-1; Lung Neoplasms [ ${ }^{\star}$ drug therapy] [ethnology] [genetics]; Mutation; Quality of Life; Quinazolines [adverse effects] [ ${ }^{\star}$ therapeutic use]; Randomized Controlled Trials as Topic; Treatment Failure

\section{MeSH check words}

Humans 